National

Academy

of

Sciences

National Research Council

NUCLEAR SCIENCE SERIES

\title{
The Radiochemistry of the Rare Earths, Scandium, Yttrium, and Actinium
}




\section{COMMITTEE ON NUCLEAR SCIENCE}

L. F. CURTISs, Chairman

National Bureau of Standards
ROBLEY D, EVANs, Vice Chairmar

Massachusetts Institute of Technology

J. A. DeJUREN, Secretary

Westinghouse Electric Corporation

\section{J. BORKOW8KI}

Oak Ridge National Laboratory

ROBERT G. COCHRAN

Texas Agricultural and Mechanical

College

SAMUEL EPSTEIN

Callfornia Institute of Technology

U. FANO

National Bureau of Standards

HERBERT GOLDSTEIN

Nuclear Development Corporation of America
J. W. IRVINE, JR.

Massachusetts Institute of Technology

E. D. KLEMA

Northwestern Unlversity

W. WAYNE MEINKE

Unlveraity of Michigan

J. J. NICKSON

Memorial Hospital, New York

ROBERT L. PLATZMan

Laboratoire de Chimie Physique

D. M. VAN PATTER

Bartol Research Foundation

\section{LIAISON MEMBERS}

PAUL C. AEBERSOLD

Atomic Energy Commission

J. HOW ARD MCMILLEN

National Bcience Foundation
CHARLES K. REED

U. S. Air Force

WILLIAM E. WRIGHT

Office of Naval Research

\section{SUBCOMMITTEE ON RADIOCHEMISTRY}

W. WAYNE MEINKE, Chairman

University of Michigan

GREGORY R. CHOPPIN

Florida State University

GEORGE A. COWAN

Los Alamos Scientific Laboratory

ARTHUR W. FAIRHALL

University of Washington

JEROME HUDIS

Brookhaven National Laboratory

EARL HYDE

University of California (Berkeley)
HAROLD KIRBY

Mound Laboratory

GEORGE LEDDICOTTE

Oak Ridge National Laboratory

JULIAN NIELSEN

Hanford Laboratories

ELLIS P. STEINBERG

Argonne National Laboratory

Peter C. STEvenson

University of Callfornia (Livermore)

LEO YAFFE

McGill University

\section{CONSULTANTS}

NATHAN BALLOU

Centre d'Etude de l'Energle Nucleaire

Mol-Donk, Belgium
JAMES DeVOE

University of Michigan

WILLIAM MARLOW

National Bureau of Standards 


\section{DISCLAIMER}

This report was prepared as an account of work sponsored by an agency of the United States Government. Neither the United States Government nor any agency Thereof, nor any of their employees, makes any warranty, express or implied, or assumes any legal liability or responsibility for the accuracy, completeness, or usefulness of any information, apparatus, product, or process disclosed, or represents that its use would not infringe privately owned rights. Reference herein to any specific commercial product, process, or service by trade name, trademark, manufacturer, or otherwise does not necessarily constitute or imply its endorsement, recommendation, or favoring by the United States Government or any agency thereof. The views and opinions of authors expressed herein do not necessarily state or reflect those of the United States Government or any agency thereof. 


\section{DISCLAIMER}

Portions of this document may be illegible in electronic image products. Images are produced from the best available original document. 


\title{
The Radiochemistrv of the Rare Earths, Scandium, Yttrium, and Actinium
}

\author{
By P. C. STEVENSON \\ and W. E. NERVIK \\ Lawrence Radiation Laboratory \\ University of California \\ Livermore, Calif. \\ Issuance Date: February 1961
}

Subcommittee on Radiochemistry

National Academy of Sciences - National Research Council 


\section{FOREWORD}

The Subcommittee on Radiochemistry is one of a number of subcommittees working under the Committee on Nuclear Sclence within the National Academy of Sclences - National Research Counc1l. Its members represent government, 1ndustrial, and university laboratories in the areas of nuclear chemistry and analytical chemistry

The Subcommlttee has concerned itself with those areas of nuclear sclence which involve the chemist, such as the collection and distribution of radiochemical procedures, the estabIlshment of speciflcations for radiochemically pure reagents, avallability of cyclotron time for service irradiations, the place of radiochemistry in the undergraduate college program, etc.

Th1s serles of monographs has grown out of the need for up-to-date compliations of radiochemical information and procedures. The subcommittee has endeavored to present a series which will be of maximum use to the working scientist and which contains the latest available information. Each monograph collects in one volume the pertinent information required for radlochemical work with an individual element or a group of closely related elements.

An expert in the radiochemistry of the particular element has written the monograph, following a standard format developed by the Subcommittee. The Atomic Energy Commission has sponsored the printing of the series.

The Subcommittee is confident these publications will be useful not only to the radiochemist but also to the research worker in other fields such as physics, biochemistry or medicine who wishes to use radiochemical techniques to solve a specific problem. 


\section{INTRODUCTION}

This report has been prepared as one of a series of monographs on the radiochemistry of the elements for the Subcommittee on Radiochemistry of the Committee on Nuclear Science within the National Academy of Sciences. Information presented here has been obtained in a search which included the Chemical Abstracts from 1947 to April 25, 1960; Nuclear Science Abstracts from 1947 to April 15, 1960; Abstracts of Declassified Documents for 1947 and 1948; Analytical Abstracts from 1954 to April 1960; and the authors' personal experiences from 1950 to the present. Data have been included primarily for radiochemists working with the rare earths, but it is hoped that others will also find the information useful.

Although the list of references is long, no pretense can possibly be made that it is complete. We have attempted to cover all phases of rareearth chemistry that could conceivably be of interest to a radiochemist and to include all of the more significant references in each phase. During the course of the writing, however, we were continually finding important articles which had been missed in the literature search and doubtless there are many which we still have not found. We would be most appreciative if these omis sions could be brought to our attention so that they may be included in future revisions of the manuscript.

The authors wish to acknowledge most heartily the assistance of Carl Wensrich and Carol Patrick of the LRL library staff. Without their aid in obtaining reprints of the references this volume could hardly have been prepared.

We also wish to express our sincerest appreciation to Mrs. Margaret Dixon for typing the final manuscript with alacrity, precision, and perseverance.
W. E. Nervik
P. C. Stevenson 


\section{CONTENTS}

Page No.

1. GENERAL REVIEWS OF THE INORGANIC AND ANALYTICAL CHEMISTRY OF THE RARE EARTHS, SCANDIUM, YTTRIUM, AND ACTINIUM

II. GENERAL REVIEWS OF THE RADIOCHEMISTRY OF THE RARE EARTHS, SCANDIUM, YTTRIUM, AND ACTINIUM

III. TABLE OF ISOTOPES 3

IV. CHEMISTRY OF THE RARE EARTHS, SCANDIUM, YTTRIUM, AND ACTINIUM

1. METALS, AMALGAMS, AND VARIOUS OXIDATION STATES $\cdot$. . . . . . . . .

A. METALS

B. AMALGAMS AND VARIOUS OXIDATION STATES

2. SOLUBLE SALTS

3. INSOLUBLE SALTS

A. INSOLUBLE SALTS AND GRAVIMETRIC COMPOUNDS

1. Introduction

2. Hydroxide

3. Fluoride

4. Oxalate . . . . . . . . . . . 19

5. 8-Hydroxyquinolate . . . . . . 22

6. Ammonium tartrate . . . . . . . 24

7. Complex cyanides . . . . . . . 24

8. Phosphate and related anions . . . . 25

9. Iodate . . . . . . . . . . 25

10. Cupferron . . . . . . . . . . 27

11. Chloride . . . . . . . . 27 
12. Miscellaneous precip.tants . . . . 27

13. Sensitivity of various precipitants . . . 28

B. COPRECIPITATION . . . . . . . . . 29

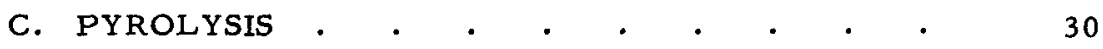

1. Oxalate . . . . . . . . . 30

2. 8-Hydroxyquinolate and related anions . . 34

3. Cupferrate and neocupferrate . . . . 39

4. Other anions . . . . . . . . . . . 41

4. SPECTROPHOTOMETRY, TITRATION, AND COLORIMETRY

A. SPECTROPHOTOMETRY OF SIMPLE IONS . . 41

B. TITRATION AND COLORIMETRY • . . . . 46

5. COMPLEX IONS AND CHELATE COMPOUNDS . . 48

A. INTRODUCTION

B. COMPOUNDS WITH INORGANIC ADDITIVES . 50

1. Sulfates . . . . . . . . . . . 50

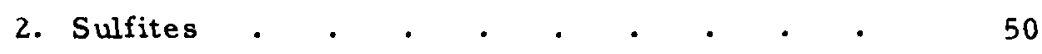

3. Thiosulfates . . . . . . . . 51

4. Halides . . . . . . . . . 52

5. Nitrates . . . . . . . . . 53

6. Nitrites . . . . . . . . . . 53

7. Carbonates . . . . . . . . . 54

8. Chromates . $. \quad . \quad . \quad . \quad . \quad . \quad . \quad 54$

9. Phosphates . . . . . . . . 54

10. Heteropoly compounds . . . . . . 55

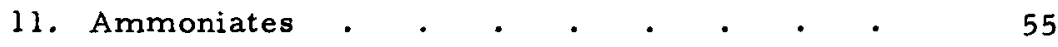

C. COMPOUNDS WITH ORGANIC ADDITIVES . . 56

1. Carboxylic acids . . . . . . . . . 56

a. Acetic acid . . . . . . . 56

b. Stearic acid . . . . . . . . 57

c. Oxalic acid . . . . . . . . 57

d. Malonic acid . . . . . . . . 58

e. Succinic acid . $\quad . \quad$. $\quad . \quad$. $\quad . \quad 58$

f. Glutaric acid . . . . . . . . 59

g. Adipic acid . . . . . . . . . 59

h. Pimelic acid . . . . . . . . . 59

i. Azelaic and sebacic acids . . . . 59

j. Camphoric acid . . . . . . . . 59

k. Maleic and fumaric acids . . . . 60 
Page No.

l. Citraconic acid . . . . . . 61

m. Tricarballylic acid . . . . . 61

n. Aconitic acid . . . . . . . . . 62

o. Kojic acid . . . . . . . . . 62

p. Salicylic acid . . . . . . . 62

2. Hydroxycarboxylic acids . . . . . . 63

a. Glvcolic acid . . . . . . . . 63

b. Lactic acid . . . . . . . 64

c. Amygdalic acid . . . . . . . 64

d. Oxalacetic acid . . . . . . . 64

e. Tartaric acid . . . . . . . . 64

f. Mucic acid . . . . . . . . 65

g. Saccharic acid . . . . . . 65

h. Citric acid . . . . . . . . 66

3. Amino acids . . . . . . . . . . . 68

4. Aminopolyacetic acids . . . . . 70

a. Nitrilotriacetic acid (TRILO) . . . 70

b. Ethylenediaminetetraacetic acid (EDTA) . 71

c. N-hydroxyethyl-ethylene diamine triacetic acid (HEDTA) . . . . . 72

d. 1,2-diaminocyclohexanetetraacetic acid (DCTA) . . . . . . . 72

e. Diethylenetriaminepentaacetic acid (DTPA) . $\quad . \quad . \quad . \quad . \quad . \quad 73$

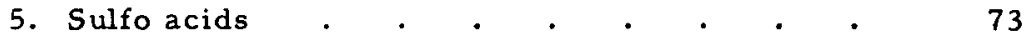

6. Diphenylvioluric acid . . . . . . . 44

D. COMPOUNDS WITH ORGANIC AMINES . . . 74

1. Antipyrine . . . . . . . . . 74

2. Pyramidone . . . . . . . . 76

3. Pyridine . . . . . . . . 76

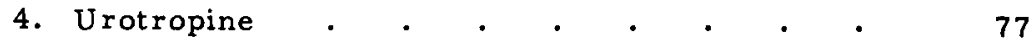

5. Hydroxyquinoline . . . . . . . . 47

6. Cupferron . . . . . . . . . . . . 49

7. Neocupferron . . . . . . . 80

8. Disalicylidal ethylenediamine . . . . 80

9. Methyl amine . . . . . . . 80

10. Ethylenediamine . . . . . . . . 81

E. COMPOUNDS WITH $\beta$-DIKETONES . . . 81 
F. COMPOUNDS WITH POLYPHENOLS . . . . 83

G. COMPOUNDS WITH ALIZARIN-S . . . . . 83

H. COMPOUNDS WITH CYCLOPENTADIENAL SODIUM $. \quad . \quad . \quad . \quad . \quad . \quad . \quad . \quad . \quad . \quad 84$

I. METAIOOORGANIC COMPOIINDS OF RAREEARTH ELEMENTS . . . . . . . . . 84

J. SUMMARY OF THE COMPLEX-FORMING CHARACTERISTICS OF THE RARE-EARTH ELEMENTS

6. EXTRACTION . . . . . . . . . . . 86

A. INTRODUCTION . . . . . . . . . . . . 86

B. SEPARATION OF A GROSS RARE-EARTH FRACTION FROM OTHER ELEMENTS: SOLVENT EXTRACTION OF THE RAREEARTH GROUP .

1. Tributyl phosphate (TBP) . . . . . 86

2. Salicylic acid and other carboxylic acids . . 88

3. Thenoyltrifluoroacetone (TTA) . . . . . 88

4. Substituted phosphoric acids . . . . 92

5. Acetylacetone . . . . . . . . . 92

6. Oxine and oxine derivatives . . . . . 94

7. Other chelating reagents . • . . . . 96

C. REMOVAL OF CONTAMINANTS FROM RARE EARTHS BY SOLVENT EXTRACTION • . . . 96

D. SEPARATION OF THE INDIVIDUAL RAREEARTH ELEMENTS FROM THE GROUP BY SOLVENT EXTRACTION . . . . . . . . 98 1. Simple salts . . . . . . . . . . . 98

2. Tributyl phosphate (TBP) . . . . . . 98

3. Chelating organophosphorous compounds. . 105

4. Thenoyltrifluoroacetone (TTA) . . . . 106

E. SOLVENT EXTRACTION SEPARATIONS OF CERIUM(IV) . . . . . . . . . . . 107

1. Nitrates . . . . . . . . . . 107

2. Tributyl phosphate (TBP) . . . . . 109

3. Amine extractants . . . . . . . 110

4. Di(2-ethyl hexyl) phosphoric acid (HDEHP) . 110

5. Thenoyltrifluoroacetone (TTA) . . . . 110 
F. SOLVENT EXTRACTION SEPARATIONS OF

Page No.

SCANDIUM . . . . . . . . . 110

1. Nitrate . . . . . . . . . . . 110

2. Thiocyanate . . . . . . . . 110

3. Tributyl phosphate (TBP) . . . . . $111^{\circ}$

4. Thenoyltrifluoroacetone (TTA) . . . . 111

5. Acetylacetone . . . . . . . . 113

6. Cupferron . . . . . . . . . . 113

7. Salicylate . . . . . . . . . .

G. SZILARD-CHALMERS REACTION FOR THE

RARE EARTHS . . . . . . . . 113

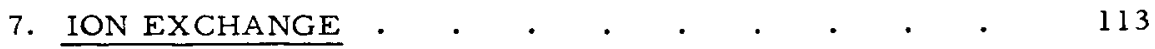

A. INTRODUCTION . . . . . . . . . . 113

1. Review . . . . . . . . . . . . 113

2. Effect of variables in ion exchange . . . 114

B. CATION-EXCHANGE RESINS . . . . . 122

1. Introduction . . . . . . . . . 122

2. Citric acid . . . . . . . . . 125

3. Lactic acid . . . . . . . . . 135

4. Glycolic acıd . . . . . . . . . 143

5. a-hydroxyisobutyric acid . . . . . $14 l_{s}$

6. Amino-polyacetıc acıds . . . . . 145

7. Other eluants . . . . . . . . . 149

8. Comparison of eluants . . . . . 151

C. ANION-EXCHANGE RESINS • . • . . 156

1. Introduction . . . . . . . . . 156

2. Chloride . . . . . . . . . 156

3. Nitrate . . . . . . . . . 159

4. Thiocyanate . . . . . . . . 160

5. Sulphate . . . . . . . . 161

6. Fluoride . . . . . . . . 162

7. Oxalate . . . . . . . . . 164

8. Phosphate . . . . . . . . 166

9. Carbonate . . . . . . . . 168

10. Hydroxide . . . . . . . . 168

11. Organic complexes . . . . . . . 168

12. Other anions . . . . . . . . . 169

D. CELLULOSE AND PAPER
CHROMATOGRAPHY . . . . . . . . . . 169 
E. INORGANIC EXCHANGERS

Page No.

F. EXTRACTION-EXCHANGE

171

172

8. ELECTRIC AND MAGNETIC FIELD

SEPARATION

174

A. INTRODUCTION

174

B. ELECTROPHORESIS . . . . . . . 174

C. MAGNETOPHORESIS . . . . . . . . 175

D. FOCUSING ION EXCHANGE . . • • . 175

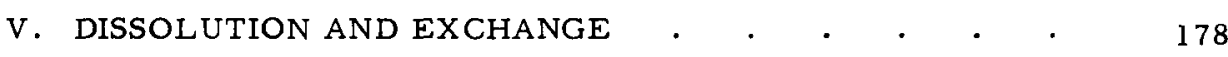

1. DISSOLUTION . . . . . . . . . . . . .

2. EXCHANGE. . . . . . . . . 180

VI. COUNTING TECHNIQUES . . . . . . . $\quad$. 181

VII. COLLECTION OF DETAILED RADIOCHEMICAL

PROCEDURES . . . . . . . . . . . . 186 


\title{
The Radiochemistry of the Rare Earths, Scandium, Yttrium, and Actinium
}

\author{
P. C. STEVENSON and W. E. NERVIK \\ Law rence Radiation Laboratory \\ University of California \\ Livermore, Calıf.
}

I. GENERAL REVIEWS OF THE INORGANIC AND ANALYTICAL CHEMISTRY OF THE RARE EARTHS, SCANDIUM, YTTRIUM, AND ACTINIUM

1. R. Bock, "Recent Progress in the Separation of the Rare Earths," Angew. Chem. 62, 375-82 (1950).

2. R.W. Clarke, "Actınıum - A Biblıography of Unclassified and Declassified Atomic Energy Project Reports and References to the Published Literature (1906-1953)," AERE-INF/BIB-95, 24 pp. (1954).

3. M.C. Sneed and R.C. Brasted, "Comprehensive Inorganic Chemistry," Vol. IV, D. Van Nostrand Co., Inc., Princeton, 1955.

4. H.E. Kremers in "Rare Metals Handbook," ed. by C.A. Hampel, Reinhold Publıshing Corp., New York, 1956.

5. "Rare Earths in Biochemical and Medical Research: A Conference Sponsored by the Medical Division, ORINS, Oct. 1955," ed. by C. Kyker and E.B. Anderson, ORINS-12 (1956).

6. J.K. Marsh, "The Separation of the Lanthanons (Rare Earth Elements)," Quart. Revs. (London) 1 , 126-43 (1947).

7. G.H. Morrison and H. Freiser, "Solvent Extraction in Analytical Chemistry," John Wiley and Sons, Inc., New York, 1957.

8. A.A. Noyes and W.C. Bray, "A System of Qualitative Analysis for the Rare Elements," The Macmillan Co., New York, 1948.

9. F. T. Hagemann, "Actınıum Processing," in "Progress in Nuclear Energy Series IIl, Process Chemistry," Vol. 2, McGraw-Hill Book Co., Inc., New York, 1956. 
10. D.I. Ryabtchikov, M.M. Senyavin, and Y.S. Sklyarenko, "Isolation of Rare-Earth Elements," A/CONF 15/P/2231 (2nd Geneva Conf), (1958).

11. "Redkozemel Nyye Elementy; Polucheniye, Analiz, Primeniye" (Rare-Earth Elements; Production, Analysis, and Use), Moscow, IZD-vo AN SSSR, 331 pp. (1959). (Akad. Nauk SSSR, Institut Geokhimi i Analiticheskoy Khimii.)

12. W.R. Schoeller and A.R. Powell, "The Analysis of Minerals and Ores of the Rarer Elements," Third Edition, Hafner Publishing Co., New York, 1955.

13. E.B. Sandell, "Colorimetric Determination of Traces of Metals," Third Edition, Interscience Publishers, Inc., New York, 1959.

14. R.C. Vickery, "Chemistry of the Lanthanons," Butterworths Scientific Publications, London, 1953.

15. H. Vetter, "Rare Earths and Rare Elements," Euro-Ceram. $\underline{8}$, $219-32,246$ (1958).

16. A.W. Wylie, "The Rare Earths or 'Lanthanons'," Roy. Australian Chem. Inst. J. \& Proc. 17, 377-97 (1950).

17. D.M. Yost, H. Russell, Jr., and C.S. Garner, "The Rare-Earth Elements and Their Compounds," John Wiley and Sons, Inc., New York, 1947.

18. J.J. Katz and G.T. Seaborg, "The Chemistry of the Actinide Elements," John Wiley and Sons, Inc., New York, 1957.

19. F.T. Hagemann, "The Chemistry of Actinium," in "The Actinide Elements," Div. IV, Vol. 14A of National Nuclear Energy Series, ed. by G.T. Seaborg and J.J. Katz, McGraw-Hill Book Co., Inc., New York, 1954.

20. "Encyclopedia of Chemical Technology," Vol. 11, ed. by R.E. Kirk and D.F. Othmer, The Interscience Encyclopedia, Inc., New York, 1953, pp. 503-21.

21. "Encyclopedia of Chemical Reactions," ed. by C. A. Jacobson and C. A. Hampel, Reinhold Publishing Corp., New York, 1946-59. (Mostly old references.)

22. S. Misumi, "Chemistry of the Lanthanides," Kagaku to Kठgy 8 (Tokyo) 10, 118-28 (1957); French translation, CEA-tr-X-143, $17 \mathrm{pp}$.

23. C.J. Rodden, "Minutes of the Yttrium Analytical Conference, (Held at Argonne National Laboratory), November 7-8, 1956," TID-7533 (1957), Decl. Oct. 1, 1959. (See Nuclear Sci. Abstr. 14, 173.) 
II. GENERAL REVIEWS OF THE RADIOCHEMISTRY OF THE RARE EARTHS, SCANDIUM, YTTRIUM, AND ACTINIUM

1. N. Saito, T. Kiba, and K. Kimura, "Radiochemical Studies of Fissile and Fission Produced Elements," A/CONF/15/P/1 323 (2nd Geneva Conf), (1958).

2. "Collected Radiochemical Procedures," Second Edition, ed. by J. Kleinberg, LA-1721 (1958).

3. K. W. Bagnall, "Chemistry of the Rare Radioelements Po, Ac," Academic Press, Inc., New York, 1957.

4. E.K. Hyde, "Radiochemical Separation Methods for the Actinide Elements," Proc. Intern. Conf. Peaceful Uses Atomic Energy, Geneva, 1955, 7, 281-303 (1956).

5. P.E. Bell and S.R. Harris, "Bibliography on Fission; 1952 to Present," AEC LAMS-2302 (1959).

6. "Radiochemical Procedures in Use at the University of California Radiation Laboratory (Livermore)," ed. by M. Lindner, UCRL-4377 (1954).

7. "Radiochemical Studies: The Fission Products," Book 3, Div. IV, Vol. 9 of National Nuclear Energy Series, ed. by C.D. Coryell and N. Sugarman, McGraw-Hill Book Co., Inc., New York, 1951.

\section{TABLE OF ISOTOPES}

Data are reproduced in Figs. 1-5 from the G.E. Chart of the Nuclides (KAPL), 5th Ed., Revised to April 1956. For more detailed information consult: D. Strominger, J.M. Hollander, and G.T. Seaborg, "Table of Isotopes," Revs. Modern Phys. 30, No. 2, Pt. 2, 585-904 (1958).

IV. CHEMISTRY OF THE RARE EARTHS, SCANDIUM, YTTRIUM, AND ACTINIUM

IV. 1. METALS, AMALGAMS, AND VARIOUS OXIDATION STATES IV. 1A. METALS

Although the rare earths have been known for more than one hundred years, it is only during the last fifteen years or so that techniques have been developed for separating pure compounds of individual members of this group of elements. The best methods for preparing pure rare-earth metals are less than ten years old, and intensive effort has gone into study of the properties of these newly available materials. 


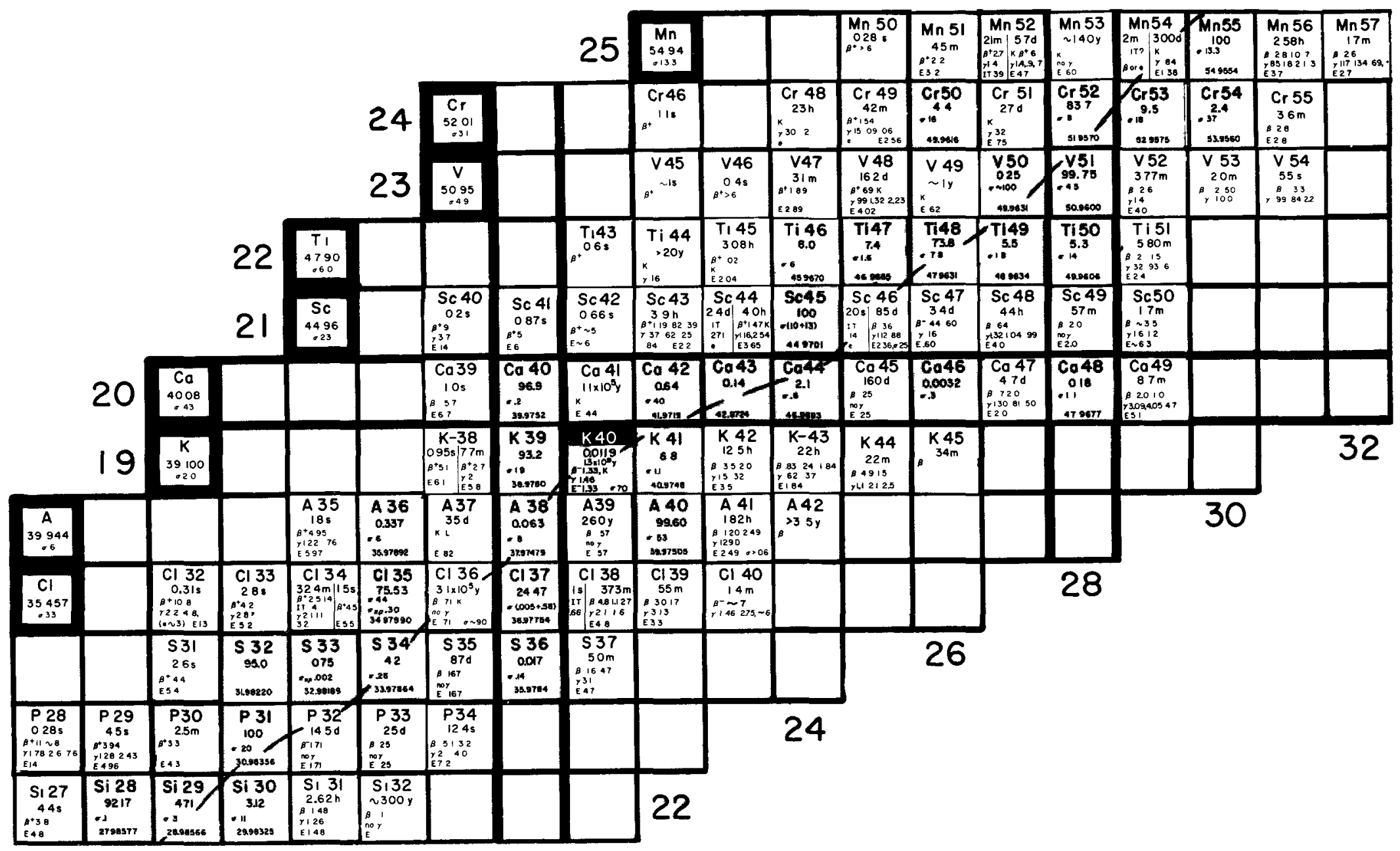

Fig. 1. 


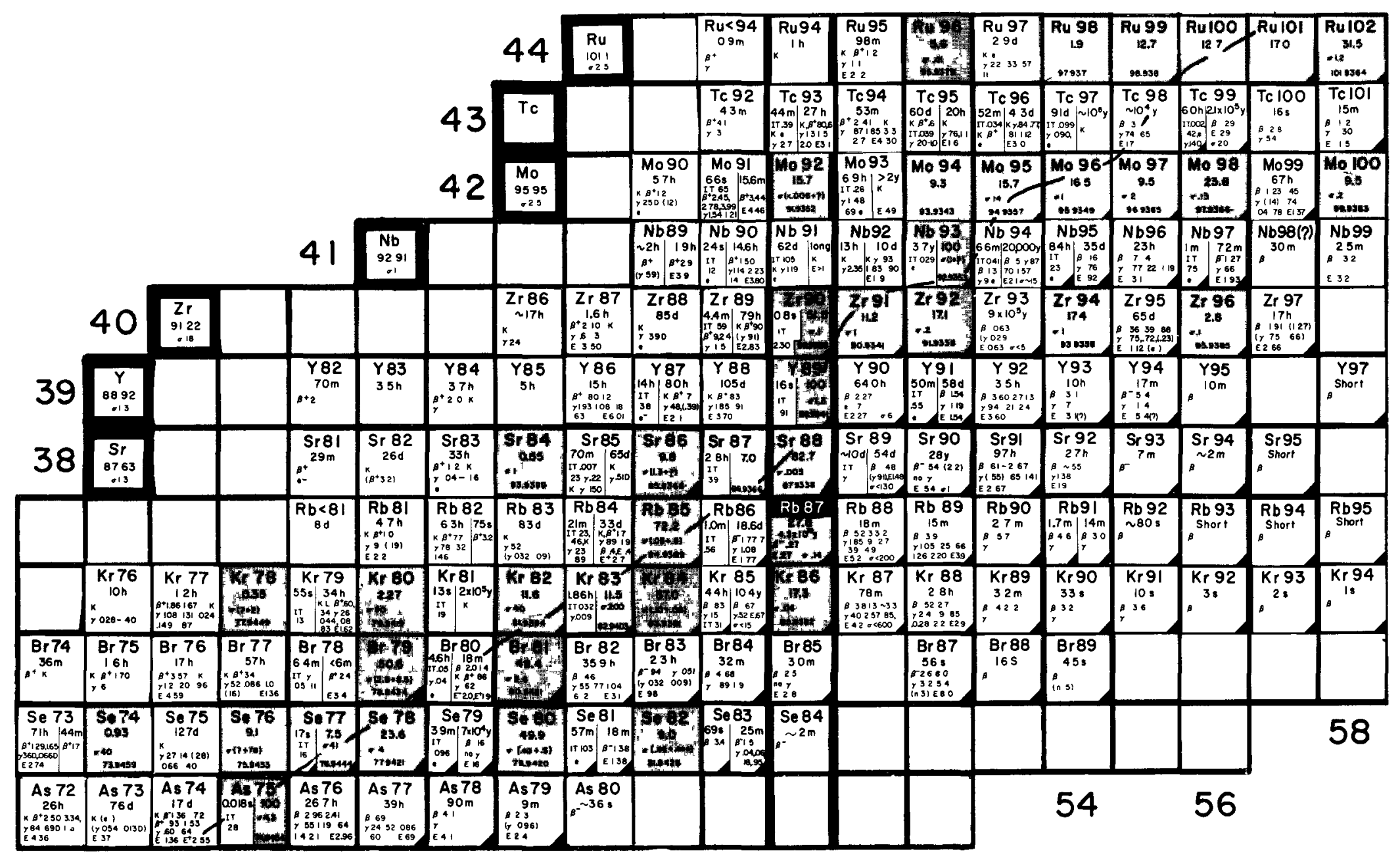

Fig. 2 . 


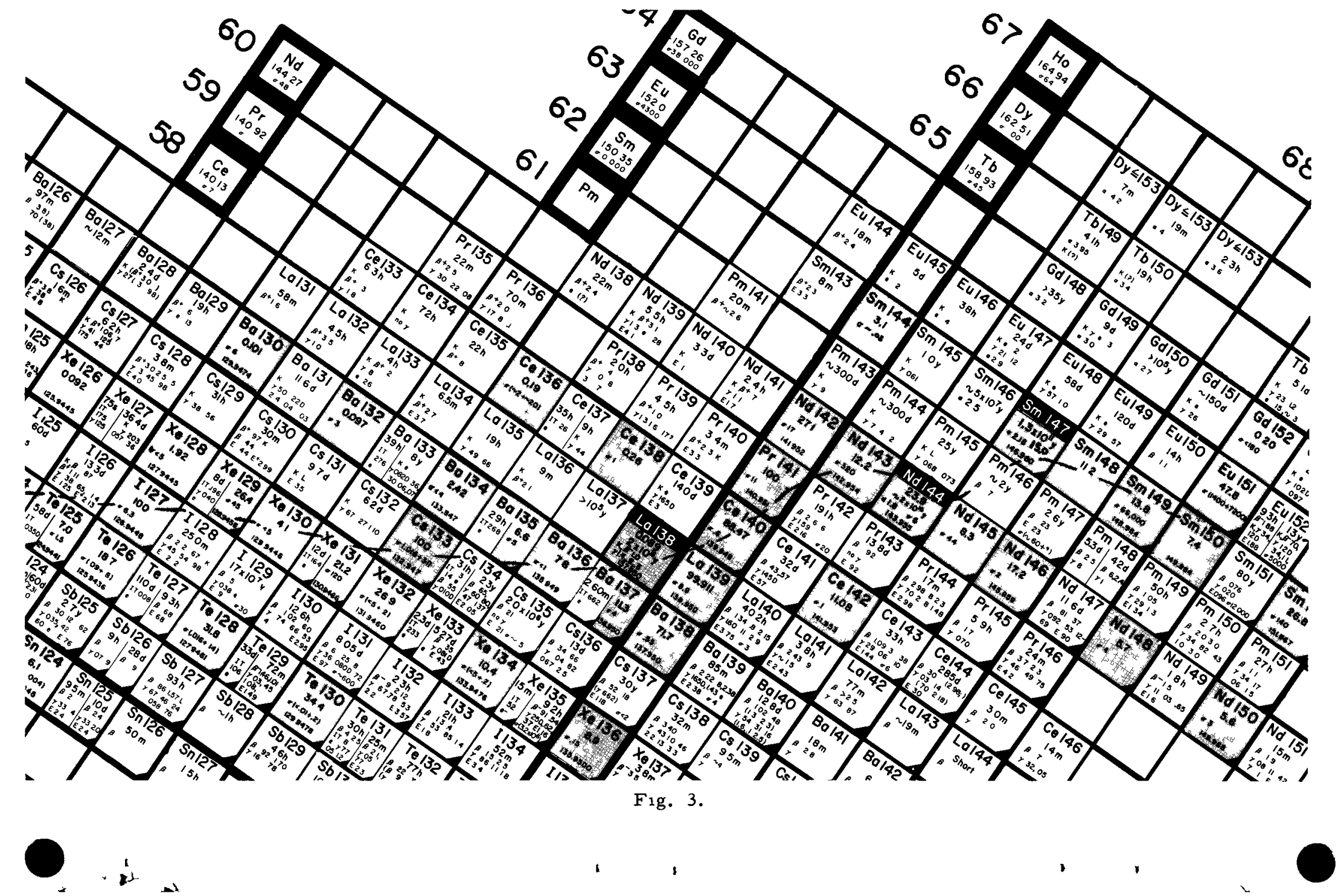




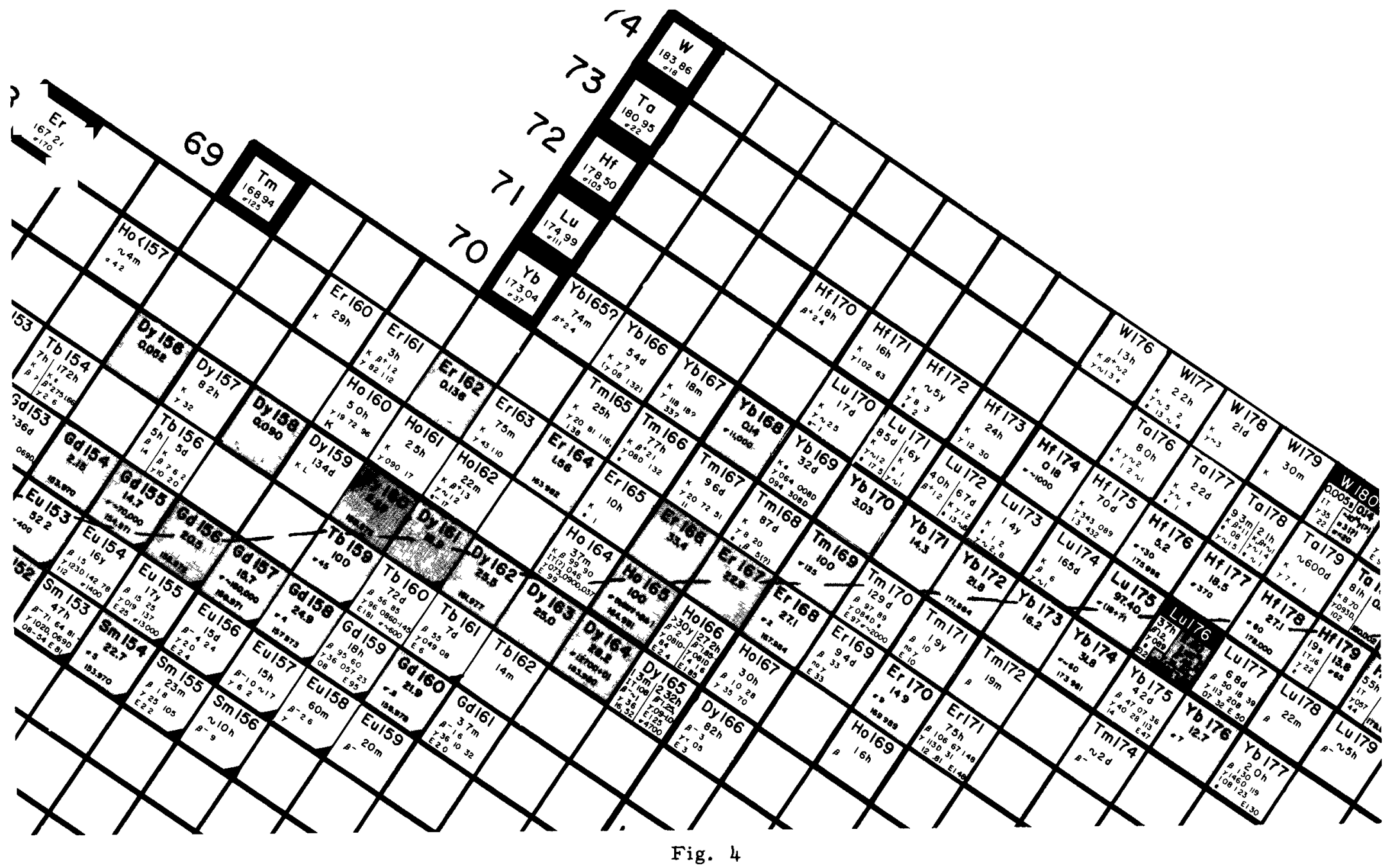




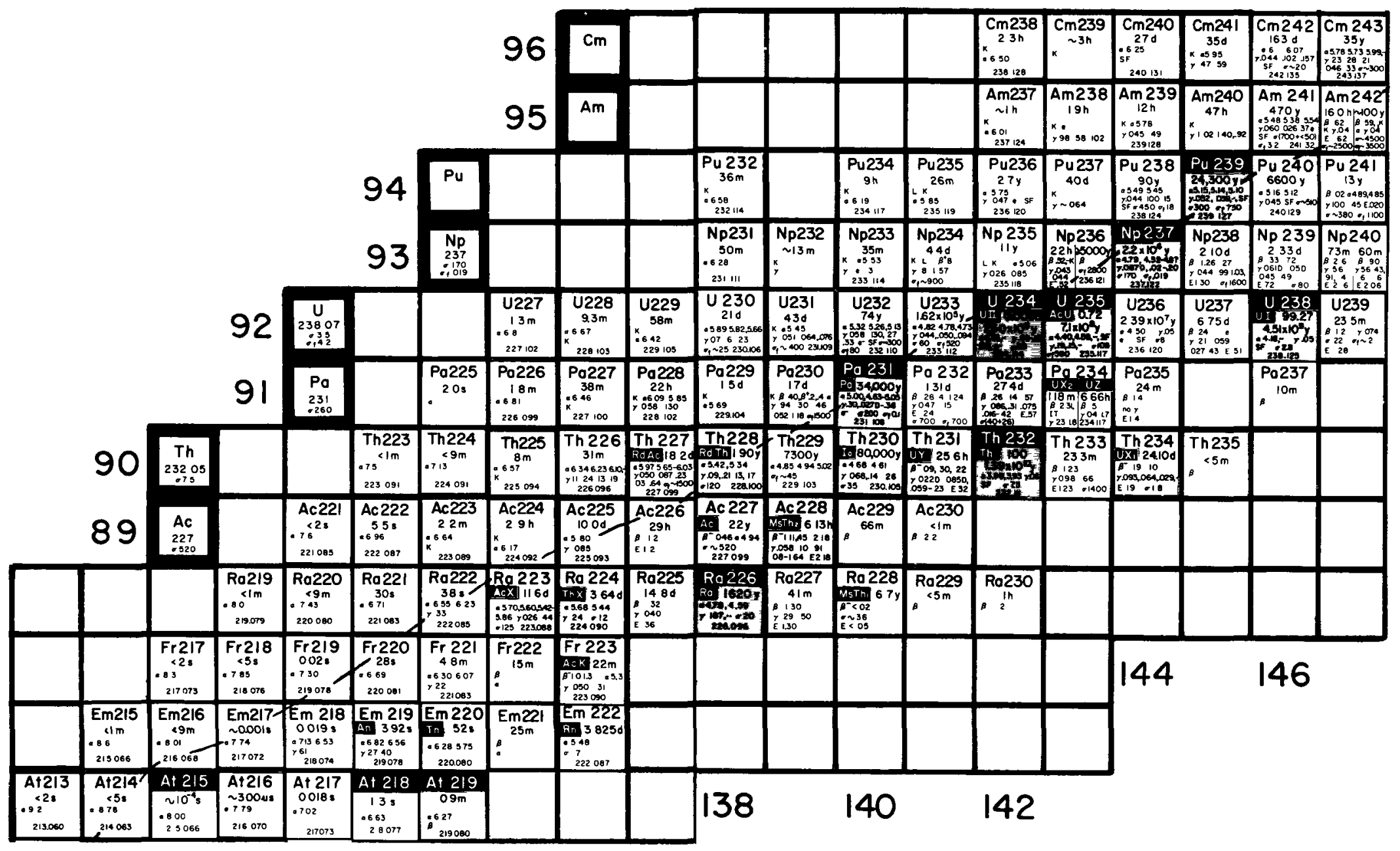

Fig. 5 
LScandium and yttrium are, strictly speaking, not rare earths, but their chemical behavior is very similar to that of the lanthanide group (lanthanum to lutetium) and they will be included in all subsequent discussions of the chemistry of these elements. Actinium is a homologue of lanthanum and is included as representative of the actinide group of elements (actinium to nobelium), which also behave very much like the lanthanides in most chemical operations. Thus, in all discussions of the "rare earths" or "lanthanides" which follow, scandium, yttrium, and the tripositive members of the actinide group are meant to be included.]

The rare-earth elements are quite electropositive and, completely aside from the separation of pure compounds, preparation of the pure metals is not an easy task. Trombe ${ }^{489}$ has written an excellent comprehensive review on all aspects of the preparation and properties of the rare-earth metals, while Spedding and Daane 449,454 and Banks et al. ${ }^{16}$ have published fine reviews of the work that has been done in this field at Iowa State College. Although it might have very little application to radiochemical procedures, Huffine and Williams 548 have written an excellent review of the techniques used to refine and purify rare-earth metals, and Morrice and co-workers 549 have described details of the electrolytic reduction of ceric oxide and cerous fluoride to cerium metal in a molten fluoride solvent.

Electrodeposition of metallic rare earths from aqueous media does not usually give satisfactory results because the newly deposited metal reacts with water to give the oxide. Lange, Herrmann, and Strassmann, 256 however, report a procedure for separating $\mathrm{Sr}^{90}-\mathrm{Y}^{90}$ mixtures by electrolysis in dilute aqueous nitric acid solution. The exact nature of the carrier-free $\mathrm{Y}^{90}$ deposit on the cathode was not determined but the $\mathrm{Y}^{90}$ yields were good $(90-98 \%)$ and the separation from Sr ${ }^{90}$ was fair. $\mathrm{Sr}^{90}-\mathrm{Y}^{90}$ separation factors of approximately 100-200 per deposition were obtained and the authors report that with four deposition cycles the $\mathrm{Y}^{90}$ contained on the order of only $1 \times 10^{-5} \% \mathrm{Sr}^{90}$ impurity. Hamaguchı, Ikeda, and Kawashima ${ }^{187}$ have also described a procedure for the electrolytic separation of $\mathrm{Sr}^{90}-\mathrm{Y}^{90}$ mixtures.

Techniques have been developed for producing rare-earth metals by electrolysis of fused salts using cathodes of carbon, molybdenum, tungsten, mercury, or, at higher temperatures, molten cadmium or zinc. ${ }^{489}$ These procedures are capable of giving good results but the best method currently in use for production of pure metals seems to be that developed by Daane and the Spedding group at Iowa State. ${ }^{449,454}$ This method involves reduction of the anhydrous rare-earth fluorides by metallic calcium in tantalum crucibles under an inert atmosphere. Operating temperatures are kept high enough to melt both the rare-earth metal and the $\mathrm{CaF}_{2}$ slag so that when the 
crucible has cooled the tantalum and slag may be peeled away and the rareearth metal obtained as a solid ingot.

Metallic scandium, yttrium, and all of the rare earths except samarium, europium, and ytterbium have been prepared by this technique. Promethium and the actinides, of course, are not included since they are not normally available in macroscopic ar ounts, although Stone 465 has described a method for preparing $\mathrm{Ac}$ metal by reducing $\mathrm{AcF}_{3}$ in vacuo with lithium metal at $1000^{\circ} \mathrm{C}$. When attempts were made to reduce the $\mathrm{Sm}, \mathrm{Eu}$, and $\mathrm{Yb}$ halides with calcium no metal was produced but the divalent salts were found in the slag. These elements behaved the same whether alone or mixed with other rare earths and, indeed, reduction by calcium has been used by the Spedding group to separate Gd-Sm and Lu-Yb mixtures, the Sm and $Y b$ in each case being found in the slag. In the Lu-Yb case, for instance, a sample which contained $30 \%$ $\mathrm{Yb}$ initially was reduced to lutetium metal containing less than $0.25 \%$ ytterbium impurity in one step. 449

The Iowa State group has succeeded in obtaining pure metallic Sm, Eu, and $\mathrm{Yb}$ by a process which involves reduction of the pure oxide by lanthanum metal in a tantalum crucible. 449,454 Lanthanum is the least volatile of the rare-earth metals and lanthanum oxide has the highest heat of formation of the rare-earth oxides. At the proper temperature, therefore, the reaction

$$
\mathrm{La}+\mathrm{Sm}_{2} \mathrm{O}_{3} \rightleftarrows \mathrm{La}_{2} \mathrm{O}_{3}+\mathrm{Sm}
$$

can be made to go to completion by distilling off the samarium metal as it is formed. The distilled metal is condensed on a cool part of the tantalum reaction vessel and may often be obtalned better than $99.9 \%$ pure.

This technique of reducing the rare-earth oxide with lanthanum and distilling off the newly formed metal has also been used by Spedding and Daane 449 on a mixture of rare earths. The vapor pressures of the rareearth metals are sufficiently different so that by fractional distillation a significant separation of the metals may be obtained. The authors report a possible order of volatility of some of the rare earths as: Eu $>\mathrm{Yb}>\mathrm{Sm}>$ $\mathrm{Lu}>\mathrm{Tm}>\mathrm{Ho}, \mathrm{Dy}>\mathrm{Er}>\mathrm{Gd}$. Trombe 488 has also described the distillation separation of a mixture of rare-earth metals, with the order of volatility* $\mathrm{Sm}>\mathrm{Nd}>\mathrm{Pr}, \mathrm{Ce}>\mathrm{La}$.

Since the pure rare-earth metals have been avallable for such a short time, an accurate determination of all of their physical properties has not as yet been completed to everyone's satısfaction. A tabulation by Spedding and Daane, ${ }^{454}$ however, is shown in Table I and indicates the surprisingly wide variation of some of the physical properties of this group of very similar elements. A more recent compilation of the physical properties of 
Table 1. Properties of rare earth metals (454)

\begin{tabular}{|c|c|c|c|c|c|c|c|c|c|}
\hline Element & $\begin{array}{l}\text { Melting } \\
\text { point } \\
\left({ }^{\circ} \mathrm{C}\right)\end{array}$ & $\begin{array}{l}\Delta H_{\text {melting }} \dagger \\
(\mathrm{kcal} / \mathrm{mole})\end{array}$ & $\begin{array}{c}\text { Boiling } \\
\text { point } \\
\left({ }^{\circ} \mathrm{C}\right)\end{array}$ & $\begin{array}{c}\Delta H_{\text {vaportzation }} \\
\text { (kcal/mole) }\end{array}$ & $\begin{array}{c}\text { Transformation } \\
\text { temperatures } \\
\left({ }^{\circ} \mathrm{C}\right)\end{array}$ & $\begin{array}{c}C, \text { at } 0^{\circ} \mathrm{C} \\
\text { (cal/mole deg })\end{array}$ & Structure & $\begin{array}{l}\text { Lattice } \\
\text { constants } \\
\text { (A) }\end{array}$ & $\begin{array}{l}\text { Density } \\
\left(\mathrm{g} / \mathrm{cm}^{3}\right)\end{array}$ \\
\hline $\mathrm{La}$ & $920 \pm 5$ & $2 \cdot 4$ & 4515 & 81 & $\begin{array}{l}260 \\
868\end{array}$ & 665 & hcp & $\begin{array}{l}a=3770 \\
c=12159\end{array}$ & 6162 \\
\hline $\mathrm{Ce}$ & $804 \pm 5$ & 22 & 3600 & 79 & $\begin{array}{c}\left(100-200^{\circ} \mathrm{K}\right) \\
754\end{array}$ & 689 & $\mathrm{fcc}$ & $a=51612$ & 6768 \\
\hline$P_{\mathbf{r}}$ & $935 \pm 5$ & $2 \cdot 4$ & 3450 & 79 & 798 & 645 & hcp & $\begin{array}{l}a=36725 \\
c=118354\end{array}$ & 6769 \\
\hline Nd & $1024 \pm 5$ & 26 & 3300 & 69 & 868 & 720 & hcp & $\begin{array}{l}a=36579 \\
c=117992\end{array}$ & 7007 \\
\hline $\mathrm{Sm}$ & $1052 \pm 5$ & 26 & $1900^{*}$ & $46^{*}$ & 917 & $649 \dagger$ & $\begin{array}{l}\text { Rhombo- } \\
\text { hedral }\end{array}$ & $\begin{array}{l}a=8996 \\
\alpha=23^{\circ} 13^{\prime}\end{array}$ & 7540 \\
\hline $\begin{array}{l}\mathrm{Eu} \\
\mathrm{Gd}\end{array}$ & $\begin{array}{l}900^{*} \\
1350 \pm 20^{*}\end{array}$ & $\begin{array}{l}23 \\
37\end{array}$ & $\begin{array}{l}1700^{*} \\
3000^{*}\end{array}$ & $\begin{array}{l}40^{*} \\
72\end{array}$ & & $\begin{array}{r}600+ \\
1120\end{array}$ & $\begin{array}{l}\text { bcc } \\
h c p\end{array}$ & $\begin{array}{l}a=4606 \\
a=36360\end{array}$ & $\begin{array}{l}5166 \\
7868\end{array}$ \\
\hline $\mathrm{Tb}$ & $1400-1500^{*}$ & 39 & $2800^{*}$ & $70^{*}$ & & $654 \dagger$ & hcp & $\begin{array}{l}c=57826 \\
a=36010 \\
c=56936\end{array}$ & 8253 \\
\hline Dy & $1475-1500 *$ & 41 & 2600 & 67 & & 672 & hcp & $\begin{array}{l}a=35903 \\
c=56475\end{array}$ & 8565 \\
\hline Ho & $1475-1525$ & 41 & $2700^{*}$ & $68^{*}$ & & 645 & hcp & $\begin{array}{l}a=35773 \\
c=56158\end{array}$ & 8799 \\
\hline Er & $1475-1525 *$ & 41 & $2600^{*}$ & $67^{*}$ & & 665 & $h c p$ & $\begin{array}{l}a=35588 \\
c=55874\end{array}$ & 9058 \\
\hline $\operatorname{Tm}$ & $1500-1550^{*}$ & 44 & $2400^{*}$ & $51^{*}$ & & $645 \dagger$ & hcp & $\begin{array}{l}a=35375 \\
a=55546\end{array}$ & 9318 \\
\hline $\mathbf{Y b}$ & $824 \pm 5$ & $2 \cdot 2$ & $1800 \dagger$ & $32^{*}$ & 798 & $600 \dagger$ & fcc & $a=54862$ & 6959 \\
\hline $\mathbf{L u}$ & $1650-1750^{*}$ & 46 & $3500^{*}$ & $75^{*}$ & & $645 t$ & hcp & $\begin{array}{l}a=35031 \\
c=55509\end{array}$ & 9849 \\
\hline Sc & $1550-1600^{*}$ & 38 & $2750^{*}$ & $73^{*}$ & & $601 \dagger$ & hcp & $\begin{array}{l}a=33090 \\
c=52733\end{array}$ & 2995 \\
\hline $\mathbf{Y}$ & $1475-1525 *$ & 41 & $3500^{*}$ & $94^{*}$ & & $601 \uparrow$ & hcp & $\begin{array}{l}a=36474 \\
c=57306\end{array}$ & 4472 \\
\hline
\end{tabular}

* Estimates from work in Ames Laboratory.

$\dagger$ Estimates made by D.R. Stull and G.C. Sienke, "The Thermodynamic Properties of the Elements in Their Standard States," The Dow Chemical Company, Midland, Michigan.

rare-earth metals, alloys, and compounds has been completed by Gibson, Miller, Kennedy, and Rengstorff, ${ }^{172}$ and Savitskii ${ }^{409}$ has also completed a recent review of the properties, application, and production of rare-earth metals.

The rare-earth metals, being quite electropositive, have high heats of oxidation and react readily with most oxidizıng agents. Reaction rates, however, may vary considerably amongst the individual rare earths under certain conditions. Spedding and Daane, ${ }^{449}$ for instance, state that a bar of lanthanum metal left exposed to moist air will crumble to powder in a few weeks time, but samarium and neodymium will remain bright for months under the same conditions. Trombe ${ }^{489}$ reports that europium metal reacts rapidly with water but samarium does not, and cerium and lanthanum react only slowly even in hot water. No specific data are avallable in the literature but it seems reasonable to assume that in acid solution with "normal" dis solution techniques these differences in reaction rates would be completely negligible. 


\section{IB. AMALGAMS AND VARIOUS OXIDATION STATES}

The rare earths exist in aqueous solution, under normal conditions, only as the trivalent ions. Their like charge and similar ionic radius, of course, account for their very similar chemical behavior. Certain of the rare earths, however, can exist in other than the +3 oxidation state, and this fact is often of value in effecting their separation from other members of the group.

Cerium is the only rare earth which has a useful +4 oxidation state. $\left(\mathrm{Pr}^{+4}\right.$ and $\mathrm{Tb}^{+4}$ have been prepared as their oxides but there is no evidence to indicate that they are stable in aqueous solution.) The $\mathrm{Ce}^{+3}-\mathrm{Ce}^{+4}$ couple has a potential of -1.61 volts in acid solution, 257 and cerous cerium is easily oxidized by strong oxidizing agents such as $\mathrm{S}_{2} \mathrm{O}_{8}=\mathrm{Co}^{+3}$, or, in strong acıd, $\mathrm{BrO}_{3}^{-}$. Brezhneva and co-workers ${ }^{45}$ used ozone as an oxidant for cerium on nitric acid solution. The oxidation is acid dependent. Their data are presented in Figs. 7 and 8 . Ozone is particularly convenient for remote-control operations and for operations in which it is not desired to add nonvolatile matter to the solution. $\mathrm{Ce}^{+4}$ behaves very much like $\mathrm{Zr}^{+4}$ and $\mathrm{Th}^{+4}$ and may, for instance, be separated from all the other rare earths by precipitation as the iodate. $\mathrm{Ce}^{+4}$ is not completely stable, however, but oxidizes water very slowly. 238 Duke and Anderegg ${ }^{108}$ have shown that the reaction is surface catalyzed and Evans and Uri ${ }^{129}$ have shown that it is photosensitive, so reasonable precautions must be taken if $\mathrm{Ce}^{+4}$ solutions are to be kept for any length of time.

Europium, ytterbium, and samarium form +2 ions which have proven to be very useful in separating these elements from the rest of the rareearth group. Europium has the lowest oxidation potential $\left(\mathrm{Eu}^{+2}=\mathrm{Eu}^{+3}\right.$, $\left.E^{0}=0.43, \mathrm{Yb}^{+2}=\mathrm{Yb}^{+3}, \mathrm{E}^{0}=0.578, \mathrm{Sm}^{+2}=\mathrm{Sm}^{+3}, \mathrm{E}^{\circ}>0.9\right)^{257}$ of the se three elements and is the easiest to reduce. Europous europium may be obtained by passing a solution containing $\mathrm{Eu}^{+3}$ over zinc in a Jones reductor, 148,298 by slurrying an $\mathrm{Eu}^{+3}$ solution with zinc dust, ${ }^{23}$ or by reduction with chromous chloride at low $\mathrm{pH}^{\prime} \mathrm{s}$. Eu ${ }^{+2}$ behaves very much like $\mathrm{Ba}^{+2}$ (1.e., it precipitates as $\mathrm{EuSO}_{4}$ but the hydroxide does not precipitate in $\mathrm{NH}_{4} \mathrm{OH}$ ) and may be separated from the rest of the rare-earth group by simple chemical procedures. Eu ${ }^{+2}$ is not very stable towards oxidation, however, and care must be taken to keep its solution free from $\mathrm{O}_{2}$ and other oxidizing agents.

$\mathrm{Yb}^{+2}$ and $\mathrm{Sm}^{+2}$ are much less stable than $\mathrm{Eu}^{+2}$ in aqueous solution. They evolve hydrogen in water and are oxidized at the slightest provocation so their preparation by simple reduction methods is no easy task. Clifford and Beachell, ${ }^{81}$ however, have succeeded in separatıng samarium from a 


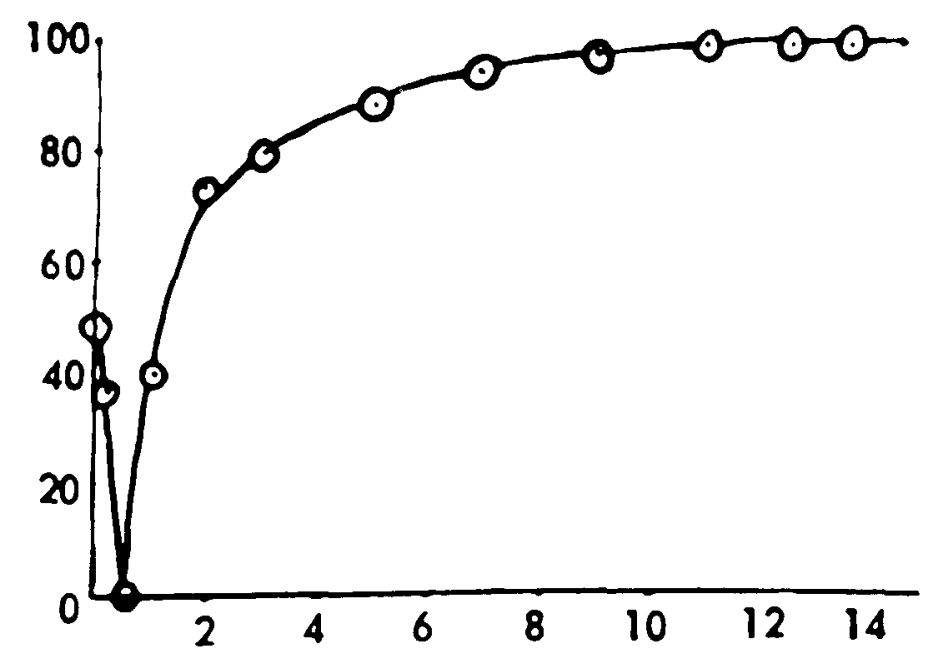

Fig. 7. Percent oxidation of cerium by ozone as a function of nitric acid concentration (one molar per liter) (45)

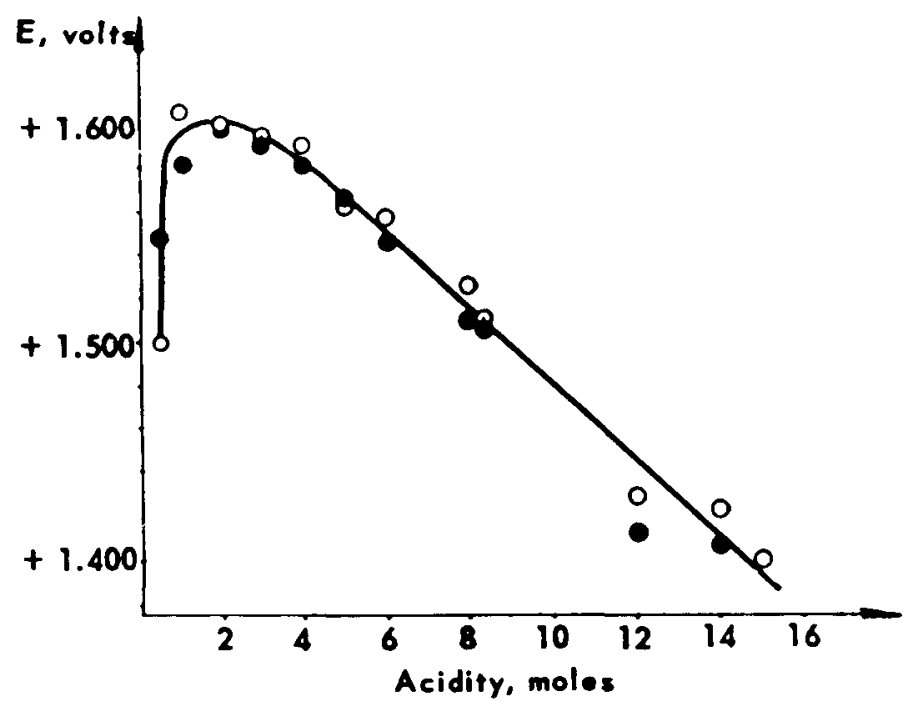

Fig. 8. Oxidation-reduction potential of $\mathrm{Ce}^{+4} / \mathrm{Ce}^{+3}$ couple as a function of nitric acid concentration (one molar per liter). The sign of the potential is according to the European (Russian) convention (45)

lanthanide mixture by reducing with $\mathrm{Mg}$ in solvents of ethanol- $\mathrm{HCl}$ or 50-50 dioxane-ethanol saturated with strontium and barium chlorides. Ambrozhii and Luchnikova ${ }^{8}$ have also reported reduction of $\mathrm{Sm}^{+3}$ by $\mathrm{Mg}$ in an ethanol $\mathrm{HCl}$ solvent. The $\mathrm{SmCl}_{2}$ is deposited on the magnesium surfaces and is not very stable, but it persists long enough so that the supernatant solution may be decanted and the magnesium washed, which, after all, is all that is needed to effect a separation from the original rare-earth contaminants. 
A more effective method for reducing $\mathrm{Eu}, \mathrm{Sm}$, and $\mathrm{Yb}$ involves the use of electrolysis in aqueous solution. McCoy, 299, 300 using a basic citrateacetate solution, a mercury cathode, and a platinum anode, has succeeded in obtaining amalgams of each of these metals. The yield per pass was approximately $90 \%$ for $\mathrm{Eu}, 20 \%$ for $\mathrm{Yb}$, and $10 \%$ for $\mathrm{Sm}$ but by multiple passes essentially all of each of these elements could be recovered from the original solution. Riabtchikov, Skliarenko, and Stroganova, ${ }^{39} 8$ however, have made an excellent systematic study of all the factors affecting ytterbium reduction in the same type of system used by McCoy, and have succeeded in getting $\mathrm{Yb}$ yields of approximately $98 \%$ per pass.

When the electrolyte contains the proper anion it is possible to obtain the insoluble divalent rare-earth salt directly by electrolysis. Thus Yntema ${ }^{542}$ and Ball and Yntema ${ }^{13}$ got europous and ytterbous sulfate instead of the amalgam when the electrolyte contained some sulfuric acid, and Chang ${ }^{72}$ has precipitated europous oxine-sulfonate by electrolysis of an ammoniacal solution of 8-hydroxyquinoline -5 sulfonic acid.

A variation of the electrolytic reduction method has been published by Onstott, $344,345,347$ who purified europium, samarium, and the other rare earths by electrolysis with a lithium amalgam cathode. This technique seems to be more efficient than that used by McCoy, and good yields of high-purity $\mathrm{Eu}$ and $\mathrm{Sm}$ can be obtained without undue effort.

Marsh, in an excellent series of papers, 280-283, 288 has developed procedures for isolating $\mathrm{Eu}, \mathrm{Sm}$, and $\mathrm{Yb}$ by using sodium amalgam without electrolysis. Reduction is carried out in acetic acid solution and proceeds quite vigorously. Lanthanum and the lighter rare earths are also reduced by sodium amalgam but their yields are low and they do not usually present a problem. Moeller and Kremers 312 have studied the effect of various anions on the reduction of ytterbium by sodium amalgam and conclude that in dilute solution the efficiency of the reduction is inversely proportional to the coordinating tendency of the anion, with perchlorate and chloride giving the best results. In concentrated solutions, however, acetate is to be preferred because of the formation of troublesome sludges with perchlorate or chloride. Holleck and Noddack ${ }^{201}$ have used strontium amalgam to reduce rare earths to the +2 state in sulfate solution. $\mathrm{Eu}, \mathrm{Yb}$, and $\mathrm{Sm}$ seem to be reduced with the greatest efficiency, although some reduction of $\mathrm{Sc}, \mathrm{Gd}, \mathrm{Ce}$, $\mathrm{Pr}$, and $\mathrm{Nd}$ is reported; but it is not clear that this technique has any advantages over the sodium amalgam reduction method.

A far out procedure for separating divalent species of the rare-earth elements has been published by Achard. 2, 3 The method involves hightemperature vacuum distillaticn of the $\mathrm{Yb}^{+2}, \mathrm{Eu}^{+2}$, and $\mathrm{Sm}^{+2}$ oxides from 
a mixture of +3 rare earth oxides and carbon. He succeeded in separating all of the $\mathrm{Yb}$ as pure $\mathrm{YbO}$ from a mixture of $\mathrm{Y}, \mathrm{Tb}, \mathrm{Dy}, \mathrm{Ho}, \mathrm{Er}$, and $\mathrm{Yb}$ oxides by mixing the oxides with $25 \%$ of their weight of carbon and heating for three hours at $1400^{\circ} \mathrm{C}$ in a vacuum of $10^{-3} \mathrm{~mm} \mathrm{Hg}$. In another exper1ment, complete separation of a binary mixture of Lu and Yb oxides was achieved by three distillations. Sm and Eu are also removed from mixed rare earths by this method and may be separated from each other by accurate control of the temperature.

\section{2. SOLUBLE SALTS}

There is a surfeit of information avallable in the literature on the solubilities of certain rare-earth salts. For many years fractional crystallization was the best method known for separating these elements and many authors published articles in this field. Fractional crystallization is of no significant value in modern radiochemical techniques, however, so no attempt will be made to review the subject here.

Rare-earth salts are quite soluble in most acids, including hydrochloric, nitric, perchloric, sulfuric, acetic, etc., but accurate values for the solubilities are not readily available. Such values as are available in the "Handbook of Chemistry and Physics,"199 Lange's "Handbook of Chemistry," 255 and Seidell's "Solubilities of Inorganic and Metal Organic Compounds 1430 are reproduced in Table 2 and indicate the range of solubilities of several common salts of these elements.

Very little is known about the solubility of simple rare-earth salts in organic solvents. Stewart and Wendlandt, ${ }^{463}$ however, have recently published an article on the solubility of lanthanum nitrate -6 hydrate in a large number of organic solvents, which, for lack of better information, may be taken as indicative of the general behavior of all the rare earths.

\section{3. INSOLUBLE SALTS}

IV. 3A. INSOLUBLE SALTS AND GRAVIMETRIC COMPOUNDS IV. $3 \mathrm{~A}-1$. Introduction

There is always a problem, when discussing the soluble, insoluble, and complex salts of the rare-earth elements, in deciding just where to draw the lines of demarcation. "Soluble salts, "obviously, will precipitate if the concentrations are high enough, "insoluble salts" are not insoluble in all solutions, and complex salts may dissolve, precipitate, and then dissolve again as the $\mathrm{pH}$ is raised. Thus, the lines of demarcation must be chosen rather arbitrarily. In the last section, "soluble salts" were meant to in- 
clude those rare-earth compounds which do not precipitate in most radiochemical operations. In this section, those insoluble rare-earth salts which are used as gravimetric compounds or as quantitative precipitants in radiochemical separations procedures will be discussed. And Section IV-4 will cover the large family of rare-earth complex and chelate compounds.

IV. $3 A-2$. Hydroxide

While it is undoubtedly convenient to discuss the chemical behavior of the "rare earths" as a group (including scandium, yttrium, the lanthanides, and the actinides in one great melange), it is often not very realistic. Individual elements of the group will behave differently from all the other members of the group in all chemical reactions. The differences of behavior are usually very small, but they can be quite large, and every chemist working with these elements should develop a fine sense of when these large and small differences can be used to his advantage.

A simple illustration of this point may be served by the rare-earth hydroxides. Precipitation of the rare-earth hydroxides is a standard operation which is used in almost all rare-earth radiochemical separation procedures. The precipitation is quantitative, easy to perform, and all the rare-earth elements behave as a group most of the time. Under certain conditions, however, quite different results may be obtained. Moeller and Kremers, 313 in an excellent review of the basicity of the rare earths, conclude that the order of decreasing basicity is: $\mathrm{Ac}, \mathrm{La}, \mathrm{Ce}^{+3}, \mathrm{Pr}, \mathrm{Nd}$, $\mathrm{Sm}, \mathrm{Eu}, \mathrm{Gd}, \mathrm{Tb}, \mathrm{Dy}, \mathrm{Y}, \mathrm{Ho}, \mathrm{Er}, \mathrm{Tm}, \mathrm{Yb}, \mathrm{Lu}, \mathrm{Sc}, \mathrm{Ce}^{+4}$.

The data of Table 3, taken mostly from the Moeller and Kremers article, substantiate this conclusion and indicate several very interesting features. Lanthanum is the most basic element for which data are presented in Table 3; $\mathrm{La}(\mathrm{OH})_{3}$ has the highest solubility in water, the highest $\mathrm{pH}$ of precipitation incidence, and the highest solubility product of any of the rare earths. $\mathrm{Ce}(\mathrm{OH})_{4}$ and $\mathrm{Sc}(\mathrm{OH})_{3}$, on the other hand, are at the opposite extremes in each of these categories. The differences between adjacent elements are not large, but the differences over the entire group are significant. These differences, of course, form the basis for all of the rare-earth fractional precipitation procedures. Separations are certainly not quantitative, but they are large enough to have warranted a considerable amount of work up to the time when more efficient techniques were developed.

Thus, the behavior of the rare-earth hydroxides may be considered as typical of the insoluble rare-earth salts; they are all quite insoluble and they can all be precipitated together if that is desired, or, by varying the conditions of precipitation, significant separations within the group may be carried out. 
Table 2. Solubility of rare-earth salts

\begin{tabular}{|c|c|c|c|c|}
\hline & \multicolumn{4}{|c|}{ Solubility $\left(\mathrm{g} / 100 \mathrm{ml} \mathrm{H}_{2} \mathrm{O}\right.$, at ${ }^{\circ} \mathrm{C}$ temp shown in superscript) } \\
\hline & Chloride & Nitrate & Sulfate & Acetate \\
\hline Scandium & vs & $\mathbf{s}$ & $39.9 \frac{25}{}^{\circ}$ & \\
\hline Yttrium & $217 \frac{20}{}^{\circ}, 233^{50^{\circ}}$ & $134^{22^{\circ}}, 211 \frac{66}{}^{\circ}$ & $9.76 \frac{20}{0}^{\circ}, 4.6{\frac{100^{\circ}}{}}^{\circ}$ & $9.03^{25^{\circ}}$ \\
\hline Lanthanum & vs & $151 \frac{25}{}^{\circ}$ & $3.9 \frac{0}{\circ}^{\circ}, 0.9{\frac{100^{\circ}}{}}^{\circ}$ & $20.4^{18^{\circ}}, 16.99^{25}$ \\
\hline $\begin{array}{r}\text { Cerium }+3 \\
+4\end{array}$ & 100 & $63.7{\frac{25^{\circ}}{}}^{\circ} 73.9 \underline{50}^{\circ}$ & $25^{0^{\circ}}, 7.6 \frac{40}{}^{\circ}$ & $26.55^{\circ}, 16.26^{\circ}$ \\
\hline Praseodymium & $334^{14^{\circ}}, \infty{\frac{100^{\circ}}{130}}^{\circ}$ & $60{\frac{22^{\circ}}{2}: 756^{\circ}}^{\circ}$ & $200^{\circ}, 3.5 \frac{80^{\circ}}{300}$ & $27.4^{25^{\circ}}$ \\
\hline Neodymium & $246 \frac{13}{}^{\circ}, 512{\frac{100^{\circ}}{}}^{\circ}$ & $153^{25^{\circ}}$ & $8 \frac{20}{}^{\circ}, 1.5{\frac{100^{\circ}}{40^{\circ}}}^{\circ}$ & 26.2 \\
\hline $\begin{array}{l}\text { Samarium } \\
\text { Europium }\end{array}$ & $\mathbf{s}$ & & $\begin{array}{l}2.7 \frac{20}{20}^{\circ}, 2.0 \frac{40^{\circ}}{40} \\
2.6 \frac{20}{2}^{\circ}, 2.2 \frac{10}{4}^{\circ}\end{array}$ & $152^{\circ}$ \\
\hline Gadolınium & s & vs & $3.30^{\circ}, 2.5 \frac{40}{}^{\circ}$ & $11.65^{\circ}$ \\
\hline Terbium & $\mathbf{s}$ & $\mathbf{s}$ & $3.56 \frac{20}{0}^{\circ}, 2.51 \frac{40}{\circ}^{\circ}$ & \\
\hline $\begin{array}{l}\text { Dysprosium } \\
\text { Holmium }\end{array}$ & $\mathbf{s}$ & $\mathbf{s}$ & $5.1 \frac{20^{\circ}}{8.180^{\circ}}, 3.33^{\circ}, 44^{\circ}$ & $\mathbf{s}$ \\
\hline Erbium & $\mathbf{s}$ & $\mathbf{s}$ & $16 \frac{20}{}^{\circ}, 6.530^{\circ}$ & \\
\hline Thulıum & vs & & & \\
\hline $\begin{array}{l}\text { Ytterbium } \\
\text { Lutetium }\end{array}$ & vs & & $\begin{array}{l}34.8 \frac{20}{}^{\circ}, 22.940^{\circ} \\
66 \underline{20}^{\circ}, 2240^{\circ}\end{array}$ & vs \\
\hline
\end{tabular}

Table 3 The rare-earth hydroxides

\begin{tabular}{|c|c|c|c|c|c|c|c|}
\hline \multirow[b]{2}{*}{ Element } & \multirow{2}{*}{$\begin{array}{l}\text { Hydroxide solu- } \\
\text { bility product } \\
\text { (at } 25^{\circ} \mathrm{C} \text { ) }\end{array}$} & \multirow{2}{*}{$\begin{array}{l}\text { Water solubility } \\
\text { (gram molecules } \\
\text { per } 10^{6} \text { liters) }\end{array}$} & \multicolumn{4}{|c|}{$\begin{array}{c}\mathrm{pH} \text { at } \\
\text { precipitation incidence }\end{array}$} & \multirow[b]{2}{*}{ Reference } \\
\hline & & & $\mathrm{NO}_{3}{ }^{-}$ & $\mathrm{Cl}^{-}$ & Acetate & $\mathrm{SO}_{4}=$ & \\
\hline $\mathrm{Sc}$ & $1 \times 10^{-28}$ & & & & 6.1 & & 313 \\
\hline $\mathbf{Y}$ & $5.2 \times 10^{-22}$ & $1.2-1.9$ & 7. 39 & 6.78 & 6.83 & 6.83 & 313 \\
\hline La & $1 \times 10^{-19}$ & $7.8-9.2$ & 8. 35 & 8.03 & 7.93 & 7.61 & 313 \\
\hline $\mathrm{Ce}^{+3}$ & $0.8-1.5 \times 10^{-20}$ & $4.1-4.8$ & 8.1 & 7.41 & 7.77 & 7.07 & 313 \\
\hline $\mathrm{Ce}^{+4}$ & $2 \times 10^{-48}$ & & $(2.65)$ & & & & 241,495 \\
\hline $\operatorname{Pr}$ & $2.7 \times 10^{-20}$ & 5.4 & 7. 35 & 7.05 & 7.66 & 6.98 & 313 \\
\hline $\mathrm{Nd}$ & $1.9 \times 10^{-21}$ & 2.7 & 7.00 & 7.02 & 7.59 & 6.73 & 313 \\
\hline $\mathrm{Sm}$ & $6.8 \times 10^{-22}$ & 2.0 & 6.92 & 6.83 & 7. 40 & 6.70 & 313 \\
\hline Eu & $3.4 \times 10^{-22}$ & 1.4 & 6.82 & & 7. 18 & 6.68 & 313 \\
\hline $\mathrm{Gd}$ & $2.1 \times 10^{-22}$ & 1.4 & 6.83 & & 7.10 & 6.75 & 313 \\
\hline $\mathrm{Tb}$ & & & & & & & \\
\hline Dy & & & & $(4.91)$ & & & 495 \\
\hline \multicolumn{8}{|l|}{ Ho } \\
\hline EI & $1.3 \times 10^{-23}$ & 0.8 & 6.76 & & 659 & 6.50 & 313 \\
\hline $\operatorname{Tm}$ & $3.3 \times 10^{-24}$ & 0.6 & 6.40 & & 6.53 & 6.21 & 313 \\
\hline $\mathrm{Yb}$ & $2.9 \times 10^{-24}$ & 0.5 & 6.30 & & 6.50 & 6.16 & 313 \\
\hline $\mathrm{Lu}$ & $2.5 \times 10^{-24}$ & 0.5 & 6.30 & & 6.46 & 6.18 & 313 \\
\hline Ac & & & & & & & \\
\hline
\end{tabular}


The most frequent use of the rare-earth hydroxides in radiochemical procedures involves the separation of the rare earths as a group from contaminating elements; but the hydroxide may be used also as the final precipitate and ignited to the oxide for gravimetric determinations. The data of Table 1 indicate that it should be possible to separate $\mathrm{Ce}^{+4}$ or $\mathrm{Sc}^{+3}$ from other members of the rare-earth group by precipitation as the hydroxide, but this method has not been reported in any radiochemical separation procedures. Scandium hydroxide is likely to present difficulties, since Vickery 506 has shown quite conclusively that scandium is somewhat amphoteric, forming a scandate ion in strong alkali, and also that scandium is capable of forming a soluble hexammino scandium cation in excess ammonia.

An interesting radiochemical separation involving rare-earth hydroxides has been reported by Duval and Kurbatov 13 who recovered carrier-free scandium activity from a calcium target by adsorbing the scandium hydroxide on filter paper at a $\mathrm{pH}$ of approximately 8.5. Schweitzer and Jackson, 426 and Schweitzer, Stein, and Jacks on 427 used essentially the same technique to separate $\mathrm{Ba}^{140}-\mathrm{La}^{140}$ and $\mathrm{Sr} 90-\mathrm{Y}^{90}$ mixtures by adsorption of the basic radiocolloids on glass frit filters. The lauthors report that the method is fairly rapid, that the separation is good, and that the yields can be made to approach $100 \%$ by proper control of the experimental conditions.

Meloche and Vratney ${ }^{308}$ have recently published a study of the solubility products of several rare-earth hydroxides as a function of temperature in the $10^{\circ}-40^{\circ} \mathrm{C}$ temperature range.

IV. $3 \mathrm{~A}-3$. Fluoride

The rare-earth fluorides are also used extensively for group separations of the rare earths from other elements in radiochemical purification procedures. They are quite insoluble and precipitate easily even in strong acid solution. It is unfortunate that so very little quantitative data are available on the solubility of these salts. Kury ${ }^{250}$ has studied the reaction

$$
\mathrm{REF} \mathrm{F}_{3} \rightleftarrows \mathrm{RE}^{+3}+3 \mathrm{~F}^{-}
$$

and reports the solubility product values:

\begin{tabular}{|c|c|}
\hline & $\mathrm{K}_{\mathrm{s}}$ \\
\hline $\mathrm{La}^{+3}$ & $1.4 \times 10^{-18}$ \\
\hline $\mathrm{Ce}^{+3}$ & $1.4 \times 10^{-18}$ \\
\hline $\mathrm{Gd}^{+3}$ & $6.7 \times 10^{-17}$ \\
\hline
\end{tabular}

Weaver and Purdy 512 have also studied the cerous fluoride system and obtained a $K_{s}$ value of $(8.1 \pm 1.1) \times 10^{-16}$ radiometrically and $(1.1 \pm 0.5) \times$ 
$10^{-15}$ by conductometric methods. The Weaver and Purdy curve for $\mathrm{CeF}_{3}$ solubility as a function of $\mathrm{pH}$ is reproduced in Fig. 9 and may be indicative of the behavior of the other rare earths

The behavior of scandium differs very considerably from that of the other rare earths in fluoride solution In 1 M acid solution, $\mathrm{SCF}_{3}$ may be precipitated essentially quantitatively. At lower acid concentrations, with ammonium ion present. the $\mathrm{ScF}_{6}{ }^{-3}$ complex forms, ${ }^{140}$ and in a buffered $\mathrm{NH}_{4}{ }^{+}$ solution at $\mathrm{pH} 5$ the rare-earth fluorides may be precipitated quantitatively while essentially all of the scandium remains in solution. 41

Some evidence exists to indicate that the actinide fluorides are somewhat more soluble than the rare-earth fluorides. Pressiy 353,379 has developed a procedure for separating Am-Pm mixtures by precipitating PmF in solutions of fluosilicic acid. Am remains in solution. The separation is not clean-cut, however, and multiple precipitations are required to get large separation factors.

Perros and Naeser ${ }^{363}$ have reported the existence of a soluble K-Pr-F salt, produced when $\mathrm{PrF}_{3}$ or $\mathrm{Pr}_{6} \mathrm{O}_{11}$ is added to a melt of potassium hydrogen fluoride, but no information is avallable on the stability of this praseodymium fluoride complex in aqueous solution.

IV. $3 A-4$. Oxalate

The oxalate anion is probably used more than any other for precipitation of the rare-earth elements. In dilute acid solution it is reasonably specific

- for this group of elements; the precipitate settles rapidly, has a granular crystalline structure that permits thorough washing, and the oxalate may easily be ignited to the oxide for accurate gravimetric determinations.

A considerable amount of information has appeared in the literature about the behavior of the rare-earth elements in various aqueous oxalate media. It 18 not practical to give all the data here, but an attempt will be made to cover the more significant details. The solubility of all of the rareearth oxalates in water is quite low. As can be seen from the curve of Fig. 10 , which has been reproduced from Vickery's book on the lanthanons, ${ }^{495}$ the hydrated oxalate solubilities range from about $0.4 \mathrm{mg} / 1 \mathrm{lter}$ for $\mathrm{Ce}^{+3}$ to about $4 \mathrm{mg} /$ liter for Lu. In these same units, data of Feibush, Rowley, and Gordon 131 indicate that the solubility of yttrium oxalate is approximately $0.9 \mathrm{mg} / \mathrm{liter}$, while Fischer and Bock 140 state that the solubility of scandium oxalate is about $156 \mathrm{mg} / \mathrm{liter}$ at $25^{\circ} \mathrm{C}$. No specific data are avallable on the solubility of actınıum oxalate in water, but Salutsky and $\mathrm{K}_{1 \mathrm{rby}}{ }^{404}$ report that in $0.1 \mathrm{~N} \mathrm{HNO}_{3}$ O $5 \mathrm{~N}$ oxalic acid the actinium oxalate solubility is $24 \mathrm{mg} / \mathrm{l}$ ter. Fried, Hagemann, and Zachariasen ${ }^{154}$ have also prepared actinium oxalate by precipitation from dilute acid solution but give no precise solubility data. 


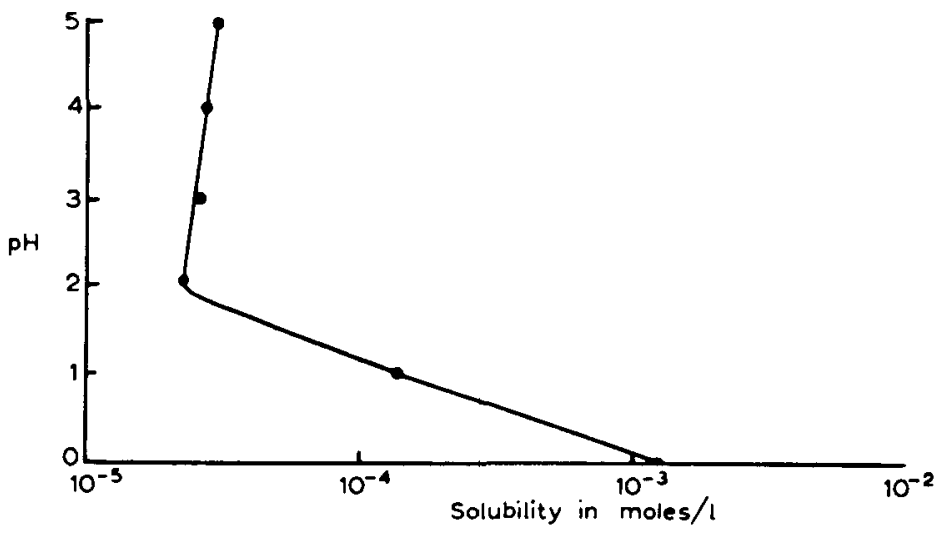

Fig. 9. pH-solubility relationship for cerous fluoride (512)

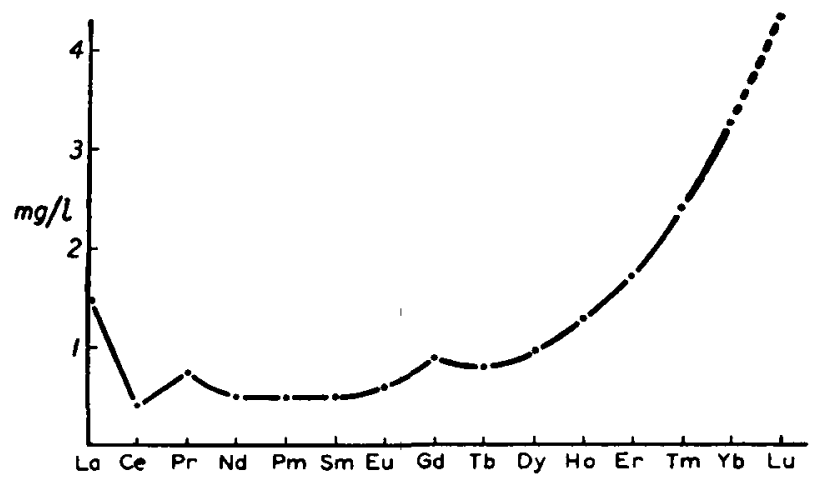

Fig. 10. Solubilities of the hydrated oxalates in water at $25^{\circ} \mathrm{C}$ (495)

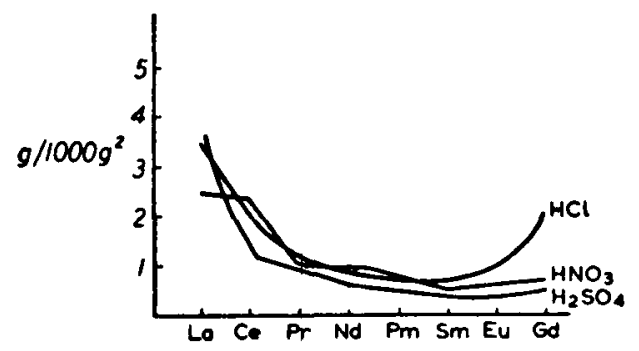

Fig. 11. Solubilities of rare-earth oxalates in $1 \mathrm{~N}$ acid at $25^{\circ} \mathrm{C}$ (495) 
The rare-earth oxalates are usually precipitated in dilute oxalate solution at a $\mathrm{pH}$ of 2 to 3 . In more acid solutions (Fig. 11) the solubilities increase considerably and the very finely divided precipitates are slow to form.

In Fig. 10, it is evident that oxalates of the heavy rare earths are more soluble in water than are those of the light rare earths. In alkali oxalate solutions this difference in solubility is increased, with the lighter earths being practically insoluble and the heavy earths somewhat soluble. Vickery, ${ }^{495}$ for example, states that the relative solubilities of the oxalates in ammonium oxalate are: Th 2663, Yb 104, Y 10.99, Ce 1.8, Nd 1.44, Pr 1.13, and La 1.0. Scandium is a special case - Vickery ${ }^{507}$ presents very convincing evidence that scandium forms not only an anionic oxalate complex in excess oxalate, but also a cationic hexammino scandium ion in the presence of excess ammonium ion, which seriously increases the solubility of the compound. Although these relatively high solubilities have been utilized for the fractional precipitation separation of the heavy rare earths, their main interest for radiochemists lies in the losses and low yields that might occur if the chemist does not realize that they exist. The rare earths are often separated from one another on ion-exchange resin columns and recovered by precipitation of the oxalate from fairly strong (up to $1 \underline{M}$ ) ammonium citrate or ammonium lactate solution. For the lighter rare earths, this presents no difficulty, but for the Ho-Lu group the rareearth oxalate's solubility may easily lead to undesirable losses. Under these conditions, the authors have found that the heavy rare earths may be recovered more efficientiy by precipitation as the 8 -hydroxyquinolates.

Crouthamel and Martin have studied the solubility of ytterbium oxalate and complex ion formation in oxalate solutions 96 and found that their results could be explained by the existence of $\mathrm{Yb}\left(\mathrm{C}_{2} \mathrm{O}_{4}\right)^{+}$and $\mathrm{Yb}\left(\mathrm{C}_{2} \mathrm{O}_{4}\right)_{2}^{-}$complex ions. Experiments 97 with Nd disclosed the existence of similar complexes although the total neodymium concentration in solution was approximately fifty times less than the Yb. With $\mathrm{Ce}^{+3}, 97$ however, it was necessary to postulate the existence of a $\mathrm{Ce}\left(\mathrm{C}_{2} \mathrm{O}_{4}\right)_{3}^{-3}$ complex in addition to the $\mathrm{Ce}\left(\mathrm{C}_{2} \mathrm{O}_{4}\right)^{+}$ and $\mathrm{Ce}\left(\mathrm{C}_{2} \mathrm{O}_{4}\right)^{-}$complexes in order to explain the data. Feibush, Rowley, and Gordon 131 have used the same techniques to study the yttrium oxalate system and they, too, require that the $\mathrm{Y}\left(\mathrm{C}_{2} \mathrm{O}_{4}\right)_{3}^{-3}$ complex be formed in order to explain their results. No explanation is given for this difference in behavior between $\mathrm{Yb}-\mathrm{Nd}$ and $\mathrm{Y}-\mathrm{Ce}{ }^{+3}$, but there seems no question that the complexes exist. An interesting consequence of these experiments is that they show that the total concentration in solution of those rare earths which form the trioxalate complex is increasing with the $3 / 2$ power of the oxalate concentration while those which form only the dioxalate increase with the $1 / 2$ power (Figs. 12,13). If this behavior extends into more concentrated 


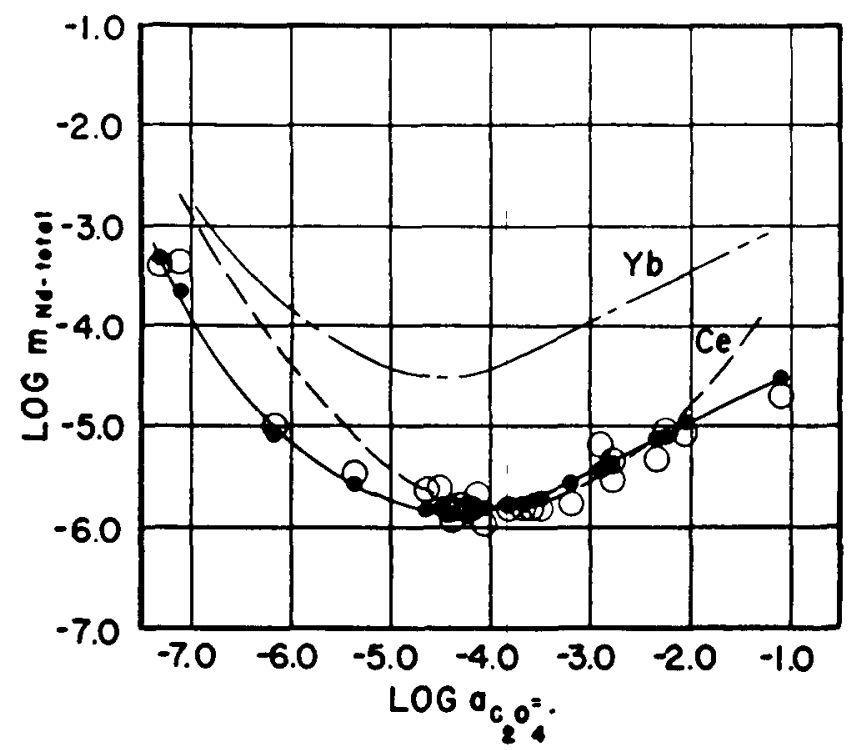

Fig. 12. Total $\mathrm{Yb}, \mathrm{Ce}^{+3}$, and Nd concentratiuns in buffered oxalate solutions. $\mathrm{Yb}$ and $\mathrm{Ce}$ curves are labeled, solid curve and experimental points are for Nd (96)

oxalate solutions some very interesting reversals of the order of solubility may be expected among the rare-earth group of elements.

$\mathrm{Ce}^{+4}$ oxalate is considerably more soluble than the trivalent rare-earth oxalates. Ryabchikov and Vagina ${ }^{399}$ report that the bright orange ceric oxalate complex is reasonably stable in aqueous solution at room temperature bit decomposes on heating, with the formation of a cerous oxalate precipitate. In addition, they have used the high ceric oxalate solubility to separate cerium from a mixture of rare earths with $97-98 \%$ yields of $99.9 \%$ pure $\mathrm{CeO}_{2}$.

IV. 3A-5. 8-Hydroxyquinolate

In ammoniacal solution, 8-hydroxyquinoline may be used as a quantitative precipitant for the rare-earth elements. Very little quantitative solubility data are available but Eswaranarayana and Raghava Rao ${ }^{128}$ have used the reagent for the determination of $\mathrm{Ce}^{+3}$ and $\mathrm{La}^{+3}$, and Pokras and Bernays 367,368 have used it for $\mathrm{Sc}^{+3}$.

The precipitation is fairly sharply dependent on $\mathrm{pH}$, as shown by the Eswaranayana and Raghava Rao data in Fig. 14, and most precipitations are carried out in slightly ammoniacal solution. Pokras and Bernays indicate that there is no precipitation of scandium at $\mathrm{pH} 3.90$ and essentially complete precipitation at $\mathrm{pH} 5.72$, but they give no data for intermediate $\mathrm{pH}^{\mathrm{s}}$.

8 -hydroxyquinoline is certainly not a selective precipitant for the rareearth elements. 274 The precipitate is flocculent and often hard to wash, and 


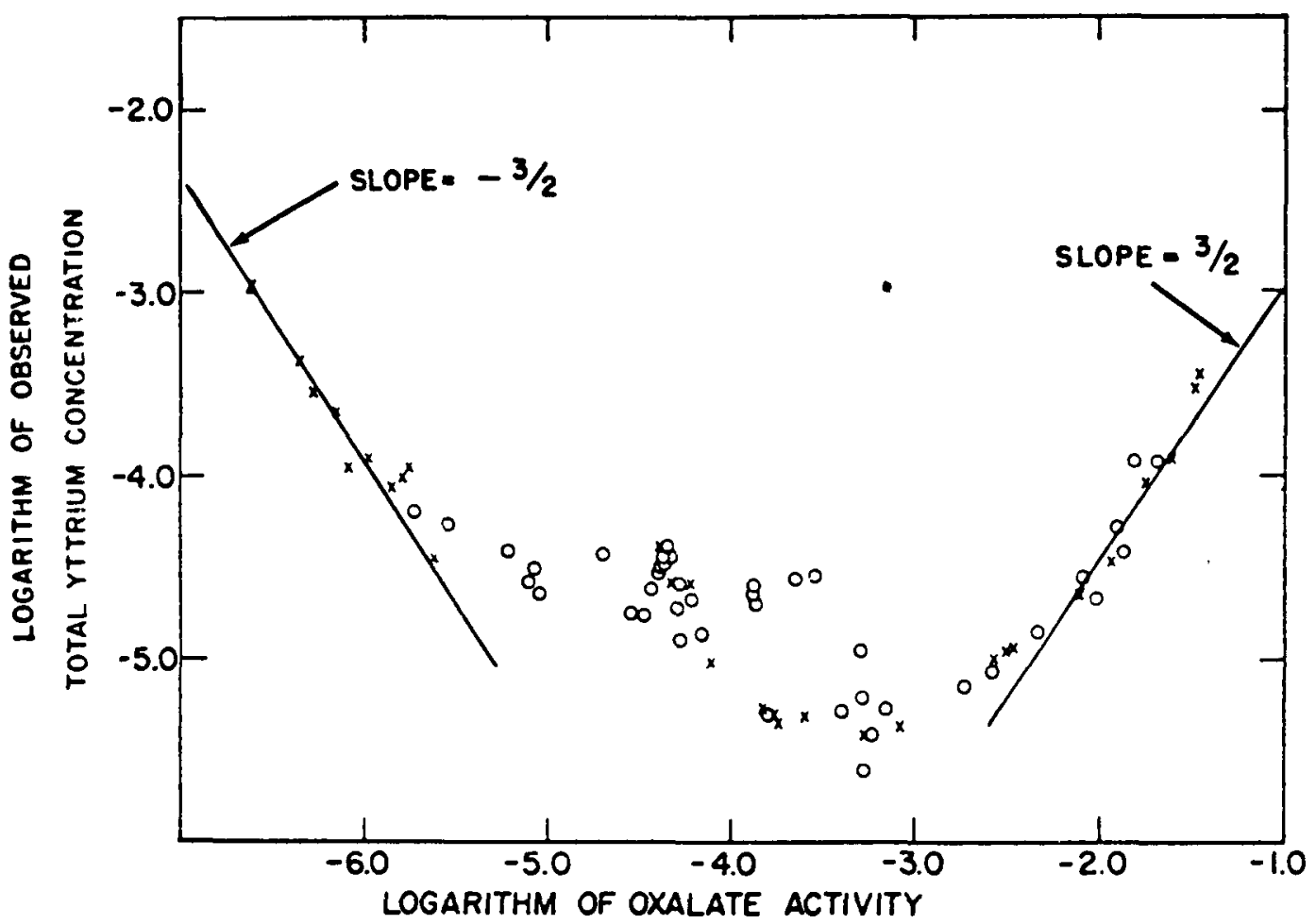

Fig. 13. Plot of logarithm of observed yttrium concentration vs logarithm of oxalaie inn activity (131)

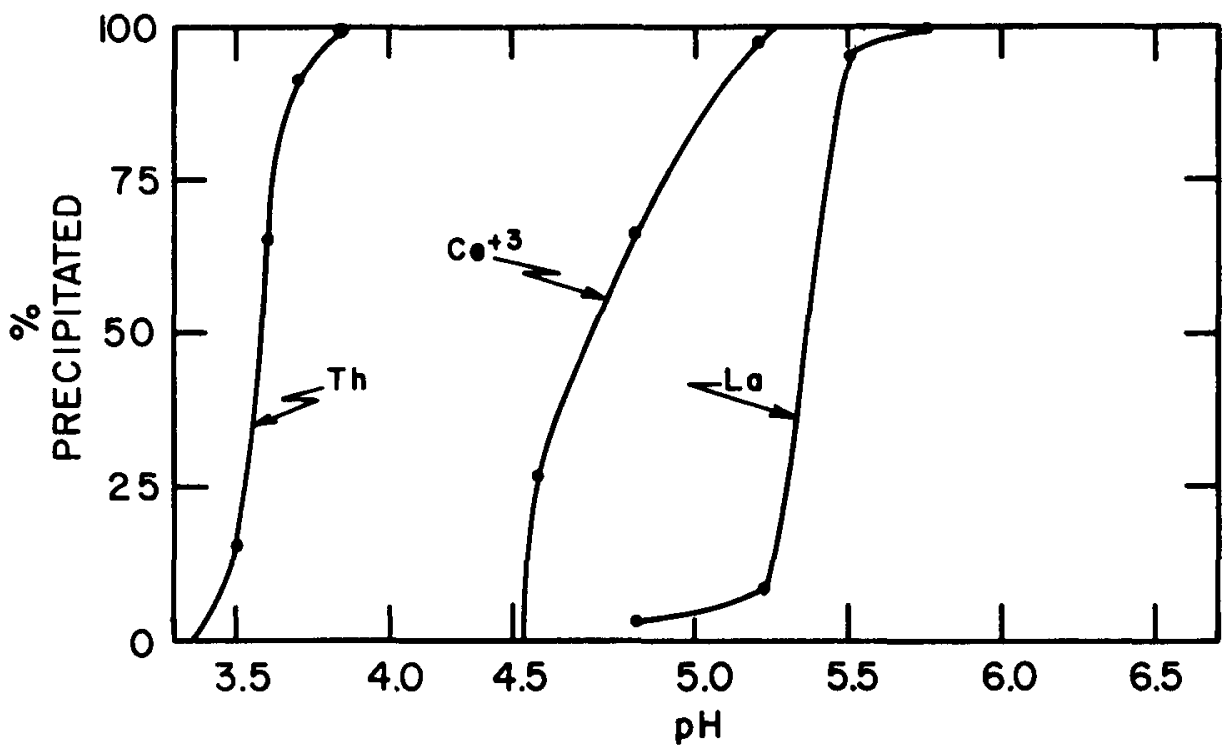

Fig. 14. Precipitation of thorium and rare earth - 8-hydroxyquinolates vs $\mathrm{pH}(128)$ 
therefore its use as a gravimetric compound is open to some question. It is of value in spite of these drawbacks, sinde it is a more sensitive reagent for the rare earths than other precipitants (see Section IV. 3A-13) and may be used to recover very small amounts of material from solution. The authors, for example, have used 8-hydroxyquinoline to precipitate $40.1 \mathrm{mg} / \mathrm{ml}$ of Lu and $\mathrm{Yb}$ from $1 \underline{M}$ ammonium lactate solutions with essentially complete recovery of the rare earths. Under the same conditions, oxalate and hydroxide gave no precipitate whatever.

\section{3A-6. Ammonium Tartrate}

Ammonium tartrate is often used as a precipitant to separate scandium from a large number of other elements. Fischer and Bock ${ }^{140}$ state that in an ammoniacal solution containing an excess of ammonium tartrate the solubility of scandium ammonium tartrate is approximately 3 to $4 \mathrm{mg} \mathrm{Sc} \mathrm{O}_{3} / \mathrm{liter}$ soln. Fischer, Steinhauser and Hohmann 139 have extended the Fischer and Bock study and show that tartrate may be used to separate scandium from very large excesses of $\mathrm{Y}, \mathrm{Fe}, \mathrm{Mn}, \mathrm{Ti}, \mathrm{Mg}, \mathrm{Ca}, \mathrm{Al}, \mathrm{Cu}, \mathrm{Cd}, \mathrm{Zn}, \mathrm{Pb}, \mathrm{Ga}$, Ge, Sn, Nb, Cr, V, Mo, and Ni. They used solutions which were either $10 \%$ or $20 \%$ in ammonium tartrate and $0.2 \mathrm{~N}$ td $1.5 \underline{\mathrm{N}}$ in $\mathrm{NH}_{4} \mathrm{OH}$. No specific solubility data are available on the ammonium tartrates of other rare earths, but according to Meyer 310 the ceric earths afe quite soluble and the yttrium earths difficulty soluble. The data of reference 139 indicate that yttrium

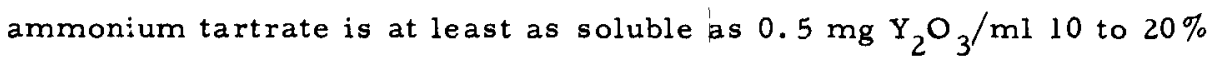
ammonium tartrate soln. It is reasonable to expect the heaviest rare-earth tartrates to be less soluble than yttrium, so that they might well coprecipitate with scandium if they are present in any significant amount.

\section{3A-7. Complex Cyanides}

The rare earths are reported to form quite insoluble complex cyanides. 495 Most of the work has been carried out with the ferrocyanide, ferricyanide, and cobalticyanide salts. 495,547 The insoluble rare-earth salts are quite complex in that their compositions and solubilities are functions of the cation as well as the anion of the precipitant. Thus Tananaev and Seifer ${ }^{474}$ report

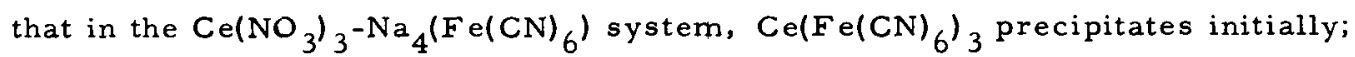
but with an excess of reagent $\mathrm{Na}_{4} \mathrm{Ce}_{8}\left(\mathrm{Fe}(\mathrm{CN})_{6}\right)_{7}$ precipitates (solubility $2.1 \times$ $10^{-4}$ mole/liter). In the $\mathrm{Y}\left(\mathrm{NO}_{3}\right)_{3}-\mathrm{K}_{4}\left(\mathrm{Fe}(\mathrm{CN})_{6}\right)$ system, $\mathrm{K}_{4} \mathrm{Y}_{8}\left(\mathrm{Fe}(\mathrm{CN})_{6}\right)-3 \mathrm{OH}_{2} \mathrm{O}$ precipitates (solubility $6.2 \times 10^{-6}$ mole/liter); but in the $\mathrm{Y}\left(\mathrm{NO}_{3}\right)_{3}-\mathrm{Rb}_{4}\left(\mathrm{Fe}(\mathrm{CN})_{6}\right)$ system, $\mathrm{RbY}\left(\mathrm{Fe}(\mathrm{CN})_{6}\right)-2 \mathrm{H}_{2} \mathrm{O}$ is the precipitate (solubility $1.8 \times 10^{-4} \mathrm{~mole} /$ liter); and in the $\mathrm{Y}\left(\mathrm{NO}_{3}\right)_{3}-\mathrm{Li}_{4}\left(\mathrm{Fe}(\mathrm{CN})_{6}\right)$ and $\mathrm{Y}\left(\mathrm{NO}_{3}\right)_{3}-\mathrm{Na}_{4}\left(\mathrm{Fe}(\mathrm{CN})_{6}\right)$ systems the authors report that there is no ferrocyanide precipitate at all. 
While the complex rare-earth cyanides appear to be quite insoluble, their use has been restricted mainly to fractional precipitation separations, especially of the yttrium earths, 495 and the authors know of no cases where they have been used in radiochemical separations of any kind.

IV. 3A-8. Phosphate and Related Anions

The rare-earth phosphates are quite soluble in acid solution. As the $\mathrm{pH}$ is increased, however, solubility decreases, and in solutions above $\mathrm{pH}$ 4 to 5 precipitation is essentially complete. A fairly large number of elements also precipitate under these conditions 274 and there are indications of fairly large differences of solubility of individual members of the rareearth group. 279 No precise data are available on the rare-earth phosphate solubility vs solution $\mathrm{pH}$, and the use of phosphate eithe $\mathrm{r}$ as a quantitative gravimetric precipitant or as a desirable precipitant to separate the rare earths from other elements is open to some question.

Scandium forms useful insoluble salts with several phosphate relatives. Beck $^{22}$ has reported that scandium pyrophosphate is very sparingly soluble, even in mineral acids. In mineral acids, too, the scandium salts of aneurin pyrophos phate (cocarboxylase) and phytic acid $\left(\mathrm{C}_{6} \mathrm{H}_{6}\left(\mathrm{OPO}(\mathrm{OH})_{2}\right)_{6}\right)$ a re quite insoluble, and the scandium salt of adenosin triphosphate is insoluble in $30 \%$ acetic acid. $\mathrm{Zr}$ also precipitates under each of these conditions, but $\mathrm{Mg}, \mathrm{Ca}$, $\mathrm{Ba}, \mathrm{Al}, \mathrm{Y}, \mathrm{Th}, \mathrm{Cu}, \mathrm{Hg}, \mathrm{Tl}, \mathrm{Cr}, \mathrm{Mn}$, and $\mathrm{Fe}$ do not.

Vickery ${ }^{508}$ has published an excellent review of the precipitation and extraction reactions of scandium which gives more precise data than are available anywhere else in the literature. Table 4 is reproduced from his article and indicates the fraction of scandium that may be precipitated under optimum conditions with a large number of reagents. For specific data as to the optimum conditions in each case, the original article should be consulted. Bomberger ${ }^{40}$ has reported that hypophosphorous acid may be used as a gravimetric reagent for scandium. The precipitation is essentially quantitative $(\sim 99.9 \%)$ when the initial precipitate is digested over steam for one hour. Optimum conditions are in the area of $1 \mathrm{~N} \mathrm{HCl}-0.5 \mathrm{~N} \mathrm{H}_{3} \mathrm{PO}_{2}$, but considerable latitude is possible with small loss in efficiency. Any substance that oxidizes hypophosphorous acid under hot, acid conditions, or any one of a fairly long list of elements ( $\mathrm{Z}, \mathrm{Hf}, \mathrm{Th}, \mathrm{Ta}, \mathrm{Ca}, \mathrm{Ag}, \mathrm{Au}, \mathrm{Hg}, \mathrm{Bi}, \mathrm{Sb}, \mathrm{As}$, Sn, Se, Te, Pd, Al, Ga, In, Y, V, Cr, Mo, U, F, Fe, Co, and Pt), inter feres with the scandium hypophosphite precipitation, so the reagent is best used as a final precipitant in a solution which contains only scandium.

IV. $3 A-9$. Iodate

$\mathrm{Ce}^{+4}$ forms an insoluble ceric iodate ${ }^{48}$ which permits easy and rapid 
Table 4. Precipitation of scandium by various precipitants. Tabulated data are \% Se prectpitated under optimum conditions (508)

\begin{tabular}{|c|c|c|c|c|c|c|}
\hline \multirow[b]{2}{*}{ Precipitant } & \\
\hline & 1 & 5 & 10 & 50 & 75 & 100 \\
\hline $\mathrm{NaOH}$ & 80 & 90 & - & 98 & 98 & - \\
\hline KOH & 80 & - & 100 & - & 一 & - \\
\hline $\mathrm{NH}_{4} \mathrm{OH} \quad \ldots \ldots \ldots \ldots \ldots . . . . . . .$. & 60 & 69 & - & 82 & - & 85 \\
\hline $\mathrm{Na}_{2} \mathrm{CO}_{3} \quad \ldots \ldots \ldots \ldots \ldots$ & Nil & Nil & 10 & - & $\vec{\sim}$ & 16 \\
\hline $\mathrm{K}_{2} \mathrm{CO}_{3} \ldots \ldots \ldots \ldots \ldots$ & 50 & -7 & 72 & $\overline{10}$ & 85 & - \\
\hline$\left(\mathrm{NH}_{4}\right)_{2} \mathrm{CO}_{3} \quad \ldots \ldots \ldots \ldots$ & Nil & Nil & $\mathrm{Nil}$ & 10 & & 12 \\
\hline 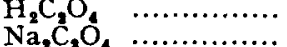 & Nil & $12 \cdot 5$ & 27 & $\overline{25}$ & 37 & $\begin{array}{l}52 \\
61\end{array}$ \\
\hline 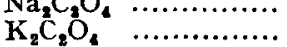 & $\begin{array}{l}\text { Nil } \\
\text { Nil }\end{array}$ & - & $\overline{20}$ & $\underline{25}$ & 二 & $\begin{array}{l}61 \\
43\end{array}$ \\
\hline$\left(\mathrm{NH}_{4}\right)_{2} \mathrm{C}_{2} \mathrm{O}_{4} \ldots \ldots \ldots \ldots$ & Nil & Nil & Nil & - & 16 & \\
\hline $\mathrm{HF} \quad \ldots \ldots \ldots \ldots \ldots \ldots$ & 90.5 & & 95 & 94 & - & 96 \\
\hline $\mathrm{NaF}, \ldots \ldots \ldots \ldots \ldots \ldots$ & 35 & 42 & - & 55 & - & 72 \\
\hline $\mathrm{KF} \quad \ldots \ldots \ldots \ldots \ldots \ldots$ & 86 & & - & 90 & 92 & 92 \\
\hline $\mathrm{NH}_{4} \mathrm{~F} \ldots \ldots \ldots \ldots \ldots$ & Nil & Nil & Nil & - & - & - \\
\hline $\mathrm{H}_{3} \mathrm{PO}_{1}, \ldots \ldots \ldots \ldots$ & Nil & & 一 & - & - & Nil \\
\hline $\mathrm{NaH}, \mathrm{PO}, \quad \ldots \ldots \ldots \ldots$ & 90 & 90 & - & 95 & - & 97 \\
\hline $\mathrm{Na}_{2} \mathrm{HPO}_{4} \quad \ldots \ldots \ldots \ldots$ & 99 & - & 100 & 100 & - & 100 \\
\hline $\mathrm{Na}_{3} \mathrm{PO}_{4}, \ldots \ldots \ldots \ldots \ldots$ & $\mathbf{5 3}$ & - & 76 & - & 82 & 84 \\
\hline $\mathrm{K}_{2} \mathrm{H}_{2} \mathrm{P}_{2} \mathrm{O}, \ldots \ldots \ldots \ldots$ & 95 & - & 97 & - & 99 & - \\
\hline $\mathrm{Na}_{2} \mathrm{H}_{2} \mathrm{P}_{2} \mathrm{O}_{7} \ldots \ldots \ldots \ldots$ & 96 & - & - & 98 & - & 99 \\
\hline Cocarboxylase $\quad \ldots \ldots$. & 93 & 93 & - & 98 & - & 99 \\
\hline Phytin $\ldots \ldots \ldots \ldots \ldots \ldots$ & 99 & 100 & - & 100 & - & 100 \\
\hline $\mathrm{Na}_{2} \mathrm{SO}_{4}$ & Nil & - & - & - & Nil & - * \\
\hline $\mathrm{K}_{2} \mathrm{SO}_{4} \ldots \ldots \ldots \ldots \ldots \ldots$ & 66 & - & 73 & - & 81 & $-*$ \\
\hline$\left(\mathrm{NH}_{4}\right)_{2} \mathrm{SO}_{4}, \ldots \ldots \ldots \ldots$ & Nil & Nil & - & Nil & - & $\mathrm{Nil} *$ \\
\hline AcOH $\ldots \ldots \ldots \ldots \ldots \ldots$ & Nil & $\mathrm{Nil}$ & 32 & - & - & 63 \\
\hline NaOAc $\quad \ldots \ldots \ldots \ldots \ldots$ & 66 & 70 & - & 74 & - & 72 \\
\hline $\mathrm{NH}_{4} \mathrm{OAc} \ldots \ldots \ldots \ldots \ldots$ & $\mathrm{Nil}$ & - & Nil & - & $\mathrm{Nil}$ & - \\
\hline Tartaric acid $\ldots \ldots \ldots$ & Nil & - & 50 & - & 63 & - \\
\hline Na K tartrate ....... & Nil & - & - & Nil & - & - \\
\hline$\left(\mathrm{NH}_{4}\right)_{2}$ tartrate ...... & 81 & 92 & - & 96 & 99 & - \\
\hline Citric acid & & 30 & - & 39 & - & 42 \\
\hline $\mathrm{KIO}_{3} \quad \ldots \ldots \ldots \ldots \ldots$ & Nil & Nil & - & - & - & Nil \\
\hline $\mathrm{Na}_{8} \mathrm{~B}_{4} \mathrm{O}_{3}, \ldots \ldots \ldots \ldots \ldots$ & 93.5 & 一 & - & 99 & $\overrightarrow{0}$ & 99 \\
\hline Tannin $\quad . . . \ldots \ldots \ldots . . . .$. & .85 & - & 86 & - & 90 & - \\
\hline Oxine & 85 & 93 & - & $99 \cdot 3$ & - & 700 \\
\hline Alizarin $\quad \ldots \ldots \ldots \ldots \ldots$ & 89 & 91 & 99 & - & - & 100 \\
\hline
\end{tabular}

Precipitation of $\mathrm{Sc}(\mathrm{OH})_{3}$ in presence of $\mathrm{NH}_{4} \mathrm{Cl}$ (concn., $50 \mathrm{mg}$. of $\mathrm{Sc}_{2} \mathrm{O}_{3}$ per $m l$.).

NH.Cl concn. (mg./ml.)

Pptn. (\%) by NaOH

.. $\quad$ aq. $\mathrm{NH}_{3}$

5
96
95

96

89

15
85
87
75

$\begin{array}{ll}\mathbf{2 5} & 50 \\ 79 & 63 \\ 75 & 60 \\ \mathbf{6 2} & 45\end{array}$

Inhibition of $\mathrm{Sc}(\mathrm{OH})_{3}$ precipitation (50 mg. of $\mathrm{Sc}_{2} \mathrm{O}_{3}$ per ml.).

Hydroxy-acid concn. (\%)

Pptn. (\%) by $\mathrm{NaOH}$ (citrate)

(tartrate)

1
80

86

5
$\mathbf{4 2}$

15
27

22 
separation of cerium from the other rare earths. The precipitation is usually carried out in approximately $4 \underline{\mathrm{M}} \mathrm{HNO}_{3}$ solutions. $\mathrm{Zr}^{+4}$ and $\mathrm{Th}^{+4}$ iodates precipitate under the same conditions and a most effective radiochemical separation is obtained by reducing cerium with $\mathrm{H}_{2} \mathrm{O}_{2}$, scavenging the solution with zirconium lodate, oxidizing $\mathrm{Ce}^{+3}$ with bromate, and precipitating ceric lodate.

Venkataramaniah and Raghavarao ${ }^{494}$ have reported an interesting procedure for separating $\mathrm{Ce}^{+4}$ from the other rare earths and thorium by precipitating ceric periodate. The precipitation is carried out by adding a 1:5 $\mathrm{HNO}_{3}$ solution saturated with potassium periodate to a $1: 5 \mathrm{HNO}_{3}$ solution containing $\mathrm{Ce}^{+4}$ and digesting in a boiling water bath for 10 to $15 \mathrm{~min}$. Precipitation is quantitative and the salt may be dried at $100-110^{\circ} \mathrm{C}$ and weighed as $\mathrm{CeHIO}_{6} \cdot \mathrm{H}_{2} \mathrm{O}$. Neither $\mathrm{Th}^{+4}$ nor the other rare earths precipitate under these conditions.

IV. $3 A-10$. Cupferron

Cupferron and neocupferron form insoluble salts with the rare-earth elements which may be of value in quantitative determination of these elements. ${ }^{372}$ The precipitates are somewhat soluble below $\mathrm{pH} 2$ and the opt mum $\mathrm{pH}$ for precipitation seems to be about 3. 5. Significant amounts of the precipitant are occluded in the rare-earth salts so it is necessary to ignite the cupferrate to the oxide to get the best results; but ignition proceeds smoothly, and final results are comparable in accuracy to those obtained by the oxalate method. The reagents are far from selective for the rare earths, ${ }^{274}$ however, and care must be taken that there are no interfering cations present when the rare earths are precipitated.

Sinha and Shome ${ }^{441}$ report that $\mathrm{Th}^{+4}$ and $\mathrm{Ce}^{+3}$ may be precipitated quantitatively by $n$-benzoylphenylhydroxylamine and determined by ignition to the oxide. The authors do not mention the other rare earths but presumably they behave very much like $\mathrm{Ce}^{+3}$.

IV. $3 \mathrm{~A}-11$. Chloride

Fischer, Wernet, and Zumbusch-Pfisterer ${ }^{138}$ have reported that the rare earths are relatively insoluble in saturated $\mathrm{HCl}$ solution ( $24 \mathrm{mg} \mathrm{Y}_{2} \mathrm{O}_{3} /$ $100 \mathrm{ml}$ at $\left.0^{\circ} \mathrm{C}\right)$ and much less soluble in saturated $\mathrm{HCl}$ - diethyl ether (1.5 mg $\mathrm{Y}_{2} \mathrm{O}_{3} / 100 \mathrm{ml} \mathrm{l:1}$ soln. at $\left.0^{\circ} \mathrm{C}\right)$. Scandium is considerably more soluble in each of these cases ( $>1.5 \mathrm{~g} \mathrm{Sc}_{2} \mathrm{O}_{3} / 100 \mathrm{ml} \mathrm{HCl}$ at $0^{\circ} \mathrm{C},>4 \mathrm{~g} \mathrm{Sc}_{2} \mathrm{O}_{3} / 100 \mathrm{ml}$ $\mathrm{HCl}$ - ether at $0^{\circ} \mathrm{C}$ ) and the authors suggest that this might be a useful means of separating $\mathrm{Sc}$ - rare-earth mixtures under some circumstances.

IV. 3A-12. Miscellaneous Precipitants

Takashima 473 reports that scandium may be determined gravimetrically 
as the hexamminecobalt fluoscandate $\left[\mathrm{Co}\left(\mathrm{NH}_{3}\right)_{6}\right]\left[\mathrm{ScF}_{6}\right]$. Precipitation is carried out in a pH 3 to 4 solution and the precipitate is dried at $110^{\circ} \mathrm{C}$. The author reports that 0.5 to $5 \mathrm{mg}$ of scandi $n$ can be determined with an error of less than $3 \%$.

Reddy, Sarma, and Raghava $R$ ao $^{385}$ report that La may be separated from the rare earths excluding cerium by controlled precipitation of lanthanum chromate.

IV. $3 A-13$. Sensitivity of Various Precipitants

In radiochemical investigations it is often desirable to know the smallest amounts of rare-earth carrier that may be precipitated in a given set of conditions. Relatively few articles are available which make a direct comparison of the sensitivity of various precipitants to the rare-earth elements. Wendlandt and Hayes ${ }^{521}$ have compared the oxalate and cupferrate sensitivity of the light rare earths and $W$ endlandt and Sewel1 ${ }^{552}$ have extended the study to several salts of the heavy rare earths. Their data are combined in Table 5 and serve to indicate the limits of precipitation for each of these reagents under optimum conditions. Only four reagents have been compared in Table 5; of these, 8 -hydroxyquinoline is the most sensitive and oxalic acid the least sensitive precipitant for the rare earths.

Table 5. Sensitivity of the rare earths to various precipitants $(521,552)$

$\mu g M^{+3}$ per ml

Metal Oxalic

Ion Acid Cupferron 8-Hydroxyquinoline 2-Methyl 8-Hydroxyquinoline

\begin{tabular}{llcll}
\hline $\mathrm{La}$ & 6.3 & 2.4 & & \\
$\mathrm{Ce}+3$ & 6.4 & 1.6 & & \\
$\mathrm{Pr}$ & 6.4 & 1.6 & & \\
$\mathrm{Nd}$ & 6.6 & 2.5 & & 17 \\
$\mathrm{Sm}$ & 6.9 & 5.1 & & \\
$\mathrm{Eu}$ & 35 & 5.2 & 1.7 & 7.1 \\
$\mathrm{Gd}$ & 17.8 & 17.8 & & 7.4 \\
$\mathrm{~Tb}$ & 36 & 7.1 & 1.4 & 13 \\
$\mathrm{Dy}$ & 19 & 7.4 & 1.1 & 9.5 \\
$\mathrm{Y}$ & 10.2 & 10.2 & & 20 \\
$\mathrm{Ho}$ & 38 & 13 & 3.8 & \\
$\mathrm{Er}$ & 57 & 17 & 3.8 & 4.0 \\
$\mathrm{Yb}$ & 40 & 30 & & \\
\hline
\end{tabular}


IV. 3B. COPRECIPITATION

Coprecipitation is a difficult subject to discuss coherently under the best of circumstances. Discussion of the rare earths is doubly difficult, of course, since they will "coprecipitate" one with another in almost all their precipitation reactions. One may always use one rare earth as a carrier to coprecipitate another, and the variation in chemical behavior within the rareearth group permits some selectivity as to the carrier efficiency (e.g., one would expect $\mathrm{Yb}$ to be a better carrier for Lu than $\mathrm{La}$ ). But too close a similarity in chemical behavior may sometimes introduce as many difficulties as it solves (e.g., the Lu-Yb separation is not an easy one).

For the purposes of this section, however, let us assume that the rare earths behave as a single element and divide the subject into two parts. coprecipitation of the rare earths with other precipitates, and coprecipitation of other elements with rare-earth precipitates

In general, it is reasonable to expect that the rare earths will coprecipitate with the insoluble salt of any anion with which they are normally insoluble. Thus, ferric hydroxide will coprecipitate carrier-free rare earths without difficulty, or the rare earths may be carried on calcium oxalate precipitates. 380,381 Brezhneva et al. ${ }^{45}$ studied the carrying of cerium and of yttrium on calcium oxalate at $\mathrm{pH} 4$ to 5 as a function of oxalate concentration They found that 0.075 molar/liter of calcium was necessary for optimum carrying. Both lanthanides show a maximum in the amount carried down at a particular optimal oxalate concentration (see Fig 15), the decrease with increasing oxalate at high oxalate concentration being attributed to the formation of oxalate complexes as proposed by Crouthamel and Martin 96, 97

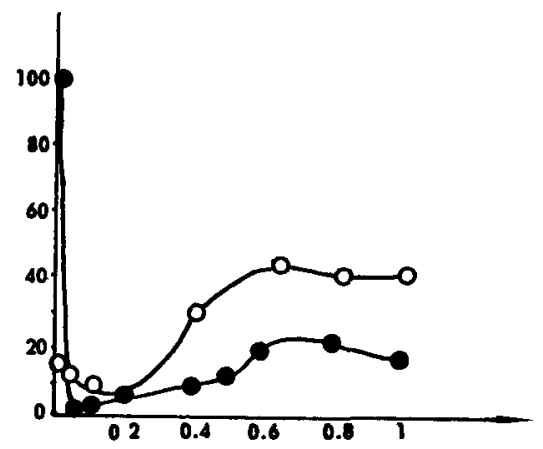

Fig. 15. Coprecipitation of cerium and yttrium with calcium oxalate at various total concentrations of oxalate. The equilibrium concentration of cerium and yttrium is shown as a percentage along the ordinate axis, and the excess concentration of oxalate in $\mathrm{g}$ eq/ 1 along the abscissa axis (45)

$10=$ Cerium, $O=$ Yttrium, $\mathrm{pH}$ of solution: 4-5) 
In $4 \mathrm{M} \mathrm{HNO}_{3}$, less than $1 \%$ of rare-earth activities carry on thorium iodate precipitates, ${ }^{434}$ but McLane and Peterson ${ }^{303}$ have shown that in solutions of low ionic strength Ac may be carried completely by zirconium iodate. Presumably the carrying efficiency for the entire rare-earth group would be quite high under the same conditions. In the same paper McLane and Peterson indicate that Ac may be carried on either bismuth phosphate or barium sulphate, and Rogers and Watrous ${ }^{390}$ report that Ac may be carried quite efficiently on lead sulfate, but few data are available on the behavior of the rest of the rare-earth group in these systems.

Conversely, when the rare earths are precipitated it is reasonable to expect that cations which form insoluble or moderately soluble salts with the precipitating anion will be coprecipitated. Thus, the rare-earth hydroxides will carry a whole host of elements which are insoluble in basic solution, or the rare-earth oxalate will coprecipitate calcium. These are rather obvious events, of course, and the sort of thing that radiochemists accept as routine. Perhaps that is why no articles on this specific aspect of rare-earth radiochemistry have appeared in the literature. It may be useful, however, to point out that not all of the coprecipitation reactions are self-evident. The authors have found, for instance, that $\mathrm{Ba}$ and $\mathrm{Zr}$ have some tendency to coprecipitate with the rare-earth fluorides. Gest, Burgus, and Davies ${ }^{171}$ have shown that the $\mathrm{Zr}$ coprecipitation is very sharply dependent on the $\mathrm{Zr}$ concentration, and Gest, Ballou, Abraham, and Coryell 170 have shown a somewhat lesser concentration dependence for $\mathrm{Ba}$. Radiochemists, therefore, should not be too surprised when unexpected elements sometimes tag along in their rare-earth chemistry.

IV. 3C. PYROLYSIS

IV. $3 \mathrm{C}-1$. Oxalate

For any gravimetric determination of the rare earths, precipitates must be dried, and the obvious figure of merit for this operation is the temperature range over which a salt of known composition is stable. Since the oxalates are probably used more often than any other salt in the gravimetric determination of the rare earths, it is perhaps appropriate that their pyrolitic behavior has been investigated more thoroughly than other rare-earth salts. The curve for the thermal decomposition of $\mathrm{Nd}_{2}\left(\mathrm{C}_{2} \mathrm{O}_{4}\right)_{3} \cdot 1 \mathrm{OH}_{2} \mathrm{O}$, which has been reproduced from an article by Caro and Loriers, 70 is shown in Fig. 16 and may be considered as fairly typical of all the rare-earth oxalates. The decahydrate begins losing water steadily at about $50^{\circ} \mathrm{C}$ and the sample decomposes continuously until $\mathrm{Nd}_{2} \mathrm{O}_{3}$ is formed at about $700^{\circ} \mathrm{C}$. There are no level portions of the curve which denote a stable, weighable intermediate compound, and the usual practice is to decompose the oxalate completely and weigh as the 
oxide. Wendlandt 525,526 has also studied the pyrolysis of the rare-earth oxalates and, since his curves are in a concise form, his data are reproduced in Figs. 17-20 and Table 6. The most obvious feature of the curves is that there are so few weighable intermediate rare-earth oxalate compounds. Where these exist at all, the temperature range for stability is fairly small, so some care must obviously be taken if these intermediate salts are to be weighed accurately. Above $800^{\circ} \mathrm{C}$, however, all of the oxalates are completely decomposed to oxides and may be weighed accurately. It should perhaps be noted that $\mathrm{CeO}_{2}$ is formed at $360^{\circ} \mathrm{C}$, much lower than the other rare-earth oxides.

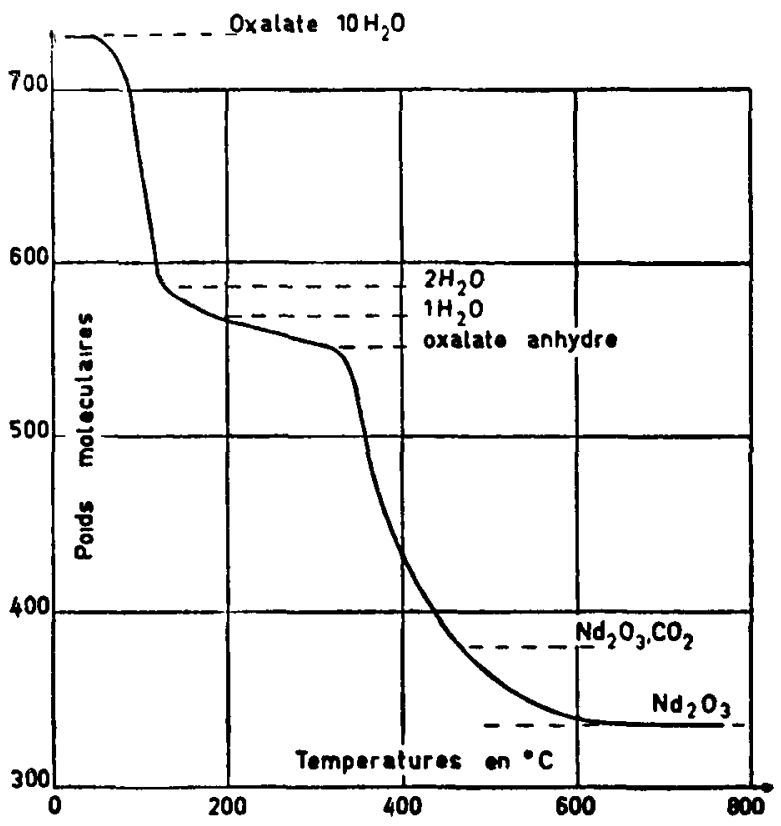

Fig. 16. Thermolysis curve of $\mathrm{Nd}_{2}\left(\mathrm{C}_{2} \mathrm{O}_{4}\right)_{3} \cdot 10 \mathrm{H}_{2} \mathrm{O}(70)$

Fig. 17. Thermal decomposition curves of scandium oxalate. A. Scan- dium oxalate 2-hydrate. B. Scandium oxalate 6-hydrate (525)

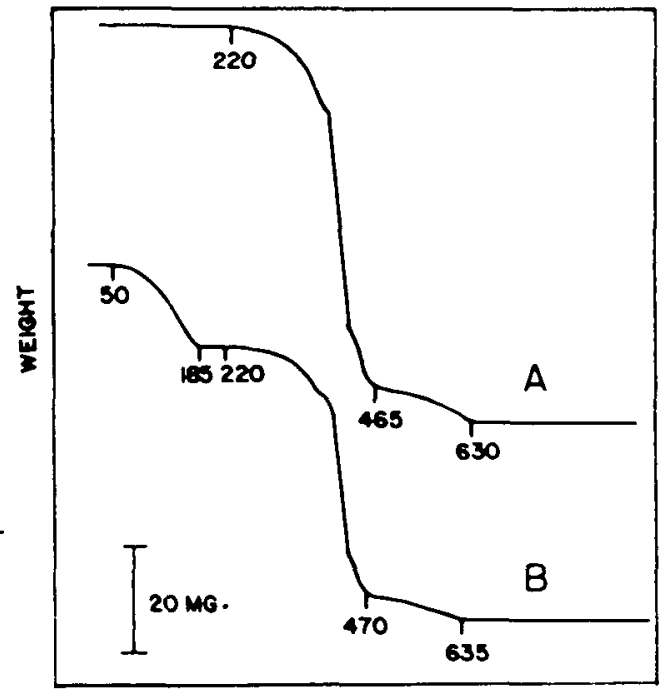

TEMP * $\mathrm{C}$. 


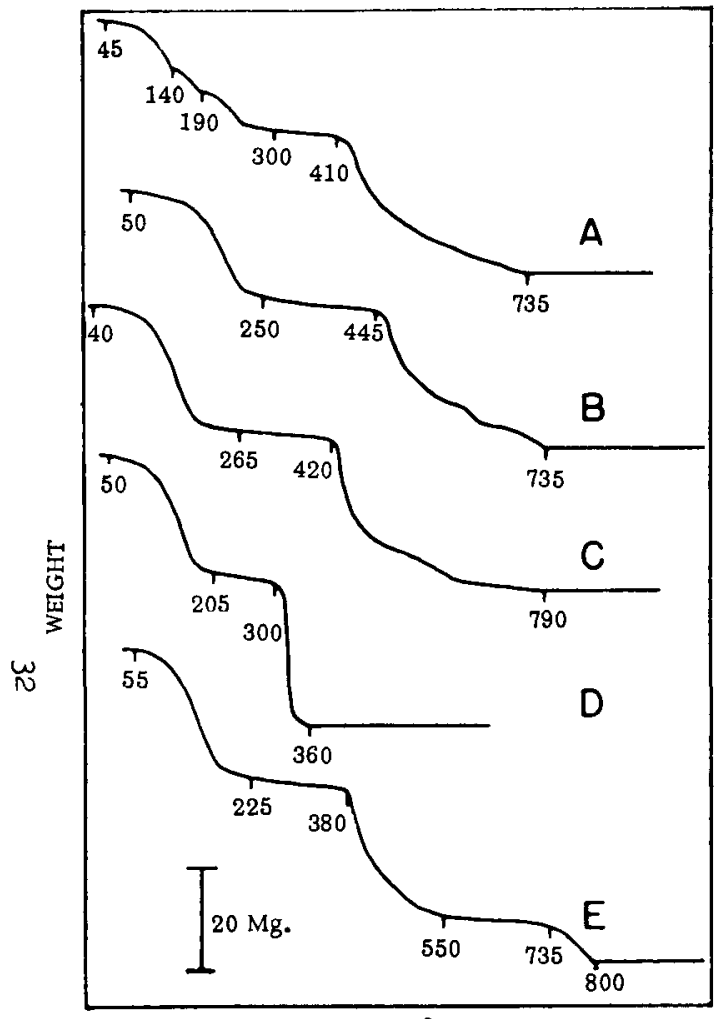

TEMP. ${ }^{\circ} \mathrm{C}$

Fig. 18. Thermal decomposition curves of rare-earth metal oxalates. A. Samarium oxalate $10 \mathrm{H}_{2} \mathrm{O}$. B. Neodymium oxalate $10 \mathrm{H}_{2} \mathrm{O}$. C. Praseodymium oxalate $10 \mathrm{H}_{2} \mathrm{O}$. D. Cerium oxalate $10 \mathrm{H}_{2} \mathrm{O}$. E. Lanthanum oxalate $10 \mathrm{H}_{2} \mathrm{O}(525)$

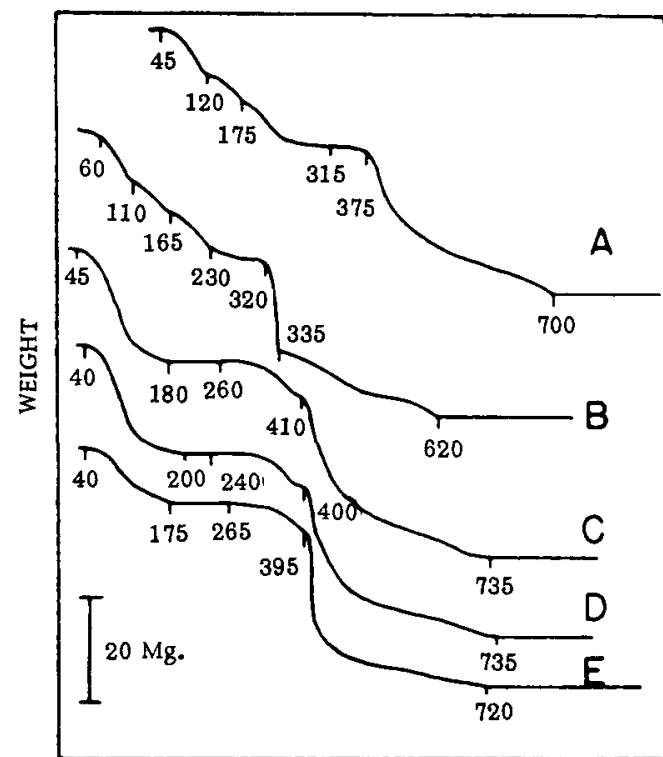

TEMP. ${ }^{\circ} \mathrm{C}$

Fig. 19. Thermal decomposition of yttrium and rare-earth metal oxalates. A. Gadolinium oxalate 10-hydrate. B. Europium oxalate $10 \mathrm{H}_{2} \mathrm{O}$. C. Yttrium oxalate $9 \mathrm{H}_{2} \mathrm{O}$. D. Holmium oxalate $10 \mathrm{H}_{2} \mathrm{O}$. E. Erbium oxalate $6 \mathrm{H}_{2} \mathrm{O} \quad(525)$

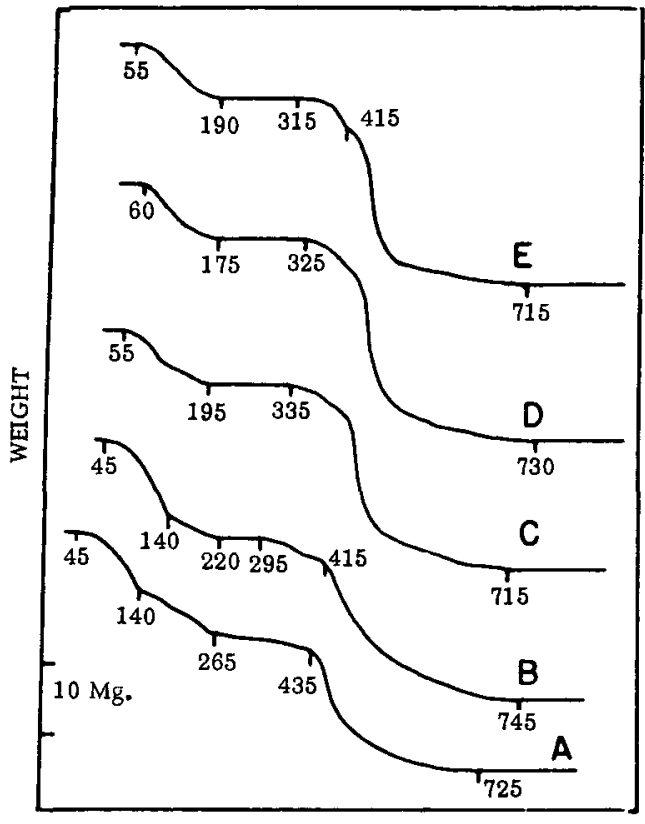

TEMP. ${ }^{\circ} \mathrm{C}$

Fig. 20. Thermal decomposition curves of rare-earth metal oxalates. A. Terbium oxalate $10 \mathrm{H}_{2} \mathrm{O}$. B. Dys prosium oxalate $10 \mathrm{H}_{2} \mathrm{O} .{ }^{2} \mathrm{C}$. Thulium oxalate $5 \mathrm{H}_{2} \mathrm{O}$. D. Ytterbium oxalate $5 \mathrm{H}_{2} \mathrm{O}$. E. Lutetium oxalate $6 \mathrm{H}_{2} \mathrm{O}$ $(526)$ 


\section{Rare Earth Metal}

Lanthanum

Cerium

Praseodymium

Neodymium

Samarium

Europium

Gadolinium

Terbium

Dysprosium

Holmium

Erbium

Thulium

Ytterbium

Lutetium

Yttrium

Scandium
Temp.,

55-380

380-550

735-800

50-360

40-420

420-790

$50-445$

445-735

45-300

410-735

60-320

$320-620$

45-120

120-315

375-700

45-140

140-265

265-435

435-725

45-140

140-220

295-415

415-745

40-200

240-400

400-735

40-175

265-395

395-720

55-195

335-730

60-175

325-730

55-190

315-715

45-180

$260-410$

410-735

50-185

$220-635$
Transition

10-hydrate $\rightarrow$ anhydrous

Anhydrous $\rightarrow \mathrm{La}_{2} \mathrm{O}_{3} . \mathrm{CO}_{2}$

$\mathrm{La}_{2} \mathrm{O}_{3} \cdot \mathrm{CO}_{2} \rightarrow$ oxide

10-hydrate $\rightarrow$ oxide

10-hydrate $\rightarrow$ anhydrous

Anhydrous $\rightarrow$ oxide

10-hydrate $\rightarrow$ anhydrous

Anhydrous $\rightarrow$ oxide

10-hydrate $\rightarrow$ anhydrous

Anhydrous $\rightarrow$ oxide

10-hydrate $\rightarrow$ anhydrous

Anhydrous $\rightarrow$ oxide

10-hydrate $\rightarrow$ 6-hydrate

6-hydrate $\rightarrow$ anhydrous

Anhydrous $\rightarrow$ oxide

10-hydrate $\rightarrow$ 5-hydrate

5-hydrate $\rightarrow$ 1-hydrate

1-hydrate $\rightarrow$ anhydrous

Anhydrous $\rightarrow$ oxide

10-hydrate $\rightarrow$ 4-hydrate

4-hydrate $\rightarrow$ 2-hydrate

2 -hydrate $\rightarrow$ anhydrous

Anhydrous $\rightarrow$ oxide

10-hydrate $\rightarrow$ 2-hydrate

2-hydrate $\rightarrow$ anhydrous

Anhydrous $\rightarrow$ oxide

6-hydrate $\rightarrow$ 2-hydrate

2-hydrate $\rightarrow$ anhydrous

Anhydrous $\rightarrow$ oxide

5-hydrate $\rightarrow$ 2-hydrate

2-hydrate $\rightarrow$ oxide

5-hydrate $\rightarrow$ 2-hydrate

2-hydrate $\rightarrow$ oxide

6-hydrate $\rightarrow$ 2-hydrate

2-hydrate $\rightarrow$ oxide

9-hydrate $\rightarrow$ 2-hydrate

2-hydrate $\rightarrow$ anhydrous

Anhydrous $\rightarrow$ oxide

6-hydrate $\rightarrow$ 2-hydrate

2-hydrate $\rightarrow$ oxide 
IV. 3C-2. 8-Hydroxyquinolate and Related Anions

The rare-earth-8-hydroxyquinolates differ from the oxalates in that they are stable at fairly high temperatures. Wendlandt's data ${ }^{518}$ for several of the rare earths are reproduced in Table 7 and Fig. 21.

Table 7. Decomposition temperatures for the rare-earth 8 -quinolinol chelates (518)

\begin{tabular}{|c|c|c|c|}
\hline $\mathrm{M}\left(\mathrm{C}_{9} \mathrm{H}_{6} \mathrm{NO}\right)_{3}$ & $\begin{array}{c}\text { Stage I } \\
{ }^{\circ} \mathrm{C}\end{array}$ & $\begin{array}{c}\text { Stage II } \\
{ }^{\circ} \mathrm{C} \\
\end{array}$ & $\begin{array}{c}\text { Stage III } \\
{ }^{\circ} \mathrm{C}\end{array}$ \\
\hline Lanthanum & 360 & $420-510$ & 800 \\
\hline Cerium (III) & 350 & -- & 420 \\
\hline Praseodymium & 280 & $320-520$ & 575 \\
\hline Neodymium & 250 & $330-510$ & 730 \\
\hline Samarium & 260 & $410-500$ & 700 \\
\hline Gadolinium & 250 & $400-525$ & 755 \\
\hline Yttrium & 175 & $370-525$ & 740 \\
\hline
\end{tabular}

In Table 7, the decomposition is classified in three stages: (I) A small loss of weight (about $1 \%$ ) in the temperature range $250-300^{\circ} \mathrm{C}$; (II) The oxidation of organic matter in the temperature range $350-525^{\circ} \mathrm{C}$, and (III) The formation of the oxide in the temperature range $700-800^{\circ} \mathrm{C}$.

Only seven of the rare earths are represented in Fig. 21, of course, and it is natural to expect that the remaining rare earths will behave in pretty much the same manner as those shown. Pokras and Bernays, ${ }^{367}$ however, report that scandium 8-hydroxyquinolate loses measurable amounts of weight when heated at $110^{\circ} \mathrm{C}$ and very large amounts when heated for long periods at $165^{\circ} \mathrm{C}$, so it may be wise to ignite the heavy rare-earth oxinates to oxides until such time as their decomposition behavior is determined.

Wendlandt has also studied the thermal decomposition of substituted rare-earth 8 -hydroxyquinolates, ${ }^{522,523}$ the data for which are shown in Figs. 22-27. 

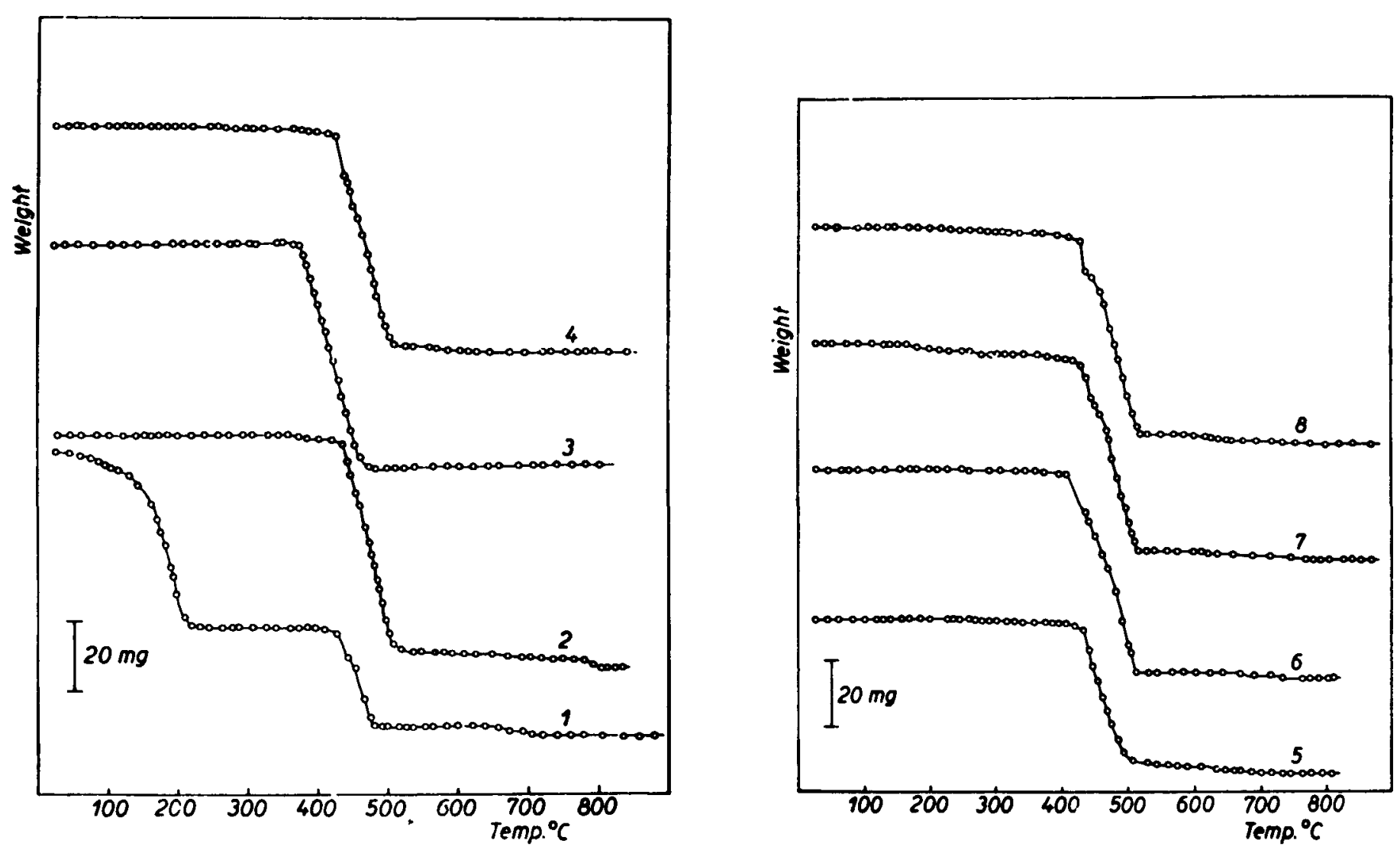

Fig. 21. Thermolysis curves of the 8-quinolinol chelates of the rare-earth metals (518): 1. Lanthanum + coprecipitated oxine, 2. Lanthanum, 3. Cerium (+3), 4. Praseodymium, 5. Samarium, 6. Neodymium, 7. Yttrium, 8. Gadolinium. 


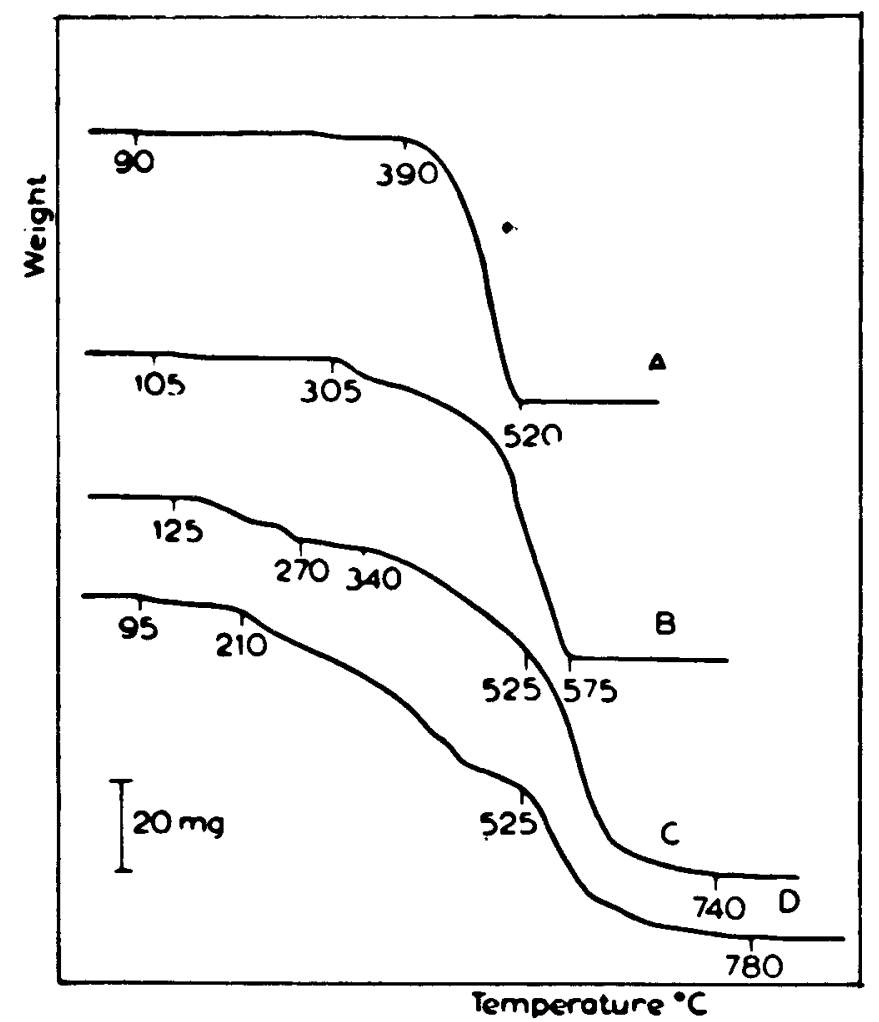

Fig. 22. Thermal decomposition curves of the rare-earth metal chelates (523): A. Cerium (+4) 5, 7 dibromo-8-quinolinol; B. Cerium (+4) 5,7 dichloro-8-quinolinol; C. Lanthanum 5, 7, dibromo-8-quinolinol; D. Lanthanum 5, 7-dichloro-8-quinolinol.

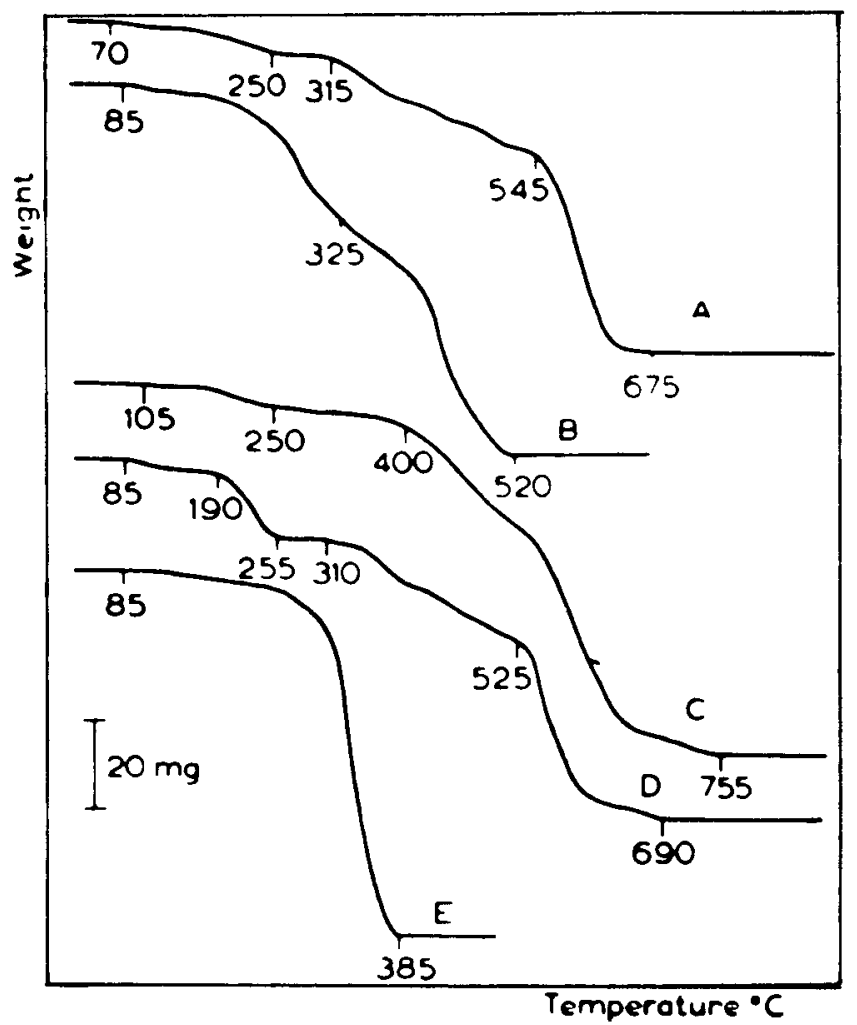

Fig. 23. Thermal decomposition curves of the rare-earth metal chelates (523): A. Neodymium 5, 7-dichloro-8-quinolinol; B. Praseodymium 5, 7-diiodo-8-quinolinol; C. Praseodymium 5, 7-dibromo-8-quinolinol; D. Praseodymium 5, 7-dichloro-8-quinolinol; E. Cerium ( \pm 4$) 5$, 7-diiodo-8-quinolinol. 


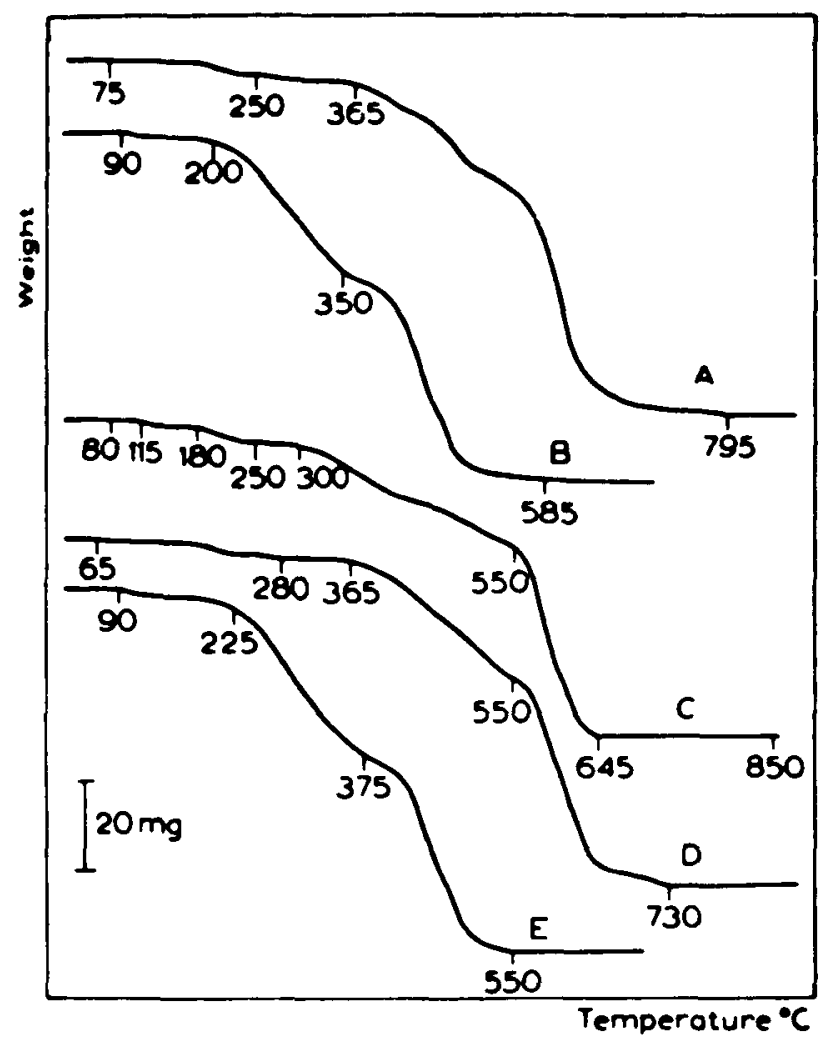

Fig. 24. Thermal decomposition of the rare-earth metal chelates (523):

A. Samarium 5, 7-dibromo-8-quinolinol;

B. Samarium 5,7-diiodo-8-quinolinol;

C. Samarlum 5, 7-dichloro-8-quinolinol;

D. Neodymium 5, 7-dibromo-8-quino-

linol; E. Neodymium 5, 7-dilodo-8-quinolinol.

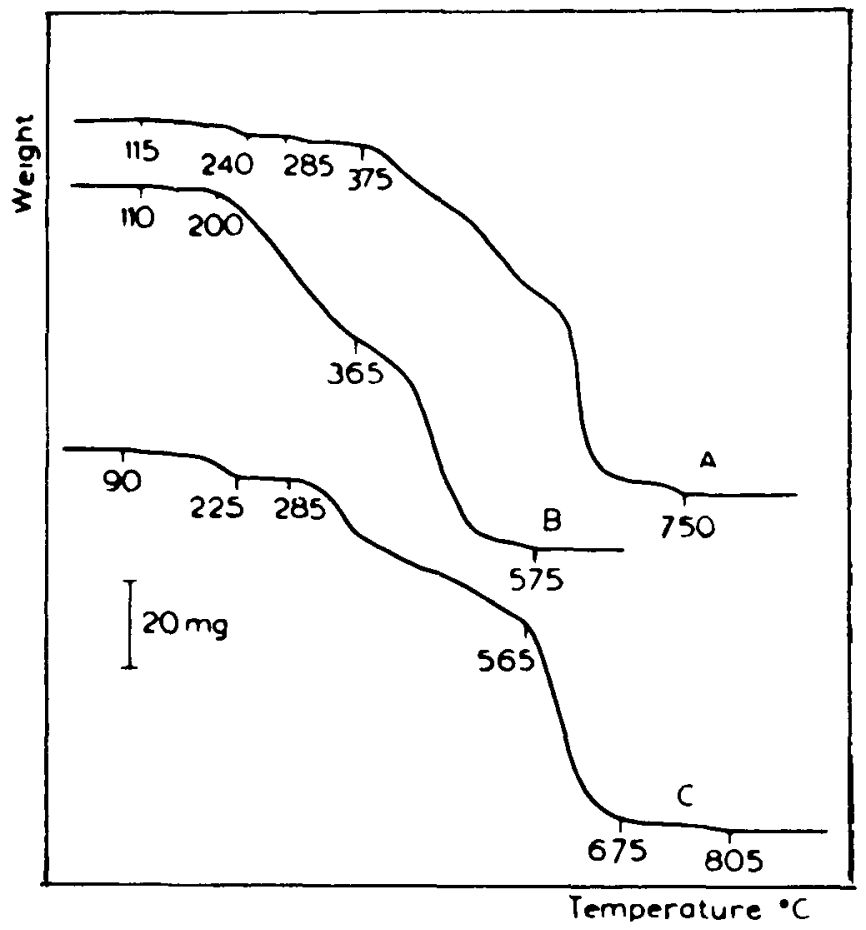

Fig. 25. Thermal decomposition curves of yttrium chelates (523): A. Yttrium 5, 7-dibromo-8-quinolinol; B. Yttrium 5, 7-diiodo-8-quinolinol; C. Yttr1um 5, 7-dichloro-8-quinolinol. 


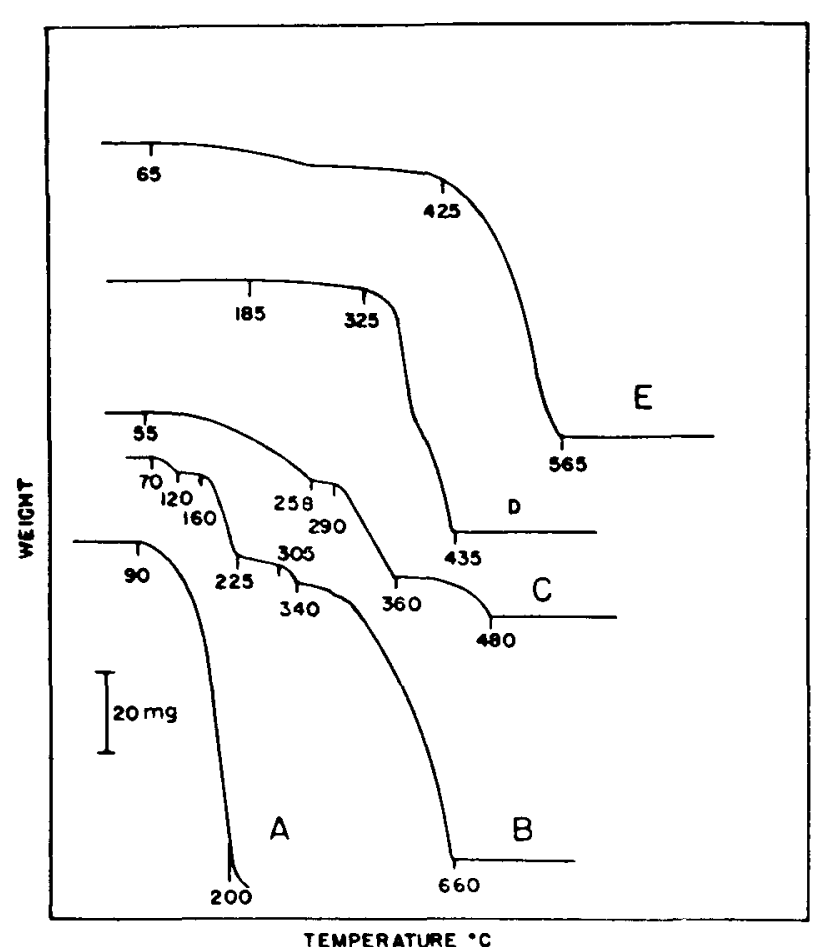

Fig. 26. The thermal decomposition curves of the chelating agent and metal chelates (522): A. 2-methyl-8-quino1inol; B. Scandium 2-methy1-8-quinolinol; C. Uranium $(+6)$ 2-methyl-8quinolinol; D. Thorium 2-methyl-8quinolinol; E. Yttrium 2-methyl-8quinolinol.

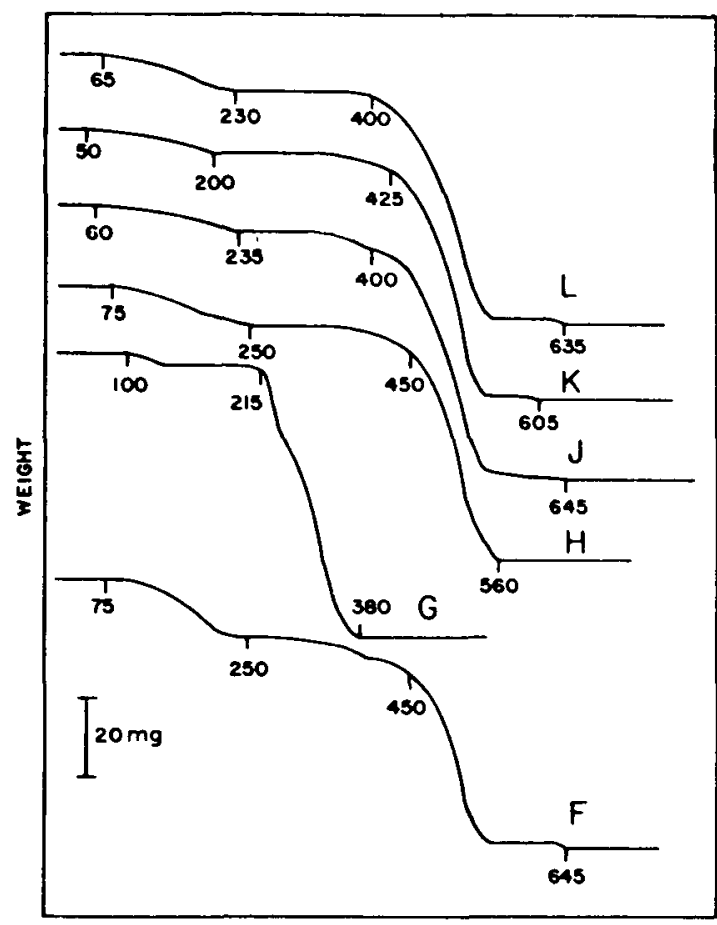

TEMPERATURE * $\mathrm{C}$

Fig. 27. The thermal decomposition curves of the rare-earth chelates (522): F. Lanthanum 2-methyl-8-quinolinol; G. Cerium 2-methyl-8-quinolinol; H. Praseodymium 2-methy1-8-quinolinol; I. Neodymium 2-methyl-8-quinolinol; J. Samarium 2-methyl-8-quinolinol; K. Gadolinium 2-methy1-8-quinolinol. 
IV. 3C-3. Cupferrate and Neocupferrate

Wendlandt $515,516,529$ has studied the thermal decomposition of the rare-earth cupferrates and neocupferrates, data for which are reproduced in Figs. 28 and 29.
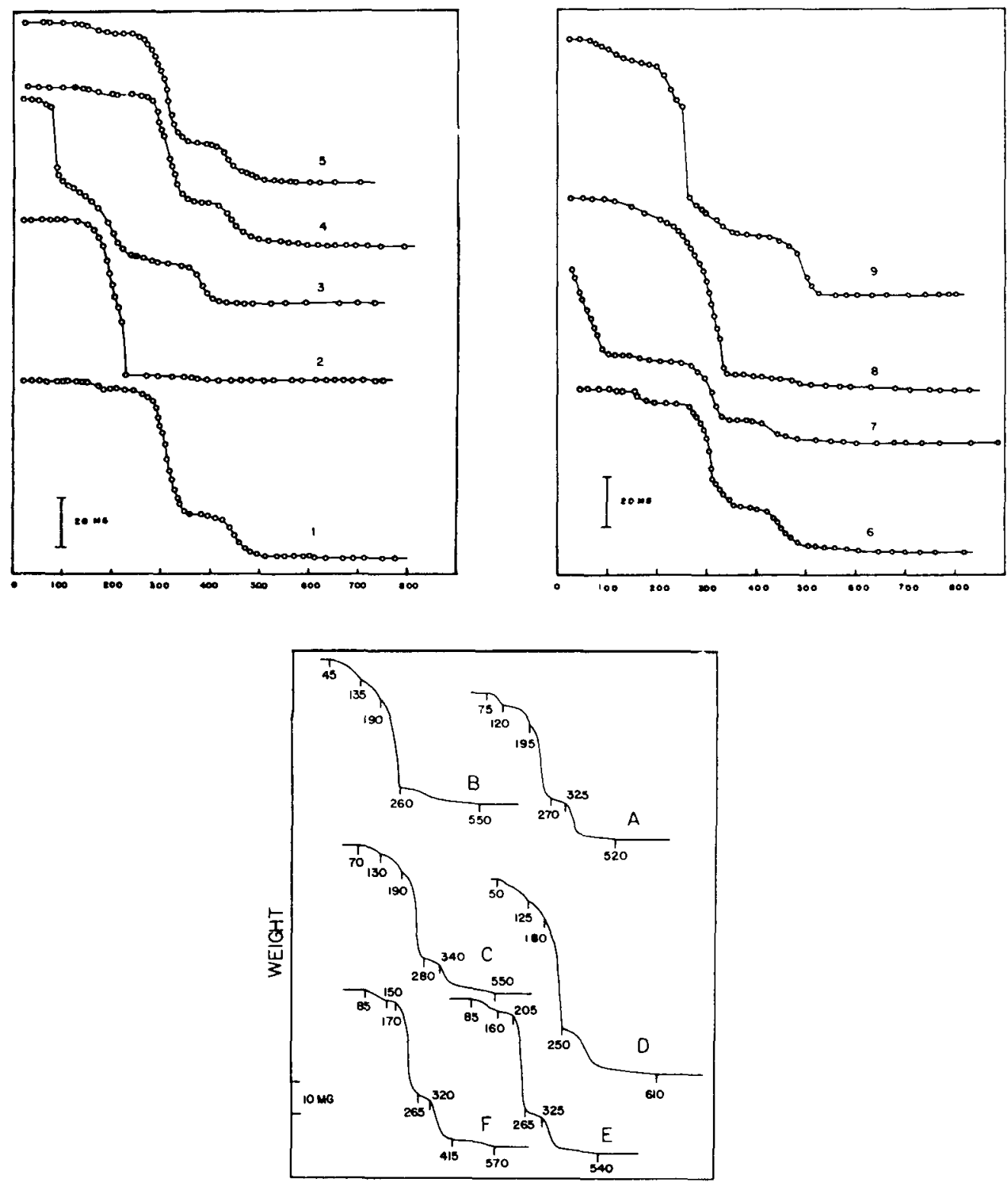

TEMPERATURE $\mathrm{C}$

Fig. 28. Pyrolysis curves of scandium, yttrium, and rare-earth cupferrates. 1. Lanthanum, 2. Cerium (III), 3. Cerfum (IV), 4. Praseodymium, 5. Neodymium, 6. Samarium, 7. Gadolinium, 8. Yttrium, 9. Scandium, A. Ytterbium, B. Erbium, C. Dysprosium, D. Holmium, E. Terbium, F. Europium. 

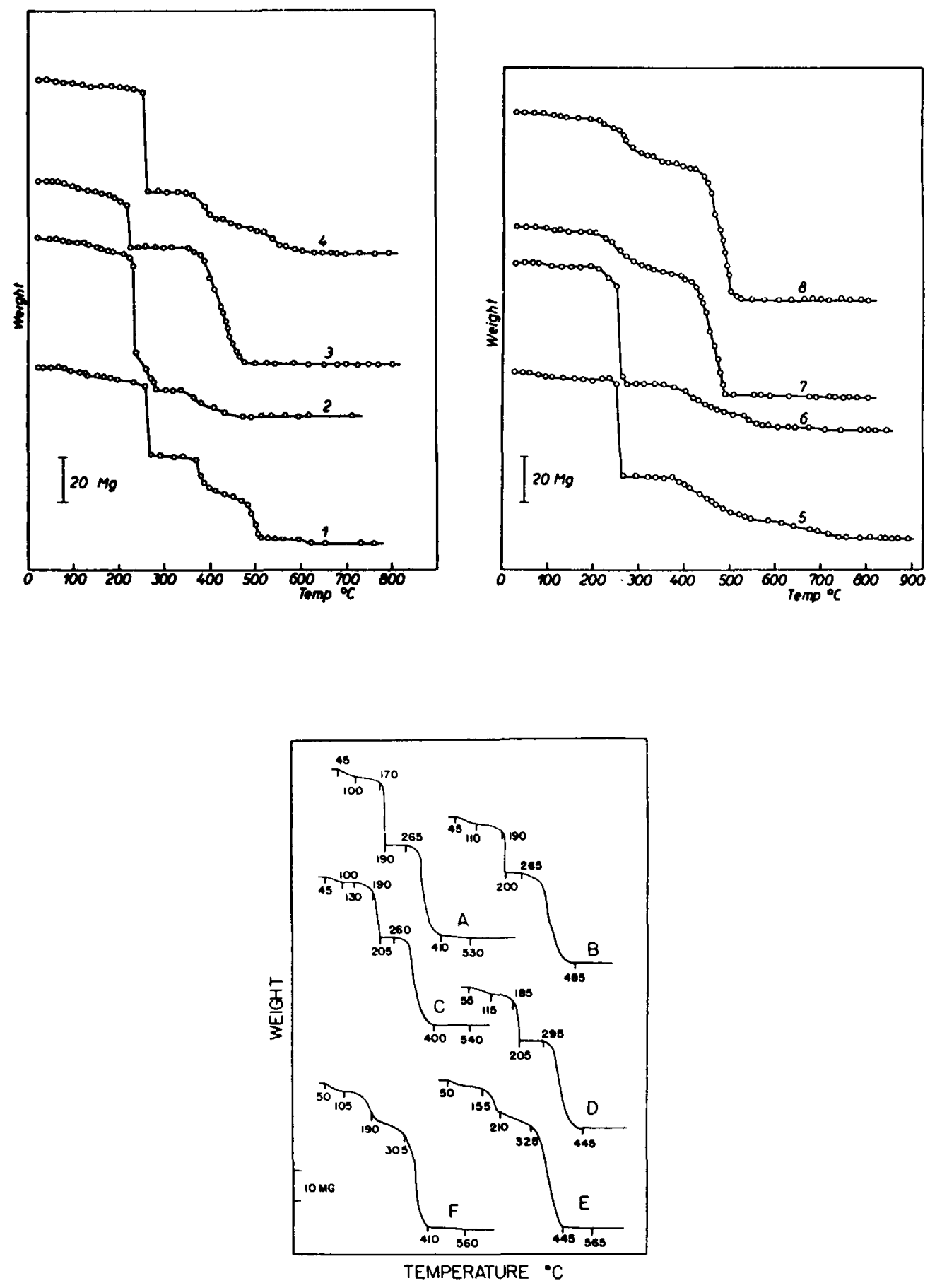

Fig. 29. Pyrolysis curves of yttrium and rare-earth neocupferrates.

1. Lanthanum, 2. Cerium (III), 3. Cerium (IV), 4. Praseodymium, 5. Neodymium, 6. Samarium, 7. Gadolinium, 8. Yttrium, A. Erbium, B. Ytterbium, C. Dysprosium, D. Holmium, E. Terbium, F. Europium. 
IV. 3C-4. Other Anions

Wendlandt has studied the thermal decomposition of the rare-earth chlorides 524,527 and fluorides, ${ }^{528}$ and Chretien and Capestan ${ }^{78}$ have studied the sulfamates, but since these salts are not used for gravimetric determinations their pyrolysis curves will not be reproduced here.

\section{4. SPECTROPHOTOMETRY, TITRATION, AND COLORIMETRY}

\section{4A. SPECTROPHOTOMETRY OF SIMPLE IONS}

Thirteen of the fifteen lanthanide elements possess the interesting property of showing light absorption bands in solutions of their simple salts. These bands are relatively narrow and are very useful for qualitative and quantitative estimation of individual rare earths. Lanthanum, lutetium, and yttrium do not exhibit any usable absorption bands, and may not be determined by this method.

A fairly large number of papers on the spectrophotometric measurement of the rare earths have appeared in the literature, perhaps the best of which have been published by Stewart and Kato, ${ }^{462}$ Moeller and Brantley, 314 Rodden, ${ }^{388,389}$ Holleck and Hartinger, ${ }^{203}$ and Banks and Klingman. 14

Figures 30-33 have been reproduced from the paper by Stewart and Kato 462 and indicate the useful peaks for all of the rare earths in the visible, infrared, and ultraviolet regions. Wavelength positions and molecular extinction coefficient values for "index peaks" which have been recommended by Stewart and Kato for determining the rare earths are shown in Table 8 . Where more than one peak is listed for a given element, the "primary," or most highly recommended, peak is listed first. It is apparent that the re are interferences for each of the peaks listed in Table 8. For detailed information on the extent of each interference the original paper should be consulted.

Additional data on the absorption spectra of the rare earths may be obtained from papers by Prandtl and Scheiner ${ }^{377}$ (all the rare earths), Wylie 540 (Pr, Nd, Sm), Jorgensen ${ }^{223}$ (Dy, Ho, Er), and Onstott and Brown ${ }^{346}$ (Tb).

Promethium, of course, is seldom encountered in sufficient amounts to measure spectrophotometrically. Stewart, ${ }^{459}$ however, has measured its absorption spectra and has shown it to be quite complicated.

Butement ${ }^{65}$ has studied the absorption and fluorescence spectra of bivalent samarium, europium, and ytterbium. The spectra for each of these species are simpler than the spectra for the corresponding trivalent ion, but no attempt to use the absorption peaks for analys is is reported.

Although the simple salts of yttrium and lanthanum cannot be determined by absorption spectra, other techniques have proven useful. Legrand and Loriers 267 have published a paper which indicates that $\mathrm{x}-\mathrm{ray}$ fluorescence 


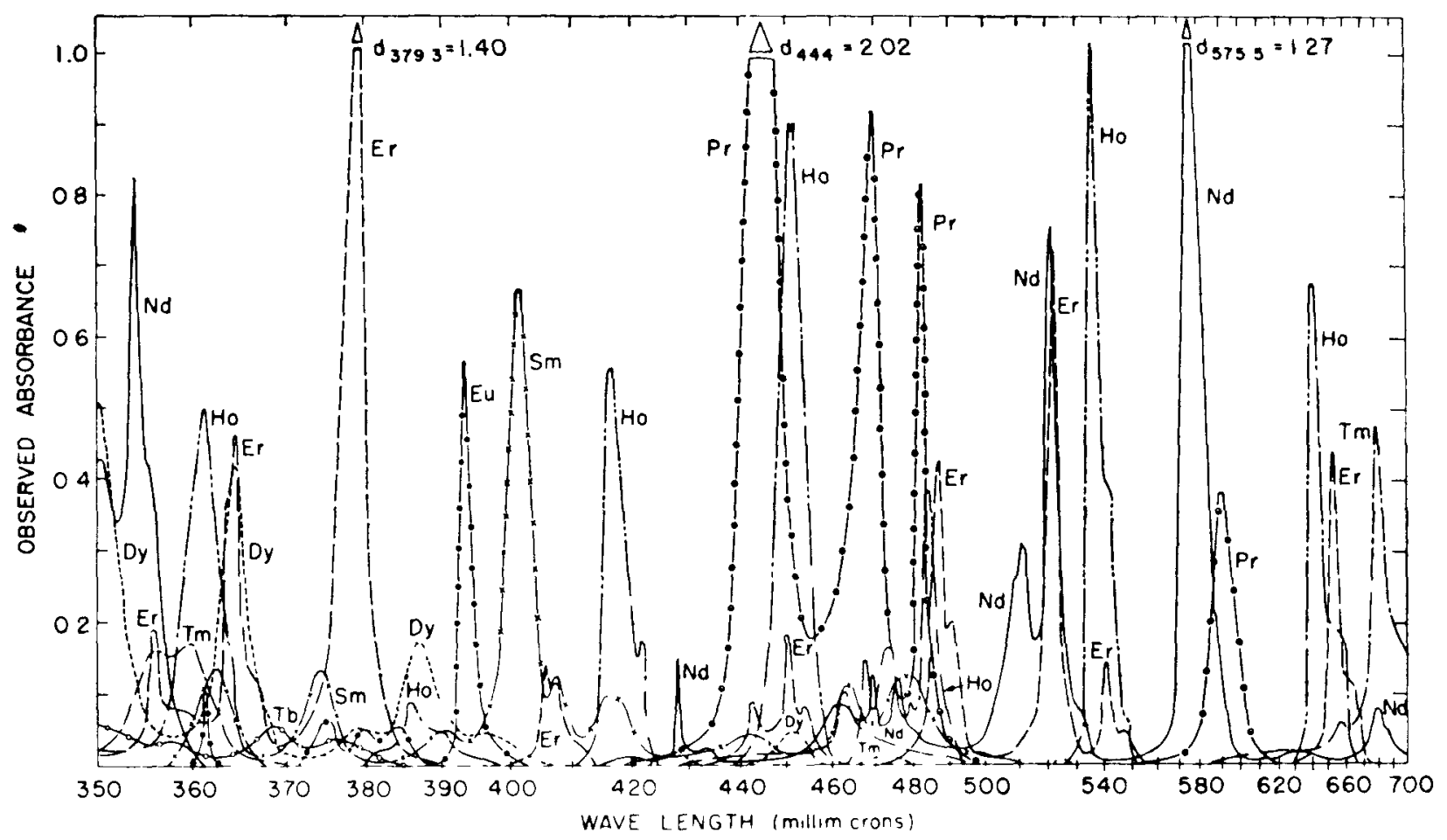

Fig. 30. Absorption spectra of all rare earths in visible range (462) 


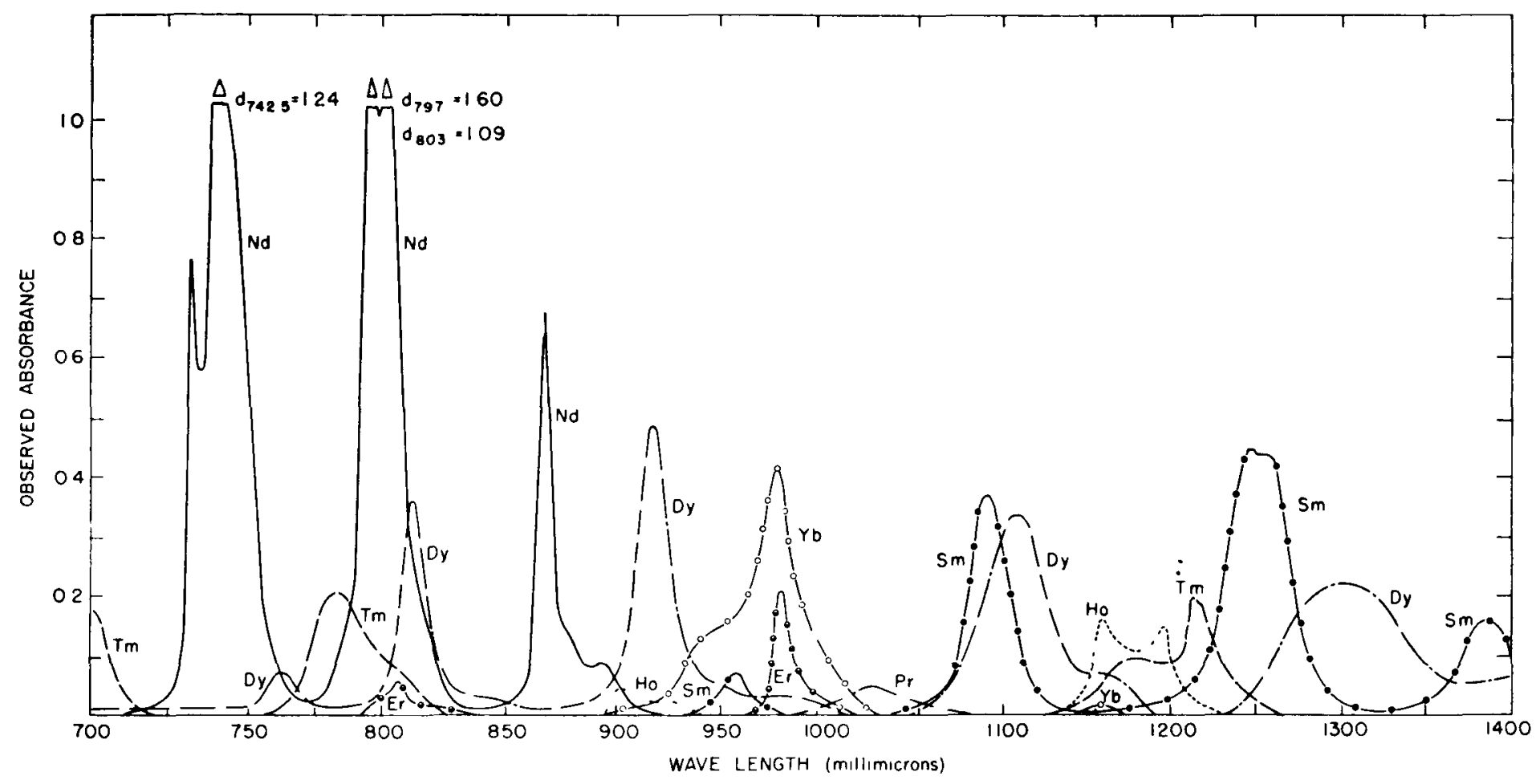

Fig. 31. Absorption spectra of all rare earths in near-infrared (462) 


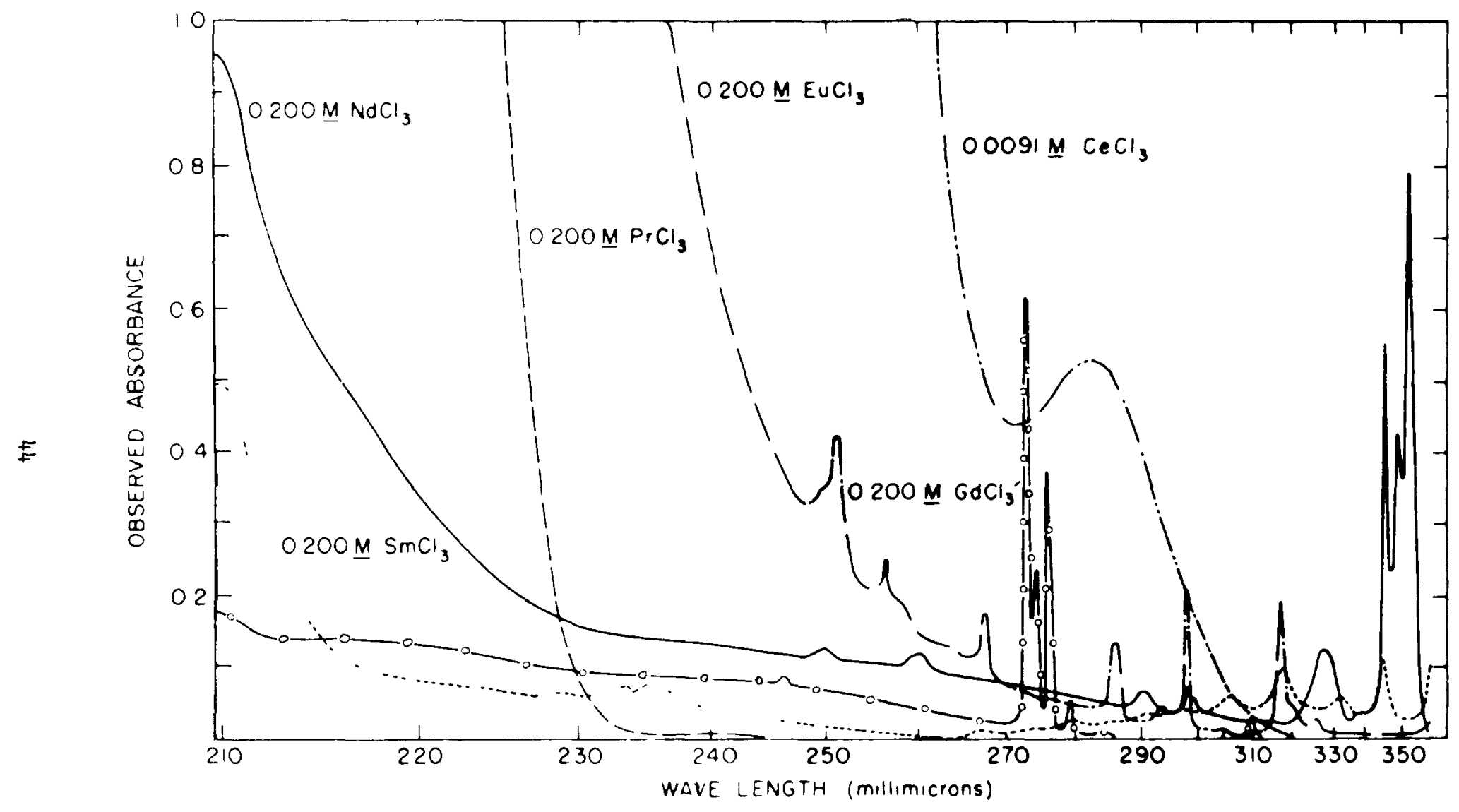

Fig. 32. Absorption spectra of light rare earths in ultraviolet range (462) 
ज

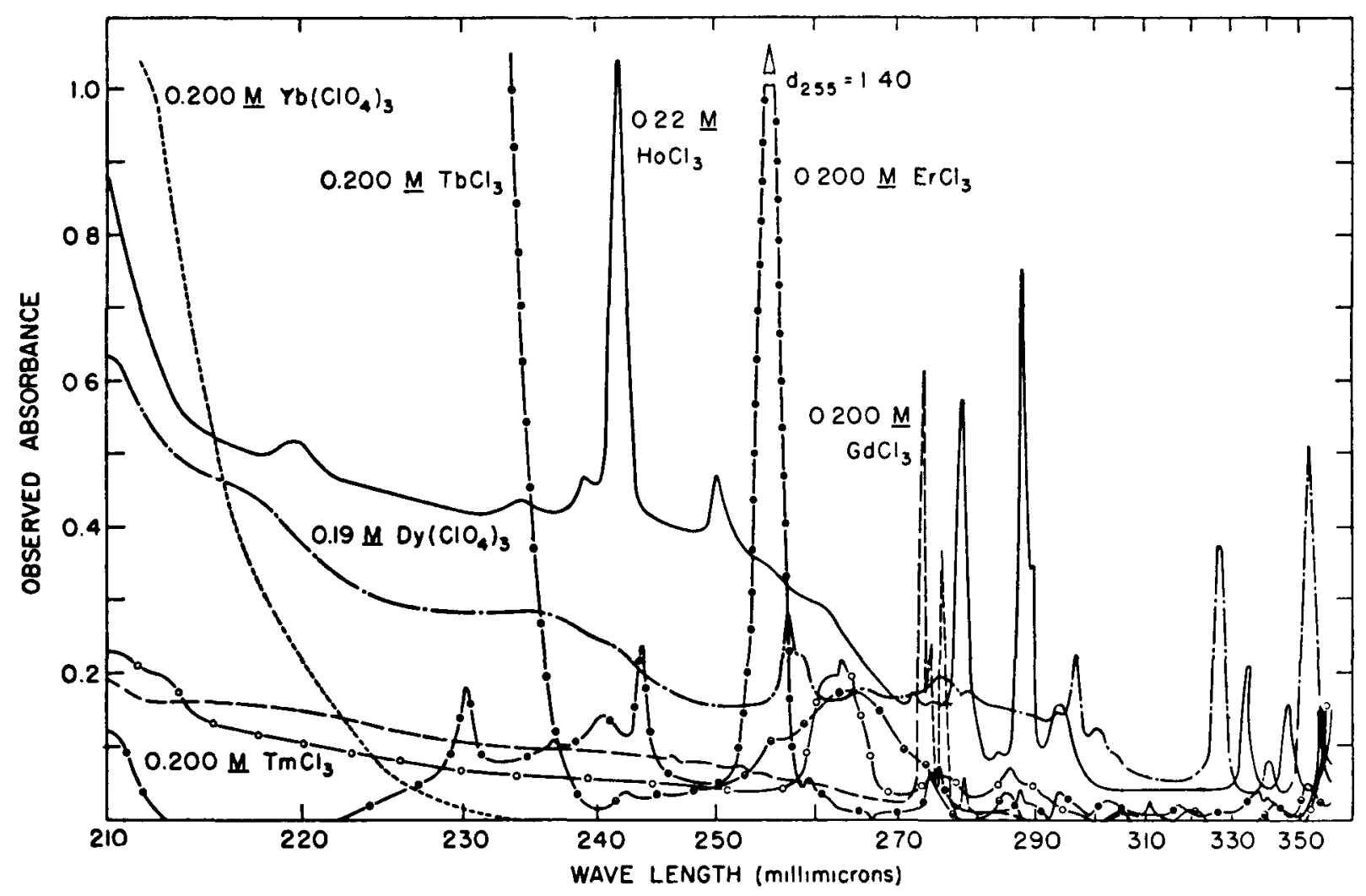

Fig. 33. Absorption spectra of heavy rare earths in ultraviolet range (462) 
Table 8. Index peaks, extinction coefficients, and interfering rare-earth elements in the spectrophotometric determination of individual rare earths (462)

\begin{tabular}{|c|c|c|c|}
\hline Element & $\lambda-\max (\mathrm{m} \mu)$ & $\epsilon$ & Interfering Element \\
\hline $\mathrm{Ce}$ & $\begin{array}{l}253 \\
296\end{array}$ & $\begin{array}{r}755 \\
26\end{array}$ & $\begin{array}{l}\text { Most elements interfere. (See } \\
\text { refs. } 462,178 .)\end{array}$ \\
\hline Pr & $\begin{array}{l}444.0 \\
482.5 \\
590\end{array}$ & $\begin{array}{l}10.1 \\
4.1 \\
1.95\end{array}$ & $\begin{array}{l}\text { Sm, Ho, Er } \\
\text { Nd, Sm, Ho, Er } \\
\text { Nd }\end{array}$ \\
\hline $\mathrm{Nd}$ & $\begin{array}{l}575.5 \\
742.5 \\
868 \\
522.3\end{array}$ & $\begin{array}{l}6.34 \\
6.22 \\
3.10 \\
2.74\end{array}$ & $\begin{array}{l}\text { Pr } \\
\text { Dy } \\
\text { Dy } \\
\text { Er }\end{array}$ \\
\hline $\mathrm{Sm}$ & $\begin{array}{l}401.6 \\
1250 \\
1095\end{array}$ & $\begin{array}{l}3.30 \\
2.19 \\
2.00\end{array}$ & $\begin{array}{l}\text { Eu, Dy } \\
\text { Dy, Tm } \\
\text { Dy (See ref. 326.) }\end{array}$ \\
\hline $\mathrm{Eu}$ & 394.3 & 2.90 & $\mathrm{Sm}, \mathrm{Dy}, \mathrm{Ho}$ \\
\hline Gd & $\begin{array}{l}272.7 \\
275.6\end{array}$ & $\begin{array}{l}3.16 \\
1.90\end{array}$ & $\underset{" 1 "}{\text { See }} \underset{11}{\text { ref. }} 462$. \\
\hline $\mathrm{Tb}$ & 219 & 374 & Eu, Pr, Ce (See ref. 462.) \\
\hline Dy & $\begin{array}{r}911 \\
1102\end{array}$ & $\begin{array}{l}2.40 \\
1.80\end{array}$ & $\begin{array}{l}\mathrm{Yb}, \mathrm{Ho} \\
\mathrm{Sm}\end{array}$ \\
\hline Ho & $\begin{array}{l}536.5 \\
416.1 \\
641\end{array}$ & $\begin{array}{l}4.55 \\
2.52 \\
3.04\end{array}$ & $\begin{array}{l}\operatorname{Er} \\
\text { Sm } \\
\operatorname{Er}, \quad \operatorname{Tm}\end{array}$ \\
\hline Er & $\begin{array}{l}523.5 \\
379.3 \\
654\end{array}$ & $\begin{array}{l}3.55 \\
6.66 \\
2.04\end{array}$ & $\begin{array}{l}\mathrm{Nd} \\
\mathrm{Nd} \\
\mathrm{Ho}, \mathrm{Tm}, \mathrm{Nd}\end{array}$ \\
\hline $\operatorname{Tm}$ & $\begin{array}{l}682.5 \\
781\end{array}$ & $\begin{array}{l}2.36 \\
1.00\end{array}$ & $\begin{array}{l}\text { Nd } \\
\text { Nd, Dy }\end{array}$ \\
\hline $\mathrm{Yb}$ & $\begin{array}{l}973 \\
950\end{array}$ & $\begin{array}{l}2.10 \\
0.77\end{array}$ & $\begin{array}{l}\text { Er, Dy } \\
\text { Dy, Sm }\end{array}$ \\
\hline
\end{tabular}

techniques may be used to measure yttrium quantitatively in the presence of other rare earths; and Menis, Rains, and Dean ${ }^{546}$ report that flame spectrophotometric methods may be used for quantitative determination of lanthanum. IV. 4B. TITRATION AND COLORIMETRY

Titration has proven to be a very useful method for quantitative deter mination of the rare-earth elements. Most published procedures involve addition of a standard solution of a strong complexing agent such as ethylene- 
diaminetetraacetic acid (EDTA) to a rare-earth solution. The end point at which all of the rare earth has been complexed is identified by a change of indicator color in the solution. The change in color is often followed spectrophotometrically for the best results but this is not always necessary.

Typical EDTA titration papers have been published by Brunisholz and Cahen, ${ }^{56}$ who used a mixed alizarin sulfonate-methylene blue indicator, by Flaschka, 145 and Wunsch, ${ }^{539}$ who used erlochrome black T, by Fritz and Pletrzyk, ${ }^{158}$ who titrated scandium with copper as an indicator, by Jenıckova, Suk, and Malat, ${ }^{219}$ who used brompyrogallol red for the rare earths, by Cheng, ${ }^{75}$ Cheng and Willıams, ${ }^{74}$ and Flaschka and Abdine, ${ }^{146}$ who used 1-(2-pyrıdyl-AZO)-2 naphthol (PAN) as indicator for scandium and the rare earths, by Crouch and Swaınbank, ${ }^{92}$ who used xylenol orange as an indicator in an ultra-micro method for the estimation of the rare earths, by Bril, Holzer, and Rethy, ${ }^{47}$ who used alızarin red $S$ in a simultaneous determination of thorium and rare earths in their mixtures, and by Frum, ${ }^{160}$ who used monochrome Bordeaux $\mathrm{C}$ to detect $\mathrm{La}^{+3}$ in the presence of $\mathrm{Ce}^{+3}$ and $\mathrm{Ce}^{+4}$. Hall, Gibson, Wilkınson, and Philips ${ }^{186}$ have published a procedure which involves titration with EDTA and conductometric determination of the end point, while Hara and West ${ }^{190}$ have used high-frequency titrations.

Perhaps the best volumetric method for measuring the rare earths involves the use of arsenazo (3-(2 arsonophenylazo) -4, 5 dihydroxy $-2,7$ naphthalene disulfonic acid, trisodium salt) as an indicator, a procedure first developed by Kuznetsov. ${ }^{253}$ This reagent may be used as complexing agent for direct colorimetric determination of the rare earths $155,15,252$ or in conjunction with EDTA titration. 156

The rare earth-arsenazo color intensity increases as the temperature is increased, and Kuznetsov and Petrova ${ }^{254}$ have measured small amounts of rare earths at elevated temperatures in the presence of $\mathrm{Th}$ with greater accuracy than is possible at ordinary temperatures.

A close relative of arsenazo is 2(0-arsonophenylazo)-1, 8-dihydroxy-3, 6 naphthalene disulfuric acid (neothorone), which has been used by Shibata, Takeuch1, and Matsumas 437 to measure lanthanum colorimetrically.

These references do not exhaust all of the reports which have been published on EDTA titration of the rare earths. A much more thorough coverage of the entire subject of EDTA titration has been written by Barnard, Flaschka, and Broad ${ }^{18}$ and their series of review articles should be consulted for additional references.

Papers on the direct colorimetric determination of the rare earths have also been published by Holleck, Eckardt, and Hartinger ${ }^{204}$ who found sulfosalicylic acid and aurin tricarboxylic acid to be the best color-forming reagents for spectrophotometric determination of the rare earths. Rinehart, 387 
however, has found alizarin red $S$ to be quite satisfactory for the rare earths and yttrium; Eberle and Lerner ${ }^{122}$ have used the same reagent for quantitative determination of scandium; Bergstresser ${ }^{25}$ has used 8 -hydroxyquinoline for colorimetric determination of lanthanum in plutonium with good results, and Alimarin, Przheval'skii, Puzdrenkova, and Golovina ${ }^{6}$ have used the same reagent for $\mathrm{Ce}^{+3}$ and $\mathrm{Ce}^{+4}$.

Vanossi 493 has reported a colorimetric procedure for scandium which involves the use of carminic acid in acetic acid solution and claims a sensitivity of $1 \mu \mathrm{g} \mathrm{Sc}$ for the method, while Biryuk and Nazarenko ${ }^{30}$ have used derivatives of 2:3:7 trihydroxy-6 fluorone to detect 0.04 to $2 \mu \mathrm{g}$ of scandium per $\mathrm{ml}$, and Korenman, Gunina, and Trifonova ${ }^{242}$ have studied the color reaction of scandium with hydroxyanthraquinone and 1,1 dihydroxyazo dyes.

Popa, Negoiu, and Baiulescu 370 have developed a procedure for determining $\mathrm{Ce}^{+4}$ in the presence of trivalent lanthanide elements which uses 0 -dianisidine in $20 \% \mathrm{H}_{2} \mathrm{SO}_{4}$ solution.

Goto and Kakita ${ }^{176}$ have extracted the cerium-methylene blue complex into organic solvents and determined the cerium concentration colorimetrically.

The titration procedures described above may be used for fairly large samples of rare earths, of course, but perhaps the main advantage of both the titration and colorimetric procedures is that they may be used to determine very small amounts of rare earths with good precision. Many of the procedures were designed specifically to measure microgram quantities of these elements and seem to do so very nicely.

\section{5. COMPLEX IONS AND CHELATE COMPOUNDS}

\section{5A. INTRODUCTION}

Although the rare earths have been known for a great many years, until comparatively recently most published articles have been concerned primarily with relatively simple salts of these elements. With the advent of ion-exchange resins and liquid-liquid extraction procedures, however, a considerable literature on the formation of complex salts and chelate compounds of the rareearth elements began to appear and at present there is information available on a very large number of these species. Terent'eva 477 has published a masterful review of this aspect of rare-earth chemistry and this section will, to a great extent, consist of a translation of that paper, supplemented where necessary by additional or more recently published data.

Many methods are known for disclosing complex compounds of rareearth elements in solution. For example, the distribution of ions of rareearth elements between ion exchangers and aqueous solutions containing different complexing agents makes it possible to discern the comparative structures of complex compounds. Comparison of the results of polarographic re- 
duction of $\mathrm{Eu}^{+3}$, in the presence and absence of different ions, indicates formation of complex compounds. Transfer of the rare earths from the aqueous to the organic phase in the presence of $\beta$-diketones, tributyl phosphate, and other agents, indicates formation of complexes. A change in the transport number, and in the electroconductivity, confirms the formation of complex compounds. Rare-earth transfer to the anode during electrolysis in the presence of organic anions indicates formation of negatively charged complex ions, while the change in spectral characteristics of rare-earth elements in the presence of complexing agents likewise indicates complex formation. The absence of a characteristic reaction under conditions where the rare earths normally are precipitated may be used as a simple indication of the presence of complexes, the sensitivity of this method decreases with increasing solubility of the rare-earth salt in the order $\mathrm{F}^{-}>\mathrm{C}_{2} \mathrm{O}_{4}{ }^{=}>\mathrm{OH}^{-}>$ $\mathrm{Fe}(\mathrm{CN})_{6}{ }^{-4}$.

Although a large number of complex compounds of the rare earths are known, these elements are notably more reluctant to form complex species than, for instance, are the transition elements. Moeller 316 attributes this reluctance to a combination of (1) electronic configurations unfavorable to the orbital hybridizations necessary for covalent bond formation and (2) comparatively large size which precludes the development of many very strong electrostatic or ion-dipole attractions The main differences between individual rare earths lie in the number of 4 f orbital electrons and Moeller assumes that, since the 4 f electrons are shielded by $5 \mathrm{~s}$ and $5 \mathrm{p}$ orbitals, any covalent bonding must involve higher energy orbitals such as $5 d, 6 s, 6 \mathrm{p}$, etc., and not the 4 f electrons. Terent'eva ${ }^{477}$ disagrees with this assumption on the grounds that the very large number of complex compounds now known could not all involve ionic bonding or covalent bonding with high-energy orbitals. The nature of these bonds has obviously not been determined to everyone's satisfaction, and a considerable amount of work needs to be done in this field. Meanwhile, apparently contradictory evidence continues to appear. Gulyas ${ }^{181}$ classifies the rare earth-acetylacetone complex bond as a covalent type with higher $d, s$, and $p$ orbital electrons because the $4 f$ electrons are not involved, but Jones ${ }^{222}$ concludes that rare-earth bonding with ethylene-diamine-tetraacetic acid (EDTA) is ionic in nature by analogy with the alkali and alkaline-earth-element complexes.

Whatever the final disposition of this question, however, it is plain from the following survey that the number of complex rare-earth compounds is rather high. In the first part of the survey are presented the complex compounds with salts of inorganic acids and ammonia, while in the second (and considerably broader) part are the complex compounds with organic additives. 
IV. 5B-1. Sulfates

The sulfates of alkaline metals can play a significant role in separating a mixture of rare-earth elements into subgroups. In the interaction of the sulfates of potassium and sodium with the salts of the rare-earth metals, there are formed somewhat insoluble sulfates of the type $\mathrm{Me}_{2}\left(\mathrm{SO}_{4}\right)_{3} \cdot \mathrm{nH}_{2} \mathrm{O}$, where $n=5,8,9$. Upon addition of an excess of reagent, the sulfates of the elements of the yttrium subgroup dissolve and sulfates of the elements of the cerium subgroup remain in suspension (the sulfates of the intermediate elements possess intermediate solubilities).

The solubility of the sulfates of the elements of the yttrium subgroup, in a solution of alkali metal sulfates, may be explained by the formation of complex compounds of the type $\mathrm{Me}_{3}^{\mathrm{I}}\left[\mathrm{Me}\left(\mathrm{SO}_{4}\right)_{3}\right]$ or $\mathrm{Me}^{\mathrm{I}}\left(\mathrm{Me}\left(\mathrm{SO}_{4}\right)_{2}\right]$, where $\mathrm{Me}^{\mathrm{I}}=\mathrm{K}, \mathrm{Na}, \mathrm{NH}_{4}$. This hypothesis is supported by the fact that a solution containing the ions $\mathrm{Y}^{3+}$ and an excess of $\mathrm{SO}_{4}^{2-}$ ions does not show an yttrium reaction with $\mathrm{K}_{4}\left[\mathrm{Fe}(\mathrm{CN})_{6}\right]$; upon addition of $\left(\mathrm{NH}_{4}\right)_{2} \mathrm{C}_{2} \mathrm{O}_{4}$, the yttrium oxalate does not precipitate but causes only an opalescence.

Various authors 228 have noted a tendency toward formation of complex sulfates even by such a basic element as lanthanum. It has been discovered that when a mixture of a concentrated solution of $\mathrm{La}\left(\mathrm{NO}_{3}\right)_{3}$ stands with concentrated $\mathrm{H}_{2} \mathrm{SO}_{4}, \mathrm{H}_{3}\left[\mathrm{La}\left(\mathrm{SO}_{4}\right)_{3}\right]$ is precipitated in the form of fine-grained spicules.

Korenman, 240 in determining the solubility of oxalates of rare-earth elements in acids, found that their greater solubility in $\mathrm{H}_{2} \mathrm{SO}_{4}$ than in $\mathrm{HCl}$ indicates formation of complex sulfates.

From the $\mathrm{pH}$ value of saturated solutions of oxalates in $\mathrm{H}_{2} \mathrm{SO}_{4}$, and the total concentration of $\mathrm{C}_{2} \mathrm{O}_{4}^{2-}$ ( or $\mathrm{Me}^{3+}$ ) in these solutions, he calculated the constants of instability for complex ions of type $\mathrm{MeSO}_{4}{ }^{+}$. Kuntz, ${ }^{249}$ studying the oxidation-reduction potentials of the $\mathrm{Ce}^{3+} / \mathrm{Ce}^{4+}$ systems in sulfuric acid solution, discovered the appearance of complex-formation between the ions $\mathrm{SO}_{4}^{2-}, \mathrm{HSO}_{4}^{-}$, and $\mathrm{Ce}^{4+}$, while Hardwick and Robertson ${ }^{192}$ have shown that ceric ion as sociates with sulfate to form successively $\mathrm{Ce}\left(\mathrm{SO}_{4}\right)^{++}, \mathrm{Ce}\left(\mathrm{SO}_{4}\right)_{2}$, and $\mathrm{Ce}\left(\mathrm{SO}_{4}\right)_{3}^{-2}$.

Newton and Arcand ${ }^{336}$ and Fronaeus ${ }^{159}$ have studied the $\mathrm{Ce}^{+3}-\mathrm{SO}_{4}=$ system and Fronaeus has shown that the mono-, di-, and tri-sulfato complexes of this ion also exist.

IV. $5 B-2$. Sulfites

During interaction of the salts of elements of the cerium subgroup with $\mathrm{K}_{2} \mathrm{SO}_{3}$, precipitates of colloidal character are formed which in the course of 
time convert to spheroidal crystals. The salts of yttrium and erbium initially also make colloidal suspensions, with further addition of $\mathrm{K}_{2} \mathrm{SO}_{3}$ the precipitate is dissolved, which can be explained by formation of the complex compounds $\left[\mathrm{Me}\left(\mathrm{SO}_{3}\right)_{3}\right]^{3-}$. Upon standing out of solution for extended times they become very coarse crystals, in the form of plates, and druse which seems to be associated with the decomposition of the complex compound.

Complex sulfites have been studied by Vickery. ${ }^{504}$ While studying the titration of $\mathrm{Me}(\mathrm{OH})_{3}$ with $\mathrm{H}_{2} \mathrm{SO}_{3}$, he discovered that at the ratio of $\mathrm{Me}: \mathrm{SO}_{3}=1: 3$ a compound is formed having the composition $\mathrm{H}_{3}\left[\mathrm{Me}\left(\mathrm{SO}_{3}\right)_{3}\right]$. Spectrophotometric study of the "bisulfite" solution indicated that this compound has a structure close to the structures of solutions of complex compounds of lanthanides with "complexons." The maximum change in the spectrum, in comparison with the spectra of solutions of simple salts of rare-earth elements, is found at $\mathrm{pH} 5.5$ to 6.1. During titration of the "bisulfite" solution of a rare-earth element at $\mathrm{pH} 3.8$ by $\mathrm{NaOH}$, a sediment is precipitated whose makeup is $\mathrm{Na}_{3}\left[\mathrm{Me}\left(\mathrm{SO}_{3}\right)_{3}\right]$. Upon further titration the $\mathrm{SO}_{3}{ }^{=}$ions are dis placed by $\mathrm{OH}^{-}$ions and become first $\mathrm{Na}\left[\mathrm{Me}\left(\mathrm{SO}_{3}\right)_{2}(\mathrm{OH})_{2}\right]$, then $\mathrm{Na}_{3}\left[\mathrm{Me}\left(\mathrm{SO}_{3}\right)\right.$ $\left.(\mathrm{OH})_{4}\right]$, and finally precipitate $\mathrm{Me}(\mathrm{OH})_{3}$. The existence of the complex anion $\left[\mathrm{Me}\left(\mathrm{SO}_{3}\right)_{3}\right]^{3-}$ is confirmed by experiments with anion-exchange resins. Three $\mathrm{Cl}^{-}$ions of the anion exchanger ( $\mathrm{RCl}$ ) are displaced by the one ion $\left[\mathrm{Me}\left(\mathrm{SO}_{3}\right)_{3}\right]^{3-}$ :

$$
3 \mathrm{RCl}+\mathrm{H}_{3}\left[\mathrm{Me}\left(\mathrm{SO}_{3}\right)_{3}\right] \rightarrow 3 \mathrm{HCl}+\mathrm{R}_{3}\left[\mathrm{Me}\left(\mathrm{SO}_{3}\right)_{3}\right] \text {. }
$$

Solutions of the complex compound $\mathrm{H}_{3}\left[\mathrm{Me}\left(\mathrm{SO}_{3}\right)_{3}\right]$ are easily oxidized by oxygen to sulfates:

$$
4 \mathrm{H}_{3}\left[\mathrm{Me}\left(\mathrm{SO}_{3}\right)_{3}\right]+3 \mathrm{O}_{2} \rightarrow 2 \mathrm{Me}_{2}\left(\mathrm{SO}_{4}\right)_{3}+6 \mathrm{SO}_{2}+6 \mathrm{H}_{2} \mathrm{O}
$$

The oxidation proceeds without intermediate formation of simple sulfites. As Vickery noted, in contrast to other complex compounds of rare-earth elements, the stability of the complex sulfites decreases with increase of the atomic number of the rare-earth element. According to speed of oxidation, the yttrium compound takes an intermediate position between the compounds of neodymium and samarium. The ability of complex sulfites gradually to be oxıdized by oxygen is utilized for separating mixtures of rare-earth elements.

Mayer and Schwartz 296 have studied the $\mathrm{Ce}^{+3}-\mathrm{SO}_{3}=$ system using cation-exchange resins and give a dissociation constant of $1.1 \times 10^{8}$ for the reaction

$$
\mathrm{Ce}^{+3}+\mathrm{HSO}_{3}^{-}=\mathrm{CeSO}_{3}^{+}+\mathrm{H}^{+}
$$

IV. 5B - 3. Throsulfates

When mixing concentrated solutions of the salts of rare-earth elements 
and the thiosulfate of sodium, there are formed thiosulfates of the rare-earth elements of composition $\mathrm{Me}_{2}\left(\mathrm{~S}_{2} \mathrm{O}_{3}\right)_{3}$. Being moderately soluble in water, they are precipitated as well-formed crystals having the colors characteristic of the ions of rare-earth elements. Upon ignition ${ }^{394}$ they are changed into products of composition $\mathrm{Me}_{2} \mathrm{O}\left(\mathrm{SO}_{3}\right)_{2}$. The thiosulfate of cerium, upon ignition, forms $\mathrm{CeO}_{2}$ which is not soluble in concentrated salt solutions. These characteristics are used for separation of cerium from residual rare-earth elements. When dissolving thiosulfates of rare-earth metals in excess thiosulfates of alkaline metals, the complex compounds $\mathrm{Na}_{5}\left[\mathrm{Me}\left(\mathrm{S}_{2} \mathrm{O}_{3}\right)_{4}\right]$ and $\mathrm{K}_{3}\left[\mathrm{Me}\left(\mathrm{S}_{2} \mathrm{O}_{3}\right)_{3}\right]$ result, a fact which has been established by the electroconductivity method. 110

\section{5B-4. Halides}

Simple fluorides seem to be one of the most difficult-to-dissolve salts of rare-earth elements. However, Dergunov, ${ }^{103}$ by studying diagrams of the fusibility of mixtures of rare-earth fluorides and alkaline metals, succeeded in tracing the complex fluorides $\mathrm{K}\left[\mathrm{LaF}_{4}\right]$ and $\mathrm{Na}\left[\mathrm{LaF}_{4}\right]$, and likewise $\mathrm{M}_{3}\left[\mathrm{MeF}_{6}\right]^{3-}$ (where $\mathrm{M}=\mathrm{K}, \mathrm{Rb}$, and $\mathrm{Cs}$ ), which are soluble in dilute acids. Other researchers ${ }^{363}$ have also noted that when dissolving $\mathrm{PrF}_{3}$ in a melt of $\mathrm{KHF}_{2}$, a complex fluoride of praseodymium is formed which is soluble in dilute acid salts.

Scandium is considerably more soluble in aqueous fluoride solution than are the other rare earths. Kury, Paul, Hepler, and Connick 251,352 report the existence of $\mathrm{ScF}^{++}, \mathrm{ScF}_{2}^{+}, \mathrm{ScF}_{3}(\mathrm{aq})$, and $\mathrm{ScF}_{4}^{-}$species and give the equilibrium quotients at $25^{\circ} \mathrm{C}$ for the reactions:

$$
\begin{aligned}
\mathrm{Sc}^{+3}+\mathrm{F}^{-} & =\mathrm{ScF}^{+2} & \mathrm{~K}_{1} & =1.2 \times 10^{7} \\
\mathrm{ScF}^{+2}+\mathrm{F}^{-} & =\mathrm{ScF}_{2}^{+} & \mathrm{K}_{2} & =6.4 \times 10^{5} \\
\mathrm{ScF}_{2}^{+}+\mathrm{F}^{-} & =\mathrm{ScF}_{3}(\mathrm{aq}) & \mathrm{K}_{3} & =3.0 \times 10^{4} \\
\mathrm{ScF}_{3}(\mathrm{aq})+\mathrm{F} & =\mathrm{ScF}_{4} & \mathrm{~K}_{4} & =7 \times 10^{2}
\end{aligned}
$$

There is nothing conclusive in the literature on complex halides of trivalent rare-earth elements of the type $\left[\mathrm{MeCl}_{6}\right]^{3-}$. There is information ${ }^{323}$ on separation of hexachlorocerium acid of tetravalent cerium: $\mathrm{H}_{2}\left[\mathrm{CeCl}_{6}\right]$. A suspension of pure dry cerium oxide in anhydrous dioxane was treated with dry gaseous $\mathrm{HCl}$ over the course of several hours. The solution colored quickly to an orange-red hue and the temperature rose to $50^{\circ} \mathrm{C}$. After separation of the yellow-colored sedimentation it was maintained for 24 hours at $2-3^{\circ} \mathrm{C}$. Spicule-shaped crystals of orange-red hue evolved. The crystals were removed, scrubbed with dioxane and then with a petroleum ether, and dried in a stream of dry air. Data of analysis corresponded to the formula $\mathrm{H}_{2}\left[\mathrm{CeCl}_{6}\right] \cdot 4 \mathrm{C}_{4} \mathrm{H}_{8} \mathrm{O}_{2} \cdot$ A double salt with pyridine $\mathrm{H}_{2}\left[\mathrm{CeCl}_{6}\right] \cdot\left(\mathrm{C}_{5} \mathrm{H}_{5} \mathrm{~N}\right)$ was 
obtained from a solution of these crystals in methanol.

Further evidence for the extreme reluctance of the rare earths to form chloride complexes is provided by Diamond, Street, and Seaborg ${ }^{104}$ and Hulet, Gutmacher, and Coops, ${ }^{209}$ who show that even in very concentrated $\mathrm{HCl}$ or $\mathrm{LiCl}$ the formation of rare-earth chloride complexes is slight.

\section{5B-5. Nitrates}

The nitrates of rare-earth elements give (with alkaline nitrates, alkaline earth, and some other elements) well-crystallized double salts - for example, with magnesium, $\mathrm{Mg}\left(\mathrm{NO}_{3}\right)_{2} \cdot \mathrm{Me}\left(\mathrm{NO}_{3}\right)_{3} \cdot 24 \mathrm{H} 2 \mathrm{O}$. D.I. Mendeleyev in 1873 first used the crystallization of double nitrates of ammonia for separation of La from "Di." These salts are still used today for preparatory separation of elements of the cerium subgroup. Double nitrates, found in aqueous solution, display a complex character. In the presence of a large surplus of $\mathrm{NO}_{3}{ }^{-}$, the rare-earth elements of the yttrium subgroup yield, upon addition of $\left(\mathrm{NH}_{4}\right)_{2} \mathrm{C}_{2} \mathrm{O}_{4}$, an oxalate precipitate only after standing for some time. One may suppose that the complex ions $\left[\mathrm{Me}\left(\mathrm{NO}_{3}\right)_{6}\right]^{3-}$ exist in the solution.

According to the data of Noyes and Garner, ${ }^{343}$ in aqueous nitric acid solutions of $\mathrm{Ce}\left(\mathrm{NO}_{3}\right)_{4}$ there exists an excess of $\mathrm{NO}_{3}{ }^{-}$ions, forming the complex ions $\left[\mathrm{Ce}\left(\mathrm{NO}_{3}\right)_{6}\right]^{2-}$. The existence of the latter is demonstrated by the fact that, during electrolysis of a solution of $\mathrm{Ce}^{4+}$ salts in $6 \mathrm{~N} \mathrm{HNO}_{3}$, cerium appears in the anode region. The expressed hypothesis was supported by data published later by other authors. ${ }^{433,235}$ The capability to give similar complex compounds is widely used today for separation of cerium from other rare-earth elements. Cerium is extracted by ethyl ether from nitric acid, in the form of a complex acid $\mathrm{H}_{2}\left[\mathrm{Ce}\left(\mathrm{NO}_{3}\right)_{6}\right]$.

In 1956 an article was published 304 on extraction of the double salts of La, Ce, Pr, and Nd with the nitrate of triphenylbenzylphosphonium. These salts are crystalline substances, easily soluble in organic solvents. They are hydrolyzed in aqueous solutions. On the basis of analytical data the author presented their formula in the form: $\left[\left(\mathrm{C}_{6} \mathrm{H}_{5}\right)_{3}\left(\mathrm{C}_{2} \mathrm{H}_{5} \mathrm{CH}_{2}\right) \mathrm{P}\right] \cdot\left[\mathrm{Me}\left(\mathrm{NO}_{3}\right)\right]_{5}$ (where Me = La, Ce, Pr, Nd).

Miss L.O. Tuazon ${ }^{551}$ has shown that even in relatively dilute nitrate solution $\mathrm{Ce}(+4)$ forms a $\mathrm{Ce}\left(\mathrm{NO}_{3}\right)(\mathrm{OH})^{+2}$ complex and, to a lesser extent, $\mathrm{Ce}\left(\mathrm{NO}_{3}\right)_{2}^{+2}$.

IV. 5B-6. Nitrites

Nitrites of the type $\mathrm{Cs}_{2} \mathrm{Na}\left[\mathrm{Me}\left(\mathrm{NO}_{2}\right)_{6}\right]$ (where $\mathrm{Me}=\mathrm{La}, \mathrm{Ce}, \mathrm{Pr}, \mathrm{Y}$ ) were prepared by Ferrari et al. ${ }^{133}$ by slowly diffusing an aqueous solution of $\mathrm{CsNO}_{3}$ through a parchment membrane into solution consisting of $\mathrm{Me}\left(\mathrm{NO}_{3}\right)_{3} \cdot 6 \mathrm{H}_{2} \mathrm{O}$ 
and $\mathrm{NaNO}_{2}$. The compound isolated by the authors, $\mathrm{Cs}_{2} \mathrm{Na}\left[\mathrm{La}\left(\mathrm{NO}_{2}\right)_{6}\right]$, appeared as faintly greenish, almost colorless crystals.

IV. 5B-7. Carbonates

When $\mathrm{CO}_{2}$ is passed into a suspension of hydroxides of rare-earth elements, crystalline carbonate is obtained. Under the action of a saturated solution of $\mathrm{K}_{2} \mathrm{CO}_{3}$ on the solution, the salts of the cerium group of elements secrete a slimy residue which, in the course of further addition of reagent, is dissolved with formation of a complex compound which is not decomposed by the action of $\left(\mathrm{NH}_{4}\right)_{2} \mathrm{C}_{2} \mathrm{O}_{4}$. If a more dilute carbonate solution is added, a residue is obtained which is not soluble in an excess of reagent. The solubility of carbonates in a saturated solution of $\mathrm{K}_{2} \mathrm{CO}_{3}$ increases with the increase in atomic number of the rare-earth elements. The composition of the complex carbonates soluble in water seems to be $\mathrm{K}_{3}\left[\mathrm{Me}\left(\mathrm{CO}_{3}\right)_{3}\right]$. Fischer 142 used carbonates for fractionally separating mixtures of rare-earth elements. Axelrod" has completed a Ph. D. thesis on "Studies of the Rare-Earth Carbonates" in which he prepared various forms of the rare-earth carbonates by hydrolysis of trichloroacetate or urea solutions containing fairly high concentrations of the rare-earth elements.

IV. 5B-8. Chromates

A spectrophotometric study ${ }^{484}$ was made of a $1 \underline{\mathrm{M}}$ solution of $\mathrm{HClO}_{4}$ containing $\mathrm{Ce}^{4+}$ and $\mathrm{Cr}^{6+}$ (at $25^{\circ} \mathrm{C}$ ). It was found that a complex compound exists in the solution containing $1 \mathrm{Ce}^{4+}$ ion to $1 \mathrm{Cr}^{6+}$ ion.

IV. 5B-9. Phosphates

Serebrennikov ${ }^{432}$ reports that, during conductometric titration of a $0.1 \mathrm{~N}$ solution of $\left(\mathrm{NH}_{4}\right)_{2}\left[\mathrm{Ce}\left(\mathrm{NO}_{3}\right)_{6}\right]$ by a $0.1 \mathrm{~N}$ solution of $\mathrm{Na}_{4} \mathrm{P}_{2} \mathrm{O}_{7}$, he noted in the solution a complex compound of $\mathrm{Ce}^{4+}$ with the pyrophosphate ion: $\mathrm{Na}_{4} \mathrm{Ce}\left(\mathrm{P}_{2} \mathrm{O}_{7}\right)_{2}$. The author explained the composition of this compound by the fact that, in it, the pyrophosphate ion exhibits a coordination capacity of three (which appears somewhat unexpected).

Addition of sodium phosphate (and polyphosphates) to an aqueous rareearth solution adjusted to $\mathrm{pH} 4.5$ results in the precipitation of normal phos phates (and polyphosphates) corresponding to the formulae $\mathrm{R}\left(\mathrm{PO}_{4}\right), \mathrm{R}_{4}\left(\mathrm{P}_{2} \mathrm{O}_{7}\right)_{3}$, and $\mathrm{R}_{5}\left(\mathrm{P}_{3} \mathrm{O}_{10}\right)_{3} \cdot{ }^{66}$ At higher concentrations of pyrophosphates and triphos phates, Giesbrecht and Audrieth ${ }^{173}$ have shown that soluble species exist in which the ratio of rare-earth metal ion to triphosphate is $1: 2$ (they postulate an anionic complex with the formula $\left[\mathrm{Na}_{4}(\mathrm{RE})\left(\mathrm{P}_{3} \mathrm{O}_{10}\right)_{2}\right]^{3-}$ as one possibility). Genge and Salmon, ${ }^{169}$ using elution of cations from ion-exchange resin solumns as a criterion, conclude that scandium has a somewhat greater tendency to form complexes with orthophosphoric acid than do the other rare earths. 
IV. 5B-10. Heteropoly Compounds

The known ${ }^{17}$ compounds are $\mathrm{Me}_{8}^{\mathrm{I}}\left[\mathrm{Ce}\left(\mathrm{Mo}_{2} \mathrm{O}_{7}\right)_{6}\right] \cdot 8 \mathrm{H}_{2} \mathrm{O}$ and $\mathrm{Me}_{8}^{\mathrm{I}}\left[\mathrm{Ce}\left(\mathrm{W}_{2} \mathrm{O}_{7}\right)_{6}\right]$. $8 \mathrm{H}_{2} \mathrm{O}$, where $\mathrm{Me}^{\mathrm{I}}=\mathrm{K}, \mathrm{Na}, \mathrm{NH}_{4}$. The first of these was obtained in the form of yellow crystalline sediment upon drop-by-drop addition of a normal solution of ammonium molybdate into a boiling mixture of $\left(\mathrm{NH}_{4}\right)_{2}\left[\mathrm{Ce}\left(\mathrm{NO}_{3}\right)_{6}\right]$. A double salt of composition $\left(\mathrm{NH}_{4}\right)_{6} \mathrm{H}_{2}\left[\mathrm{Ce}\left(\mathrm{Mo}_{2} \mathrm{O}_{7}\right)_{6}\right]$ was precipitated from the sulfuric acid solution. Ammonium ions, being located on the exterior sphere of the

- polycerium molybdate, are capable of interchanging with other cations - frequently for $\mathrm{Ag}^{+}$and ions of trivalent rare-earth elements. The resulting compounds are difficult to dissolve in mineral acids. ${ }^{432}$ Their complex character is emphasized by the fact that they do not produce a reaction in $\mathrm{Ce}^{4+}$ with hydrogen peroxide, oxalic acid changes this compound into cerium oxalate incompletely and only after boiling.

Komarovski1 and Korenman 239 produced a compound of the type $\left(\mathrm{NH}_{4}\right)_{3}$ $\left[\mathrm{MeMo}_{7} \mathrm{O}_{24}\right] \cdot 12 \mathrm{H}_{2} \mathrm{O}$ (where $\mathrm{Me}=\mathrm{La}$ or $\mathrm{Ce}$ ).

IV. 5B-11. Ammoniates

Complex ammoniates of rare-earth elements can be produced $80,125,21$ in a medium of liquid ammonia, or by means of uninter rupted hours-long passage of a stream of ammonia through a solution of $\mathrm{Me}\left(\mathrm{NO}_{3}\right)_{3}$ with a somewhat raised temperature $\left(\sim 40^{\circ}\right)$. A crystalline substance of composition $\mathrm{Me}\left[\left(\mathrm{NH}_{3}\right)_{6}\right] \mathrm{NO}_{3}$ is produced.

In 1955 Popov and Wendlandt ${ }^{371}$ discovered a barely stable complex compound of divalent samarium with ammonia. A batch of dehydrated $\mathrm{SmCl}_{3}$ was placed in a porous glass filter, in a special closed system, and cooled by solid $\mathrm{CO}_{2}$. The surface of the batch was covered with a solution of sodium and liquid ammonia, and for several minutes the solution was filtered. The sodium residue was removed by repeated scrubbing with ammonia. The reaction product, a solid substance of a red-brown color, was heated to room temperature in atmospheric nitrogen. In air it rapidly lost the ammonia, and this guaranteed, apparently, that it was connected with the oxidation of $\mathrm{Sm}^{2+}$ to $\mathrm{Sm}^{3+}$ and the breakdown of the complex ammonia. One may assume that the compound had a composition of $\left[\mathrm{Sm}\left(\mathrm{NH}_{3}\right)_{4}\right] \mathrm{Cl}_{2}$, however, because of insufficient stability it could not be analyzed.

Vickery 506, 507 has convincingly demonstrated the existence of a hexammino scandium cation in aqueous solution. The stability of the complex is sufficiently great so that the precipitation of scandium as oxalate or hy droxide from solutions containing ammonium ion is seriously interfered with. 


\section{5C-1. Carboxylic Acids}

In the domain of organic substances, acids seem to be one of the strongest complex-forming agents for rare-earth elements. It is noteworthy that the structure of the resultant complex compounds depends in a significant degree on the structure of the acid; i.e., on length of hydrocarbon chains, basicity, and relative position of functional groups.

Simple carboxylic acids do not present special interest. The first members of this series, although they do form complex compounds, exhibit insignificant stability in solution; and acids with a hydrocarbon chain of 10 to 15 atoms produce only salts difficult to dissolve in water. We will mention only a few of their representatives.

IV. $5 \mathrm{C}-1(\mathrm{a})$. Acetic Acid, $\mathrm{CH}_{3}-\stackrel{\mathrm{O}}{\mathrm{C}}-\mathrm{OH}$. Ammonium acetate produces complex compounds, but they are unstable and exist only in a significant excess of reagent. In these circumstances the complex compounds are not broken down under the action of $\mathrm{K}_{4}\left[\mathrm{Fe}(\mathrm{CN})_{6}\right]$. Weinlandt and Henrichson ${ }^{514}$ found that upon addition of nitric acid to cerium acetate solution, a complex cationic species is formed containing three atoms of cerium and three radicals of acetic acid: $\left[\mathrm{Ce}_{3}\left(\mathrm{CH}_{3} \mathrm{COO}\right)_{3}\right]\left(\mathrm{NO}_{3}\right)_{6} \cdot 13 \mathrm{H}_{2} \mathrm{O}$. There were also precipitated complex compounds in which the anion consisted of perchlorate, chromate, or picrate.

Canneri ${ }^{69}$ produced complex cerium acetates in which three supplementary valencies in the inner sphere were taken by three molecules of urea: $\left.\left[\mathrm{Ce}\left(\mathrm{CH}_{3} \mathrm{COO}\right)_{3}\right] \cdot 3 \mathrm{CO}\left(\mathrm{NH}_{2}\right)_{2}\right]$.

In 1950, Vickery 497 discovered complex compounds having, in their inner spheres, acetate ions and molecules of ammonia: $\left[\mathrm{Me}_{3}\left(\mathrm{CH}_{3} \mathrm{COO}\right)_{3}\right.$. $\left.\left(\mathrm{NH}_{3}\right)_{3}\right]\left(\mathrm{SO}_{4}\right)_{3} \cdot \mathrm{xH}_{2} \mathrm{O}$ (where $\left.\mathrm{Me}=\mathrm{Pr}, \mathrm{Nd}, \mathrm{Sm}\right)$. He did not succeed in forming similar compounds for $\mathrm{La}, \mathrm{Ce}^{3+}$, and $\mathrm{Ce}^{4+}$. The complexes were produced during fractional crystallization of the double sulfates of rare-earth elements from an ammonium-acetate solution in the presence of $\mathrm{H}_{2} \mathrm{SO}_{4}$ and $\mathrm{HCl}$; the emergence of similar complex compounds interrupted the normal course of crystallization. Solutions of this compound with neodymium, according to the observations of the author, exhibited a blue fluorescence under a mercury lamp - a characteristic which may be utilized for qualitative determination of neodymium.

Seaton ${ }^{428}$ has made a very thorough investigation of the behavior of neodymium and, to a lesser extent, yttrium in acetic acid solution; and Sonesson ${ }^{444}$ has determined the complexity constants of the acetate complexes of $\mathrm{La}^{+3}, \mathrm{Ce}^{+3}, \mathrm{Nd}^{+3}$, and $\mathrm{Gd}^{+3}$. 
The study of the characteristics of acetate complexes has practical interest. For example, when precipitating various rare-earth elements by electrolytic methods in acetic acid, knowledge of the composition of the resultant compounds, and their composition as a function of the $\mathrm{pH}$ of the solution, alds in the correct choice of electrolytical conditions. 398

IV. $5 \mathrm{C}-1(\mathrm{~b})$. Stear1c AC1d, $\mathrm{CH}_{3}\left(\mathrm{CH}_{2}\right)_{16}-\stackrel{\mathrm{O}}{\mathrm{C}}-\mathrm{OH}$. Rare-earth elements with this acid create only salts poorly soluble in water.

IV. 5C-I(c). Oxalic Acid, HOOC-COOH. The introduction of a second $\mathrm{COOH}$-group into a molecule of a restricted acid, especially in the a-position, increases stability of the complex compound. ${ }^{480}$ With increase of space between the $\mathrm{COOH}$ groups, the tendency toward complex-formation diminishes. For example, at a distance of only 7 to 8 atoms of carbon between carboxyl groups, complex compounds are no longer formed with elements of the yttrium subgroup.

The first member of the series of dibasic carboxylic acids - oxalic acid - forms a somewhat stable complex compound with succeeding members of the group of rare-earth elements. This explains their loss when precipitating a mixture of these elements with ammonium oxalate. Complex compounds are formed which appear to have the composition $\left(\mathrm{NH}_{4}\right)_{3}\left[\mathrm{Me}\left(\mathrm{C}_{2} \mathrm{O}_{4}\right)_{3}\right]$. Orlov, ${ }^{348}$ studying oxalates of rare-earth elements, found that cerium in higher valencies is capable of forming complex oxalates. This characteristic has often been utilized 399 for separating out cerium from a mixture with other rare-earth elements. The oxalate mixture is dissolved in hot $\mathrm{H}_{2} \mathrm{SO}_{4}$, diluted with water, and poured into a great abundance of ammonium oxalate. The solution takes on a dark orange color as a result of the formation of a complex cerium oxalate, and all the remaining elements of this group are precipitated in the residue which contains an insignificant admix ture of trivalent cerium. This residue is rapidly filtered out, $\mathrm{Ce}^{4+}$ remains in the solution and appears to have the form of a complex compound of type $\left(\mathrm{NH}_{4}\right)_{2}\left[\mathrm{Ce}\left(\mathrm{C}_{2} \mathrm{O}_{4}\right)_{3}\right]$ or $\left(\mathrm{NH}_{4}\right)_{4}\left[\mathrm{Ce}\left(\mathrm{C}_{2} \mathrm{O}_{4}\right)_{4}\right]$. When standing, the filtrate loses color due to reduction of the cerium which in the residue has become $\mathrm{Ce}_{2}\left(\mathrm{C}_{2} \mathrm{O}_{4}\right)_{3}$. To speed the process of reduction of the cerium, $\mathrm{Na}_{2} \mathrm{SO}_{3}$ is added to the solution and the mixture is heated.

Crouthamel and Martin 96,97 have proven the existence of complexes of the form $\operatorname{RE}\left(\mathrm{C}_{2} \mathrm{O}_{4}\right)^{+}$and $\mathrm{RE}\left(\mathrm{C}_{2} \mathrm{O}_{4}\right)_{2}^{-}$for $\mathrm{Yb}$ and $\mathrm{Nd}$, and, in addition to the mono- and $d_{1}$-oxalate complexes, a species of the form $R E\left(C_{2} O_{4}\right)^{-3}$ for $Y$ and $\mathrm{Ce}^{+3}$.

Brezhneva and co-workers ${ }^{45}$ studied the carrying of cerıum and yttrium on calcium oxalate. They found that at high oxalate concentrations the ef- 
ficiency of carrying decreased with increasing oxalate concentration. This effect they ascribe to the formation of complex oxalates.

Vickery 507 has reported the preparation of an anionic scandium oxalate complex that would not stick to cation exchange resins but he gives no formula, presumably it is $\mathrm{Sc}\left(\mathrm{C}_{2} \mathrm{O}_{4}\right)_{3}^{-3}$.

IV. 5C-1(d). Malonic Acıd, HOOC $-\mathrm{CH}_{2}-\mathrm{COOH}$. When mixing solutions of ammonium malonate and salts of cerium group elements ( $\mathrm{La}, \mathrm{Ce}, \mathrm{Pr}$ ), a powdery residue rapidly precipitates which is soluble in an excess of reagent. However, after 20 to 30 minutes well-formed spicule-shaped crystals are deposited from the transparent solution and joined in a druse reminiscent of needles and spheres. The transparent solution (until precipitation of the crystalline residue) produces a negative reaction on an ion of the rare-earth element with the solution $\mathrm{K}_{4}\left[\mathrm{Fe}(\mathrm{CN})_{6}\right]$, which indicates the formation of a complex compound.

During interaction of yttrium and erbium salts with ammonium malonate, no precipitate is formed. Addition of solutions of $\mathrm{K}_{4}\left[\mathrm{Fe}(\mathrm{CN})_{6}\right]$ or $\mathrm{NH}_{4} \mathrm{OH}$ does not induce deposit of a precipitate, $\mathrm{KOH}$ precipitates $\operatorname{Er}(\mathrm{OH})_{3}$, but it does not precipitate $\mathrm{Y}(\mathrm{OH})_{3}$. Addition of $\left(\mathrm{NH}_{4}\right)_{2} \mathrm{C}_{2} \mathrm{O}_{4}$ immediately deposits the precipitate of the oxalates of both elements. Introduction into the solution of a significant excess of ammonium malonate does not strengthen the complexes. It is interesting to note the fact that with the passing of time crystals begin to deposit from the transparent solutions. Chemical analysis shows these residues to be of the general formula $\mathrm{Me}\left(\mathrm{C}_{3} \mathrm{H}_{2} \mathrm{O}_{4}\right) \cdot \mathrm{nH}_{2} \mathrm{O}$, 1. e., a simple malonate of rare-earth elements. Gelles and Nancollas 167 have studied solutions of malonates of rare-earth elements by electrochemical methods and have come to the conclusion that the subject elements definitely form complex malonates. As one of the possible formulas for these compounds the authors consider $[\mathrm{MA}]^{+}$(where $\mathrm{A}^{2-}$ is the anion of the malonic acid).

IV. $5 \mathrm{C}-1(\mathrm{e})$. Succinic Ac1d, HOOC $-\left(\mathrm{CH}_{2}\right)_{2}-\mathrm{COOH}$. When pouring together a solution of ammonium succinate and solutions of the salts $\mathrm{La}, \mathrm{Ce}$, and $\mathrm{Pr}$, an amorphous residue is deposited which then dissolves. With a longer period, crystals begin to precipitate in the form of spicules. If an excess of a salt of a rare-earth element is added to the ammonium succinic acid solution, there is an immediate deposition of a hard-to-dissolve precipitate. For elements of the yttrium subgroups ( $Y, E r)$, a somewhat different result is obtained. When flowing a solution of succinic acid in excessive quantity into a solution containing yttrium or erbium salt, initially no residue is deposited and the solution remains transparent. When experimenting with this solution in $\mathrm{NH}_{4} \mathrm{OH}$ and $\left(\mathrm{NH}_{4}\right)_{2} \mathrm{C}_{2} \mathrm{O}_{4}$, the characteristic residues of hydroxides and oxalates of 
these elements are rapidly deposited, under the action of $\mathrm{K}_{4}\left[\mathrm{Fe}(\mathrm{CN})_{6}\right]$, the residue is precipitated - not immediately, but after a few minutes. If the original transparent solution remains standing, then gradually (more rapidly for $Y$ than for $E r$ ) a crystalline residue of simple salt begins to precipitate.

IV. $5 \mathrm{C}-1(\mathrm{f})$. Glutaric Acid, HOOC $-\left(\mathrm{CH}_{2}\right)_{3}-\mathrm{COOH}$. During interaction of a solution of the ammonium salt of glutaric acid with a solution of $\mathrm{Y}\left(\mathrm{NO}_{3}\right)_{3}$, no residue is formed. From the clear solution under action of $\mathrm{NH}_{4} \mathrm{OH}$ and $\left(\mathrm{NH}_{4}\right)_{2} \mathrm{C}_{2} \mathrm{O}_{4}$, a precipitate is deposited. $\mathrm{K}_{4}\left[\mathrm{Fe}(\mathrm{CN})_{6}\right]$ does not create a precipitate. These qualitative experiments exhibit that here a complex compound is formed which is stable in solution.

IV. 5C-1(g). Adipic Acid, HOOC $-\left(\mathrm{CH}_{2}\right)_{4}-\mathrm{COOH}$. Upon interaction of ammonium adipinate with the salts La, Ce, Pr, Nd, and Sm, crystals of residue are deposited immediately in the form of long spicules which are not soluble in an abundance of reagent. With salts of elements in the yttrium subgroup, the residue is not obtained immediately, but after the solution has stood for a time, the crystals are deposited in the form of rhombohedrons. Under the action of $\mathrm{K}_{4}\left[\mathrm{Fe}(\mathrm{CN})_{6}\right]$ on the clear solution, the mixture deposits its characteristic crystalline residue of ferrocyanide rare-earth elements after a few minutes. With $\mathrm{NH}_{4} \mathrm{OH}$ and $\left(\mathrm{NH}_{4}\right)_{2} \mathrm{C}_{2} \mathrm{O}_{4}$, the precipitate is formed immediately. It follows that the resultant complex compounds possess insignificant stability. IV. 5C-1(h). Prmelic Ac1d, HOOC $-\left(\mathrm{CH}_{2}\right)_{5}-\mathrm{COOH}$. Upon action of ammonium pimelic acid on the solution $\mathrm{La}\left(\mathrm{NO}_{3}\right)_{3}$, a $\mathrm{f}_{3} \mathrm{ne}$, crystalline residue is deposited which is not soluble in abundant reagent. For $\mathrm{Y}\left(\mathrm{NO}_{3}\right)_{3}$ there is a different behavior: At first the residue is not formed, but after several minutes crystals separate whose form differs from crystals of lanthanum salt. IV. $5 \mathrm{C}-1(1)$. Azelaic Acid, HOOC $-\left(\mathrm{CH}_{2}\right)_{7}-\mathrm{COOH}$, and Sebacic Acid, HOOC $-\left(\mathrm{CH}_{2}\right)_{8}-\mathrm{COOH}$. Ammonium salts of the highest homologous series of dibasic acid (azelaic and sebacic), during interaction with the salts of cerium and yttrium subgroups, immediately produce an abundant finelycrystalline precipitate which is insoluble in excess reagent. This precipitate 15 composed of the simple azelaics and sebacics of rare-earth elements. IV. $5 \mathrm{C}-1(\mathrm{\jmath})$. Camphoric Acid has the structural formula<smiles>CCC(C)(C)C(=O)O</smiles>

The d-Camphorates of rare-earth elements are prepared ${ }^{105}$ by double decomposition of aqueous solutions of their chlorides and sodium camphorate. 
According to the degree of increase of the latter, the voluminous amorphous deposits which have become colored are precipitated characteristically for ions of rare-earth elements. They form a powder which does not melt when heated to $300^{\circ} \mathrm{C}$.

Chemical analysis data correspond to the general formula $\mathrm{Me}_{2}\left(\mathrm{C}_{10} \mathrm{H}_{14} \mathrm{O}_{4}\right)_{3}$, i.e., the formula for simple camphorates. At $20^{\circ} \mathrm{C}$ the camphorates are soluble in water; their solubility decreases in the series $\mathrm{Nd}, \mathrm{Pr}, \mathrm{Ce}$, and La, and lessens with increase of temperature. Upon heating of an aqueous solution, hydrolysis occurs with the formation of subsalts. In organic solvents camphorates are practically insoluble.

Regrettably, the authors 477 did not examine the capability of camphoric acid in the role of a complex-forming agent. In view of the fact that camphoric acid is able to produce inherent anhydrides, we might reasonably expect that it is capable of forming complex compounds (although perhaps not very stable ones):

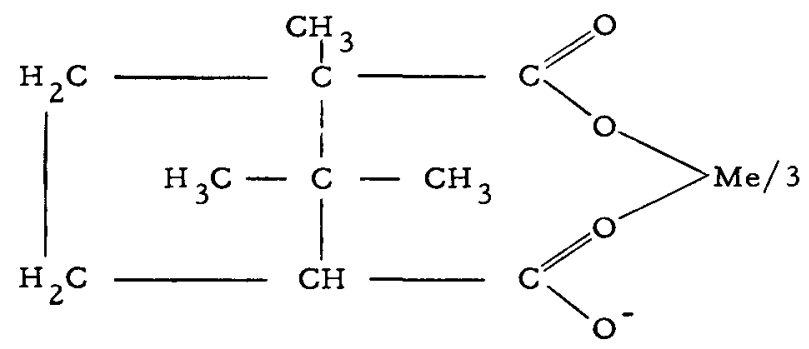

Complex compounds of rare-earth elements with dibasic organic acids possess one interesting peculiarity: they decompose in the course of time, producing a simple salt (of the appropriate acid) that is hard to dis solve in water. This process of decomposition takes place more rapidly for elements of the cerium subgroup which form less stable complex compounds, and takes place more slowly for elements of the yttrium subgroup. This rule is observed for malonic, succinic, adipic, and pimelic acids.

IV. 5C-1(k). Maleic and Fumaric Acids. The most important unsaturated dibasic acids are the $\beta$-dicarboxylic acids. The best studied are the first representatives of this series, namely maleic and fumaric, which are stereois omers:<smiles>O=C(O)/C=C\C(=O)O</smiles>

cis-form (maleic)<smiles>O=C(O)C=CC(=O)O</smiles>

trans-form

(fumaric) 
Under the action of various factors (temperature, light, hydrogen ion, etc.), the less stable maleic acid converts to the more stable fumaric acid. Upon interaction of $\mathrm{La}\left(\mathrm{NO}_{3}\right)_{3}$ with ammonium maleate, no external changes occur; however, the experiments indicated that, in the resultant solution, $\mathrm{La}^{3+}$ is not detected by the action of $\mathrm{K}_{4}\left[\mathrm{Fe}\left(\mathrm{CN}_{6}\right)\right]$ and $\mathrm{NH}_{4} \mathrm{OH}$. This indicates that a complex compound was formed. If one runs a solution of ammonium fumaric acid into a solution of $\mathrm{La}\left(\mathrm{NO}_{3}\right)_{3}$, a crystalline deposit is laid down which is insoluble in excess reagent. This fact might be explained in the following manner. Maleic acid (in the same way as dibasic saturated acids) produces, with rare-earth elements, soluble complex compounds of the type

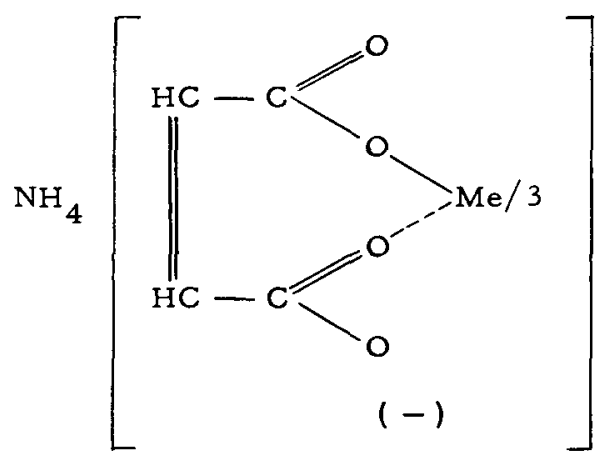

Fumaric acid possesses no capability of forming complex compounds, and in its case the hard-to-dissolve simple salts are deposited rapidly. When it stands (or is heated) in the presence of $\mathrm{HBr}$, there occurs a gradual conversion of the easily soluble complex maleinates of the rare-earth elements in the hard-to-dissolve salts of the fumaric acid.

IV. $5 \mathrm{C}-1(\ell)$. Citraconic Acid, $\mathrm{CH}_{3}-\mathrm{C}(\mathrm{COOH})=\mathrm{C}(\mathrm{COOH})-\mathrm{H}$, like maleic acid, has the cis-form. It is easily converted into the trans-form which is mesaconic acid. In regard to the salts of rare-earth elements, citraconic acid acts similarly to maleic - creating water-soluble complex compounds which do not decompose under the action of $\mathrm{K}_{4}\left[\mathrm{Fe}\left(\mathrm{CN}_{6}\right)\right]$ and $\mathrm{NH}_{4} \mathrm{OH}$. One may assume that, under the action of known agents, the soluble complex compounds of citraconic acid will revert into hard-to-dissolve mesaconics of rare-earth elements.

Tribasic carboxylic acids create significantly more stable complex compounds than do the dibasics.

IV. $5 \mathrm{C}-1(\mathrm{~m})$. Tricarballylic Acid, $\mathrm{CH}_{2}(\mathrm{COOH})-\mathrm{CH}(\mathrm{COOH})-\mathrm{CH}_{2}-\mathrm{COOH}$, with rare-earth elements forms a precipitate which is dissolved by further addition of the acid in large quantities. It is remarkable that salts of elements of the yttrium subgroup are easier to dissolve than salts of the cerium 
subgroup. In the transparent solutions produced, rare-earth elements do not appear under the action of $\mathrm{K}_{4}\left[\mathrm{Fe}(\mathrm{CN})_{6}\right]$ and $\mathrm{NH}_{4} \mathrm{OH}$, and with the addition of $\left(\mathrm{NH}_{4}\right) \mathrm{C}_{2} \mathrm{O}_{4}$ only a slight opalescence is created. When acidifying this solution the stability of the complex decreases.

IV. $5 \mathrm{C}-\mathrm{l}(\mathrm{n}) \cdot \frac{\text { Aconitic Acid. } \quad \mathrm{H}-\mathrm{C}-\mathrm{COOH}}{\mathrm{HOOC}-\mathrm{CH}_{2}-\mathrm{C}-\mathrm{COOH}}$

Aconitic acid is an unsaturated tribasic acid of the cis-series. Pouring a solution of its ammona salts into a solution of rare-earth-element salts $(\mathrm{L}, \mathrm{Y})$ causes a residue to be deposited which is soluble in excess reagent.

In the solution a complex compound is created which is not decomposed under the action of $\mathrm{K}_{4}\left[\mathrm{Fe}(\mathrm{CN})_{6}\right]$ and $\mathrm{NH}_{4} \mathrm{OH}$, ammonium oxalate causes only a slight opalescense. This example again confirms the fact that acids of the c1s-form produce complex compounds soluble in water.

IV. $5 \mathrm{C}-1(0)$. Kojlc Acid. Musante 325 reports that kojlc acid (see structural formula below) precipitates La, $\mathrm{Pr}, \mathrm{Nd}$, and $\mathrm{Sm}$ from solution essentially completely but does not indicate any complex formation.<smiles>O=c1cc(CO)occ1O</smiles>

IV. $5 \mathrm{C}-1(\mathrm{p})$. Salicylic Ac1d (see below) has been reported ${ }^{134}$ to form compounds of the type La(Sal) 3 , and Sudarikov, Zaytsev and Puchkov ${ }^{469}$ have succeeded in extracting salicylate complexes of several rare earths into iso-amyl alcohol.<smiles>O=C(O)c1ccccc1O</smiles>

In this medium, scandium exhibits the interesting property of being essentially completely extracted in the $\mathrm{pH}$ range 3.5 to 6 but not extracted at all at $\mathrm{pH}^{\prime}$ ' greater than 7.5. All the other rare earths are extracted completely at all $\mathrm{pH}$ 's above 6 .

Fialkov and Ermolenko 135 have recently published a paper on the lanthanum salicylate complexes and their dissociation constants. The "normal" lanthanum salicylate salt

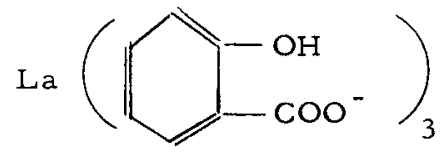


is relatively insoluble (the authors report that the $\mathrm{La}^{+3}$ concentration in $0.05 \mathrm{M}$ sodium salicylate solution is $3.7 \times 10^{-8} \mathrm{M}$ ) and lanthanum salicylate does not dissolve in an excess of sodium salicylate. When the $\mathrm{pH}$ is raised to the point where the phenolic hydrogen is dissociated, however, three distinct complexes can be formed. Addition of one mole of $\mathrm{NaOH}$ to one mole of

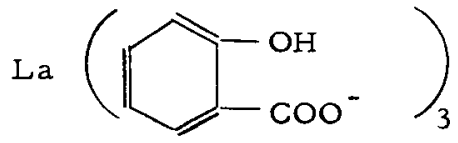

gives the product:

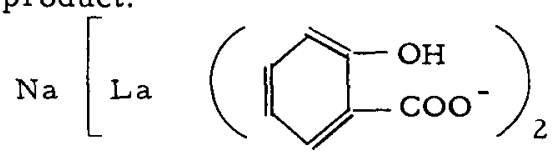

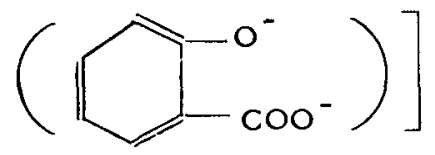

which is also quite insoluble $\left(3.5 \times 10^{-3} \mathrm{~mole} / 1\right)$. Addition of a second mole of $\mathrm{NaOH}$ gives the soluble complex

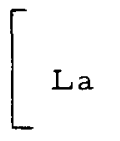

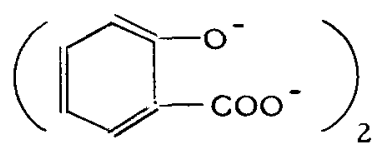

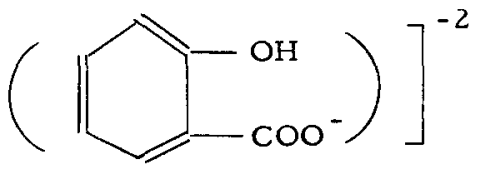

or the somewhat less soluble

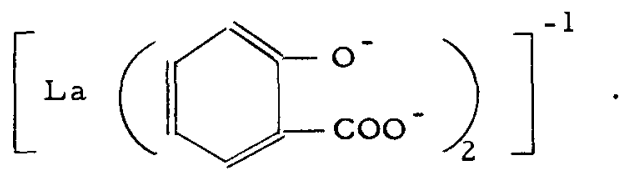

IV. 5C-2. Hydroxycarboxylic Acids

The presence in carboxylic acid of the $O H$ group, especially in the a position to the $\mathrm{COOH}$ group, notably strengthens its character as a complexforming agent.

IV. 5C-2(a). Glycolic Acid, $\mathrm{H}_{2} \underset{\mathrm{O}}{\mathrm{C}}-\mathrm{COOH}$, which differs from acetic acid $\mathrm{H}$

only by the presence of an $\mathrm{OH}-\mathrm{group}$, combines with elements of the cerium and yttrium subgroups to form complex compounds, more stable than acetates, which do not decompose under the action of either $\mathrm{K}_{4}\left[\mathrm{Fe}(\mathrm{CN})_{6}\right]$ or $\mathrm{NH}_{4} \mathrm{OH}$. Sonesson 445,446 has made a very detailed study of the glycolate rare-earth complex system, and has found that anionic rare-earth glycolate complexes exist. Complex glycolates can be utilized for separation of rare-earth elements. ${ }^{458}$ It is noted that glycolic acid permits, in specific conditions, the same degree of separation as citric acid, and has some advantages over the latter: Its complexes are less sensitive to change of the $\mathrm{pH}$ of the solution, 
it is more stable in aqueous solutions, and it can be well-preserved for weeks, not changing $\mathrm{pH}$ and not losing its eluant property.

IV. $5 \mathrm{C}-2(\mathrm{~b}) . \quad$ Lactic Acid, $\mathrm{H}_{2} \mathrm{C}-\mathrm{O}_{\mathrm{O}}^{\mathrm{CH}}-\mathrm{COOH}$. In $1913 \mathrm{Jantsch}^{218}$ described $\mathrm{H}$

compounds with lactic acid. The complex character of these compounds has been supported by electroconductivity measurements of their aqueous solutions. During interaction of a solution of salts of rare-earth elements with ammonium lactate, in the same way as with ammonium glycolate, no visible change occurs and the solution remains transparent - although in the resultant solution, under action of $\mathrm{K}_{4}\left[\mathrm{Fe}(\mathrm{CN})_{6}\right]$ and $\mathrm{NH}_{4} \mathrm{OH}$, no $\mathrm{Me}^{3+}$ ions are detected. If the transparent solution containing a mixture of ammonium lactate and rareearth element salt is allowed to stand, after 15 to 20 minutes a crystalline residue is deposited. In this characteristic, lactic acid is reminiscent of analogous compounds with dibasic acids - malonic, succinic, and adipic.

Recently, lactates have begun to be used successfully for separating mixtures of rare-earth elements. 334,536

IV. $5 \mathrm{C}-2(\mathrm{c})$. Amygdalic Acid, $\mathrm{C}_{6} \mathrm{H}_{4}(\mathrm{OH}) \mathrm{CH}_{2} \mathrm{COOH}$, with rare-earth elements forms simple salts of composition $\mathrm{Me}\left(\mathrm{C}_{8} \mathrm{H}_{7} \mathrm{O}_{3}\right)_{3} \cdot \mathrm{nH}_{2} \mathrm{O}$ (where $\mathrm{n}=2,3$ ), which differ from each other significantly in solubility. Solubility of these salts depends strongly on the $\mathrm{pH}$ of the solution and its temperature. This fact was exploited by weaver ${ }^{511}$ for separation of mixtures of rare-earth elements and likewise for $Y$-removal from heavy elements of the rare-earth group. In Weaver's work there is no mention of the fact that salts of amygdalic acid form complex compounds with rare-earth elements; however, it seems to us that such possibility is not excluded.

IV.5C-2(d). Oxalacetic Acid. Rare-earth elements form complex oxalacetates which are somewhat stable in solution 168,127 The hypothesis is expressed that they can exist in two forms:
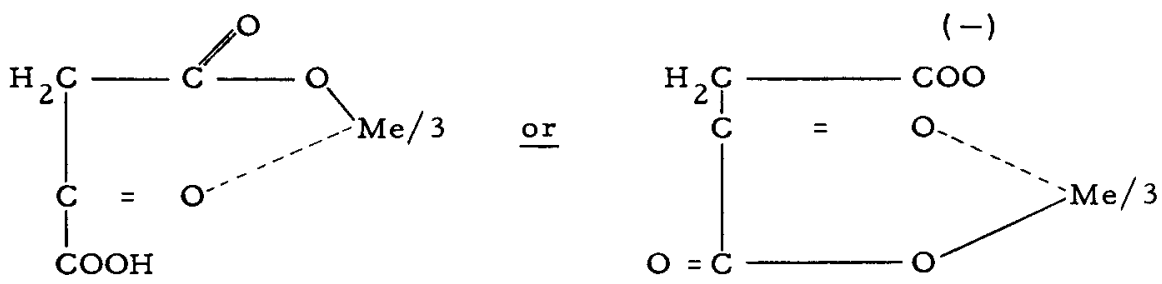

IV. 5C-2(e). Tartaric Acid (see below) and its salts are widely used in analytical chemistry for complexing ions of various heavy metals. During inter- 
action of alkaline salts of tartaric acid with rare-earth elements, there is<smiles>O=C(O)C(O)C(O)C(=O)O</smiles>

formed a complex compound of a significant stability which does not decay under the action of $\mathrm{K}_{4}\left[\mathrm{Fe}(\mathrm{CN})_{6}\right], \mathrm{NH}_{4} \mathrm{OH}$, and $\left(\mathrm{NH}_{4}\right)_{2} \mathrm{C}_{2} \mathrm{O}_{4}$.

The process of forming tartaric-acid complex compounds takes place in two stages: 1) formation of an intermediate salt that is hard to dissolve in water, and 2) dissolving of the intermediate salt in excess alkali tartrate. For erbium, in particular, the intermediate salt is a powder of a rose color that is characteristic of all simple erbium salts. Its composition corresponds to $\mathrm{Er}_{2}\left(\mathrm{C}_{4} \mathrm{H}_{4} \mathrm{O}_{6}\right)_{3} \cdot 8 \mathrm{H}_{2} \mathrm{O}$. The salt is difficult to dissolve in water, but dis solves easily in excess ammonium tartrate and forms a complex compound. The latter can be deposited from the solution (after removal of $\mathrm{NH}_{4} \mathrm{Cl}$ ) by the addition of ethyl alcohol. An oily liquid is formed which, after evaporation of the alcohol, hardens into a glassy mass. Complex tartrates, with properties very close to those of complex citrates, are sometimes used in the role of an eluant when separating mixtures of rare-earth elements on ion exchangers. ${ }^{164}$ As regards the structure of complex tartrates, one may assume that it will be analogous to the structure of the complex tartrate of indium produced by Cozzi and Vivarelli: ${ }^{91}$

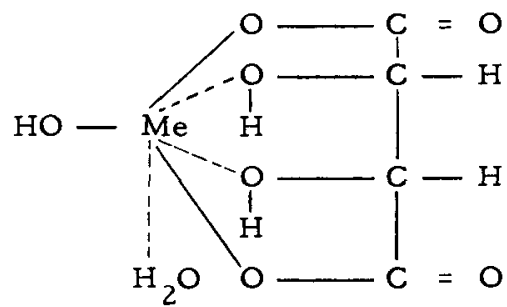

IV. $5 \mathrm{C}-2(\mathrm{f})$. Mucic Acid, $\mathrm{HOOC}-(\mathrm{CHOH})_{4}-\mathrm{COOH}$. Upon interaction of ammonium mucic acid with salts of rare-earth elements, a simple salt is formed which, upon addition of reagent, dissolves due to formation of a complex compound. The resultant solution, as in the case of complex tartrates, does not react with known reagents. However, if ammonium oxalate is poured into the solution, in time there will be spontaneously deposited oxalate of the rare-earth element; acidification of the solution speeds decay of the complex compound and deposit of the residue.

IV. $5 \mathrm{C}-2(\mathrm{~g})$. Saccharic Acid. It is interesting to note that saccharic acid, which is a stereoisomer of mucic, does not form soluble complex compounds with rare-earth elements. During interaction of sodium saccharate with 
lanthanum, neodymium, and yttrium salts, a copious powdery residue is formed which is not soluble in excess precipitant.

IV. 5C-2(h). Citric Acid is a tribasic oxy acid of the saturated series

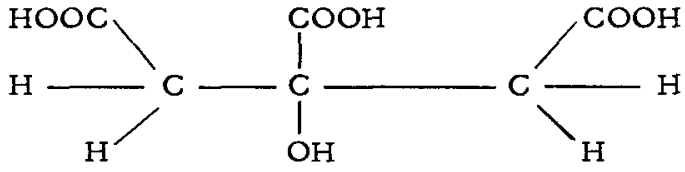

In a molecule of this acid, one has the very fortunate union of three carboxyl groups and one hydroxyl group. When citric acid acts on a solution of salts of rare-earth elements, no visible change occurs; ${ }^{395}$ but if one pours a solution of citrate salts into a solution of the salts of the cerium group, a precipitate is rapidly deposited which is difficult to dissolve in water but easy to dissolve in abundant alkali citrate. In the case of $\mathrm{Sm}$ and its succeeding elements, no precipitate is observed. When testing the transparent solutions produced in both mentioned cases by a series of precipitants, one fails to obtain precipitates of rare-earth elements. In alkaline solution, even under the action of $\mathrm{NH}_{4} \mathrm{~F}$, no fluorides of rare-earth elements are deposited. Therefore, only a very stable complex compound is created in the solution. The process of complex-compound formation takes place in two stages:

1) formation of an intermediate salt difficult to dissolve in water,

$$
\left(\mathrm{C}_{6} \mathrm{H}_{5} \mathrm{O}_{7}\right)^{-3}+\mathrm{Nd}^{+3}=\mathrm{NdC}_{6} \mathrm{H}_{5} \mathrm{O}_{7} \text {; }
$$

2) dissolving of the intermediate (precipitated) salt in excess sodium citrate, with formation of the complex compound

$$
\mathrm{NdC}_{6} \mathrm{H}_{5} \mathrm{O}_{7}+\left(\mathrm{C}_{6} \mathrm{H}_{5} \mathrm{O}_{7}\right)^{-3}=\left[\mathrm{Nd}\left(\mathrm{C}_{6} \mathrm{H}_{5} \mathrm{O}_{7}\right)_{2}\right]^{-3} \text {. }
$$

The resultant $\mathrm{HCl}$ is driven off by evaporation in a water bath, and the residue is diluted with water. The resultant solution is carefully neutralized with a solution of $\mathrm{KOH}$. This neutral solution is processed with 4 to 5 times its volume of ethyl alcohol. A heavy, oily fluid of a rosy hue separates. The upper layer is decanted, the alcohol is evaporated, and the syrupy mass of residue is dried in a desiccator. After a few hours, it is converted into a transparent, fragile product. Analytical data conform to the formula $\mathrm{K}_{3}\left[\mathrm{Nd}\left(\mathrm{C}_{6} \mathrm{H}_{5} \mathrm{O}_{7}\right)_{2}\right]_{2} \cdot 3 \mathrm{H}_{2} \mathrm{O}$. This same salt can be produced by interaction of a determined quantity of $\mathrm{NdCl}_{3}$ and citric acid salts, with further addition of ethyl alcohol.

Ammonium salt is produced by the neutralization of $\mathrm{H}_{3}\left[\mathrm{Nd}\left(\mathrm{C}_{6} \mathrm{H}_{5} \mathrm{O}_{7}\right)_{2}\right]$ with a solution of ammonia gas, the residue of which is driven off by heating. Calcium salt of composition $\mathrm{Ca}_{3}\left[\mathrm{Nd}\left(\mathrm{C}_{6} \mathrm{H}_{5} \mathrm{O}_{7}\right)_{2}\right]_{2} \cdot 3 \mathrm{H}_{2} \mathrm{O}$ is formed upon addition of $\mathrm{a} \mathrm{CaCl}_{2}$ solution to the above-described complex compounds. During processing of the reaction mixture by alcohol, calcium salt is deposited in 
the form of a powdery residue. It is worthy of note that the $\mathrm{Ca}_{3}\left[\mathrm{La}\left(\mathrm{C}_{6} \mathrm{H}_{5} \mathrm{O}_{7}\right)_{2}\right]_{2}$ compound is significantly less soluble than a compound of other elements of the cerium group. It is precipitated directly from an aqueous solution, without addition of alcohol.

In the outer sphere of complex citrate compounds one may produce all kinds of interchanges, in particular, ammonium and alkali metal ions can easily be replaced by ions of rare-earth elements: $\mathrm{Ce}\left[\mathrm{Nd} \cdot\left(\mathrm{C}_{6} \mathrm{H}_{5} \mathrm{O}_{7}\right)_{2}\right]$. This salt is a crystalline substance of a light rose color. It is difficult to dissolve in alcohol, but markedly soluble in solutions of citric acid and its alkaline salts. In the latter case, a mixture of complex citrate compounds of cerium and neodymium is produced in solution.

The existence of a stable complex of $\left[\mathrm{Me}\left(\mathrm{C}_{6} \mathrm{H}_{5} \mathrm{O}_{7}\right)_{2}\right]^{3-}$ in the solution is demonstrated by a series of methods. Thus, when passing a fixed current through a solution of the citrate complex for a certain time, in the anode region a flocculent residue is formed as a simple citrate of a rare-earth element. This indicates that the rare earth-citrate complex is negatively charged. Under the action of an electric current it heads for the anode, here, the complex decomposes and forms a simple citrate of the rare-earth element. Polarographic investigation of the solutions of complex citrates established that the complex possesses significant stability. In the presence of the citrate ion, the halfwave characteristic for sons of rare-earth elements was not detected. When neutral solutions of complex citrates were passed through a column with a cation exchanger, the complex ion was not absorbed.

All this indicates that ions of rare-earth elements form a complex with citrate ions, carrying a negative charge and possessing significant stability in solution, under these conditions, rare-earth elements possess a coordination number equal to $s i x$. Here it is interesting to note the influence of ion radius on complex-forming properties of rare-earth elements. According to the findings of Ketelle and Boyd, ${ }^{226}$ a specific succession in absorption capability (at a specific $\mathrm{pH}$ ) occurs in the presence of a citrate-1on:

$$
\mathrm{La}>\mathrm{Ce}>\mathrm{Pr}>\ldots \ldots \text {... }>\text { Dy }>\mathrm{Y}>\mathrm{Ho} \ldots \ldots . . . \mathrm{Lu} \text {. }
$$

This series exactly coincides with the decreasing order of the size of ionic radil of these elements. It therefore follows that the stability of complex citrates increases with decreasing ion radil of rare-earth elements.

In 1955 Bobtelsky and Graus ${ }^{35}$ published a study of complex citrates of trivalent cerium. The investigations were made by the heterometric method. A solution of $\mathrm{Ce}\left(\mathrm{NO}_{3}\right)_{3}$ was titrated by a solution of $\mathrm{Na}_{3} \mathrm{C}_{6} \mathrm{H}_{5} \mathrm{O}_{7}$ (abbreviated $\left.\mathrm{Na}_{3} \mathrm{C}_{1 \mathrm{t}}\right)$. The maximum optical density was found at the molar ratio $[\mathrm{Ce}]$. [Citr $]=1: 1$. Upon attaining the ratio of $[\mathrm{Ce}]:\left[\mathrm{Citr}_{1}\right]=2: 3$, the precipitate dissolved with formation of $\left[\mathrm{Ce}_{2} \mathrm{Citr}_{3}\right]^{3-}$. With further addition of 
$\mathrm{Na}_{3} \mathrm{Citr}$ the complex changed into $\left[\mathrm{CeCitr}_{2}\right]^{3-}$, likewise soluble in water. Upon addition of a $\mathrm{Ce}\left(\mathrm{NO}_{3}\right)_{3}$ solution to the complex thus created, a precipitate was deposited. The precipitated substance was either $\mathrm{Ce}\left(\mathrm{CeCitr}_{2}\right)$ or $\mathrm{Ce}\left[\mathrm{Ce}_{2} \mathrm{Citr}_{3}\right]$; it was impossible to establish which as they both have the composition [CeCitr $]_{n}^{0}$.

Data of the heterometric method were supported by the conductometric method of titration and by measurement of the pH. The authors proposed a whole series of structural formulae for the citrate complexes discovered, in particular for $\left[\mathrm{CeCitr}_{2}\right]^{3-}$ :

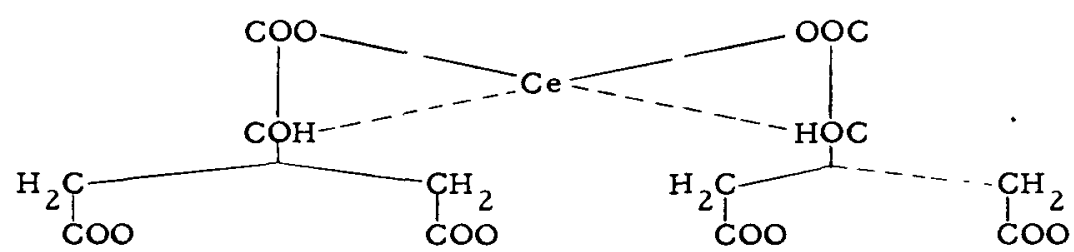

In this structural formula the coordination number for trivalent cerium was taken to equal four.

Complex citrates have found a wide usage for separation of mixtures of rare-earth elements by ion exchange. $226,220,448,450,374,10$

\section{5C-3. Amino Acids}

When glycine, $\mathrm{CH}_{2}\left(\mathrm{NH}_{2}\right)-\mathrm{COOH}$, and a-alanine, $\mathrm{CH}_{3}-\mathrm{CH}_{2}\left(\mathrm{NH}_{2}\right)-$ $\mathrm{COOH}$, act on lanthanum and erbium salts in solution, no visible change occurs. ${ }^{396}$ However, a negative reaction on $L a$ and $E r$ with ammonia indicates that a complex compound is formed.

In the case of aspartic acid, $\mathrm{HOOC}-\mathrm{CH}_{2}-\mathrm{CH}\left(\mathrm{NH}_{2}\right)-\mathrm{COOH}$, the fol lowing phenomena are found: In the first moment after mixing the solution, its ammonium salt and the solutions of lanthanum and erbium salts form a precipitate which disappears with further addition of reagent. $\mathrm{K}_{4}\left[\mathrm{Fe}(\mathrm{CN})_{6}\right]$ and $\mathrm{NH}_{4} \mathrm{OH}$ do not induce precipitation, and $\left(\mathrm{NH}_{4}\right)_{2} \mathrm{C}_{2} \mathrm{O}_{4}$ creates opalescence. It seems that in this case a fairly stable complex compound is formed.

When a-glutamic acid, HOOC $-\mathrm{CH}\left(\mathrm{NH}_{2}\right)-\left(\mathrm{CH}_{2}\right)_{2}-\mathrm{COOH}$, reacts with salts of lanthanum and neodymium, there is formed a flocculent precipitate soluble in an excess of precipitant. Upon interaction of the resultant trans parent solutions with $\mathrm{K}_{4}\left[\mathrm{Fe}(\mathrm{CN})_{6}\right]$, residue is not deposited and under the action of ammonia a slight precipitate is formed.

The first of the amino acids of the aromatic series is anthranilic acid, $\left(0-\mathrm{NH}_{2} \cdot \mathrm{C}_{6} \mathrm{H}_{4}\right)-\mathrm{COOH}$, which forms, with salts of rare-earth elements, an abundant curdled deposit that is very difficult to dissolve even in abundant precipitant. When these residues are washed with water they become crystals. After baking at $85-90^{\circ} \mathrm{C}$ the crystals take a reddish tone. 
The ammonium salt of phenyl-anthranilic acid forms with the salts of lanthanum, cerium, and erbium, a voluminous residue of greenish hue which darkens when heated. The residue is not soluble in an excess of reagent.

In 1950 Vickery 498,501 studied the process of interaction of salts of rare-earth elements with amino acids and came to the conclusion that, of all the amino acids, only histidine,

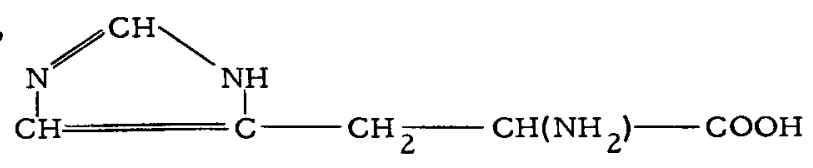

and glycine are capable of reacting with hydroxides of rare-earth elements in neutral or ammonium solutions to produce complex compounds.

With cistine,

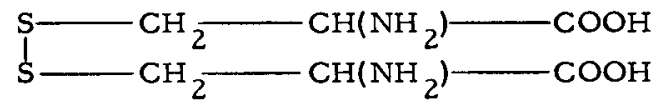

Vickery made the compound $\mathrm{Me}_{2}\left(\mathrm{C}_{6} \mathrm{H}_{10} \mathrm{O}_{4} \mathrm{~N}_{2} \mathrm{~S}_{2}\right)_{3}$, which appears as a monoclinic rosette; with glutamic acid, $\mathrm{Me}_{2}\left(\mathrm{C}_{5} \mathrm{H}_{7} \mathrm{O}_{4} \mathrm{~N}\right)_{3}$, which forms in plates of rhombic shape; and with aspartic acid, $\mathrm{Me}_{2}\left(\mathrm{C}_{4} \mathrm{H}_{5} \mathrm{O}_{4} \mathrm{~N}\right)_{3}$, which forms monoclinic prisms.

Vickery writes that he discovered two types of coordination between rare-earth elements and amino acids. If an excess quantity of hydroxide of a rare-earth element is mixed in an aqueous solution of glycine or histidine, and the excess hydroxide is filtered out, then fractionating with the help of oxalic acid causes separation in normal sequence: i.e., first, elements with the larger atomic numbers, and then, those with the smaller numbers (there are some deviations from this sequence, however, which are related to solubility of the oxalates of the rare-earth elements). If amino acids are added in corresponding excess to a fully dissolved hydroxide, then, when fractionating the precipitate in the form of oxalates, in the first series to be deposited will be lanthanum, and after it will come elements in order of increasing atomic number. Data on analysis of the precipitated compounds are introduced, and are the basis of formulae for the "complex" compounds with glycine, $\mathrm{Me}\left(\mathrm{NH}_{2} \cdot \mathrm{CH}_{2} \mathrm{COO}\right)_{3}$, and histidine, $\mathrm{Me}\left(\mathrm{C}_{6} \mathrm{H}_{8} \mathrm{O}_{2} \mathrm{~N}_{3}\right)_{3}$. Moeller, 316 in referring to the above-noted work of Vickery, writes that the mentioned compounds with amino acids have the character of salts rather than complex compounds, with which one may fully agree. Evidently the process of interaction of these two components takes place in two stages. When dissolving the excess quantity of $\mathrm{Me}(\mathrm{OH})_{3}$ in amino acid, a simple salt of amino acid with the rare-earth element if formed. This salt dissolves well in water. Naturally, with the introduction of $\mathrm{C}_{2} \mathrm{O}_{4}^{2-}$ ions into the solution, oxalates of rare-earth elements begin to precipitate in normal order; i.e., beginning with the very "heaviest." If the excess amino acids are now removed, a compound of interior-complex type is formed (also easily soluble in water); its solution 
does not produce the characteristic reactions on $\mathrm{Me}^{3+}$ with such precipitators as $\mathrm{K}_{4}\left[\mathrm{Fe}(\mathrm{CN})_{6}\right]$ and $\mathrm{NH}_{4} \mathrm{OH}$. With the introduction into the solution of $\mathrm{C}_{2} \mathrm{O}_{4}^{2-}$ ions the reverse order of depositing oxalates of rare-earth elements is found. The depositing begins with oxalate of lanthanum - the element being the least weakly complex-forming of the rare-earth series.

IV. 5C-4. Aminopolyacetic Acids

The aminopoly acids in which more than one $\mathrm{CH}_{2} \mathrm{COOH}$ group is attached to one nitrogen atom (i.e., the aminopolyacetic acids of the amino diacetic type $\mathrm{RN}\left(\mathrm{CH}_{2} \mathrm{COOH}\right)_{2}$, nitrilotriacetic type $\mathrm{N}\left(\mathrm{CH}_{2} \mathrm{COOH}\right)_{3}$, etc.) form significantly more stable complex compounds than simple amino acids. 423,285 Fitch and Russell 143 studied complex compounds of rare-earth elements with hydrazinodiacetic, benzyl iminodiacetic and o-carboxy aniline - NN-diacetic acids. Hydrazino-NN-diacetic acid,<smiles>CCCCCCCCCCN(N)CC(=O)O</smiles>
was first used by the authors ${ }^{144}$ in the role of an eluant when separating La from adjoining elements. Vickery ${ }^{503}$ showed that stable complex compounds are produced at the ratio $\mathrm{Me}: \mathrm{HA}=1: 3$. He found that these compounds are unstable in acid, but stable in neutral and alkaline media. Thus, when $\mathrm{pH} \leq 6$, solutions of these give absorption spectra characteristic for ions of $\mathrm{Me}^{3+}$; and when $\mathrm{pH}>6$, the spectra are analogous to spectra of complex compounds with "complexons."

IV. $5 \mathrm{C}-4(\mathrm{a})$. Nitrilotriacetic Acid (TRILO). The first complexons were produced by Schwarzenbach 422 in 1945 and since that time they have found ever wider usage in preparative and analytical chemistry. Beck ${ }^{19-21}$ discovered that nitrilotriacetic acid forms stable complex compounds with rare-earth elements of type $\left[\mathrm{Me}\left\{\mathrm{N}\left(\mathrm{CH}_{2} \mathrm{COO}\right)_{3}\right\}_{2}\right]^{3-}$. He isolated a hard-to-dissolve double compound

$$
\left[\mathrm{Co}\left(\mathrm{NH}_{3}\right)_{6}\right]\left[\mathrm{La}\left\{\mathrm{N}\left(\mathrm{CH}_{2} \mathrm{COO}\right)_{3}\right\}_{2}\right] \text {. }
$$

In the presence of precipitating agents such as oxalate or fluoride, these complexes exist only in media with $\mathrm{pH}$ higher than certain minima. The more stable the complex, the lower the $\mathrm{pH}$ at which it can exist. Beck used the following values of $\mathrm{pH}$ in order to induce precipitation of the oxalates: La - 6.0; Pr, Nd - 5.5; Sm - 5.0; Gd - 4.5; Er - 4.0. This relationship is widely used when separating mixtures of rare-earth elements. 397,272 Boulanger ${ }^{43}$ prepared a series of mixtures of $\mathrm{Pr}_{2}\left(\mathrm{SO}_{4}\right)_{3}$ with sodium nitrilotriacetate, and then added ammonium oxalate. The precipitate appeared only during the ratio $\operatorname{Pr}^{3+}: \mathrm{TA}>2$, where $\mathrm{TA}$ is nitrilotriacetate. On this basis Boulanger proposed the theory that the composition of this complex com- 
pound must correspond to the formula $\left[\operatorname{Pr}(T A)_{2}\right]^{3-}$, i.e., the formula sug gested by Beck. Evidently the structural formula of this compound can be depicted as:

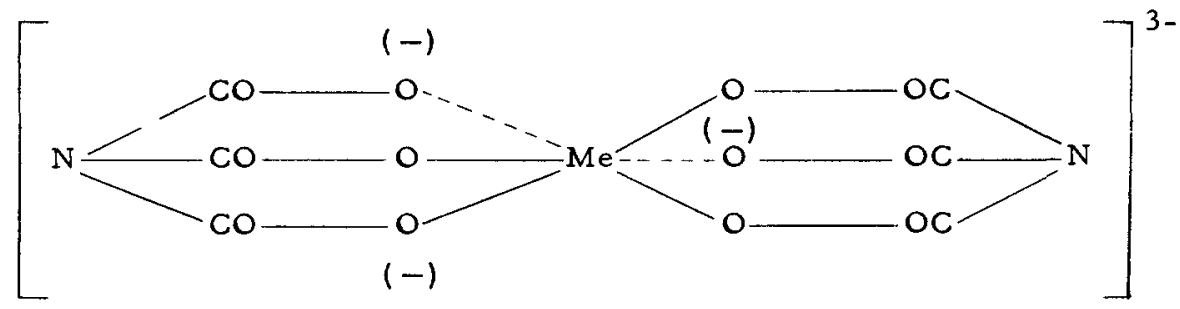

As in all the above-described compounds, the rare-earth elements have a coordination number equal to six.

IV. 5C-4(b). Ethylenediaminetetraacetic Acid (EDTA)<smiles>CCC(CN(CC(=O)O)CC(=O)O)N(CC(=O)O)CC(=O)O</smiles>

and its ammonium salt have been widely used in the separation of mixtures of rare-earth elements. The rare earth-EDTA complexes are exceptionally stable; and Betts and Dahlinger, ${ }^{28}$ in a thermodynamic study of these complexes, attribute this stability to a large positive increase in entropy which occurs when the complex is formed.

Brunisholz et al. ${ }^{54}$ got complex compounds of type $\mathrm{Na}[$ La(enta) $] \cdot \mathrm{xH}_{2} \mathrm{O}$ by interaction of a solution of $\mathrm{LaCl}_{3}$ with $\mathrm{Na}_{4}$ (enta). Tri-, hexa-, octa-, and nona-hydrates were isolated. The first were crystallized at $50^{\circ} \mathrm{C}$ in the form of prisms, the second were in the form of spicules (conditions of their formation were not established), the third were at $35^{\circ} \mathrm{C}$ in the form of pyramids, and the last were at $25^{\circ} \mathrm{C}$ in the form of plates. The complex compounds $\mathrm{Ce}, \mathrm{Pr}, \mathrm{Nd}$, and $\mathrm{Sm}$ crystallize only in the form of octahydrates. The crystals have the form of orthorhombic pyramids and possess piezoelectric characteristics. When hydrates are heated, they easily lose water. Anhydrous compounds are stable up to $350^{\circ} \mathrm{C}$. Brunisholz also separated complex compounds of the type $\mathrm{NH}_{4}[\mathrm{Me}($ enta) $]$ for La, Ce, Pr, Nd, Sm, Gd, and Dy, and studied their various crystalline forms.

Complex compounds of the type $\mathrm{H}\left[\mathrm{Me}(\right.$ enta) $] \cdot \mathrm{xH}_{2} \mathrm{O}$ were obtained by Moeller, Moss, and Marshall 319,289 from interaction of $\mathrm{H}_{4}$ (enta) with an aqueous suspension of $\mathrm{Me}_{2} \mathrm{O}_{3}$. The reaction takes place at room temperature when the mixture is shaken. If solutions containing $\mathrm{H}$ [Me(enta)] (where $\mathrm{Me}=\mathrm{Nd}, \mathrm{Sm}$ ) and other rare-earth elements of the cerium group are allowed to stand at room temperature for several days, or are heated in a water bath for several hours, a finely crystalline residue is precipitated. 
In the $\mathrm{Y}$ case no precipitation of crystals is found. This difference in the characteristics of compounds in the cerium and yttrium groups of elements can be utilized for their separation. Data of the chemical analysis of the crystals indicate the formula $\mathrm{Me}\left[\mathrm{Me}(e n t a)_{3}\right]_{3} \cdot \mathrm{yH}_{2} \mathrm{O}$; the magnitude of the $y$ coefficient was not determined. There was no success in producing anhydrous compounds. Sodium salts are easily obtained by neutralization of $\mathrm{H}[\mathrm{Me}(\mathrm{enta})]$ with alkali, and concentration by evaporation until crystallization. Salts of type $\mathrm{Na}[\mathrm{Me}($ enta $)]: \mathrm{zH}_{2} \mathrm{O}$ were gotten for $\mathrm{Pr}, \mathrm{Nd}, \mathrm{Sm}, \mathrm{Gd}$, and $\mathrm{Y}$.

Brucine, strychnine, quinine, and cinchoninic salts of the acids $\mathrm{H}[\mathrm{Nd}(\mathrm{enta})]$ and $\mathrm{H}[\mathrm{Y}(\mathrm{enta})]$ were gotten by a direct reaction of free alkaloids with acids, taking place in equimolecular quantities in aqueous solutions with subsequent crystallization. The products of interaction of the $Y$ salts with strychnine and brucine are crystalline; those of neodymium with strychnine, quinine, and cinchona are glasslike substances. A compound of $\mathrm{Y}$ with quinine and cinchona was obtained in the form of a gelatinous residue. The products were dried at $110-120^{\circ}$. Analysis of the compounds for brucine indicate the formula $\mathrm{C}_{23} \mathrm{H}_{26} \mathrm{~N}_{2} \cdot \mathrm{H}[$ Me(enta)]

On the basis of his investigations Moeller drew the conclusion that the re are two types of complex compounds: one characterized by the relation Me: enta = 1: l (type I), and the other by the relation Me: enta $=4: 3$ (type II). Compounds of type I can be considered as $\mathrm{H}[\mathrm{Me}$ (enta)] acids, and compounds of type II as salts of rare-earth elements of the acid $\mathrm{Me}[\mathrm{Me}(\mathrm{enta})]_{3}$. One may produce compounds where Me in external and internal spheres will be different. In this case, in the internal sphere obviously there must exist the stronger complex-forming agent; and in the exterior, the weaker. For example, one may get the salt La [Er(enta)] 3 , but it is impossible to get the salt Er [La(enta) $]_{3}$. This rule was utilized by vickery 499,500 for a unique method of separating rare-earth elements, based on the displacement of the more fundamental elements $\left(\mathrm{Me}_{\mathrm{A}}^{3+}\right)$ by the less fundamental $\left(\mathrm{Me}_{\mathrm{B}}^{3+}\right)$

$$
\left[\mathrm{Me}_{\mathrm{A}} \text { enta }^{-}+\mathrm{Me}_{\mathrm{B}}^{3+} \rightarrow \mathrm{Me}_{\mathrm{A}}^{+}+\left[\mathrm{Me}_{\mathrm{B}} \text { enta }\right]\right. \text {. }
$$

Eckardt and Holleck ${ }^{124}$ studied polarographically the capability of divalent europium to create complex compounds with ethylenediaminetetracetic acid. As disclosed, on the mercury electrode in the acid medium, in the presence of the above-mentioned additives, there occurs simultaneously reduction of $\mathrm{Eu}^{3+}$ to $\mathrm{Eu}^{2+}$ and complex-formation.

IV. $5 \mathrm{C}-4(\mathrm{c})$. N-hydroxyethyl-ethylene diamine triacetic Acid (HEDTA), and

IV. $5 \mathrm{C}-4(\mathrm{~d})$. 1,2-diaminocyclohexanetetraacetic Acid (DCTA). Horwitz 206 
has studied the complexing behavior of the rare earths with several diaminopolyacetic acids and has obtained stability constant data for $\mathrm{N}$-hydroxyethylethylene diamine triacetic acid (HEDTA) and 1,2-diaminocyclohexanetetraacetic acid (DCTA), as well as EDTA. Stable complexes with a $1: 1$ ratio of rare-earth metal to HEDTA and DCTA were prepared for Nd, Sm, Eu, Gd, and Y.

Ethylenediaminotetraacetic acid and its salts are very widely used for analysis of mixtures of rare-earth elements 18,190 and separation of them. $1,55,57-60,114,175,273,287,425,451,532$ Recently there have appeared many reports $10,202,455$ of new aminopolyacetic acids successfully being used in the role of complex-forming agents for rare-earth elements. It is appropriate to note the unusual similarity between rare-earth elements and calcium as complex-producers. Johnston ${ }^{221}$ tested a series of organic acids of various classes in the role of complex-forming agents for calcium, especially $\mathrm{H}_{4}$ (enta), and discovered the very same mechanisms which have been disclosed for rare-earth elements.

IV. 5C-4(e). Diethylenetriaminepentaacetic Acid (DTPA). Harder and Chabarek 191 have made a very thorough study of the chelating behavior of the rare-earth elements with diethylenetriaminepentaacetic acid (DTPA). All of the rare earths form stable complexes containing one mole of rare earth to one mole DTPA. This reagent is quite unusual, however, in that the most stable rare earth-DTPA complex is formed by dysprosium. The curve of complex stability vs atomic number rises steadily from La to Dy and decreases slowly from $D y$ to $L u$. The stability constant for yttrium falls between Nd and Sm, so DTPA looks most promising as an eluant for cationexchange separation of $\mathrm{Y}-\mathrm{D} y$ mixtures.

IV. 5C-5. Compounds with Sulfo Acids

Toluenesulfonic acid does not form complex compounds with rare-earth elements. When solutions of its ammonium salts are added to the latter, no change occurs. Ions of rare-earth elements in the solution are immediately detected with the use of $\mathrm{K}_{4}\left[\mathrm{Fe}(\mathrm{CN})_{6}\right]$. Sulfanilic acid behaves similarly to toleunesulfonic acid.

Sulfo acids of the naphthalene series are divided into two groups according to their behavior toward rare-earth elements. To the first group belong the acids causing rapid deposition of hard-to-dissolve precipitates: a-naphthalenesulfo acid; $1,3,6$-naphthalenetrisulfo acid; $a$-amino- $\beta$-sulfo acid; and $\beta$-anthraquinone sulfonic acid.

Members of the other group of acids, to which belong $\beta$-naphthalene sulfo acid, 1-amino-3,5-disulfo acid, 2-oxi-3,6-disulfo acid (R-acid), and 
1-5-naphthalene disulfo acid, do not create precipitates, and also do not form complex compounds. Under the action of $\mathrm{K}_{4}\left[\mathrm{Fe}(\mathrm{CN})_{6}\right]$ and other known reagents, abundant residue is precipitated.

Sodium salt arsenazo (benzol-2-arsenic acid-1-azo-2-1, 8 dioxinaphthalene-3,6-disulfo acid) dissolves in water, taking on a rose color; it develops a red-violet coloration in a neutral medium ( $\mathrm{pH} 7.2)$ with rare-earth elements. 253 The reagent permits detection of these elements at dilutions of $1: 3,000,000$. The detectable minimum is $\sim 0.4 \mu \mathrm{g}$ at the noted dilution. Arsenazo acts as a group reagent on rare-earth elements.

IV. 5C-6. Compounds with Diphenylvioluric Acid

During interaction of concentrated aqueous solutions of $\mathrm{Ce}^{3+}$ salts with a saturated solution of ammonium salt of diphenylvioluric acid, there is produced $^{439}$ a crystalline compound of yellowish-brown color. Its decomposition temperature is above $290^{\circ}$ and absorption maximum in acetone is $450 \mathrm{~m} \mu$. Chemical analysis on metal content and nitrogen corresponds to the formula $\mathrm{CeD}_{3}$ ( $\mathrm{D}$ is diphenylvioluric). The compound belongs to the inner-complex group.

A molecule of diphenylvioluric acid exists in two isomeric forms. In nitrosoenol form it contains a free atom of $\mathrm{H}$ which can be exchanged for metal. On the other hand, the $\mathrm{N}$ atom of the nitro group can unite with a metal whose coordination link closes a 5-member cycle. Thus the structural formula of complex diphenylviolurate of cerium can be shown in the form

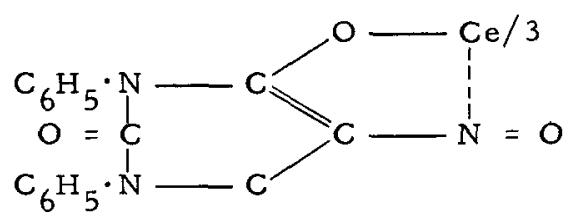

Hydroxamic acid, for example $\mathrm{N}$-phenylbenzohydroxamic (see below),<smiles>O=C(c1ccccc1)N(O)c1ccccc1</smiles>

is a good complex-forming agent for rare-earth elements, particularly for lanthanum.

IV. 5D. COMPOUNDS WITH ORGANIC AMINES

IV. 5D-1. Antipyrine<smiles>Cc1cc(=O)n(-c2ccccc2)n1C</smiles> 
The first compounds with antipyrine were produced in 1913 by Kolb: ${ }^{237}$

$$
\begin{array}{ll}
\mathrm{La}\left(\mathrm{NO}_{3}\right)_{3} \cdot 3 \mathrm{C}_{11} \mathrm{H}_{12} \mathrm{ON}_{2}, & \operatorname{Sm}\left(\mathrm{NO}_{3}\right)_{3} \cdot \mathrm{C}_{11} \mathrm{H}_{12} \mathrm{ON}_{2}, \\
\mathrm{Ce}\left(\mathrm{NO}_{3}\right)_{3} \cdot \mathrm{C}_{11} \mathrm{H}_{12} \mathrm{ON}_{2}, & \operatorname{Er}\left(\mathrm{NO}_{3}\right)_{3} \cdot 4 \mathrm{C}_{11} \mathrm{H}_{12} \mathrm{ON}_{2} \cdot
\end{array}
$$

Later ${ }^{393}$ it was discovered that ions of rare-earth elements ordinarily coordinate around themselves six molecules of antipyrine.

The compound $\left[\mathrm{Nd}\left(\mathrm{C}_{11} \mathrm{H}_{12} \mathrm{ON}_{2}\right)_{6}\right] \mathrm{I}_{3}$ was produced by mixing concentrated solutions of $\mathrm{NdCl}_{3}$, antipyrine, and $\mathrm{KI}$. In this reaction, there $1 \mathrm{~s}$ abundant precipitation of a light-yellow crystalline residue which is easy enough to dissolve in water and alcohol. The melting temperature of this compound is $232-238^{\circ}$ (with decomposition).

When mixing concentrated solutions of $\mathrm{NdCl}_{3}$, antipyrine, and $\mathrm{KClO}_{4}$, an abundant crystalline residue of white color is formed, which is somewhat difficult to dissolve in water and has the composition $\left[\mathrm{Nd}\left(\mathrm{C}_{11} \mathrm{H}_{12} \mathrm{ON}_{2}\right)_{6}\right] \cdot\left(\mathrm{ClO}_{4}\right)_{3} \cdot$ It was established that an interaction of salts of rare-earth elements with antipyrine generally takes place according to the equation

$$
\mathrm{MeX}_{3}+6 \mathrm{C}_{11} \mathrm{H}_{12} \mathrm{ON}_{2}=\left[\mathrm{Me}\left(\mathrm{C}_{11} \mathrm{H}_{12} \mathrm{ON}_{2}\right)_{6}\right] \mathrm{X}_{3} \text {. }
$$

where $\mathrm{Me}=\mathrm{La}, \mathrm{Ce}, \mathrm{Pr}, \mathrm{Nd}$, and $\mathrm{X}$ is the anion.

The compound $\left[\mathrm{Nd}\left(\mathrm{C}_{11} \mathrm{H}_{12} \mathrm{ON}_{2}\right)_{6}\right] \mathrm{Cl}_{3}$ was produced by blending concentrated aqueous solutions of equivalent quantities of $\mathrm{NdCl}_{3}$ and antipyrine, with subsequent concentration in a water bath. There remained a rose-colored olly liquid which on cooling was transformed into a hard, glassy, transparent mass.

The reaction with $\mathrm{Nd}\left(\mathrm{NO}_{3}\right)_{3}$ occurs similarly, except that the reaction product is in crystalline form.

It is not possible to produce analogous complex compounds with such anions as $\mathrm{F}^{-}, \mathrm{SO}_{4}^{2-}, \mathrm{H}_{2} \mathrm{PO}_{2}^{-}$, and $\mathrm{C}_{2} \mathrm{O}_{4}^{2-}$. Under the action of the enumerated anions on the complex compounds, the re occur destruction of the complex and precipitation of simple salts - fluorides, sulfates, and so on - which indicate insufficient stability of these compounds. Double complex compounds of type $\left[\mathrm{Me}\left(\mathrm{C}_{11} \mathrm{H}_{12} \mathrm{ON}_{2}\right)_{6}\right]\left[\mathrm{Cr}(\mathrm{SCN})_{6}\right]$ were also obtained.

The easily soluble compounds of the type $\left[\mathrm{Nd}\left(\mathrm{C}_{11} \mathrm{H}_{12} \mathrm{ON}_{2}\right)_{6}\right]\left(\mathrm{NO}_{3}\right)_{3}$, during interaction with $\mathrm{K}_{3}\left[\mathrm{Cr}(\mathrm{SCN})_{6}\right.$, deposit a loose, powdery, lilac-rose residue. Under ordinary circumstances the reaction takes place instantly. The product possesses insignificant solubility in water and therefore it is easily separated and washed clean of admixtures. In the series of similar complex compounds for different rare-earth metals, the color of the complex is almost unchanging. It has been discovered that the elements of the yttrium 
group (Y, Er) coordinate with only 3 molecules of antipyrine, not 6 as has been the case for all elements of the cerium group.

In 1953 a paper appeared by Dutt and Goswami ${ }^{111}$ on their separation of compounds of composition $\mathrm{La}_{2}\left(\mathrm{~S}_{4} \mathrm{O}_{6}\right)_{3} \cdot 6 \mathrm{C}_{11} \mathrm{H}_{12} \mathrm{ON}_{2}$ and $\mathrm{Pr}_{2}\left(\mathrm{~S}_{4} \mathrm{O}_{6}\right)_{3}$. $6 \mathrm{C}_{11} \mathrm{H}_{12} \mathrm{ON}_{2}$ or $\left[\mathrm{La}_{2}\left(\mathrm{C}_{11} \mathrm{H}_{12} \mathrm{ON}_{2}\right)_{6}\right]\left(\mathrm{S}_{4} \mathrm{O}_{6}\right)_{3}$. It is evident from the formulae that, in these compounds, for one atom of rare-earth element there have to be three molecules of antipyrine.

Complex compounds with antipyrine are used ${ }^{286}$ when fractionating elements of the yttrium subgroup, frequently for concentration of lutetium.

IV. 5D-2. Pyramidone

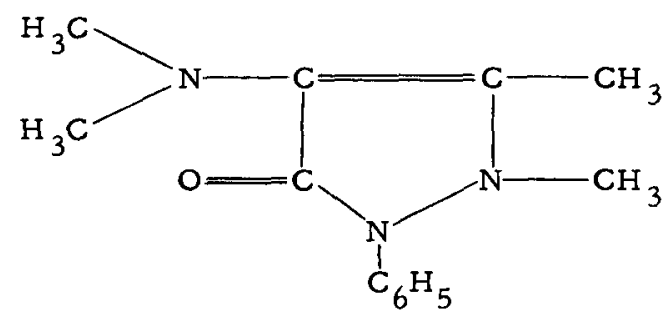

Pyramidone differs from antipyrine by the presence of a dimethylamine group. The nitrogen of this group exhibits an intensely electronegative character and is able to exist combined with metals. As in the antipyrine case, ${ }^{39} 3$ a reaction with pyramidone occurs instantly for rare-earth elements in most cases:

$$
\mathrm{MeX}_{3}+3 \mathrm{C}_{13} \mathrm{H}_{17} \mathrm{ON}_{3}=\left[\mathrm{Me}\left(\mathrm{C}_{13} \mathrm{H}_{17} \mathrm{ON}_{3}\right)_{3}\right] \mathrm{X}_{3}
$$

(where $\mathrm{Me}=\mathrm{La}, \mathrm{Ce}, \mathrm{Pr}, \mathrm{Nd}, \mathrm{Er}$, and $\mathrm{Y}$; and $\mathrm{X}$ is the univalent anion).

The coordination number is six, characteristic for elements of the rareearth group; it is satisfied by three molecules of pyramidone, each of which has a coordination capacity of two.

In the same way as for compounds with antipyrine, interaction of complex salt solutions with solutions of sulfuric acid and oxalic acid salts leads to destruction of the complex, and formation of simple, hard-to-dissolve sulfates and oxalates of rare-earth metals.

For complex compounds of rare-earth elements with pyramidone or with antipyrine, there is a characteristic reaction with the chromo-thiocyanate ion:

$\left[\mathrm{Me}\left(\mathrm{C}_{13} \mathrm{H}_{17} \mathrm{ON}_{3}\right)_{3}\right] \mathrm{X}_{3}+\mathrm{K}_{3}\left[\mathrm{Cr}(\mathrm{SCN})_{6}\right]=\left[\mathrm{Me}\left(\mathrm{C}_{13} \mathrm{H}_{17} \mathrm{ON}\right)_{3}\right]\left[\mathrm{Cr}(\mathrm{SCN})_{6}\right]+3 \mathrm{KX}$.

As a result of the reaction, a voluminous, powdery, violet-rose precipitate is formed.

IV. 5D-3. Pyridine<smiles>c1ccncc1</smiles> 
Formation of the complex anion $\mathrm{Nd}\left(\mathrm{C}_{5} \mathrm{H}_{5} \mathrm{~N}\right)_{n}{ }^{3+}$ in solution is easily dislosed by a reaction with $\mathrm{K}_{3}\left[\mathrm{Cr}(\mathrm{SCN})_{6}\right]$. As in the antipyrine and pyramidone cases 393 the reaction results in a double salt of composition $\left[\mathrm{Me}\left(\mathrm{C}_{5} \mathrm{H}_{5} \mathrm{~N}\right)_{n}\right]$ [Cr(SCN) $\left.{ }_{6}\right]$.

The number of adjoining pyridine molecules is not as fixed as in the preceding cases. Plainly, molecules of pyridine are less stably joined with a central atom and are easily separated from it.

When mixing alcoholic solutions of $\mathrm{Ce}\left(\mathrm{NO}_{3}\right)_{3}$, pyridine, and $\mathrm{K}_{3}\left[\mathrm{Cr}(\mathrm{SCN})_{6}\right]$, a heavy, oily, violet liquid is separated. During concentration in a water bath the alcohol is removed and the residue forms a glassy mass which in the course of time starts to crystallize. Chemical analysis results correspond to the formula $\left[\mathrm{Ce}\left(\mathrm{C}_{5} \mathrm{H}_{5} \mathrm{~N}\right)_{4}\right]\left[\mathrm{Cr}(\mathrm{SCN})_{6}\right]$.

IV. 5D-4. Urotropine (Hexamethylenetetramine)

Dutt and Goswami 111 produced complex compounds with urotropine, of composition $\mathrm{Me}_{2}\left(\mathrm{~S}_{4} \mathrm{O}_{6}\right)_{3} \cdot 4 \mathrm{C}_{6} \mathrm{H}_{12} \mathrm{~N}_{4}$ (where Me = La, Ce, Pr).

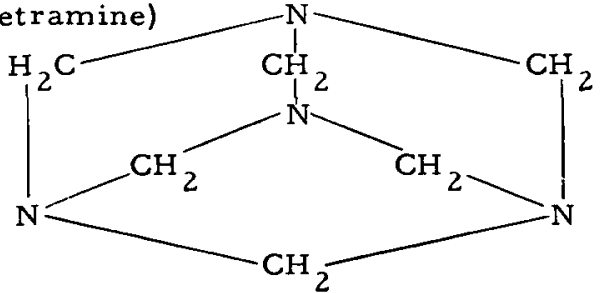

IV. 5D -5 . Hydroxyquinoline

Rare-earth elements form complex compounds with oxine (8-hydroxyquinoline):
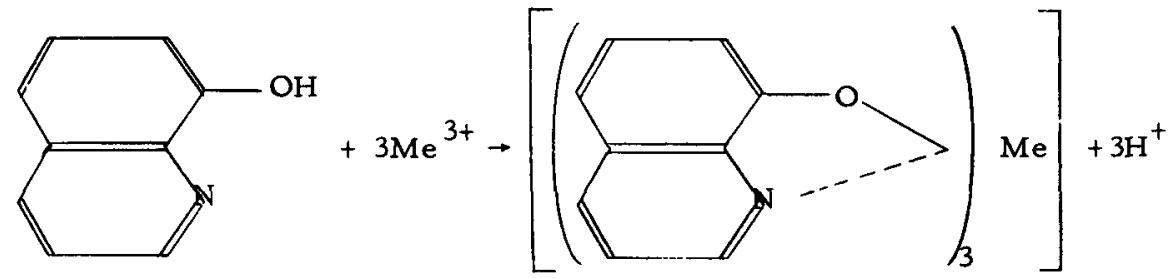

There are data ${ }^{115}$ indicating that the reaction of oxine with $\mathrm{Me}^{3+}$ takes place in two stages during which (in $50 \%$ dihydroxyquinone solution) one may find the compound $[\mathrm{MeOx}]^{2+}$ (where $\mathrm{Ox}=\mathrm{C}_{9} \mathrm{H}_{6} \mathrm{ON}$ ).

The compound [Me(oxine) ${ }_{3}$ ] can be extracted with organic solvents such as chloroform or hexone (methylisobutyl ketone). 116,118,128

A significant lowering of the pH occurs, during which the complex oxinates are withdrawn in a $\mathrm{pH}$-dependent sequence. The critical $\mathrm{pH}$ ranges from 9.4 for $\mathrm{Nd}$ to 8.3 for Er. In other words, the complex oxinates of $\mathrm{Er}$ are more stable than the complex oxinates of $\mathrm{Nd}$, and "endure" a more acid medium. Although this $\mathrm{pH}$ difference is not high, nevertheless it can be utilized for separating mixtures of rare-earth elements by extraction methods.

Chloroform solutions of complex oxinates are yellow and display maximum absorption at $4000 \mathrm{~A}$. Some peaks of the chloroform solutions of these complexes are significantly more clearly expressed than for similar com- 
pounds in aqueous solutions. In particular, the peaks at $5818 \mathrm{~A}$ for $\mathrm{Nd}$ and 5208 A for Er are used for precise spectrophotometric determinations of these elements.

Wendlandt ${ }^{519}$ has produced the complex oxinates of $\mathrm{Ce}^{3+}$ and $\mathrm{Ce}^{4+}$ : $\mathrm{Ce}(\mathrm{Ox})_{3}$ and $\mathrm{Ce}(\mathrm{Ox})_{4}$.

A report on producing oxinate of tetravalent praseodymium is interesting. ${ }^{248}$ (To date, no one has separated any $\operatorname{Pr}^{4+}$ compound.) A solution of 8-hydroxyquinoline sulfonic acid in ammonia is mixed with $\operatorname{Pr}\left(\mathrm{NO}_{3}\right)_{3}$; the resultant solution is transferred to a glass in which is placed a small cup, half full of a solution of $\mathrm{NH}_{4} \mathrm{NO}_{3}$. A round the small cup in a solution of $\mathrm{Pr}\left(\mathrm{NO}_{3}\right)_{3}$ is placed a cylindrical platinum leaf which acts as an anode; and in the solution of $\mathrm{NH}_{4} \mathrm{NO}_{3}$ is a platinum wire which acts as the cathode. Electrolysis is started. During the electrolysis the anode liquid is stirred energetically and kept alkaline. After the end of the process, the anode liquid is mixed with oxine and the mixture is heated in a sealed tube at $100^{\circ}$ for two hours. Fine crystals are deposited, then filtered out, washed with hot water containing ammonia, alcohol, and ether, and dried at room temperature. Chemical analysis gives data corresponding to the formula $\operatorname{Pr}\left(\mathrm{C}_{9} \mathrm{H}_{6} \mathrm{NO}_{4} \cdot 2 \mathrm{H}_{2} \mathrm{O}\right.$. The substance takes on a yellowish color. It is stable in ammonium solution even in the presence of various reducers, but it is gradually decomposed by alkali. In an acid medium, $\operatorname{Pr}^{4+}$ is reduced to $\operatorname{Pr}^{3+}$. The substance is insoluble in water and organic solvents. The oxinate of trivalent praseodymium, $\operatorname{Pr}\left(\mathrm{C}_{9} \mathrm{H}_{6} \mathrm{NO}\right)_{3} \cdot \mathrm{H}_{2} \mathrm{O}$, is produced by interaction of an acidified acetic acid of a dilute solution of $\operatorname{Pr}\left(\mathrm{NO}_{3}\right)_{3}$, with an alcohol-oxine solution. The solution is alkalized by ammonia and heated in a water bath. A substance is deposited in the form of yellow powder. It is removed and dried in the same way as described above. It is insoluble in water and organic solvents, but decays under the action of acid and alkali. A report 330 on the stabilization of $\mathrm{Nd}^{4+}$ by oxine is evidently in error. 384,423

Ishimori 212 produced a complex oxinate of promethium. A water solution containing $\mathrm{Pm}^{147}$ and sodium tartrate was prepared. The $\mathrm{pH}$ was regulated by addition of $\mathrm{NH}_{4} \mathrm{OH}$. A chloroform solution of oxine was added to the water solution, containing Pm ${ }^{147}$, and the mixture was stirred vigorously. The chloroform separated in a layer and was evaporated over an infrared lamp. The radioactivity of the residue was measured by a counter and compared with the original. The greatest extraction was noted at $\mathrm{pH} 9$.

One can assume (considering that $\mathrm{Pm}$ in the solution is trivalent like its neighbors) that the complex oxinate of promethium can be depicted by the formula $\mathrm{Pm}(\mathrm{Ox})_{3}$.

There has also been produced a complex oxinate of yttrium. ${ }^{324}$ A water solution containing $\mathrm{Y}^{90}$ and tartrate of potassium-sodium was mixed with a 
chloroform solution of oxine, and then the quantity of $\mathrm{Y}^{90}$ was determined from oxine extracted at different $\mathrm{pH}$. Parallel tests we re made on extractions of yttrium by pure chloroform (at the same $\mathrm{pH}$ values) - but yttrium was not extracted. It was found that a molecule of yttrium oxinate possesses 2 anions of $O x$ for each atom of yttrium $Y(O x)_{2} X$, where $X$ is a univalent anion, differing from $(O x)^{-}$.

It was proposed to utilize the reaction forming complex oxinates for quantitative determination of rare-earth elements. However, it was discovered by Dyrsen ${ }^{119}$ that reaction products with oxine possess somewhat less oxine than predicted by the theory. This is connected, evidently, with hydrolytic decomposition of these compounds in solution. In view of this, it is doubtful whether it is expedient to use oxine for quantitative determination of rare-earth elements. For this goal it is better to use di halidederivative oxines for example, 5,7-dichlor-8-hydroxyquinolinates. 315 They give a complex compound less easily dissolved in water, and they are more convenient to handle. They are likewise soluble in organic solvents and are extracted at determined $\mathrm{pH}$ values from the inorganic phases to the organic for example, in chloroform.

Complex oxinates are used for exhibiting chromatograms on paper when separating mixtures of rare-earth elements. 261,260 The chromatographs are developed by a solution of hydroxyquinoline and are 1 rradiated by ultraviolet light. During this process, for example, a patch of La gives a green fluorescence, and Dy gives a black spot.

Freasier, Oberg, and Wendlandt ${ }^{149}$ have prepared the 8 -quinolinol-5sulfonic acid chelates of the rare earths and report these complexes to be somewhat less stable than the corresponding 8-qunolinol and 2-methyl-8quinolınol chelates.

\section{IV.5D-6. Cupferron}

Cupferron, $\mathrm{C}_{6} \mathrm{H}_{5} \mathrm{~N}(\mathrm{OH}) \mathrm{NO}$, with rare-earth elements forms complex compounds which are difficultly soluble in water and organic solvents, and (at $\mathrm{pH} 3-4$ ) can be used for group separation of these elements. $115,162,372$

Wendlandt ${ }^{515}$ studied thermal decomposition of cupferronates. He established that the pyrolysis curves of the cupferronates La, Pr, Nd, and $\mathrm{Sm}$ have an identical character. Some intermediate plateaus could be noted at $150-180^{\circ}, 280-290^{\circ}$, and $450-600^{\circ}$, which do not correspond to any sort of storchiometric compound and seem to be a mixture of decomposition products. Similarity is evident in the pyrolysis curves for cupferronates $\mathrm{Ce}^{3+}$ and $\mathrm{Y}$. Here, intermediate plateaus are not found. These compounds are rapidly decomposed to oxides. The least stable cupferronates are $\mathrm{Ce}^{4+}$ and $\mathrm{Gd}^{+3}$. They begin to decay even at room temperature. 
Neocupferron forms analogous compounds. ${ }^{516}$ The thermal decay curves of the neocupferronates $\mathrm{La}, \mathrm{Pr}, \mathrm{Nd}$, and $\mathrm{Sm}$ are identical. The curve for $\mathrm{Y}$ is identical to the Gd curve, and the $\mathrm{Ce}^{3+}$ and $\mathrm{Ce}^{4+}$ curves differ from the first two types. For all three types, decay begins at $80^{\circ}$. This decay corresponds to lessening of the molecular weight by 18 units, which corresponds exactly to the loss of 1 molecule of $\mathrm{H}_{2} \mathrm{O}$. However, it was established by analysis that the neocupferronates do not contain water of crystallization. Evidently the origin of these water molecules is connected with intermolecular rearrangements in the complex compound.

IV. 5D-8. Disalicylidal Ethylenediamine

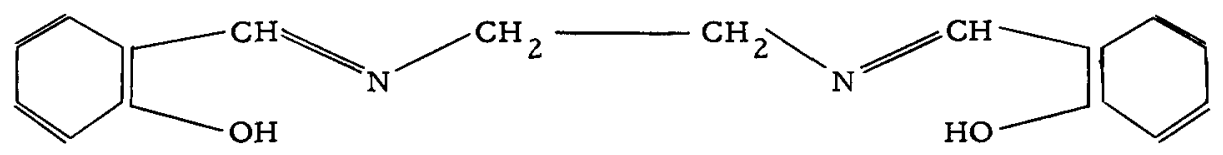

As Dyrssen showed, 116,118 complex compounds with rare earths are not formed.

\section{5D-9. Methyl Amine}

The salts of rare-earth elements with methyl amine form complex compounds of composition $\mathrm{MeCl}_{3} \cdot \mathrm{nCH}_{3} \mathrm{NH}_{2} \cdot \mathrm{A}$ batch of anhydrous $\mathrm{MeCl}_{3}$ was placed $^{373}$ in a reaction vessel. Into this vessel, which was cooled by ice, was injected dry methyl amine. It slowly merged with the chloride. The methyl amine injection was continued until establishment of equilibrium (4-12 hours). The composition of the stable material was calculated from the quantity of absorbed methyl amine. After achievement of equilibrium the produced methylammoniate was subjected to thermal decomposition. An ice bath under the reaction vessel was controlled by a thermostat to keep the temperature to an accuracy of $\pm 1^{\circ}$ in the $25-300^{\circ}$ interval. The temperature was gradually raised and after every 2-3 minutes the quantity of desorbed methyl amine was measured by buret. The transition from one compound to the other occurred in stages. Therefore it was established that $\mathrm{MeCl}_{3}$ forms with methyl amine a compound of the general formula $\mathrm{MeCl}_{3}$. $\mathrm{nCH}_{3} \mathrm{NH}_{2}$ (where $\mathrm{Me}=\mathrm{La}, \mathrm{Ce}^{3+}, \mathrm{Pr}, \mathrm{Nd}, \mathrm{Sm}$, and $\mathrm{Gd} ; \mathrm{n}=1-5$ ).

An yttrium compound of type $\mathrm{YCl}_{3} \cdot \mathrm{CH}_{3} \mathrm{NH}_{2}$ was studied 517 from the curves of isobaric-thermal decomposition. Four compounds were discovered, where $n=1-4$. The temperatures of decay of these compounds correspondingly equal $82,180,232$, and $360^{\circ}$. Compounds where $\mathrm{n}=5$, found in chlorides of other rare-earth elements, were not discovered even at $0^{\circ}$. 
IV. 5D-10. Ethylenediamine

Ethylenediamine, $\mathrm{NH}_{2}-\left(\mathrm{CH}_{2}\right)_{2}-\mathrm{NH}_{2}$, forms ${ }^{440}$ with $\mathrm{Ce}^{4+}$ salts the complex compounds: $\left[\mathrm{Ce}\left(\mathrm{NH}_{2}-\left(\mathrm{CH}_{2}\right)_{2}-\mathrm{NH}_{2}\right)_{2}\right]\left(\mathrm{SO}_{4}\right)_{2} \cdot 2 \mathrm{H}_{2} \mathrm{SO}_{4} \cdot 7 \mathrm{H}_{2} \mathrm{O}$. Equimolecular quantities of $\mathrm{Ce}\left(\mathrm{SO}_{4}\right)_{2}$ and ethylenediamine hydrate were mixed respectively in $2 \underline{\mathrm{N}}$ and $4 \underline{\mathrm{N}} \mathrm{H}_{2} \mathrm{SO}_{4}$. Both solutions were blended, and the mixtures were condensed by evaporation and let stand over night. Orangecolored crystals were formed. The crystals were filtered out, washed with absolute alcohol and dried at $60^{\circ}$. This compound is fully stable in air. Its solutions do not decay when boiled. The reagent is used in analytical chemistry in the role of a good oxidizer.

\section{5E. COMPOUNDS WITH $\beta$-DIKETONES}

Rare-earth-element salts react with $\beta$-diketones according to the system:

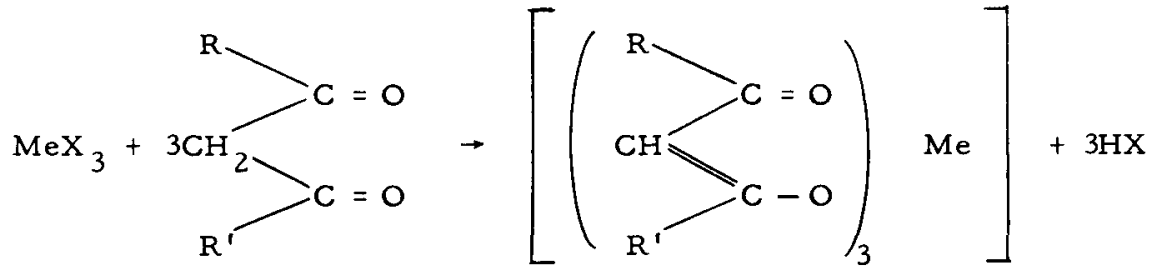

In 1886, Urbain ${ }^{491}$ produced the acetylacetonates of La, Ce, Pr, Nd, and $\mathrm{Sm}$. They combine with pyridine, acetonitrile and ammonia, in the latter case, the compounds obtained are of the composition $2 \mathrm{MeAc}_{3} \cdot \mathrm{NH}_{3}$ and $3 \mathrm{MeAc}_{3} \cdot 2 \mathrm{NH}_{3}$ (where Ac is the acetylacetone molecule).

Erametsa and Hamalä ${ }^{126}$ have recently published a review of the solubility of the rare-earth acetylacetonates in various organic solvents, including acetone, chloroform, acetylacetone, carbon tetrachloride, ethyl ether, methanol, ethanol, and butanol.

Moeller, Gulyas, and Marshall, 321,289 using an interestıng technique which involved adsorbing yttrium or gadolinıum acetylacetonates on columns of d-lactose hydrate or d-lactose followed by elution with benzene-petroleum ether, report partial resolution of these chelates into optically active isomers.

Acetylacetonates are a source of great interest for the researcher studying rare-earth elements ${ }^{181}$ - especially their spectral characteristics because they crystallize without water and are somewhat soluble in organic solvents. In 1948 a new method of producing acetylacetonates, different from Urbain's method, was worked out. ${ }^{464}$ It consists of the following: A solution of ammonium acetylacetonate is added slowly with stirring to a chloride solution of a rare-earth element. The solution $\mathrm{pH}$ is maintained barely lower than that at which the hydroxides of the rare-earth elements began to precipitate. After 12 hours of mixing, formation of crystalline acetylacetonates is completed. 
Later 402 the benzoyl acetone and dibenzoyl acetone derivatives of La, $\mathrm{Pr}$, and $\mathrm{Nd}$ were isolated. No stable compounds of $\mathrm{Ce}^{+3}$ were separated; only complexes for $\mathrm{Ce}^{4+}$ were obtained.

Dutt and Bandyopadhyay 112 and Izatt, Fernelius, Haas, and Block 215 have measured the equilibrium constants for acetylacetone and benzoyl acetone for several of the rare-earth elements.

Derivatives of benzoyl acetone and dibenzoyl acetone exist as crystalline substances of a color close to that of the ions of the rare-earth elements. They are produced by adding an alcohol solution of benzoyl acetone to a wateralcohol solution of nitrate of a rare-earth element. Heating of the reaction mixture occurs. The mixture is diluted with water, the alcohol solution neutralizes the ammonium ion, and a precipitate is deposited which is scrubbed with alcohol and water.

The tendency of $\mathrm{Ce}^{3+}$ to oxidize into $\mathrm{Ce}^{4+}$ in the process of complexformation is used for separating Ce from associated elements. A mixture of a nitrate alcohol solution with benzoyl acetone is neutralized by ammonia and heated, whereupon $\mathrm{Ce}\left(\mathrm{C}_{10} \mathrm{H}_{9} \mathrm{O}_{2}\right)_{4}$ is deposited. The derivatives La, Nd, $\mathrm{Pr}$, and Sm, in contrast to the Ce compound, are easily soluble in hot alcohol. Under prolonged heating they separate and form oily drops.

In 1954, complex compounds with thenoyltrifluoracetone (TTA) were produced. 224 When a solution of $\mathrm{PrCl}_{3}$ is shaken with a benzene solution of $\mathrm{TTA}$, praseodymium divides between the water and benzene phases. In the aqueous layer, praseodymium exists in the form of free ions of $\mathrm{Pr}^{3+}$; in the organic, in the form of the complex:

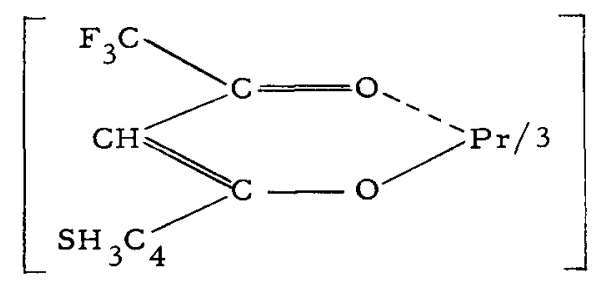

It has been found 290 that the substitution of a hydrogen ion by fluorine in the methyl group of acetylacetone lowers the melting point and increases both the solubility in organic solvents and the thermal stability of the rareearth complex compounds.

Mattern ${ }^{295}$ has used the La-TTA equilibrium to measure dissociation constants for a number of lanthanum complexes, including $\mathrm{Cl}^{-}, \mathrm{NO}_{3}{ }^{-}, \mathrm{SO}_{4}{ }^{-}$, $\mathrm{ClO}_{3}{ }^{-}$, acetate, succinate, tartrate, phthalate, lactate, citrate, oxalate, thiosulfate, and peroxide, while Bronaugh and Suttle ${ }^{50}$ have made a very extensive study of the chelation of the rare earths as a function of $\mathrm{pH}$ using TTA. 
IV. 5F. COMPOUNDS WITH POLYPHENOLS

Polyphenols of the type of pyrocatechin, $\mathrm{C}_{6} \mathrm{H}_{4}(\mathrm{OH})_{2}(1,2)$ and pyrogallol, $\mathrm{C}_{6} \mathrm{H}_{3}(\mathrm{OH})_{3}(1,2,3)$, containing hydroxide groups in ortho position, form complex compounds with rare-earth elements which exist as nonelectrolytes. 132,435 The cerium compound has a characteristic violet color which is a peculiarity utilized for qualitative detection of cerium.

A paper was published in $1954^{23}$ on producing complex compounds of rare-earth elements with pyrocatechin, in the inner sphere of which are found molecules of ethylenediamine: $\mathrm{En}_{3}\left[\mathrm{Me}\left(\mathrm{C}_{6} \mathrm{H}_{4} \mathrm{O}_{2}\right)_{3}\right]_{2}$, where En stands for the ethylenediamine.

Rare-earth elements, in particular La, Pr, Nd, Sm, and Gd, form colored complex compounds with naphthazarine, $(5,8$-dihydroxy-1, 4 naphthoquinone)

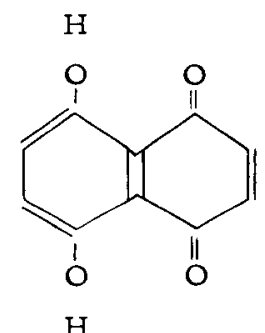

When mixing chloride solutions of rare-earth elements with naphthazarine in ethanol solutions, complex compounds are produced. The color of the reagent during the reaction changes from red to reddish blue. The change in coloration is noted when concentrating the rare-earth element to $0.31 \mathrm{mg}$ equ/iter. In colored complex compounds the molar ratio of reagent to rareearth element is $2: 1$. Naphthazarine can act as a group reagent for rareearth elements.

Hematoxylin, $\mathrm{C}_{16} \mathrm{H}_{14} \mathrm{O}_{6} \cdot 3 \mathrm{H}_{2} \mathrm{O}$, (acidified) forms an intensely colored lake with lanthanum and yttrium salts, stable at $\mathrm{pH} 6.0-6.5 .407$ These lakes are complex compounds in which the ratio of metal to reagent is 1. 2. The resultant complex compounds are used in colorimeters. Thus, with the help of this reagent one can determine $Y$ and La in quantities of 0.5 and $0.2 \mathrm{mg} / \mathrm{l}_{1}$ ter (computed as oxides).

IV. 5G. COMPOUNDS WITH ALIZARIN-S

Alizarin-S forms, 387,382 with lanthanum and yttrium salts, intensely colored lakes which appear as complex compounds. For use as a solvent, it is recommended that a $60 \%$ water solution of acetone be used (which guar -

- antees the most intense coloration of the complex). Aqueous solutions $1 \times 10^{-3} \underline{M}$ of nitrates of $\mathrm{La}$ and $\mathrm{Y}$ were prepared from pure oxides, as in 
the solution of alizarin-S in acetone. For spectrophotometric study, the nitrate solutions of $\mathrm{La}$ and $\mathrm{Y}$ and the reagent were mixed in different relations and water (or acetone) was added to the resultant $60 \%$ acetone solution. It was found that at the reagents' ratio of $1: 1$ the complex compound of La has maximum absorption at $520 \mathrm{m \mu}$, and the compound of $\mathrm{Y}$, at $510 \mathrm{m \mu}$. The color reaction of $\mathrm{L} a$ and $\mathrm{Y}$ with alizarin-S is very sensitive, and it is used for disclosure of micro quantities of these elements.

\section{5H. COMPOUNDS WITH CYCLOPENTADIENAL SODIUM}

Rare-earth elements, particularly La, Ce, Pr, Sm, Gd, Er, Yb, and $\mathrm{Y}$, form 535,29 compounds of type $\mathrm{Me}\left(\mathrm{C}_{5} \mathrm{H}_{5}\right)_{3}$ with cyclopentadiene.

They are produced by shaking up anhydrous chlorides of metals with cyclopentadienal sodium in tetrahydrofuran. The solvent is recovered and the residue is heated in vacuum. The compounds $\mathrm{Me}\left(\mathrm{C}_{5} \mathrm{H}_{5}\right)_{3}$ are obtained in the form of a sublimate with a yield of $65 \%$. They appear as a crystalline substance, with thermal stability to $400^{\circ}$. At temperatures above $220^{\circ}$ and at $10^{-4} \mathrm{~mm} \mathrm{Hg}$ they sub-

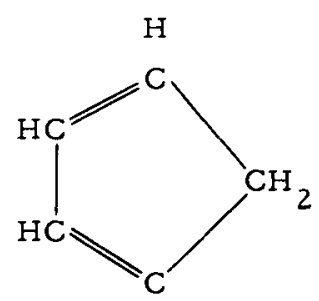

$\mathrm{H}$ lime. The compounds of Pr, La, and Nd are colored characteristically for trivalent ions of these elements; the compounds of Gd and $\mathrm{Y}$ are light yellow; of $\mathrm{Ce}$ and $\mathrm{Sm}$, orange.

In their chemical characteristics they are very much alike. They decompose in air, and $\mathrm{Ce}\left(\mathrm{C}_{5} \mathrm{H}_{5}\right)_{3}$ darkens in the presence of traces of oxygen; under the action of water they decompose into cyclopentadienal and hydroxides of the metal which are easily soluble in tetrahydrofuran and dimethylglycol ether and dioxane. Under the action of $\mathrm{CS}_{2}, \mathrm{CCl}_{4}$, and $\mathrm{CHCl}_{3}$ they decompose rapidly; they react slowly with $\mathrm{CO}_{2}$, maleic anhydride, and ketones. When interacting with $\mathrm{FeCl}_{2}$ they form ferrocen. With liquid $\mathrm{NH}_{3}$ they form the addition compounds $\mathrm{Me}\left(\mathrm{C}_{5} \mathrm{H}_{5}\right)_{3} \cdot \mathrm{NH}_{3}$. The absorption spectrum in tetrahydrofuran resembles spectra of rare-earth elements in aqueous solutions; this similarity is also recorded in magnetic properties. These data bear witness that the bonds in these compounds have an ionic character, although in another paper 391 it is indicated that bonds in cyclopentadienal complexes are typically covalent.

\section{IV.5I. METALO-ORGANIC COMPOUNDS OF RARE-EARTH ELEMENTS}

A whole series of experiments designed to produce metalorganic compounds of rare-earth elements ended in failure. Alone among all the authors, Plets ${ }^{366}$ reported having produced a thermally stable esterate of triethylyttrium $\left(\mathrm{C}_{2} \mathrm{H}_{5}\right)_{3} \mathrm{Y} \cdot\left(\mathrm{C}_{2} \mathrm{H}_{5}\right)_{2} \mathrm{O}$. This was produced by interaction of ethylmag- 
nesium bromide with anhydrous $\mathrm{YCl}_{3}$. It appeared as an anhydrous liquid with a unique sweetish aroma, with boiling point $222-225^{\circ}$ (at $760 \mathrm{~mm} \mathrm{Hg}$ ), and $\mathrm{d}=1.132$.

Afanas'ev and Tsiganova, ${ }^{5}$ and also other authors, ${ }^{89}$ performed experiments reproducing Plets' work; however, they were unable to attain positive results.

Nesmayanov in $1945^{335}$ wrote: "Alkyl groups can stably be bound with elements only at the expense of the $s-$, p-valent levels, whereas the presence near the atom - even if unused - of $d$ - or $f$-valent electrons sharply influences the stability of the produced alkyl derivatives or even wholly eliminates their capability for existence." Evidently this behavior, in the instance of rareearth elements, is wholly confirmed.

\section{5J. SUMMARY OF THE COMPLEX-FORMING CHARACTERISTICS} OF THE RARE-EARTH ELEMENTS

From these data, several general statements concerning the complexforming characteristics of the rare-earth elements may be made. The capability of these elements for complex-formation, as a rule, increases with decrease of their ion radii. The coordination number of rare-earth elements occurring in trivalent states, in the overwhelming majority of cases, is six. Tetravalent praseodymium and especially cerium form complex compounds, and complex compounds of bivalent europium and samarium have also been discovered. Rare-earth elements, in contrast to such active complex-producers as platinum, palladium, iron, cobalt, etc., do not create stable complex compounds with $\mathrm{Cl}^{-}, \mathrm{NH}_{3}, \mathrm{CN}^{-}$, and $\mathrm{NO}$.

The most stable complex compounds are formed by rare-earth elements with organic additives. For these elements the characteristic bond is through the oxygen atom of the carboxyl, carbonyl, and hydroxyl groups. Stability of the complex compounds with organic acids depends on basicity of the acid and its structure. Especially stable are complex compounds with polybasic organic acids, and likewise with aminopolyacetic acids. Dibasic unbound acids of the cis-series form water-soluble complex compounds; at the same time, acids of the trans-series form difficultly soluble salts. The phenyl, and likewise the sulfo, groups weaken the acid's properties as a complexforming agent. The amino group has little influence on stability of complex compounds. Stability of all the noted complex compounds strongly depends on $\mathrm{pH}$ of the medium.

Less characteristic for rare-earth elements is the bond $\mathrm{N}$. . Me - O and completely uncharacteristic is the bond $\mathrm{R}-\mathrm{Me}-\mathrm{X}$ (where $\mathrm{X}$ is a halide).

In the literature there is still no light on the question of the influence of the steric factor on the properties of complex compounds of rare-earth 
elements. For example, there is information on complex compounds with tartaric acid, but there is no information on complex compounds with mesotartaric, there is information on compounds with mucic acid, but no data on compounds with saccharic acid. There is nothing on complex compounds with sugars either, although here very fine stereochemical differences can be developed.

Researches in the field of rare-earth elements to date have made only small use of organic chemistry with its unique possibilities. This is a fertile field for the future.

\section{IV.6. EXTRACTION}

\section{6A. INTRODUCTION}

Solvent extraction processes are of interest to applied rare-earth chemistry in two main fields first, the separation of uranium, thorium, and other nuclear fuels from high-cross-section impurities which include several lanthanides, on an industrial scale, and second, the large-scale separation of rare earths from each other in high purity. For research purposes, solvent extractions may be used to separate rare earths as a group from other materials (with the sometimes important advantage that added carrier is usually. not necessary). Scandium and ceric cerium may readily be separated from other elements, including the trivalent lanthanides, by solvent extraction processes, the rapid separation of the individual lanthanides from the group on a laboratory scale is apparently not yet practical, although much work has been done on individual differences in extraction behavior.

\section{6B. SEPARATION OF A GROSS RARE-EARTH FRACTION FROM OTHER ELEMENTS SOLVENT EXTRACTION OF THE RARE-EARTH GROUP}

Reagents used to extract trivalent rare earths from aqueous solutions

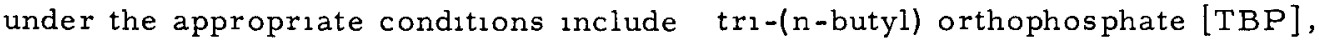
salicylic acid, thenoyl trifluoracetone [TTA], di(2-ethyl hexyl) orthophosphoric acid, mono- and di-(n-butyl) orthophosphoric acid, 8-hydroxy quinoline and its halogenated derivatives, and cupferron.

IV. 6B-1. Tributyl Phos phate (TBP)

Warf 510 made a study of the extraction of ceric cerium (see section IV. 6 E below) with water-saturated TBP from nitric acid-ammonium nitrate solutions. He noted poor separation from the trivalent lanthanides but did not pursue the phenomenon. Blackmore, Bearse, and Calkıns ${ }^{34}$ studied the distribution of various rare earths and thorium between nitric acid solutions of various concentrations and TBP diluted with an inert solvent. They showed that lanthanide extractions were extremely sensitive to TBP concentration over the entire range studied (20 to $50 \% \mathrm{TBP}$ ), that a flat maximum in ex- 
tractability of the lighter rare earths exists at $\approx 1.5 \mathrm{M} \mathrm{HNO}_{3}$, that the heavier rare earths extract increasingly well at higher nitric acid concentrations, and finally, that thorium was able to compete successfully with the trivalent lanthanides for possession of the TBP, 1.e., that the presence of thorium in the organic phase reduced the extraction of the lanthanides in a manner resembling reduction of $T B P$ concentration. On that basis they suggested that TBP extraction proceeded via actual compound formation - a suggestion strongly supported by later work. The extractions they obtained for rare earths were small - of the order of $5 \%$ of the total.

Peppard, Faris, Gray, and Mason ${ }^{354}$ conducted an extensive study of the extractability of the lighter rare earths. Their data will be discussed in greater detail in section IV. 6D below. They confirmed the strong dependence of extractability on TBP concentration. Very good extraction of all rare earths was noted from $7.2 \mathrm{M} A l\left(\mathrm{NO}_{3}\right)_{3}-0.2 \mathrm{M} \mathrm{HNO}_{3}$ and from $10 \underline{\mathrm{M}} \mathrm{NH}_{4} \mathrm{NO}_{3}-0.2 \mathrm{M} \mathrm{HNO}_{3}$, using $100 \%$ TBP. According to Knapp, Smutz, and Spedding 236 only certain cationic transition elements having two or less electrons in the d-orbitals will extract into TBP, we therefore expect extraction only of $\mathrm{T}_{1}, \mathrm{Zr}, \mathrm{Hf}, \mathrm{Ce}(\mathrm{IV})$ and the higher valent actinides in addition to rare-earthlike elements (Sc, Y, La and lanthanides, Ac and trivalent actinides). In addition, certain anionic species show extraction - Mo(VI), $\mathrm{Cr}(\mathrm{VI})$, and of course the elemental halogens. We may therefore expect extraction of the rare earths from heavily salted, slightly acid nitrate solutions to separate well from all but the listed impurities.

Peppard, Faris, Gray, and Mason ${ }^{354}$ also stated that the dependence of rare-earth extractability of TBP concentration was approximately third power, indicating an extracted species containing three TBP molecules per rare-earth atom. This hypothesis also has been confirmed by later work. 193 Wendlandt and Bryant ${ }^{520}$ listed the solubilities of many metal nitrates in $100 \%$ TBP. Solubilities are fairly large for many compounds. The solubility of $\mathrm{La}\left(\mathrm{NO}_{3}\right)_{3} \cdot 6 \mathrm{H}_{2} \mathrm{O}$ in TBP is about $20 \mathrm{~g} / 100 \mathrm{~g}$ solvent.

McKay and Rees ${ }^{301}$ reported that the rate of transfer of rare-earth nitrates between aqueous and TBP phases was fairly high, of the order of $10^{-6} \mathrm{~g} / \mathrm{cm}^{2}$ sec per g/l $\times 10^{6}$.

Nikolaev and Sorokına 338 have recently published a paper which indicates that the rare earths have a mutual exclusion effect with regard to their TBP extractability. For high concentrations of any rare earths in the aqueous phase, the extraction coefficients of all the rare earths are decreased. Kirby 230 published a procedure for removing traces of thorium from cerium by extracting the impure cerium into $50 \%$ TBP in benzene from saturated $\mathrm{Ce}\left(\mathrm{NO}_{3}\right)_{3}$ in water, stripping the $\mathrm{Ce}$ from the organic layer with $8 \underline{\mathrm{M}}$ 
$\mathrm{HNO}_{3}$, and washing the strip with $50 \%$ TBP and with benzene. He reported an $80 \%$ recovery of cerium, with a decontamination factor of about 50 from thorium. The $\mathrm{Ce}^{+3}$ ion acts as its own salting agent.

Bernström and Rydberg ${ }^{26}$ reported a study of the extraction of several elements including $\mathrm{La}$ from $\mathrm{HNO}_{3}-\mathrm{Ca}\left(\mathrm{NO}_{3}\right)_{2}$ solutions using $100 \%$ TBP. They found that extraction of La was fairly good $(K \approx 10)$ from heavily salted low-acid systems, but became rapidly worse as the acidity was raised. The system appears to offer no special advantage.

Hiller and Martin ${ }^{197}$ separated a rare-earth fraction from thorium and thorium fission products by extracting the thorium with mesityl oxide from $\mathrm{HCl}$ saturated with $\mathrm{Al}\left(\mathrm{NO}_{3}\right)_{3}$; the rare earths were then precipitated as hydroxides, dissolved in $1 \mathrm{~N}^{-} \mathrm{HNO}_{3}$ saturated with $\mathrm{Al}\left(\mathrm{NO}_{3}\right)_{3}$, extracted into TBP, and re-extracted into water. Further specific chemical steps were then performed to separate Ce from the other lanthanides and accompanying fission products.

Peppard, Mason, and Maier ${ }^{356}$ have studied the extraction of hydrochloric acid and of nitric acid by TBP. Their results (presented in Figs. 34 and 35$)$ clearly show the need for pre-equilibration of the solvent with acid of the desired concentration.

IV. 6B-2. Salicylic Acid and Other Carboxylic Acids

Hök-Bernstrom 200 reported on a study of salicylic acid, cinnamic acid, and 3-5 dinitro-benzoic acid as extractants for $\mathrm{Th}^{+4}, \mathrm{La}^{+3}$ and $\mathrm{UO}_{2}^{++}$into chloroform or hexone. In general, $\mathrm{Th}^{+4}$ and $\mathrm{UO}_{2}^{+2}$ were much more extractable than La; thorium and uranyl ions were extracted essentially completely at $\mathrm{pH} \approx 3$, while the complete extraction of lanthanum required $\mathrm{pH} \approx 7$. No studies were made of other trivalent lanthanides.

Sudarikov, Zaytsev, and Puchkov ${ }^{469}$ reported that a solution of 100 grams of salicylic acid per liter of solution in isoamyl alcohol was an effective jextracting agent for uranium, thorium, scandium, yttrium, lanthanum, and cerium. Their data are reproduced in Fig. 36. Of particular interest is the behavior of scandium, which back-extracts completely into the aqueous phase at high $\mathrm{pH}$ values, and of uranium, which back-extracts partially at high $\mathrm{pH}$ values.

\section{6B-3. Thenoyltrifluoroacetone (TTA)}

A widely used reagent for solvent extraction is the $\beta$-diketone, thenoyltrifluoroacetone (TTA). The structure of the compound is:

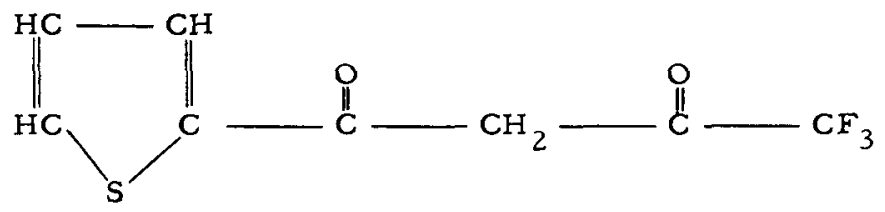




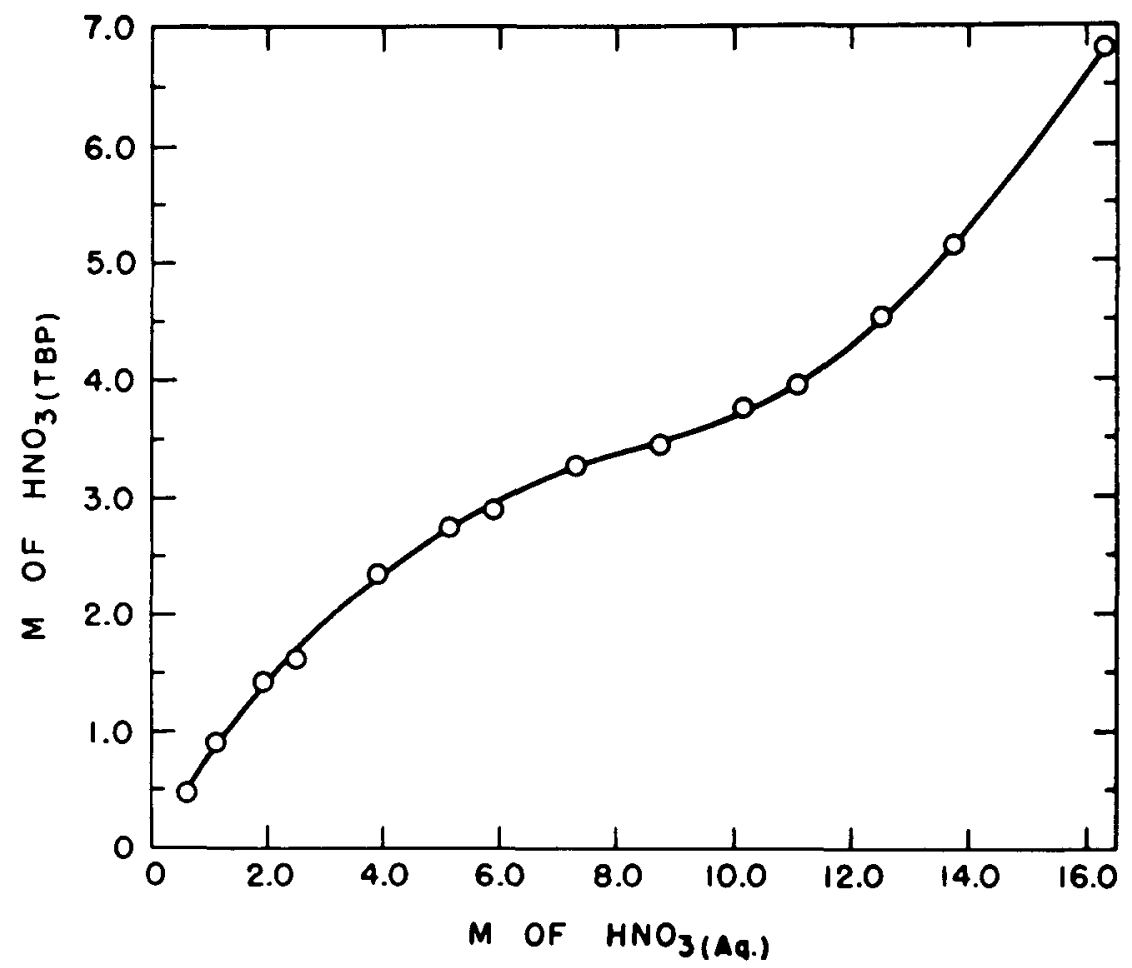

Fig. 34. Partition of $\mathrm{HNO}_{3}$ between aqueous and $100 \%$ TBP phases at $22 \pm 2^{\circ} \mathrm{C} \quad$ (356)

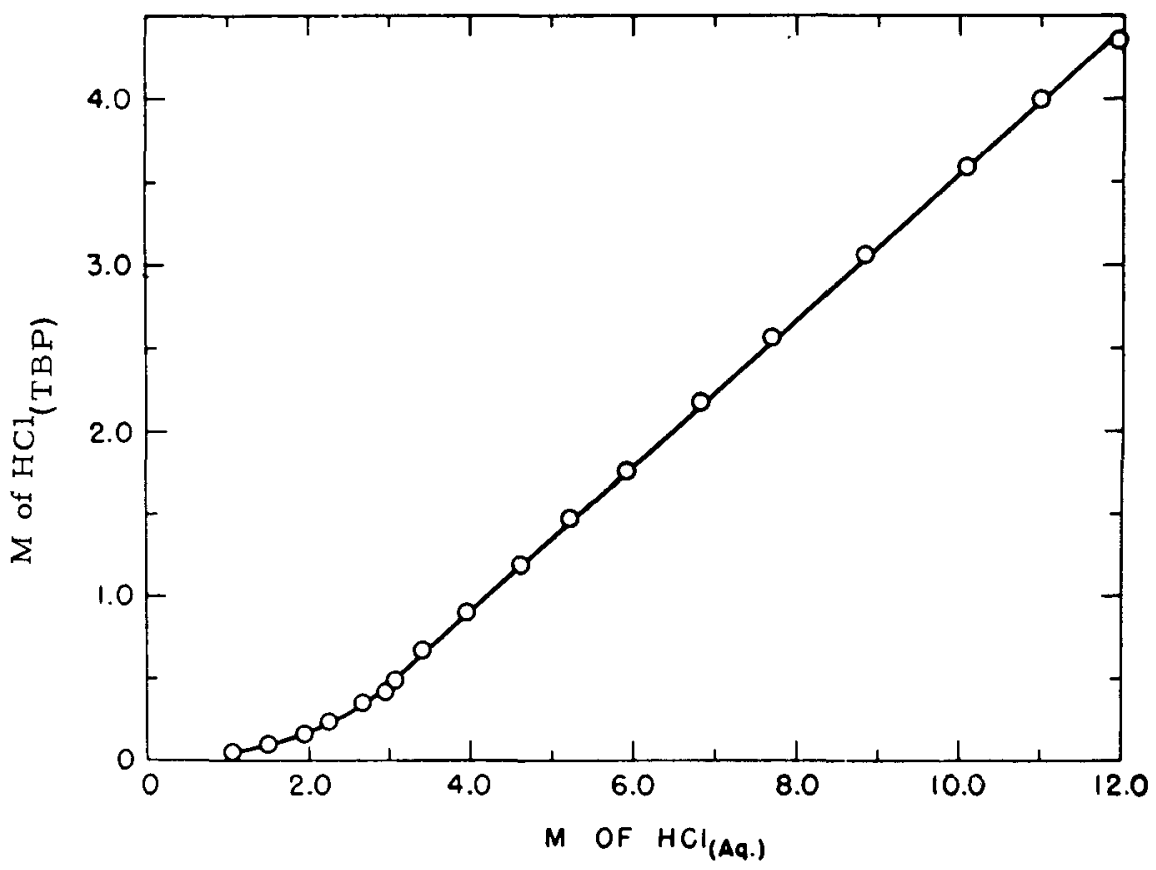

Fig. 35. Partition of $\mathrm{HCl}$ between aqueous and 100\% TBP phases at $22 \pm 2^{\circ} \mathrm{C}$ (356) 


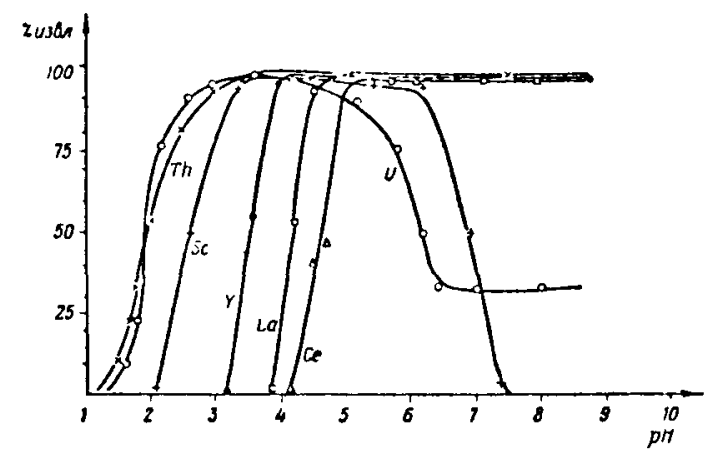

F1g. 36. Extraction of various elements into isoamyl alcohol with salicylic acid as a function of $\mathrm{pH}(469)$

Reid $^{386}$ gives the acid constant of the enol form of TTA as $5 \times 10^{-5}$ $\left(25^{\circ} \mathrm{C}\right)$ and the enol/keto ratio in water as 0.016 . The reagent acts as a monobasic acid, reacting with cations to make neutral chelate complexes, i.e., an n-valent cation reacts with $n$ molecules of TTA. The chelate complexes formed are soluble to some extent in organic solvents such as chloroform, carbon tetrachloride, and benzene, and also in many polar solvents. Benzene has been most often used, though toluene or xylene are sometimes preferred because of their lower volatility.

Several compilations of extraction behavior with TTA have been published, including those by Hagemann, ${ }^{183,184}$ Sheperd and Meinke, ${ }^{436}$ and Moore. ${ }^{322}$ Their combined data are given in Fig. 37.

Broido ${ }^{49}$ reported a purlfication of scandium and separation of $\mathrm{Ca}-\mathrm{Sc}$ mixtures by extraction of aqueous solutions with TTA in benzene. He reports

$$
\begin{aligned}
& \mathrm{K}(\mathrm{Sc})=\frac{\left[\mathrm{ScT}_{3}\right] \text { org }\left[\mathrm{H}^{+}\right]^{3} \text { aq }}{\left[\mathrm{Sc}^{+3}\right] \mathrm{aq}[\mathrm{HT}]^{3} \text { org }} \approx 0.9, \\
& \mathrm{~K}(\mathrm{Ca})=\frac{\left[\mathrm{CaT}_{2}\right] \text { org }\left[\mathrm{H}^{+}\right]^{2} \text { aq }}{\left[\mathrm{Ca}^{+2}\right] \mathrm{aq}[\mathrm{HT}]^{2} \text { org }} \approx 10^{-12} .
\end{aligned}
$$

As a result, calcium does not extract appreciably at $\mathrm{pH}$ values below 6 , even with 1.0 molar TTA solutions, while the extraction of scandium is appreciable even at $\mathrm{pH} 1$.

He further noted that in unbuffered solutions, since $\mathrm{H}^{+}$is liberated as scandium extracts, the $\mathrm{Sc}^{+3}-\mathrm{ScT}_{3}$ mixture will act to buffer the final acidity close to $\mathrm{pH} 1.5$, with an initial $\mathrm{pH}$ ranging between 3 and 11 and a scandium concentration of $1 / 2 \mathrm{mg} / \mathrm{ml}$.

He noted that, as in most solvent extraction procedures, addition of carrier was not necessary. 


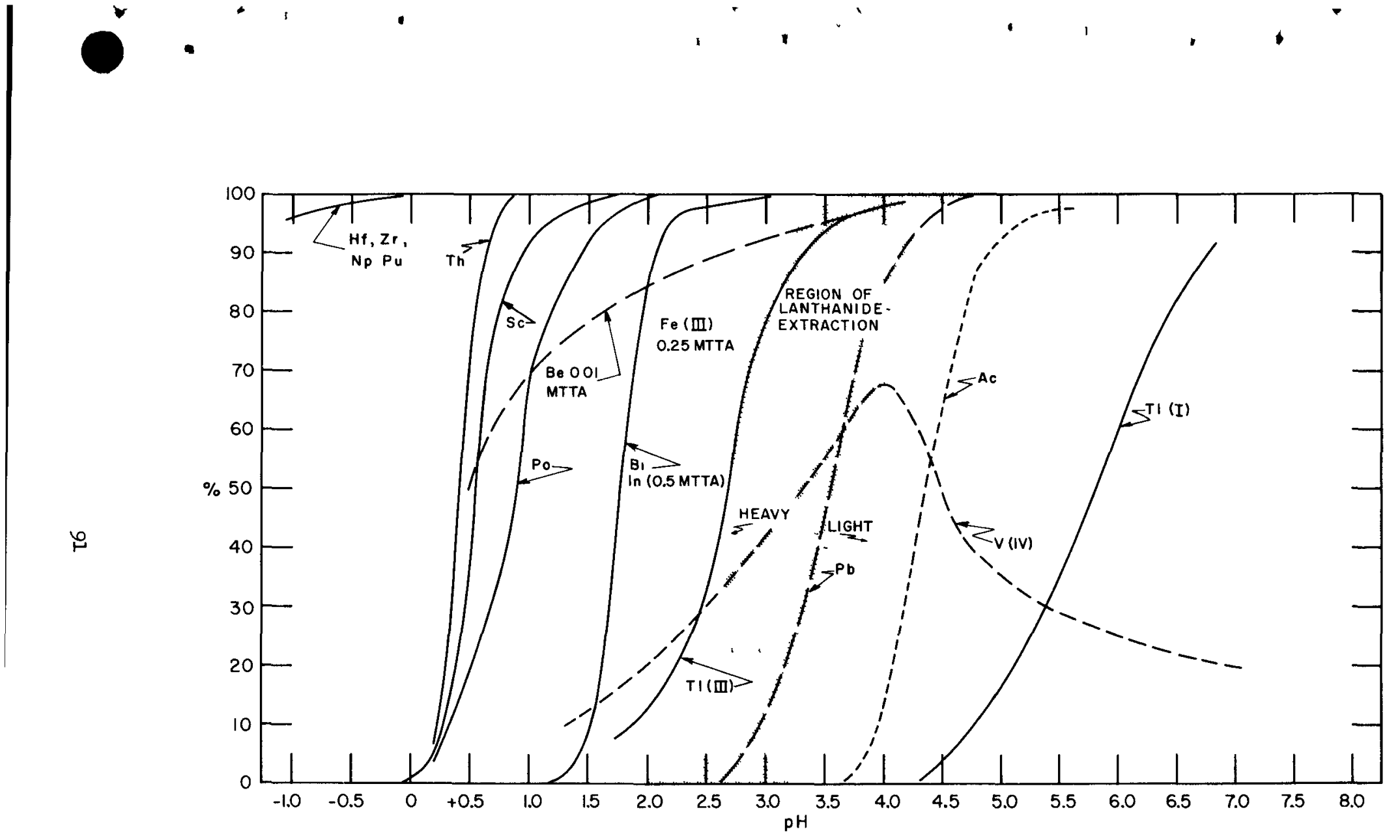

Fig. 37. Extraction of various elements with thenoyltrifluoroacetone (T TA) $(436,184,322,49)$ 
Werner and Perlman 530 used TTA extraction to separate americium from large amounts of lanthanum. They report $50 \%$ extraction of americium by $0.2 \mathrm{M}$ TTA at $\mathrm{pH} 3.17,50 \%$ extraction of lanthanum at $\mathrm{pH} 3.95$.

Magnusson and Anderson 275 noted that $0.2 \underline{M}$ TTA would extract Eu, $\mathrm{Yb}, \mathrm{Ac}, \mathrm{Am}, \mathrm{Cm}, \mathrm{Bk}, \mathrm{Cf}, 99$, and 100 from aqueous solutions of $\mathrm{pH} 3.4$.

IV. 6B-4. Substituted Phosphoric Acids

In the course of an investigation into a solvent extraction separation of zirconium and niobium from fission products, Scadden and Ballou 410 remarked that mono- and di-n-butyl phosphoric acids extracted Ho, Y, La, and Ce to some extent from nitric acid solutions, with yttrium and holmium much more readily extracted than lanthanum or cerium. Since the primary purpose of their work was not rare-earth separation, their data on lanthanides are not very complete.

Dyrssen ${ }^{121}$ remarked that dibutyl phosphoric acid extracted metal ions at lower pH than TTA and was in many instances to be preferred for that reason. He reported a procedure for milking $\mathrm{Y}^{90}$ from $\mathrm{Sr}^{90}$, using dibutyl phosphoric acid in chloroform as a solvent. Since dibutyl phosphoric acid is highly dimerized in chloroform solution, he presumed the reaction to be

$$
\mathrm{Y}^{+3} \mathrm{aq}+3 \mathrm{H}_{2} \mathrm{~A}_{2} \text { org } \rightleftarrows \mathrm{Y}\left(\mathrm{HA}_{2}\right)_{3} \text { org }+3 \mathrm{H}^{+} \text {aq }
$$

where HA represents dibutyl phosphoric acid. He measured the extraction coefficient using $0.1 \mathrm{M}$ nitric acid for the aqueous phase and 0.003 to $0.10 \underline{\mathrm{M}}$ dibutyl phosphoric acid in chloroform for the organic phase; also 0. 10M dibutyl phosphoric acid and 0.10 to $10.0 \mathrm{M}$ nitric acid. The results were consistent with the postulated reaction, with $\log K=3.24 \pm 0.10$. Some of his data are shown in Fig. 38. He obtained a decontamination from $\mathrm{Sr}^{90}$ of more than $10^{4}$.

Peppard, Mason and Moline 357 used di(2-ethyl hexyl) phosphoric acid (HDEHP) to extract several lanthanide species. They showed that cerium(IV) could be extracted into a $0.75 \mathrm{M}$ or $0.30 \mathrm{M}$ solution of HDEHP in heptane from $10 \mathrm{~N}$ nitric acid, with a ratio of extraction constants $K$ (IV)/K(III) of more than $10^{\frac{6}{6}}$. They also extracted $\mathrm{La}{ }^{140}$ from Ba ${ }^{140}, \mathrm{Y}^{90}$ from $\mathrm{Sr}^{90}$, and successfully separated $\mathrm{Y}^{90}$ from La ${ }^{140}$. The conditions of separation are given in Table 9.

IV.6B-5. Acetylacetone

Since TTA is such a successful reagent for extracting rare earths, it seems reasonable to assume that the lanthanides would form chelate compounds with other $\beta$-diketones. Acetylacetone, the simplest member of the class, has been examined in some detail. Urbain ${ }^{492}$ had prepared crystalline acetylacetonates of the rare earths, generally by adding ammonium or sodium 


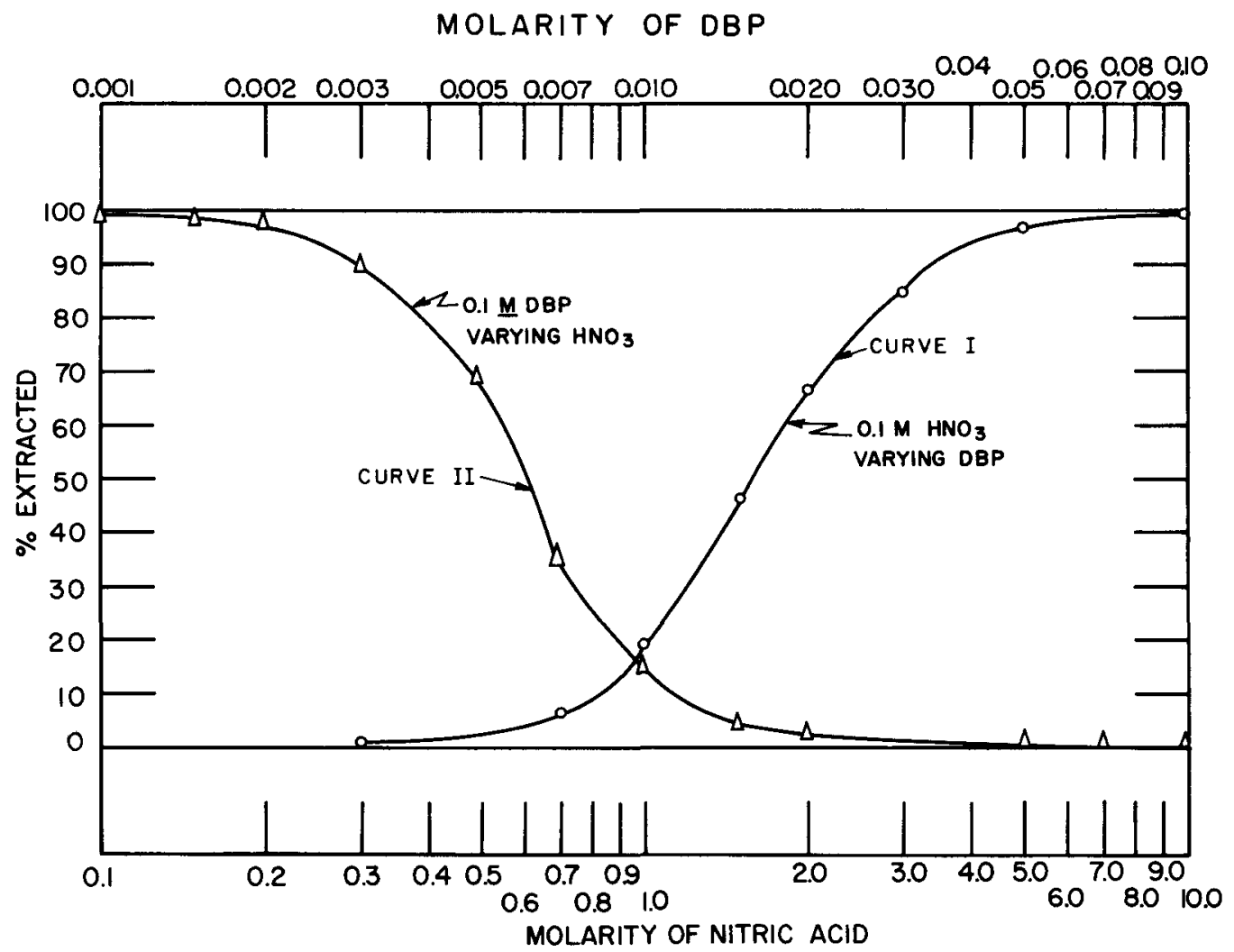

Fig. 38. Extraction of yttrium by dibutyl phosphoric acid in dibutyl ether. Curve I - from 0 . I molar nitric acid as a function of dibutyl phosphoric acid molarity. Curve II - with 0.1 molar dibutyl phosphoric acid as a function of nitric acid molarity (121)

acetylacetonate to slightly acid rare-earth-nitrate solutions. Marsh ${ }^{284}$ proposed the formula $\mathrm{R}\left[\mathrm{CH}\left(\mathrm{COCH}_{3}\right)_{2}\right]_{3}$ for these compounds, and his suggested formula was verified for the neodymium compound by Erämetsä and Hämälä, 126 although Seehof $^{429}$ prepared $\mathrm{Ce}\left[\mathrm{CH}\left(\mathrm{COCH}_{3}\right)_{2}\right]_{3} \cdot 2 \mathrm{NH}_{4}\left[\mathrm{CH}\left(\mathrm{COCH}_{3}\right)_{2}\right]$. Erämetsä and Hämälä 126 also measured the solubilities of the acetylacetonates of La, Pr, $\mathrm{Nd}, \mathrm{Sm}, \mathrm{Eu}, \mathrm{Gd}, \mathrm{Y}$, and Dy in many common solvents, and found that the solubilities were very low except in methanol. Rydberg ${ }^{400}$ reported failure in attempts to extract lanthanum and samarium into acetylacetone or acetylacetone solutions. Krishen, 247 however, reported that while lanthanum(III) and praseodymium(III) did not extract, due apparently to the very low solubility of their acetylacetonates in the organic phase (acetylacetone), cerium(III) acetylacetonate extracted very efficiently, extraction being essentially complete at $\mathrm{pH}>4$ and appreciable at $\mathrm{pH}$. He attributes the difference to the fact that cerous acetylacetonate formed from water solution has water of coordination, while lanthanum and praseodymium acetylacetonates do not, although the composition reported by Seehof 429 seem to show that the com- 
Table 9. Distribution equilibrium constants (K) for the elements $\mathrm{Sr}, \mathrm{Ba}$, $\mathrm{Y}, \mathrm{La}$, and Ce for extraction with di(2-ethyl hexyl) phosphoric acld (HDEHP) under various experimental conditions (357)

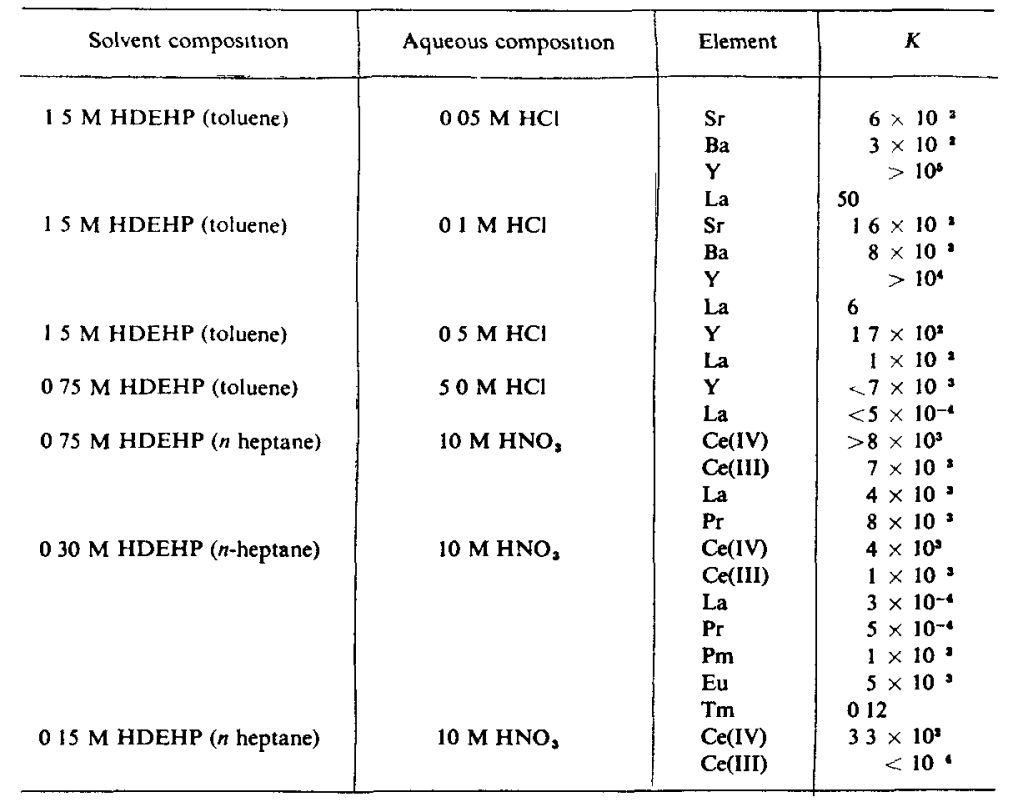

pound is actually a double salt without water of hydration. The unique be havior of $\mathrm{Ce}$ (III) indicates that the reagent should be tried on each individual rare earth.

IV.6B-6. Oxine and Oxine Derivatives

The reagent oxine ( 8 -hydroxyquinoline) is much used in analytical chem1stry, since it forms water-insoluble compcunds with many metallic ions under the appropriate conditions. By varying the conditions, considerable specificity can often be obtained. The compounds formed are in general colored and usually soluble in organic solvents, colorimetric analyses are frequently performed on chloroform extracts of metal oxinates. The halogenated derivatives of oxine have similar properties.

Moeller and Jackson ${ }^{315}$ and Jackson ${ }^{216}$ studied the precipitation and solvent extraction behavior of the oxinates and 5,7-dichlorooxinates of neodymium, as a typical light rare earth, and erbium, as a typical heavy rare earth, using chloroform as the organic solvent. Their conclusion is that the halogenated oxinates are much more satısfactory compounds than the simple oxinates for solvent extraction, apparently because of the higher solubility of the chloro-compounds in chloroform. Extraction becomes appreciable at $\mathrm{pH} \approx 5$, and is essentially complete at $\mathrm{pH} \approx 8.2$ for both elements studied. 
Dyrssen and Dahlberg, 115 in one article of an extensive series $116,117,119,120$ by Dyrssen and co-workers on the solvent-extraction properties of metal chelates, reported on a study of the extraction of the oxinates and cupferrates of La, Sm, Hf, Th, and U(VI) using both chloroform and hexone as solvents. They concluded that their data could only be explained by two assumptions: 1) that the extractable complex was partially soluble in the aqueous phase, rendering complete extraction impossible; and 2) that each of a consecutive series of addition complexes was involved in the equilibrium between metal cation and reagent, the extractable form being the uncharged complex containing $n$ molecules of chelating reagent per $n$-valent cation. Their data resemble those of Moeller and Jackson ${ }^{315}$ and Jackson 216 on neodymium and erbium; hexone seems to be superior to chloroform as a solvent. The incomplete extraction behavior of the simple oxinates is confirmed.

The work of Dyrssen's group on the lanthanides and actinides was summarized by Dyrssen 118 in a most detailed article. His results pertaining to the trivalent lanthanides may be summarized as follows:

Oxine and 5,7-dichlorooxine will extract rare earths into chloroform, the halogenated compounds being more readily and completely extracted (see Fig. 39). The range in pH for suitable extraction is from 4 to 6.5 for oxine,

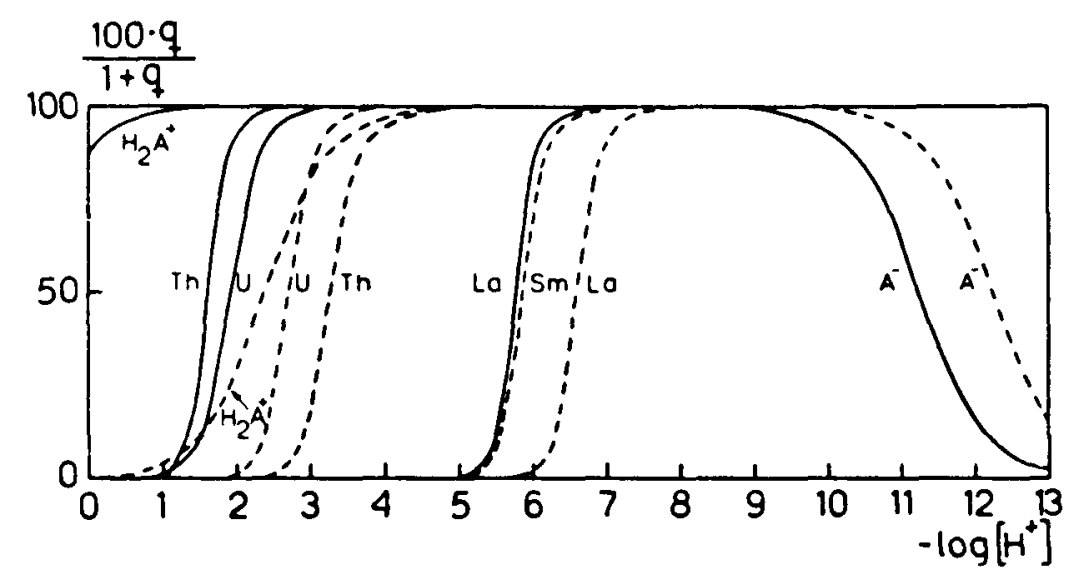

Fig. 39. Comparison of oxine (dashed curves) and 5-7-dichloro-oxine (full curves) as chelating agents for the extraction of $\mathrm{La}^{+3}, \mathrm{Sm}^{+3}, \mathrm{Th}^{+4}$ and $\mathrm{UO}_{2}^{+2}$ into chlor oform. The $\mathrm{H}_{2} \mathrm{~A}^{+}$and $\mathrm{A}^{-}$curves show the extraction of the oxines into the aqueous phase as oxinium and oxinate ions (118)

from 3 to 5.5 for dichlorooxine. This $\mathrm{pH}$ range is somewhat lower than that reported by other workers. 315,216 It is also noted that $n$-phenyl benzohydroxamic acid will extract rare earths very efficiently into chloroform at a pH of 5 to 6 (see Fig. 40). 


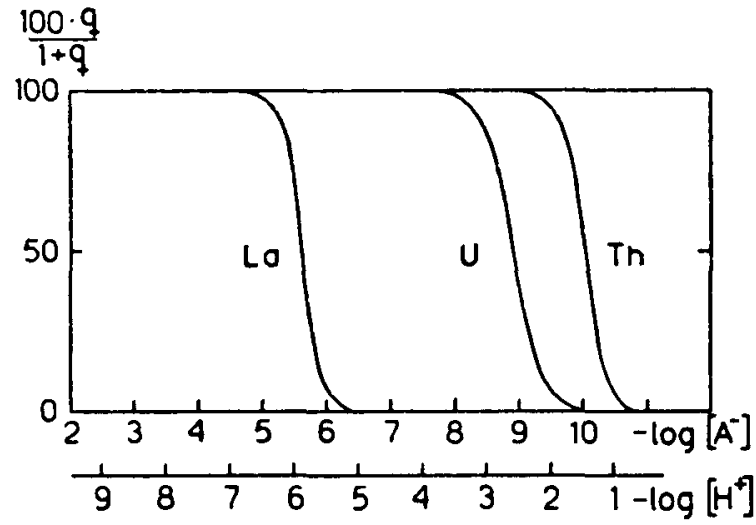

Fig. 40. The distribution of $\mathrm{La}^{+3}, \mathrm{Th}^{+4}$, and $\mathrm{UO}_{2}^{+2}$ between chloroform and $0.1 \mathrm{M}$ perchlorate solutions as a function of the $\mathrm{K}$-phenylbenzohydroxamate ion concentration in the aqueous phase. The corresponding values of $\mathrm{pH}(-\log$ $\left[\mathrm{H}^{+}\right]$) are calculated for 0.1 molar PBHA in chloroform (118)

IV.6B-7. Other Chelating Reagents

Cupferron is in general not a very satisfactory reagent for the extraction of rare earths, since the chelates have a very low solubility in chloroform. This leads to incomplete extraction even at high $\mathrm{pH}$ values and limits the useful metal ion concentration to below $10^{-4} \underline{\mathrm{M}}$. The chelate solubility in, hexone is much higher, and better results are obtained with this solvent.

Vickery ${ }^{508}$ reports that chloroform will extract the oxine chelate of scandium (conditions not given) but again he prefers the thiocyanate extraction. Rudenko ${ }^{392}$ reports that extraction of carrier-free yttrium with 0.05 to 0.2 molar oxine in chloroform is complete at $\mathrm{pH} 8$, and that back-extraction is complete at $\mathrm{pH} 3$, but that the extraction is only useful at yttrium concentrations below about $5 \times 10^{-4}$ molar.

Gruzensky and Engel ${ }^{180}$ have reported a procedure for obtaining rare earths from euxenite ore which involves extracting the rare earths from nitric acid solution into an organic layer which consists of tri-n-butylamine in 3 methyl-2 butanone. Separation factors between the rare earths were not high but some separation was achieved. No more than $60 \%$ of the rare earths were transferred to the organic phase, even under the best of conditions.

\section{6C. REMOVAL OF CONTAMINANTS FROM RARE EARTHS}

\section{BY SOLVENT EXTRACTION}

Many solvent-extraction systems exist which remove unwanted materials from aqueous solutions of the rare earths without serious losses of lanthanides. Such processes may be very useful in radiochemical separations to remove large amounts of target material prior to precipitation of a rare-earth fraction, or to remove major active species to permit easier and safer handling. 
Many workers $12,37,106,302,401,475,502$ have shown that the extraction of simple salts of the rare earths (nitrates, chlorides, thiocyanates) into many classes of organic solvents such as alcohols, esters, ketones and ethers is very low, even from highly salted systems. This suggests the removal by extraction of large quantities of many elements by solvent extraction - iron from chloride solution or uranium from salted nitrate solutions, for example.

The very high sensitivity to reagent concentration of the extractability of rare earths with tributyl phosphate may be used to advantage for removal of certain species from the rare earths with diluted TBP. Blackmore, Bearse, and Calkıns ${ }^{34}$ showed that thorium could be readily removed from the trivalent lanthanides by extracting with dilute $(\approx 20 \%)$ TBP from 6 molar nitric acid. A progress report from the New Brunswick Laboratory of the Atomic Energy Commission ${ }^{4}$ describes the solvent extraction removal of thorium from yttrium and ytterbium by 22.5 volume percent TBP in inert diluent. Bernström and Rydberg ${ }^{26}$ report the rather low extraction of lanthanum by diluted TBP even in highly salted systems, and show that uranium, plutonium, thorium, and zirconxum may be effectively removed. Gal and Ruvarac ${ }^{163}$ report that $30 \% \mathrm{TBP}$ in dibutyl ether will extract $\mathrm{Cd}$ and $\mathrm{VO}_{3}$ quite well from hydrochloric acid, $\mathrm{Fe}$ and $\mathrm{Zr}$ will extract very well at high $\mathrm{HCl}$ concentrations (7-8 molar), and uranium(VI) will extract quite well from $\approx 6 \underline{\mathrm{M}} \mathrm{HCl}$. Extraction of cerium(III) is very low.

A systematic study of long-chain aliphatic amines has been carried out at Oak Ridge National Laboratory over the past several years. $52,93,94,95$ These compounds in inert solvents (hydrocarbons) act like, and are some times referred to as, liquid anion exchangers. Primary long-chain amines show some very slight extraction of the rare earths from low -acid sulfate solutions, but secondary and tertiary amines show practically none, while extraction of uranium and thorium are extremely high. These reagents would apparently repay study as decontaminating agents for the rare earths, since anion-exchange resins are inherently limited in their utility when high speed is necessary.

Rydberg 400 reports that 0.1 molar acetylacetone in hexone, benzene, or chloroform will extract thorium away from samarium and lanthanum in slightly acid solutions. According to Vickery, ${ }^{508}$ scandium will extract into ethyl acetate containing acetylacetone at $\mathrm{pH} 4.5$, but this behavior is probably specific for scandium among the rare-earth-like ions.

Cowan 90 has obtained a patent on a process for separating thorium from the rare earths in salicylate solution. Between $\mathrm{pH} 2$ and 5 (buffered by acetate) thorium is extracted by a mixed ether-ester solvent whlle the rare earths remain in the aqueous layer. 
IV.6D-1. Simple Salts

Unt1l the advent of the cation-exchange technique, the separation of individual members of the rare-earth group presented a chemical problem of the first magnitude. The methods most often used were based on fractional crys tallization, but some early work was done on fractionation by solvent extractıon. Fischer, Dietz, and Jübermann 136 in 1937 reported that the separation factor (ratio of extraction coefficients) for pairs of adjacent rare earths was of the order of 1.5 for the extraction of the chlorides into various alcohols, ethers, and ketones. The amount extracted was very small, however. Templeton and Peters on 475 reported some separation by extracting nitrates of La, Ce(III), and Nd into higher alcohols from nearly saturated water solutions of the salts. They reported that the degree of extraction was not large, and was very sensitive to salt concentration. They measured a separation factor of 1.4 between neodymium and lanthanum - a considerably lowe $r$ value than that of Fischer, Dietz and Jübermann. 136

Fischer and his co-workers ${ }^{141}$ studied the possibility of separating the rare earths by extraction from lithium nitrate solutions with ether or with $n$-pentanone-2. Extractions were very slight (coefficients of the order of $10^{-3}$ ) but some degree of separation was attained. Eberle and Lerner 123 studied the extraction of gadolinium, dysprosium, samarium, europium, and yttrium from slightly acid thiocyanate solutions with a large variety of solvents. They found that tributyl phosphate and isopropyl alcohol were quite effective solvents for extracting rare earths $(K \approx 1)$ and that tert-butyl alcohol was somewhat effective $(K \approx 0.3)$, but that many other solvents, including glycols, ketones, esters, ethers, and halogenated solvents, were very ineffective. Even other alcohols were very poor. They noted that gadolinium, samarium, dysprosium and europium all behaved similarly, while yttrium was less readily extracted. They used this phenomenon to concentrate the other lanthanides with respect to yttrium.

IV. 6D-2. Tributyl Phos phate (TBP)

Considerably greater success has been attained by the use of tributyl phosphate as an extractıng agent. A great deal of published work exists, much of it of very high quality, on the individual differences of extraction behavior in the rare earth-TBP system. Blackmore, Bearse, and Calkıns 34 observed some differences in behavior between individual rare earths in their study on rare earth-thorium separations. Peppard, Faris, Gray, and Mason, ${ }^{354}$ in their detalled study previously referred to, concluded that the 
logarithm of the extraction coefficient $K$ was an increasing linear function of atomic number $Z$ for the lighter rare earths, using $100 \%$ TBP and 15.6 molar nitric acid. They assigned an artificial $Z$ of 66.5 to yttrium in order to include that element in the scheme. The separation factor between adjacent lanthandes was reported as 1.9. Gray and Thompson 177 supplemented the data of Peppard, Faris, Gray, and Mason 354 and compared the data on lanthanides with their measurements on several trivalent actinides. They verified the logarithmic dependence of $K$ on $Z$, but observed evidence for anomalous behavior in the neighborhood of $\mathrm{Z}=67$. Their data and those of Peppard et al. are shown in Figs. 41 and 42. Peppard, Gray, and Markus 355 used the comparative extraction data to demonstrate the analogy between the actinide series and the lanthanide series. Topp and Weaver ${ }^{485}$ also studied $100 \%$ TBP - nitric acid systems, using gadolinium and samarium. Their separation factor is in rough agreement with that of Peppard et al. ${ }^{354}$

Scargill, Alcock, Fletcher, Hesford, and McKay 411 also studied the lighter rare earths in TBP-nitrate-nitric acid systems. Their data agree in general with those of previous workers. They extended their investigation to very low TBP concentrations and showed that the limiting dependence on TBP concentration was very close to third power. They therefore proposed a solvated extractable form containing three TBP molecules. Their data are presented as Table 10 and Figs. 43 and 44. They emphasize that free TBP alone is effective as an extracting agent, excess nitric acid tends to reduce extraction efficiency by combining with TBP. The increased extraction ef ficiency at low acidities and high nitrate concentration is therefore explained. Peppard, Driscoll, Sironen, and McCarty ${ }^{358}$ extended the study of the TBP-nitric acid system to the heavier lanthanides and americium. They verified the linear relationship between $\log K$ and $Z$ for the lighter lanthanıdes, but observed an abrupt change in behavior at $Z=64$. The heavier lanthanides also give a roughly linear relationship between $\log K$ and $Z$, but of different slope - somewhat lower slope at very concentrated (18.5 molar) nitric acid, becoming still lower as the nitric acid concentration is reduced, and actually becoming negative at low acidities (see Fig. 45). They postulate that the extracting species is $\left[\mathrm{M}(\mathrm{TBP}) \mathrm{A}\left(\mathrm{H}_{2} \mathrm{O}\right) \mathrm{x}-\mathrm{A}\right]\left(\mathrm{NO}_{3}\right)_{3}$, where $\mathrm{A}$ is a function of nitric acid concentration and of $Z$. Hesford, Jackson, and McKay 195 also investigated the heavier lanthanides with results in good agreement with Peppard et al. ${ }^{358}$ but again extended their work to much lower TBP concentrations. They disagree with the interpretations of Peppard's group, ascribing the behavior of the system at high TBP concentrations to deviations from ideality. They claim the species extracted are in all cases $M(T B P)_{3}$ $\left(\mathrm{NO}_{3}\right)_{3}$. Their data are presented in Figs. 46, 47, 48, and 49 with the data of Peppard et al. 358 included for comparison. 


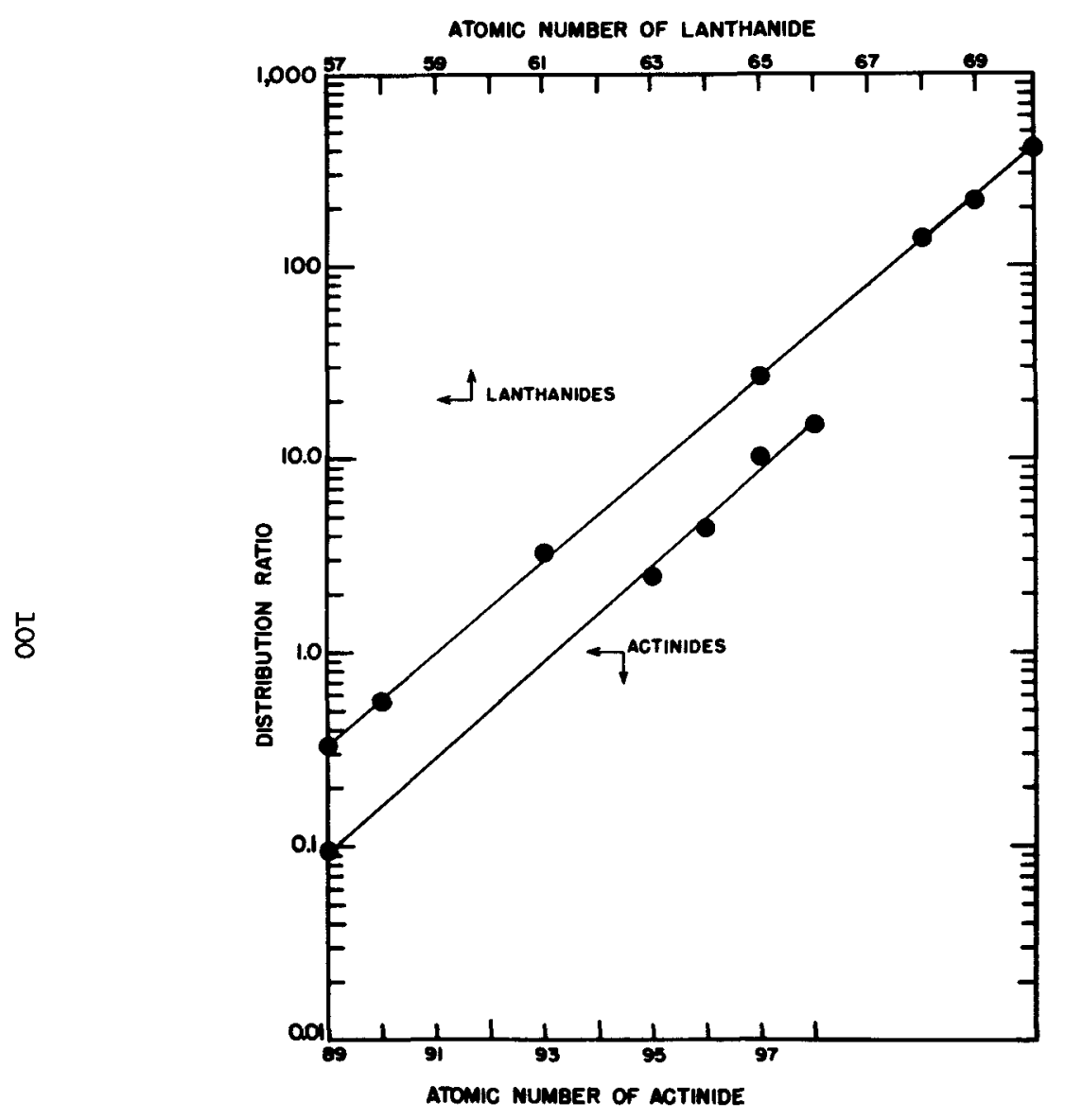

Fig. 41. Solvent extraction behavior of trivalent lanthanide and actinide elements into tributyl phos phate from 15. $6 \mathrm{~N} \mathrm{HNO}_{3}$ (177)

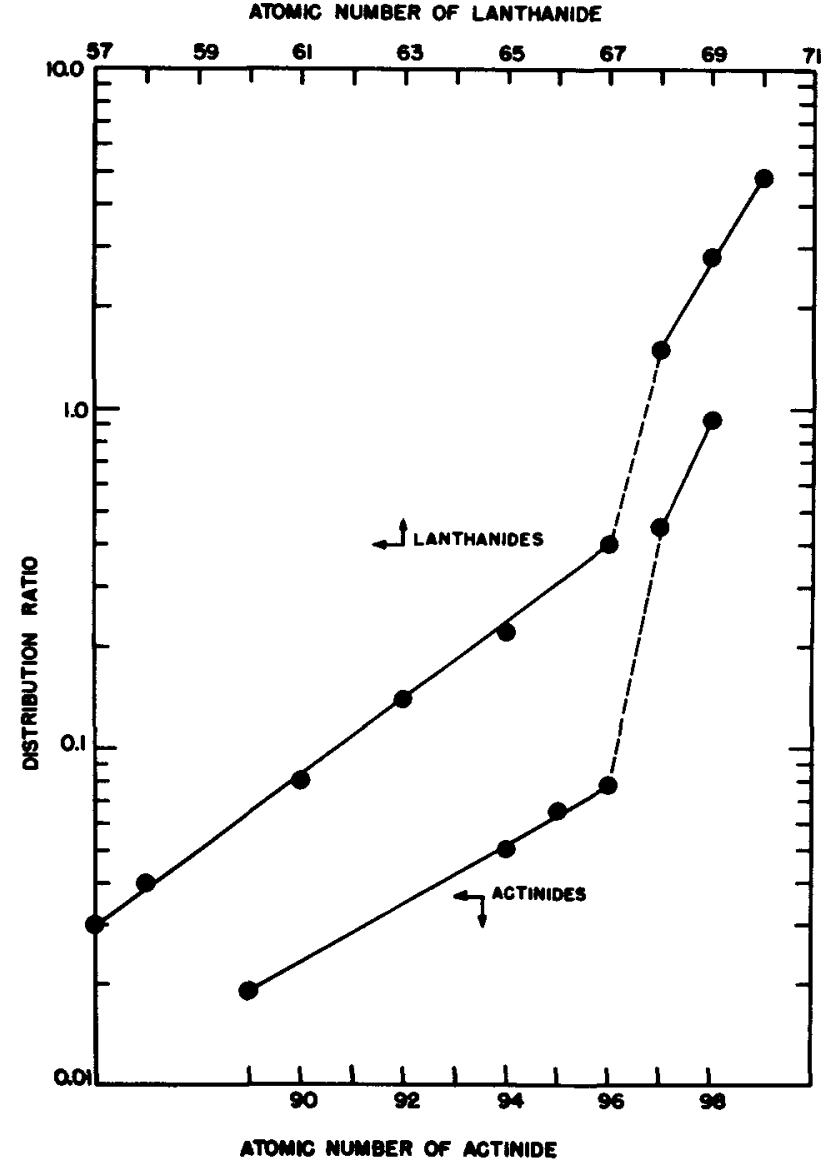

Fig. 42. Solvent extraction behavior of trivglent lanthanide and actinide elements into tributyl phosphate from 12. $\mathrm{ON} \mathrm{HCl} \mathrm{(177)}$ 


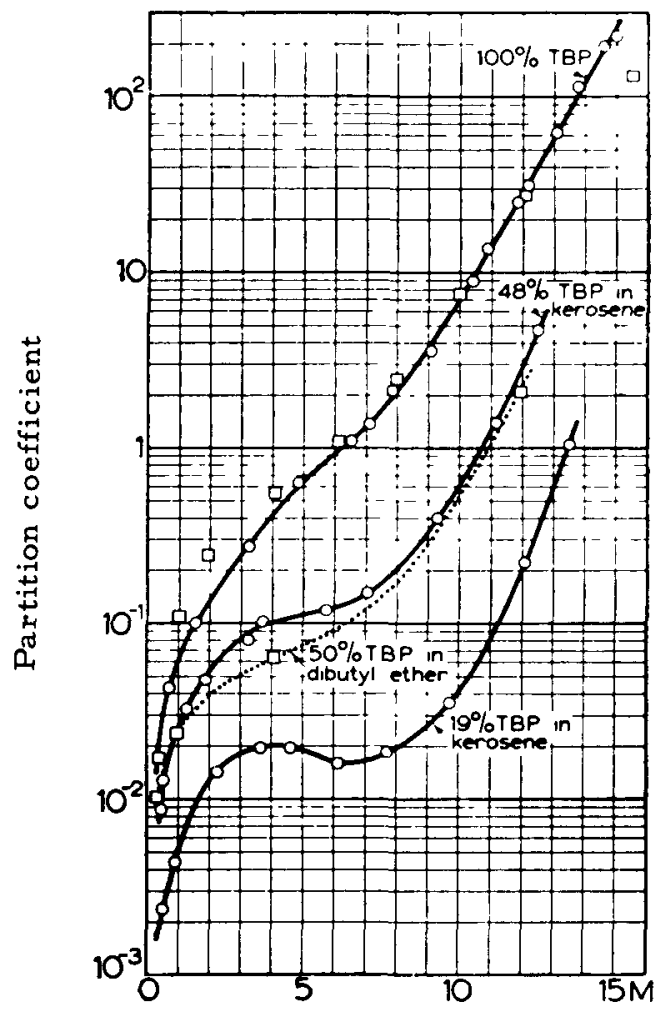

Aqueous nitric acid concentration

Fig. 43. The partition coefficient of yttrium between various concentrations of TBP and nitric acid.

O Data of Scargill et al.(411)

$\square$ Data of Peppard, Faris, Gray and Mason (354)

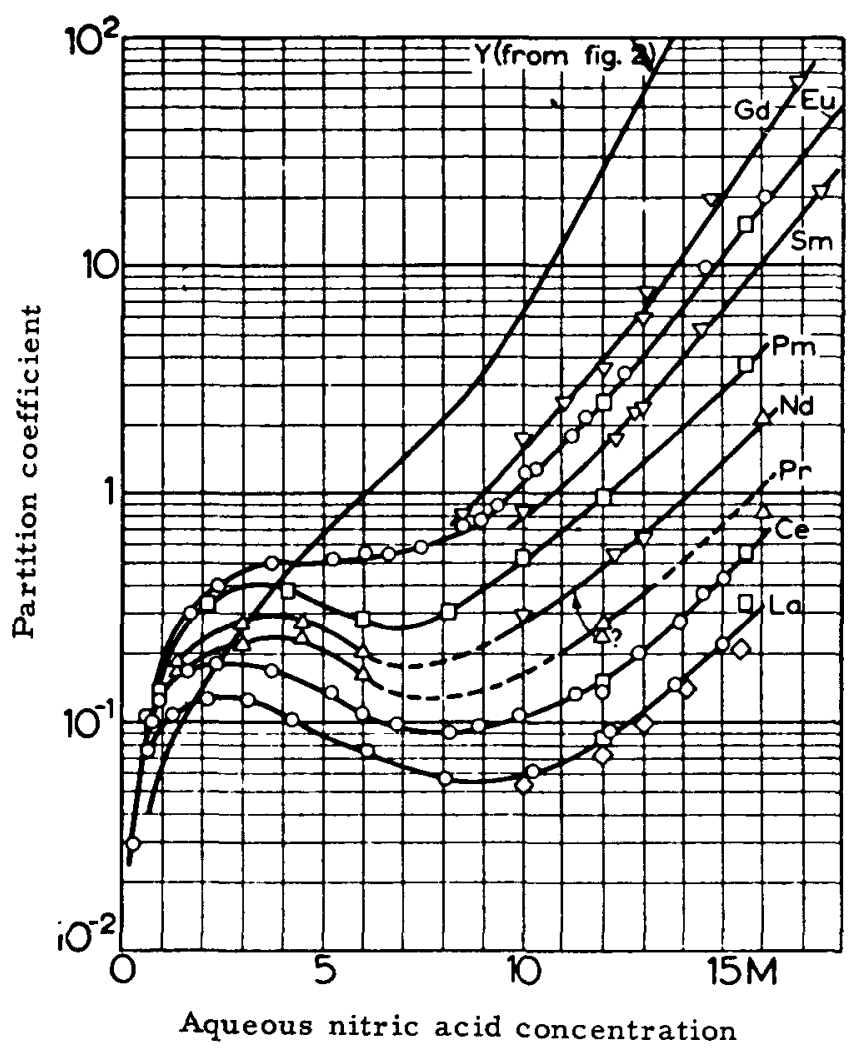

Fig. 44. The partition coefficients of the lower lanthanide nitrates: $100 \%$ TBP. nitric acid system.
O Data of Scargill et al. (411)
$\triangle$ Data of Cuninghame et al. (98)
$\checkmark$ Data of Peppard et al. $(354,355)$
$\nabla$ Data of Topp and Weaver (485)

$\diamond$ Data of Suttle and Stampfer (472) 
Table 10. Partition coefficients of various rare earths between organic phases containing TBP and aqueous nitric acid (411)

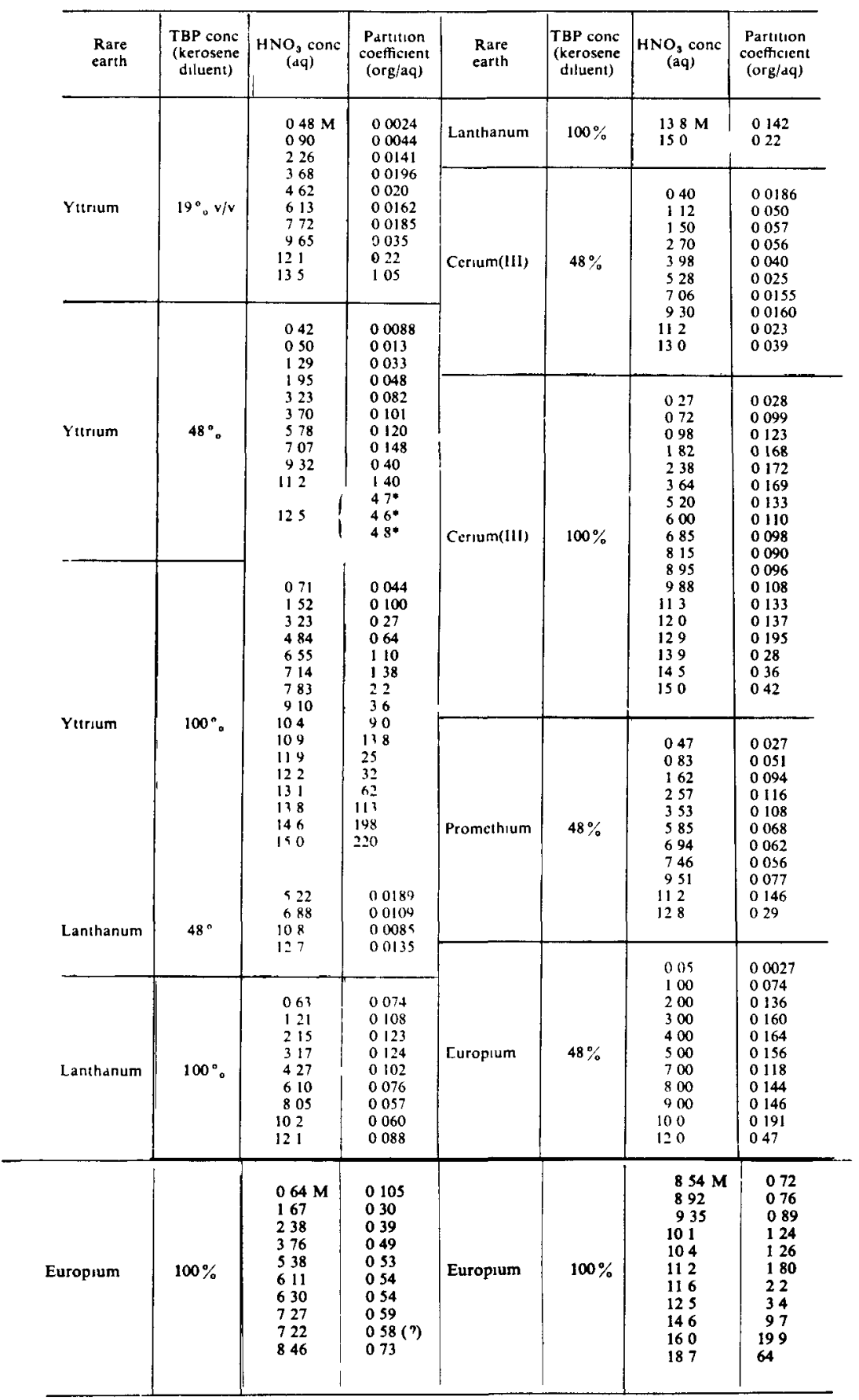

* Repeat experiments 


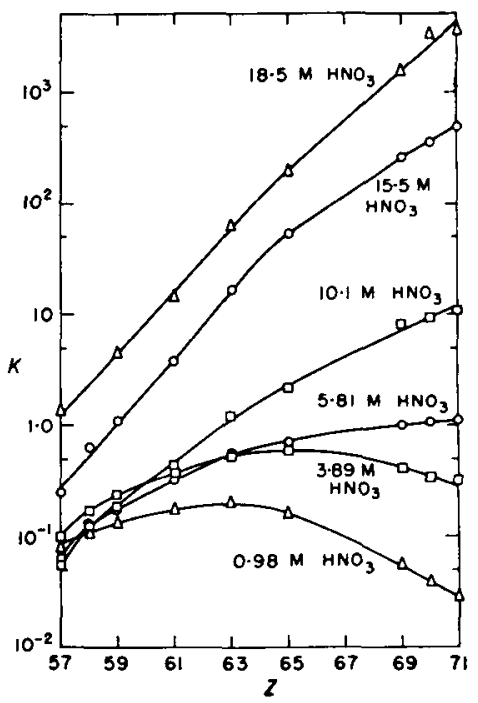

Fig. 45. Extraction of lanthanides into TBP from aqueous nitric acid phases of selected molarity as a function of $Z$ (358)

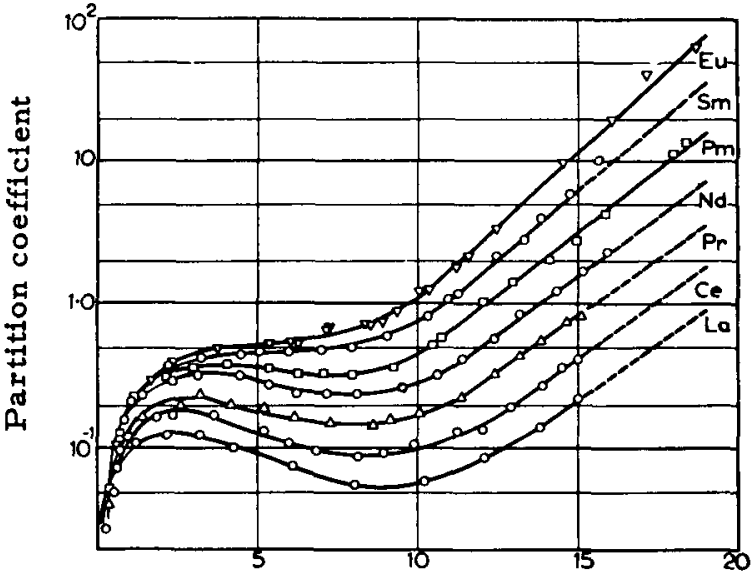

Nitric acid concentration, Aqueous, $M$

Fig. 46. Extraction of the lower lanthanides by $100 \%$ TBP (195)

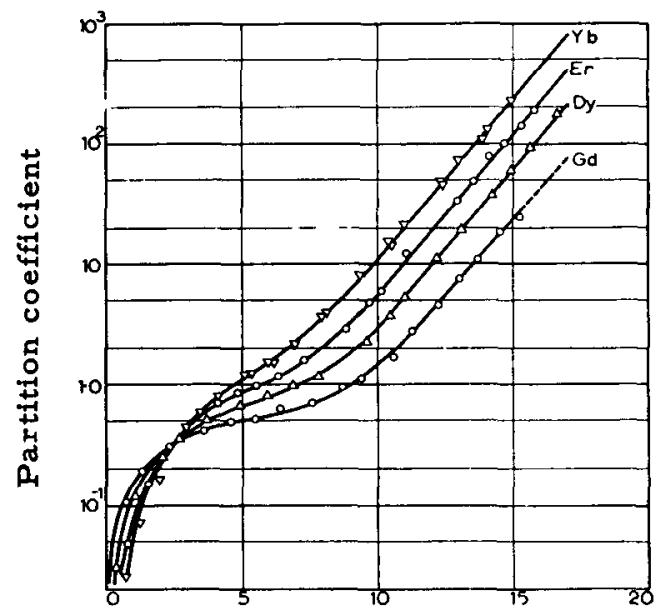

Fig. 47. Extraction of the even-Z higher lantbanides by $100 \%$ TBP (195)

Nitric acid concentration, Aqueous, M 


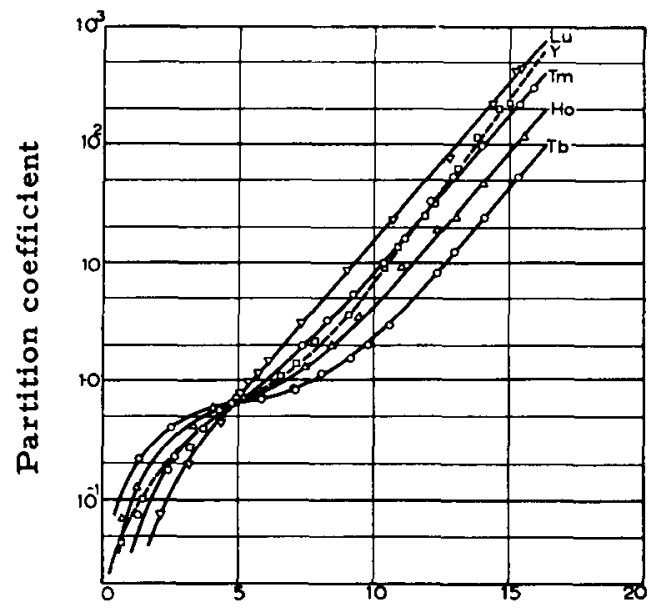

Nitric acid concentration, Aqueous, $M$
Fig. 48. Extraction of yttrium and the odd- $\mathrm{Z}$ higher lanthanides by $100 \%$ TBP (195)

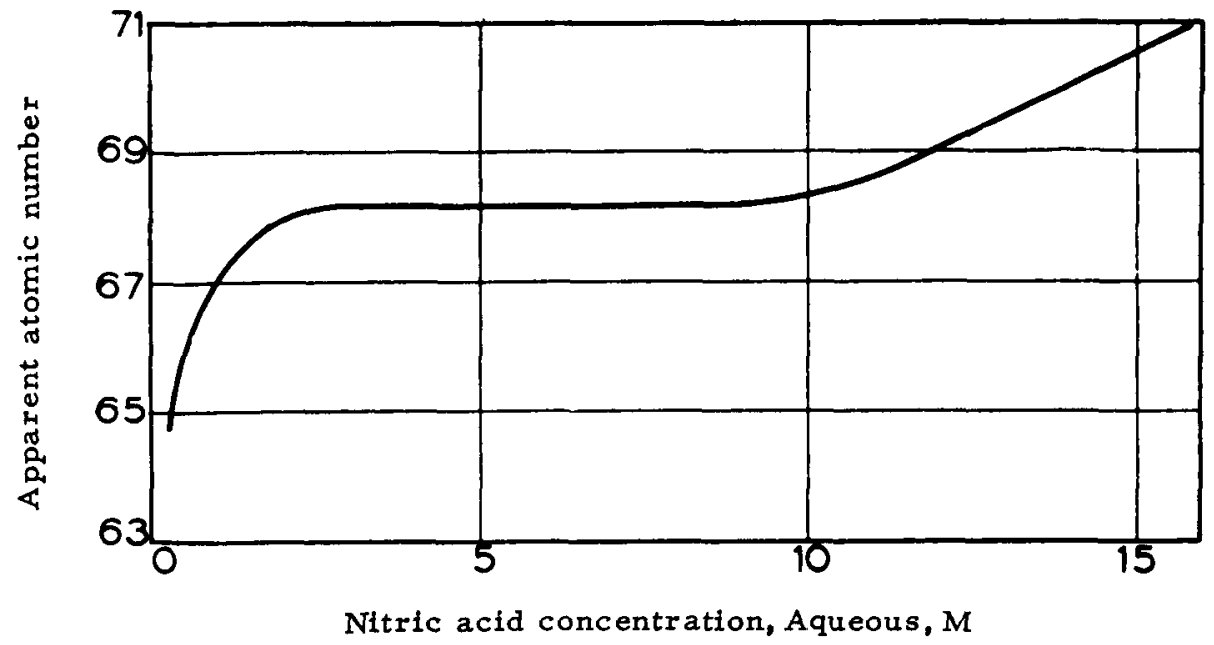

Fig. 49. Apparent atomic number of yttrium regarded as an odd- $z$ pseudolanthanide (195)

Many engineering-scale applications have been made of solvent-extraction separations of the rare earths from each other. Bochinski, Smutz, and Spedding, 36 Foos and Wilhelm, 147 Knapp, Smutz and Spedding, 236 Topp and Weaver, 485 and Brown, Coleman, Crouse, and Ryan 53 all have reported encouraging results on large-scale multistage extraction separations using TBP systems. The only reported attempt to develop a small-scale laboratory separation, by Cuninghame, Scargill, and $W$ illis, 98 was based on extraction from nitric acid-ammonium nitrate with TBP-kerosene containing TTA. Their observed separation factors per stage were never better than 3 for the La-Pr pair. They concluded that the system was unlikely to represent any improvement over ion exchange. (See, however, page 172, this report.) 
Brezhneva, Levin, Korpusov, Manko; and Bogochova ${ }^{45}$ used a 20-stage mixer-settler solvent extraction system to separate multicurie amounts of radioactive europium and promethium from aged fission-product solutions. They used 14-15 molar nitric acid for their aqueous phase and pre-equilibrated, undiluted TBP for their organic phase. Separation of yttrium from promethium was good, but separation of europium from yttrium was poor. This defect was not serious, since yttrium was separated only from relatively young fissionproduct solutions in which europium was not a major activity, while separation of europium activity was done from quite old (2.5-3 years) solutions in which yttrium was no longer present to any great degree. Their data are presented in Fig. 50. The advantage claimed for solvent extraction over ion exchange in this case is, first, that of simplicity and ease of handling by remote control; and second, that for the very high levels of radiation at which they were working, there were far fewer difficulties due to radiation effects, such as bubble formation and radiation damage.

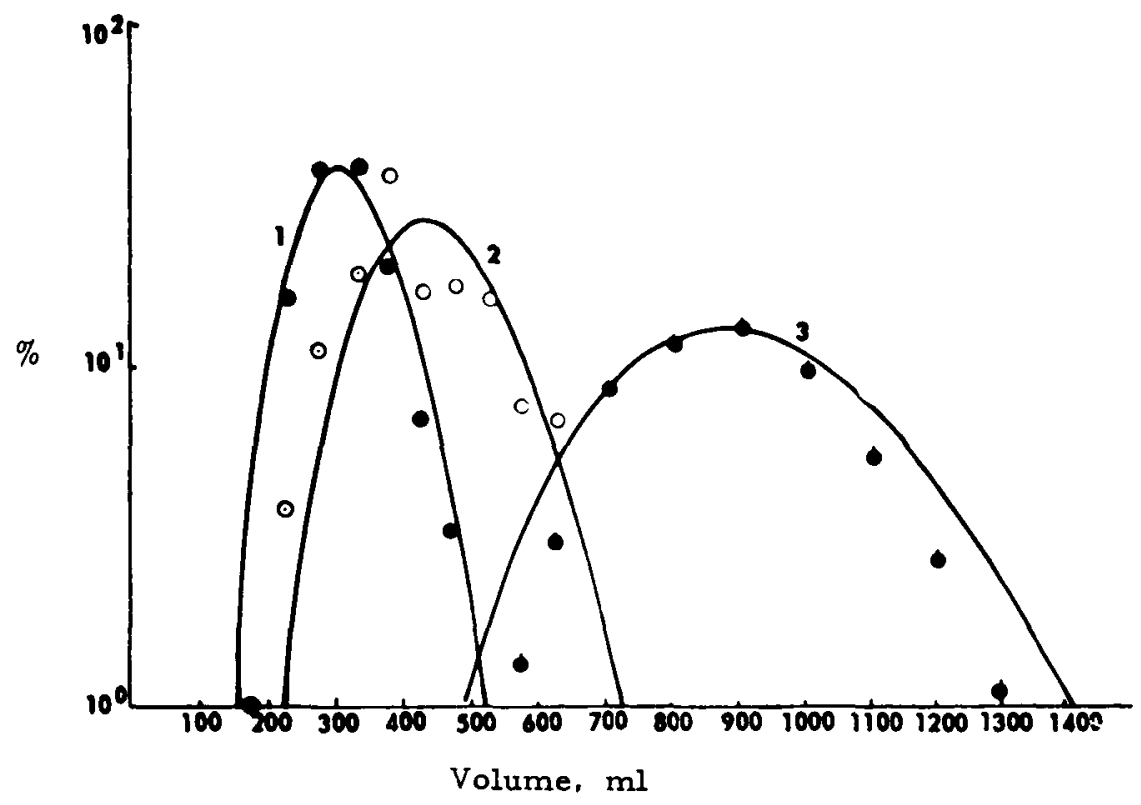

Fig. 50. Distribution of the concentrations of radioisotopes. The volume of tributyl phosphate which has passed through the apparatus is shown along the abscissa axis, and the concentrations of the radioelement as a percentage of the initial concentration along the ordinate axis. Solld lines denote theoretically computed distribution: 1-yttrium; 2 -europium; 3 -promethium (45)

\section{6D-3. Chelating Organophos phorous Compounds}

The data of Scadden and Ballou 410 indicated that dibutyl phosphoric acid or similar compounds might show differences in extracting powe $r$ for different rare earths; this was confirmed by the very careful and complete 
work of Peppard, Mason, Maier, and Driscoll, 359 using di-(2 ethyl hexyl) orthophosphoric acid (symbolized HDEHP) in an organic diluent as an extracting medium for the lanthanides. They found a direct third-power dependence on HDEHP concentration and an inverse third-power dependence on hydrogen ion, indicating that the reaction was

$$
\mathrm{M}^{+3}+3 \mathrm{HDEHP} \rightleftharpoons \mathrm{M}(\mathrm{DEHP})_{3}+3 \mathrm{H}^{+},
$$

analogous to the dibutyl phosphoric acid reaction proposed by Dyrssen. 1

They report a linear relationship between $Z$ and $\log K$ over the entire rare-earth region, with a separation factor between adjacent lanthanides of approximately 2.5. The "apparent $Z$ " of yttrium in a system 0.75M HDEHP/ toluene/0.5 $\mathrm{M} \mathrm{HCl}$ is 67.5. Small amounts of the monoester, however, perturb the relationships seriously by increasing the extraction of the lighter rare earths markedly. Their data are presented in Fig. 51. They consider the analogy of HDEHP to TTA as valid, the extractable species being
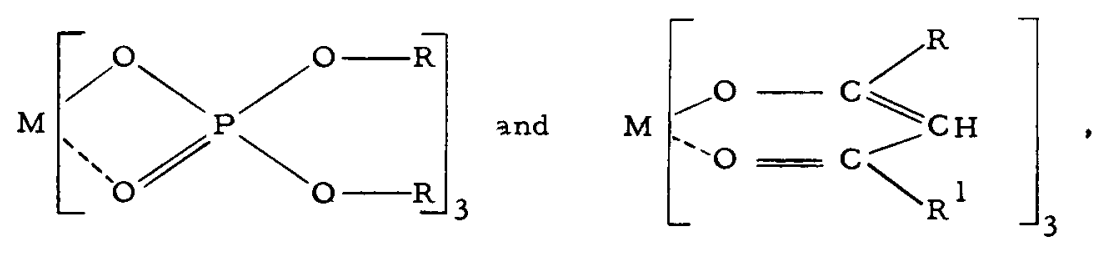

respectively. HDEHP has the marked advantage that it is useful at much higher acidities than TTA, thus avoiding many difficulties with hydrolysis. Again, however, there is no obvious application to a simple laboratory-scale separation of the individual members of the rare-earth group.

\section{6D-4. Thenoyltrifluoroacetone (TTA)}

Much work has been done on the individual differences in extraction behavior of the rare earths with TTA. Bronaugh and Suttle ${ }^{50}$ published a complete series of TTA equilibrium constants for the rare earths including scandium and yttrium, reproduced in Table 11 . They were unable to obtain a supply of erbium for their research, but the behavior of erbium may be assumed to be intermediate between that of holmium and that of thulium. They reported complete equilibrium was attained in less than five minutes.

Cornish ${ }^{84}$ reported an equilibrium constant of $3.6 \times 10^{-8}$ for dys prosium, which does not agree with that of Bronaugh and Suttle; ${ }^{50}$ Keenan and Suttle 224 report $K=3.3 \times 10^{-9}$ for praseodymium, in good agreement with Bronaugh and Suttle. ${ }^{50}$ Again, there seems to be no simple way of applying the relatively slight differences in extraction behavior to a simple laboratory-scale separation. 


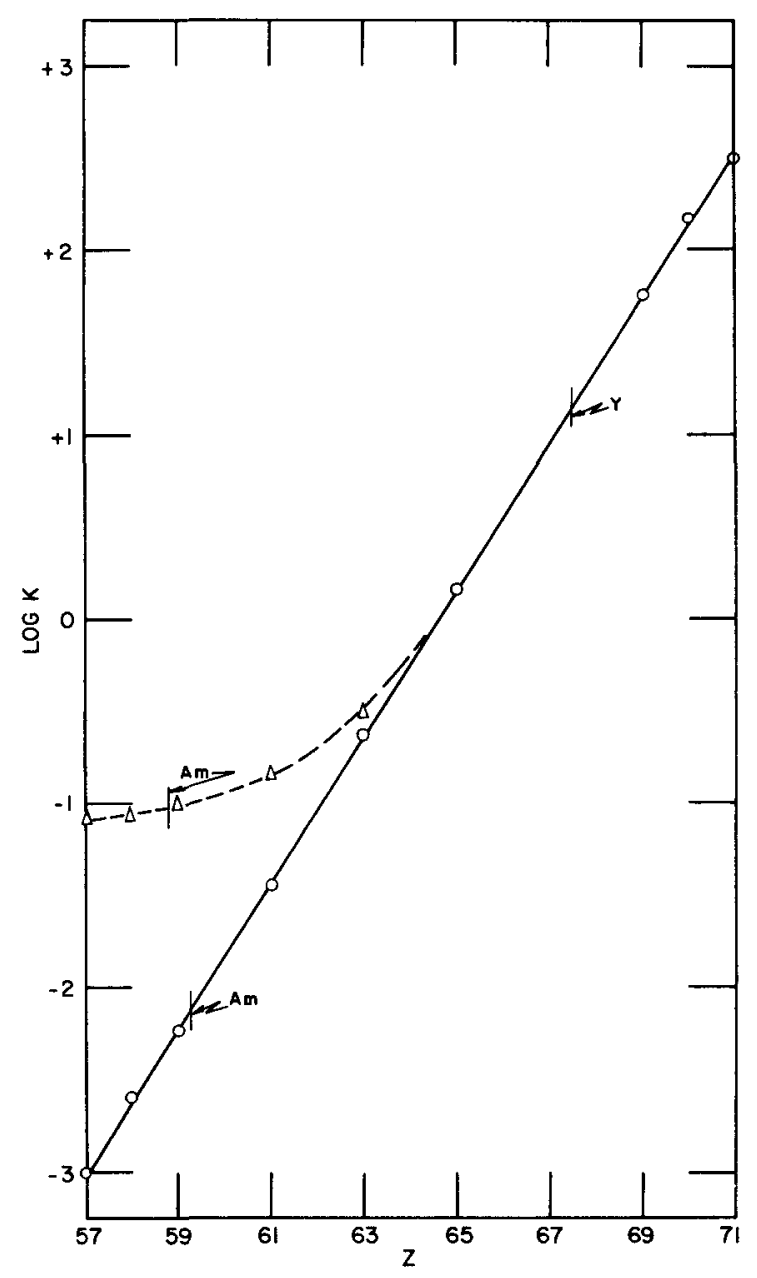

Fig. 51. Variation of the logarithm of the partition coefficient $\mathrm{K}$ with $\mathrm{Z}$ in the $0.75 \mathrm{M}$ HDEHP - $0.5 \mathrm{M} \mathrm{HCl}$ system, yttrium and americium shown on the curve. Broken curve shows the effect of mono(2-ethyl hexyl) ortho phosphoric acid contaminant (359)

\section{6E. SOLVENT EXTRACTION SEPARATIONS OF CERIUM(IV) \\ IV. $6 \mathrm{E}-1$. Nitrates}

The first reported solvent extraction separation of ceric cerium is that of Imre 210 who extracted ceric nitrate into diethyl ether. Bock and Bock 38 studied the extraction of $\mathrm{Ce}(\mathrm{IV})$ into various solvents from nitric acid. They found that cerium extracts well into diethyl ether from nitric acid more concentrated than 4.5M. Di isopropyl ether, di-n-butyl ether, methyl n-propyl ketone and nitromethane were less effective as solvents. Scandium was found to extract fairly well $(\mathrm{K} \approx 5)$ from 1 molar nitric acid saturated at elevated temperature $\left(\approx 35^{\circ} \mathrm{C}\right)$ with lithium nitrate. Lanthanum did not extract under these conditions. They also reported that thorium would extract into ether 
Table 11. Average $K_{e q}$ values for the reaction $M^{+3}$ (aqueous) +3 TTA (organic) $\rightleftarrows \mathrm{M}(\mathrm{TTA})_{3}$ (organic) $+3 \mathrm{H}^{+}$(aqueous) $(50)$

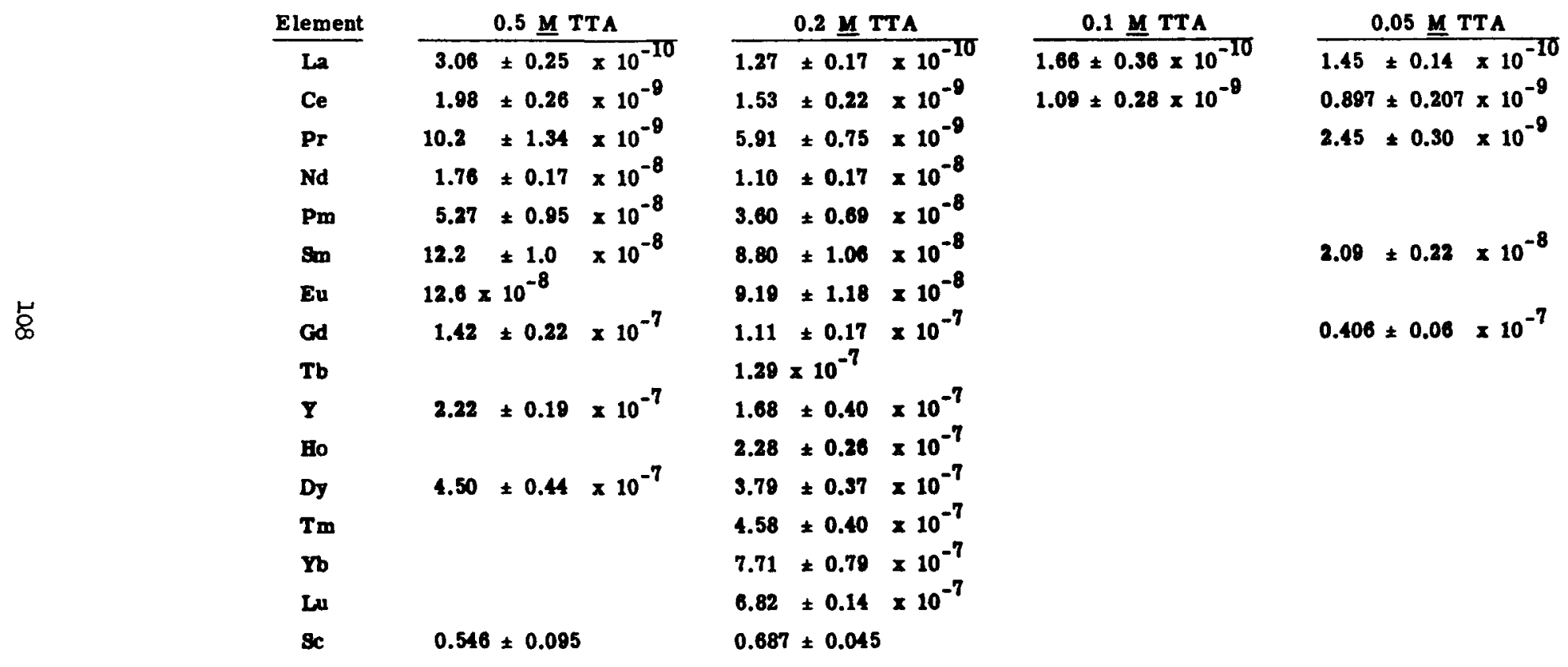


from 1 molar nitric acid salted with nitrates of zinc, calcium, or lithium, but hardly at all when salted with nitrates of sodium, potassium, ammonium, strontium, or barium. No explanation is given this cation effect.

They also note the necessity for removing peroxides from diethyl ether prior to use in order to avoid the possibility of explosion.

Wylie 541 confirmed the results of Bock and Bock ${ }^{38}$ and also reported that the reduction of cerium(IV) during extraction was photocatalyzed. He examined butyl, amyl, and benzyl ethers and various ketones and reported that diethyl ether was superior to all solvents examined. He verified the results of $\mathrm{Warf}^{510}$ on the extraction of Ce(IV) by TBP; he also reported contamination of the TBP phase by trivalent lanthanides. He reports that Ce(IV) does not extract into ether from ammonium nitrate solutions.

Liang and $\mathrm{Yeh}^{269}$ report good extraction of $\mathrm{Ce}(\mathrm{IV})$ into butyl acetate from 7-10 molar nitric acid.

Glendenin, Flynn, Buchanan, and Steinberg ${ }^{174}$ give the distribution coefficient for $\mathrm{Ce}(\mathrm{IV})$ between nitric acid and hexone (methyl isobutyl ketone) as a function of nitric acid molarity. Their data show maximum distribution coefficient of 3.0 between 8 and 10 molar nitric acid. This solvent is obviously inferior to diethyl ether.

Klinaev and Senyavin, 234 and Vickery 502 have both reported separations of $\mathrm{Ce}(\mathrm{IV})$ from trivalent lanthanides by diethyl ether extraction from nitric acid.

Brezhneva and co-workers ${ }^{45}$ used nitromethane as a solvent to extract fission-product cerium on a large scale away from the other lanthanides and strontium. The aqueous phase was 3-5 molar in nitric acid and 3-4 molar in calcium nitrate. They used ozone for an oxidant. Nitromethane has the advantage of being extremely resistant to ozone oxidation.

IV. 6E-2. Tributyl Phos phate (TBP)

According to Knapp. Smutz, and Spedding, 236 ionic size affects the ease of extraction with TBP very markedly. One would therefore expect the ceric ion to be much more extractable than any trivalent lanthanide ion. This expectation is fulfilled, as shown by Nikolaev, Sorokina, and Maslennikova 337 and by the previously cited work of $W$ arf 510 and Wylie. ${ }^{541}$ The Russian group extracts cerium from 6-8 molar nitric acid containing bromate ion, using pure TBP. They report $95 \%$ extraction.

As seen from the data on the trivalent lanthanides, however, TBP extraction is probably inferior to ethe $\mathbf{r}$ extraction as a purification process for cerium. Douglass and Bauer, ${ }^{550}$ however, have written an excellent article on the liquid-liquid extraction of cerium from bastnasite ore concentrate; $a$ process in which they preferred TBP to ether as the extracting medium. 
Brown, Coleman, Crouse, Denis, and Moore 52 reported the extraction of ceric cerium with a distribution coefficient greater than 50, using a longchain primary amine (Carbon and Carbide Chemical Company amine \#21F81) in 0.1 molar solution in a hydrocarbon diluent. The aqueous phase was 1.0 molar in sulfate ion, adjusted to $\mathrm{pH}$ between 0.3 and 1.8. Their results with secondary and tertiary amines were inconclusive. Trivalent lanthanides did not extract appreciably.

IV. 6E-4. Di(2-ethyl hexyl) Phosphoric Acid (HDEHP)

Peppard, Mason, and Moline 357 showed that ceric ion could be extracted from 10 molar nitric acid by 0.75 molar or 0.30 molar HDEHP in heptane. The ratio of distribution coefficients for $\mathrm{Ce}$ (IV)/Ce(III) was greater than $10^{6}$. They used the extraction to prepare a highly purified cerium sample, essentially free of lanthanide contaminants, and to separate cerium target material from $\operatorname{Pr}^{143}$ and $\mathrm{Pr}^{144}$ daughter activities (by a factor of $10^{7}$ ) in less than ten minutes. This reagent appears to be potentially very useful.

IV. 6E-5. Thenoyltrifluoroacetone (TTA)

Smith and Moore 443 reported a rapid separation from fission products based on the very high extractability of the $\mathrm{Ce}(\mathrm{IV})$ ion by TTA. They extract from 1 molar sulfuric acid containing potassium dichromate and sodium bromate, using 0.5 molar TTA in xylene, and back-extract the cerium with 10 molar nitric acid. They report severe interference from chloride ion, which effectively prevents the oxidation.

IV. 6F. SOLVENT EXTRACTION SEPARATIONS OF SCANDIUM IV. $6 \mathrm{~F}-1$. Nitrate

Bock and Bock 37 remarked that "under certain conditions" scandium nitrate was extractable into diethyl ether, but conditions were not given. IV. $6 \mathrm{~F}-2$. Thiocyanate

The most specific separation for scandium from trivalent lanthanides makes use of the solvent extraction of the thiocyanate into ether. Fischer and Bock, 137 in their classic article on the chemistry of scandium, recommend the following conditions: 0.5-1.0 molar hydrochloric acid, $53 \mathrm{~g}$ of ammonium thiocyanate per hundred $\mathrm{ml}$ of solution. Scandium will extract $\approx 95 \%$ into an equal volume of diethyl ether. Sulfate, and especially phosphate, interfere markedly. Beryllium, aluminum, indium, and ferric iron c tract quite well; other lanthanons extract less than $0.1 \%$. Bock ${ }^{39}$ confirmed the results of Fischer and Bock ${ }^{137}$ and reported data on many other 
elements. He reported very slight extraction of $\mathrm{Li}, \mathrm{NH}_{4}, \mathrm{Cd}, \mathrm{Ni}$, and $\mathrm{Pd}$; slight extraction ( $\approx 2 \%$ ) of $\mathrm{Cu}(\mathrm{I})$ and $\mathrm{Sb}(\mathrm{III})$; moderate extraction of $\mathrm{Fe}(\mathrm{III})$, $\mathrm{Al}, \mathrm{In}, \mathrm{UO}_{2}{ }^{++}$; and excellent extraction of $\mathrm{Be}, \mathrm{Zn}, \mathrm{Sc}, \mathrm{Ga}, \mathrm{Sn}(\mathrm{IV}), \mathrm{Mo}(\mathrm{V})$, and $\mathrm{Co}$. Some results confirming some of the above information have been reported by West ${ }^{531}$ and by Vickery. ${ }^{508}$ Vickery ${ }^{502}$ also regards the thiocyanate extraction as the best single separation technique from the lanthanides.

IV. 6F - 3. Tributyl Phosphate (TBP)

Scandium is markedly more extractable into TBP than the other trivalent lanthanides. Peppard, Mason, and Maier ${ }^{356}$ studied the extraction of scandium, thorium, and zirconium by TBP from nitric acid and from hy drochloric acid. Their data are presented in Figs. 52 and 53 . It can be seen that scandium can be well separated from thorium by extraction with $100 \%$ TBP from 8.1 molar hydrochloric acid where for scandium $K \approx 100$, for thorium $\mathrm{K} \approx 0.5$; or by extraction with $100 \%$ TBP from 2 molar nitric acid, where for scandium $K \approx 0.5$, for thorium $K \approx 20$. In the TBP-HCl system, the behavior of zirconium is nearly identical to that of scandium; in the TBP-HNO 3 system, the data are not very complete, but a separation from zirconium would seem to be difficult with $100 \%$ TBP. With $25 \%$ TBP the authors report that approximate measurements on zirconium (not shown in the figure) show zirconium to be more extractable than thorium from both 4 molar and 6 molar nitric acid. Under these conditions scandium extracts poorly; a separation is therefore possible.

Eberle and Lerner 122 also used the hydrochloric acid - TBP extraction system to separate a pure sample of scandium for analysis. They present data which is in essential agreement with that of Peppard, Mason, and Maier. ${ }^{356}$ Their data have been included in Fig. 52 for comparison, but since they did not pre-equilibrate their solvent with acid, perfect agreement is not to be expected. They report good separation from yttrium, using equal volumes of concentrated hydrochloric acid and "as received" TBP. According to $G$ al and Ruvarac, $16330 \%$ TBP in dibutyl ether will extract $\mathrm{Cd}, \mathrm{VO}_{3}, \mathrm{Fe}(\mathrm{III}), \mathrm{Zr}$ and $\mathrm{UO}_{2}{ }^{++}$ions from hydrochloric acid; these species and others may be expected to accompany scandium in a TBP-HCl extraction separation.

Peppard and Nachtman 360 have obtained a patent on a separation of scandium from the lanthanides and yttrium by solvent extraction with TBP from 6 molar hydrochloric acid.

IV. 6 F - 4. Thenoyltrifluoroacetone (TTA)

Because of its very small ionic size, scandium is very efficiently ex- 


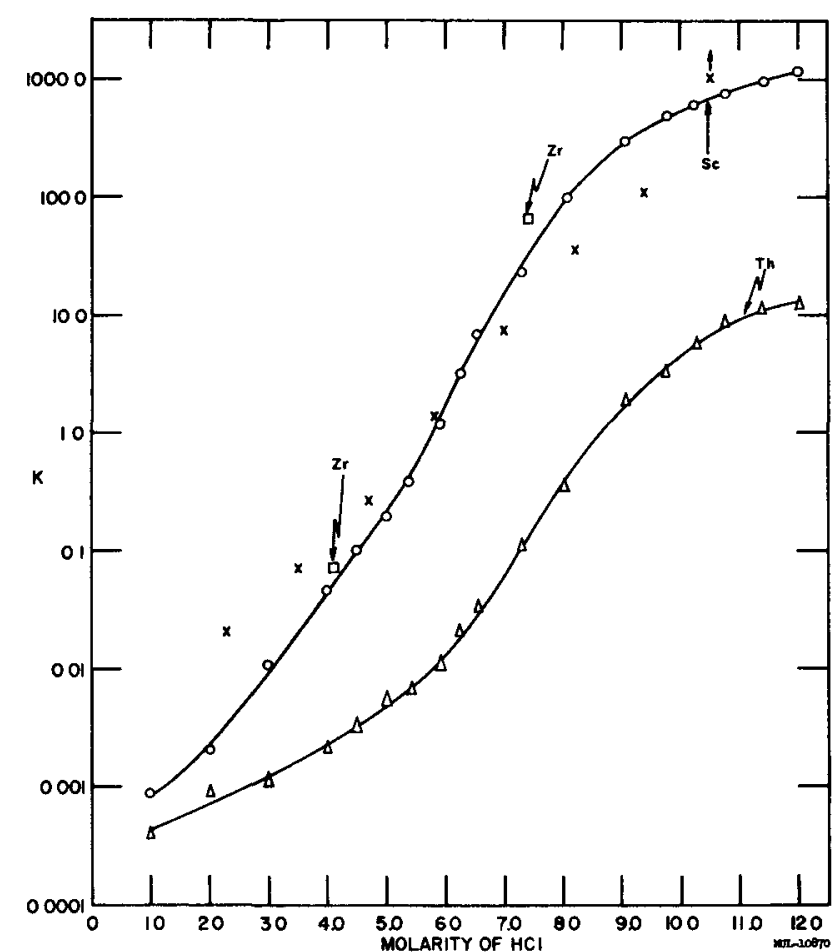

Fig. 52. Variation of the distribution ratios of $\mathrm{Sc}, \mathrm{Th}$, and $\mathrm{Zr}$ with aqueous $\mathrm{HC} 1$ concentration using $100 \%$ TBP. (The approximate TBP concentration varies nearly linearly from $3.4 \mathrm{M}$ at $1,0 \mathrm{M} \mathrm{HCl}$ to $2.8 \mathrm{M}$ at $11.4 \mathrm{M} \mathrm{HCl}$.)

O, $\square, \bar{\Delta}$ Data of Peppard et al. (356)

$\times$ Data of Eberle et al. on Sc (122)

Curve drawn through data of Peppard et al.

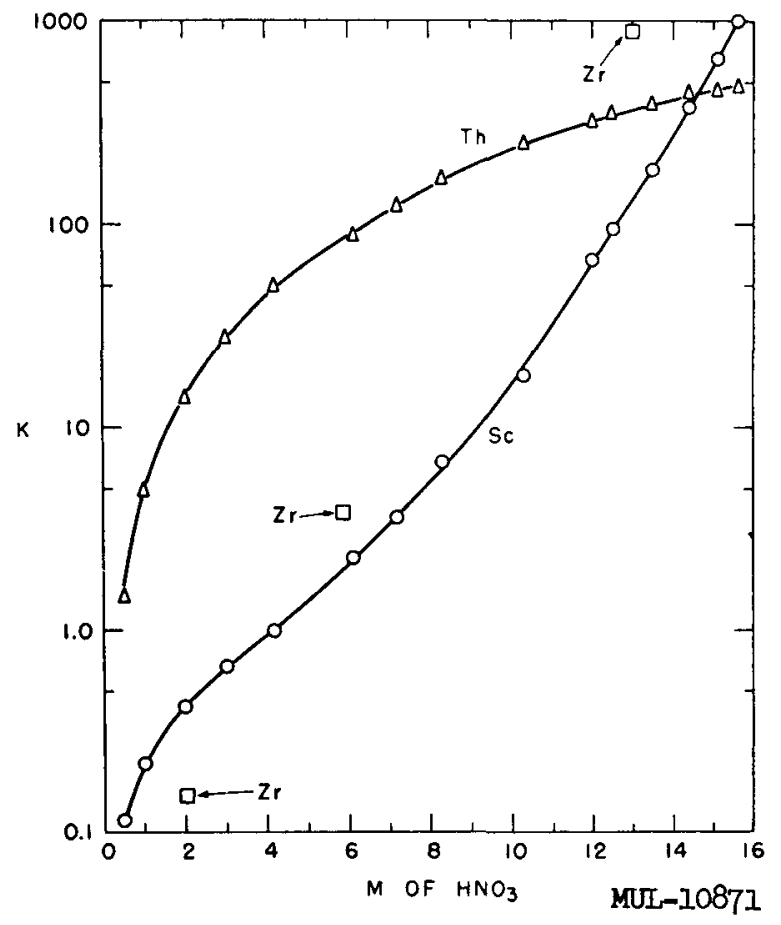

Fig. 53. Variation of distribution ratios of $\mathrm{Sc}, \mathrm{Th}$, and $\mathrm{Zr}$ with aqueous $\mathrm{HNO}_{3}$ concentration using $100 \%$ TBP (the approximate TBP concentration varies nearly linearly from $3.5 \mathrm{M}$ at $0.5 \underline{\mathrm{M}} \mathrm{HNO}_{3}$ to $2.7 \underline{\mathrm{M}}$ at $\left.16 \underline{\mathrm{M}} \mathrm{HNO}_{3}\right)(356)$ 
tracted by TTA. Reference to the section on TTA extraction of the rareearth group, especially to Table 11 and Fig. 37, will give conditions for separation of scandium from most elements with TTA.

IV. $6 \mathrm{~F}-5$. Acetylacetone

Vickery 508 reports that scandium acetylacetonate will extract into ethyl acetate from solutions of $\mathrm{pH} 4.5$, but he regards the thiocyanate extraction as superior.

IV. $6 \mathrm{~F}-6$. Cupferron

Miller ${ }^{311}$ and Eberle and Lerner ${ }^{122}$ have removed impurities from scandium by extracting cupferrates into chloroform from mineral acid solutions. Scandium does not extract.

IV. $6 \mathrm{~F}-7$. Salicylate

The interesting behavior of scandium on extraction with salicylic acid in isoamyl alcohol has already been referred to (see section IV.6B above). IV. 6G. SZILARD-CHALMERS REACTION FOR THE RARE EARTHS

An application of solvent extraction to permit a Szilard-Chalmers reaction on the rare earths was reported by Herr. 194 He condensed excess phthalodinitrile with rare-earth chlorides at $320^{\circ} \mathrm{C}$ to make blue $-\mathrm{green}$ compounds, soluble in concentrated sulfuric acid and in certain organic solvents. Excess reagent was removed by subliming it off at $100^{\circ} \mathrm{C}$.

The compounds so prepared could be purified by precipitating them from sulfuric acid by adding water, or from solvents such as quinoline or benzonitrile by adding diethyl ether. They were apparently completely nonexchangeable; after neutron irradiation, $80 \%$ of the activity could be removed from quinoline solution with $5 \%$ sulfuric acid containing sodium citrate. The aqueous phase contains only about $10^{-4}$ of the rare earth. This technique appears to offer great promise as a means of preparing high-specific-activity lanthanide tracers.

IV. 7. ION EXCHANGE

IV. 7A. INTRODUCTION

IV. 7A-1. Review

During the past fifteen years the ion exchange process has developed into the most powerful single method for separating the rare-earth elements from each other. An extraordinary number of articles have appeared in the literature describing techniques which involve a wide variety of ion exchange media and a bewildering assortment of experimental conditions. In this sec- 
tion an attempt will be made to present a reasonably balanced picture of these techniques in their most modern refinements. It must be realized at the outset, however, that the ion exchange separation process has inherent in it such a tremendous flexibility that it is almost always possible to establish experimental conditions which will be distinctive to a given separation problem. These conditions will usually be chosen in such a way as to give the best possible separation in the shortest possible time with the least possible effort. With these conditions in mind, data in this section will be presented in such a way that the reader should be able to make a reasonable choice of the optimum conditions for any radiochemical separation problem.

Ion exchange materials have received such general acceptance as a useful tool in the analysis or separation of the whole periodic table of elements that it seems reasonable to assume that all practicing chemists are familiar with their history and basic properties. Those in whom this assumption is not well founded we refer to an excellent little book by Kitchener 231 or the somewhat older book by Samuelson. ${ }^{405}$ Nachod, 327,328 Osborn, 349 Kitchener, 232 and the Faraday Society ${ }^{79}$ have published several books which include background material on the theory, structure, and properties of ion exchange materials. A series of papers published in the Journal of the American Chemical Society, 277 while not a book, may properly be considered as prime source material on the fundamental properties of ion exchange resins. Numerous articles have appeared in the literatures reviewing the field of ion exchange as a whole. Thomas and Frysinger, ${ }^{478}$ Tompkins, ${ }^{483}$ Hale, ${ }^{185}$ and Hudgens 207 have been authors of excellent articles in this category. Also, many articles have appeared which review the use of ion exchange in the separation of the rare-earth elements. Since it is intended that this paper will supersede earlier reviews, their data, where pertinent, will be included in later sections on specific techniques.

IV. 7A-2. Effect of Variables in Ion Exchange

There are literally an infinite number of experimental conditions under which the rare earths may be separated by ion exchange methods. When a chemist approaches the problem of choosing a set of conditions which will give him a desired result he should know qualitatively how his results may be affected by major experimental variables such as kind and brand of resin, mesh size and cross linkage, eluant, flow rate, temperature, mass of the sample to be separated, etc.

Choice of an ion exchange medium is obviously an important first step in any ion exchange procedure. When ion exchange materials were first being used for rare-earth separations there were very serious fluctuations in the quality and performance of the products which were commercially available. 
It was accepted as more or less standard practice that an experimenter had to purchase a single large batch of ion exchange resin, for instance, and use it exclusively if he wished to get consistent results. Variation in the performance of different batches of the same resin produced by the same manufacturer were often great enough to make one batch quite satisfactory and another completely worthless for a given separation. Happily, this situation has been corrected, at least for the synthetic ion-exchange resins, to such a point that the chemist may expect reasonably consistent performance from any given brand of resin. It is still wise, however, to check each new batch to be sure that it will perform as expected.

For separations involving elements as closely similar as the rare earths the ideal ion-exchange medium should have a large number of exchange sites per unit volume (high capacity), it should be chemically inert, thermally stable, adaptable to a wide variety of experimental conditions, reasonably inexpensive, and available.

The sulphonated styrene-divinylbenzene cation-exchange resins (Dowex-50, Nalcite HCR, Amberlite IR-120, KU-2, etc.) meet these requirements admirably and have been used most extensively in the ion exchange separation of the rare earths. The quaternary-amine styrenedivinylbenzene anion-exchange resins (Dowex-1, Dowex-2, Amberlite IRA400 , etc.) are equally satisfactory in those systems where anionic species are being separated.

Other types of exchangers such as cellulose or the inorganic zeolites have found some special applications but they have not proven to be as versatile as the exchange resins. The usual drawback is that their low capacity requires either separations on a carrier-free scale or equipment that is too bulky to be handled easily.

In the overwhelming majority of experiments which involve the ion exchange separation of radiochemical mixtures of rare earths the main goal is isolation of pure individual rare-earth elements in as short a time as possible. Important factors which affect the purity of product and the column operating time for a given separation problem are:

a. Columinsize. The area and length of an ion exchange column will usually be determined by the mass of the sample to be separated. Modern cation-exchange resins such as Dowex-50 have an exchange capacity of approximately $5 \mathrm{meq} / \mathrm{g}$ (dry) or $1.9 \mathrm{meq} / \mathrm{ml}$ (wet). As the weight of carrier is increased, the volume of resin needed to retain the initial loading of rare earths before elution increases proportionately. Tompkins, Harris, and Khym, 482 investigating the effect of a number of column variables, concluded 
that the width of an individual rare-earth elution peak (expressed in column volumes) varies as the logarithm of the column area, while the logarithm of peak width varies inversely as the square root of the column length. Thus the column should be as long and narrow as possible, consistent with other requirements of the separation. The authors have found it a useful rule of thumb to make the column length at least fifty times its diameter and to have the initial rare-earth loading occupy no more than five percent of the column length. This will certainly not apply to all separation problems but it will indicate the general range of dimensions that are required. For carrier-free separations of radioactive species the minimum column width is limited more by resin particle size and channeling effects than anything else, and a column of $2 \mathrm{~mm}$ diameter is usually quite adequate.

b. Resin particle size. Ketelle and Boyd ${ }^{226}$ have investigated the effect of resin particle size on the shape of the rare-earth elution peak. Their curve is reproduced in Fig. 54. With all other factors constant, the larger the particle size, the greater the "tailing" of the elution peak, and, for elements which elute close together, the worse the separation. Thus it is advisable to use as small a resin particle as possible, consistent with getting liquid to flow through the column.

c. Cross-linkage. One of the factors which determine the porosity of a resin particle, and thus the accessibility of its exchange sites to migrating ions, is its degree of cross-linking. The lower the cross-linking, the more porous the structure. Thus Dowex-50 with $1 \%$ divinylbenzene cross-linking is an almost colorless bead which looks very much like a gel in aqueous solution, while $16 \%$ cross linked Dowex-50 is a very hard, almost black material. The lower cross-linked resins, however, have the undesirable property of changing volume markedly as the acidity of the solution is changed. Thus it is usually expedient to compromise between low cross linking and low swelling by using a resin with about $8 \%$ crosslinking.

d. Flow rate. In their article on column variables, Tompkins, Harris, and Khym 482 show that for a column containing Amberlite IR - 1 cation-exchange resin operating at room temperature, with $5 \%$ citrate as the eluting agent, the width of the elution curve is a discontinuous function of the flow rate. Their data are shown in Fig. 55, and indicate that the width of an elution peak is independent 


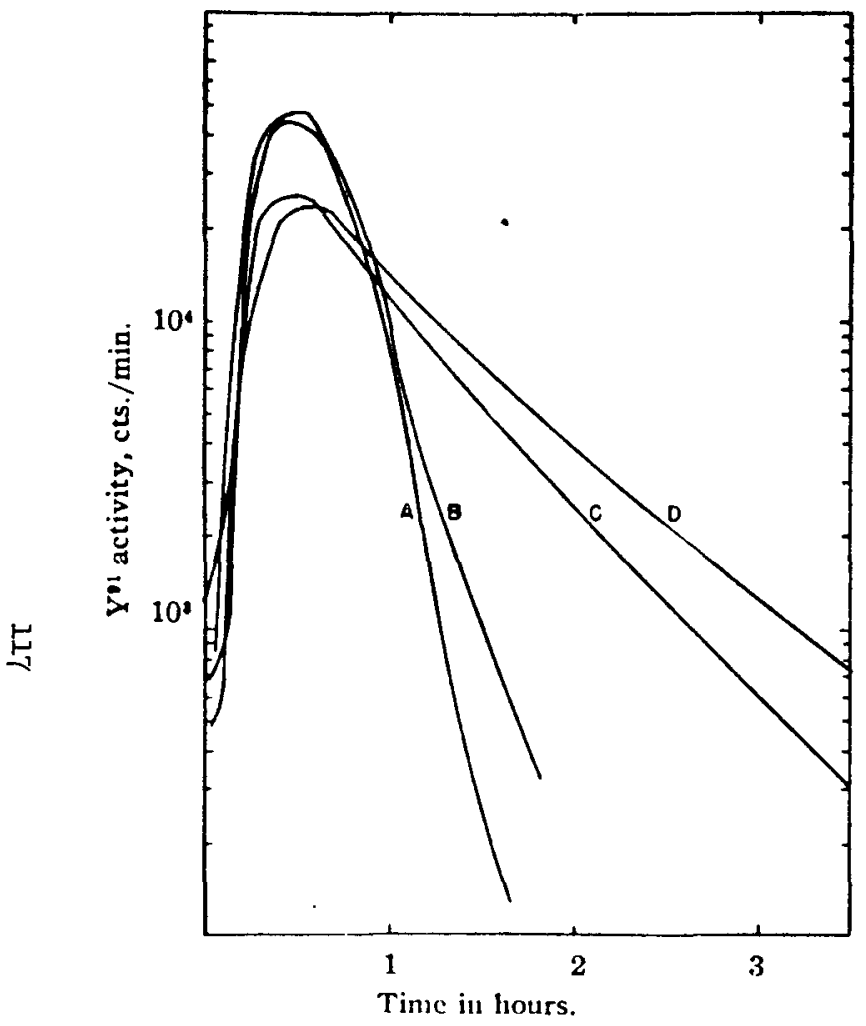

Fig. 54. Effect of mesh size of Amberlite IR-1 on desorption band width:

A, 270/325 mesh; B, 170/200 mesh;

C, 50/60 mesh; D, 30/40 mesh (226)

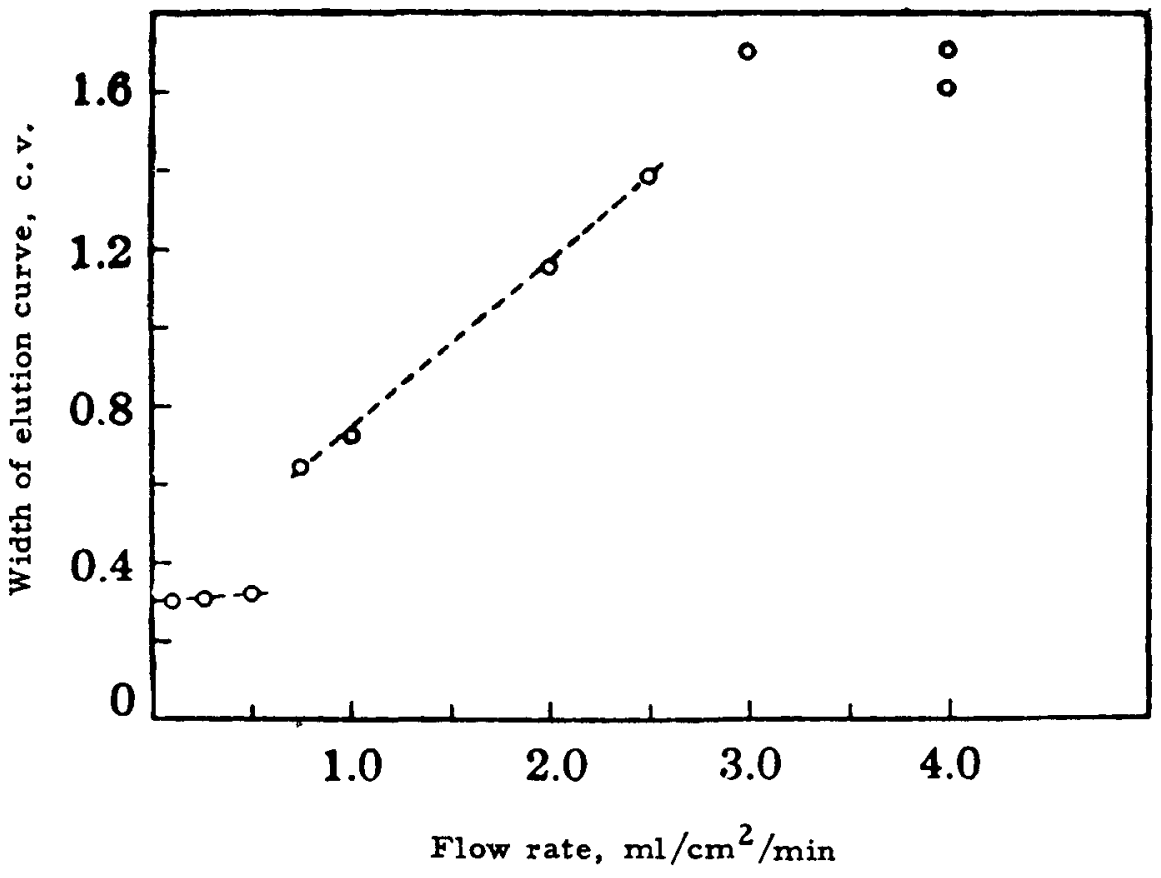

Fig. 55. The variation of the width of the elution curve with flow rate (482) 
of flow rate at very low rates. Above a certain rate, however, the peak width increases as a linear function of the flow rate, while there is a second zone of independence at very high rates. For their experimental arrangement, the point at which the peak width ceased to be independent of flow rate was approximately $0.5 \mathrm{ml} /$ $\mathrm{cm}^{2} / \mathrm{min}$. It seems reasonable to assume that this value can be increased significantly by using high column temperatures or lower cross-linked resins, both of which will increase the equilibration rate, but the qualitative conclusions drawn from the data in Fig. 55 should be applicable to any ion-exchange-resin system.

e. Temperature. Ketelle and Boyd 226 have measured the effect of elevated temperature on the degree of separation of a mixture of rare earths. Their data are reproduced in Fig. 56 and indicate that for a given elution time, columns operated at $100^{\circ} \mathrm{C}$ give narrower elution peaks, and better separation of rare-earth mixtures, than those at $20^{\circ} \mathrm{C}$. Columns running at close to boiling temperatures are liable to prove troublesome, however, because of formation of bubbles which disrupt flow of the eluant through the resin bed. For most applications, therefore, it is expedient to operate at a lower temperature, $80-90^{\circ} \mathrm{C}$ usually being quite satisfactory. Kraus and Raridon 246 have studied the temperature dependence of the cation-exchange equilibria of several elements in the temperature range from 0 to $200^{\circ} \mathrm{C}$. La and Eu are included in the study, and the authors show that there is an inversion in the absorption of these ions by Dowex-50 in the neighborhood of $45-50^{\circ} \mathrm{C}$. At lowe $r$ temperatures $\mathrm{La}$ is more strongly adsorbed than $\mathrm{Eu}$, while at higher temperatures the reverse is true. It should be noted that these effects were observed for simple salt solutions of $\mathrm{La}$ and $\mathrm{E} \mathrm{u}$ in contact with the resin and did not include the effect of complexing agents on the adsorbability of these elements.

f. Mass of the sample. A great many radiochemical problems involve not only the separation of a mixture of rare-earth activities but the separation of a mixture of rare-earth carriers, The choice of experimental conditions which will give an effective separation depends on the atomic number as well as the mass of each of the elements in the mixture. Nervik ${ }^{334}$ has published an elution curve which illustrates the effect of unequal amounts of carrier on the shape of the eluted peaks. The curve is shown in Fig. 57 and represents the elution curve that was obtained from the elution of a mixture of rare-earth activities plus $8 \mathrm{mg}$ of yttrium, $10 \mathrm{mg}$ of europium, $8 \mathrm{mg}$ of neodymium and $2 \mathrm{mg}$ of praseodymium carriers. 


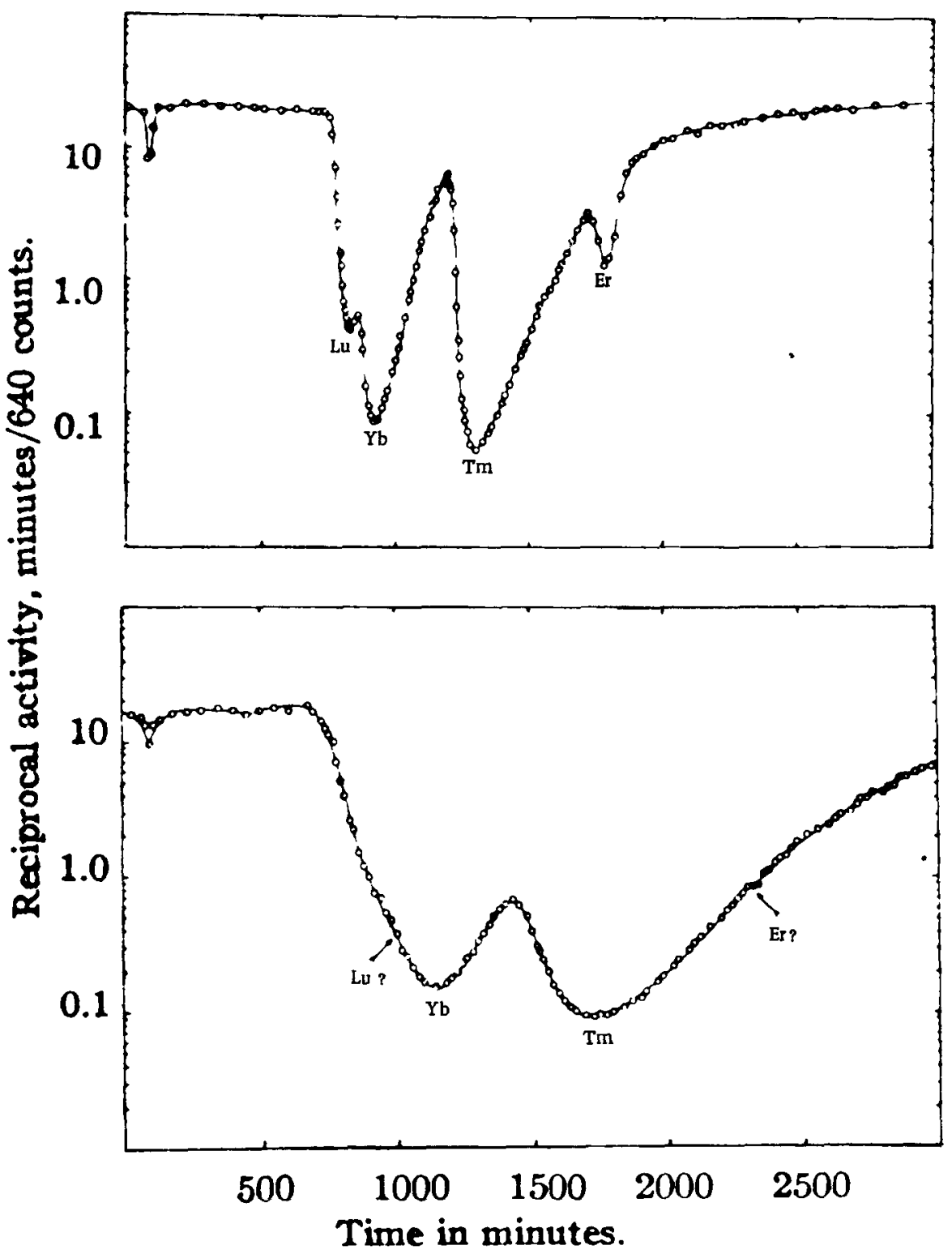

Fig. 56. Effect of temperature on the separation of the yttrium group earths with a $270 / 325$ mesh Dowex-50 column: bed dimensions, $91 \mathrm{~cm}$ by $0.26 \mathrm{~cm}^{2}$; upper curve for $100^{\circ}$, flow rate $0.35-0.45 \mathrm{ml} / \mathrm{cm}^{2} / \mathrm{min}$, and

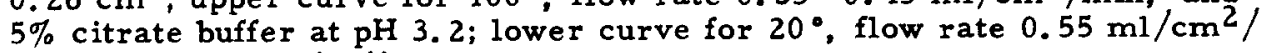
$\min$ and $\mathrm{pH} 2.98 \quad(226)$ 
to

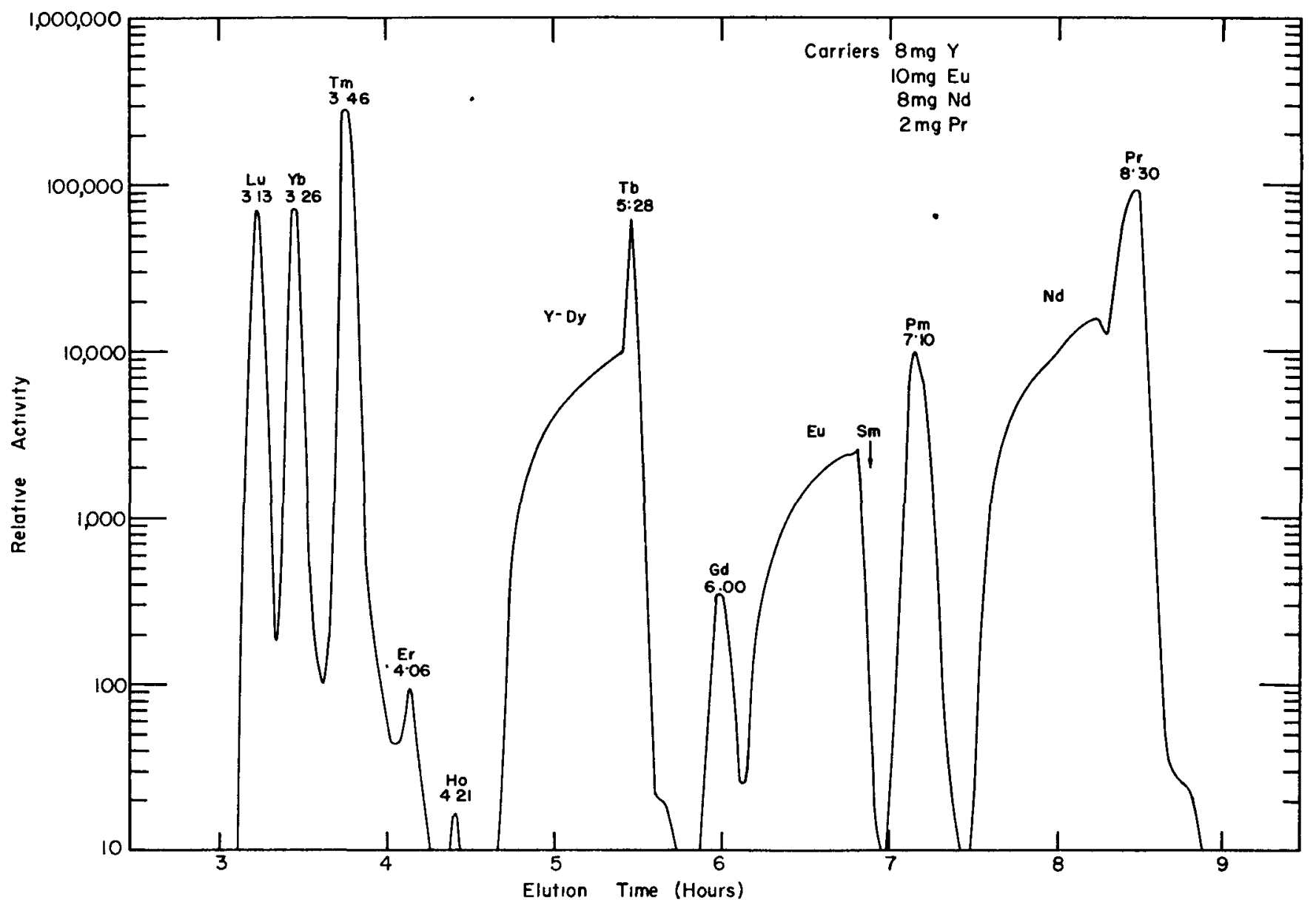

Fig. 57. Elution curve of rare-earth tracer activities plus $8 \mathrm{mg}$ of yttrium, $10 \mathrm{mg}$ of europium, $8 \mathrm{mg}$ of neodymium, and $2 \mathrm{mg}$ of praseodymium carriers; initial pH 3.19, IM lactic acid, pH changed continuously at $0.1 \mathrm{pH}$ unit/hour (334) 
This particular column was operated with the "gradient elution" technique but the conclusions which may be drawn from it apply equally well to more conventional methods. In Fig. 57 the carrierfree elements $L u, Y b$, and $T m$, which have not been perturbed by the presence of carriers, have been eluted in fairly narrow symmetrical peaks with good separation between adjacent elements. The $Y, E u$, and Nd peaks, however, contain the largest amount of carrier and are considerably wider than those for the carrier-free elements. In addition, they affect the elution of following elements to a degree which is dependent on the amount of carrier. Thus the $\mathrm{Sm}$ activity is hidden by the trailing edge of the Eu peak, while the $\mathrm{Tb}$ and $\mathrm{Pr}$ activities can be seen as sharp spikes on the trailing edges of the $Y$ and Nd peaks because their activities were relatively high. If the amount of carriers had been different, i.e., if $30 \mathrm{mg}$ of yttrium were present, one would expect to see more than one element ( $\mathrm{Tb}, \mathrm{Gd}$, and perhaps $\mathrm{Eu}$ ) hidden under the trailing edge of the yttrium peak and not separated at all from one another.

This type of elution curve (Fig. 57) suggests several general rules for operating an ion exchange column with any given mixture of rare-earth activities and carriers:

1. Any mixture of carrier-free rare-earth activities may be separated completely and quickly without difficulty.

2. Any essentially carrier-free rare earth may be easily separated from massive amounts of a rare earth of lower atomic number so long as there are no excessive massive amounts of a rare earth of heavier atomic number present. In Fig. 57, for example, Lu, $\mathrm{Yb}, \mathrm{Tm}, \mathrm{Eu}$ and Ho were separated from relatively large amounts of yttrium. Gadolinium was separated from europium but would not have been pure if larger amounts of yttrium carrier had been present.

3. If a small amount of one rare earth is to be separated from massive amounts of a rare earth of higher atomic number, the most effective method seems to be one in which the column is run under saturation conditions, e.g., the yttrium-terbium separation of Fig. 53. The terbium fraction was not completely free of yttrium after the first run, but the amount of yttrium carrier had been greatly reduced. A second column run on the terbium fraction should then give complete separation of the yttrium and terbium peaks without any significant loss in the total terbium activity.

4. When massive amounts of adjacent rare-earth elements are present 
the chemist has two choices if well-defined peaks are desired. He may either use a wider and longer column to give an "unsaturated" rare earth carrier load per unit area of resin or he may operate a "saturated" column in such a way as to give a "square wave" type of elution curve, i.e., one element following directly behind another as in rule 3 above. This type of operation requires a second column separation if significant amounts of carrier are not to be lost.

From this brief discussion of ion-exchange-column variables it should be apparent that, while the ion exchange resins make possible separations which were out of the question twenty years ago, the separation of the rare earths with ion exchange resins still requires a certain amount of judgment, experience, and experimental skill from the chemist.

A "black art" some call it, but with the present techniques it is usually possible to separate most radiochemical mixtures of rare earths in just a few hours. The main problem is simply one of choosing the proper experimental conditions for a given separation, and in the following sections the more significant techniques will be discussed in greater detail.

IV. 7B. CATION-EXCHANGE RESINS

IV. 7B-1. Introduction

Almost all applications of cation-exchange resins to the separation of the rare-earth elements involve two major steps: a) adsorption of the rareearth mixture by the resin from a solution, and b) selective desorption of individual elements by an appropriate eluting solution.

For the adsorption of a rare-earth ion by a cation-exchange resin the reaction may be written as

$$
\mathrm{M}^{+3}+3 \mathrm{NaR}=\mathrm{MR}_{3}+3 \mathrm{Na}^{+} .
$$

where $M^{+3}$ is the rare-earth ion and $R$ the resin anion. Boyd, Schubert, and Adamson 44 have shown that the equilibrium constant for this reaction may be written

$$
k_{1}=\frac{\left(\mathrm{MR}_{3}\right)\left(\mathrm{MR}_{3}+\mathrm{NaR}\right)^{2}}{(\mathrm{NaR})^{3}} \frac{\left(\mathrm{Na}^{+}\right)^{3}}{\left(\mathrm{M}^{+3}\right)} \text {. }
$$

where $\mathrm{NaR}$ and $M R_{3}$ are expressed in mole fractions for ideal solid solutions and $\left(\mathrm{M}^{+3}\right)$ and $\left(\mathrm{Na}^{+}\right)$are the activities of the ions in solution. For low concentrations of rare-earth ions $\left(\mathrm{MR}_{3}+\mathrm{NaR}\right) \cong \mathrm{NaR}$ and $\mathrm{Eq}$. (2) becomes

$$
\mathrm{k}_{1}=\frac{\mathrm{MR}_{3}}{\mathrm{NaR}} \frac{\left(\mathrm{Na}^{+}\right)^{3}}{\left(\mathrm{M}^{+3}\right)} .
$$


In adsorption processes the value of primary interest is the distribution of the rare-earth ions between the aqueous and resin phases: i.e.,

$$
\mathrm{K}_{\mathrm{d}}=\frac{\mathrm{MR}_{3} / \text { mass of resin }}{\mathrm{M}_{\ell} / \text { volume of soln }}=\frac{\mathrm{MR}_{3}}{\mathrm{M}_{\ell}} \times \frac{\text { vol soln }}{\text { mass resin }},
$$

in which $\mathrm{K}_{\mathrm{d}}$ is the "distribution coefficient" and $M R_{3}$ and $M_{\ell}$ are the amounts of the cation in the resin and liquid phases. For the rare earths, if $M R_{3}, M_{\ell}$, and the mass of the resin are expressed in moles and the volume of solution in liters, Eq. (4) may be written

$$
\mathrm{K}_{\mathrm{d}}=\frac{\mathrm{MR}_{3}}{\mathrm{NaR}} \times \frac{\mathrm{V}}{\mathrm{M}_{\ell}}=\frac{\mathrm{MR}_{3}}{\mathrm{NaR}} \times \frac{1}{\left(\mathrm{M}^{+3}\right)},
$$

where $\left(M^{+3}\right)$ is the concentration of the rare-earth ion. Substitution of $\left(M^{+3}\right)$ from Eq. (3) in Eq. (5) gives

$$
\mathrm{K}_{\mathrm{d}}=\mathrm{c} \frac{\mathrm{k}_{1}}{\left(\mathrm{Na}^{+}\right)^{3}} \text {. }
$$

where $c$ is a proportionality constant. Since the distribution coefficient decreases as the third power of the ( $\mathrm{Na}$ ) concentration, and since all cations in the aqueous phase compete with the rare-earth ions for the resin exchange sites, transfer of the rare-earth material to the resin is best done in a solution of very low ionic strength.

In addition to varying with ionic strength, the distribution coefficient for a given rare earth can very markedly with rare-earth concentration.

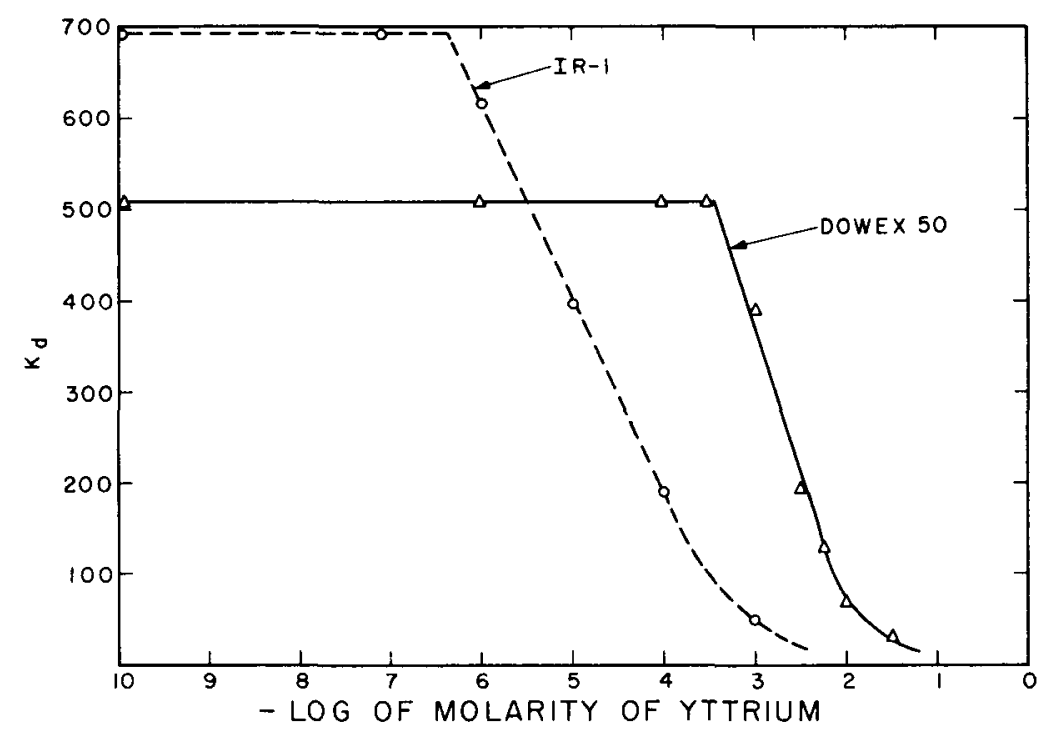

Fig. 58. Variation of the $\mathrm{K}_{\mathrm{d}}$ with concentration of rare earth, $0.5 \mathrm{M} \mathrm{NH}_{4} \mathrm{ClO}_{4}$ solution, Dowex-50 resin, 40-60 mesh, $\mathrm{NH}_{4}^{+}$form (481) 
Tompkins and Mayer, ${ }^{481}$ whose data are reproduced in Fig. 58, show that in $0.5 \mathrm{M} \mathrm{NH}_{4} \mathrm{ClO}_{4}$ solutions at room temperature the $\mathrm{K}_{\mathrm{d}}$ for yttrium on Dowex-50 remains constant until the yttrium concentration increases to approximately $3 \times 10^{-4} \mathrm{M}$, at which point the $\mathrm{K}_{\mathrm{d}}$ begins to decrease very rapidly. With Amberlite IR-1 resin the $\mathrm{K}_{\mathrm{d}}$ begins to decrease at an yttrium concentration of $4 \times 1 \cdot 0^{-7} \mathrm{M}$. A similar type of behavior was noted for $\mathrm{Ce}^{+3}$ and $\mathrm{Pr}^{+3}$ by the same authors, and presumably occurs with all the rare earths. It is well to keep this phenomenon in mind when adsorption must be done out of solutions of high ionic strength, where a $\mathrm{K}_{\mathrm{d}}$ that has been depressed by the salt concentration may be depressed still further by too high a rare earth concentration.

For a given resin in a solution of given composition each of the rare earths will have a distribution coefficient that differs slightly from the others.

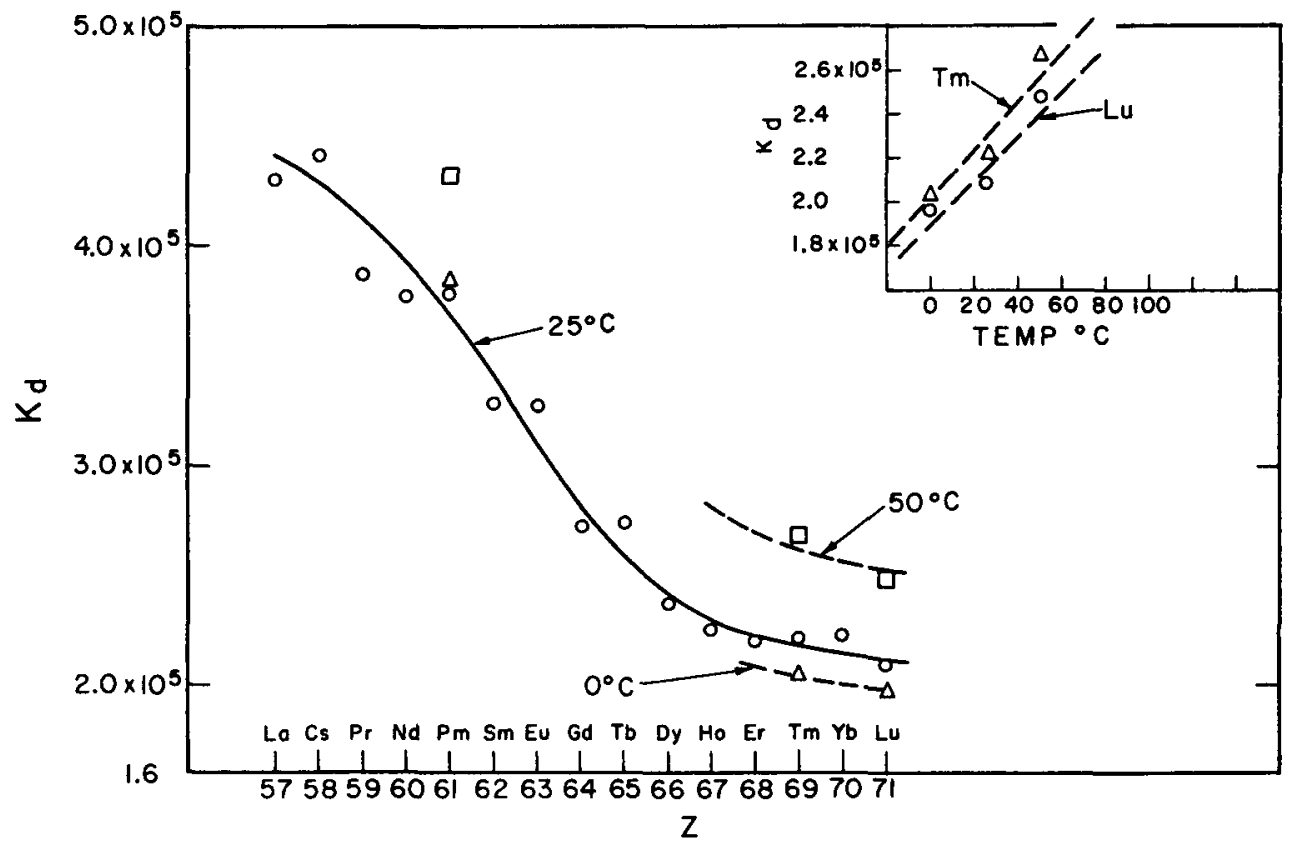

Fig. 59. Log $K_{d}$ vs atomic number, Dowex-50, $0.5-1 \mathrm{~cm} / \mathrm{min}$ settling rate, $4 \%$ cross-linked, in $0.1 \mathrm{M}^{-} \mathrm{HClO}_{4}$. Inset - temperature dependence of $\mathrm{K}_{\mathrm{d}}$ (470)

Surls and Choppin 470 have measured the adsorption of various rare earths on Dowex-50 resin in $0.1 \mathrm{M} \mathrm{HClO}_{4}$ solutions. Their data have been plotted in Fig. 59 and indicate that there is approximately a factor of two difference between the distribution coefficients of the lightest and the heaviest rare earths, with the lower $Z$ rare earths being most strongly held by the resin. The curve of $K_{d}$ vs atomic number is not linear, although there is a gradual decrease in $K_{d}$ from $L a$ to Dy. Between Dy and Lu, however, the distribution coefficient remains practically constant. 
The distribution coefficient does not seem to vary too much with temperature, increasing approximately $10 \%$ for each $20^{\circ}$ rise in temperature, and indications are that this behavior is reasonably uniform for all the rare earths .

In most radiochemical applications of cation-exchange resins to the separation of the rare earths the initial step involves transfer of all of the rare-earth material to the resin. Equilibration is carried out, at elevated temperatures if possible, in solutions whose ionic strength is as low as is practicable. Instead of achieving a separation in the adsorption step every attempt is made to have a small, uniform band of activity deposited at the top of the ion exchange column.

The actual separation of the rare-earth mixture is then carried out by the selective desorption of individual elements by an appropriate eluting agent. The simplest type of desorption process is one in which an appropriately high concentration of a cation such as $\mathrm{H}^{+}$is used to displace the rare-earth elements from the ion exchange sites and advantage is taken of the small differences in $\mathrm{K}_{\mathrm{d}}$ shown in Fig. 59 to effect the separation.

Several authors $479,104,466$ have published data on the use of hydrochloric acid as an eluting agent in separations of this sort. The curves of Diamond, Street, and Seaborg 104 are reproduced in Fig. 60 and indicate that separation of certain mixtures of rare earths may be achieved by this method. The small $\mathrm{K}_{\mathrm{d}}$ differences between adjacent rare earths, however, preclude their separation by such a simple elution technique and recourse must be taken to eluting solutions which contain complexing agents.

\section{7B-2. Citric Acid}

The complexing agent which received the earliest and most intensive study as an eluting agent for the separation of the rare earths was citric acid. When citric acid is added to a solution of a rare earth in equilibrium with resin the distribution of rare earth between the solution and resin is changed because of the formation of the rare earth-citrate complex. Since citric acid has three ionized forms,

$$
\begin{array}{ll}
\mathrm{H}_{3} \mathrm{Cit}=\mathrm{H}^{+}+\mathrm{H}_{2} \mathrm{Cit}^{-} & \mathrm{K}_{8}=\frac{\left[\mathrm{H}^{+}\right]\left[\mathrm{H}_{2} \mathrm{Cit}^{-}\right]}{\left[\mathrm{H}_{3} \mathrm{Cit}\right]}, \\
\mathrm{H}_{2} \mathrm{Cit}^{-}=\mathrm{H}^{+}+\mathrm{HCit}^{-} & \mathrm{K}_{9}=\frac{\left[\mathrm{H}^{+}\right]\left[\mathrm{HCit}^{-}\right]}{\left[\mathrm{H}_{2} \mathrm{Cit}^{-}\right]}, \\
\mathrm{HCit}^{-}=\mathrm{H}^{+}+\mathrm{Cit}^{\equiv} & \mathrm{K}_{10}=\frac{\left[\mathrm{H}^{+}\right]\left[\mathrm{Cit}^{\equiv}\right]}{\left[\mathrm{HCit}^{-}\right]},
\end{array}
$$



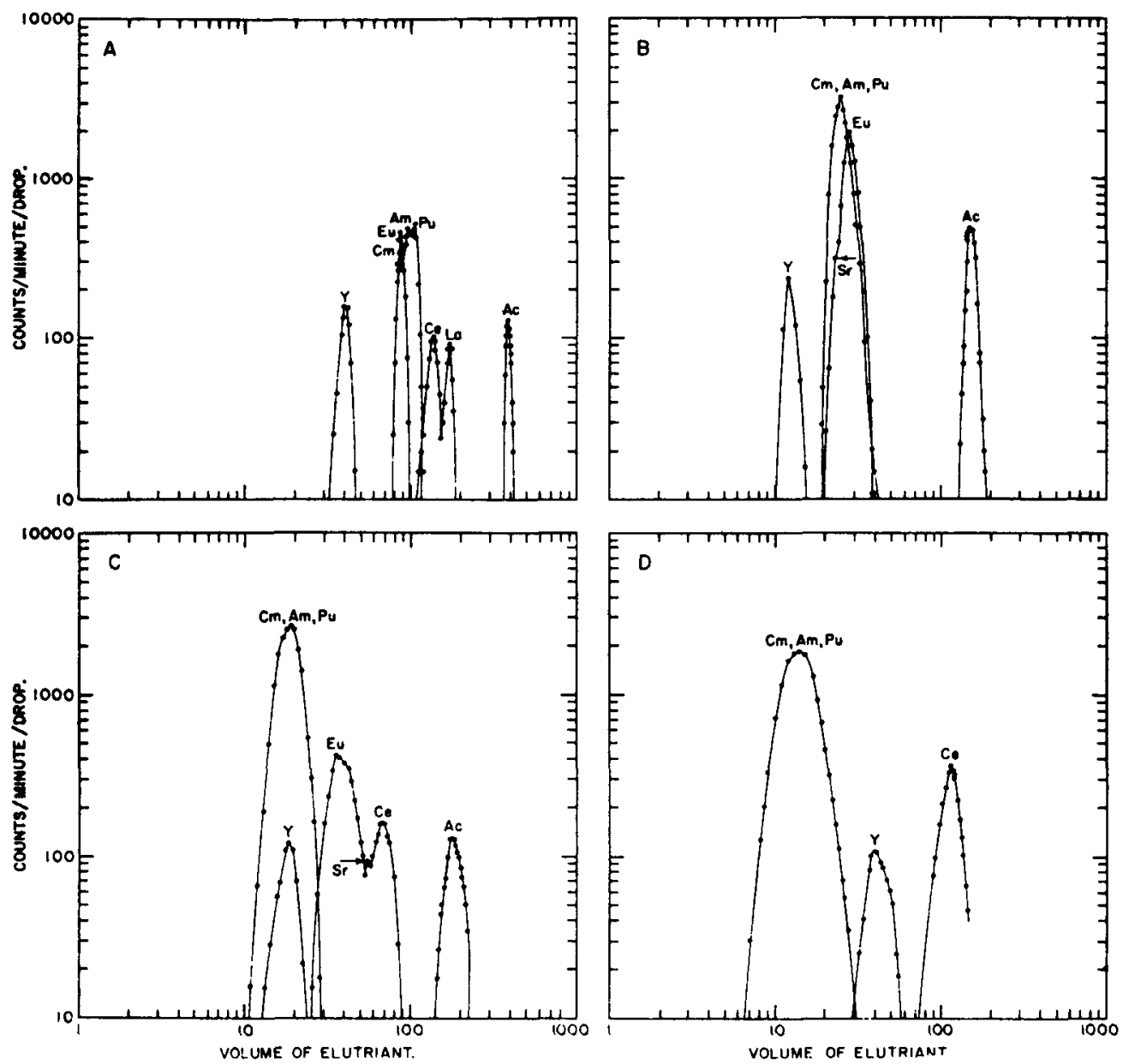

Fig. 60. Elution of lanthanides and actinides from Dowex-50 cation-exchange resin with $\mathrm{HCl}$. Columns $10 \mathrm{~cm} \times 1-1.5 \mathrm{~mm}$; Dowex $-50, \mathrm{H}^{+}$form, 250-500 mesh, wet graded settling rate approximately $0.5 \mathrm{~cm} / \mathrm{min}$; room temperature; carrier-free tracer activities. Typical elution curves in: $\mathbf{A}, 3 \mathrm{M} \mathrm{HCl} \mathbf{B}$, $6 \underline{\mathrm{M}} \mathrm{HCl} ; \mathrm{C}, 9 \underline{\mathrm{M}} \mathrm{HCl} ; \mathrm{D}, 12 \mathrm{M} \mathrm{HCl}$ (104)

the exact nature of the complex is dependent on $\mathrm{pH}$, but the equilibrium can be expressed by

$$
M^{+3}+n\left(H_{x} C i t\right)^{x-3}=M\left(H_{x} C i t\right){ }_{n}^{3+n(x-3)}
$$

and

$$
K_{2}=\frac{\left[M^{+3}\right]\left[H_{x}(C i t)^{x-3}\right]^{n}}{\left[M\left(H_{x} C i t\right)_{n}^{3+n(x-3)}\right]} .
$$


If the $\mathrm{pH}$ is such that only Eq. (7) is involved in the rare earth-citrate complex equilibrium, Eq. (11) may be written

$$
K_{2}=\frac{\left[\mathrm{M}^{+3}\right]\left[\left(\mathrm{H}_{2} \mathrm{Cit}\right)^{-}\right]^{3}}{\left[\mathrm{M}\left(\mathrm{H}_{2} \mathrm{Cit}\right)_{3}\right]} \text {. }
$$

Combining Eqs. (5), (7), and (12) and rearranging gives

$$
\frac{\mathrm{MR}_{3}}{\mathrm{NaR}}=\frac{\mathrm{K}_{\mathrm{d}_{2}} \mathrm{~K}_{2}}{\mathrm{~K}_{8}^{3}} \frac{\left[\mathrm{M}\left(\mathrm{H}_{2} \mathrm{Cit}\right)_{3}\right]\left[\mathrm{H}^{+}\right]^{3}}{\left[\mathrm{H}_{3} \mathrm{Cit}\right]^{3}} .
$$

Thus the amount of rare earth in the resin phase, to a first approximation, is seen to decrease with the third power of the $\mathrm{H}^{+}$concentration as the $\mathrm{pH}$ is increased, and with the third power of the $\mathrm{H}_{3} \mathrm{Cit}$ concentration as the total citric acid is increased. Similar strong dependence on the $\mathrm{pH}$ and citrate concentrations is found as the $\mathrm{pH}$ is increased to the point where the second and third ionization constants become important.

Tompkins and Mayer ${ }^{481}$ (using $10 \mathrm{ml} 0.23 \underline{\mathrm{M}}$ citrate, $0.5 \underline{\mathrm{M}} \mathrm{NH}_{4} \mathrm{ClO}_{4}$. $\mathrm{Tb}^{+3}<10^{-6} \mathrm{M}, 0.3657 \mathrm{~g}$ Dowex-50 resin, 40-60 mesh) show that the formula for the rare earth-citrate complex at $\mathrm{pH}^{\prime} \mathrm{s}$ below 3.2 is $\mathrm{M}\left(\mathrm{H}_{2} \mathrm{Cit}\right)_{3}$. Spedding and Powell, ${ }^{450}$ on the other hand, indicate that on Nalcite HCR columns eluted with $0.1 \%$ citrate in the $\mathrm{pH}$ range 5.4-8.2 the predominant rare-earth complex is $\mathrm{M}(\mathrm{Cit}) 2_{2}$. Whatever the $\mathrm{pH}$ and whatever the nature of the citrate complex, however, the primary figure of merit is the distribution coefficient of one rare earth relative to that of its immediate neighbors; this will determine how effectively a pair of adjacent rare earths may be separated under a given set of experimental conditions. Tompkins and Mayer ${ }^{481}$ have meas ured the ratio $\mathrm{K}_{\mathrm{d}(\mathrm{Pm})} / \mathrm{K}_{\mathrm{d}(\mathrm{Eu})}$ as a function of $\mathrm{pH}$. Their data, plotted in Fig. 61, indicates that in citrate solutions the ratio of distribution coefficients

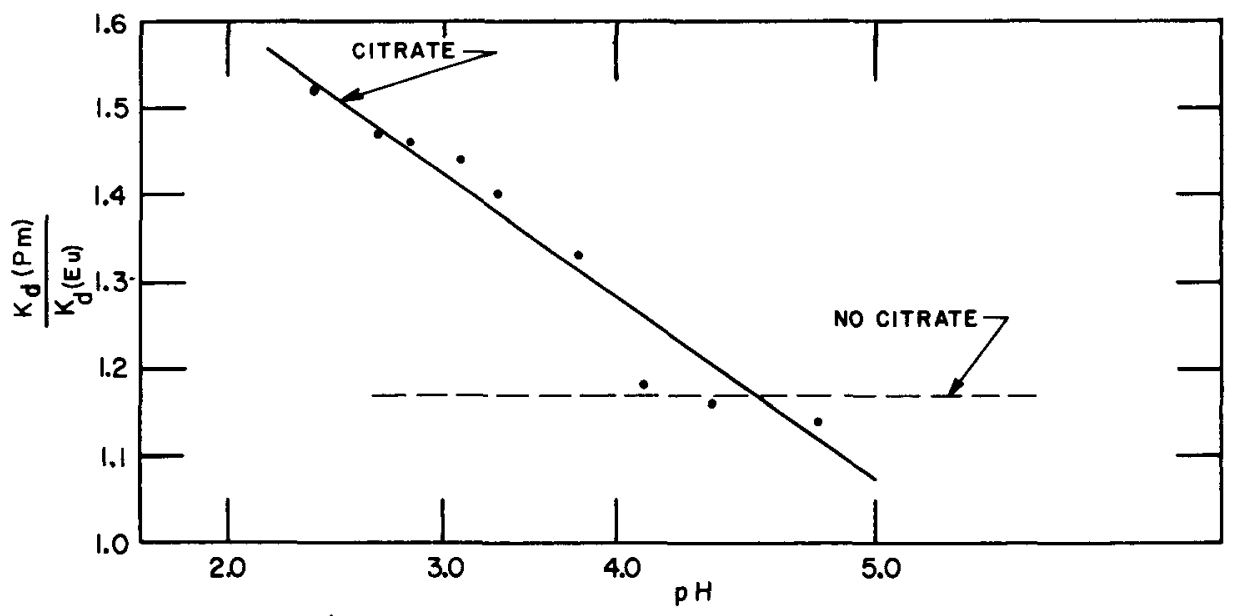

Fig. 61. $\mathrm{K}_{\mathrm{d}}(\mathrm{Pm}) / \mathrm{K}_{\mathrm{d}}(\mathrm{Eu})$ vs $\mathrm{pH}$, citrate solutions, Dowex-50 resin (481) 
decreases markedly as the $\mathrm{pH}$ is increased, approaching that to be expected from the resin alone above a $\mathrm{pH}$ of about 4 , and they conclude that with citric acid the most effective rare-earth separations are obtained at $\mathrm{pH}$ 's below 3. 2 .

While it is true that the lower the $\mathrm{pH}$ the better the separation factor for adjacent rare earths, it is equally true that the lower the pH the longer the time required for elution of a given element. Here again, if time is a factor in the separation, a compromise must be made in choosing an adequate set of experimental conditions.

Representative of the type of radiochemical rare-earth separations which may be made with citrate as the eluting agent are those reported by Ketelle and Boyd 226, 227 (Fig. 62) in which they separated less-than-milligram amounts of each of a large number of rare earths on $97 \mathrm{~cm} \times 0.26 \mathrm{~cm}^{2}$ columns of $270 / 325$ mesh Dowex -50 operating at $100^{\circ} \mathrm{C}$. Five percent citrate buffered in the $\mathrm{pH}$ range 3. 20-3.40 was used and, while the column running times to individual peaks varied between 6 and 110 hours, separation of adjacent rare earths was quite good, so that these early curves represented a major step forward in the chemistry of the rare-earth elements.

Wilkins on and Hicks ${ }^{534}$ (Fig. 63) have separated $10-$ to $20-\mathrm{mg}$ mixed samples, predominantly of the heavy rare earths, on $50 \mathrm{~cm} \times 0.4 \mathrm{~cm}$ Dowex-50 columns by using $5 \%$ citric acid, $\mathrm{pH} 3.05$, at room temperature.

Cornish $^{86}$ (Fig. 64) and Brooksbank and Leddicotte ${ }^{51}$ have used citrate columns to separate mixtures of rare-earth activities in the neutron activation analysis method for detecting trace rare-earth impurities.

In Fig. 64 it may be noted that solutions with five different pH's were used during a single column run. One of the most distinctive characteristics of these elution curves becomes apparent when an eluant at a single $\mathrm{pH}$ is used to separate a mixture of all the rare earths. If the $\mathrm{pH}$ is such that the first elements eluted (Lu-Yb) are adequately separated, column running times be tween the peaks of each of the succeeding elements increase in a more or less regular manner. Thus in Fig. 64, where the time between the Lu and $\mathrm{Tm}$ peaks is approximately 4 hours, if a $\mathrm{pH}$ of 3.20 had been used continuously the time between the Pr and Ce peaks may well have been 20 hours. In order to cut down on the time required to complete the separation without affecting the purity of any of the elements Cornish ${ }^{86}$ elected to change the eluting solution $\mathrm{pH}$ in discrete steps. A more complete discussion of this phenomenon, and of more effective ways of dealing with it, will be presented in the section on lactate columns.

Heretofore no mention has been made of the behavior of scandium and actinium on ion exchange resins. In most radiochemical separations involving these elements other types of separation steps are found to be more practical 

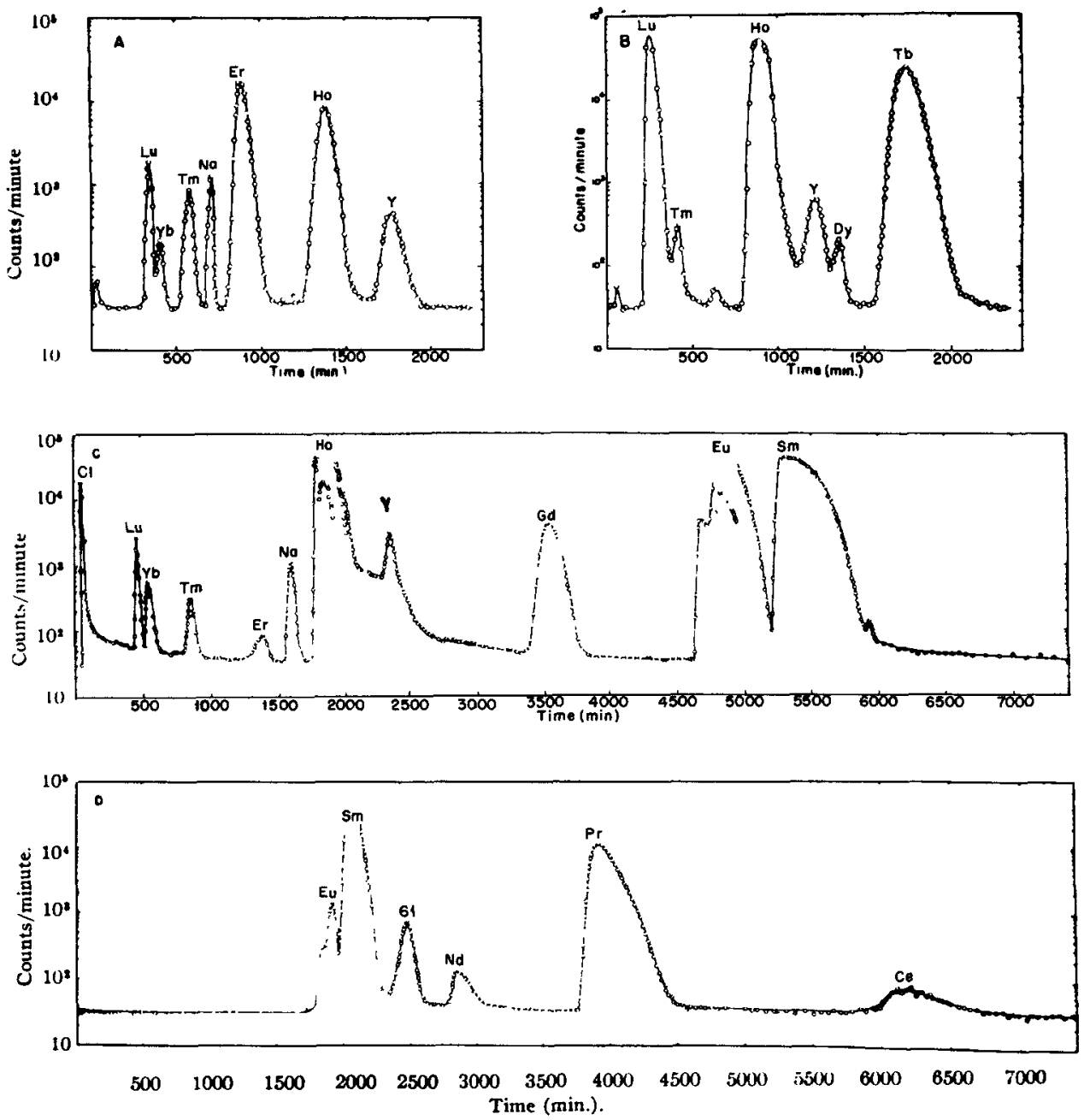

Fig. 62. Demonstrations of rare-earth separations effected with a $270 / 325$ mesh Dowex-50 column at $100^{\circ}$; bed dimensions, $97 \mathrm{~cm}$ by $0.26 \mathrm{~cm}^{2}$; flow rate, $1.0 \mathrm{ml} / \mathrm{cm}^{2} / \mathrm{min}$ except in A where $2.0 \mathrm{ml} / \mathrm{cm}^{2} /$ min was used: (A) fractionation of activities produced by neutron irradiation, $0.8 \mathrm{mg}$ spectrographic grade $\mathrm{Er}_{2} \mathrm{O}_{3}$ (Hilger) $(\mathrm{pH} 3.20)$; (B) fractionation of heavy rare-earth mixture consisting of $0.1 \mathrm{mg}$ each of $\mathrm{Lu}_{2} \mathrm{O}_{3}, \mathrm{Yb}_{2} \mathrm{O}_{3}, \mathrm{Ho}_{2} \mathrm{O}_{3}$ and $\mathrm{Tb}_{2} \mathrm{O}_{3}[\mathrm{Tm},(\mathrm{Er}), \mathrm{Y}$ and Dy present as impurities] ( $\mathrm{pH} 3.20$ ); (C) fractionation of intermediate rare-earth mixture consisting of $0.1 \mathrm{mg} \mathrm{Ho} 2 \mathrm{O}_{3}$ and $1.0 \mathrm{mg}$ each of $\mathrm{Dy}_{2} \mathrm{O}_{3}$, $\mathrm{Gd}_{2} \mathrm{O}_{3}, \mathrm{Eu}_{2} \mathrm{O}_{3}$ and $\mathrm{Sm}_{2} \mathrm{O}_{3}\left(\mathrm{Cl}, \mathrm{Lu},{ }^{\mathrm{Yb}}, \mathrm{Tm}, \mathrm{Er}\right.$ and $\mathrm{Na}$ present as impurities, pH 3.25 for 4550 minutes, then $\mathrm{pH} 3.33$ ); (D) fractionation of light rare-earth mixture consisting of $0.1 \mathrm{mg}$ each of $\mathrm{Sm}_{2} \mathrm{O}_{3}$ and $\mathrm{Nd}_{2} \mathrm{O}_{3}$ plus $0.01 \mathrm{mg}$ each of $\mathrm{Pr}_{2} \mathrm{O}_{3}{ }_{3} \mathrm{Ce}_{2} \mathrm{O}_{3}$ and $\mathrm{La}_{2} \mathrm{O}_{3}$ (Eu present as impurity, 61 produced by $1.7 \mathrm{~h} \mathrm{Nd} 149 \rightarrow 47^{\mathrm{h}} 61^{149}, \mathrm{pH} 3.33$ for 1610 minutes, then $\mathrm{pH} 3.40)(226,227)$

than ion exchange. The ion exchange resins may be used, however, and

- several authors have published papers involving the use of citrate as an eluting agent. 


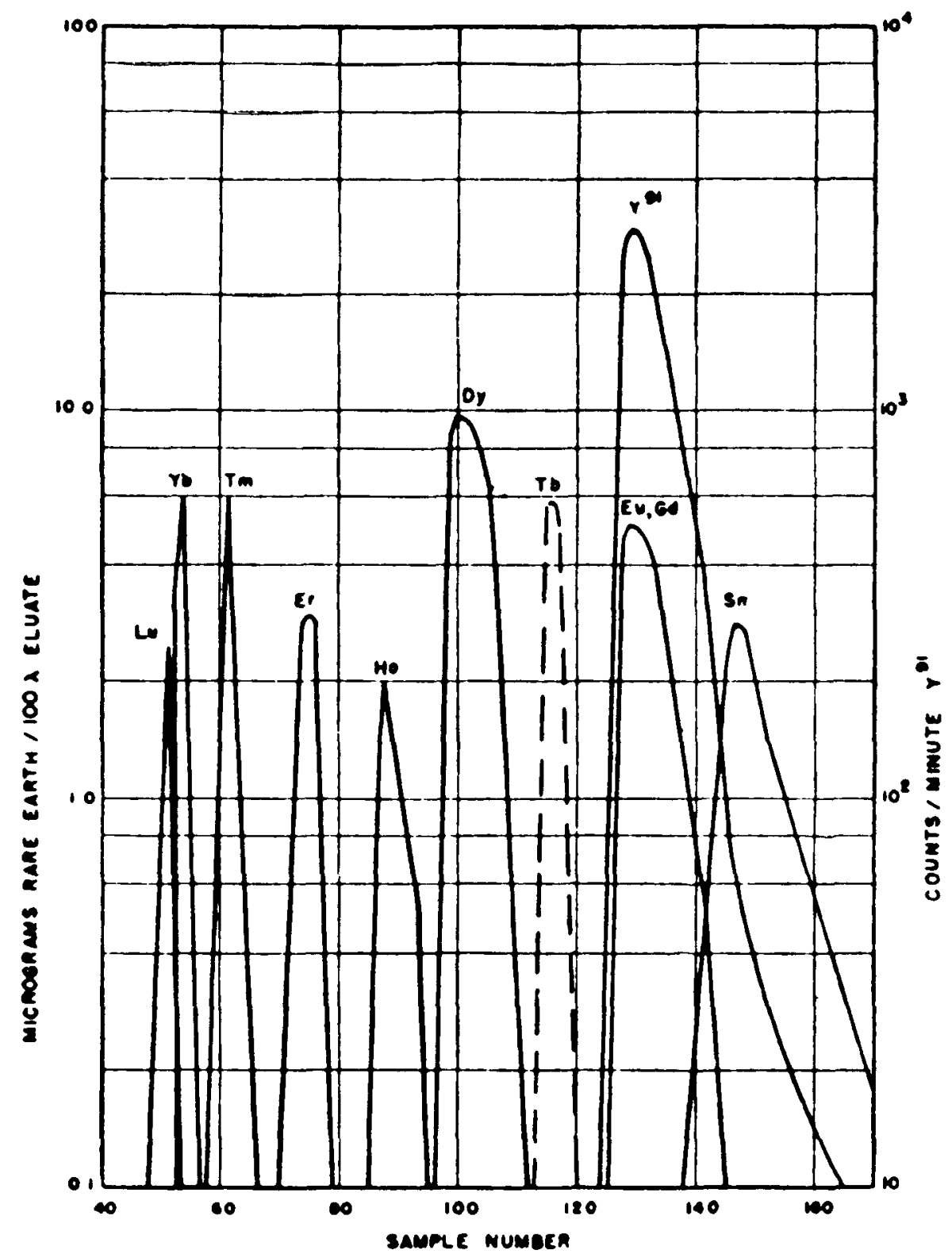

Fig. 63. Standard rare-earth elution. $50 \times 0.4 \mathrm{~cm}$ Dowex-50 column. Flow rate $0.08 \mathrm{ml} / \mathrm{cm}^{2} /$ min. Sampling time 15 minutes; eluate volume in milliliters is $0.282 \times$ sample number. Y 91 was measured by its radioactivity, other rare earths spectroscopically. Terbium is estimated since the cyanogen bands obscure the terbium lines. Eluting agent is citric acid adjusted to $\mathrm{pH} 3.05$ with ammonium hydroxide (534)

In general, scandium will elute faster than the fastest of the rare-earth elements ( $L u)$ and actinium will elute slower than the slowest (La).

Radhakrishna, ${ }^{383}$ using 80-120 mesh Amberlite IR-100-H resin, at room temperature, in columns $36.3 \mathrm{~cm}$ long and $0.7 \mathrm{~cm}$ in diameter, has eluted 


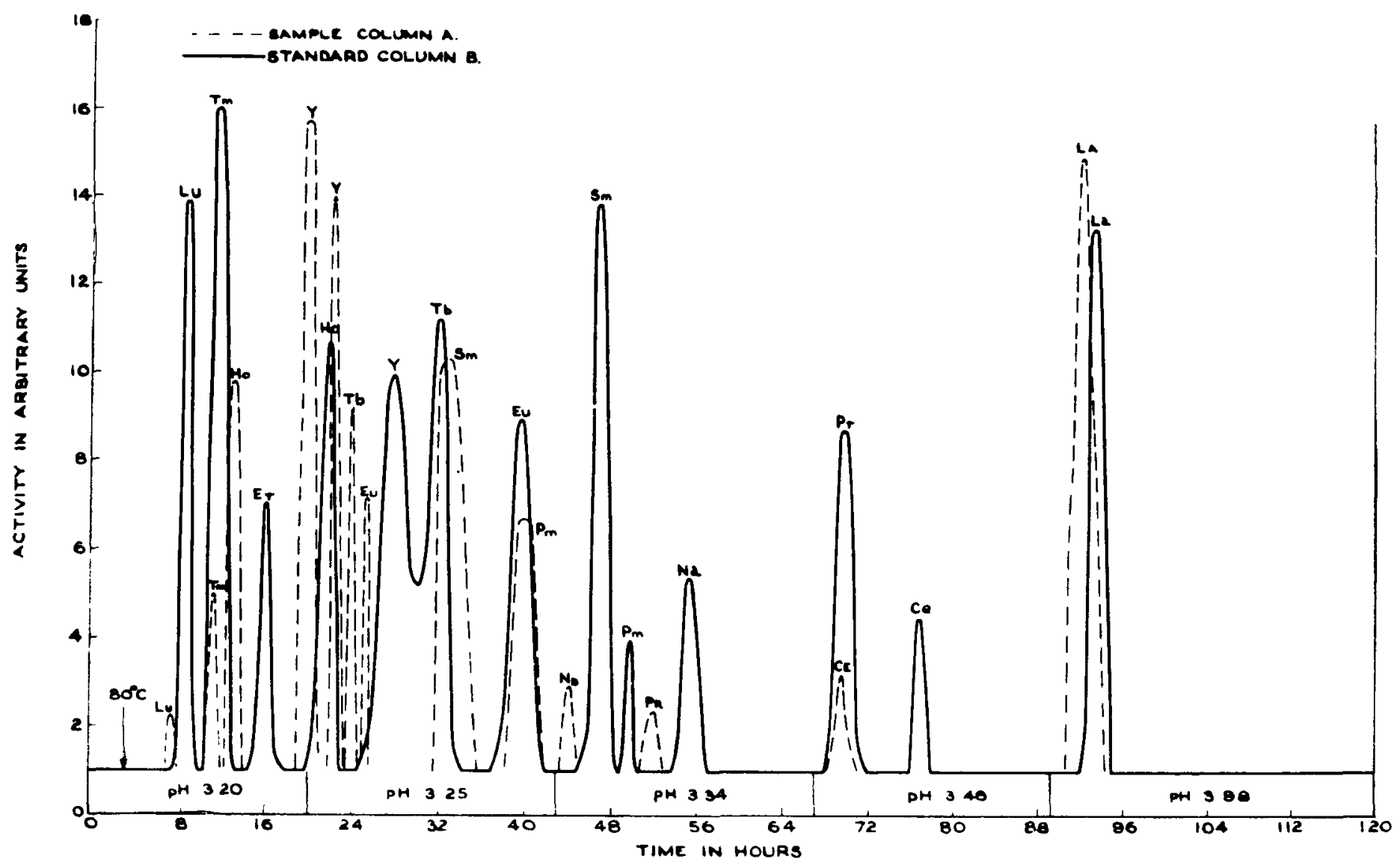

Fig. 64. Separation of rare earths using column of ZEO-KARB $225 \quad(300-330$ mesh, $115 \mathrm{~cm}$ $\times 0.20 \mathrm{~cm}^{2}$, free col. vol. $11 \mathrm{ml}$ ), $5 \%$ ammonium citrate solution initially at $\mathrm{pH} 3.20$, temperature $80^{\circ} \mathrm{C}$. Flow rates: column A, $0.114 \mathrm{ml} / \mathrm{min}$; column B, $0.109 \mathrm{ml} / \mathrm{min}$ (86) 
a $1.0 \mathrm{mg} \mathrm{Sc}-3.7 \mathrm{mg} \mathrm{La}$ mixture with $5 \%$ citrate at a pH of 2.8 . When all of the Sc was eluted, he raised the $\mathrm{pH}$ to 3.2 for elution of the La. Iya ${ }^{214}$ has separated fairly large samples of scandium from the rare earths by this method. Figure 65 shows the elution curve he obtained for a 6.3-g sample of scandium with $5 \%$ citrate at a $\mathrm{pH}$ of 3.0 . While the column is much larger, and the Sc peak much wider, than would be the case in most radiochemical separations, it can be seen that most of the scandium is eluted before any of the rare earths appear.

Tsong 490 used $5 \%$ citrate at a $\mathrm{pH}$ of 5.5 on Amberlite IR-100 resin to separate $3.12 \mathrm{mc}$ of $\mathrm{Ac}^{227}$ from $160 \mathrm{mg}$ of La. His curve in Fig. 66 indicates that the column was run under saturated conditions but another run could have been made for a more complete separation.

In addition to being used to separate the rare earths from one another, citrate may be used to separate the rare earths from other elements. An example of this type of application is the $\mathrm{Y}^{90}-\mathrm{Sr}^{90}$ separation done by Lepscky and Restelli, ${ }^{268}$ who used $5 \%$ citric acid at a pH of 5.2 to milk carrier-free $\mathrm{Y}^{90}$ from it $\mathrm{Sr}{ }^{90}$ parent on a Dowex-50 column, and Bonnin, 42 who used a $\mathrm{pH}$ of 3.2 to do the same thing.

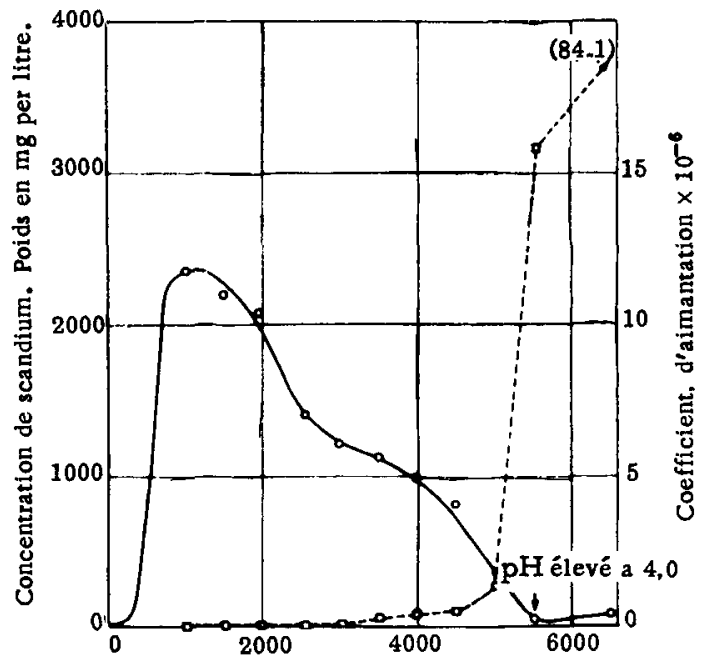

Fig. 65. Elution of a mixture of Sc and rare earths: $6.3 \mathrm{~g} \mathrm{Sc}, 115 \mathrm{~cm} \times 3 \mathrm{~cm}$ column, Dowex-50 (60-90 mesh), 5\% citrate, pH 3.0, flow rate $300 \mathrm{ml} / \mathrm{hr}$ (214)

Concurrently with the development of the elution techniques we have been discussing here, Spedding and his co-workers at lowa State College, shortly after World War II, developed a technique for large scale production of pure rare earths. Although they used very large amounts of rare earths and their earlier techniques have been discarded for more efficient procedures, perhaps a short discussion of their method is in order here. 


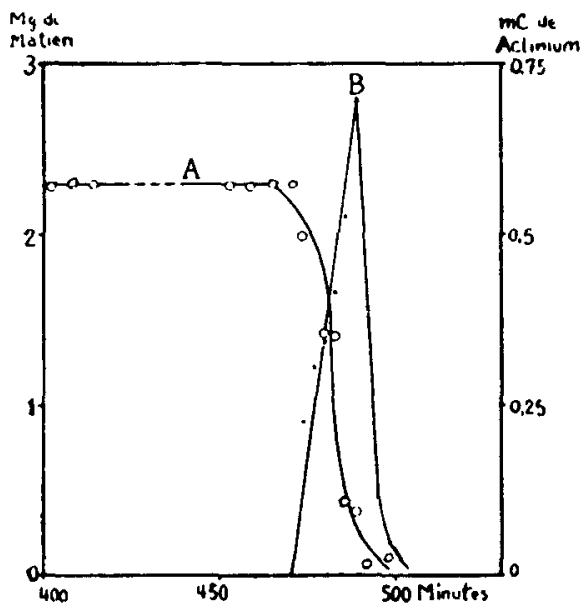

Fig. 66. Elution of $160 \mathrm{mg} \mathrm{La}, 3.12 \mathrm{mC} \mathrm{Ac} 227$ from Amberlite IR-100 resin with $5 \%$ citrate, pH 5.5. Curve A, mg La eluted, curve B, mC Ac eluted (490)

In the early work on rare-earth ion-exchange columns everyone was using $5 \%$ citrate as the eluant, spedding et al. included. In 1947 they began publication of a series of papers 447 describing their progress in separating macro amounts of the rare-earth elements. At first they used 5\% citrate at a pH of 2.5-3.0 for an eluting agent but as they gained experience and had the opportunity to investigate other conditions, their attention shifted to more dilute solutions at higher $\mathrm{pH}$ 's, culminating in a pair of papers 450,452 describing their operations with $0.1 \%$ citrate in the $\mathrm{pH}$ range 5.0-8.0.

An example of the type of elution curve that they obtained under these conditions is shown in Fig. 67, when 5-g samples of impure $\mathrm{Nd}_{2} \mathrm{O}_{3}$ were separated with $0.1 \%$ citrate, $\mathrm{pH} 6.15$, in columns of various lengths. The most obvious feature of these curves, of course, is that all of the rare earths are eluted in one "total rare-earth" peak; there are no widely separated peaks for individual elements. For large scale operations this is not a drawback. Indeed, it is the condition for which one strives, for if the experimental conditions are chosen properly all of the rare earths will come off the column "head to tail," with one rare earth immediately behind another, and each one pure except for a small region of overlap between adjacent elements.

One prerequisite for operating columns in this manner, however, is a large rare-earth loading per unit area of resin bed. A characteristic of elutions carried out under these conditions is that each element, whatever its mass on the column, will, if the column is long enough, develop into a band. The length of each band is dependent on the amount of each rare earth present but once a band is formed it will not increase in length or separate from its adjacent elements no matter how long the column. Theoretically, 


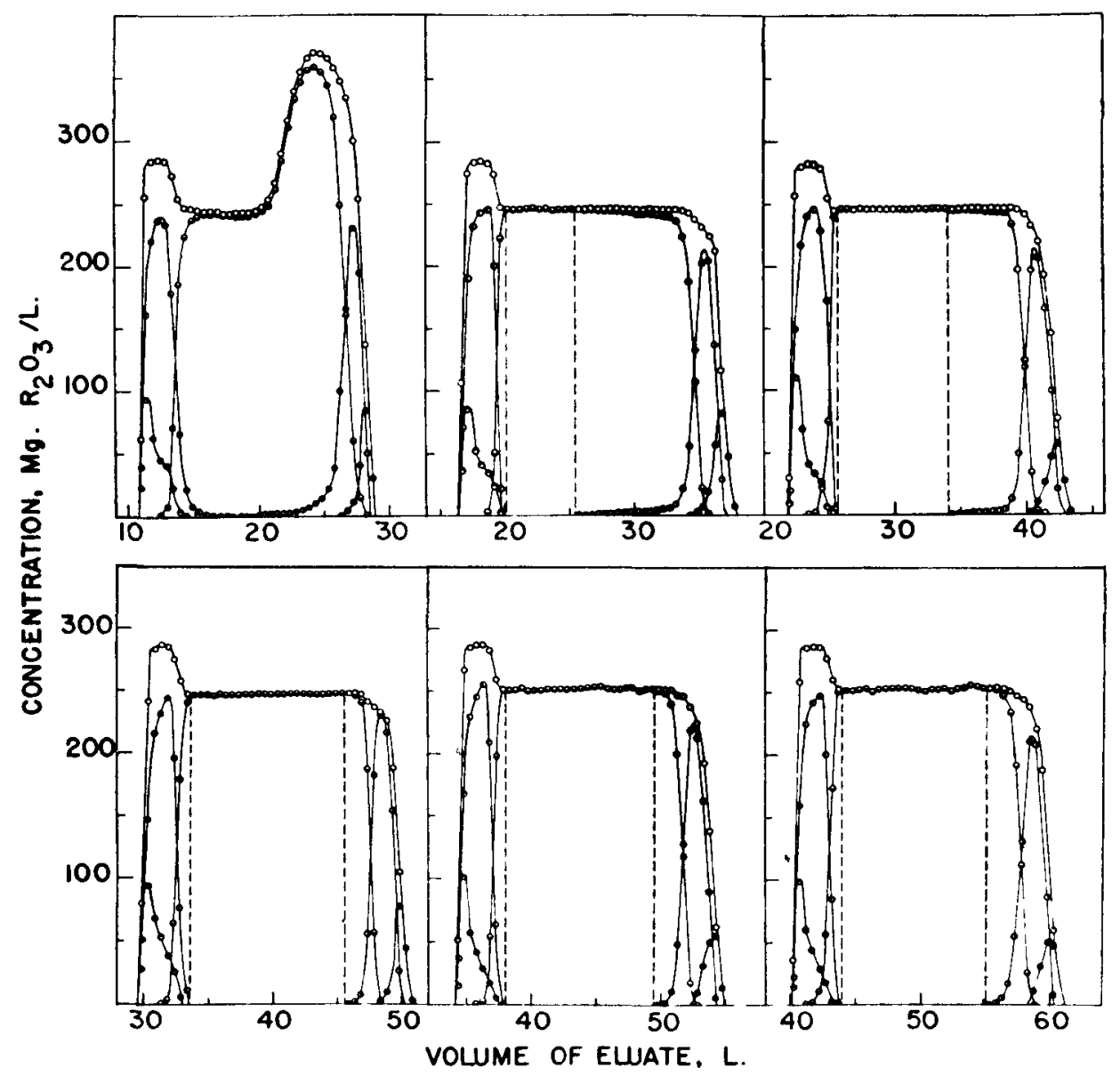

Fig. 67. The elution of $5-\mathrm{g}$ samples of $76 \% \mathrm{Nd}_{2} \mathrm{O}_{3}, 11 \% \mathrm{Sm}_{2} \mathrm{O}_{3}, 9 \% \mathrm{Pr}_{6} \mathrm{O}_{11}$ and $4 \%$ other $\mathrm{R}_{2} \mathrm{O}_{3}$ from $-40+50$ Nalcite $\mathrm{HCR}$ resin beds, $22 \mathrm{~mm}$ in diameter and $30,40,50,60,70$ and $80 \mathrm{~cm}$ long, with $0.1 \%$ citrate solution at a $\mathrm{pH}$ of 6.15 and a flow rate of $0.5 \mathrm{~cm} / \mathrm{min}: \theta$, heavy $\mathrm{R}_{2} \mathrm{O}_{3} ; 0, \mathrm{Sm}_{2} \mathrm{O}_{3} ; \theta, \mathrm{Nd}_{2} \mathrm{O}_{3} ; 0$, $\mathrm{Pr}_{6} \mathrm{O}_{11} ; \bullet, \mathrm{La}_{2} \mathrm{O}_{3}$ and $\mathrm{CeO}_{2} ; O$, total mixed $\mathrm{R}_{2} \mathrm{O}_{3}$; vertical dashed lines indicate Nd fractions $99.9 \%$ pure $(447$, paper VI $)$

the interface between bands should be infinitely sharp, with no contamination of one element by another, but in practice there is always some tilting of the interface or channeling effect which causes mixing of adjacent elements. Thus a developed band must be much longer than it is wide if the cross-contamination of one element by its neighbors is not to be significant.

The application of this technique to radiochemical separations seems rather limited, but if the situation does arise where small amounts of one element must be separated from very large amounts of an element which elutes ahead of it on the column, this method may be the best one available. There will be an overlap of the elements, of course, but it should not be necessary to make more than two column runs to effect a complete separation of any mixture. 
IV. 7B-3. Lactic Acid

Although citrate was used almost exclusively as an eluting agent in the early ion-exchange work with the rare earths, its use entailed several difficulties which did not exactly endear it to the users. The most serious of these was the length of time required to make a separation. Even with carrier-free samples, column runs took many hours, or even days, for most separations, and this was quite undesirable in cases where short-half-lived activities were being investigated. Another difficulty was the fact that the nature of the rare earth-resin-citrate complex equilibrium could not be deduced as a function of $\mathrm{pH}$ very easily because of the three ionizable hydrogens on the citric acid molecule. Thus many chemists were looking for complexing agents which would give better rare-earth separations in shorter times, and which would be more amenable to theoretical treatment.

Mayer and Freiling 297 published a paper in 1953 which indicated that lactic acid should be more effective than citric acid for separating the rare earths, and Freiling and Bunney followed it up with a second paper ${ }^{150}$ describing a procedure for separating a mixture of fission-product rare-earth activities containing $20 \mathrm{mg}$ each of $\mathrm{Ce}, \mathrm{Pr}, \mathrm{Nd}$, and $\mathrm{Sm}$ carriers. Their apparatus consisted of a 3-mm-diameter column of Dowex-50 resin (settling rate 6 in. in $5-9 \mathrm{~min}$ ) operated at $87^{\circ} \mathrm{C}$. The best result that they obtained in a series of trials is shown in Fig. 68 and indicates that all of the activities

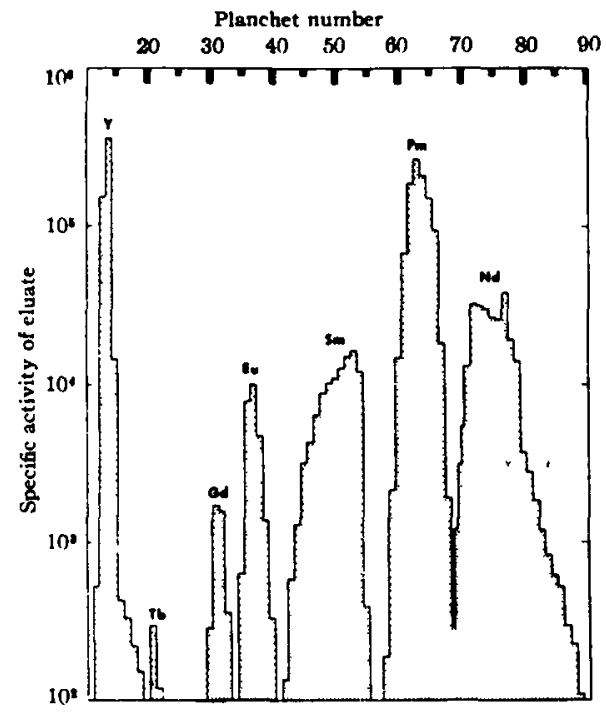

Fig. 68. Ion-exchange-column separation of fission-product rare-earth activities plus $20 \mathrm{mg} \mathrm{Sm}, 20 \mathrm{mg} \mathrm{Nd}$. Dowex-50 $(29-62 \mu), 3-\mathrm{mm}$-diam column, $87^{\circ} \mathrm{C}$. Eluting agent: $10 \mathrm{ml} 0.85 \mathrm{M}$ lactic acid, $10 \mathrm{ml} 0.90 \mathrm{M}$, remainder IM lactic acid, all at $\mathrm{pH} 3$. Planchets collected $1-1.5 \mathrm{ml}$ eluant each half-hour (150) 
were well separated in about forty hours, although four different concentrations of lactate had to be used.

Almasy ${ }^{7}$ has recently published the results of a search for a procedure which could be used for quantitative determination of individual elements in a mixture of rare earths. He used columns of Dowex $-50,10 \mathrm{~mm}$ in diameter $\times$ $200 \mathrm{~cm}$ long, at elevated temperatures to effect the separation of samples in the range 50-200 $\mathrm{mg}$ total rare-earth weight. One molar lactic acid was used as the eluant and the $\mathrm{pH}$ was increased in discrete steps during the elution, with the number, timing, and size of each step dependent on the composition of the rare-earth mixture being separated. The author felt that this type of multiple-step elution procedure was more favorable for the purposes of quantitative determination than the "gradient elution" method (to be described later) since the relative quantities of rare-earth metals to be separated could more easily be taken into account.

Others who have reported separations of rare earths in the weight range 10 to $20 \mathrm{mg}$ per element include Petrow, ${ }^{364}$ who separated Nd and $\mathrm{Pr}$ on an $11 \mathrm{~mm} \times 35 \mathrm{~cm}$ column of colloidal Dowex -50 at room temperature with $4.25 \%$ lactic acid at $\mathrm{pH}$ 3. 30, and Troianello and Sugihara, 487 who used $1 \mathrm{~cm} \times 80 \mathrm{~cm}$ columns of colloidal Dowex -50 at room temperature with $0.70 \underline{M}$ lactic acid at $\mathrm{pH} 3.30$ to separate $8-15 \mathrm{mg}$ each of $\mathrm{Y}, \mathrm{Sm}, \mathrm{Eu}$, and $\mathrm{Nd}$.

While these results are significantly better than those to be expected from a citrate column with the same rare-earth load, the column running time is still excessive for some purposes. Using only $1 \mathrm{mg}$ of $\mathrm{Y}, \mathrm{Eu}, \mathrm{Sm}, \mathrm{Nd}, \mathrm{Pr}$, and $\mathrm{Ce}$ as a carrier load, Cuninghame, Sizeland, Willis, Eakings, and Mercer 99 have shown how a mixture of all of the rare earths below europium may be separated in approximately 10 hours. Their data, reproduced in Fig. 69, were obtained with ZEO-KARB 225 resin, and indicate good separation for the Eu to La peaks, although the elements above Eu are not separated too well.

In an attempt to find conditions under which separation of rare-earth samples could be made quickly on a routine basis, one of the authors ${ }^{334}$ made a systematic study of the "gradient elution" technique using lactic acid as the eluant. As has been mentioned previously in the citrate section, one of the most distinctive characteristics of a rare-earth elution curve obtained with a single $\mathrm{pH}$ of eluant is the increased spacing between peaks of successive elements as they are eluted. This is shown again in Fig. 70, where tracer activities were used and the $\mathrm{pH}$ was chosen to give a reasonably good separation between the Lu-Yb-Tm peaks. As can be seen in Fig. 70, the running time between peaks increases from 22 minutes for the Lu-Yb pair to 8 hours and 40 minutes for Eu-Sm. Other chemists had tried to obtain more evenly spaced peaks by changing the eluting solution in discrete steps, either by increasing the pH (Fig. 64) or by increasing the concentration (Fig. 68). Both 


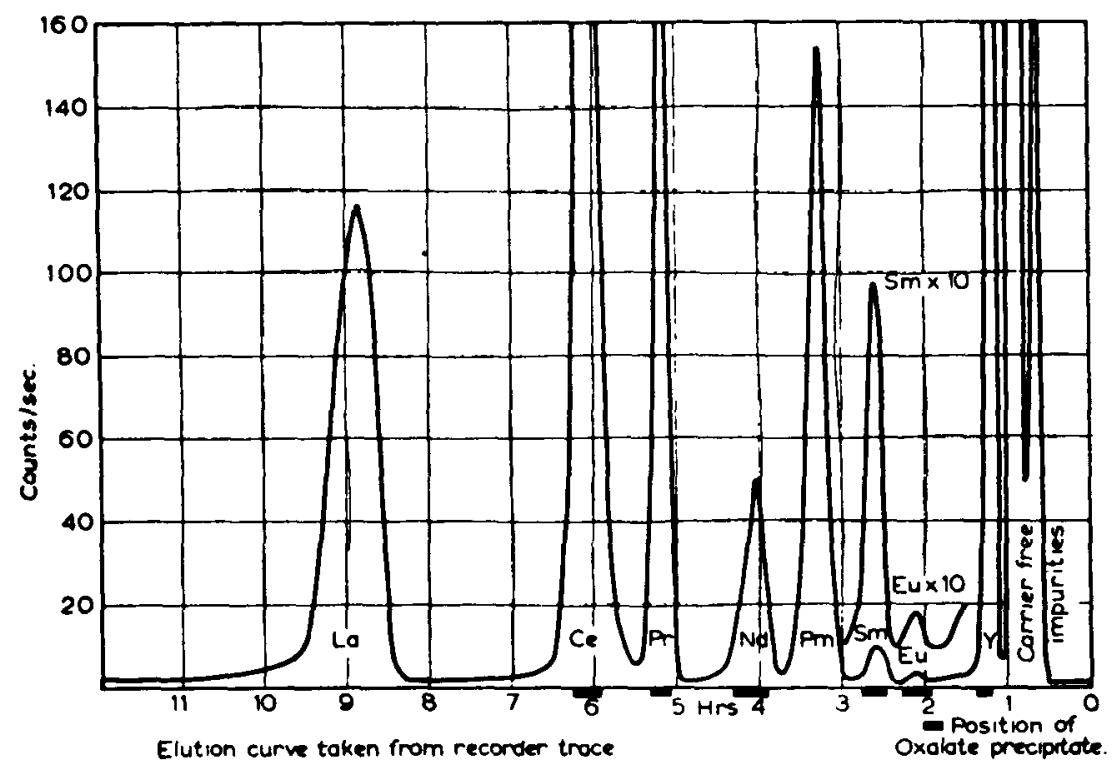

Fig. 69. Separation of rare-earth activities plus $1 \mathrm{mg}$ each of $\mathrm{Y}$, Eu, $\mathrm{Sm}$, Nd, $\mathrm{Pr}$, and Ce. Column 3-4 mm $\times$ 20-30 cm, ZEO-KARB 225, settling rate $0.5-1.0 \mathrm{~cm} / \mathrm{min}, 87^{\circ} \mathrm{C}$. Eluant $\mathrm{IM}$ lactic acid, $\mathrm{pH} 3.25 \pm$ 0.03 , flow rate $10-12 \mathrm{ml} / \mathrm{hr}$ (99)

of these operations, however, require the presence of the chemist to change the eluting solution reservoirs, and, if very many columns are being operated at one time, could involve a great deal of work.

With the gradient elution technique, however, the goal of more evenly spaced peaks is reached by changing the $\mathrm{pH}$ of the eluting solution continuously and automatically. A schematic diagram of apparatus which is currently in use in this laboratory is shown in Fig. 71. In normal operation the "high pH solution" is allowed to drip into the "low pH solution" at a rate which will give the desired increase in $\mathrm{pH}$ per unit time. The "low $\mathrm{pH}$ solution", thoroughly mixed, is then forced through the column in the normal manner. The desired rate of change of $\mathrm{pH}$ will, of course, depend on the separation that is to be made, but Fig. 72 indicates the type of elution curve which may be expected when using this method. Here the initial conditions were the same as those in Fig. 70, but the $\mathrm{pH}$ of the $1 \mathrm{M}$ lactic acid eluant was increased continuously at $0.107 \mathrm{pH}$ unit/hour. There is still an adequate separation between the Lu-Yb peaks but now the Eu-Sm peaks are only 19 minutes apart as compared to 8 hours and 40 minutes for the constant $\mathrm{pH}$ run. In addition, the column running time to the $\mathrm{Sm}$ peak has been cut from 38 hours 25 minutes to 4 hours 58 minutes without affecting the purity of any of the rare-earth elements at all. 


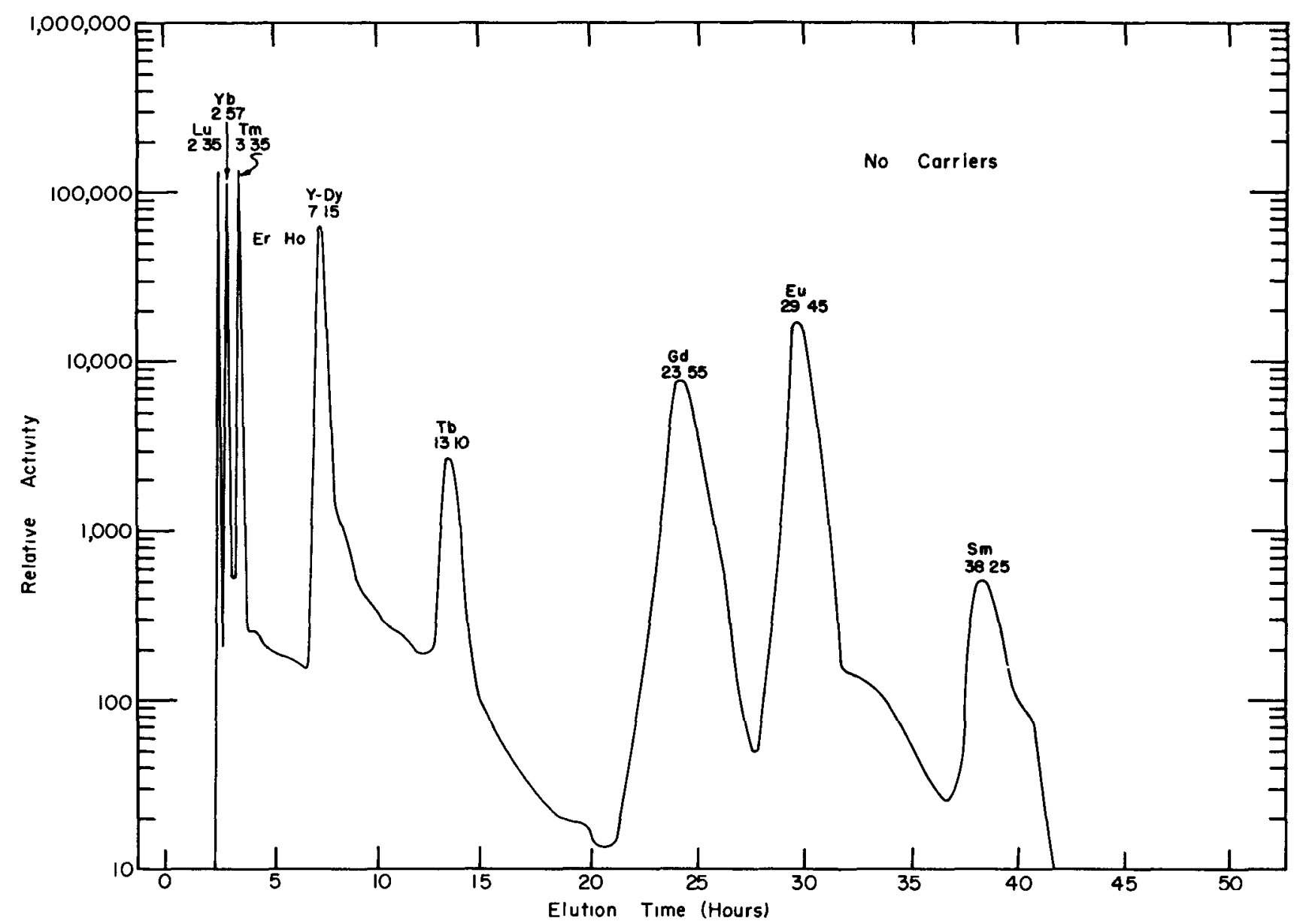

Fig. 70. Elution curve of carrier-free rare-earth tracer activities at a constant pH of 3.19. Column $7 \mathrm{~mm} \times 60 \mathrm{~cm}$, Dowex-50, settling rate $1.0-1.5 \mathrm{~cm} / \mathrm{min}$. Eluant $1 \mathrm{M}$ lactic ac1d (334) 


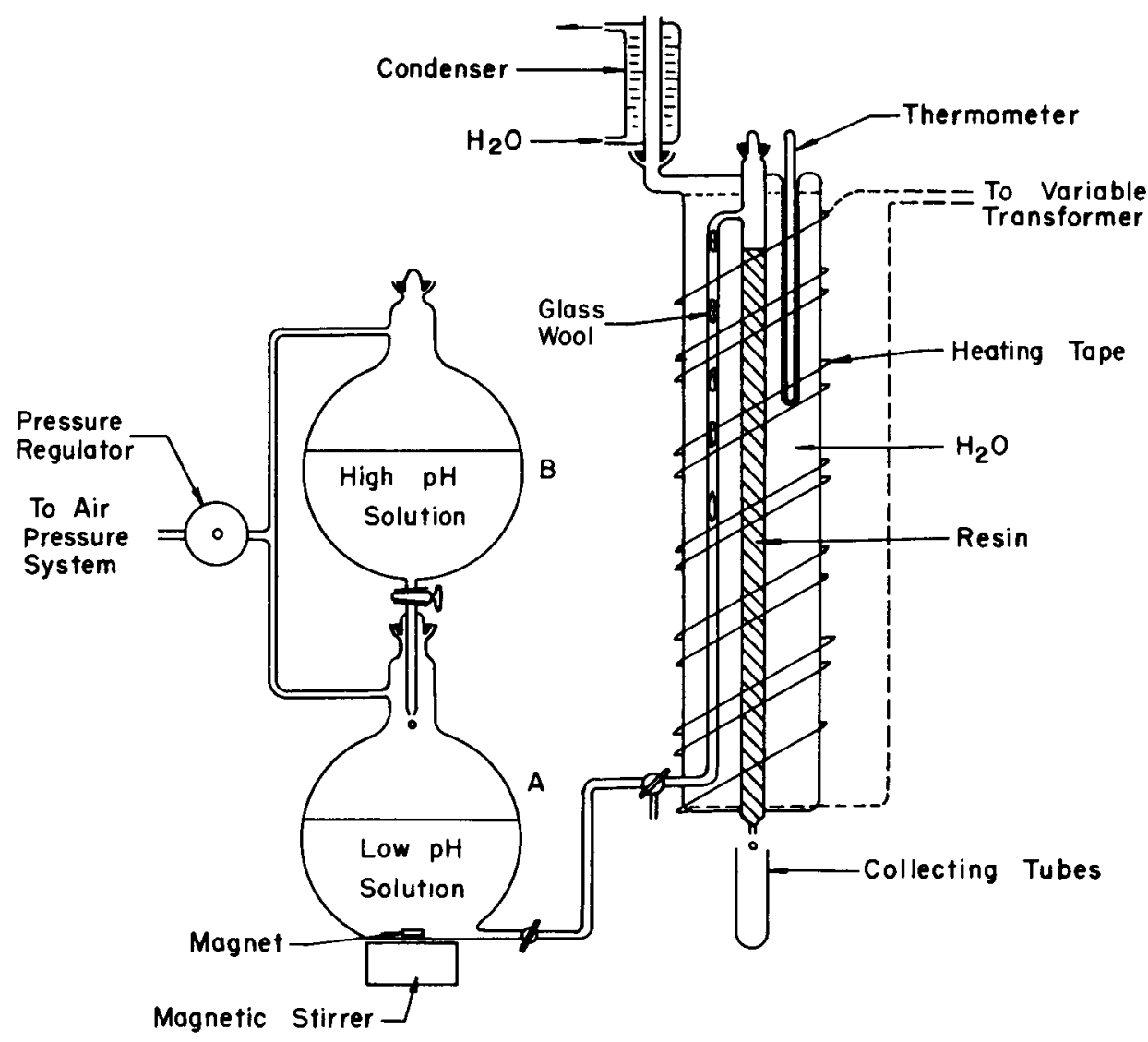

Fig. 71. A schematic diagram of an ion-exchange column apparatus in which the $\mathrm{pH}$ of the eluting agent may be changed continuously (334)

The gradient elution technique is obviously an improvement over previous metrods for separating carrier-free mixtures of the rare-earth elements. It can be used just as effectively for rapid separation of weighable amounts of rare-earth carriers but requires careful judgment to establish the proper operating conditions. As the mass of a given rare earth is increased the column quickly becomes saturated with respect to that element and its elution peak broadens. As is shown in Fig. 57 and Fig. 73, the width of the peak is very sharply dependent on the amount of carrier. In these examples $2 \mathrm{mg}$ of $\operatorname{Pr}\left(5.2 \mathrm{mg} \mathrm{Pr} / \mathrm{cm}^{2}\right.$ resin bed) was enough to give a noticeable increase in the width of the Pr peak and $8 \mathrm{mg}$ of $Y\left(20.8 \mathrm{mg} \mathrm{Y} / \mathrm{cm}^{2}\right)$ was enough to make the trailing edge of the $\mathrm{Y}$ peak mix with the $\mathrm{Tb}$ activity. It should be mentioned, however, that with $1 \underline{M}$ lactic acid these highly loaded peaks have a distinctive shape, with a slowly rising leading edge and a very abrupt trailing edge. Only a small adjustment, either in $\mathrm{dpH} / \mathrm{dt}$ or column loading, would have been necessary, therefore, to give a complete separation of these mixtures. It has been the experience of the authors, based on the separation of thousands 


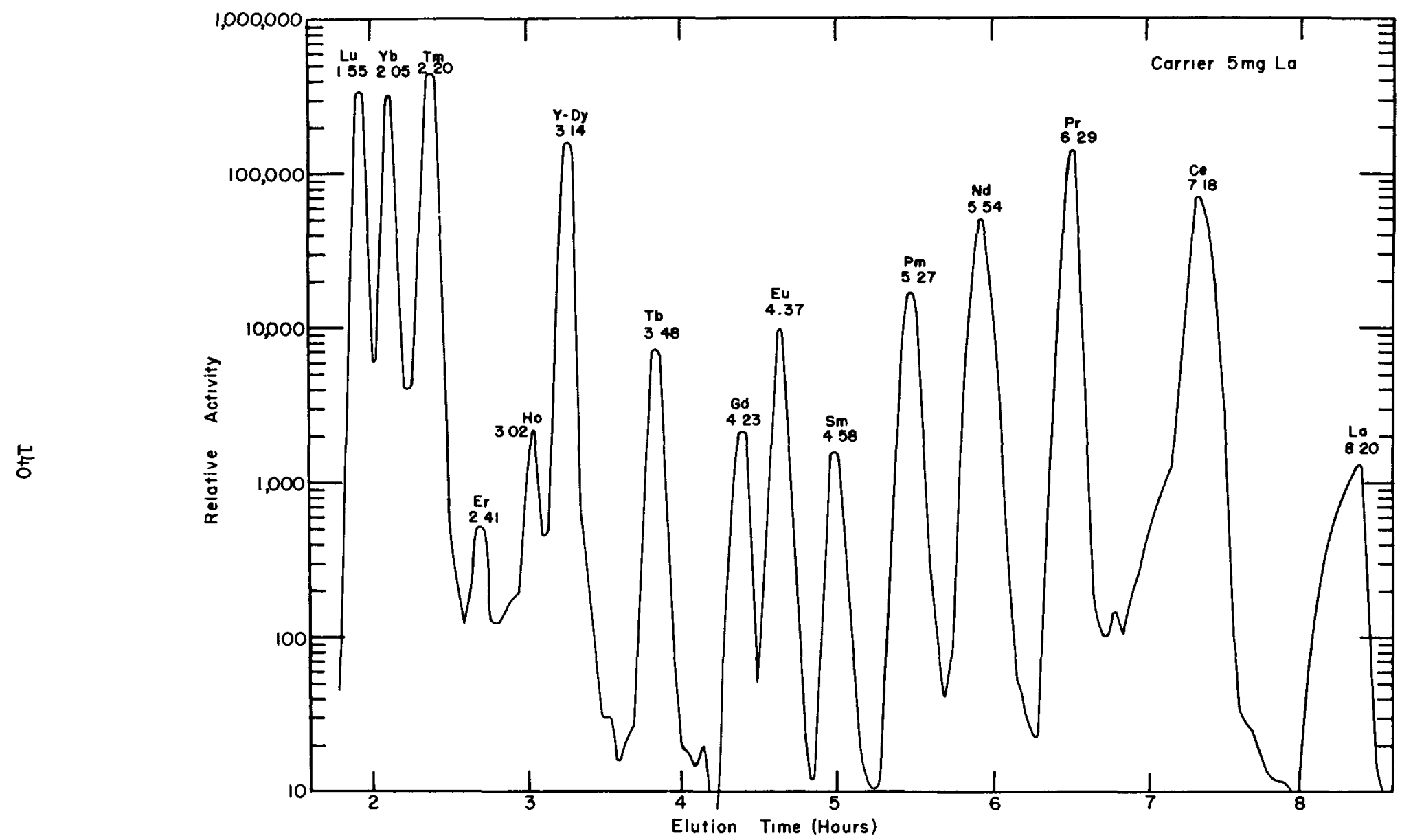

Fig. 72. Elution curve of rare-earth tracer activation plus $5 \mathrm{mg}$ of lanthanum, initial pH 3.19 , $\mathrm{pH}$ changed continuously at $0.107 \mathrm{pH}$ unit/hour (334) 


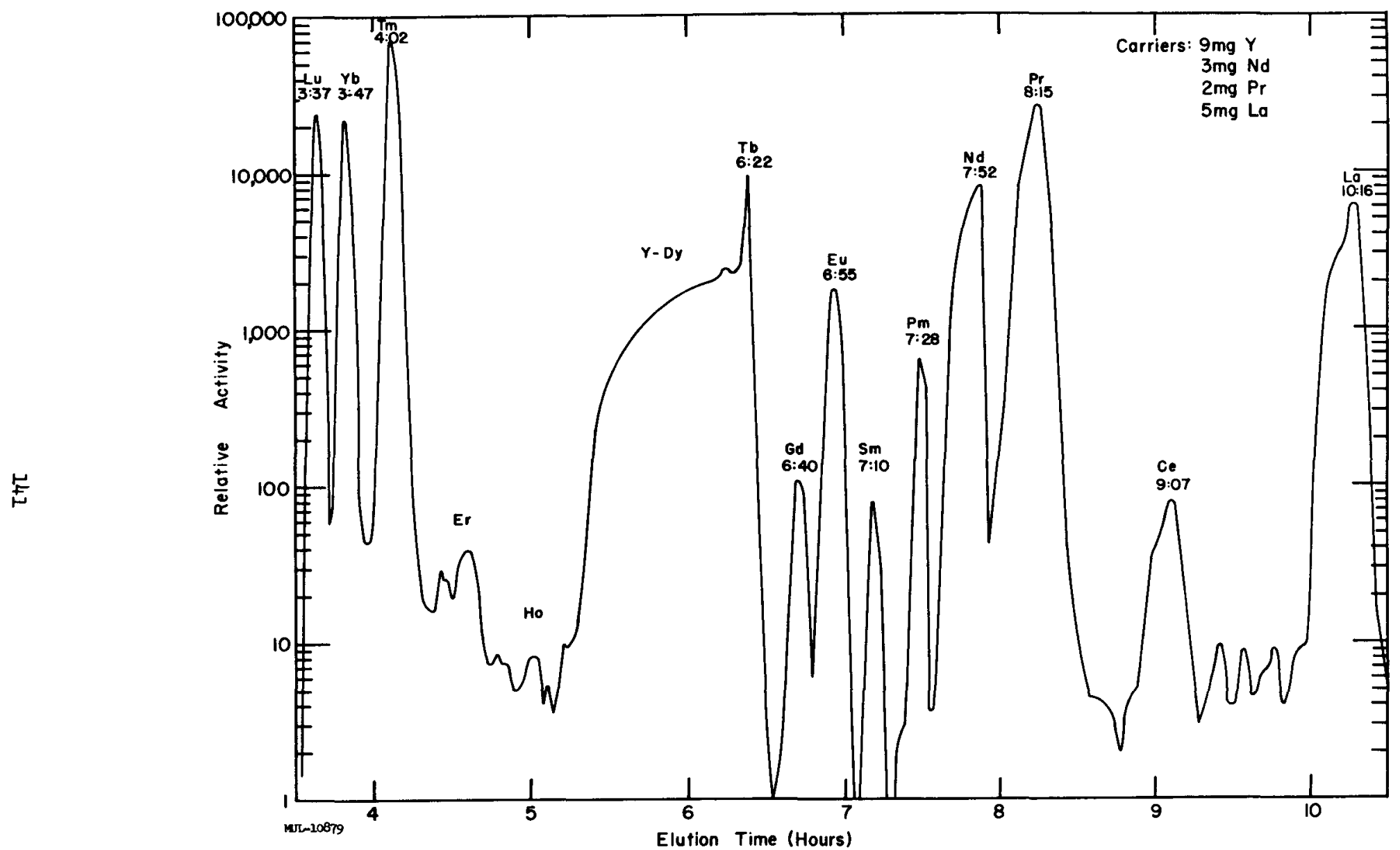

Fig. 73. Elution curve of rare-earth tracer activities plus $9 \mathrm{mg} \mathrm{Y}, 3 \mathrm{mg} \mathrm{Nd}, 2 \mathrm{mg} \operatorname{Pr}$, and $5 \mathrm{mg}$ La carriers; initial $\mathrm{pH} 3.19 ; \mathrm{pH}$ changed continuously at $0.1 \mathrm{pH}$ unit/hour, same apparatus as Fig. 70 (334) 
of rare-earth samples, that any mixture of rare-earth elements in the $10-\mathrm{mg}-$ per-element weight range may be separated, one or two dozen samples at a time, on a routine basis without difficulty with the gradient elution technique.

For mixtures of tracer activities, the gradient elution technique may be used with fairly small columns to give rapid separation of the rare earths. Figure 74 shows an elution curve of a mixture of rare-earth fission products which was obtained on a $1 \mathrm{~mm} \times 10 \mathrm{~cm}$ column. The separation between adjacent elements is reasonably good and the column running time of less than an hour for most of the elements permits study of fairly short-lived activities.

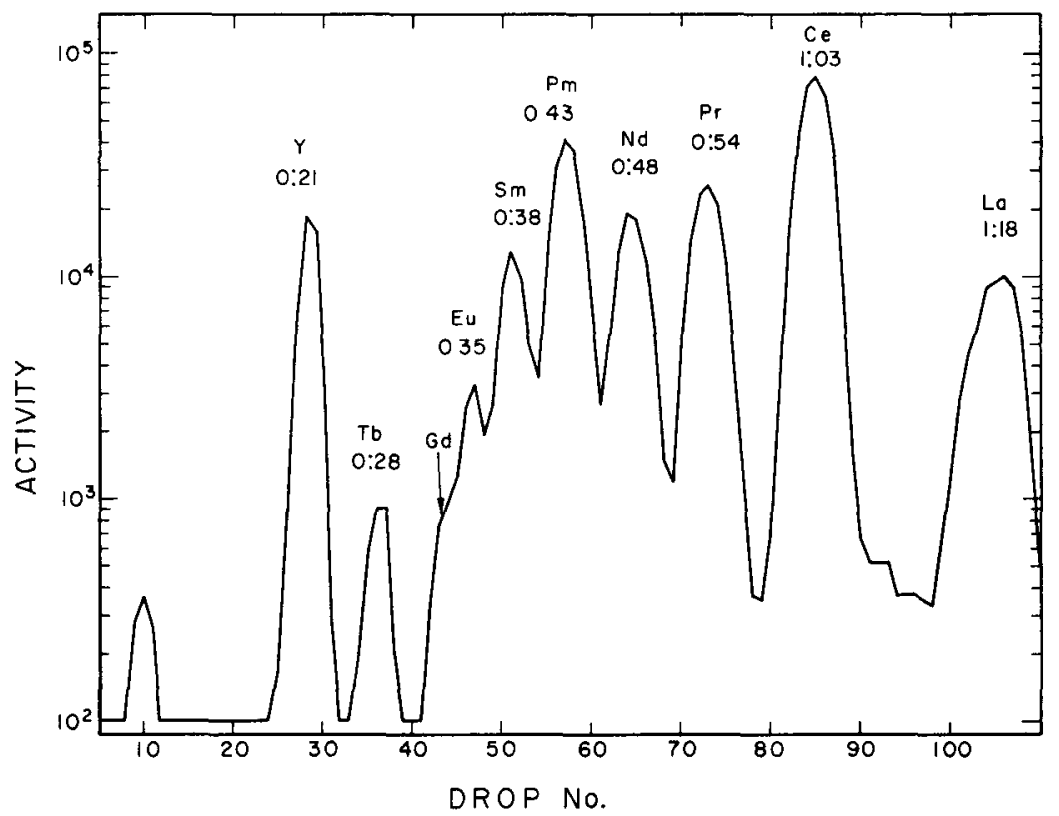

Fig. 74. Elution curve of rare-earth tracer activities; column $1 \mathrm{~mm} \times 10 \mathrm{~cm}$, Dowex-50, settling rate $1-1.5 \mathrm{~cm} / \mathrm{min}$, eluant $1 \mathrm{M}$ lactic acid, $\mathrm{pH} 3.00, \mathrm{dpH} / \mathrm{dt}$ $0.2 \mathrm{pH}$ unit/hour, temperature $87^{\circ} \mathrm{C} \quad(334)$

Preobrazhensky, Kalyamin, and Lilova ${ }^{378}$ have also used the gradient elution technique to effect very rapid separations of rare-earth tracer activities. They used $2 \mathrm{~mm} \times 18 \mathrm{~cm}$ columns of $6 \%$ cross-linked KU-2 resin and, instead of changing the $\mathrm{pH}$, used neutral solutions of ammonium lactate and gradually increased the concentration. Figure 75 shows the curve that they obtained from a mixture of rare-earth tracer activities when the ammonium lactate concentration was increased from $0.19 \mathrm{M}$ to $0.5 \mathrm{M}$ during the run. The separation between elements is very good, including the $Y-D y$ peak, and the column running time of about 3 hours to the Nd peak is fairly short. The authors claim, however, that the KU-2 resin reaches equilibrium at least 5 times as rapidly as Dowex -50 and that the column in Fig. 75 could have been run at a faster flow rate without affecting the separation significantly. 


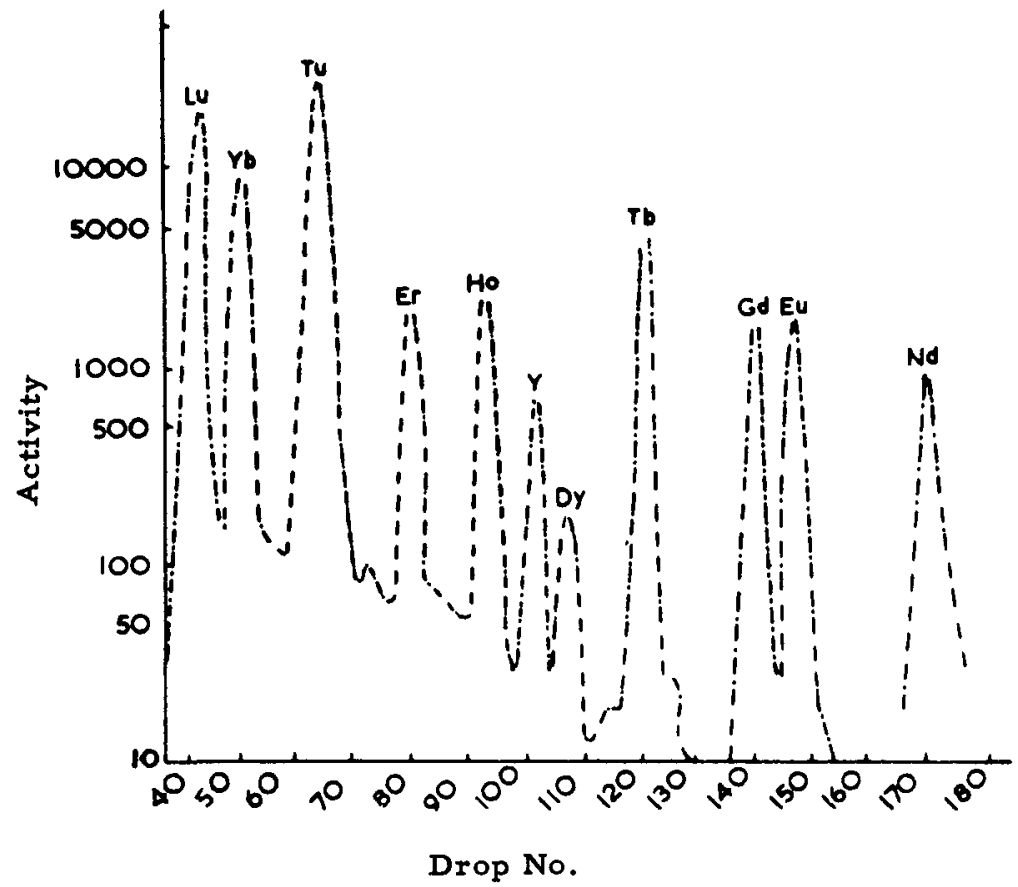

Fig. 75. The separation of radioactive rare-earth elements on KU-2 resin in a column $18 \mathrm{~cm}$ long $\times 2 \mathrm{~mm}$ diam; temperature $90^{\circ} \mathrm{C}$, average resin particle size 15 microns, flow rate approximately $1 \mathrm{drop} / \mathrm{min}$, eluant $0.19 \mathrm{M}$ ammonium lactate, gradually increased to approximately $0.5 \mathrm{M}$ during the run (378)

Indeed, they have used this resin to separate Lu-Yb activities in 5 minutes (Fig. 76) at $90^{\circ} \mathrm{C}$, and Lu-Yb-Tm mixtures in less than $1-1 / 2$ hours (Fig. 77) at room temperature.

Ever since the discovery of the gradient elution technique the theoretical details of chromatography by this method have received attention. Drake, 107 Freiling, 151,152 and Piez ${ }^{365}$ have published excellent papers dealing with the theory of various aspects of gradient elution. It should be pointed out, however, that theories which predict the position, shape, and purity of eluted elements have so far been restricted to carrier-free mixtures which give essentially gaussian-shaped peaks. When weighable amounts of carrier are used and the peak shape becomes distorted, the theories break down. At the present state of the art, in any case, empirical calibrations are necessary to insure that a given separation can be performed properly.

IV. 7B-4. Glycolic Acid

Another eluant which received attention at about the same time that the lactate systems were being developed was glycolic acid. Relatively few papers concerning the glycolate systems have appeared in the literature but Stewart 460 has used it on very short columns for rapid separation of the yttrium group of rare earths and has described ${ }^{461}$ the behavior of carrier-free rare earths on 


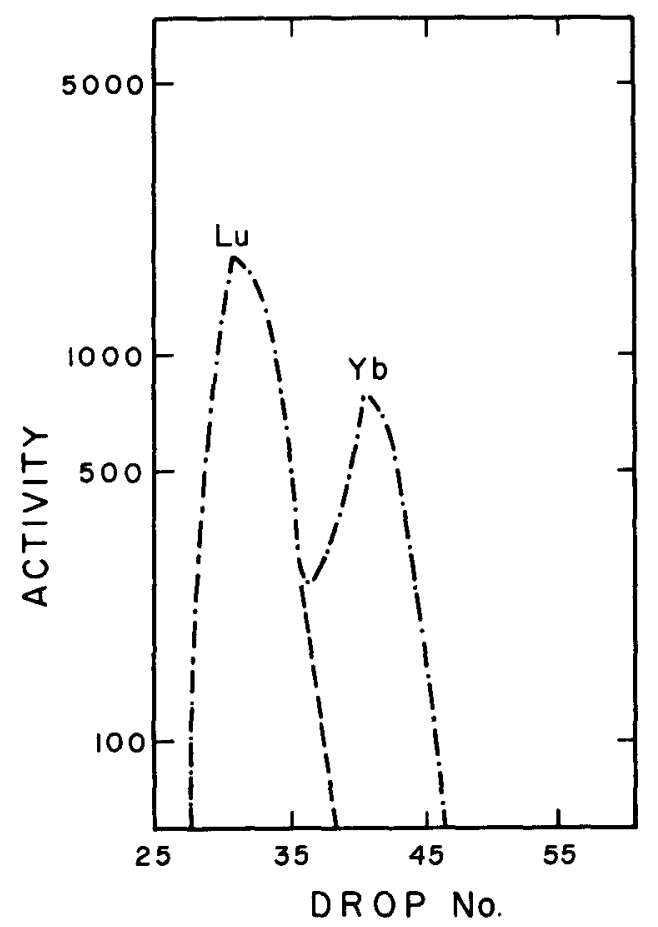

Fig. 76. Separation of $\mathrm{Lu}$ and $\mathrm{Yb}$ in 5 minutes. Column $5 \mathrm{~cm}$ long, temperature $90^{\circ} \mathrm{C}$, eluant flow rate 1 drop every 7 seconds (50 drops $/ \mathrm{ml}$ ) (378)

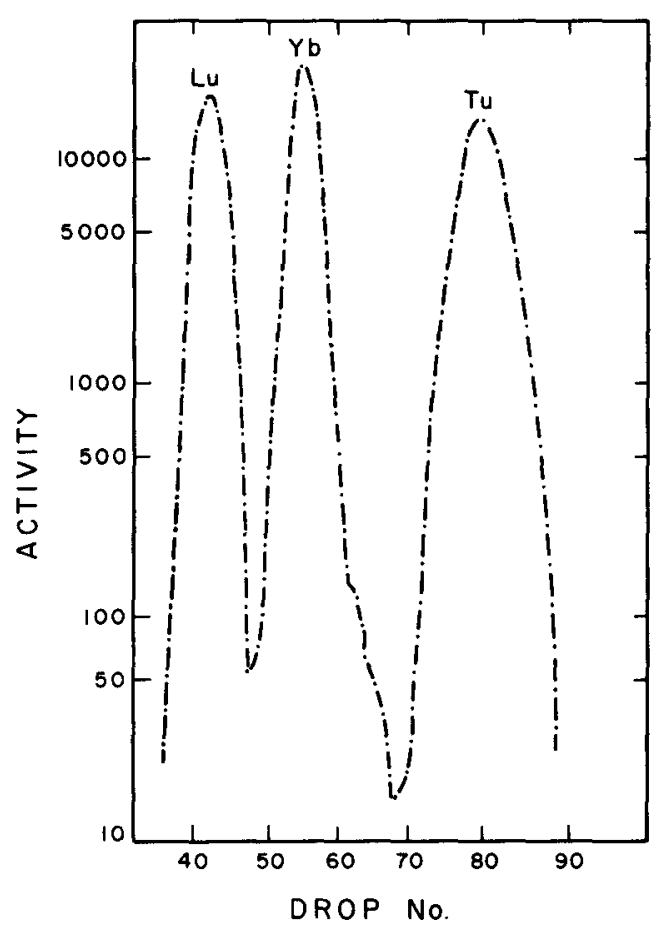

Fig. 77. Separation of $L u, Y b$, and Tm without heating, in a column $10 \mathrm{~cm}$ long. Flow rate less than a drop per minute (378)

columns at room temperature and at $87^{\circ} \mathrm{C}$. No data is available on elution of weighable amounts of rare earths with glycolate eluant but indications are that glycolate and lactate are quite comparable in their behavior.

IV. 7B-5. a-Hydroxyisobutyric Acid

An eluant which has effectively supplanted all others in the separation of the transplutonium elements, and which looks most promising for the rare earths, is a-hydroxyisobutyric acid (a-but). Choppin, Harvey, and Thompson, 77 early in 1956, showed how it could be used for the trans-Pu elements and in a subsequent paper Choppin and Silva ${ }^{76}$ showed a-hydroxyisobutyric (a-but) to be more effective than either lactate or citrate in separating rare earths on a tracer scale. An elution curve that they obtained from a $5 \mathrm{~cm} \times 2 \mathrm{~mm}$ column of Dowex $-50 \times 12$ at $87^{\circ} \mathrm{C}$ is shown in Fig. 78. The separation of adjacent elements is excellent, but it is difficult to make a fair comparison between the various eluants just on the basis of the elution curves shown here. Additional data will be presented in a later section on comparison of eluants.

Choppin and Silva indicated that room-temperature operation of a-but columns does not decrease the separation factors by more than $10 \%$ and $\mathrm{Smith}$ 


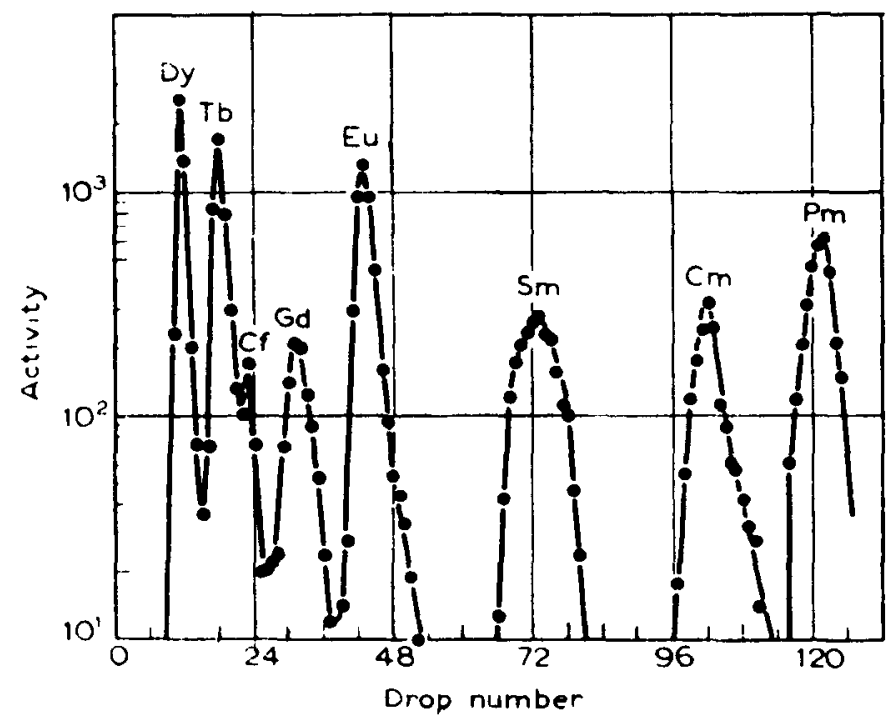

Fig. 78. Elution of tracer rare-earth-actinide activities with a-bydroxyisobutyric acid. Column $5 \mathrm{~cm} \times 2 \mathrm{~mm}$ Dowex-50 $\times 12(400+\mathrm{mesh})$, temperatare $87^{\circ} \mathrm{C}$, flow rate $1.0 \mathrm{ml} / \mathrm{cm}^{2} / \mathrm{min}, 0.2-0.4 \mathrm{M}$ solution, $\mathrm{pH} 4.0-4.6$ (76)

and Hoffmann 442 have shown that very effective separations can be made under these conditions.

Here again, no data are available on elution of weighable amounts of rare earths with a-hydroxyisobutyric acid but the separation factors are so much better than, and the structure is so similar to, lactic acid that the a-but system should be the most efficient one for all but macro-scale separations of the rare-earth elements.

One factor which seldom intrudes in discussions of this sort, but appears in practical applications, is cost. At the present time a-hydroxyisobutyric acid is approximately seventy times as expensive as lactic acid; and if very large volumes of eluant are needed, cost might be an important factor in the choice of the eluant to be used.

IV. 7B-6. Amino-Polyacetic Acids

It has long been known that the amino-polyacetic acid group of compounds form very tight complexes with a large number of metallic ions. The member of the group which has been investigated most thoroughly, and which has received the greatest acceptance, in the separation of the rare earth elements is ethylenediaminetetraacetic acid (EDTA):

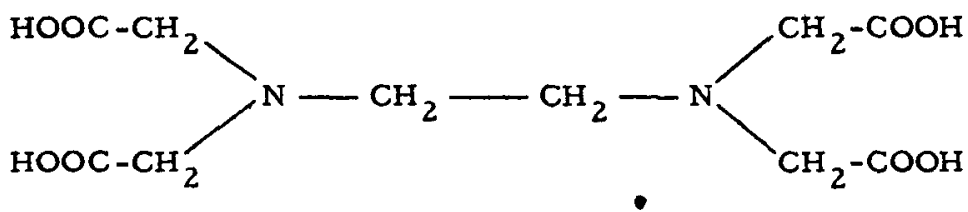


Mayer and Freiling, 297 in a 1953 article on the comparison of eluant efficiencies, showed that the rare-earth separation factors for EDTA are much larger than those for citrate, lactate, glycolate, or malate. Duyckaerts and Fuger ${ }^{14}$ describe a procedure for separating small amounts of a mixture of $\mathrm{Y}, \mathrm{Eu}, \mathrm{Pm}$, and Ce activities with a $2.5 \times 10^{-2} \mathrm{M}$ EDTA solution at a $\mathrm{pH}$ of 3.15-3.2, but Cornish, Phillips, and Thomas, ${ }^{85}$ investigating the dis tribution coefficient of rare earths between $0.005 \mathrm{M}$ EDTA + 0.14M acetate and ZEO-KARB 225, report that, while the separation factors between rare earths are large, the actual separation is poorer than with citric acid. This may account for the fact that so few articles have appeared in the literature concerning small-scale rare-earth separations with EDTA as the eluant.

By far the major application of EDTA has been in the large-scale production of pure rare-earth compounds. At high $\mathrm{pH}$ 's, and under the proper conditions, EDTA is admirably suited to the elution of large amounts of rare earths with the "head-to-tail" type of elution curve described in the citrate section. The low solubility of EDTA requires that columns be used in other than the $\mathrm{H}^{+}$form but this is not a serious restriction on most operations. Excellent articles on the separation of rare earths on EDTA-Cu ${ }^{++}$columns have been published by Spedding, Powell, and Wheelwright 453 and Powell and Spedding. 375,376 B runishol ${ }^{57}$ has used an eluant of $\mathrm{NH}_{4}^{+}-\mathrm{Mg}^{++}-\mathrm{EDTA}$ on $\mathrm{Cu}^{++}-\mathrm{NH}_{4}^{+}$columns, and Fuger ${ }^{161}$ has used EDTA on $\mathrm{Co}^{++}, \mathrm{Zn}^{++}$, and $\mathrm{Ca}^{++}$columns for fairly large-scale separations.

In addition, Spedding, Powell, Daane, Hiller, and Adams 456 have used EDTA-Cu ${ }^{++}$columns, and Iya and Loriers ${ }^{213}$ have used EDTA-NH ${ }_{4}^{+}$acetate columns for the large-scale separation of scandium from the rare-earth elements.

An interesting application of EDTA complexing to ion exchange separations has been published by Fritz and Umbreit, ${ }^{157}$ in which they used short columns of Dowex-50 resin to filter cationic species out of solutions containing a mixture of elements plus EDTA. The retention of cations by the resin is a fairly sharp function of $\mathrm{pH}$, as shown by their data in Fig. 79, but there is sufficient difference between certain mixtures of elements to permit simple, rapid separations to be made. Thus, the authors suggest that it should be possible to separate any of the rare earths from scandium, iron $(+3)$, bismuth, or copper; or, at $\mathrm{pH} \mathrm{2,} \mathrm{rare} \mathrm{earths} \mathrm{through} \mathrm{samarium} \mathrm{could}$ be separated from thorium, ytterbium, or lutetium; or a complete separation of thorium from iron or bismuth could be made; or a nearly complete separation of thorium from zirconium or scandium could be made by this method.

Another interesting application, although somewhat less useful for radiochemical separations, has been reported by Bril, Bril, and Krumholz, 46 who use electrodialysis to separate cationic, anionic, and uncharged species 


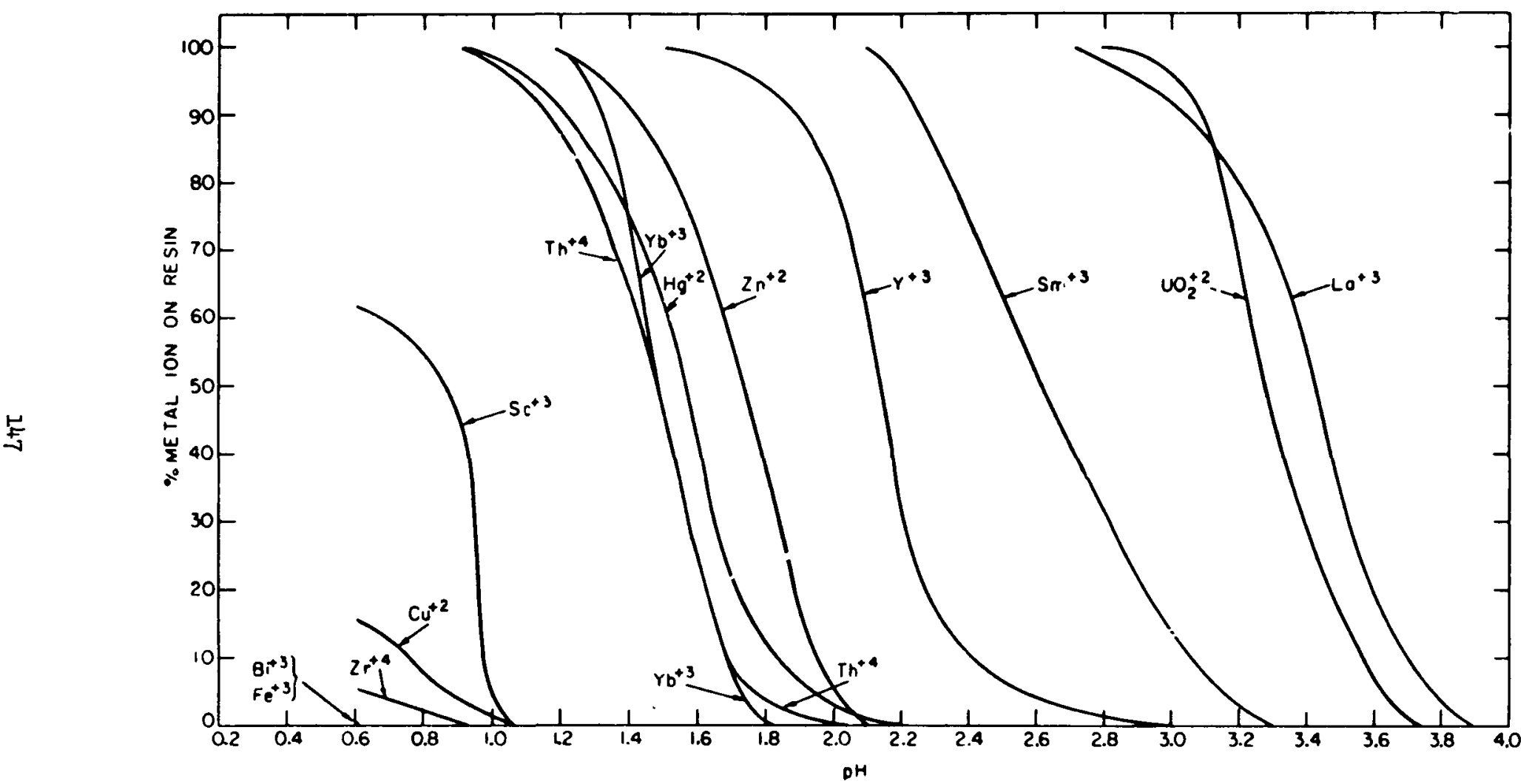

Fig. 79. Retention of different metal ions by Dowex-50 resin as a function of $\mathrm{pH}$ of solutions containing EDTA (157) 
in solutions containing EDTA. The solution between electrodes is compartmented by sheets of cation- and anion-exchange membranes which act as filters for the desired ions or complexes, and the authors report significant separations of Nd-La, Nd-Pr-La, and Th-Nd mixtures, although the over-all efficiency of the system was fairly low.

A close relative of EDTA which has been used to a limited extent for separation of certain rare-earth mixtures is $n$-hydroxyethyl-ethylene diamine triacetic acid (HEDTA):

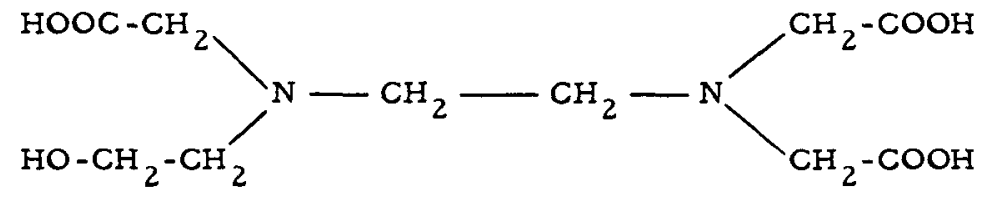

Spedding and his co-workers at Iowa State have published several papers 376,533 dealing with separation of rare earths with HEDTA. The consensus, however, is that HEDTA is not as efficient in separating all of the rare earths from each other as is EDTA. Its main usefulness seems to lie in the separation of Sc-rare earth mixtures, ${ }^{456}$ and Y-Dy mixtures, 9 (yttrium elutes between Sm and Nd with HEDTA instead of between Dy-Tb).

Fitch and Russell ${ }^{143}$ examined various imino-diacetic acids as possible complexing agents in the ion exchange separation of the rare earths and reported excellent separations with nitrilotriacetic acid (TRILO):

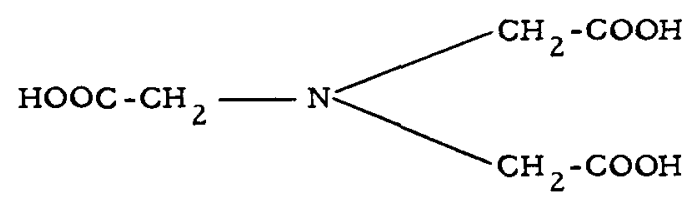

TRILO has received fairly wide acceptance as an eluting agent for rare-earth separations but, as with EDTA, its use has been confined mainly to production of large amounts of rare-earth compounds. TRILO is analogous to EDTA, too, in that most large-scale production procedures use retaining ions other than $\mathrm{NH}_{4}^{+}$. Thus, while Loriers and Carminati, 272 Holleck and Hartinger, 205 and Topp ${ }^{486}$ have used $\mathrm{NH}_{4}^{+}$columns with TRILO, Massonne $293,294,538$ has used $\mathrm{Zn}^{++}$, Noddack $340,341^{4}$ has used $\mathrm{Cu}^{++}, \mathrm{Ni}^{++}$ or $\mathrm{Na}^{+}$, and Weidmann and $\mathrm{Li}$ ebold ${ }^{513}$ have used $\mathrm{Cu}^{++}, \mathrm{Ni}^{++}$, or $\mathrm{Co}^{++}$columns for separating various mixtures of rare earths.

A fairly large number of amino-polyacetic acids, aside from those already discussed, have been mentioned in the literature in connection with the rare earths. Fitch and Russell ${ }^{143}$ investigated O-carboxyaniline $-N-N-$ diacetic acid, benzyl imino-diacetic acid, and hydrazinodiacetic acid as well as TRILO. They found TRILO to be the best of this group but hydrazinodi- 
acetic acid was promising enough to warrant a second paper ${ }^{144}$ describing a procedure by which La could be kept on an IR-120 column while all of the other rare earths were eluted. Wolf and Massonne 537 have reported successful large-scale separations of rare earths with $\beta$-oxyethyl-imino-diacetic acid at $70^{\circ} \mathrm{C}$ using columns of Wofatit KPS -200 resin.

Holleck and Hartinger 202 investigated the series of amino-tetraacetic acids: ethylenediaminetetraacetic acid, ortho-cyclohexanyl-diamino-tetraacetic acid, $\beta \beta^{\prime}$-diaminoethyl-ether-tetraacetic acid, and ethylene glycolbis- $\beta$-aminoethyl-ether-tetraacetic acid. They report that, at a given $\mathrm{pH}$, the separation factor increases in the sequence given, with the best separation shown by ethylene-glycol-bis- $\beta$-amino-ethyl-ether-tetraacetic acid at $\mathrm{pH} 6.75$.

The Iowa State group 9 has reported successful Nd-Pr separations using salts of diamino-diethyl-ether-tetraacetic acid and diamino-cyclohexanetetraacetic acid, and state that the performance of diamino-diethyl-ethertetraacetate on hydrogen beds is excellent, but they do not give any elution curves for these complexing agents.

Although there are relatively few articles in the literature concerning radiochemical separations using amino-polyacetic acids, it is not to be concluded that these complexing agents have no value in this type of operation. Perhaps they have not received the attention which is their due; or they may have been used and the procedures not published. As an example of this, Bunney, Hutchin, 64 and the authors have used diethylenetriamine-pentaacetic acid to separate 5-mg-per-element mixtures of $\mathrm{Y}-\mathrm{Dy}$ (Hutchin's curve is shown in Fig. 80) but nothing about this technique has appeared in the literature. Whatever the reason for the paucity of data in the past, however, the use of this group of complexing agents in the radiochemical separation of rare-earth elements warrants further study.

\section{7B-7. Other Eluants}

In addition to the systems that have already been discussed, a number of very interesting cation-exchange procedures dealing with rare-earth separations have appeared in the literature.

Yoshimura, Takashima, and $\mathrm{W}_{\text {aki }}{ }^{543}$ have obtained effective separation of weighable amounts of Sc from Er on Dowex -50 resin with a solution $0.5 \mathrm{M}$ in $\mathrm{NH}_{4}$ acetate and $0.5 \underline{\mathrm{M}}$ in acetic acid. Scandium passes through the column and erbium sticks.

Subbaraman, Rajan, and Gupta 467 have reported preliminary experiments which indicate that reasonably good rare-earth separations may be made on Dowex -50 resin with $0.3-0.5 \%$ solutions of sodium tripolyphosphate $(\mathrm{pH} \mathrm{3.6)}$ as the eluant. 


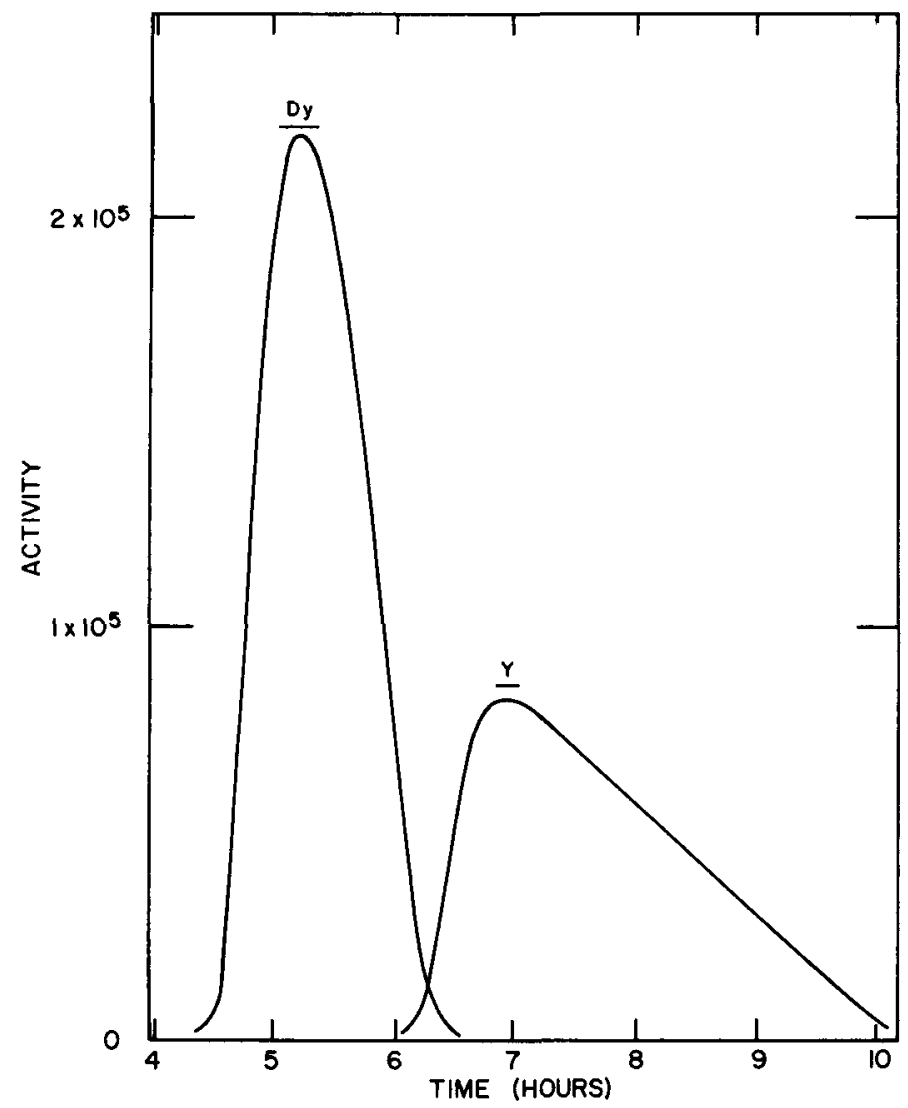

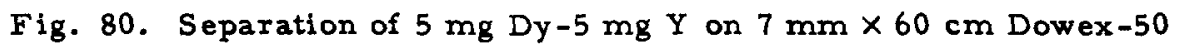
columns, temperature $90^{\circ} \mathrm{C}$, eluant $0.008 \mathrm{M}$ diethylenetriamine-pentaacetic acid, $\mathrm{pH} 4.25$, flow rate approximately $0.3 \mathrm{ml} / \mathrm{min}$.

Surls and Choppin 471 have investigated the Dowex-50-NH ${ }_{4}$ CNS system and report that the lanthanides elute in the usual sequence of decreasing atomic number with ammonium thiocyanate as the eluant, but the separation between adjacent elements does not seem to be great enough to permit easy purification of complex mixtures.

James and Bryan 217 have reported effective separation of small amounts of $\mathrm{Y}-\mathrm{E} u$ mixtures on Dowex-50 columns using solutions of thenoyltrifluoroacetone-dioxane-water ( $5 \mathrm{~g}$ TTA-45 ml dioxane-50 ml water, or $2 \mathrm{~g}$ T TA-38 $\mathrm{ml}$ dioxane- $60 \mathrm{ml}$ water) as an eluant. Excellent separations were obtained in the $\mathrm{pH}$ region 5.8-6.0, with $\mathrm{Y}$ eluting behind the Eu, but no data are available for other rare earths.

Ionescu, Constantinescu, Topor, and Gard 211 have used acetone-water$\mathrm{HCl}$ mixtures as eluants to separate $\mathrm{Ce}$ and La on columns of $\mathrm{KU}-2$ resin. An elution curve that they obtained with an eluant containing $65 \%$ acetone, $20 \%$ $\mathrm{HCl}(\mathrm{d}=1.16)$, and $15 \%$ water is shown in $\mathrm{Fig} .81$. The most remarkable feature of this curve is the fact that La elutes before Ce. If this behavior is 
systematic with all of the other rare earths this elution method could have important applications in certain types of separations.

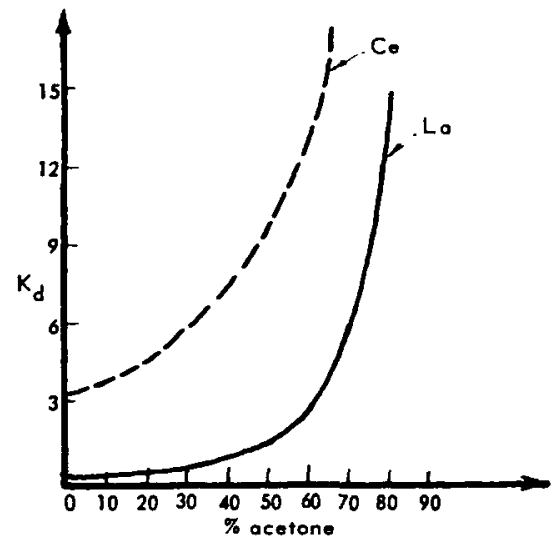

Fig. $81(\mathrm{a})$. Distribution coefficient variation for the La-Ce system (KU-2 resin with $\mathrm{HCl}$-acetone eluant) (211)

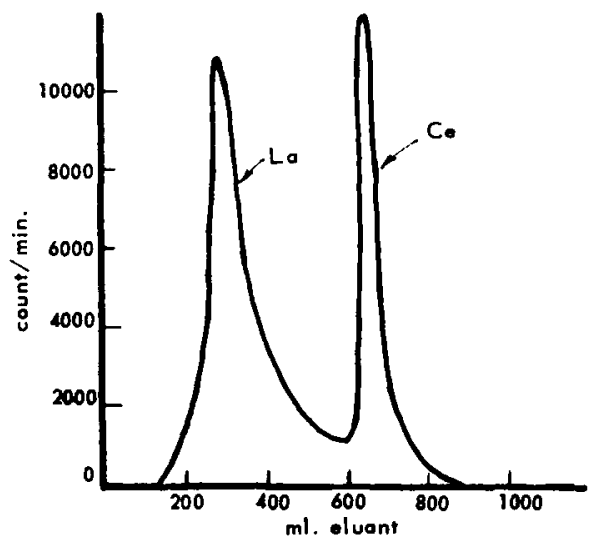

Fig. 81(b). Elution of Ce-La tracers from KU-2 resin with the eluant: $65 \%$ acetone, $20 \% \mathrm{HCl}$ $(d=1.16), 15 \%$ water $(211)$

\section{7B-8. Comparison of Eluants}

It is extremely difficult to make a quantitative comparison of eluants based on data which have appeared in the literature since so few experiments have been reported in which the eluant was the only variable. It is useful, nevertheless, to plot such data as are available for whatever qualitative conclusions may be drawn from them.

Powell and Spedding, 376 in their review article on separation of the rare earths with aminopolyacetic acids, have published curves of stability constant vs atomic number for various complexing agents in this group. Their curves are reproduced in Fig. 82 and have several very interesting features. To a first approximation the stability constants determine the degree of separation of rare earths with these eluants. Thus, in Fig. 82, the best separations should be obtained with that material whose curve has the highest slope. Nitrilotriacetic acid (TRILO) has a continuous upward slope and, as we have seen, may be used to separate all of the rare earths. Ethylenediaminetetracetic acid (EDTA) and diaminocyclohexane-tetraacetic acid (DCTA) have considerably larger slopes and commensurately larger separation factors. The curve for hydroxyethyl-ethylenediamine-triacetic acid (HEDTA), however, has an inflection in the Sm-Er region, so that separation of this group of elements is poor. And with diethylene-triamine-pentaacetic acid (DTPA) the curve has

- a maximum at dysprosium, which makes the Pm-Lu group of elements difficult to separate. 


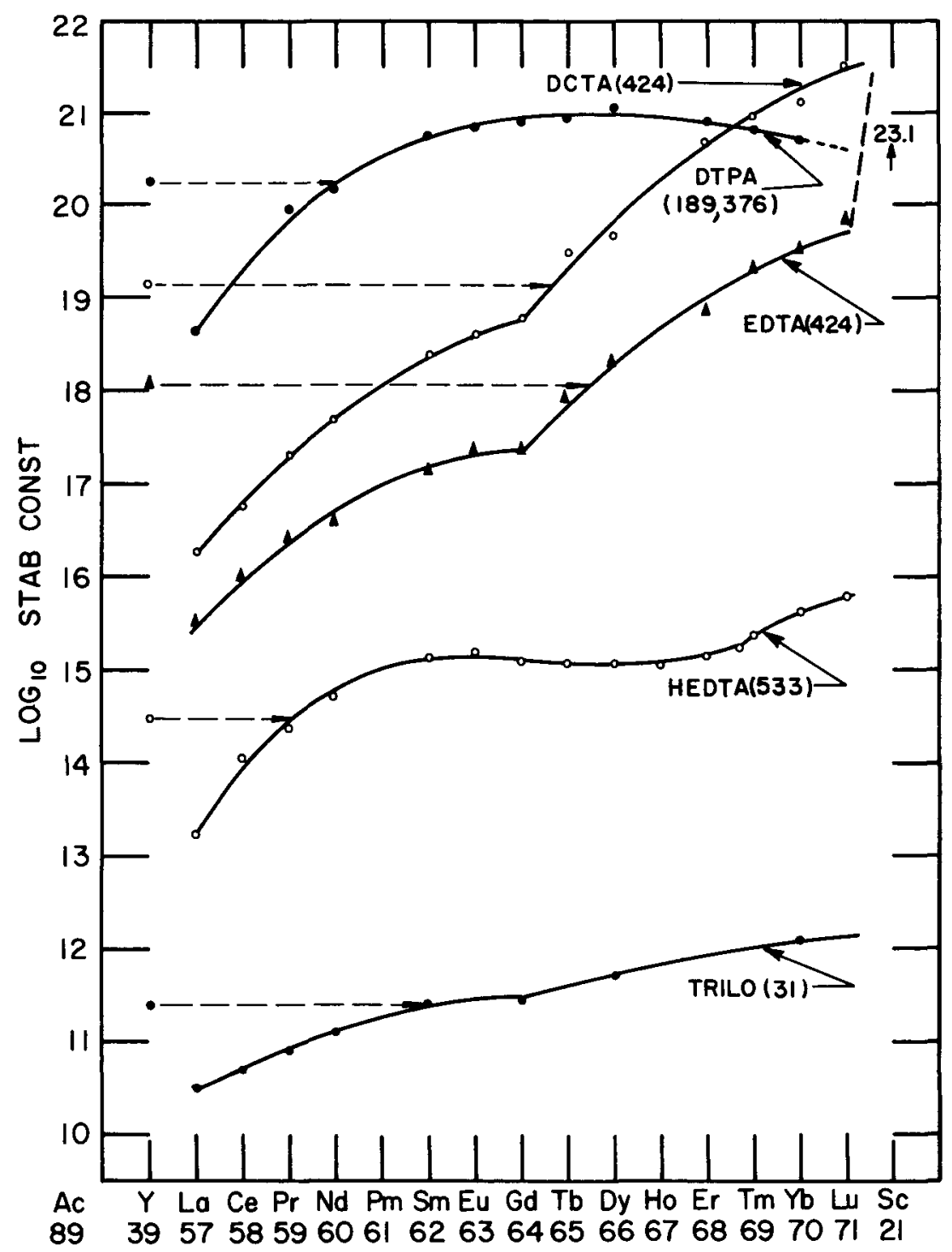

Fig. 82. Stability constants of various rare-earth chelates. The numbers in parentheses are keys to the references from which the data was obtained(376) 
The behavior of yttrium varies widely with these eluants. With EDTA it elutes between Dy-Tb, with DCTA between Tb-Gd, with TRILO between Sm-Eu, with DTPA near Nd, and with HEDTA near Pr. Thus it should be relatively easy to separate yttrium from a binary mixture with any rare earth by proper choice of an eluant.

Hiller ${ }^{198}$ has measured the stability constants for scandium complexes with EDTA, HEDTA, DCTA, and DETPA, but his data had not been received at the time this monograph was completed.

While the curves of Fig. 82 do not represent all of the aminopolyacetic acids that have been investigated they just about exhaust the available stability constant data. As more information of this type becomes available additional curves may be drawn.

Data for a number of other eluants have been plotted in Fig. 83. Here the information has been obtained entirely from elution curves, and the logarithm of the peak elution position is plotted vs atomic number. All peak elution positions are normalized to a value of 1.00 for europium and the curves have been adjusted vertically for clarity of presentation. Most of the data have been obtained from Stewart's 461 review of ion exchange methods, although some additional information has been obtained from articles which have already been quoted in the sections on the various eluants. Preobrazhenskii ${ }^{545}$ has published a review of the ion exchange separation of the rare earths and actinides in which he tabulates the separation factors for these elements in lactate, hydroxyisobutyrate, and glycolate eluants. He obtained his data from essentially the same sources as were used for Fig. 83 and, since he includes separation factors for the actinide elements, his tabulation is reproduced in Table 12. Note that the peak elution positions are normalized to $G d=1.00$. For each

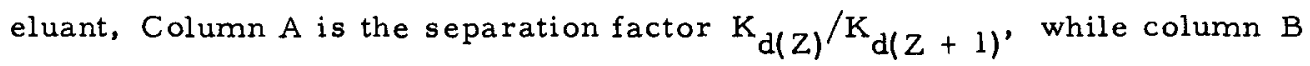
is the peak elution position relative to $\mathrm{Gd}$.

In Fig. 83, the best eluant, so far as separation factors are concerned, is the one whose curve has the highest slope. In Fig. 83, a-hydroxyisobutyrate (a-but) $\left(87^{\circ} \mathrm{C}\right)$ has the steepest slope, followed by lactate $\left(87^{\circ} \mathrm{C}\right)$, glycolate $\left(87^{\circ} \mathrm{C}\right)$, and citrate $\left(87^{\circ}-100^{\circ} \mathrm{C}\right)$ in that order. The room-temperature citrate and glycolate columns seem to be definitely inferior for separation of the middle rare earths, and, to a lesser extent, the heavy rare earths, although they seem to be quite satisfactory for the light rare earths.

In the high-temperature columns yttrium elutes near dysprosium, while in the room-temperature citrate and glycolate columns it elutes near Eu. Smith and Hoffmann ${ }^{42}$ report that with room-temperature a-but columns yttrium continues to elute near Dy.

Very few data are available for either Sc or Ac but if a generalization may be made from the curves of Fig. 83, the Ac peak has a separation factor 


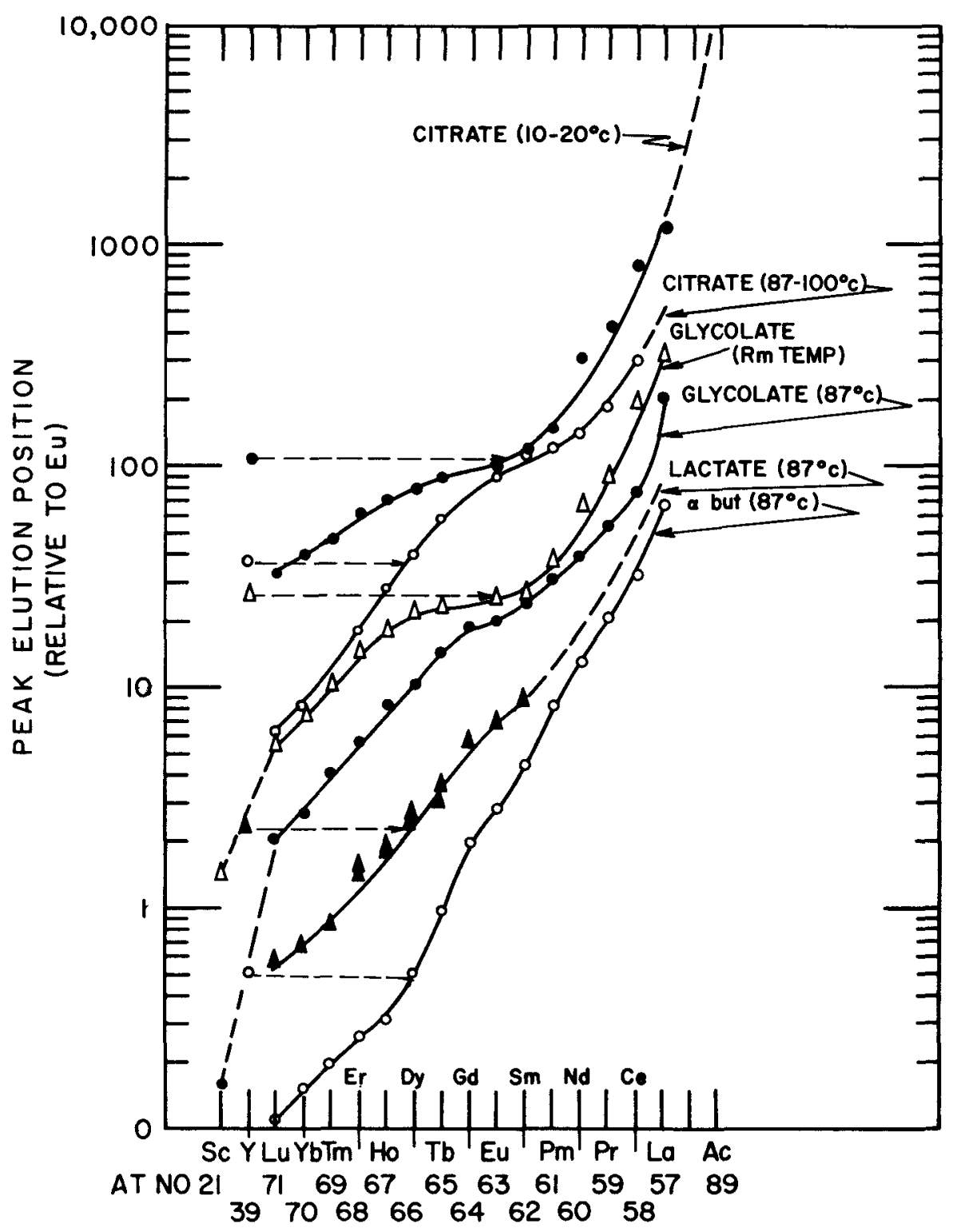

Fig. 83. Logarithm of peak elution position vs atomic number for various eluants. Peak elution positions are normalized to 1.00 for Eu and curves are adjusted vertically for clarity of presentation. 
Table 12. Elution characteristics of rare-earth and actinide elements on Dowex-50 cation-exchange resin with several eluants. Column $A$, separation factor between pairs of elements. column B, elution position of each element relative to gadolimium (545)

\begin{tabular}{|c|c|c|c|c|c|c|c|}
\hline \multirow[b]{4}{*}{ Element } & \multicolumn{7}{|c|}{ Eluant } \\
\hline & \multicolumn{2}{|c|}{ Lactate } & \multicolumn{2}{|c|}{ a-Hydroxyssobutyrate } & \multicolumn{3}{|c|}{ Glycolate } \\
\hline & $90^{\circ} \mathrm{C}$ & $20^{\circ} \mathrm{C}$ & $87^{\circ} \mathrm{C}$ & $20^{\circ} \mathrm{C}$ & $87^{\circ} \mathrm{C}$ & \multicolumn{2}{|c|}{$20^{\circ} \mathrm{C}$} \\
\hline & A & $\mathbf{A}$ & $\mathbf{A}$ & $\mathbf{A}$ & A & A & $\mathbf{B}$ \\
\hline \multirow[t]{2}{*}{ Lu } & 0.063 & 0.053 & 0.055 & 0.050 & 0.107 & & 0.222 \\
\hline & 1.31 & 1.4 & 1.36 & 1.45 & 1.32 & 1.33 & \\
\hline \multirow[t]{2}{*}{$\mathrm{Yb}$} & 0.083 & 0.073 & 0.075 & 0.073 & 0.14 & & 0.295 \\
\hline & 1.43 & 1.54 & 1.33 & 1.37 & 1.5 & 1.37 & \\
\hline \multirow[t]{2}{*}{$\operatorname{Tm}$} & 0.119 & 0.112 & 0.10 & 0.10 & 0.21 & & 0.405 \\
\hline & I. 47 & 1.54 & 1.3 & -- & 1.4 & 1.4 & \\
\hline \multirow[t]{2}{*}{ Er } & 0.175 & 0.173 & 0.13 & -- & 0.3 & & 0.566 \\
\hline & 1.52 & 1.60 & 1.23 & -- & 1.5 & 1.28 & \\
\hline \multirow[t]{2}{*}{ Ho } & 0.266 & 0.28 & 0.16 & 0.177 & 0.45 & & 0.725 \\
\hline & 1.21 & 1.34 & 1.56 & 1.77 & -- & $\cdots$ & \\
\hline \multirow[t]{2}{*}{$\mathbf{Y}$} & 0.321 & 0.37 & 0.25 & 0.314 & -- & & 1.04 \\
\hline & 1.14 & 1.08 & 1.04 & 1.1 & -- & 1.3 & \\
\hline \multirow[t]{2}{*}{ Dy } & 0.366 & 0.40 & 0.26 & 0.346 & 0.55 & & 0.89 \\
\hline & 1.56 & 1.65 & 1.88 & 1.84 & 1.39 & 1.04 & \\
\hline \multirow[t]{2}{*}{$\mathrm{Tb}$} & 0.572 & 0.67 & 0.49 & 0.64 & 0.77 & & 0.93 \\
\hline & 1.73 & 1.50 & 2.2 & 1.57 & 1.3 & 1.08 & \\
\hline \multirow[t]{2}{*}{ Gd } & 1.00 & 1.00 & 1.00 & 1.00 & 1.00 & & 1.00 \\
\hline & 1.22 & 1.04 & 1.4 & 1.54 & 1.06 & 1.00 & \\
\hline \multirow[t]{2}{*}{$\mathbf{E u}_{\mathbf{u}}$} & 1.22 & 1.04 & 1.40 & 1.54 & 1.06 & & 1.00 \\
\hline & 1.28 & 1.20 & 1.6 & 2.06 & 1.22 & 1.08 & \\
\hline $\mathrm{Sm}$ & 1.56 & 1.25 & 2.25 & 3. 18 & 1.29 & & 1.08 \\
\hline & 1.32 & 1.32 & 1.82 & 1.57 & 1.29 & 1,33 & \\
\hline $\mathrm{Pm}$ & 2.06 & 1.65 & 4.10 & 5.0 & 1.67 & & 1.44 \\
\hline & 1.33 & 1.35 & 1.61 & 2.09 & 1.26 & 1.83 & \\
\hline $\mathbf{N d}$ & 2.74 & 2.22 & 6.60 & 10.45 & 2.1 & & 2.63 \\
\hline & 1.36 & 1.38 & 1.57 & -- & 1.4 & 1.37 & \\
\hline Pr & 3.74 & 3.07 & 10.45 & - & 2.94 & & 3.60 \\
\hline & 1.73 & 2.04 & 1.6 & -- & 1.5 & 2.2 & \\
\hline $\mathrm{Ce}$ & 6.47 & 6.27 & 16.70 & 15.5 & 4.42 & & 7.93 \\
\hline & 1.83 & 2.1 & 2.2 & - & 2.6 & 1.64 & \\
\hline$\underline{\mathrm{La}}$ & 11.8 & 13.2 & 34.10 & -- & 12 & & 15.45 \\
\hline $\mathrm{Mv}$ & & & 0.189 & & & & \\
\hline & & & 1.4 & & & & \\
\hline $\mathrm{Fm}$ & 0.43 & & 0.264 & & & & \\
\hline & 1.43 & & 1.86 & & & & \\
\hline $\mathbf{E}$ & 0.62 & & 0.49 & 0.59 & & & 0.457 \\
\hline & 1.24 & & 1.54 & 1.46 & & 1.20 & \\
\hline $\mathrm{Cf}$ & 0.77 & & 0.76 & 0.86 & & & 0.543 \\
\hline & 1.58 & & 2.25 & 2.0 & 1.17 & & \\
\hline Bk & 1.21 & & 1.63 & 1.68 & & & \\
\hline & 1.54 & & & 2.7 & 1.43 & & \\
\hline $\mathrm{Cm}$ & 1.87 & 1.47 & 3.45 & 4.55 & & & 1,16 \\
\hline & 1.21 & 1.23 & & 1.4 & 1.14 & 1.25 & \\
\hline $\mathrm{Am}$ & 2.27 & & 5.0 & 6.3 & & & 1.45 \\
\hline
\end{tabular}


of about 10 behind $\mathrm{La}$, and the Sc peak has a separation factor of between 5 and 10 ahead of Lu.

In summary, then, the consensus of the literature articles seems to be that a-hydroxyisobutyric acid is the best eluant for most small-scale cationexchange-resin separations of the rare-earth elements, followed by lactic acid, glycolic acid, and citric acid in that order. For large-scale production of pure rare earths EDTA is used most extensively, followed by nitrilotriacetic acid.

IV. 7C. ANION-EXCHANGE RESINS

IV. 7C-1. Introduction

The use of synthetic anion-exchange resins in the purification of the rare-earth elements has become a widely accepted part of many rare-earth radiochemical procedures. Under most conditions, however, the rare-earth elements do not form species which will stick to the resin, so the anionexchange resin columns are used as filters to remove undesired impurities from the rare earths as a group in one step of their purification. In this type of operation, therefore, it is desirable to know the anion-exchange-resin behavior of the whole periodic table of elements so that a single most efficient separation may be carried out. Unfortunately, information of this broad a scope is not easily come by and we must make do with what is available.

Kraus, Moore, Nelson, and co-workers at Oak Ridge have been studying the anion-exchange-resin behavior of a large number of elements for many years and have written a superb series of articles on the subject. An excellent review article on metal separations by anion exchange has been published in 1958 by Kraus and $\mathrm{Nelson}{ }^{244}$ which discusses $\mathrm{HCl}_{2} \mathrm{Cl}^{-}, \mathrm{HCl}-\mathrm{HF}, \mathrm{NO}_{3}^{-}$, $\mathrm{SO}_{4}=$, and other anion systems, while subsequent papers 331,245 deal with more recent developments in the field.

IV. 7C-2. Chloride

The HCl-Dowex-I system has been studied more completely than any other. Kraus and Nelson's 244 curves are reproduced in Fig. 84 and indicate that a rare-earth solution which is greater than $6 \underline{\mathrm{M}}$ in $\mathrm{HCl}$ will, when it is passed through a short Dowex-1 column, leave a large number of elements on the resin and pass the rare earths. This is the procedure used by the authors in routine rare-earth purification and has been found to be quite satisfactory.

A similar application, although one with more sophisticated overtones, is the anion-exchange separation of the lanthanides from the actinide group of elements. In most chemical steps, including cation-exchange column elution, the actinide elements will behave essentially the same as the rare earths and 

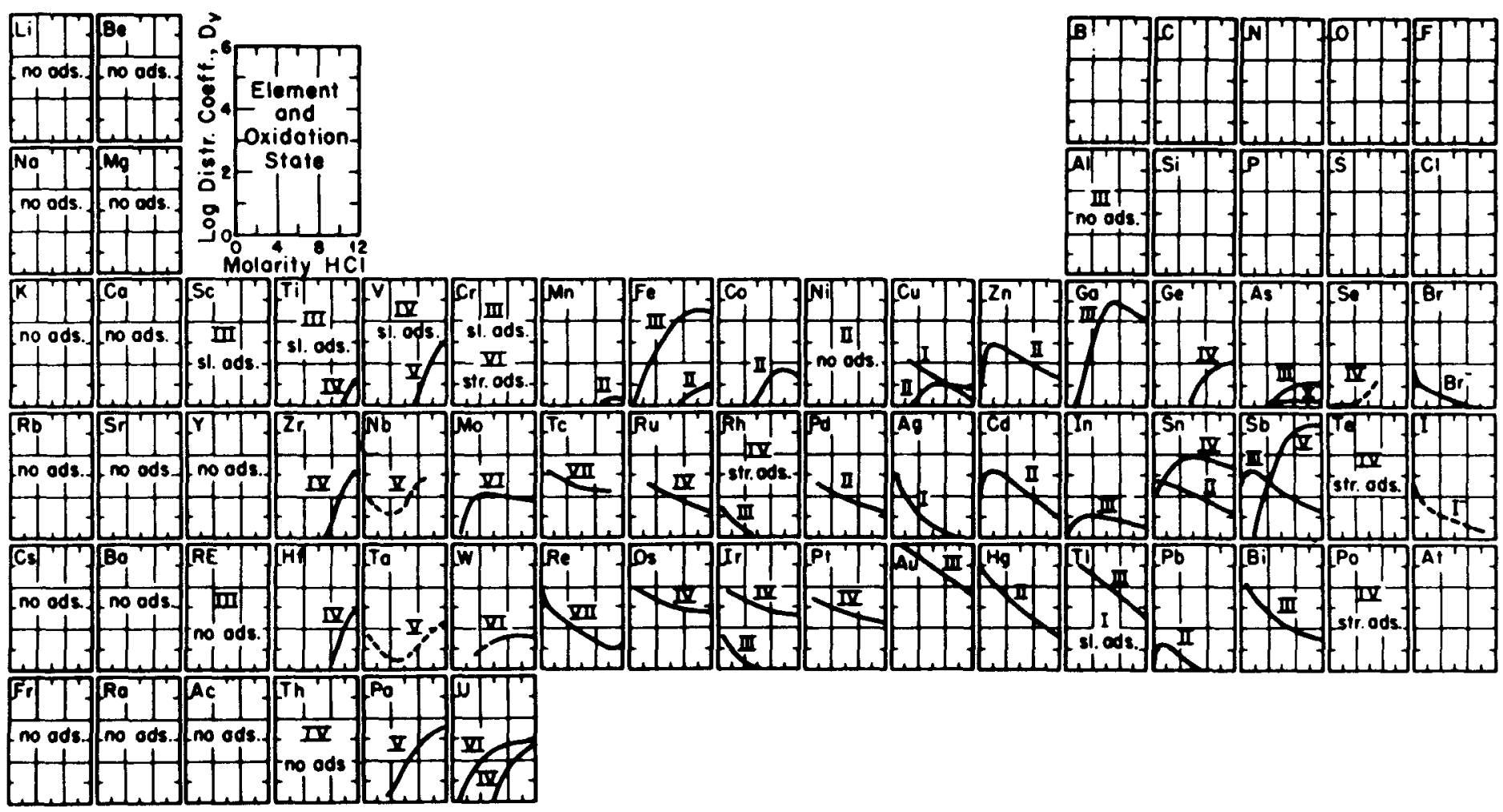

Fig. 84. Adsorption of the elements from hydrochloric acid on Dowex $-1 \times 8$ anionexchange resin. Legend: no ads. = no adsorption for $0.1<\mathrm{MHCl}<12$; s1. ads. =

slight adsorption in $12 \underline{\mathrm{M}} \mathrm{HCl}\left(0.3 \leq \mathrm{D}_{\mathrm{v}} \leq 1\right)$; str. ads. = strong adsorption ( $\left.\mathrm{D}_{\mathrm{v}} \gg 1\right)(244)$ 
will not separate from them. Several years ago, however, Street, Diamond, and Seaborg 104, 466 noted that on Dowex-50 with strong $\mathrm{HCl}$ as eluant the actinides eluted ahead of their "normal" position with respect to their lanthanide homologues (see Fig. 60) and, conversely, Thompson, Harvey, Choppin。 and Seaborg 479 reported that on anion-exchange resins the lanthanides elute before the actinides with concentrated $\mathrm{HCl}$. This effect has subsequently been found to be more pronounced in concentrated LiCl solutions, and Hulet, Gutmacher, and Coops 209 have recently completed a systematic study of this system. They found that excellent lanthanide-actinide separations as well as separations of the transplutonium elements (either individual elements or two-member groups) were achieved at $87^{\circ} \mathrm{C}$ with Dowex-1-8\% DVB (8-15 $\mathrm{mm} / \mathrm{min}$ settling rate in water) using $10 \underline{\mathrm{M}} \mathrm{LiCl}$ acidified to $0.1 \underline{\mathrm{M}} \mathrm{HCl}$ at flow rates of $0.3-0.6 \mathrm{ml} / \mathrm{cm}^{2} \mathrm{~min}$. An elution curve which they obtained with a mixture of 14 rare earths plus selected actinides is shown in Fig. 85.

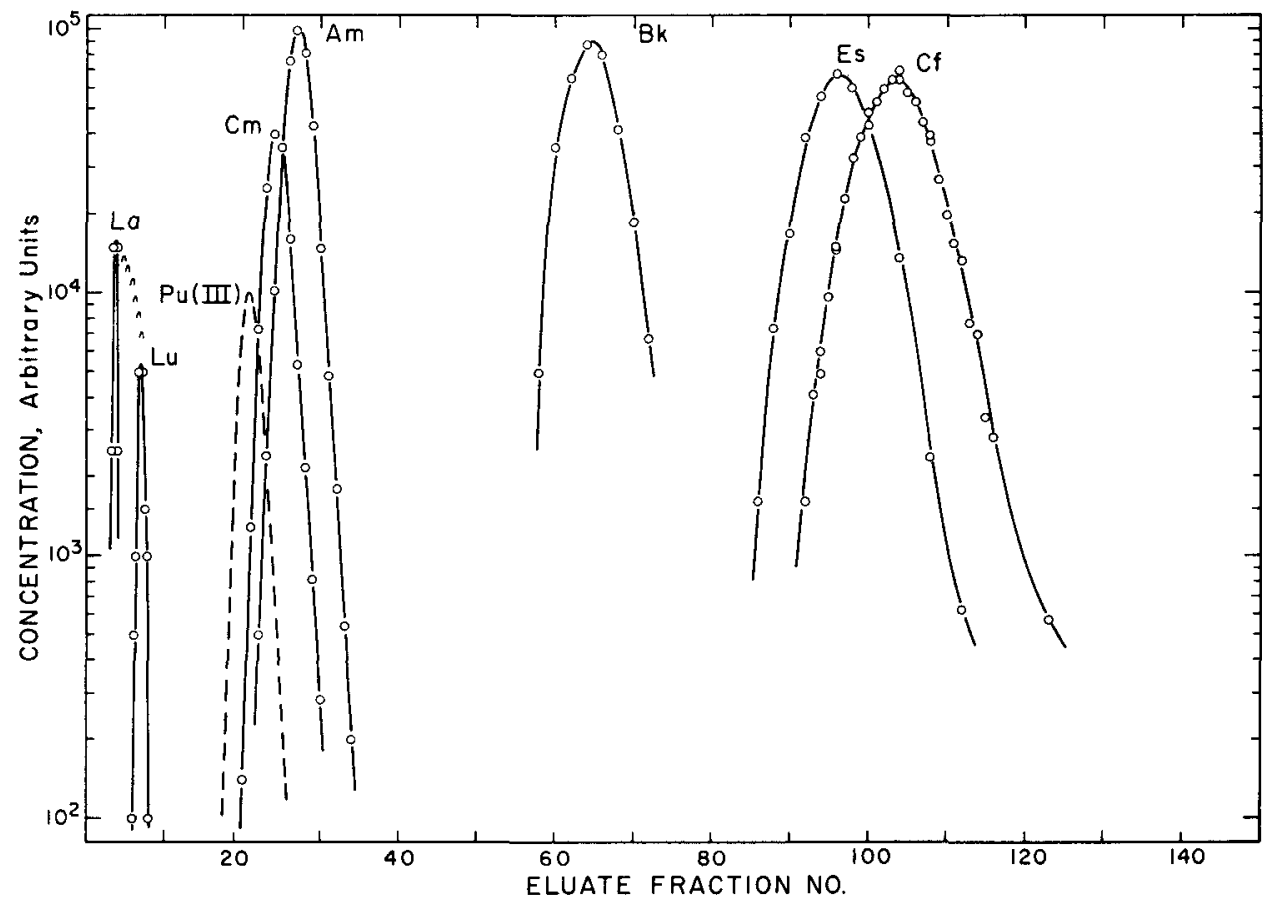

Fig. 85. Elution of lanthanides and tripositive actinides from Dowex-1, $8 \% \mathrm{DVB}$ at $87^{\circ} \mathrm{C}$ using $9.92 \mathrm{M} \mathrm{LiCl}-0.106 \mathrm{M} \mathrm{HCl}$ at a flow rate of $0.27 \mathrm{ml} / \mathrm{cm}^{2}$ min. Resin bed $=1 \mathrm{~cm}$ diam $\times 12 \mathrm{~cm}(209)$

Under these conditions the lanthanides elute very quickly, and essentially as a group, while the actinides are retained by the resin.

Yashimura, Takashima, and $\mathrm{W} \mathrm{ki}^{543}$ have reported that scandium may be separated from erbium (and presumably from the other rare earths) by adsorbing it on a column of Dowex-1 $1 \times 8$ anion-exchange resin from $13 \mathrm{M} \mathrm{HCl}$ 
solution. The scandium is then eluted with dilute $\mathrm{HCl}$. This separation must be done carefully, however, since Gardner ${ }^{165}$ reports a carrier-free scandium chemistry which is based on the fact that $\mathrm{SC}$ will not stick to Dowex-2 resin in $11 \mathrm{M} \mathrm{HCl}$, and Dowex-1 and Dowex -2 behave very much alike. G.M. Iddings of LRL has been unable to duplicate the results in $13 \mathrm{M}$ HCl solution.

- IV. 7C-3. Nitrate

A number of very interesting papers have appeared in the literature recently dealing with the anion-exchange resin-nitrate system. Buchanan, Faris, Orlandini, and Hughes 61 have reported the behavior of a large number of elements in the Dowex-1- $\mathrm{HNO}_{3}$ system, and their data are reproduced in Fig. 86. According to this figure, none of the rare earths, with the exception of approximately $25 \%$ of the $\mathrm{Ce}$ in the 4-8M $\mathrm{HNO}_{3}$ concentration range, are adsorbed by Dowex-l in nitric acid solution. This behavior is very use ful, therefore, in separating the rare earths as a group from those elements which do stick to the resin under these conditions, and the authors have found this method very satisfactory for separating the rare earths from thorium. It should be pointed out, however, that the data of Buchanan, et al., in Fig. 86 do not agree in all respects with data of other authors who have investigated the same system. Bunney, Ballou, Pascual, and Foti, ${ }^{63}$ for instance, have published curves of $\mathrm{K}_{\mathrm{d}}$ vs $\mathrm{HNO}_{3}$ concentration for a number of elements with Dowex -2 resin (Fig. 87) and their results for Ru, Mo, and $\mathrm{Zr}$ are significantly different from the Buchanan data. It would perhaps be wise, therefore, to use the $\mathrm{HNO}_{3}$ curves of $\mathrm{Fig}$. 86 with caution until this apparent discrepancy is resolved.

While the rare earths do not adsorb to any great extent on anion-exchange resins from nitric acid solutions, their behavior varies widely in nitrate salt solutions. Thus Danon 101 reports that the adsorption of praseodymium on Dowex-I increases with the nature of the cation of the supporting nitrate solution in the order $\mathrm{H}<\mathrm{NH}_{4}<\mathrm{Li}<\mathrm{Ca}<\mathrm{Cu}<\mathrm{Fe}<\mathrm{Al}$, and describes a procedure for separating Ac-La mixtures using a 4. $4 \mathrm{M} \mathrm{LiNO}_{3}$ solution as eluant (Fig. 88). Marcus and Nelson 278 have also investigated the Dowex-1-LiNO 3 systems and have obtained excellent separation of complex mixtures of rare-earth tracers using anion-exchange resins. Their data are reproduced in Figs. 89 and 90 and indicate that there are very significant differences between the adso:ption coefficients of various rare earths in strong $\mathrm{LiNO}_{3}$ solution. Above 3-4M $\mathrm{LiNO}_{3}$ these differences become large enough to permit separation of individual elements and, as shown in Fig. 90, separations may be carried out very nicely with the gradient elution technique. It should be emphasized, however, that the distribution coefficients can be influenced very strongly by the presence of $\mathrm{H}^{+}$ion. Marcus and Nelson state that the $\mathrm{K}_{\mathrm{d}}$ for La in $4 \mathrm{M}$ LiNO 3 

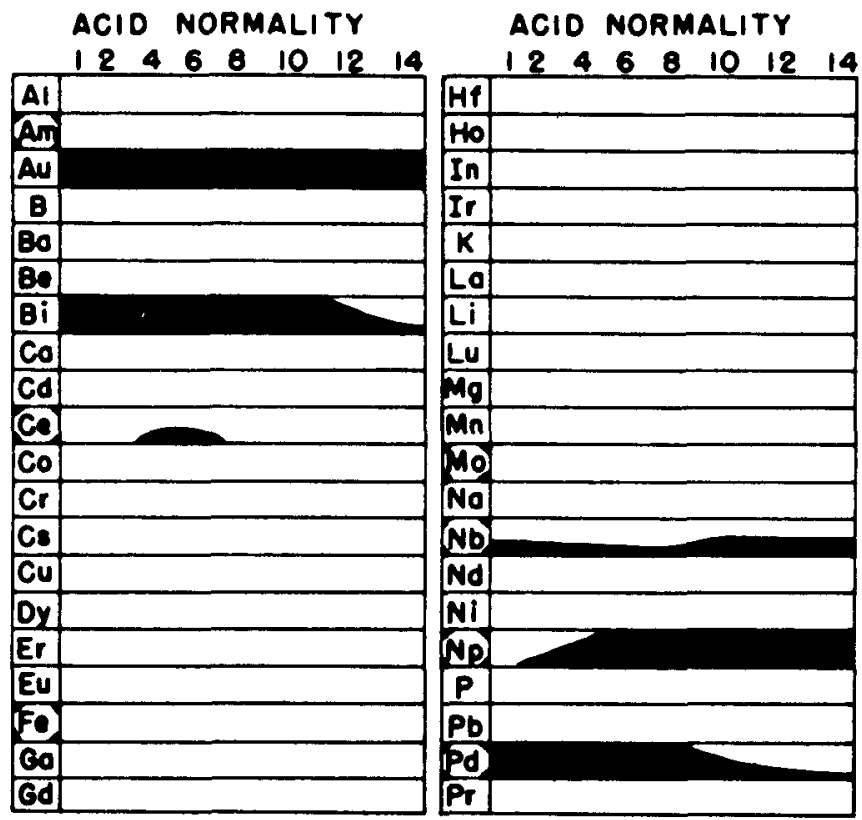

ACID NORMALITY

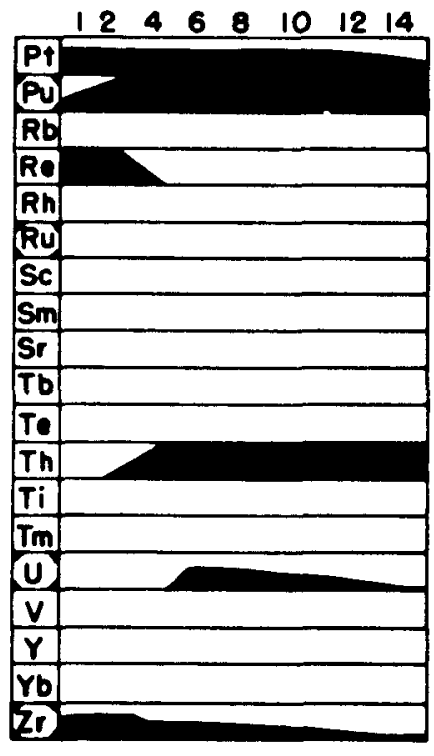

Not Adsorbed

UNCERTAIN

Adsorbed

Elements were determined rodiochemically, oll others ore spectrographic estimotions.

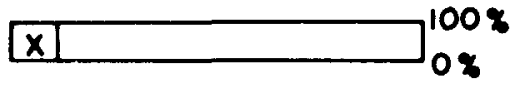

Fig. 86. Elution through Dowex-1 resin column with nitric acid (61)

remains constant between $10^{-2}$ and $10^{-4} \underline{\mathrm{M}} \mathrm{HNO}_{3}$, but decreases rapidly at $\mathrm{H}^{+}$concentrations greater than $10^{-2} \underline{\mathrm{M}}$.

The elution curve of Fig. 90 is of interest, too, in that it shows the rare earths to be eluted in order of decreasing atomic number, which is the same sequence shown on cation-exchange column elutions and directly opposite to the $\mathrm{L}_{1} \mathrm{Cl}$ anion-exchange elution order (Fig. 85).

Marcus and Nelson also report that the parent-daughter nuclides $\mathrm{Ba}^{140}$ $\mathrm{La}^{140}$ are easily separated in a few minutes with $3-4 \underline{\mathrm{M}} \mathrm{LiNO}_{3}$ and a $1-\mathrm{cm}$ long column. Lanthanum is adsorbed while Ba passes through.

IV. 7C-4. Thiocyanate

Surls and Choppin 47 have studied the ion-exchange behavior of the lanthande and actinide elements in thiocyanate solution. On Dowex-1 at room temperatures the distribution coefficients are sufficiently high in $2 \mathrm{M}$ $\mathrm{NH}_{4} \mathrm{SCN}$ to permit transfer of the rare-earth activities to the resin and column elution steps to be carried out. The $K_{d}$ differences between individual rare 


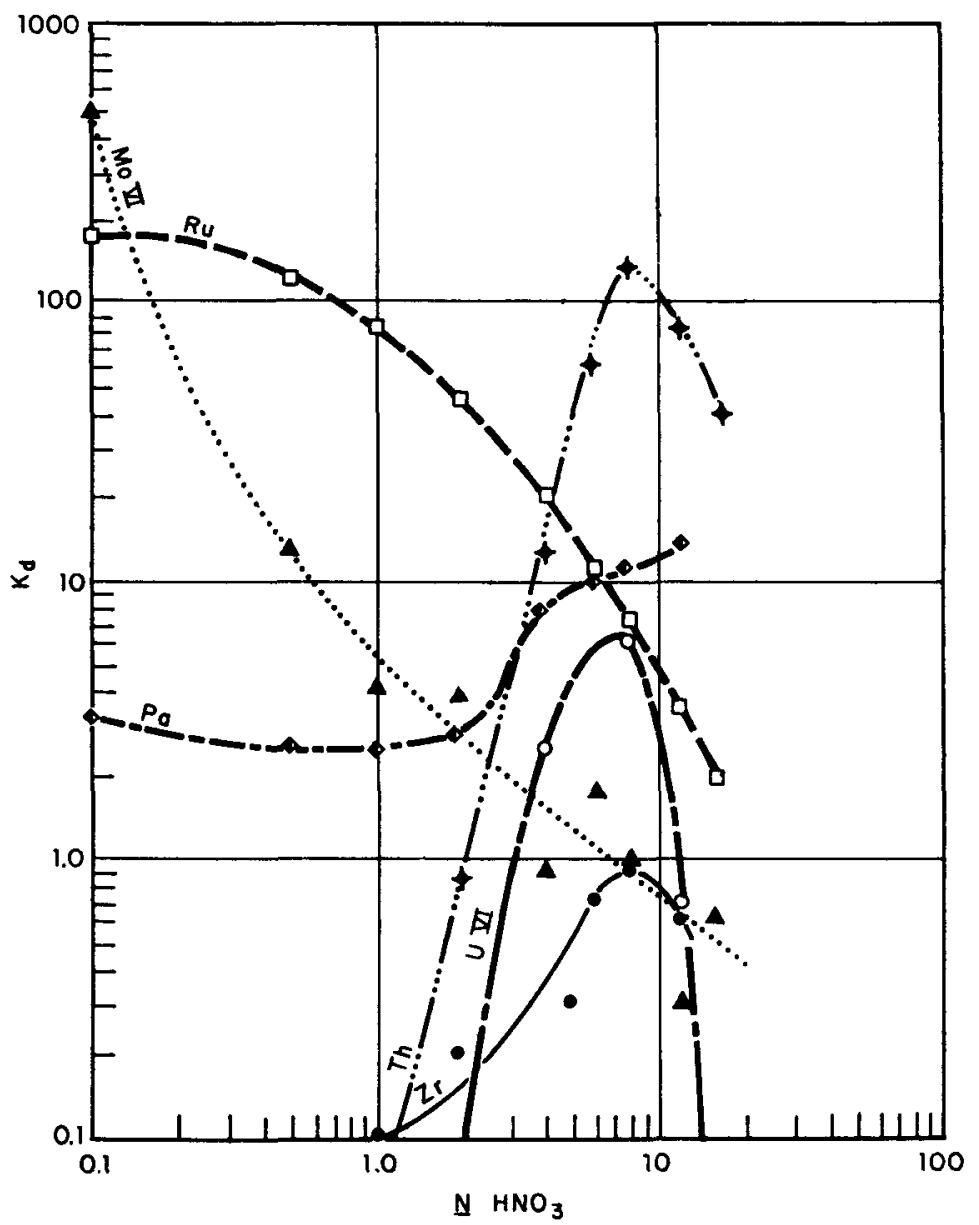

Fig. 87. Equilibrium adsorption on Dowex-2 anion-exchange resin in $\mathrm{HNO}_{3}$

earths, however, are not great enough to effect a separation of individual elements under these conditions; but there is a large enough difference in behavior between the lanthanides and actinides to allow relatively easy group separations to be carried out on ammonium thiocyanate columns. Coleman, Penneman, Keenan, LaMar, Armstrong, and Asprey ${ }^{83}$ have taken advantage of this fact to separate gram amounts of americium from large quantities of light rare earths in a simple one-step process using Dowex-1 $\times 8$ resin and 5 M $\mathrm{NH}_{4} \mathrm{SCN}$ eluant.

IV. 7C-5. Sulphate

Very little work has been done with the rare earths in the anion-exchange resin-sulphate system. Bunney, Ballou, Pascual, and Foti ${ }^{63}$ report that $Y$, $\mathrm{Ce}$, and $\mathrm{Am}$ do not show any significant adsorption by Dowex-2 resin at any $\mathrm{H}_{2} \mathrm{SO}_{4}$ acid concentration, and presumably none of the rare earths are adsorbed in this medium. Other elements do stick, however, and relatively 


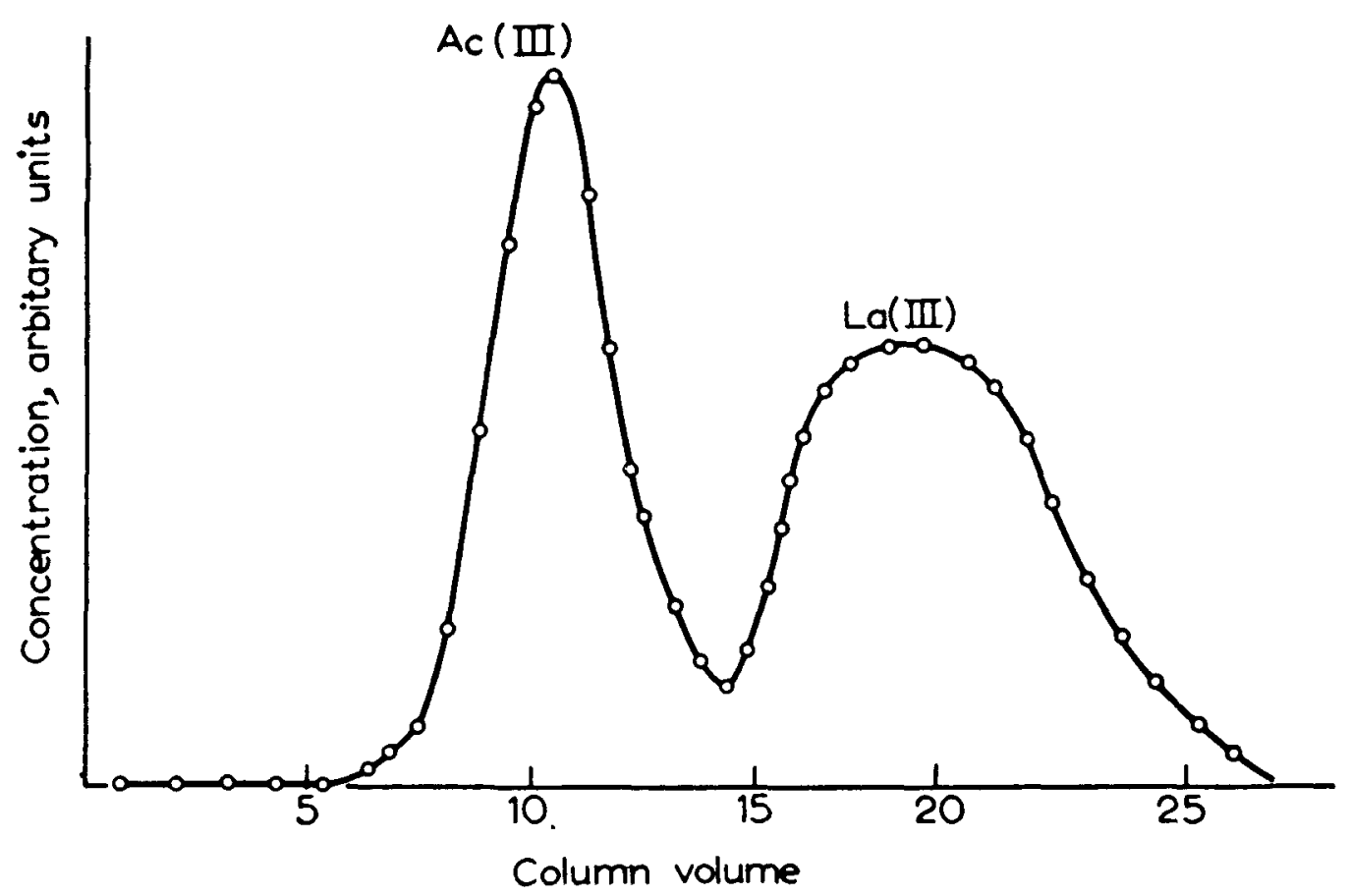

Fig. 88. Elution of tracer $\mathrm{Ac}$ and $30 \mathrm{mg}$ of $\mathrm{La}\left(\mathrm{NO}_{3}\right)_{3}$ from Dowex-l with 4. $4 \mathrm{M} \mathrm{LiNO}_{3}$. Column $30 \mathrm{~cm} \times 0.24 \mathrm{~cm}^{2}$, Dowex-1 $\times 8 \%$ DVB, 50-100 mesh, flow rate $0.4 \mathrm{~cm} / \mathrm{min}(101)$

simple purification of the rare-earth group may be carried out on sulfate columns. Fig. 91 reproduces the data of Bunney et al., and indicate that the rare earths may be separated very easily from $R u, T h, P a, Z r, U^{+6}, N b$, and $\mathrm{MO}^{+6}$ in $0.1 \mathrm{~N} \mathrm{H}_{2} \mathrm{SO}_{4}$. Indeed, Nagle and Murthy ${ }^{329}$ have used Amberlite IRA -400 and $\mathrm{pH} 2.0-2.5$ sulphate solution to separate $\mathrm{Ce}$ and $\mathrm{Th}$ in monazite sand analysis with very good results, and Sekine and Saito 431 have used the Dowex-l-dilute $\mathrm{H}_{2} \mathrm{SO}_{4}$ system to separate La-Th mixtures.

IV. 7C-6. Fluoride

The use of anion-exchange resin-fluoride systems would seem to have very little application in rare-earth radiochemistry because of the low solubility of the rare-earth fluorides. Scandium, however, forms a well-known fluoride complex which may be useful in anion-exchange separations.

Faris 130 has recently published an article in which the elution characteristics of some 50 elements in a hydrofluoric acid medium were studied on Dowex-1 resin (Fig. 92). In dilute HF solutions $S c$ apparently can be adsorbed on the resin without difficulty, although the $\mathrm{K}_{\mathrm{d}}$ decreases at higher $\mathrm{HF}$ concentrations.

Schindewolf and Irvine 412 also report this type of behavior for scandium and have used it to separate carrier-free scandium actıvity from titanium 
UCRL -5923

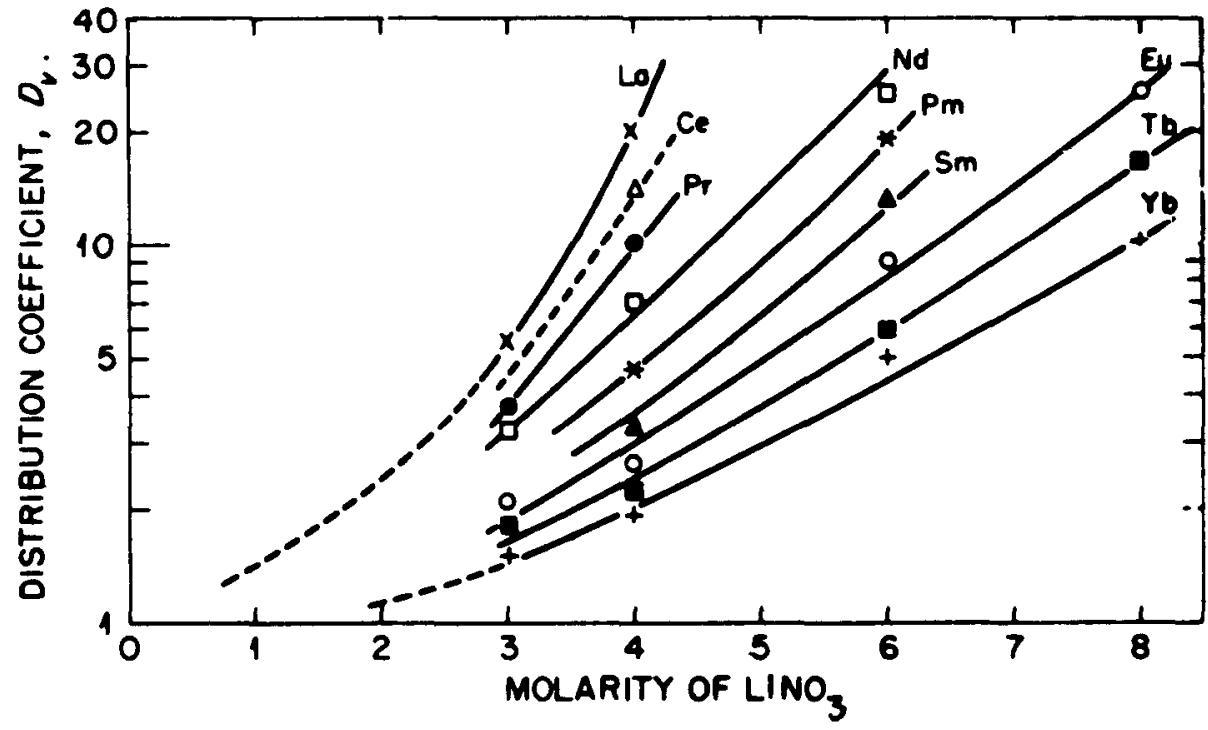

F'ig. 89. Adsorption of rare earths on Dowex-1 anion-exchange resin from lithium nitrate solutions $\left(2 \times 10^{-3} \underline{\mathrm{M}} \mathrm{HNO}_{3}, 78^{\circ} \mathrm{C} \quad(278)\right.$

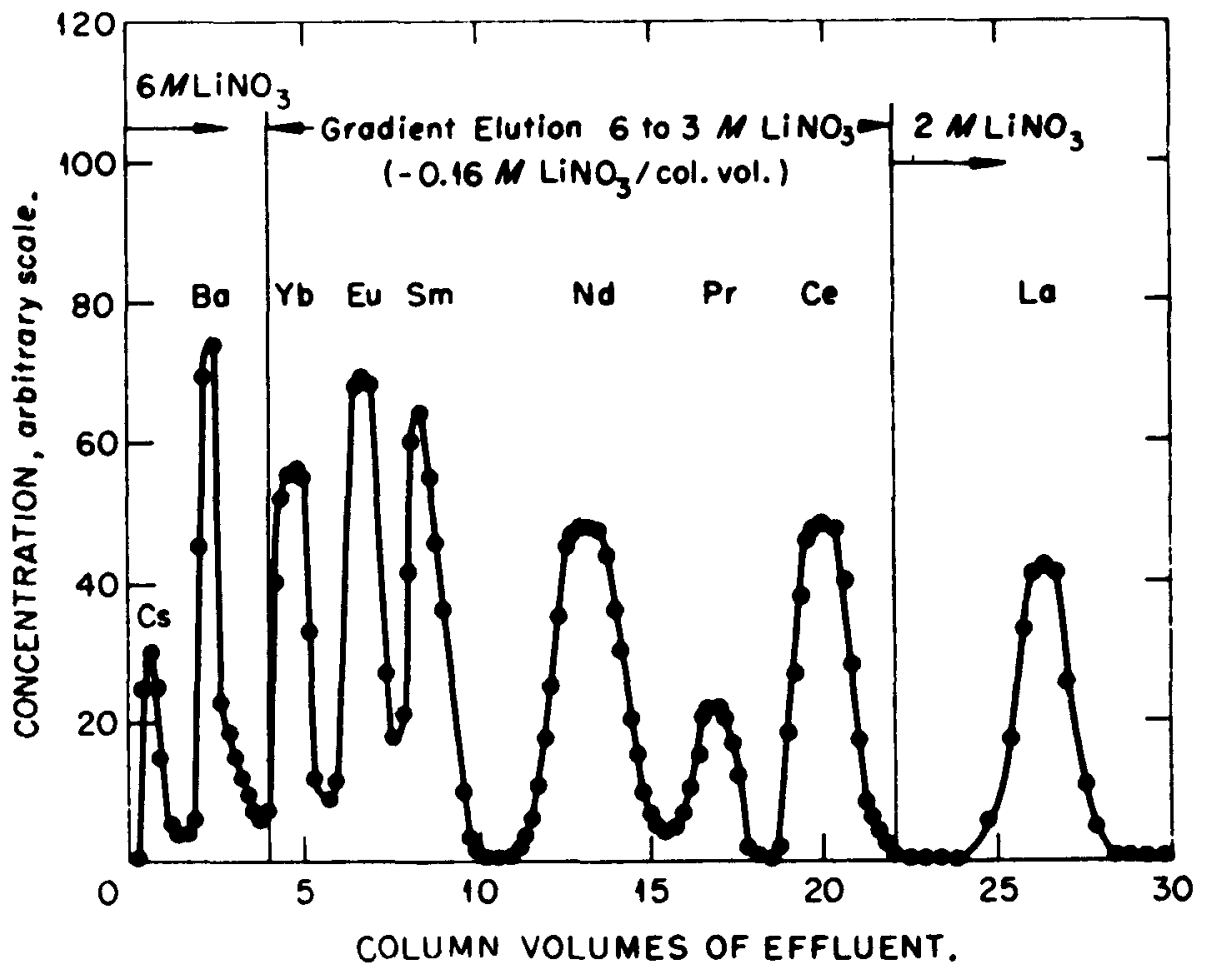

Fig. 90. Separation of $\mathrm{Cs}, \mathrm{Ba}$, and several rare earths in $\mathrm{LiNO}_{3}$ solutions (78. $\mathrm{C}, 0.25 \mathrm{~cm}^{2} \times 10.5 \mathrm{~cm}$ Dowex $-1-10 \%$ DVB columns) (278) 


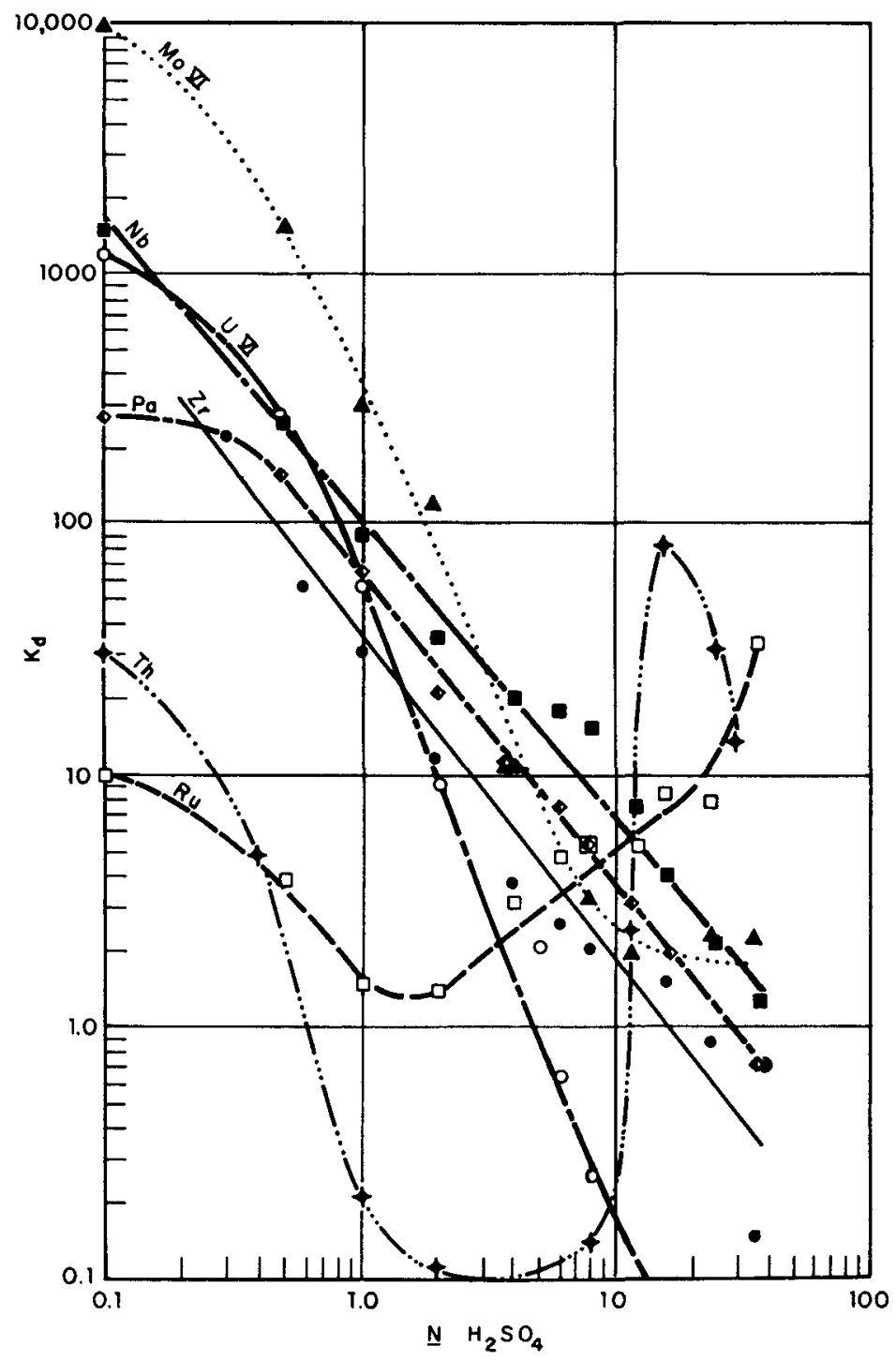

Fig. 91. Equilibrium adsorption in $\mathrm{H}_{2} \mathrm{SO}_{4}$ on Dowex-2 anion-exchange resin at room temperature (63)

targets. Scandium is adsorbed on a Dowex -1 column from $0.5 \underline{M}-2$. 5 $\underline{M}$ HF solution and eluted with $15 \mathrm{M} \mathrm{HF}$.

Nelson, Rush, and Kraus ${ }^{331}$ have recently published an article on the anion-exchange behavior of 19 elements with mixed $\mathrm{HCl}-\mathrm{HF}$ eluants.

IV. 7C-7. Oxalate

Here again the low solubility of the rare-earth oxalates precludes their very widespread use with anion-exchange resinsystems, but scandium forms a soluble complex with oxalate which may be used to advantage. Waiter 509 has investigated the behavior of scandium in dilute sodium salts of oxalate 


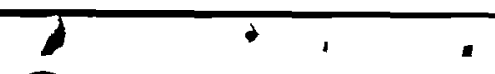

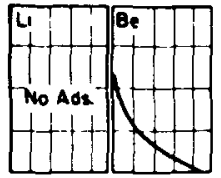

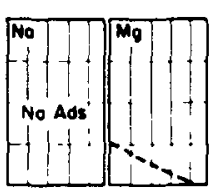

NO ADS - NO ADSORPTION FAOM IM-24M HF SL ADS - SLIGHT ADSORPTION

STR ADS - STRONG AOSORPTION LOG DIST. COEFF >2

ROMAN NUMERALS REFER TO OXIDATION STATE IN INITIAL SOLUTION
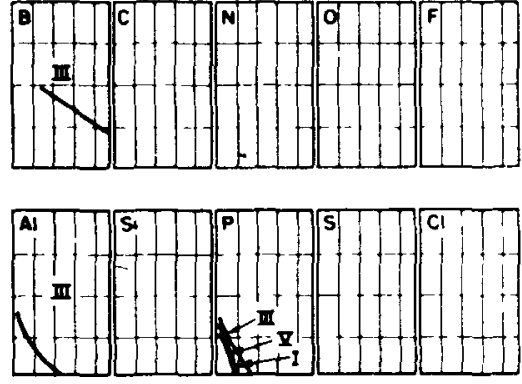

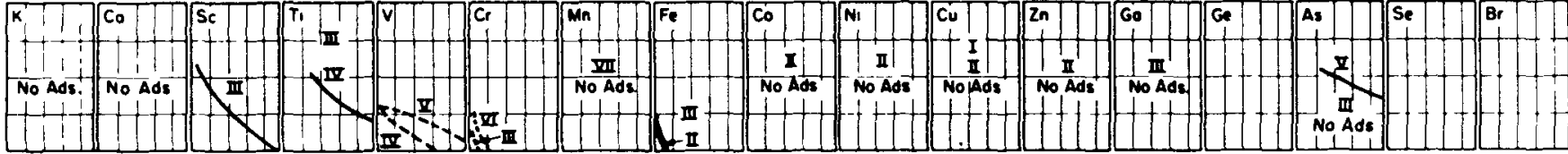

占

(1)

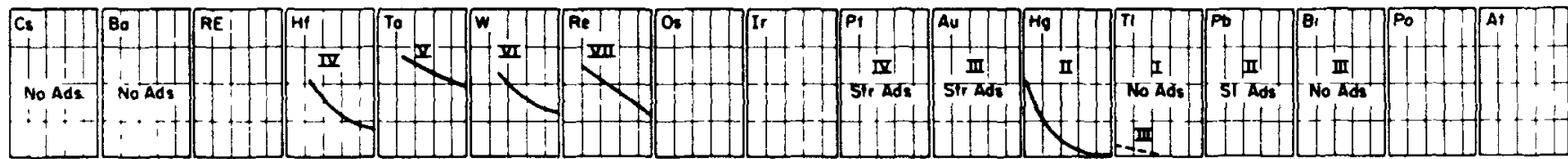

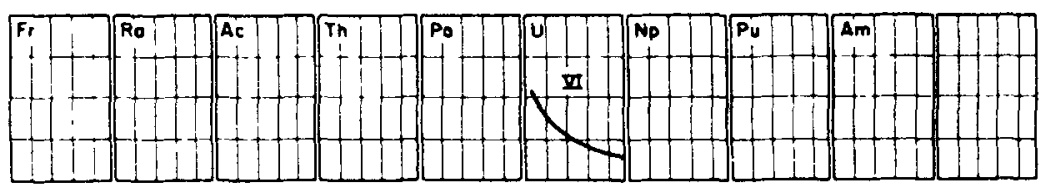

Fig. 92. Distribution coefficients in HF on Dowex-1 at room temperature (130) 


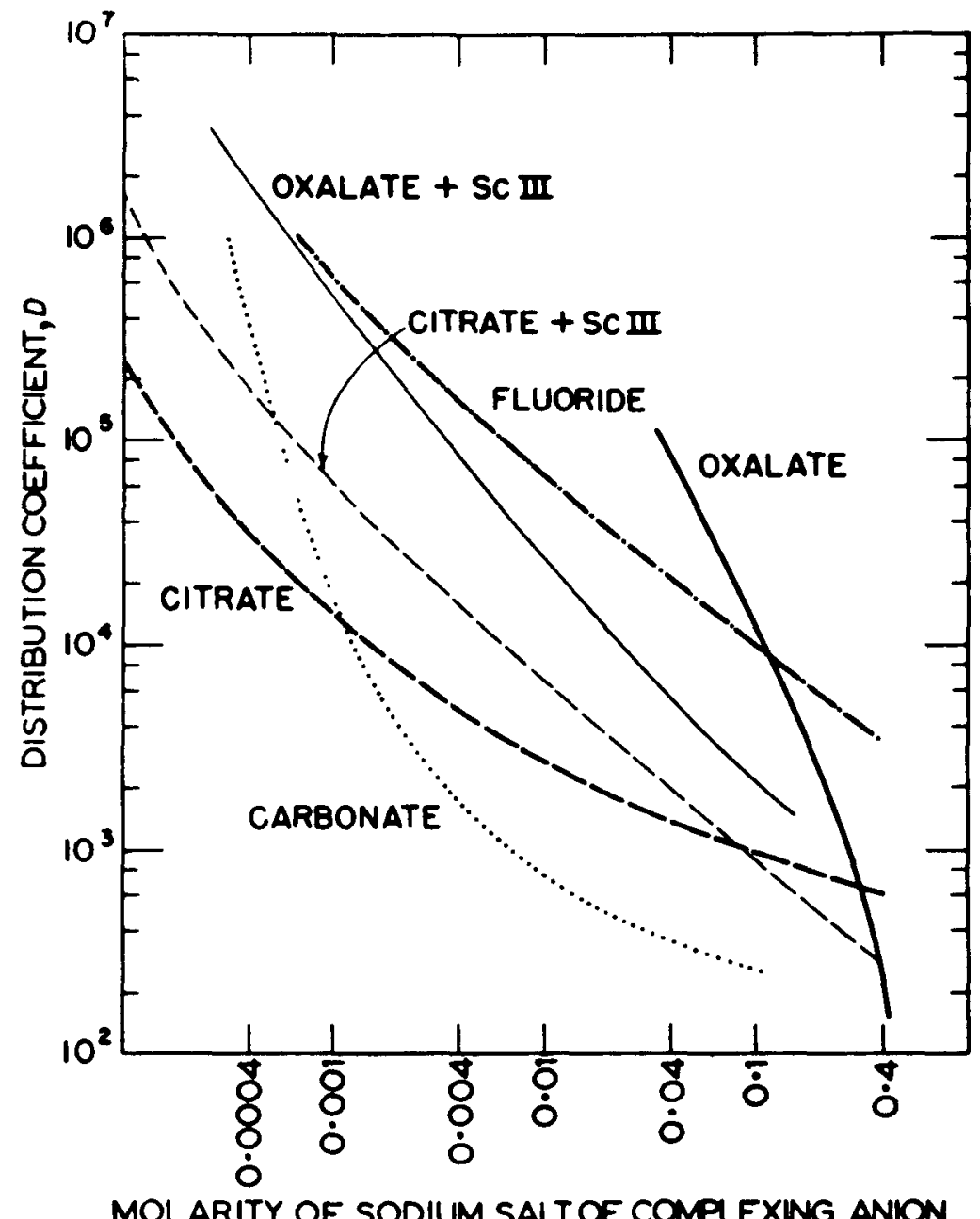

Fig. 93. Distribution coefficients of scandium(III) and vanadium(IV) on Dowex-1 anion-exchange resin as a function of chelating reagent concentration for several reagents. Light lines-scandium; heavy lines-vanadium (509)

and citrate (Fig. 93) and shows that at low oxalate concentrations scandium is very strongly adsorbed. He used a Dowex-1-dilute oxalic acid medium to separate carrier-free scandium and vanadium from $5 \mathrm{mg}$ of titanium but found that better Sc-V separations were obtained with an eluate which consisted of $0.1 \underline{\mathrm{M}} \mathrm{H}_{2} \mathrm{C}_{2} \mathrm{O}_{4}+0.1 \underline{\mathrm{M}} \mathrm{HCl}$.

IV.7C-8. Phosphate

Freiling, Pascual, and Delucchil ${ }^{153}$ have investigated the behavior of a number of elements in the Dowex-2- $\mathrm{H}_{3} \mathrm{PO}_{4}$ system (Fig. 94). If we may infer the behavior of all of the lanthanides from the data on $\mathrm{Ce}^{+3}$ in Fig. 94, the rare earths are adsorbed by the resin at low $\mathrm{H}_{3} \mathrm{PO}_{4}$ concentrations but are eluted by $6-7 \mathrm{~N}$ acid. This is significantly different from the behavior of 


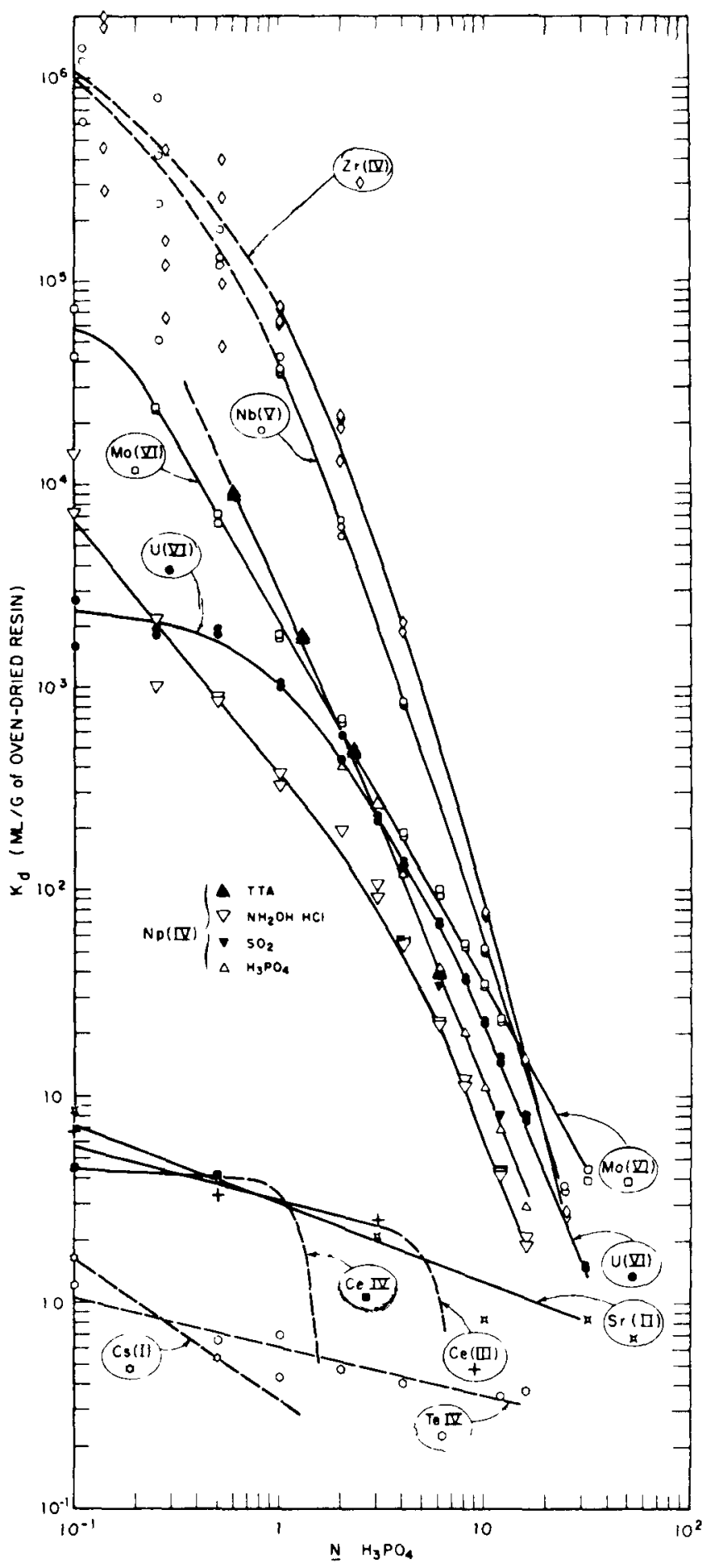

Fig. 94. Equilibrium distribution coefficients of various fission products and actinide elements between $\mathrm{H}_{3} \mathrm{PO}_{4}$ solution and Dowex-2 at room temperature (153) 
IV. 7C-9. Carbonate

Very little work has been done with the rare earths in the anion-exchange resin-carbonate system. Walter ${ }^{509}$ reports fairly high distribution coefficients for scandium in dilute sodium carbonate solutions on Dowex-l resin but states that the results were erratic. The scandium samples failed to approach equi librium smoothly with increased shaking time and often deposited a large fraction (up to half) of the total activity on the walls of the cellulose acetate vials in which they were shaken, which may be indicative of radiocolloid formation.

Saito and Sekine 403 report that in Dowex-1-sodium carbonate systems the distribution coefficient for yttrium tracer has a maximum value of approximately 3000 in $0.1 \underline{\mathrm{M}} \mathrm{Na}_{2} \mathrm{CO}_{3}$ solution, decreasing to $\approx 104$ in $0.01 \underline{\mathrm{M} \mathrm{Na}} \mathrm{CO}_{3}$, and $\approx 6$ in $1 \mathrm{M} \mathrm{Na}_{2} \mathrm{CO}_{3}$.

IV. 7C-10. Hydroxide

The rare-earth hydroxides would seem to be analogous to the fluorides and oxalates in that their low solubility prohibits their use with anion-exchange resins. In special cases, however, the low solubility of the hydroxides can be a distinct advantage.

Perkins ${ }^{362}$ has reported a procedure for separating $\mathrm{Ba}^{140}-\mathrm{La}^{140} \mathrm{mix}-$ tures which involves adsorbing the $\mathrm{La}^{140}$ on the hydroxide form of Dowex-1 resin while Ba passes through. Excellent separations can apparently be done very rapidly this way and the author reports that similar results may be obtained with $\mathrm{Sr}^{90}-\mathrm{Y}^{90}$ mixtures.

IV. 7C-11. Organic Complexes

It seems reasonable to assume that organic complexing agents which are capable of removing rare-earth ions from cation-exchange resins may form negatively charged rare-earth complex ions which might be of interest on anion-exchange resin columns. Huffman and Oswalt 208 have reported successful separation of a mixture of Pm and Eu tracers on Dowex-1 resin with $0.0125 \underline{M}$ citric acid at a $\mathrm{pH}$ of 2.1 , while Higgins and Baldwin ${ }^{196}$ report good separation of $\mathrm{Y}-\mathrm{Eu}$ tracers on Dowex-l columns with $0.16 \mathrm{M}$ EDTA at pH 11.7. (With Dowex-1-citrate, Pm elutes before Eu, which is to be expected; but with Dowex-1-EDTA, Y elutes before Eu also, which is quite unexpected.) Higgins and Baldwin state that $Y-E u$ separation on a Dowex-1EDTA column is comparable to the separation on the Dowex-50-citrate sys tem ( $\mathrm{pH} 3$, room temperature) but slightly inferior to the same system at elevated temperatures. Schonfeld, Wald, and Brund ${ }^{413}$ have shown that $\mathrm{Sr}^{90}-\mathrm{Y}^{80}$ mixtures may be separated on Dowex-1 columns by using a sodium nitrate $-(8$ hydroxyquinoline -5 sulfonic acid) solution as an eluant.

No data are available on the anion-exchange separation of more complex rare-earth mixtures with any of the organic complexing agents. 
$\mathrm{Mo}(+6), \mathrm{U}(+6), \mathrm{Nb}(+5)$, and $\mathrm{Zr}(+4)$ and may be of some advantage in effecting separations from those elements.

Subbaraman, Rajan, and Gupta 468 report that the trıphosphate complexes of the light rare earths may be adsorbed by Amberlite IRA-400 resin almost quantitatively from $\mathrm{Na}_{3} \mathrm{P}_{3} \mathrm{O}_{10}$ solution over the $\mathrm{pH}$ range $1-9$, and may be eluted with dilute $\mathrm{HCl}$ or $\mathrm{H}_{2} \mathrm{SO}_{4}$. This procedure gave good separation and recovery of $\mathrm{Sm}, \mathrm{Nd}$, and $\mathrm{Pr}$ while La was retained by the column.

\section{7C-12. Other Anions}

Marcus and Nelson 278 have reported very briefly that the rare earths are adsorbed on Dowex-1 resin from dilute sulfite, nitrite, and thiosulfate solutions, with adsorbability decreasing with increasing electrolyte concentrations, but no further data are avallable on any of these systems.

\section{7D. CELLULOSE AND PAPER CHROMATOGRAPHY}

Considering the success that has been achieved in separating complex mixtures by this method, it is probably not surprising that a considerable amount of work has been done on the cellulose column and paper chromatographic behavior of the rare-earth elements. For one reason or another, however, the consensus of the published articles in this field seems to be that, for most applications, these techniques are not as good as the synthetic ion-exchange resins for separating complex mixtures of the rare earths.

In paper strip chromatography, for instance, separations are restricted almost entirely to carrier-free samples. K1ba, Ohashi, and Tada, ${ }^{229}$ separating $\mathrm{Y}^{90}-\mathrm{Sr}^{90}$ mixtures on paper strips with an ethyl alcohol-10\% $\mathrm{NH}_{4} \mathrm{SCN}$ solvent, show that the presence of as much as $0.8 \mathrm{mg}$ of yttrium carrier is enough to distort the shape of the yttrium spot very markediy (Fig. 95).
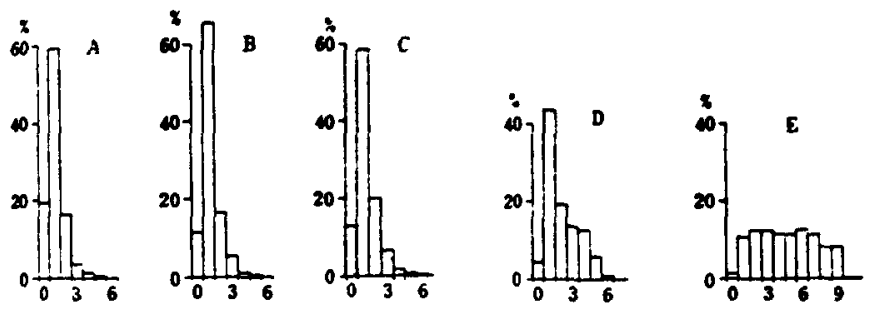

Fig. 95. Effect of yttrium carrier on paper strip chromatography. Solvent, EtOH $-10 \% \mathrm{NH}_{4} \mathrm{SCN}$ aq $(5: 2)$; solvent front, $17.5-18.5 \mathrm{~cm} ; \mathrm{A}, \mathrm{Y}$ carrier $5 \times$ $10^{-5} \mu \mathrm{g}, \mathrm{B}, 6 \times 10^{-4} \mu \mathrm{g} ; \mathrm{C}, 7 \times 10^{-3} \mu \mathrm{g} ; \mathrm{D}, 7 \times 10^{-2} \mu \mathrm{g} ; \mathrm{E}, 8 \times 10^{-1} \mu \mathrm{g}(229)$

In paper strip chromatography, too, the separation factor between individual rare earths is usually not great enough to permit separation of adjacent elements. This general behavior is illustrated by Fig. 96, which was obtained by Lederer 262 with an ethanol-10\% 2N HCl eluant. It is obvious 


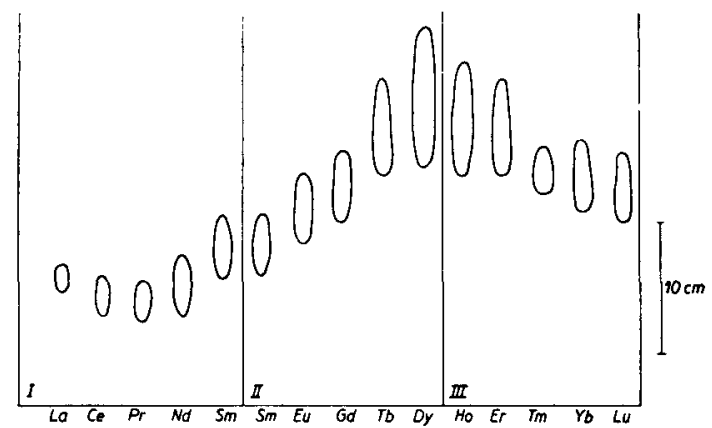

Fig. 96. Paper strip chromatograph of rare-earth chlorides developed for one week with ethanol-10\% $2 \mathrm{~N} \mathrm{HCl}$, placed in order of atomic numbers (262)

that, with this eluant, the paper strip chromatographic method can separate only selected mixtures of rare earths, such as La-Lu, Pr-Eu-Dy, etc. 。 mixtures which are not easily come by in normal radiochemical operations. As a further indication of the current state of the art, Lederer ${ }^{263}$ has published data on the movement of $\mathrm{Pr}, \mathrm{Nd}, \mathrm{Sm}, \mathrm{Eu}, \mathrm{Gd}$, and $\mathrm{Tb}$ with ethanol$\mathrm{HCl}-\mathrm{NH}_{4} \mathrm{CNS}$ solvent (Fig. 97) and states that: "In the region of the gadolinium earths this is the best separation so far recorded (1956) by paper chromatographic and electrophoretic methods."
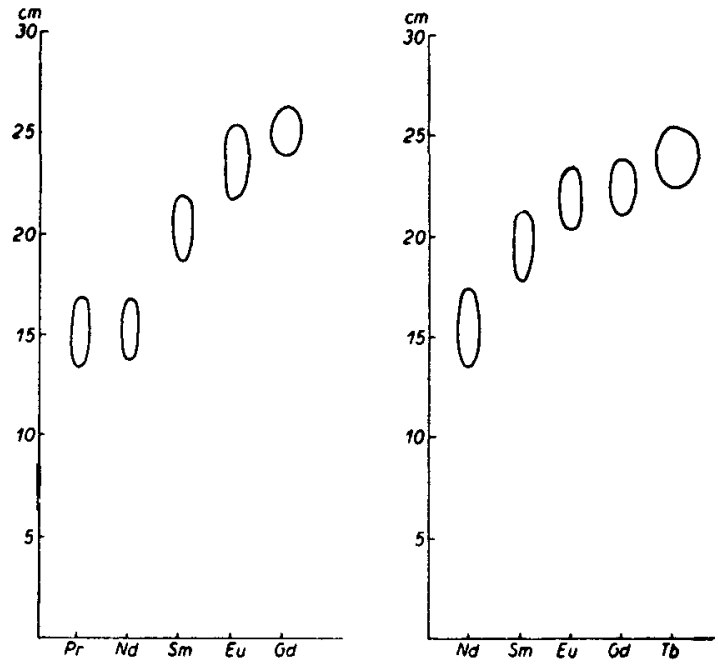

Fig. 97. Paper strip chromatography. The movement of Pr, Nd, Sm, Eu, $\mathrm{Gd}$, and $\mathrm{Tb}$ when developed for 48 hours with ethanol $(90 \mathrm{ml}), 2 \mathrm{~N} H C l(10 \mathrm{ml})$, $\mathrm{NH}_{4}$ CNS ( $\left.1 \mathrm{~g}\right)(263)$

With these very serious limitations in mind, then, additional information on the rare earths with other solvents may be obtained from an excellent review article by Lederer, ${ }^{264}$ or articles by Sarma ${ }^{406}$ and Danon and Levi. 102

All indications are that scandium moves more rapidly than any of the rare-earth elements on the paper strip. Thus Lederer 262 shows that very good Sc-rare earth separations may be obtained with ethanol-10\% $2 \mathrm{~N} \mathrm{HCl}$ 
solvent, and Danon and Levi indicate that a butanol-HNO $\mathrm{H}_{3}-\mathrm{LiNO}_{3}$ solvent should work just as well. Presumably this is a general characteristic of scandium, and carrier-free Sc-rare earth mixtures may be separated by a number of other solvents.

Very little information is available relative to the behavior of actinium in paper strip chromatography. One would expect, however, that it would move more slowly than lanthanum, and Danon and Levi have shown, with butanol- $\mathrm{HNO}_{3}-\mathrm{LiNO}_{3}$ solvent at least, that this is indeed the way Ac behaves.

Several authors have reported procedures involving the use of cellulose columns in connection with the rare earths. Center, Henry, and Householder ${ }^{71}$ have used columns of activated cellulose to separate small amounts of the rare earths as a group from thorium with an ethyl ether $-\mathrm{HNO}_{3}$ solvent but give no indication of any separation of individual rare earths.

Pollard, McOmie, and Stevens, ${ }^{369}$ on the other hand, have successfully separated macroscopic amounts of rare-earth mixtures on cellulose columns with a butanol-acetic acid-8-hydroxyquinoline solvent. It is difficult to evaluate their method accurately, however, because of the way the data are reported, but their yields of pure products seem to be significantly lower than one would expect from properly run cation-exchange resin columns.

\section{7E. INORGANIC EXCHANGERS}

Inorganic ion exchangers, of course, were among the first ion exchange media to be used for separating mixtures of elements. Very few articles have appeared in the literature, however, to indicate that these materials have significant advantages in separating the rare-earth elements.

Lindne ${ }^{270}$ has used columns of $\mathrm{AI}_{2} \mathrm{O}_{3}$ to purify 4- to $20-\mathrm{mg}$ samples of the light rare earths, but the separations were not clean-cut and the procedure does not compare with present ion-exchange resin techniques.

Nemoda 332 has recently published a very fine article on the separation of fission product mixtures on $\mathrm{Al}_{2} \mathrm{O}_{3}$ columns. The mixture of elements is placed on the column in weakly acid solution ( $\mathrm{pH}>2$ ) and successive elutions are then carried out as follows: $\mathrm{Cs}\left(0.4 \mathrm{M} \mathrm{NH}_{4} \mathrm{NO}_{3}\right)$; $\mathrm{Sr}, \mathrm{Ba}\left(1.6 \mathrm{M} \mathrm{NH}_{4} \mathrm{NO}_{3}\right)$; $\mathrm{Ma}, \mathrm{Ni}, \mathrm{Co}\left(1.6 \mathrm{M} \mathrm{NH}_{4} \mathrm{NO}_{3}+\mathrm{NH}_{3}\right) ; \mathrm{Al}, \mathrm{U}\left(0.5 \underline{\mathrm{M}} \mathrm{Na}_{2} \mathrm{CO}_{3}\right) ; \mathrm{Zr}, \mathrm{Nb}\left(1 \underline{\mathrm{M}}\left(\mathrm{NH}_{4}\right)_{2}\right.$ $\left.\mathrm{CO}_{3}\right) ; \mathrm{Fe}, \mathrm{Pb}, \mathrm{Cr}, \mathrm{Te}(\underline{\mathrm{N}}$ oxalic acid); and the rare earths are eluted as a group with $\mathrm{pH} 1 \mathrm{HCl}$.

Vickery 496 has reported the adsorption on activated charcoal of the highly colored $\mathrm{Ce}^{+4}-\mathrm{p}$-phenetidine complex and the separation of $10 \mathrm{mg}$ of $\mathrm{CeO}_{2}$ from $10 \mathrm{~g}$ of $\mathrm{La}_{2} \mathrm{O}_{3}$ by this method.

Schubert ${ }^{414}$ has obtained a patent on a process which uses columns of silica gel or fuller's earth to extract rare-earth activities from uraniumorganic solvent solutions. The solution is poured through the column and 
the rare-earth activities are retained, with fuller's earth being the more efficient of the adsorbents $(\approx 99 \%$ retention).

And finally, Cornish ${ }^{87}$ has attempted to use silica gel columns to separate individual rare earths using a thenoyltrifluoroacetone (TTA)-organic solvent eluant. An elution curve which he obtained with an essentially carrierfree Tb-Eu mixture and a TTA-benzene-methylethyl ketone solvent is shown in Fig. 98. The separation is fairly good but no further work has been done with more complex rare-earth mixtures.

IV. 7F. EXTRACTION-EXCHANGE

An interesting variation of the ion-exchange column technique - so-called "reversed-phase partition chromatography" - has been applied to separation of the rare earths by Siekierski and Fidelis. ${ }^{553}$ Fundamentally, the method involves the saturation of a column of inert absorbent - in this case the Kieselguhr "Hyflo Supercel" - with an organic solvent in which the rare earths are soluble. Siekierski and Fidelis use undiluted TBP. The column is preequilibrated by washing first with water, then with TBP-saturated $\mathrm{HNO}_{3}$ of the same concentration that is to be used in the elution, after which the rare earths are introduced into the column and elution is carried out with concentrated $\mathrm{HNO}_{3}$.

This technique obviously combines features of both extraction- and ion-exchange type operations, but it possesses certain advantages all its own. The most apparent of these is the fact that multistage extraction separations can be carried out automatically with relatively simple apparatus Siekierski and Fidelis state that they got the equivalent of a 400-plate extraction separation in a column $11 \mathrm{~cm}$ long. The eluant is plain nitric acid and does not contain organic complexing agents which sometimes complicate subsequent recovery of the rare earths. Presumably, the eluant could be evaporated to give satisfactory carrier-free samples. Another feature of this method which might be advantageous in certain separations is the fact that the rare earths are eluted in reverse of their "normal" order. With the TBP-HNO 3 system, lanthanum is the first element off the column, followed by the other elements in order of increasing atomic numbers. Yttrium elutes after terbium, presumably in the Dy-Ho region.

As an example of the kind of separations that may be carried out with this technique, Siekierski and Fidelis separated a carrier-free mixture of $\mathrm{Ce}, \mathrm{Pm}, \mathrm{Sm}, \mathrm{Eu}, \mathrm{Gd}$, and $\mathrm{Tb}$ activities on a $3 \mathrm{~mm} \times 11 \mathrm{~cm}$ TBP column with a 15. $1 \mathrm{M} \mathrm{HNO}_{3}$ eluant. Cerium was the first element off the column, followed by $\mathrm{Pm}, \mathrm{Sm}, \mathrm{Eu}, \mathrm{Gd}$, and $\mathrm{Tb}$ in that order, and all peaks were well separated from their neighbors. Column running time to the $\mathrm{Tb}$ peak was approximately 200 minutes. 


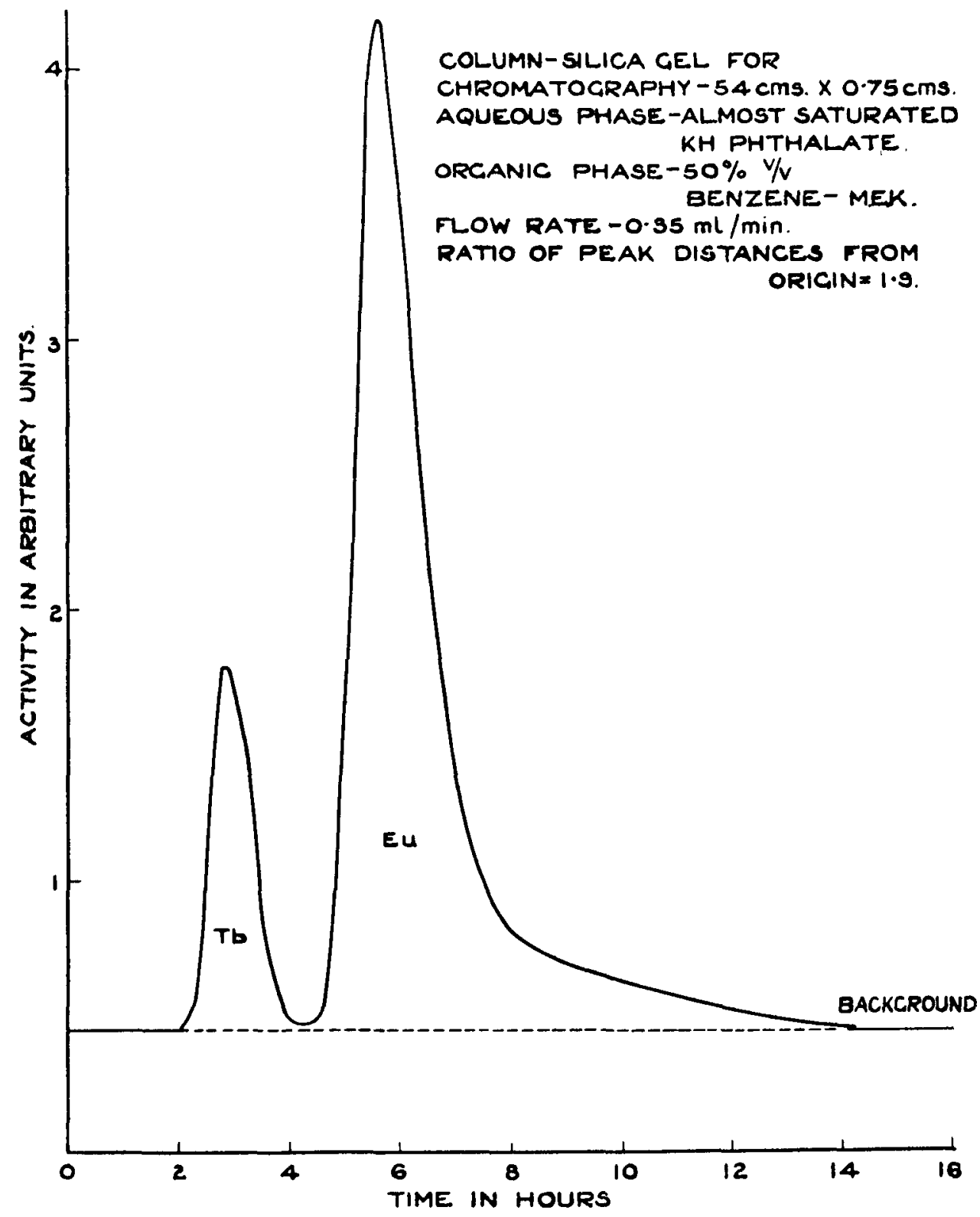

Fig. 98. Elution of carrier-free Tb-Eu activities on a silica gel column. Column dimensions, $54 \mathrm{~cm} \times 0.75 \mathrm{~cm}$ diam; "aqueous phase," silica gel + $40 \%$ by wt "almost saturated" potassium hydrogen phthalate; eluant, $50 \%$ $\mathrm{V} / \mathrm{V}$ benzene-methyl ethyl ketone $+0.02 \mathrm{M}$ TTA; flow rate, $0.35 \mathrm{ml} / \mathrm{min}$ (87)

Another way of making up columns for the extraction-exchange type of operation was patented some time ago by Hale, ${ }^{554}$ who used styrene-divinylbenzene beads as absorbing material for the organic solvent. He made no mention of any application to rare-earth separations, but presumably these beads should work as well as Kieselguhr, and it should be easier to make up the columns. 
Little data is available on specific extraction-exchange separations, but the method certainly looks interesting enough to warrant considerable attention.

\section{8. ELECTRIC AND MAGNETIC FIELD SEPARATION}

\section{8A. INTRODUCTION}

A variety of electrical and magnetic methods have been applied to the separation of rare earths from each other. With one important exception, the methods are inferior in every way to ion exchange columns for general application. They are either slow, severely limited in the amount of material handled, or give poor separations - usually suffering from at least two of these defects.

\section{IV.8B。 ELECTROPHORESIS}

Some separations based on variations in mobility in an electric field have been reported. Sato, Diamond, Norris, and Strain 408 announced successful separation by eiectrophoresis on filter paper moistened with lactic acid or tartrate-tartaric acid buffer. They used a mixture of $\mathrm{Sc}, \mathrm{Y}, \mathrm{Ce}, \mathrm{Pr}$, $\mathrm{Nd}_{0}$ and $\mathrm{Pm}$ and obtained (in $\approx 0.1$ molar lactic acid) separation into three groups. Sc was the most mobile ion; next were $\mathrm{Y}$ and $\mathrm{Nd}$, which did not separate from each other; and least mobile was a group containing $\mathrm{Ce}, \mathrm{Pr}$ and $\mathrm{Pm}$.

In the tartrate buffer system $(0.035$ molar tartaric acid-0.015 molar diammonium tartrate) Eu and Pm migrated as anions, Ce as a cation. Running times were from one to two days.

Clusius and Ramire ${ }^{82}$ modified the electrophoresis apparatus to provide a flow of solvent counter to the direction of migration. They were able to separate pure La from $\mathrm{Nd}$ and $\mathrm{Sm}$, pure Pr from Sm, and La and Sm from a La-Sm-Eu-Gd-Tb-Dy mixture, but were unable to separate Pr from Nd or Eu from Gd. Their running times were extremely long, on the order of weeks.

Maki 276 studied differential electromigration in citrate solutions of varying $\mathrm{pH}^{\prime}$ 's containing sodium chloride. She showed that there were two regions where separations were optimized - one at $\mathrm{pH} 3.05$, the ions migrating as anions, and one at $\mathrm{pH} 2.6$, the ions migrating as cations. She was able to get separations between $\mathrm{La}, \mathrm{Ce}, \mathrm{Pr}$ or $\mathrm{Nd}$, and $\mathrm{Y}$, but not between $\mathrm{Pr}$ and $\mathrm{Nd}$ 。 Her conditions were: citric acid 0.0125 to $0.050 \mathrm{molar}$; sodium chloride 0.050 molar; running time about six hours. Ammonium hydroxide or hydrochloric acid were used to change $\mathrm{pH}$ as desired.

Lederer $258,259,265$ has also studied the electromigration of rareearth ions in citric acid solution. He included yttrium and actinium, but not scandium. His running times were three to four hours. Separations 
were fairly good for the lighter rare earths and actinium, but poor for elements heavier than neodymium. By flowing his solvent continuously at right angles to the field, he was able to obtain ${ }^{259}$ a continuous electrophoretic separation of actinium from lanthanum, which was quite slow but had the advantage that since very low flow rates and fluid volumes were involved, the final actinium fraction contained much less eluant and hence less dissolved solids than that from an analogous column elution. His data are presented in Fig. 99. Kertes ${ }^{225}$ showed that in $25 \%$ thioglycolic acid the migration of gadolinium is much slower than that of many other lanthanides ( $\mathrm{La}, \mathrm{Ce}, \mathrm{Pr}, \mathrm{Nd}, \mathrm{Pm}, \mathrm{Sm}$, $\mathrm{Eu}, \mathrm{Tb}$, and $\mathrm{Er}$ ) and that separation of gadolinium from the rest of the group is possible. He used a paper strip, approximately $4 \mathrm{~cm}$ wide by $20 \mathrm{~cm}$ long, a voltage of 400 volts, and a running time of two or more hours. The current drawn under these conditions was 3-4 milliamperes. The amount of material separated was of the order of 10-100 micrograms of mixed rare earths.

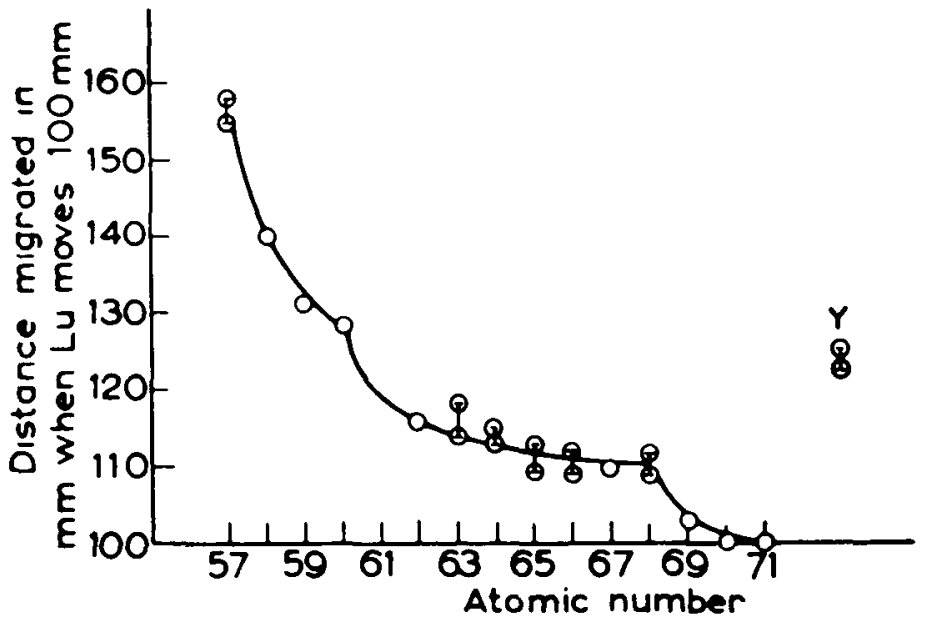

Fig. 99. Relative electrophoretic mobilities plotted against atomic numbers (in $1 \%$ citric acid) (265)

\section{8C. MAGNETOPHORESIS}

Noddack and co-workers 339,342 attempted to use the very high magnetic susceptibilities of some rare earths to separate them from yttrium $(\mu=0)$ in a strongly inhomogeneous magnetic field. He flowed a solution containing $Y$, $\mathrm{Tb}, \mathrm{Dy}, \mathrm{Ho}$, and Er perpendicular to the field gradient and permitted the solution to divide into two channels. Some separation of yttrium from the other rare earths was achieved, but the method was not very effective.

IV. 8D. FOCUSING ION EXCHANGE

Schumacher and co-workers ${ }^{415-421}$ have developed a technique called by them "focusing ion exchange." This is the only method known to us of separating 
individual rare earths (other than $\mathrm{Ce}, \mathrm{Eu}, \mathrm{Sc}$ ) in times of the order of five minutes. Although the method is limited to samples of a few micrograms or less, this limitation is unimportant in carrier-free radiochemistry.

Schumacher 415,418 has discussed the theory of the process in great detail. A rather elementary description follows: Fig. 100 is a schematic representation of the apparatus, which consists in essence of two reservoirs connected by a

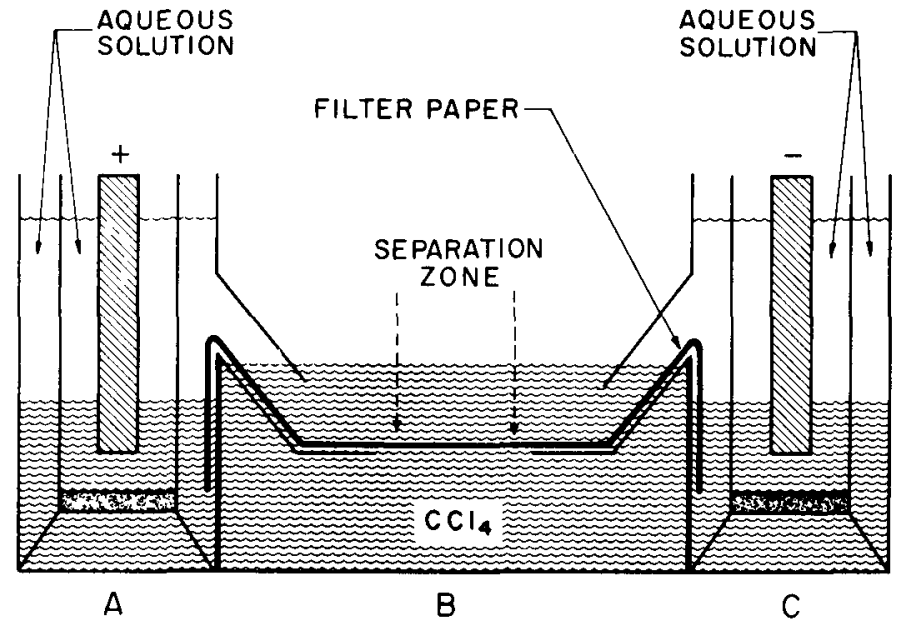

Fig. 100. A schematic representation of the focusing-ion-exchange apparatus of Schumacher and co-workers. A and $C$ are reservoirs containing respectively an anionic complex-forming reagent and a cationic complex-destroying reagent. The central paper strip forms the separation zone (415-421)

moist paper strip. Platinium electrodes (segregated by glass frits) are inserted in the reservoirs and the strip, for cooling, is immersed in a bath of carbon tetrachloride. The only function of the paper is to provide a linear region of electrolyte in which convection and turbulence are minimized.

The reservoir A contains a solution of a complexing anion $\mathrm{A}^{-}$capable of forming anionic complexes with the cations to be separated. The reservoir $C$ contains a solution of a cation $\mathrm{C}^{+}$capable of combining with $\mathrm{A}^{-}$to form a species which does not have complexing ability. The electrode in $A$ is made the cathode of the system, that in $C$ is made the anode.

Under the influence of the applied field, the species $\mathrm{A}^{-}$and $\mathrm{C}^{+}$migrate toward each other along the paper strip and react as they meet. The result is the establishment of a steady state (or a slowly changing state) in which a gradient of the concentration of $\mathrm{A}^{-}$exists along the paper.

At a fixed concentration of $A^{-}$, an added cationic species $M^{+}$will exist in equilibrium between the complexed, anionic form (MA) ${ }^{-}$and the uncomplexed cationic form $\mathrm{M}^{+}$(Note: the charge symbols are intended to indicate sign of charge only, and not its magnitude, in the discussion). The reaction $\mathrm{M}^{+}{ }^{+}$ 
$A^{-} \rightleftarrows(M A)^{-}$is assumed to be rapid in both directions. The net motion of the species $M$ in the electric field then will be governed by the relative amounts of $\mathrm{M}^{+}$and (MA) ${ }^{-}$in solution and by their respective ionic mobilities. If conditions are properly chosen, the concentration of $\mathrm{A}^{-}$at the positive end of the strip will be low enough so that the cations to be separated will migrate as cations, i.e., toward the center of the strip, while at the negative end of the strip they will migrate as anions. Obviously there exists for each species $M$ a critical concentration of $\mathrm{A}^{-}$at which the net motion in the field is zero. This concentration of $\mathrm{A}^{-}$will be found at some particular location along the strip; at positions on either side of the critical location the gradient in concentration of $\mathrm{A}^{-}$will alter conditions in a manner which will lead to net motion of the species $M$ towardits critical location. The position of the critical point of the species $M$ depends on the ionic mubility of the species $\mathrm{M}^{+}$and (MA) ${ }^{-}$and on the stability constant of the complex; these factors will in general be different for different species. One would expect, then, that a sample of solution containing a mixture of cations would migrate unde $r$ the influence of the field into a series of lines, one to each element.

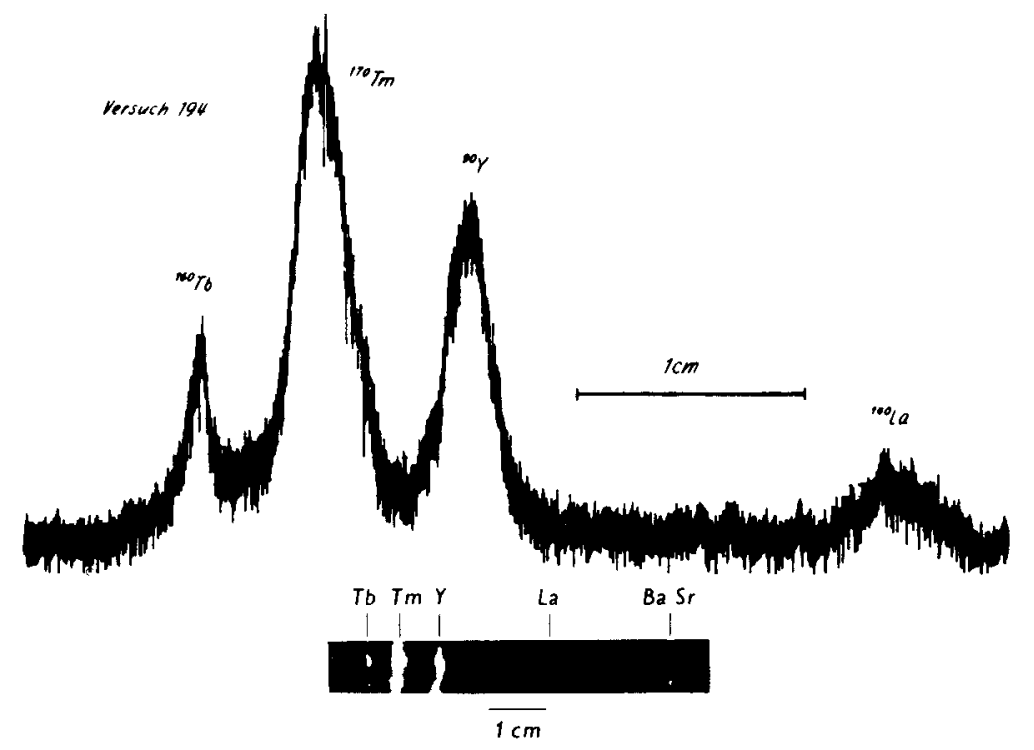

Fig. 101. Autoradiograph and scanning counter results for a typical separation. Conditions: reservoir $\mathrm{C}, 0.5$ molar $\mathrm{HCl}$; reservoir $\mathrm{A}, 0.3$ molar diammonium nitrilotriacetate + sodium trichloroacetate mixture; 500 volts; 8 minutes running time (419)

As can be seen from the accompanying illustration (Fig. 101), the predictions of the theory are verified experimentally.

A detailed theoretical study of the process 418 shows that two effects limit - the sharpness of the line obtained and hence the resolution obtainable by the method. One is the effect of diffusion, which tends to broaden the line; this 
effect is counterbalanced by increasing the electric field strength (see Fig. 102). The other effect is due to the finite velocity of the chemical reactions involved in the equilibrium between $\mathrm{M}^{+}$and (MA) ${ }^{-}$. The magnitude of this effect depends on the electric field in a sense opposite to that of diffusion (see Fig. 103), increasing with increasing field strengths. In any actual case, both effects must be present to some extent; the re exists, therefore, an optimal electric field at which the lines are the sharpest obtainable. In actual practice, the optimal field is often greater than any field which can be utilized. The method depends on the presence of a vast excess of $\mathrm{A}^{-}$over $\mathrm{M}^{+}$, so that the concentration gradient on which the separation depends is not seriously perturbed by the presence of the species being separated. Due to the small cross-section of the paper strip, this fact limits the amounts of material being separated to a few micrograms or less. Even so, the amount of power used is quite appreciable: In the example shown in Fig. 101, the voltage used was 600 volts; the current was not stated, but from similar experiments was of the order of several milliamperes. The combination of salt solutions and high voltages require great care in order to avoid dangerous accidents.

Schumacher and Fluhler ${ }^{420}$ modified the original system by flowing the solution slowly across the electric field, introducing their test mixture continuously at the upstream side and removing the separated products (coppe $r$ and cobalt) at the downstream side.

The technique appears to offer great promise and should be thoroughly investigated.

\section{DISSOLUTION AND EXCHANGE}

\section{V.1. DISSOLUTION}

The usual commercial procedures for processing rare-earth ores involve leaching with strong mineral acids. The rare earths are dissolved and separated from insoluble residues by centrifugation or filtration. Spedding's group at Iowa State, 376 for example, leach pulverized xenotime sand with $93 \% \mathrm{H}_{2} \mathrm{SO}_{4}$ at $240-250^{\circ} \mathrm{C}$ for $6-8 \mathrm{hr}$ to get the rare earths in solution.

On a large scale this type of operation may prove to be undesirable since the handling of hot concentrated acids and slimy sludges is not a pleasant task. Iya 214 has developed a method for opening thortveitite which involves roasting the ore with an excess of carbon for $35-45 \mathrm{~min}$ at $1800-2100^{\circ} \mathrm{C}$ and leaching the scandium out of the resulting carbides with $\mathrm{HCl}_{\text {. }}$ Vickery ${ }^{505}$ obtained essentially the same results by passing a stream of $\mathrm{Cl}_{2}$ over a thortveitite-carbon mixture at $800-850^{\circ} \mathrm{C}$ for about 3 to $4-1 / 2$ hours and dissolving

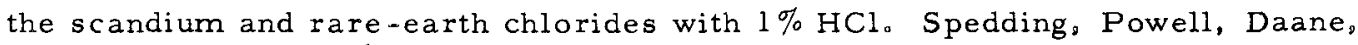
Hiller, and Adams 456 roasted a mixture of thortveitite and ammonium bi- 

fluoride overnight at $375-400^{\circ} \mathrm{C}$, reduced the $\mathrm{ScF}_{3}$ to scandium metal with calcium, and dissolved the metal in $\mathrm{HCl}$.

Most rare-earth compounds which are encountered in the laboratory may be dissolved in strong mineral acids, although heating may be required for some of the more recalcitrant species. Organic material may be destroyed by boiling $\mathrm{HNO}_{3}-\mathrm{HClO}_{4}$ or $30 \% \mathrm{H}_{2} \mathrm{O}_{2}-\mathrm{H}_{2} \mathrm{SO}_{4}$ without affecting the rare earths.

\section{V.2. EXCHANGE}

In almost all cases the rare earths exist only in the trivalent oxidation state in solution. These trivalent ions form relatively few species in aqueous solution and in mineral acids no special precautions need be taken to ensure exchange between inactive carrier and radioactive isotopes. When strong complexing agents are present the problem of exchange between the free rareearth ion and the rare-earth complex can be of concern to the chemist. Betts, Dahlinger, and Munro 27 have studied the kinetics of the exchange reaction between rare earth and rare earth-EDTA complexes, and have found that the principal path leading to exchange is the acid-catalyzed dissociation of the RE(EDTA) ${ }^{-}$complex. The rate of exchange is given by the expression: $\mathrm{R}=\mathrm{k}\left(\mathrm{H}^{+}\right)^{1.0}\left(\mathrm{RE}(\mathrm{EDTA})^{-}\right)^{1.0}\left(\mathrm{R}_{\mathrm{Aq}}{ }^{+++}\right)^{0.0}$ and for comparable conditions the rate constants for several rare earths are in the ratio $k_{L a}: k_{N d}: k_{D y}: k_{Y b}:$ : $7700: 1200: 19: 1$. At $25^{\circ} \mathrm{C}, \mathrm{k}_{\mathrm{La}}=4.2 \times 10^{5}$ liters $/ \mathrm{mole} \mathrm{min}$. Very little is known about the kinetics of the exchange reaction with other strong complexing agents.

A special case of nonexchangeable +3 rare-earth ions is found in the Szilard-Chalmers reaction reported by Herr, ${ }^{194}$ in which rare earthphthalocyanine is irradiated and the reaction products are extracted from quinoline solution by dilute $\mathrm{H}_{2} \mathrm{SO}_{4}$ without exchanging with the original rareearth target material.

When the rare earths exist in more than one oxidation state some precautions may have to be taken to ensure exchange. Divalent species of Eu, $\mathrm{Sm}$, and $\mathrm{Yb}$ may be prepared in aqueous solution. Of these, only Eu ${ }^{++}$is reasonably stable; $\mathrm{Sm}^{+2}$ and $\mathrm{Yb}^{+2}$ oxidize quickly and present no exchange problem. Meier and Garner ${ }^{305}$ found that the rate of exchange between Eu ${ }^{+2}$ and $\mathrm{Eu}^{+3}$ in chloride solution was measurable. They also found that the reaction is chloride dependent and conclude that in nonchloride systems the reaction might be slow. It would be wise, therefore, to oxidize all $\mathrm{Eu}^{+2}$ to $\mathrm{Eu}^{+3}$ in any experiment in which europium is to be separated.

Cerium is the only rare earth which can exist in solution in the +4 oxidation state. The tetravalent cerium ion is quite stable and is used in almost all radiochemical cerium separations. The $\mathrm{Ce}^{+3}-\mathrm{Ce}^{+4}$ exchange reaction 
has been the subject of a number of investigations, a good example of which is the paper by Duke and Parchen. ${ }^{109}$ The exchange rate is measurable, and, in $\mathrm{HClO}_{4}$ at least, decreases with increasing acid concentration. There seems no doubt but that the exact nature of ceric perchlorate solution is complex, and Kraus, Holmberg, and Nelson ${ }^{243}$ conclude that at least some $\mathrm{Ce}^{+4}$ is polymerized or hydrolyzed in all concentrations of $\mathrm{HClO}_{4}$. It is not clear that this holds true for all other acids, but to be on the safe side cerium carrier should be oxidized to $\mathrm{Ce}^{+4}$ and reduced to $\mathrm{Ce}^{+3}$ as a first step in any radiochemical procedure.

There seems to be no problem of the adsorption of rare-earth tracers on container walls. A study of the adsorption on various surfaces in acid solution has been made for carrier-free Pm and Ce, ${ }^{24}$ for Ba and La, 426 and for $\mathrm{Pm}$ and $\mathrm{La}{ }^{457}$ and in no case was the adsorption significant.

At higher $\mathrm{pH}^{\prime} \mathrm{s}$ the carrier rare earths may form radiocolloids which are adsorbed more strongly. Starik and Lambert 457 find the maximum adsorption of $\mathrm{Pm}$ and $\mathrm{La}$ on quartz occurs at a $\mathrm{pH}$ of approximately 6.2, while Belloni, Haissinsky and Salima ${ }^{24}$ find the peak to occur at $\mathrm{pH} 5.6$ for Pm. The "percent rare earth adsorbed" that these authors report is quite low even at the maxima of their curves but procedures have been reported in which S ${ }^{90}-\mathrm{Y}^{90}$ mixtures 427 and $\mathrm{Ba}^{140}$-La ${ }^{140}$ mixtures 426 are separated by adsorption of the rare-earth activities on glass frit filters. The authors report that at $\mathrm{pH} 7.0$ between 90 and $95 \%$ of the $\mathrm{Y}^{90}$ is adsorbed, while in solutions above pH 6 almost $100 \%$ of the $\mathrm{La}^{140}$ is retained. Duval and Kurbatov ${ }^{113}$ have used the same principle to separate carrier-free scandium from a calcium target by adsorbing the scandium on a filter paper. Maximum adsorption occurs at $\mathrm{pH} 8.5$ and the authors report that eighty percent of the Sc present can be recovered in one hour.

\section{COUNTING TECHNIQUES}

In the great majority of cases, samples of rare-earth activities may be counted by using standard $\beta^{-}$and $\gamma$ counting techniques. As a general rule, however, the authors have found that for the most precise and reproducible results samples should be $\gamma$-counted whenever possible. Corrections for self-scattering and backscattering are very much smaller for $\gamma$ rays than for beta particles and the variation in these corrections between samples of different weight is often undetectable. In many cases, too, the $\gamma$ counting efficiency is quite comparable to the $\beta^{-}$counting efficiency for the same sample so larger samples are not necessarily needed for $\gamma$ counting. Pure $\beta^{-}$emitters, of course, will usually be beta-counted, and in these cases corrections for self-scattering and self-absorption will have to be 
made in order to get consistent results between duplicate samples of different weight. $100,182,333$

In those cases where absolute disintegration rates must be determined, counting in $4 \pi$ proportional gas flow counters is often used. A number of papers have been published which deal with detals of this technique $179,291,292$ and, since the rare-earth chemistries given in section VII are ideally suited to the preparation of weightless samples, the preparation of carrier-free rare-earth samples for $4 \pi$ counting is not too formidable a task. Pascual and Freiling 351 have published a short article giving details of preparing rare-earth samples for $4 \pi$ counting and the technique developed by Bjornholm, Nielson, and Sheline 32 seems ideally suited to this type of sample. Although the goal for all $4 \pi$ counting is a sample of zeromass, this ideal is seldom realized and some correction must often be made for self-absorption in the sample. Merritt, Taylor, and Campion ${ }^{309}$ and Le Gallic and Thenard 266 have published papers on this subject which enable corrections to be made with some degree of reliability.

In $\beta^{-}$counting it is desirable to have samples of as uniform thickness as is possible. While it may not be directly applicable to counting samples, Bjornholm, Dam, Nordby, and Poulson ${ }^{33}$ have developed a method for preparing cyclotron targets which involves the electrophoretic deposition of rare-earth oxides on gold films; they report that uniform layers in the 3- to 10-mg weight range may be prepared by this technique.

The requirements of $\beta$-spectroscopy place stringent restrictions on the nature of the active sample so that special techniques are often needed to prepare satisfactory samples for this type of counting. These requirements are usually a weightless sample on a zero area and chemical techniques which have been developed for $4 \pi$ samples are often just as satisfactory for $\beta$-spectroscopy. Hansen and Sheline, 188 and Bjornholm, Nielsen, and Sheline, ${ }^{32}$ however, have published several excellent papers which deal specifically with the preparation or rare-earth samples for $\beta$-spectroscopic counting. Charpak and Suzor ${ }^{73}$ have used vacuum evaporation techniques to obtain erbium samples of approximately $0.5 \mu \mathrm{g} / \mathrm{cm}^{2}$ for $\beta$-spectroscopic analysis.

In most routine rare-earth radiochemical analyses the rare earth is finally prepared as a gravimetric compound, weighed, and counted either on a metal plate or on filter paper. For $\gamma$ counting, rare-earth samples may be counted in solution with satisfactory results. Perey ${ }^{361}$ has described a procedure by which this same technique may be used for counting actinium.

For special requirements, the rare earths may sometımes be prepared in thin sources by electroplating. Cotelle and Haissinsky ${ }^{88}$ have succeeded in preparing actinium samples by electroplating Ac-La mixtures out of 
acetone-ethyl alcohol solutions. Moeller and Zimmerman 317,318 have obtained samples of $\mathrm{Y}, \mathrm{La}$, and Nd by electrolysis in anhydrous ethylenediamine, and Gates and Edwards 166 have used the same technique to obtain point sources of $\mathrm{Pm}^{147}$. The deposit which is obtained is not gravimetric, since Moeller and Zimmerman report that their samples assayed at approximately $50 \%$ metal and contained significant amounts of occluded organic material; and the deposits are not stable but are oxidized by air, water, or any other oxidizing agent. 


\section{List of Procedures}

\begin{tabular}{|c|c|c|c|}
\hline No. & Procedure & Author & Page \\
\hline $\mathrm{RE}-1$ & Rare Earths & Nervik & 186 \\
\hline RE -2 & Rare Earths & $\begin{array}{l}\text { Bunney, Freiling, McIsaac, } \\
\text { and Scadden }\end{array}$ & 189 \\
\hline RE - 3 & Neodymium (Rare Earths) & Cushing & 191 \\
\hline $\mathrm{RE}-4$ & Rare Earths (and Cerıum) & Green and Mercer & 195 \\
\hline $\mathrm{Sc}-1$ & Scandium ( $\beta+$ emitters) & $\begin{array}{l}\text { Bonner, Iddings, Tewes, } \\
\text { Hutchin }\end{array}$ & 200 \\
\hline $\mathrm{Sc}-2$ & Scandium ( $\beta$ - pure) & $\begin{array}{l}\text { Bonner, Iddings, Tewes, } \\
\text { Hutchin }\end{array}$ & 201 \\
\hline $\mathrm{Sc}-3$ & Scandium (carrier-free) & Anders & 204 \\
\hline $\mathrm{Sc}-4$ & Scandium & Sattizahn & 205 \\
\hline $\mathrm{Sc}-5$ & Scandium & Batzel & 209 \\
\hline $\mathrm{Sc}-6$ & Scandium (carrier-free) & $\mathrm{Ha} 11$ & 209 \\
\hline Sc -7 & Scandium (carrier-free) & Hall and Meinke & 210 \\
\hline$Y-1$ & Yttrium & $\begin{array}{l}\text { Bonner, Iddings, Tewes, } \\
\text { Hutchın }\end{array}$ & 212 \\
\hline $\mathrm{Y}-2$ & Yttrium $\left(Y^{88}\right)$ & Hutchin & 214 \\
\hline $\mathrm{Y}-3$ & Yttrium (carrıer-free) & Anders & 216 \\
\hline$Y-4$ & Yttrium & Stanley & 217 \\
\hline $\mathrm{Ce}-1$ & Cerium & Hicks & 220 \\
\hline $\mathrm{Ce}-2$ & Cerium & Iddings & 220 \\
\hline $\mathrm{Ce}-3$ & Cerium & Ames & 222 \\
\hline $\mathrm{Ce}-4$ & Cerium & $\begin{array}{l}\text { Glendenın, Flynn, Buchanan, } \\
\text { and Steinberg }\end{array}$ & 225 \\
\hline$E u-1$ & Europium & Keller & 226 \\
\hline Eu-2 & Europium & Newton & 230 \\
\hline
\end{tabular}


No. Procedure

Author

$\underline{\text { Page }}$

Eu-3 Europium

Goeckermann

233

Ac-1 Actinium

Iddings

234

Ac-2 Actinium (from 1ts daughter) Cabell

234

Ac-3 Actinium

Hyde

237

Ac-4 Actinium

Meınke

239

Ac -5 Actinium

Hall

Spectrophotometric determination of chemical yield of:

Sp-1 Scandium

Herrington

241

Sp-2 Rare Earths

Herrington and Steed

242 
VII. COLLECTION OF DETAILED RADIOCHEMICAL PROCEDURES

\section{RE-1. RARE EARTHS}

W. Nervik

The isolation of individual rare-earth activities from any mixture of activities may be considered in two steps: separation of the rare earths as a group from all other elements, separation of the rare earths from one another. The procedure as outlined here has been used in this laboratory for some thousands of mixed rare-earth samples, and gives good results in a reasonable time without undue effort. Most samples consist of $10 \mathrm{mg}$ per element for about five of the rare earths. Initial chemistry on a typical batch of eight samples might be started one morning, the columns loaded in the afternoon, and separated rare earths mounted and counted the following morning.

\section{SEPARATION OF THE RARE EARTHS AS A GROUP FROM ALL OTHER} ELEMENTS

The initial solution should consist of the mixed activities and rare-earth carriers in about $20 \mathrm{ml} 3 \underline{\mathrm{M}}$ acid $\left(\mathrm{HCl}, \mathrm{HNO}_{3}\right.$, or $\mathrm{HClO}_{4}$ ) Excessive amounts of $\mathrm{Ca}$ or Th (>200 mg) will interfere and should be removed before the initial chemistry is started. (Th may be extracted from TBP-4M $\mathrm{HNO}_{3}$ solution, the rare earths may be separated from Ca by TTA extraction at pH 4 to 5 , see extraction section for details.) If trans-Pu elements are present which will interfere with the desired rare earths they too should be removed (see the chloride-anion exchange column section).

\section{Procedure}

1. Add 3 drops $Z$ r carrier (unless otherwise noted, all carrier solution concentrations are $\approx 10 \mathrm{mg} / \mathrm{ml}$ ). Adjust to $\approx 20 \mathrm{ml} 3 \mathrm{M} \mathrm{HCl}$. Add 5 drops conc. $\mathrm{H}_{3} \mathrm{PO}_{4}$. Digest in a hot bath for a few minutes. Centrifuge $\mathrm{Zr}_{3}\left(\mathrm{PO}_{4}\right)_{4}$

2. Using Lusteroid or polyethylene container, add $2 \mathrm{ml} \mathrm{l} .5 \mathrm{M} \mathrm{CrO}_{4}=$ and $1 / 2 \mathrm{ml}$ conc. HF to supernatant of step (1). Digest in hot bath $5 \mathrm{~min}$. Centrifuge (RE) $F_{3}$. Wash one time wath $20 \mathrm{ml} \mathrm{0.1}$ M HF.

3. Dissolve (RE) $F_{3}$ in $3 \mathrm{ml}$ saturated $\mathrm{H}_{3} \mathrm{BO}_{3}+2 \mathrm{ml}$ conc. $\mathrm{HNO}_{3}$. (Heat and stir well to be sure all the fluoride is dissolved.) Add 5 drops Ba car- 
rier, $1 \mathrm{ml} 6 \mathrm{M} \mathrm{H}_{2} \mathrm{SO}_{4}$, dilute to $20 \mathrm{ml}$, digest in hot bath $5 \mathrm{~min}$ Centrifuge $\mathrm{BaSO}_{4}$.

4. Adjust the supernatant of step (3) to $\mathrm{pH}>7$ with conc $\mathrm{NH}_{4} \mathrm{OH}$, digest in hot bath for a few minutes, centrifuge $\mathrm{RE}(\mathrm{OH})_{3}$. Wash one time with dilute $\mathrm{NH}_{4} \mathrm{OH}$.

5. Dissolve $\mathrm{RE}(\mathrm{OH})_{3}$ of step (4) in $4 \mathrm{ml}$ conc. $\mathrm{HCl}$ and pass through a Dowex A-1 anion-exchange column $(6 \mathrm{~mm} 1 . \mathrm{d} \times 10 \mathrm{~cm}, 50-100 \mathrm{mesh}$ resin, prevlously conditioned with $5 \mathrm{ml}$ conc. $\mathrm{HCl}$ ). The rare earths do not stick and all of the eluant and wash solution 15 to be collected. Rinse tube with $2 \mathrm{ml}$ conc. $\mathrm{HCl}$, and pass through column; wash resin with $2 \mathrm{ml}$ conc. $\mathrm{HCl}$.

6. Adjust eluate (including rinse and wash solution) of step (5) to $\mathrm{pH}>7$ with conc. $\mathrm{NH}_{4} \mathrm{OH}$. Centrifuge $\mathrm{RE}(\mathrm{OH})_{3}$. Wash one time with dilute $\mathrm{NH}_{4} \mathrm{OH}$.

7. Dissolve $\mathrm{RE}(\mathrm{OH})_{3}$ of step (6) in 6 drops conc. $\mathrm{HNO}_{3}$ or conc. $\mathrm{HCl}$. Dilute to $30 \mathrm{ml}$ with boiling $\mathrm{H}_{2} \mathrm{O}$. Add $1.5 \mathrm{ml}$ Dowex-50 resin of the same batch that is to be used for the cation exchange separation. Digest in hot bath $10 \mathrm{~min}$. Centrifuge resin and transfer to the ion exchange column for separation of the individual rare earths.

\section{SEPARATION OF THE RARE EARTHS FROM ONE ANOTHER}

The resin from step (7) above is transferred to the top of an ion-exchange resin column.

For these samples ( $\approx 60 \mathrm{mg}$ total rare-earth carrier), columns $7 \mathrm{~mm}$ 1.d. $\times 60 \mathrm{~cm}$ long are used. A schematic diagram of the apparatus has been reproduced from ref. 334 and is shown in Fig. 71. Under procedures currently in use at this laboratory, the "low-pH solution" in vessel $A$ is $1 \mathrm{M}$ lactic acid adjusted to $\mathrm{pH} 3.10$ with conc. $\mathrm{NH}_{4} \mathrm{OH}$ and containing $2 \mathrm{~g}$ phenol/ liter, and the high-pH solution in vessel $B$ is 1 M lactic acid adjusted to $\mathrm{pH}$ 6-7 with conc. $\mathrm{NH}_{4} \mathrm{OH}$ and containing the same concentration of phenol. The phenol is present to inhibit bacterial growth and a resulting $\mathrm{pH}$ change in the solution. W. Hutchins of this laboratory has found that lactate solutions stored in polyethylene containers do not have any bacterial growth and do not require phenol, but we have not as yet changed our glass storage tanks to this type of system The apparatus of Fig 71 has been modified to the extent that we have discarded the electrical heating tapes and the water condenser With prolonged usage we found that some lactate solution invariably spilled on the tapes, where it carbonized and destroyed the fine wares We now use immersion heaters inserted at an angle of about $20^{\circ}$ from the vertical at the bottom of the $\mathrm{H}_{2} \mathrm{O}$ bath which surrounds the column The first units of this design have been in continuous use for about nine months without giving 
trouble of any kind. Substitution of a short air condenser for the water condenser in Fig. 71 has proven to give quite satisfactory results. Loss of water from the heating bath is negligible and columns have been run at $90^{\circ}-95^{\circ} \mathrm{C}$ for many months without significant change in the water bath level.

In our system reservolr $A$ has a capacity of 5 liters and reservolr B 2 liters. Eight ion-exchange columns are connected to each A reservoir and may be run simultaneously. Each column is $7 \mathrm{~mm} \mathrm{1.d.} \times 60 \mathrm{~cm}$ long and consists of BioRad AG 50W $\times 12$ cation-exchange resin (Dowex 50W $\times 12$ resin, cleaned, graded, and packaged under their own label by Bıo Rad Laboratories, Richmond, Calif.), flow-graded to a settling rate of $0.8-2.4 \mathrm{~cm} / \mathrm{min}$ in water. Columns are conditioned by passing pH 7, 1 M lactate solution through them for at least 8 hours then pH 3.10, $1 \mathrm{M}$ lactate for another 8 hours.

In a "mormal" run (10 $\mathrm{mg}$ each of $\mathrm{Y}, \mathrm{Tb}, \mathrm{Eu}, \mathrm{Sm}, \mathrm{Nd}$ ) the rare-earth carrier + resin from step (7) above is transferred to the top of the conditioned column with bolling water. With elght columns running, reservoir A should contain 4-5 liters of $\mathrm{pH} 3.10 \mathrm{MM}$ lactate solution, and reservoir $\mathrm{B}$ about 1.5 liters of $\mathrm{pH}$ 6-7 $\mathrm{lM}$ lactate. Column temperatures are maintained at $90 \pm 5^{\circ} \mathrm{C}$ at all times. With the system closed, the pressure is adjusted until the flow rate out the column is about $15 \mathrm{sec} / \mathrm{drop}$ (this operating pressure is usually about $3 \mathrm{ps}$ ). Samples of eluant are taken in the collecting tubes over $10-$ minute intervals. When the columns have been running for about an hour, the magnetic stirrer is started and the high-pH solution is fed into the low-pH solution at a flow rate of about $6-7 \mathrm{sec} / \mathrm{drop}$, and maintained at this rate for the remainder of the run.

Under these conditions $Y$ comes off the column in 4-5 hours, Nd is off In about 15 hours, and $\mathrm{Tb}, \mathrm{Dy}, \mathrm{Eu}, \mathrm{Sm}$, and Pmare eluted in that order at roughly equal intervals between the $\mathrm{Y}$ and $\mathrm{Nd}$.

The collecting tubes are assayed for rare-earth carriers by adding a few drops of saturated oxalic acid to each tube. At the end of the run, the oxalate precipitates for each element are combined, washed once with water, once with acetone, ignited over a Meker burner for twenty minutes, and weighed as the oxide.

\section{Note}

It cannot be emphasized too strongly that there is no such thing as an "optimum set of conditions" which will be satisfactory for all rare-earth separations. This particular procedure has been designed for separating samples which consist of $10 \mathrm{mg}$ each of $\mathrm{Y}, \mathrm{Tb}, \mathrm{Eu}, \mathrm{Sm}$, and $\mathrm{Nd}$ and is an outgrowth of exploratory work by the author on separations of this type. ${ }^{334}$ 


\section{RE-1 (Continued)}

For other mixtures of rare-earth carriers, either in quantity or in kind, or for slower or faster separations, other conditions could undoubtedly be found which would give better results. The point is that there are so many variables affecting separations of this sort that the chemist should tailor his column operating procedures to fit each separations problem. An obvious drawback, of course, is that information with which this tailoring can be done intelligently is not too plentiful or readily available. The author ${ }^{334}$ has shown how factors such as carrier mass and changing $\mathrm{pH}$ affect ion-exchange separation of the rare earths, and the section on Ion Exchange discusses a number of other variables as well, while Cabel1 ${ }^{68}$ has published a discussion of the parameters to be considered in operating ion exchange columns. At the present state of the art, however, the best information for setting up "optimum operating conditions "for a given problem is drawn from a little experience in performing these separations. The important point to consider is that the chemical separation of almost any mixture of rare-earth activities is not really difficult and if more radiochemists were aware of this fact perhaps they would be more willing to work with these elements.

\section{RE-2 RARE EARTHS}

Bunney, Freiling, McIsaac, and Scadden 62

\section{Preliminary Isolation and Purification}

1. Add the various rare-earth carriers and. if desirable, $\mathrm{Pm}^{147}$ tracer to the acid solution containing the activity and stir well.

2. Add $5 \mathrm{mg} \mathrm{Ba}{ }^{++}$holdback carrier, make basic with $\mathrm{NH}_{4} \mathrm{OH}$. Centrifuge, discard supernatant, wash twice with $20 \mathrm{ml} \mathrm{\textrm {H } _ { 2 }} \mathrm{O}$.

3. Dissolve the hydroxide in $5 \mathrm{ml}$ conc. $\mathrm{HCl}$ and add 2 drops conc. $\mathrm{HNO}_{3}$. With sample in water bath (no ice!) saturate with $\mathrm{HCl}$ gas.

4. Pass through a bed $(6 \mathrm{~mm} \times 10 \mathrm{~cm})$ of Dowex $-2(100-200 \mathrm{mesh})$ that has been washed with conc. $\mathrm{HCl}$. Pass $5 \mathrm{ml}$ of conc. $\mathrm{HCl}$ through to wash out the rare earths.

5. Repeat steps (2), (3), and (4).

6. Make basic with conc. $\mathrm{NaOH}$, centrifuge, discard supernatant, wash with $20 \mathrm{ml} \mathrm{H}_{2} \mathrm{O}$.

7. Repeat steps (3), (4), (6).

8. Dissolve in a minimum amount of $\mathrm{HCl}$ or $\mathrm{HClO}_{4}$. 
1. Load the boiling solution from the preceding steps onto a bed $110 \mathrm{~mm}$ by $60 \mathrm{~cm}$ ) of Dowex-50 (settles through $\mathrm{H}_{2} \mathrm{O}$ at the rate of $0.6-1 \mathrm{in} . / \mathrm{min}$ ) in the $\mathrm{NH}_{4}{ }^{+}$form held at $87^{\circ} \mathrm{C}$ by the bolling vapors of trichloroethylene.

(Ed Note: These authors have subsequently shifted to electrically heated water baths for maintaining their columns at elevated temperatures.)

2. Rinse twice with an equal volume of boiling distilled water.

3. Elute with degassed $0.87 \mathrm{M}$ lactic acid at $\mathrm{pH} 3.0$ until the Ho comes off. (The rare earths elute in reverse order to their atomic number; Y falls between Ho and Dy.)

4. Elute with 1.25M lactic acid at $\mathrm{pH} 3.0$ until the Nd comes off.

5. Elute with 1.25M lactic acid at $\mathrm{pH} 3.3$ untıl the La comes off.

A flow rate of $10-25 \mathrm{ml} / \mathrm{hr}$ is used and fractions are taken every 5-15 min. An automatic fraction collector is a great aid. Where greater purity becomes necessary it is usually less time-consuming to recycle fractions rather than slow down the elution. Among the rare-earth fission products of $\mathrm{U}^{235}$ and $\mathrm{Pu}^{239}$, it is usually desirable to recycle Ho, Dy, and $\mathrm{Tb}$, since they are all usually contaminated with $Y$ activity because of the high fission yield of $Y$ relative to the others. This has been found to be true with $\mathrm{Tb}$ even in cases where the peak-to-valley ratio of the $Y 1 s 10^{6}$ or greater. The elution conditions used here are $0.95 \mathrm{M}$ lactic ac1d at $\mathrm{pH} 3.10$ for Ho and Dy With Dy it may be necessary to divide the fraction into two parts, a Dy-rich and a Y-rich fraction, and recycle each part. (Ed. Note: A recycled Dy-Y separation may be performed more efficiently by using diethylene-triaminepentaacetic acid (DTPA). See Ion Exchange Section). The columns used are identical to those previously described. Any rare earth may be further purified by recycling under the elution conditions of its original separation. The usual elution conditions used here for recycling Tb fractions (and Gd, Eu, and $\mathrm{Sm}$ ) are 1.13M lactic acid at $\mathrm{pH} 3.10$.

Gradient elution has been used at this laboratory with success. There are many variations of molarity, $\mathrm{pH}$, and volumes of eluants that may be used in gradient elutions. The most desirable set of conditions varies with each application. A system that we have found successful with the fission-product rare earths is to connect a reservoir containing $330 \mathrm{ml}$ of $1.10 \mathrm{M}$ lactic acid at $\mathrm{pH} 3.10$ to a loaded Dowex-50 column of the type described above and connect a second reservoir containing 1.25 M lactic acid at pH 3.25 to the first in such a manner that as a given volume is removed from the first reservolr half that volume is replaced from the second. This set of condi- 
tions gives good separation of the fission-product rare earths in about $30 \mathrm{hr}$. Sample Mounting

1. Select the appropriate fractions and combine.

2. Precipitate the hydroxide by adding conc. NaOH dropwise until the $\mathrm{pH}$ exceeds 9. Centrifuge, discard supernatant. Wash twice with $10 \mathrm{ml} \mathrm{H}_{2} \mathrm{O}$. (Add Nd carrier to Pm.)

3. Dissolve in 2 drops $6 \mathrm{~N} \mathrm{HCl}$ (warming may be necessary), dilute to $5 \mathrm{ml}$ with $\mathrm{H}_{2} \mathrm{O}$, heat to boiling, add saturated oxalic acid dropwise until a precipitate forms. Continue dropwise addition of oxalic acid until $2 \mathrm{ml}$ more has been added. Boil for $1 \mathrm{~min}$. Let cool.

4. Centrifuge, discard supernatant. If rapid analysis is required, transfer to a tared filter paper, wash with $\mathrm{H}_{2} \mathrm{O}$ until filtrate does not precipitate with $\mathrm{La}^{+3}$, wash twice with $3 \mathrm{ml}$ of methyl alcohol. Dry at $105^{\circ} \mathrm{C}$ for $30 \mathrm{~min}$, cool in air $15 \mathrm{~min}$, weigh, mount, and count. (Ed. Note: This drying and cooling procedure requires a minimum of 45 minutes. Direct ignition to the oxide and cooling to room temperature can be done in 10 minutes if speed is required.)

\section{RE-3. NEODYMIUM (RARE EARTHS)}

B. E. Cushing 233

\section{Introduction}

In the separation of neodymium from other fission activities, a combination of hydroxide and fluoride precipitations in the presence of neodymium and yttrum carriers is first carried out. The rare earths and yttrium are then placed on a Dowex-50-X12 cation-exchange column in $2 \mathrm{M}$ hydrochloric acid. The column is subsequently treated with $1 \underline{M}$ ammonium lactate (at $\mathrm{pH} 3.14-3.17$ ) and various fractions are collected in saturated oxalic acid. Yttrum elutes much earlier than neodymium and is recognized by the formation of the white precipitate of the oxalate. Elution of neodymium yields a blue oxalate, which is then converted to the oxide. $\mathrm{Nd}_{2} \mathrm{O}_{3}$, on ignition. The neodymium is weighed and counted in this form. The chemical yield is about $80 \%$ and approximately 24 hours are required to analyze eight aliquots of a sample. 


\section{$\underline{\text { Reagents }}$}

$\mathrm{Nd}$ carrier: $15 \mathrm{mg} \mathrm{Nd} \mathrm{O}_{3} / \mathrm{ml}$ (added as $\mathrm{Nd}_{2} \mathrm{O}_{3}$ in $3 \underline{\mathrm{M}} \mathrm{HCl}$ ), standardized

Y carrier: $15 \mathrm{mg} \mathrm{Y}_{2} \mathrm{O}_{3} / \mathrm{ml}$ (added as $\mathrm{Y}_{2} \mathrm{O}_{3}$ in $3 \mathrm{M} \mathrm{HCl}$ )

Ba carrier: $10 \mathrm{mg} \mathrm{Ba} / \mathrm{ml}$ (added as $\mathrm{Ba}\left(\mathrm{NO}_{3}\right)_{2}$ in $\mathrm{H}_{2} \mathrm{O}$ )

Sr carrier: $10 \mathrm{mg} \mathrm{Sr} / \mathrm{ml}$ (added as $\mathrm{Sr}\left(\mathrm{NO}_{3}\right)_{2} \cdot 4 \mathrm{H}_{2} \mathrm{O}$ in $\mathrm{H}_{2} \mathrm{O}$ )

$\mathrm{HCl}: 2 \mathrm{M}$

$\mathrm{HClO}_{4}:$ conc.

$\mathrm{HF}$ : conc.

$\mathrm{H}_{3} \mathrm{BO}_{3}$ : saturated aqueous solution

$\mathrm{H}_{2} \mathrm{C}_{2} \mathrm{O}_{4}$ : saturated aqueous solution

$\mathrm{NH}_{3}$ : gas

Ammonium lactate: 1 M (note 1)

Ethanol: absolute

\section{Equipment}

Centrifuge

Drying oven

Sand bath

Muffle furnace

Steam bath

Blocks for holding centrifuge tubes

Forceps

Mounting plates

Pipets: assorted sizes

Stirring rods

Ground-off Hirsch funnels: Coors 000A (one per aliquot)

Filter chimneys (one per aliquot)

No. 42 Whatman filter paper: $9 \mathrm{~cm}$

No. 42 Whatman filter circles: $7 / 8$ in. diameter, weighed

2 -inch, $60^{\circ}$ short-stem glass funnels (one per aliquot)

Wash bottle

40-ml conical centrifuge tubes: Pyrex 8320 (one per aliquot)

40-ml Lusteroid centrifuge tubes (one per aliquot)

5-ml conical centrifuge tubes: Pyrex LG 2578

50-ml Pyrex beakers (one per aliquot)

Porcelain crucibles: Coors 00 (one per standardization)

Automatic Fraction Collector (Packard Instrument Company)

Ion exchange columns: The container for the resin bed is of the 'condenser" type, $68 \mathrm{~cm}$ long, with the inner bore about $1.1 \mathrm{~cm}$ in diameter and the outer 


\section{RE-3 (Continued)}

jacket about $3.5 \mathrm{~cm}$. The column $1 \mathrm{~s}$ heated by means of the vapor of $\underline{\mathrm{n}}-\mathrm{propyl}$ alcohol. The Dowex-50-Xl2 cation resin (200-400 mesh) is placed to a height of $60 \mathrm{~cm}$ in the inner column of the "condenser. "Prior to actual use, the resin is equilibrated with about $30 \mathrm{ml}$ of $1 \mathrm{M}$ ammonium lactate (pH 3.14-3.17).

Preparation and Standardization of Carrier

Dissolve $15.0 \mathrm{~g}$ of highest purity $\mathrm{Nd}_{2} \mathrm{O}_{3}$ (note 2) in $3 \underline{\mathrm{M}} \mathrm{HCl}$ and make the solution up to a volume of 1 liter with the acid.

Pipet $5.0 \mathrm{ml}$ of this solution into a $40-\mathrm{ml}$ conical centrifuge tube and add $15 \mathrm{ml}$ of saturated $\mathrm{H}_{2} \mathrm{C}_{2} \mathrm{O}_{4}$ solution. Heat to coagulate the precipitate wich forms and permit to stand for $5 \mathrm{~min}$. Filter the precipitate onto No. 42 Whatman filter paper $(9 \mathrm{~cm})$ Transfer the precipitate and paper to a weighed porcelain crucible (Coors 00 ) and ignite at $800^{\circ}$ for $\mathrm{l} \mathrm{hr}$. Cool and weigh as $\mathrm{Nd}_{2} \mathrm{O}_{3}$.

Four standardizations are carried out with results agreeing within $0.5 \%$.

\section{Procedure}

1. To an aliquot of the sample in a $50-\mathrm{ml}$ beaker, add $1.0 \mathrm{ml}$ of standard $\mathrm{Nd}$ carrier, $1 \mathrm{ml}$ of $\mathrm{Y}$ carrier and 12 drops of conc. $\mathrm{HClO}_{4}$. Fume to dryness on a sand bath and transfer with $2 \underline{M} H C 1$ to a $40-\mathrm{ml}$ conical centrifuge tube (note 3 ).

2. Pass in $\mathrm{NH}_{3}$ gas unt1l precipitation of hydroxides is complete. Centrifuge, discard the supernate, wash the precipitate with $\mathrm{H}_{2} \mathrm{O}$, and centrifuge again. Discard the supernate.

3. Dissolve the precipitate in a minimum of $2 \mathrm{M}$ HCl and transfer the solution to a $40-\mathrm{ml}$ Lusteroid centrifuge tube. Add 10 drops each of $\mathrm{Ba}$ and $\mathrm{Sr}$ carriers and 10-20 drops of conc. HF Centrifuge the fluoride precipitate and discard the supernate.

4. Slurry the precipitate with 5 drops of saturated $\mathrm{H}_{3} \mathrm{BO}_{3}$ and add $10 \mathrm{drops}$ of $2 \underline{\mathrm{M}} \mathrm{HCl}$ to dissolve the precipitate. Add 10 drops each of $\mathrm{Ba}$ and $\mathrm{Sr}$ carriers and again precipitate the fluorides with conc HF. Centrifuge and discard the supernate.

5. Slurry the precipitate with 5 drops of saturated $\mathrm{H}_{3} \mathrm{BO}_{3}$ and add 10 drops of $2 \mathrm{M} \mathrm{HCl}$ to complete the solution process. Pass in $\mathrm{NH}_{3}$ gas until precipitation of hydroxides is complete Centrifuge and wash the precipitate with $\mathrm{H}_{2} \mathrm{O}$, discarding the supernates.

6 Dissolve the precipitate in a minimum of $2 \mathrm{M} \mathrm{HCl}$ and add the solution - onto the heated Dowex-50-X12 resin bed. Rinse the tube with about $3 \mathrm{ml}$ of $2 \mathrm{M} \mathrm{HCl}$ and add the rinsings to the column. 
7. Allow the last of the HCl solution to reach the top of the resin beds and then add $15 \mathrm{ml}$ of bolled $1 \underline{M}$ ammonum lactate. Attach to the 1on exchange column a l-liter separatory funnel containıng about $300 \mathrm{ml}$ of $1 \underline{\mathrm{M}}$ ammonium lactate. Allow the lactate to flow under gravity through the resin bed. (The flow rate is adjusted to about $3 \mathrm{ml}$ per $10 \mathrm{~min}$.)

8. Start the Automatic Fraction Collector so that 10-min samples are collected in 5-ml centrifuge tubes each containing $1 \mathrm{ml}$ of saturated $\mathrm{H}_{2} \mathrm{C}_{2} \mathrm{O}_{4}$. The first precipitate to appear is white $\mathrm{Y}_{2}\left(\mathrm{C}_{2} \mathrm{O}_{4}\right)_{3}$; this is discarded. The blue $\mathrm{Nd}_{2}\left(\mathrm{C}_{2} \mathrm{O}_{4}\right)_{3}$ precipitate appears $12-16$ hours after the start of elution. There will be $10-15$ tubes containing the $\mathrm{Nd}_{2}\left(\mathrm{C}_{2} \mathrm{O}_{4}\right)_{3}$ precipitate. The se are heated for $15 \mathrm{~min}$ on a steam bath and then filtered through the same No. 42 Whatman filter paper $(9 \mathrm{~cm})$, using a $2-1 \mathrm{n}$. $60^{\circ}$ funnel. The oxalate is ignited to the oxide at $800^{\circ}$ for $1 \mathrm{hr}$.

9. Slurry the $\mathrm{Nd}_{2} \mathrm{O}_{3}$ with absolute ethanol and transfer to a weighed No. 42 Whatman filter circle (7/8 in. diameter), using a ground-off Hirsch funnel and a filter chimney. Wash the precipitate with ethanol and dry at $110^{\circ}$ for $15 \mathrm{~min}$. Cool for $30 \mathrm{~min}$ and weigh. Mount and count.

\section{Notes}

1. The $1 \underline{M}$ ammonium lactate solution is made by mixing $420 \mathrm{ml}$ of $85 \%$ lactic acid with $3580 \mathrm{ml}$ of $\mathrm{H}_{2} \mathrm{O}$ and adjusting the $\mathrm{pH}$ to $3.14-3.17$ with $\mathrm{NH}_{3}$ gas. The water is purified prior to use by distillation, followed by passage through a de-ionizer.

2. The $\mathrm{Nd}_{2} \mathrm{O}_{3}$ was supplied by Research Chemicals, Inc., Burbank, Calif. Spectroscopic examination showed the oxide to be in a high state of purity.

3. If the uranium content of the sample is high (>1 $\mathrm{mg}$ per $\mathrm{ml}$ ), a purification step is necessary before starting step (2). Removal of uranium is accomplished by saturating the solution at this point with $\mathrm{HCl}$ gas and then passing 1t through a Dowex 1-X8 (100-200 mesh), cloride form, anion exchange column $(0.4 \mathrm{~cm} \times 7 \mathrm{~cm})$. The column is $\mathrm{r}$ insed with three $2-\mathrm{ml}$ portions of conc. $\mathrm{HCl}$. The uranium remains on the column. 

FROM FISSION PRODUCTS

1 The elements to be considered are cerium praseodymium, neodymium, samarium, europium gadolinium, terbium and their analogue yttrium The isotopic species considered are:

$\begin{array}{ll}\mathrm{Y}-90 & 61 \mathrm{~h} \text { (see strontium) } \\ \mathrm{Y}-9 \mathrm{l} & 57 \mathrm{~d} \\ \mathrm{Ce}-14 \mathrm{l} & 325 \mathrm{~d} \\ \mathrm{Ce}-143 & 33 \mathrm{~h} \rightarrow \mathrm{Pr}-143 \\ \mathrm{Ce}-144 & 282 \mathrm{~d} \rightarrow \mathrm{Pr}-144 \\ \mathrm{Pr}-143 & 138 \mathrm{~d} \text { carrier-free cer } 14 \mathrm{~m} \\ \mathrm{Pr}-144 & 175 \mathrm{~m} \\ \mathrm{Nd}-147 & 119 \mathrm{~d} \\ \mathrm{Sm}-153 & 47 \mathrm{~h} \\ \mathrm{Eu}-156 & 154 \mathrm{~d} \\ \mathrm{Gd}-159 & 18 \mathrm{~h} \\ \mathrm{~Tb}-161 & 7 \mathrm{~d}\end{array}$

(Note: 2 7-y Pm-147 is not often determined If this is needed a tracer of 50-h Pm-l49 may be prepared by irradiation of neodymium in a reactor with subsequent ion-exchange purification The presence of some $27-\mathrm{h} \mathrm{Pm-151}$ is immaterial, if a comparison technique is used If 50-h Pm-149 is required Pm-147 may be used as tracer in an amount sufficient to swamp that growing from Nd-147 In these cases samarium carrier is also needed to locate promethium in the ion exchange separation)

2 It is convenient to divide the separation into two parts: (a) yttrium te rbium, gadolinium europium, samarıum, and (b) yttrium neodymium praseodymium, cerium There are three reasons for making this division: (1) the length of time involved in separating all eight elements in one experiment, (11) the large differences in fission yield, (111) the difference in half-lives Yttrium is included in portion (a) as a 'maker" element, and need only be determined in (b). Portion (b) is left for 12 days after fission, to allow complete decay of $\mathrm{Ce}-143$ (see below) To the larger portion the following carriers are added: $0.5 \mathrm{mg}$ each yttrum, terbium, gadolinium, plus $10 \mathrm{mg}$ each europium and samarium To the smaller portion the following carriers are added: $10 \mathrm{mg}$ each yttrium, neodymium, praseodymium, cerium, and promethium tracer and samarium carrier if needed 
3. It is possible to separate all the rare earths from yttrium to praseodymium by the use of "graded elution," viz. the slow increase in concentration of the eluant, at a constant $\mathrm{pH}$ of 4.00 , from $28 \mathrm{~g} / \mathrm{l}_{1}$ ter initially to $52 \mathrm{~g} / \mathrm{l}$ ter finally. This produces a more even spacing of the peaks. $0.5-\mathrm{mg}$ quantities of each carrier are used.

4. Outline of Purification Scheme

Two fluoride-hydroxide cycles.

RE passed through Amberlite CG400 in concentrated hydrochloric acid.

RE passed through Amberlite CG400 in $4 \mathrm{M}$ hydrochloric acid.

Removal of cerium by precipitation as ceric iodate.

RE separated by elution from ZEO-KARB 225 cation-exchange resin with a-hydroxy-isobutyric acid solution.

5. Procedure

1. Add to the sample $0.5 \mathrm{mg}$ each of required rare-earth carriers and of cerium carrier if not already present; fume down with $0.2 \mathrm{ml}$ perchloric acid and $0.1 \mathrm{ml}$ concentrated nitric acid.

2 Dissolve the residue in $1 \mathrm{ml} 1 \underline{\mathrm{M}} \mathrm{nitric}$ acid, add $0.5 \mathrm{mg}$ zirconium carrier and $0.5 \mathrm{ml} 2 \underline{\mathrm{M}}$ ammonium fluoride solution. Allow the precipitate to stand for 5 minutes and centrifuge.

3. Dissolve the RE fluoride precipitate in 1 drop saturated boric acid + $0.4 \mathrm{ml}$ concentrated nitric acid, add $1 \mathrm{mg}$ barıum carrier, dilute to $2 \mathrm{ml}$, and pass ammonia gas. Centrifuge precipitate and wash once with $2 \mathrm{ml}$ of water.

4. Repeat steps (2) and (3).

5. Dissolve the hydroxide in concentrated hydrochloric acid and evaporate to dryness. Take up the residue in $0.5 \mathrm{ml}$ concentrated hydrochloric acid and transfer to an Amberlite CG400 anıon column ( $4 \mathrm{~cm} \times 5 \mathrm{~mm}$ ). Wash the column successively with $4 \times 0.5 \mathrm{ml}$ concentrated hydrochloric acid

6. Evaporate the effluent to dryness, take up in $0.5 \mathrm{ml} 5 \mathrm{M}$ hydrochloric acid and transfer to an Amberlite CG400 column ( $4 \mathrm{~cm} \times 4 \mathrm{~mm}$ ). Wash the column successively with $4 \times 0.5 \mathrm{ml} 4 \underline{\mathrm{M}}$ hydrochloric acid.

7. Evaporate the effluent to dryness and dissolve in $0.4 \mathrm{ml}$ concentrated nitric acid. Add $1 \mathrm{ml} 0.35 \mathrm{M}$ lodic acid and approximately $10 \mathrm{mg}$ sodium bromate powder. Warm solution and stir well until cerıc lodate coagulates. Note time of first separation. Centrifuge ceric iodate and wash with $2 \times 1 \mathrm{ml}$ water. Reserve ceric lodate if necessary for further cerium purification [sample (b) only]

8. Evaporate the supernate and washes to dryness. Add $1 \mathrm{ml}$ concentrated hydrochloric acid and re-evaporate. Dissolve the residue in water and pre- 


\section{RE-4 (Continued)}

cipitate RE with ammonia. Centrifuge and wash with $2 \mathrm{ml}$ water. Separate by the ion-exchange method below.

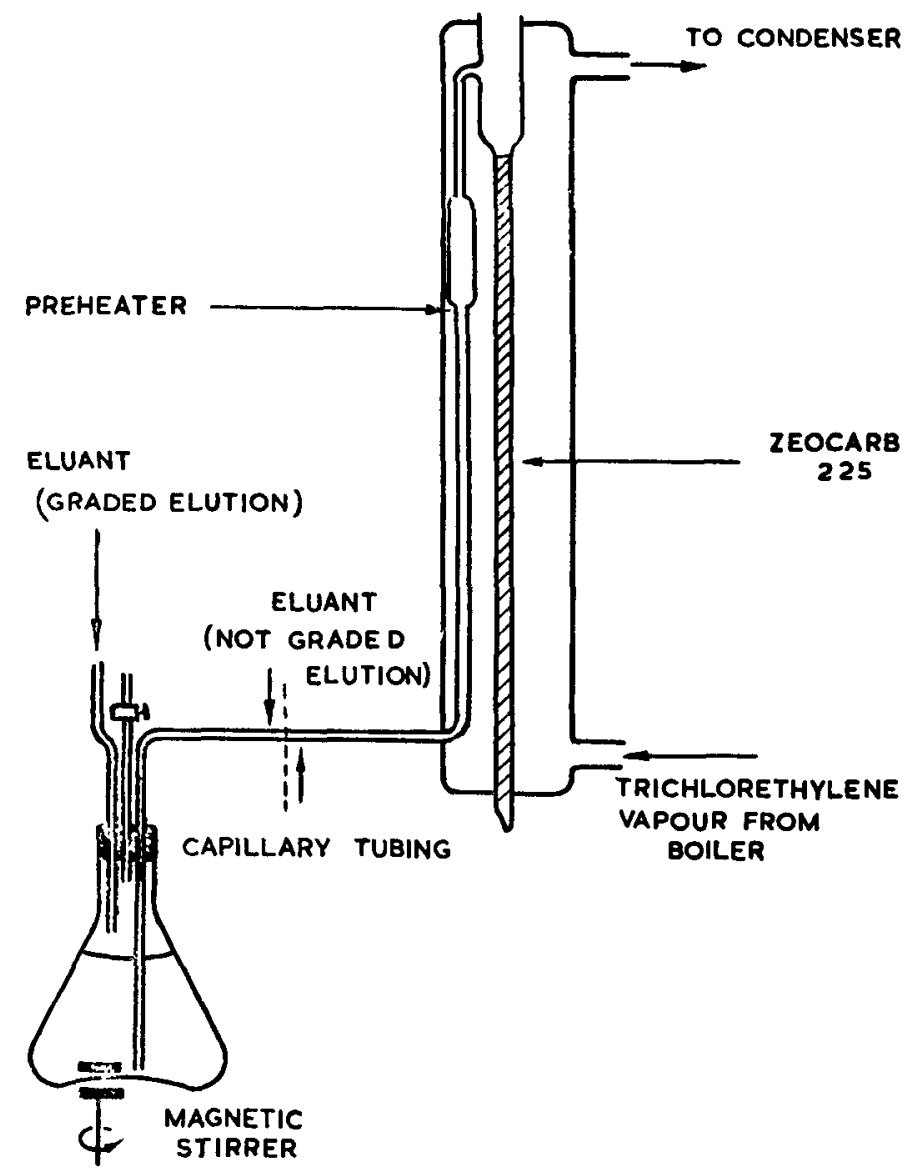

Fig. 104. Ion-exchange column apparatus.

\section{Separation Method}

6.1. Apparatus. The ion-exchange column apparatus is shown in Fig. 104 .

The main column of a tube $22 \mathrm{~cm}$ long $\times 6 \mathrm{~mm}$ diamete $r$ surrounded by a heating jacket. P. V. C. tubing connects the preheater to a gravity feed reservoir. A pressure head of eluant is adjusted to give the correct flow rate. The reservoir is a $40-\mathrm{ml}$ flask with connections as shown.

6.2. Resin. This is ZEO-KARB $225(20-30 \mu)$ prepared and pretreated as in Section 3C (see ref. 544).

6.3. Column packing. The column is filled with distilled wate $x$ and this is

- allowed to attain equilibrium temperature. The conditioned resin is heated on a steam bath, slurried into the column, and allowed to settle with no flow 


\section{$\mathrm{RE}-4$ (Continued)}

of water. The resin bed is equilibrated with about $10 \mathrm{ml}$ of eluant followed by $10 \mathrm{ml}$ water, and is then ready for use. When not in use the bed is kept under distilled water. (N B., the column must be free from bubbles.)

\subsection{Eluant}

1. For the yttrium, terbium, gadolinium, europium, samarium group the eluant is a-hydroxy-1sobutyric acid $\left(3.1 \mathrm{~g} / \mathrm{l}_{\mathrm{t}} \mathrm{er}\right)$ adjusted to a $\mathrm{pH}$ of $4.00 \mathrm{w}$ th concentrated ammonia.

2. For the yttrium, neodymium, praseodymium group the eluant is $a=$ hydroxy-1sobutyrac acid (42 g/liter) adjusted to a $\mathrm{pH}$ of 4.00 with concentrated ammonia.

3. For graded elution, preheater and reservoir are filled with $28-\mathrm{g} / \mathrm{liter}$ a-hydroxy-isobutyric acid a volume of about $30 \mathrm{ml}$ is required for the preheater and a further $40 \mathrm{ml}$ is used in the reservoir. The feed to the reservolr is $52 \mathrm{~g} /$ liter a whdroxymisobutyric acid. The $\mathrm{pH}$ is 4.00 for both solutions

Dissolve each oxalate precipitate in $0.5 \mathrm{ml}$ nitric acid $+0.5 \mathrm{ml}$ perchloric acid and evaporate to dryness in a $5-\mathrm{ml}$ beaker. Add a further $0.5 \mathrm{ml}$ nitric acid $+0.5 \mathrm{ml}$ perchloric acid and re-evaporate to dryness on a hot plate. (Traces of oxalic acid interfere with chemical-yield determination.) Dissolve residue in $1 \mathrm{ml}$ water and precipitate hydroxide with ammonia. Centrifuge precipitate and wash well with water.

Dissolve in $0.1 \mathrm{ml}$ of $1 \mathrm{M}$ hydrochloric acid, dilute suitably and take aliquots for counting and chemical yield.

\section{Cerium Purification}

7.1. Outine of purification scheme. (As in Section 4, plus two precipitations of ceric lodate.)

1. Dissolve the cerıc iodate from Section 5, step (7) by adding 1 drop $1 \mathrm{M}$ hydrochloric acid +1 drop 10 volume \% hydrogen peroxide $+0.4 \mathrm{ml}$ concen -

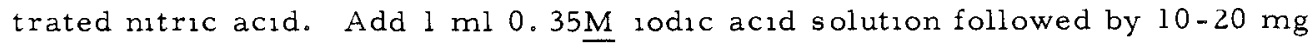
sodium bromate. Heat in water bath untıl precipitate coagulates. Centrifuge precipitate and wash twice with water.

2. Repeat step (1) noting time of the last ceric lodate precipitation, if Ce-143 is to be calculated from the cerium source。

3. Dissolve as in step (1), pass sufficient sulfur dioxide to decolorize lodine, and precipitate cerium as hydroxide with ammonia. Wash once with water.

4. Dissolve in 1 drop $1 \underline{M}$ hydrochloric acıd and make up to convenient colume Weigh out portions for chemical yield and counting. 


$$
\text { RE }-4 \text { (Continued) }
$$

\section{Source Preparation}

Evaporate a weighed portion to dryness on distrene foil in the usual way. Dissolve in 1 to 2 drops of water and precipitate RE in situ either as fluoride or hydroxide. To do this place 1 drop of concentrated hydrofluoric acid or concentrated ammonia solution alongside the main drop and re-evaporate. The method gives a more uniform nondeliquescent source.

6.5. Separation procedure. Almost fill the preheater with eluant, so that it reaches equilibrium temperature. Dissolve the rare-earth hydroxide in 0.1 $\mathrm{ml}$ of $\underline{\mathrm{M}}$ hydrochloric acid.

Remove excess water plus about $1 \mathrm{~cm}$ resin (for use as a tamper) from the top of the bed and place in a test tube on the steam bath. The top of the bed should now be horizontal.

With the first sample tube in position, place the RE solution on the resin bed and allow to percolate under gravity until the meniscus is just above the resin. Wash the test tube which has contained the rare earths with two separate $0.1-\mathrm{ml}$ portions of hot water, and transfer this to the resin in a similar manner. Replace the tamper, allow it to settle and remove any excess water. Introduce the eluant above the surface of the column carefully via the preheater and adjust the height of the reservoir to give a flow rate of $12 \mathrm{ml} / \mathrm{hr}$.

6.6. Elution. Collect the solution in $1-\mathrm{ml}$ fractions using an automatic fraction collector. The break-through volumes for a typical batch of resin are:

\begin{tabular}{|c|c|c|c|}
\hline \multicolumn{2}{|c|}{$\begin{array}{l}\text { a-hydroxy-isobutyric acid } \\
(3.12 \mathrm{~g} / \text { liter, pH } 4.00)\end{array}$} & \multicolumn{2}{|c|}{$\begin{array}{l}\text { a-hydroxy-isobuty } \\
\text { (41.6 g/liter, } \mathrm{pH}\end{array}$} \\
\hline $\mathrm{Sc}$ & $6 \pm 1 \mathrm{ml}$ & $\mathrm{Y}$ & $5 \pm 1 \mathrm{ml}$ \\
\hline $\mathrm{Y}$ & $13 \pm 1 \mathrm{ml}$ & $\mathrm{Nd}$ & $38 \pm 2 \mathrm{ml}$ \\
\hline $\mathrm{Tb}$ & $18 \pm 1 \mathrm{ml}$ & $\operatorname{Pr}$ & $57 \pm 2 \mathrm{ml}$ \\
\hline Gd & $30 \pm 2 \mathrm{ml}$ & & \\
\hline $\mathrm{Eu}$ & $43 \pm 2 \mathrm{ml}$ & & \\
\hline $\mathrm{Sm}$ & $65 \pm 2 \mathrm{ml}$ & & \\
\hline
\end{tabular}

After collection of these fractions, flush out and reject the resin.

6.7. Treatment of fractions. Add $0.3 \mathrm{ml}$ of saturated oxalic acid to each tube. Each element will then precipitate in one or more tubes. Combine the tubes containing the same element, centrifuge, and wash once with dilute oxalic acid solution. If promethium is being determined, there will be an obvious gap between the precipitates of neodymium and of the samarium used as a marker. Combine the center tubes and add $0.1 \mathrm{mg}$ of neodymium to collect the promethium. 


\title{
Sc-1. SCANDIUM $\left(\beta^{+}\right.$Emitters) \\ Threshold Detector Group \\ Radiochemistry \\ UCRL, Livermore \\ May, 1958; Revised 10/28/58
}

\begin{abstract}
This procedure is for trochoidal analyzer samples $\left(\mathrm{B}^{+}\right.$emitters), not $\beta^{-}$ pure.
\end{abstract}

Purification: From a 5-day-old solution containing $1.1 \times 10^{15}$ fissions only, a sample was obtained which had a beta activity of $2.2 \times 10^{4} \mathrm{cpm}$.

Chemical Yield: About $75 \%$.

Procedure

1. To a $25-\mathrm{ml}$ solution of mixed activities in $6 \mathrm{M} \mathrm{HCl}$ in a $40-\mathrm{ml}$ glass centrifuge cone, add $10 \mathrm{mg}$ of scandium carrier and $\approx 10 \mathrm{mg}$ of $\mathrm{Ce}^{+++}, \approx 5 \mathrm{mg}$ of $\mathrm{Te}+4$ and $\approx 2 \mathrm{mg}$ of $\mathrm{Zr}$. Add conc. $\mathrm{NH}_{4} \mathrm{OH}$ in excess. Centrifuge the $\mathrm{Sc}(\mathrm{OH})_{3}$ and discard the supernatant. Wash the precipitate twice with $\approx 15 \mathrm{ml}$ of water to remove salts and especially any $\mathrm{Na}^{+}$ions. Centrifuge and discard the wash solutions.

2. Dissolve the precipitate by adding 1-2 $\mathrm{ml}$ of $6 \mathrm{M} \mathrm{HNO}_{3}$. Transfer the solution to a $50-\mathrm{ml}$ Lusteroid tube with $\approx 4 \mathrm{ml}$ of water. Add an equal volume of $\mathrm{Na}$-free $6 \underline{\mathrm{M}} \mathrm{NH}_{4} \mathrm{~F}$, making the final solution $\approx 3 \underline{\mathrm{M}}$ in $\mathrm{NH}_{4} \mathrm{~F}$ and $\mathrm{pH}$ 4-5. Heat in a hot bath for $\approx 3$ minutes. Cool and centrifuge. Pour the supernatant into a new $50-\mathrm{ml}$ Lusteroid tube. Add $10 \mathrm{ml}$ of $3 \underline{M} \mathrm{NH}_{4} F$ to the precipitate. Heat for 3 minutes. Cool and centrifuge, combining this supernatant with the previous one. Wash the $\mathrm{CeF}_{3}$ with $\approx 5 \mathrm{ml}$ of water. Centrifuge and combine supernatants. Discard the $\mathrm{CeF}_{3}$.

3. To the $\mathrm{Sc}$ solution, add $1 \mathrm{ml}$ of sat. $\mathrm{KBrO}_{3}$ soln. and heat in a hot bath for $\approx 5 \mathrm{~min}$. Then add $\approx 10 \mathrm{ml}$ conc. $\mathrm{HNO}_{3}$. The $\mathrm{pH}$ should be $\approx 0.3$ (or less). Heat in a hot bath for $\approx 5$ minmore. Cool to room temperature. Centrifuge and discard the supernatant. Wash the precipitate with $\approx 5 \mathrm{ml}$ of water. Centrifuge and discard supernatant. Dissolve the $\mathrm{ScF}_{3}$ by adding $\approx 1 \mathrm{ml}$ of $5 \% \mathrm{H}_{3} \mathrm{BO}_{3}$. Mix thoroughly. Heat in hot bath for $\approx 3$ minutes. Add $2 \mathrm{ml}$ conc. $\mathrm{HNO}_{3}$. Transfer the solution to a $40-\mathrm{ml}$ glass cone using $2 \mathrm{ml} 6 \underline{\mathrm{M}} \mathrm{HClO}_{4}$. Heat carefully to strong fumes of $\mathrm{HClO}_{4}$. Dilute to $\approx 20 \mathrm{ml}$ with water. Precipitate $\mathrm{Sc}(\mathrm{OH})_{3}$ by adding an excess of conc. $\mathrm{NH}_{4} \mathrm{OH}$. Centrifuge and discard the supernatant. Wash the ppt. once with $\approx 30 \mathrm{ml}$ of water.

4. Dissolve the $\mathrm{Sc}(\mathrm{OH})_{3}$ in $\approx 20 \mathrm{ml}$ of $0.1 \mathrm{M} \mathrm{HCl}(\mathrm{pH}$ is $1.5-2.0)$. Transfer the solution to a $60-\mathrm{ml}$ cylindrical separatory funnel. Add $\approx 30 \mathrm{ml}$ of $0.40 \mathrm{M}$ TTA in benzene and stir vigorously for $\approx 3$ minutes. Drain aqueous layer 
and wash organic layer four times with $\approx 20 \mathrm{ml}$ of $0.05 \mathrm{M} \mathrm{HCl}$ for $\approx 3$ minutes each time.

Back-extract the scandium with $\approx 20 \mathrm{ml}$ of $2 \mathrm{M} \mathrm{HCl,} \mathrm{stirring} \mathrm{for} 2$ minutes. Allow layers to settle a few minutes before draining aqueous layer.

5. Precipitate $\mathrm{Sc}(\mathrm{OH})_{3}$ with an excess of $\mathrm{NH}_{4} \mathrm{OH}$. Centrifuge and discard the supernatant. Wash the precipitate with $\approx 30 \mathrm{ml}$ of water.

6. Dissolve the precipitate with $0.5 \mathrm{ml}$ of conc. $\mathrm{HCl}$. Add $\approx 30 \mathrm{ml}$ of $1 \underline{\mathrm{M}}$ ammonium tartrate and add conc. $\mathrm{NH}_{4} \mathrm{OH}$ dropwise until $\mathrm{pH}$ 7-8 (bromothymol blue turns from yellow to blue), then add 4 drops more. Heat in a boiling water bath for $\approx 20$ minutes. Cool to room temperature. Centrifuge and discard the supernatant. Wash the scandium ammonium tartrate with $20 \mathrm{ml}$ of water and centrifuge, discarding the supernatant.

7. Dissolve the precipitate in $5 \mathrm{ml}$ of $1 \mathrm{M} \mathrm{HCl}$ and filter through $9-\mathrm{cm}$ No. 40 Whatman paper. Then add $20 \mathrm{ml} 1 \mathrm{M} \mathrm{HCl}$ and add $\approx 2 \mathrm{ml}$ of $30 \% \mathrm{H}_{3} \mathrm{PO}_{2}$ (hypophosphorous acid) to the filtrate. Heat on a hot $\left(\approx 95^{\circ} \mathrm{C}\right)$ bath for 90 minutes. Cool and filter through a tared, 2.5-cm-diameter, No. 542 Whatman filter paper using a filter-chimney setup. Wash with water and methanol. Suck dry for $\approx$ 2 minutes before removing chimney. Dry in oven at $\approx 110^{\circ} \mathrm{C}$ for $\approx 10$ minutes. Weigh, mount and count $\beta^{+}$'s on trochoidal analyzer.

\section{Sc-2. SCANDIUM ( $\beta^{-}$Pure)}

Threshold Detector Group

Radiochemistry

LRL, Livermore

$$
1-9-59
$$

This procedure is for $\beta^{-}$pure samples.

Purification: From a two-week-old solution containing $1.1 \times 10^{16}$ fissions, a sample was obtained which had a beta activity of about $50 \mathrm{cpm}$ (with $\approx 35 \%$ geometry).

Chemical Yield: $\approx 65 \%$

Separation Time: $\approx 6$ hours

$\underline{\text { Procedure }}$

1. To a $25-\mathrm{ml}$ solution of mixed activities in $6 \underline{\mathrm{M}} \mathrm{HCl}$ in a $40-\mathrm{ml}$ glas $\mathrm{s}$ centrifuge cone, add $10 \mathrm{mg}$ of scandium carrier, $\approx 10 \mathrm{mg}$ of $\mathrm{Y}, \approx 5 \mathrm{mg}$ of 


\section{Sc-2 (Continued)}

$\mathrm{Te}+4$ and $\approx 2 \mathrm{mg}$ of $\mathrm{Zr}$. Add $2 \mathrm{ml}$ of $6 \% \mathrm{H}_{2} \mathrm{SO}_{3}$ and $1 \mathrm{ml}$ of $1 \underline{\mathrm{M}} \mathrm{H}_{3} \mathrm{PO}_{4}$. Stır and heat on a hot bath for 5 minutes. Cool to room temperature. Centrifuge and discard the precipitate. To the supernatant add $\approx 2 \mathrm{mg} \mathrm{Zr}$ and $2 \mathrm{mg} \mathrm{Te}$ and heat, repeating the $\mathrm{Zr}$ phosphate-Te metal scavenge. Discard the precipitate. Pour the supernatant into a 50-ml Lusteroid tube. Add conc. $\mathrm{NH}_{4} \mathrm{OH}$ in excess. Centrifuge the $\mathrm{Sc}(\mathrm{OH})_{3}$ and discard the supernatant. Wash the precipitate twice with $\approx 15 \mathrm{ml}$ of water to remove salts and especially any $\mathrm{Na}^{+}{ }^{+}$ions. Centrifuge and discard the wash solutions.

2. Dissolve the precipitate by adding a few drops of $6 \underline{\mathrm{M}} \mathrm{HNO}_{3}$. Add $5 \mathrm{ml}$ of water. Add an equal volume of $\mathrm{Na}-\mathrm{free} 6 \underline{\mathrm{M}} \mathrm{NH}_{4} \mathrm{~F}$, making the final solution $\approx 3 \underline{\mathrm{M}}$ in $\mathrm{NH}_{4} \mathrm{~F}$ and $\mathrm{pH} 4-5$. Heat in a hot bath for $\approx 3$ minutes. Cool and centrifuge. Pour the supernatant into a new 50-ml Lusteroid tube. Add $10 \mathrm{ml}$ of $\mathrm{Na}$-free $2 \mathrm{M} \mathrm{NH}_{4} \mathrm{~F}$ to the precipitate. Heat for 3 minutes. Cool and centriguge, combining this supernatant with the previous one. Wash the $\mathrm{YF}_{3}$ with $\approx 5 \mathrm{ml}$ of water. Centrifuge and combine supernatants. Discard the YF 3 .

3. To the $\mathrm{Sc}$ solution add $1 \mathrm{ml}$ of sat. $\mathrm{K} \mathrm{BrO}_{3}$ soln. and heat in a hot bath for $\approx 5 \mathrm{~min}$. Then add $\approx 10 \mathrm{ml}$ conc. $\mathrm{HNO}_{3}$. The $\mathrm{pH}$ should be $\approx 0.3$ (or less). Heat in a hot bath for $\approx 5$ minutes more. Cool to room temperature. Centrifuge and discard the supernatant. Wash the precipitate $\mathrm{w}_{1}$ th $\approx 5 \mathrm{ml}$ of water. Centrifuge and discard supernatant. Dissolve the $\mathrm{ScF}_{3}$ by adding $1 \mathrm{ml}$ of $5 \% \mathrm{H}_{3} \mathrm{BO}_{3}$. Mix thoroughly. Heat in hot bath for $\approx 3$ minutes. Add $2 \mathrm{ml}$ conc. $\mathrm{HNO}_{3}$. Transfer the solution to a $40-\mathrm{ml}$ glass cone using $2 \mathrm{ml} 6 \mathrm{M}$ $\mathrm{HClO}_{4}$ Heat carefully to strong fumes of $\mathrm{HClO}_{4}$. Dilute to $\approx 20 \mathrm{ml}$ with water. Precipitate $\mathrm{Sc}(\mathrm{OH})_{3}$ by adding an excess of conc. $\mathrm{NH}_{4} \mathrm{OH}$. Centrifuge and discard the supernatant. Wash the precipitate once with $\approx 30 \mathrm{ml}$ of water.

4 Dissolve the $\mathrm{Sc}(\mathrm{OH})_{3}$ in $\approx 20 \mathrm{ml}$ of $0.1 \mathrm{M} \mathrm{HCl}$ (pH is 1.5-2.0). Transfer the solution to a $60-\mathrm{ml}$ cylindrical separatory funnel. Add $\approx 30 \mathrm{ml}$ of $0.40 \mathrm{M}$ $\mathrm{TTA}$ in benzene and stır vigorously for $\approx 3$ minutes. Drain aqueous laye $r$ and wash organic layer four times with $\approx 20 \mathrm{ml}$ of $0.05 \mathrm{M} \mathrm{HCl}$ for $\approx 3$ minutes each time.

Back-extract the scandium with $\approx 20 \mathrm{ml}$ of $2 \mathrm{M} \mathrm{HCl,} \mathrm{stirring} \mathrm{for} 2$ minutes. Allow layers to settle a few minutes before draining aqueous layer.

5. Precipitate $\mathrm{Sc}(\mathrm{OH})_{3}$ with an excess of $\mathrm{NH}_{4} \mathrm{OH}$. Centrifuge and discard the supernatant. Wash the precipitate with $\approx 30 \mathrm{ml}$ of water.

6. Dissolve the $\mathrm{Sc}(\mathrm{OH})_{3}$ with $\approx 8 \mathrm{ml}$ of conc. $\mathrm{HCl}$. Pass the solution $(\approx 10$ $\mathrm{ml}$ total volume) through a Dowex-l anion-exchange resin column $(7 \mathrm{~cm}$ in length $\times 6 \mathrm{~mm}$. d., 50-100 mesh). Wash the column with $\approx 4 \mathrm{ml}$ of $12 \mathrm{M} \mathrm{HCl}$. Collect and combine both solutions.

7 Precipitate $\mathrm{Sc}(\mathrm{OH})_{3}$ with an excess of conc. $\mathrm{NH}_{4} \mathrm{OH}$ Cool, centrifuge 
and discard supernatant. Wash the precipitate with $\approx 30 \mathrm{ml}$ of water.

8. Dissolve the $\mathrm{Sc}(\mathrm{OH})_{3}$ with 3 drops of conc. HCL. Add $\approx 15 \mathrm{ml}$ of saturated $\mathrm{NH}_{4} \mathrm{SCN}$ solution. Final solution should not be more acid than $\approx \mathrm{pH}$ 0.8. Transfer the solution to a $60-\mathrm{ml}$ cylindrical separatory funnel. Add $\approx$ $25 \mathrm{ml}$ of ethyl $\mathrm{n}$-butyl ketone (3-heptanone). (Note 1) Stir the layers vigorously for 2 minutes using a motor-driven glass stirring-rod paddle. Drain and discard the aqueous layer. Wash the organic layer three times with $\approx 15 \mathrm{ml}$ of saturated $\mathrm{NH}_{4} \mathrm{SCN}$ solution for $\approx 1$ minute per wash. Discard the aqueous layers.

Back-extract the Sc from the ketone using two 7-ml portions of $6 \mathrm{M}$ HCl for 1 minute. Discard the organic layer.

9. Precipitate $\mathrm{Sc}(\mathrm{OH})_{3}$ by adding an excess of $\mathrm{NH}_{4} \mathrm{OH}$. Dilute to $\approx 40 \mathrm{ml}$ with water. Cool to room temperature, centrifuge and discard the supernatant. Wash the $\mathrm{Sc}(\mathrm{OH})_{3}$ with $\approx 30 \mathrm{ml}$ of water.

10. Dissolve the precipitate with $0.5 \mathrm{ml}$ of conc. $\mathrm{HCl}$. Add $\approx 30 \mathrm{ml}$ of $1 \underline{\mathrm{M}}$ ammonium tartrate and add conc. $\mathrm{NH}_{4} \mathrm{OH}$ dropwise until pH 7-8 (bromothymol blue turns from yellow to blue), then add 4 drops more. Centrifuge and discard any precipitate, broken glass, etc. Heat in a boiling water bath for $\approx 20$ minutes. Cool to room temperature. Centrifuge and discard the supernatant. Wash the scandium ammonium tartrate with $\approx 20 \mathrm{ml}$ of water and filter through $7-\mathrm{cm}$ No. 42 Whatman paper. Ignite to $\mathrm{Sc}_{2} \mathrm{O}_{3}$ in a furnace for $\approx 20$ minutes at $800^{\circ} \mathrm{C}$ in a No. 00 Coors porcelain crucible. Weigh, mount and count in a scintillation counter or beta counter.

Note 1: Ethyl n-butyl ketone is more specific for Sc than is hexone (methyl isobutyl ketone) which might have been used. Therefore this extraction with the washes gives a better separation from thorium and the rare earths. 


\section{Sc -3. SCANDIUM (Carrier-Free)}

Procedure by: Anders 307

Target Material: Ti

Type of Bbdt: 7.8-Mev Deuterons

Yield: $\approx 50 \%$

Degree of Purification: $\approx 10^{5}$
Time for separation: 4 hours

Equipment Required:

4 Pyrex beakers (50-m1); centrifuge; centrifuge tubes, $40-\mathrm{ml}, 15-\mathrm{ml}$;

platinum wire, 6-inch; Erlenmeyer

flask, 250-ml; medicine droppers;

glass frit filter funnel, coarse;

Whatman 42 filter paper; micropipet,

$50 \lambda$; small ion-exchange column,

Dowex-2 resin (200-400 mesh); con-

ductivity water; conc. $\mathrm{H}_{2} \mathrm{SO}_{4}, \mathrm{HNO}_{3}$ : $\mathrm{HCl}, \mathrm{NH}_{4} \mathrm{OH} ; 30 \% \mathrm{H}_{2} \mathrm{O}_{2} ; \mathrm{NaOH}$ (solid pellets); $\mathrm{NaHCO}_{3}$ (saturated solution); $\mathrm{KClO}_{3}$ (crystals); HCl-gas tank.

\section{Procedure}

1. Place tracer scandium in small beaker, add Mylar substrate. Add 2 $\mathrm{ml}$ conc. $\mathrm{H}_{2} \mathrm{SO}_{4}$ plus a few drops of $30 \% \mathrm{H}_{2} \mathrm{O}_{2}$. Add bombarded titanium foil, heat until dissolved. Oxidize purple solution with few drops of $\mathrm{HNO}_{3}$ (some $\mathrm{TiO}_{2}$ precipitates at this point, if solution is too hot, but this does not interfere). (Note 1)

2. Transfer to 50-ml centrifuge cone and precipitate $\mathrm{TiO}_{2}$. aq. with several pellets of $\mathrm{NaOH}$. Wash twice.

3. Dissolve with conc. HCl. (If solution is not complete, try adding water and heat gently). Centrifuge and transfer supernate to another centrifuge cone.

4. Add slowly a saturated solution of $\mathrm{NaHCO}_{3}$ until initial precipitate still dissolves on stirring. (Note 2)

5. Heat gently to effect homogeneous precipitation of $\mathrm{TiO}_{2}$. aq. Do not permit the $\mathrm{pH}$ to rise above about 5. 5 .

6. Repeat steps (3), (4), and (5) and combine the supernate with that of step (5).

7. Saturate combined supernates with $\mathrm{HCl}$ gas (cool!). Centrifuge off the $\mathrm{NaCl}$.

8. Evaporate to $5 \mathrm{ml}$ and repeat step (7).

9. Add a crystal of $\mathrm{KClO}_{3}$, shake and transfer to a small anion-exchange column charged with $1 \mathrm{ml}$ Dowex-2 resin which has been saturated with conc. $\mathrm{HCl}$ containing a few $\mathrm{mg} \mathrm{KClO}_{3}$ per $100 \mathrm{ml}$.

10. Permit to absorb. When liquid level reaches the resin bed add 5 drops 
of conc. $\mathrm{HCl}$ with $\mathrm{KClO}_{3}$ and permit again to reach the bed level. Elute the scandium activity with approximately $12 \mathrm{ml}$ conc. $\mathrm{HCl}-\mathrm{KClO}_{3}$.

11. Pour the eluate rapidly into a $250-\mathrm{ml}$ Erlenmeyer flask containing 30 $\mathrm{ml}$ of a soln. made of 11 parts $8 \mathrm{~N} \mathrm{NH}_{4} \mathrm{OH}$ and 1 part $30 \% \mathrm{H}_{2} \mathrm{O}_{2}$. Shake vigorously. (Note 3)

12. After fumes subside, cool the clear solution and pass it twice through a double layer of Whatman 42 filter paper positioned over a glass frit funnel. (The scandium activity remains on the filte $r$ in radio-colloidal form.)

13. Wash filter paper with $10 \mathrm{ml}$ of the mixture of step (11) to which about $3 \mathrm{ml}$ conc. $\mathrm{HCl}$ has been added.

14. Wash with $5 \mathrm{ml}$ alkaline distilled water followed by a wash with $5 \mathrm{ml}$ conductivity water.

15. Elute the scandium activity from the filter paper by passing $5 \mathrm{ml}$ of $4 \underline{\mathrm{M}} \mathrm{HCl}$ twice through the filter paper (some of the activity will still remain on the paper, but most of it will be eluted).

16. Evaporate to near dryness and plate for counting.

\section{$\underline{\text { Note }}$}

1. The Mylar is dissolved first, since titanium forms a precipitate in hot conc. $\mathrm{H}_{2} \mathrm{SO}_{4}$ solution containing peroxide.

2. $\mathrm{Ti}(\mathrm{OH})_{4}$ is precipitated homogeneously from a solution of $\mathrm{pH} 2$, while the $\mathrm{Sc}(\mathrm{OH})_{3}$ precipitates only when $\mathrm{pH}$ reaches 7 .

3. A sudden increase of the $\mathrm{pH}$ in a strongly oxidizing medium transforms any titanium present into the titanate ion whose ammonium salt is soluble, while the trace amount of scandium, being insoluble in the medium, "precipitates" in the form of a radio-colloid.

\section{Sc-4. SCANDIUM}

Sattizahn 233

1. Introduction

The procedure described herein for the determination of radio-scandium in the presence of fission-product material is an alternative to that given in LA-1566, pp. 43-49.

Excellent decontamination of radio-scandium is achieved by six successive applications of the following cycle: 
1. Lanthanum fluoride scavenging is done in a medium which is slightly acidic and contains a large excess of fluoride ion. This step gives separation from rare-earth activities; the fluoride ion keeps scandium in solution, presumably as the strongly complexed $\mathrm{ScF}_{4}^{-}$ion.

2. Iron hydroxide scavenging is carried out.

3. The destruction of the $\mathrm{ScF}_{4}^{-}$complex is accomplished by means of concentrated perchloric acid. This results in the precipitation of $\mathrm{ScF}_{3}$ which is then dissolved in ammonium hydrogen fluoride solution.

At the end of the final cycle, $\mathrm{ScF}_{3}$ is dissolved in boric acid solution and is converted to the hydroxide. Scandium is finally precipitated as $\mathrm{K}_{3} \mathrm{ScF}_{6}$ in which form it is weighed and counted. The chemical yield is about $50 \%$.

\section{Reagents}

Sc carrier: $15 \mathrm{mg} \mathrm{Sc}-\mathrm{ml}$ (added as $\mathrm{ScCl}_{3}$ in dilute $\mathrm{HCl}$ ), standardized Fe carrier: $10 \mathrm{mg} \mathrm{Fe}-\mathrm{ml}$ (added as $\mathrm{FeCl}_{3} \cdot 6 \mathrm{H}_{2} \mathrm{O}$ in very dilute $\mathrm{HCl}$ ) La carrier: $10 \mathrm{mg} \mathrm{La}-\mathrm{ml}$ (added as $\mathrm{La}\left(\mathrm{NO}_{3}\right)_{3} \cdot 6 \mathrm{H}_{2} \mathrm{O}$ in very dilute $\mathrm{HNO}_{3}$ )

$\mathrm{HCl}: 6 \underline{\mathrm{M}}$

$\mathrm{HNO}_{3}:$ conc.

$\mathrm{HClO}_{4}:$ conc.

$\mathrm{NH}_{4} \mathrm{OH}$ : conc.

$\mathrm{H}_{3} \mathrm{BO}_{3}$ : saturated aqueous solution

$\mathrm{NH}_{4} \mathrm{HF}_{2}$ : mixture of 2 volumes of $6 \mathrm{M} \mathrm{NH}_{4} \mathrm{OH}$ and 1 volume of $27 \underline{\mathrm{M}} \mathrm{HF}$ $\mathrm{NH}_{4} \mathrm{NO}_{3}: 2 \%$ aqueous solution

KF: saturated aqueous solution

Methyl red indicator soln: $0.5 \%$ in $90 \%$ ethanol

Aerosol: $0.1 \%$ aqueous solution

Zapon solution: $6.0 \mathrm{mg}$ Zapon in $25 \mathrm{drops}$ of Zapon-ethanol solution

Methanol: absolute

\section{Equipment}

Drying oven

Muffle furnace

Centrifuge

Block for holding centrifuge tubes

Mounting plates

Forceps

Pipets: assorted sizes

100-ml beakers (one per standardization)

Ground-off Hirsch funnels: Coors 000A (one per sample) 
Filter chimneys (one per sample)

Porcelain crucibles: Coors 00 (one per standardization)

No. 42 Whatman fllter circles: 7-8 in. diameter

No. 42 Whatman fllter paper: $9-\mathrm{cm}$

$2-1 n .60^{\circ}$ funnels (one per standardization)

$40-\mathrm{ml}$ conical centrifuge tubes: Pyrex 8320 (two per sample)

$40-\mathrm{ml}$ Lusteroid centrifuge tubes (13 per sample)

Steam bath

Stir ring rods

Wash bottle

4. Preparation and Standardization of Carrier

Dissolve $15.33 \mathrm{~g}$ of $\mathrm{Sc}_{2} \mathrm{O}_{3}$ in a minimum of conc. $\mathrm{HCl}$, add an additional $5 \mathrm{ml}$ of $\mathrm{HCl}$, and make the solution up to a volume of 1 liter with $\mathrm{H}_{2} \mathrm{O}$.

Pipet exactly $5 \mathrm{ml}$ of the above carrier solution into a $100-\mathrm{ml}$ beake and dilute to $20 \mathrm{ml}$ with $\mathrm{H}_{2} \mathrm{O}$. Add $5 \mathrm{ml}$ of conc. $\mathrm{NH}_{4} \mathrm{OH}$ to precipitate $\mathrm{Sc}(\mathrm{OH})_{3}$. Filter the solution through No. 42 Whatman filter paper $(9-\mathrm{cm})$, using a 2-in. $60^{\circ}$ funnel. Rinse the beaker with $5 \mathrm{ml}$ of $0.1 \mathrm{M} \mathrm{NH} \mathrm{Cl}_{4}$ and filter the washings through the paper containing $\mathrm{Sc}(\mathrm{OH})_{3}$. Transfer the precipitate to a weighed Coors 00 porcelain crucible and ignite at $900^{\circ}$ for 1 hour. Cool and weigh.

Two standardizations gave results agreeing within $0.3 \%$.

\section{Procedure}

1. To an aliquot of the sample in a $40-\mathrm{ml}$ conical, glass centrifuge tube add exactly $1 \mathrm{ml}$ of $\mathrm{Sc}$ carrier and 4 drops of La carrier and dilute to $20 \mathrm{ml}$. Add conc. $\mathrm{NH}_{4} \mathrm{OH}$ to precipitate $\mathrm{Sc}(\mathrm{OH})_{3}$. Centrifuge and discard the supernate. Nash the precipitate with $30 \mathrm{ml}$ of $2 \% \mathrm{NH}_{4} \mathrm{NO}_{3}$ and discard the washings.

2 Dissolve the precipitate in $6 \underline{\mathrm{M}} \mathrm{HClO}_{4}$. Add $3 \mathrm{ml}$ of $\mathrm{NH}_{4} \mathrm{HF}{ }_{2}$ solution, 1 drop of methyl red indicator solution, and conc. $\mathrm{NH}_{4} \mathrm{OH}$ until the solution is just acidic to the indicator. Make the volume up to $10-12 \mathrm{ml}$, centrifuge, transfer the supernate to a $40-\mathrm{ml}$ Lusteroid tube, and discard the precipitate.

3. To the solution add 4 drops of La carier, 5 drops of Fe carrier, and $1.5 \mathrm{ml}$ of conc. $\mathrm{NH}_{4} \mathrm{OH}$. Dilute to $20 \mathrm{ml}$ and heat on a steam bath for $2 \mathrm{~min}$ to coagulate the $\mathrm{Fe}(\mathrm{OH})_{3}$ precipitate. Centrifuge, transfer the supernate to a clean $40-\mathrm{ml}$ Lusteroid tube, and discard the precipitate.

4. Add $6 \mathrm{ml}$ of conc. $\mathrm{HClO}_{4}$ to the supernate and heat for $5 \mathrm{~min}$ on a steam bath. Allow to cool for $10 \mathrm{~min}$, centrifuge, and discard the supernate. (The soluble fluoscandate complex is converted to insoluble $\mathrm{Sc} F_{3}$.) 
5. To the precipitate, add $2 \mathrm{ml}$ of $\mathrm{NH}_{4} \mathrm{HF}_{2}$ solution, 1 drop of methyl red indicator solution, and conc. $\mathrm{NH}_{4} \mathrm{OH}$ until the solution is just acidic to the indicator. Add 4 drops of La carrier, make the volume up to $10-12 \mathrm{ml}$, centrifuge, transfer the supernate to a clean $40-\mathrm{ml}$ Lusteroid tube, and discard the precipitate.

6. Repeat steps (3), (4), and (5) four additional times and then repeat steps (3) and (4).

7. Dissolve the $\mathrm{ScF}_{3}$ precipitate in $2 \mathrm{ml}$ of saturated $\mathrm{H}_{3} \mathrm{BO}_{3}$ solution and $3 \mathrm{ml}$ of conc. $\mathrm{HNO}_{3}$. Dilute to $20 \mathrm{ml}$ and centrifuge. Transfer the supernate to a clean Lusteroid tube. Add $10 \mathrm{ml}$ of conc. $\mathrm{NH}_{4} \mathrm{OH}$ to precipitate $\mathrm{Sc}(\mathrm{OH})_{3}$. and discard the washings.

8. Dissolve the $\mathrm{Sc}(\mathrm{OH})_{3}$ in a minimum of $6 \mathrm{M} \mathrm{HCl}$, add $5 \mathrm{ml}$ of saturated KF solution and heat on a steam bath for $20 \mathrm{~min}$. Allow to cool for $30 \mathrm{~min}$. Swirl the mixture and transfer to a $40-\mathrm{ml}$ conical, glas centrifuge tube. Wash the Lusteroid tube with $5 \mathrm{ml}$ of saturated $\mathrm{KF}$ solution and add the washings to the glass centrifuge tube. Centrifuge and discard the supernate.

9. To the precipitate add $10 \mathrm{ml}$ of absolute methanol, stir, and transfer onto a weighed No. 42 Whatman filter circle, 7-8 in. diameter, contained in a ground-off Hirsch funnel-filter chimney setup. Rinse the centrifuge tube with two 10-ml portions of methanol and pour the washings through the filter. Dry the precipitate in an oven for $10 \mathrm{~min}$ at $110^{\circ}$. Cool for $20 \mathrm{~min}$, weigh (Note 1), and mount on two-sided Scotch tape on an Al plate. Add 4 drops of Zapon solution, allow to dry, and cover with Nylon (Note 2).

\section{Notes}

1. The scandium is weighed as $\mathrm{K}_{3} \mathrm{ScF}_{6}$. This formula was established in the following manner. Standard $S c^{46}$ tracer was added to a known amount of carrier and the scandium was then precipitated by means of a saturated solution of KF. Then step (9) of the procedure was carried out. The sample was counted on a scintillation counter and the chemical yield determined. The weight of precipitate was then corrected for chemical yield. This permitted the determination of the empirical formula of the compound, on the assumption that it contained potassium, scandium, and fluoride. This was found to correspond to $\mathrm{K}_{3} \mathrm{ScF}_{6}$. Repeated washing of the precipitate with methanol did not change the specific activity of the material.

2. For a discussion of the counting of Sc isotopes, see LA-1566, pp. 48-49. 


\section{Sc -5 . SCANDIUM}

Element separated: Scandium

Target material: Copper

Type of bbt: All $60 \mathrm{in}$, and $184 \mathrm{in}$.
Procedure by: Batze1 306

Time for sep'n: $11 / 2 \mathrm{hr}$

Equipment required: Standard

Yield: $60 \%$

Degree of purification: Factor of 100 from other activities present.

\section{Procedure}

1. Dissolve copper in minimum amount of $\mathrm{HNO}_{3}$. Boil to remove excess. Add $5 \mathrm{mg}$ of $\mathrm{Sc}$ and other carriers. Adjust to $\mathrm{IN}$ in $\mathrm{HCl}$ and treat with $\mathrm{H}_{2} \mathrm{~S}$ (Cus out).

2. Boil to remove $\mathrm{H}_{2} \mathrm{~S}$, add $\mathrm{NH}_{4} \mathrm{OH}$ and $\mathrm{NH}_{4} \mathrm{Cl}$ till ammoniacal. Centrifuge and wash ppt. with hot $\mathrm{NH}_{4} \mathrm{Cl}$ solution.

3. Dissolve ppt. in $\mathrm{HCl}$ and make $6 \mathrm{~N}$ in $\mathrm{HCl}$. Extract Fe three times with equal volume ethyl acetate. Add $\approx 3 \mathrm{mg}$ of Fe carrier and again extract Fe.

4. Make the $\mathrm{pH}$ of the solution 2.0 and extract with equal volume TTA ( 5 $\mathrm{ml}$ of $0.5 \mathrm{M}$ in benzene). Shake for 10 minutes. Wash TTA layer with three 4-ml portions of water.

5. Extract into $1 \mathrm{~N} \mathrm{HCl}$ with two $3-\mathrm{ml}$ portions.

6. Ppt. the Sc as hydroxide with $\mathrm{NaOH}$. Wash with $\mathrm{H}_{2} \mathrm{O}$. Repeat the extraction with fresh TTA.

7. The scandium can be weighed as $\mathrm{Sc}_{2} \mathrm{O}_{3}$ after precipitation as $\mathrm{Sc}(\mathrm{OH})_{3}$ and ignition.

\section{Sc-6. SCANDIUM (Carrier-Free)}

\section{Element separated: Scandium}

Target Material: Titanium

Type of bbdt: 7.8-Mev deuterons

Yield: $\approx 10 \%$

Degree of purification: $\approx 10^{2}$

Advantages: carrier-free separations for $4 \pi \beta$-counting

\section{Procedure by: Hall}

Time for sep'n: $\approx 5$ hours

Equipment required:

250-ml Phillips beaker micro bell jar, No. 00 Hirsch funnels, Whatman No. 50 filter paper, pHydrion (short range) $\mathrm{pH}$ paper

Procedure

1. Place $1 \mathrm{ml}$ conc. $\mathrm{H}_{2} \mathrm{SO}_{4}$ in $250-\mathrm{ml}$ Phillips beaker and add tracer $\mathrm{Sc}^{46}$ 


\section{Sc-6 (Continued)}

(See Remark 2). Introduce the Ti target ( $\approx 130 \mathrm{mg}$ ) and the Mylar substrate. Heat strongly to decompose the Mylar.

2. Cool, add several drops of $30 \% \mathrm{H}_{2} \mathrm{O}_{2}$, and reheat. Repeat until a clear solution is obtained above the unattacked $\mathrm{Ti}$.

3. Add $10 \mathrm{ml} 18 \mathrm{~N} \mathrm{H}_{2} \mathrm{SO}_{4}$ containing $5 \% 16 \mathrm{~N} \mathrm{HNO}_{3}$. Heat, keeping the $\mathrm{HNO}_{3}$ replenished until the $\mathrm{Ti}$ is all dissolved.

4. Dilute to $100 \mathrm{ml}$ and neutralize to $\mathrm{pH} 8.5$ (use pHydrion paper) with a 1:15 mixture of $30 \% \mathrm{H}_{2} \mathrm{O}_{2}$ and $8 \mathrm{~N} \mathrm{NH}_{4} \mathrm{OH}$. Add enough excess $\mathrm{H}_{2} \mathrm{O}_{2}$ to keep the $T i$ in solution.

5. Filter twice through the same Whatman No. 50 filter paper, using suction. Wash three times with $3 \mathrm{~N} \mathrm{NH}_{4} \mathrm{Cl}$ at $\mathrm{pH} 8.5$.

6. Remove Sc with several portions of hot $3 \underline{N} \mathrm{HCl}$.

7. Repeat steps (4), (5), and (6) twice, except in final cycle use conductivity water at $\mathrm{pH} 8.5$ to wash the Sc "precipitate."

8. Evaporate to dryness. Destroy organic matter with aqua regia. Take up with water and transfer to $4 \pi$ plates.

\section{Remarks}

1. General reference: J. D. Gile et al., J. Chem. Phys. 18, 1685 (1950).

2. The tracer is added for the purpose of determining the chemical yield.

3. Use conductivity water to make up solutions, etc.

\section{Sc-7. SCANDIUM (Carrier-Free)}

K. Lynn Hall and W. W. Meinke

Department of Chemistry

University of Michigan

Ann Arbor, Michigan

Element: Sc-No. 1. (Carrier-free)

Separated from: d-bombarded $\mathrm{Ti}$

Docontamination Factor: $\approx 10^{2}$

$\underline{\text { Procedure }}$

1. The Ti target $(\approx 130 \mathrm{mg}$ ) plus the Mylar substrate were placed in a $250-\mathrm{ml}$ beaker, containing $1 \mathrm{ml}$ conc. $\mathrm{H}_{2} \mathrm{SO}_{4}$ and $\mathrm{Sc}^{46}$ tracer (Note 1) and the Mylar decomposed upon vigorous heating. 
2. After cooling, several drops of $30 \% \mathrm{H}_{2} \mathrm{O}_{2}$ were added and the solution reheated. The treatment was repeated until a clear solution above the unattacked Ti was obtained.

3. The Ti target was dissolved in $10 \mathrm{ml} 18 \mathrm{~N} \mathrm{H}_{2} \mathrm{SO}_{4}$ containing $5 \% \mathrm{HNO}_{3}$, with heating; additional $\mathrm{HNO}_{3}$ was necessary for complete dissolution.

4. The solution was diluted to $100 \mathrm{ml}$ and adjusted to a $\mathrm{pH}$ of 8.5 ( $\mathrm{pH}$ paper) with a l:15 mixture of $30 \% \mathrm{H}_{2} \mathrm{O}_{2}$ and $8 \underline{\mathrm{N}} \mathrm{NH}_{4} \mathrm{OH}$. Excess $\mathrm{H}_{2} \mathrm{O}_{2}$ was added to keep the $\mathrm{Ti}$ in solution.

5. The solution was filtered twice through the same Whatman No. 50 filter paper with suction, and the filter paper washed three times with $3 \mathrm{~N}_{4} \mathrm{NH}_{4} \mathrm{Cl}$ which had previously been adjusted to $\mathrm{pH} 8.5$.

6. Sc was removed from the paper by washing with several portions of hot $3 \mathrm{~N} \mathrm{HCl}$.

7. Steps (4), (5), and (6) were repeated twice, and the final "precipitate" washed with conductivity water adjusted to $\mathrm{pH} 8.5$.

8. The final solution was evaporated to dryness, any organic matter destroyed with aqua regia, and the residue dissolved in water and mounted for $4 \pi$ counting.

Notes

1. $\mathrm{Sc}^{46}$ was used to determine the chemical yield $(\approx 10 \%)$.

2. All solutions were made up with conductivity water.

3. The time required was about 5 hours.

\section{$\underline{\text { References }}$}

Gile, J. D., Garrison, W. M., and Hamilton, J. G., J. Chem, Phys. 18, 1685 (1950).

Haskins, J. R., Duval, J. E., Cheng, L. S., and Kurbatov, J. D., Phys. Rev. 88,876 (1952). 


\section{Y-1. YTTRIUM}

\section{Threshold Detector Group}

Radiochemistry

LRL, Livermore

$$
1-26-59
$$

Purıfication: From a two-week-old solution containing $1.1 \times 10^{15}$ fissions, a sample was obtained which had a gamma activity of about 27 y cpm between $1700 \mathrm{kev}$ and $2000 \mathrm{kev}$ through $\approx 1100 \mathrm{mg} \mathrm{Cu} \mathrm{cm}^{-2}$ absorber on a $2-1 \mathrm{n}$. -thick $\times 1-3 / 4-1 n$. -diameter NaI crystal. For other purification see footnotes.

Chemical Yield: $\approx 65 \%$

Separation Time: $\approx 5$ hours

\section{Procedure}

1. To a $25-\mathrm{ml}$ solution of mixed activities in $6 \mathrm{M}$ HCl in a $40-\mathrm{ml}$ glass centrıfuge cone, add $20 \mathrm{mg}$ of yttrium carrier and add $\approx 2 \mathrm{mg}$ each of Sc, $\mathrm{Zr}$, $\mathrm{Te}^{+4}$, and $\mathrm{Ce}^{+3}$. Add conc. $\mathrm{NH}_{4} \mathrm{OH}$ in excess. Centrifuge the $\mathrm{Y}(\mathrm{OH})_{3}$ and discard the supernatant. Wash the precipitate twice with $\approx 20 \mathrm{ml}$ of water to remove salts and especially any $\mathrm{Na}^{+}$10ns. Centrifuge and discard the wash solutions.

2. Dissolve the precipitate by adding a few drops of $6 \underline{\mathrm{M}} \mathrm{HNO}_{3}$. Transfer the solution to a $50-\mathrm{ml}$ Lusteroid tube with $\approx 5 \mathrm{ml}$ of water. Add an equal volume of $\mathrm{Na}-$ free $6 \underline{\mathrm{M}} \mathrm{NH}_{4} \mathrm{~F}$ solution, making the final solution $\approx 3 \underline{\mathrm{M}}$ in $\mathrm{NH}_{4} \mathrm{~F}$ and $\mathrm{pH}$ 4-5. Check the $\mathrm{pH}$ with narrow-range $\mathrm{pH}$ paper. Heat in a hot bath for $\approx 3$ minutes. Cool and centrifuge. Discard the supernatant (Sc). Add $\approx 10 \mathrm{ml}$ of $3 \underline{M} \mathrm{NH}_{4} \mathrm{~F}$ to the precipitate. Heat for 3 minutes. Cool and centrifuge, discarding the supernatant $(\mathrm{Sc})$. Wash the $\mathrm{YF}_{3}$ with $\approx 5 \mathrm{ml}$ of water. Centrifuge and discard the supernatant, Sc (see Note 1 ).

3 Dissolve the $\mathrm{YF}_{3}$ by adding $\approx 3 \mathrm{ml}$ of saturated $\mathrm{H}_{3} \mathrm{BO}_{3}, \approx 10 \mathrm{ml}$ of water and an equal volume of $12 \mathrm{M} \mathrm{HNO}_{3}$, making the final solution $\approx 6 \underline{\mathrm{M}}$ in $\mathrm{HNO}_{3}^{\circ}$. Add $\approx 3 \mathrm{ml}$ of $5 \mathrm{M} \mathrm{HIO}_{3}$. Transfer the solution to a $40 \mathrm{ml}$ glass centrifuge cone. Add $\approx 1 \mathrm{ml}$ of saturated $\mathrm{NaBrO}_{3}$ solution. Stır well and heat in hot bath for $\approx 25$ minutes. Cool to room temperature and centrifuge. Discard the $\mathrm{Ce}\left(\mathrm{IO}_{3}\right)_{4}$ precipitate. To the supernatant, add $\approx 2 \mathrm{mg}$ of $\mathrm{Zr}$ carrier while stirring the solution. Centrifuge well and discard the $\mathrm{Zr}\left(\mathrm{IO}_{3}\right)_{4}$ precipitate. Repeat the $\mathrm{Zr}$ lodate scavenge. After centrifugation, pour the supernatant into a $50-\mathrm{ml}$ Lusteroid tube (see Note 2).

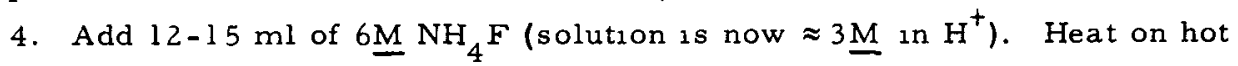
bath for 5 minutes. Cool to room temperature in a cold water bath for 5 min Centrifuge and discard the supernatant $\left(\mathrm{Np}^{+6}\right)$. Wash the $\mathrm{YF}_{3}$ with $\approx$ 
$5 \mathrm{ml}$ of water and discard the wash solution. Dissolve the $\mathrm{YF}_{3}$ with $2 \mathrm{ml}$ of saturated $\mathrm{H}_{3} \mathrm{BO}_{3}$. Mix thoroughly and add $3 \mathrm{ml}$ of conc. $\mathrm{HCl}$. Heat on hot bath for $\approx 3$ min. Dilute to $\approx 30 \mathrm{ml}$ volume with water and precipitate $\mathrm{Y}(\mathrm{OH})_{3}$ with an excess of conc. $\mathrm{NH}_{4} \mathrm{OH}$. Cool, centrifuge, and discard the supernatant. Wash the $\mathrm{Y}(\mathrm{OH})_{3}$ with $\approx 20 \mathrm{ml}$ of water. Centrifuge and discard wash.

5. Dissolve the precipitate with $\approx 20 \mathrm{ml}$ of $\approx \mathrm{pH} 1.0$ buffer solution which is $0.5 \mathrm{M}$ in $\mathrm{Na}_{2} \mathrm{SO}_{4}$ and $0.5 \mathrm{M} \mathrm{NaHSO}_{4}$ and transfer it to a $40-\mathrm{ml}$ glass cone. Add $5 \mathrm{ml}$ of toluene. Add $\approx 10 \mathrm{ml}$ of $\mathrm{CrCl}_{2}$ solution (Oxsorbent). Add $\approx 10 \mathrm{mg}$ $\mathrm{Ba}$ ( $1 \mathrm{ml}$ of solution as the chloride) dropwise while stirring slowly. Heat in hot bath $\left(\approx 95^{\circ} \mathrm{C}\right)$ for 5 minutes. Cool in a cold water bath for 5 minutes. Add $\approx 10 \mathrm{mg} \mathrm{Ba}$ dropwise while stirring slowly. Centrifuge at $>3500$ gravities and pour supernatant into a cone containing $\approx 10 \mathrm{mg}$ of $\mathrm{Ba}$. Heat for $\approx 2$ minutes in hot bath. Cool in cold bath for $\approx 3$ minutes. Add $\approx 10 \mathrm{mg} \mathrm{Ba}$ dropwise while stirring slowly, then centrifuge (see Note 3 ). Pour supernatant into a $50-\mathrm{ml}$ Lusteroid tube containing $\approx 2 \mathrm{ml}$ of conc. HF. Stir, centrifuge, and discard supernatant. Wash the $\mathrm{YF}_{3}$ with $\approx 20 \mathrm{ml}$ of water and discard the wash solution.

6. Dissolve the $\mathrm{YF}_{3}$ by adding $1 \mathrm{ml}$ of $5 \% \mathrm{H}_{3} \mathrm{BO}_{3}$. Mix thoroughly. Heat in hot bath for $\approx 3$ minutes. Add $\approx 2 \mathrm{ml}$ conc. $\mathrm{HNO}_{3}$. Transfer the solution to a $40-\mathrm{ml}$ glass cone using $2 \mathrm{ml}$ of $6 \mathrm{M} \mathrm{HClO}_{4}$. Heat carefully to strong fumes of $\mathrm{HClO}_{4}$. Cool and dilute to $\approx 20 \mathrm{ml}$ with water. Add an excess of conc. $\mathrm{NH}_{4} \mathrm{OH}$. Centrifuge the $\mathrm{Y}(\mathrm{OH})_{3}$ and discard the supernatant. Wash the precipitate with $30 \mathrm{ml}$ of water.

7. Dissolve the $\mathrm{Y}(\mathrm{OH})_{3}$ in $\approx 15 \mathrm{ml}$ of buffer solution- $0.1 \mathrm{M}$ formic acid and $1 \underline{M} \mathrm{Na}$ formate $(\mathrm{pH} \approx 4.6)$. Transfer the solution to a $60-\mathrm{ml}$ cylindrical separatory funnel and extract the $Y$ into $\approx 30 \mathrm{ml}$ of $0.40 \mathrm{M}$ TTA in benzene for 3 minutes stirring with a motor-driven glass paddle. Wash the organic layer 3 times with $\approx 15 \mathrm{ml}$ of buffer solution- $0.4 \underline{\mathrm{M}}$ formic acid and $1 \underline{\mathrm{M}} \mathrm{Na}$ formate $(\mathrm{pH} \approx 4.0)$-for 3 minutes (see Note 4 ). Back-extract the $\mathrm{Y}$ into $\approx 20 \mathrm{ml}$ of $0.05 \mathrm{M} \mathrm{HCl}$ for 3 minutes. Let layers settle for several minutes and then drain the aqueous layer into a $40-\mathrm{ml}$ glass cone. Centrifuge and discard any precipitate, broken glass, etc.

8. Add $\approx 5 \mathrm{ml}$ of saturated oxalic acid and stir vigorously. Let stand for 5 minutes then centrifuge and discard the supernatant. Wash the yttrium oxalate with a few $\mathrm{ml}$ of $0.2 \underline{\mathrm{M}}$ oxalic acid and filter through i-cm No. 42 Whatman paper. Ignite at $\approx 900^{\circ} \mathrm{C}$ for $\approx 20$ minutes in a Coors No. 00 por celain crucible. Weigh, mount on aluminum hat, and count 1.85-Mev gamma ray on 2-in. NaI scintillation counter (slit width 1.7-2.0 Mev) with $1186 \mathrm{mg}$ $\mathrm{Cu} \mathrm{cm}^{-2}$ as absorber to stop betas. 
Notes

1. Steps (2), (7), and (8) have an over-all separation factor of $\approx 4 \times 10^{5}$ of Sc from Y.

2. Steps (3) and (7) have an over-all separation factor of $>10^{6}$ of Ce from Y.

3. Step (5) has a separation factor of $\approx 10^{4}$ of Eu tracer from $\mathrm{Y}$. Nd, $\mathrm{Pr}$ and other cerium earths, if carrier-free, will separate from $Y$ in step (5) also.

4. Three washes in step (7) will separate La away from $Y$ by a factor of $\approx 100$. More washes will give a greater separation factor but there is about a $5 \%$ loss of $\mathrm{Y}$ per wash.

\section{$\underline{Y-2 . \quad Y T T R I U M}\left(Y^{88}\right)$}

Threshold Detector Group

Radiochemistry

LRI Livermore

August 1958

Procedure by: W.H. Hutchin

Purification: See Note 1

Chemical yield: $\approx 80 \%$

\section{Procedure}

1. To a solution of the activity in $20 \mathrm{ml}$ of $6 \mathrm{M} \mathrm{HNO}_{3}$ in a $40-\mathrm{ml}$ glass cone add $\approx 1 \mathrm{mg} \mathrm{Ce}{ }^{+3}, \approx 2 \mathrm{mg} \mathrm{Zr}$ and $10 \mathrm{mg} \mathrm{Y}$, all as the nitrate. Add $1 \mathrm{ml}$ of a saturated solution of $\mathrm{NaBrO}_{3}$. Stir and heat in a hot water bath for $\approx 5 \mathrm{~min}$. Add $3 \mathrm{ml}$ of $5 \mathrm{M}^{-} \mathrm{HIO}_{3}$, and stir. Centrifuge and discard ppt., pouring supernatant into a 50-ml Lusteroid cone.

2. To the supernatant add $\approx 20 \mathrm{ml} 6 \mathrm{M} \mathrm{NH} 4 \mathrm{~F}$. Stir, centrifuge, and dis card supernatant. Wash one with $\approx 20 \mathrm{ml}$ water.

3. Dissolve in $5 \mathrm{ml}$ of a saturated solution of $\mathrm{H}_{3} \mathrm{BO}_{3}$ and $5 \mathrm{ml} \mathrm{HNO}$. Dilute to $\approx 20 \mathrm{ml}$ and add $\mathrm{NH}_{4} \mathrm{OH}$ until basic. Centrifuge and discard super natant. Wash once with $20 \mathrm{ml}$ water.

4. Dissolve in 2 or $3 \mathrm{ml}$ conc. $\mathrm{HCl}$ and pass through anion column (Dowex-1 


\section{$\mathrm{Y}-2$ (Continued)}

$\times 8,50-100$ mesh) that has been equilibrated with conc. $\mathrm{HCl}$, catching eluate in a $40-\mathrm{ml}$ glass cone. Wash col. with $\approx 4 \mathrm{ml}$ conc. $\mathrm{HCl}$.

5. Dilute eluate with water and make basic with $\mathrm{NaOH}$. Centrifuge and discard supernatant. Wash ppt. once with $\approx 20 \mathrm{ml}$ water.

6. Dissolve ppt. in $25 \mathrm{ml}$ of $0.5 \underline{\mathrm{M} \mathrm{H}} \mathrm{SO}_{4}-0.5 \underline{\mathrm{M}} \mathrm{Na}_{2} \mathrm{SO}_{4}$ solution. Add $\approx 5 \mathrm{ml}$ toluene and $\approx 8 \mathrm{ml}$ of a fresh solution of $\mathrm{CrCl}_{2}$ by introducing it under the organic layer. While stirring add $\approx 10 \mathrm{mg} \mathrm{Ba}\left(\right.$ as $\mathrm{Cl}^{\top}$ ). Stir carefully, avoid mixing any air with the aqueous phase or forming a vortex in the solution. Heat in a hot water bath $\left(100^{\circ} \mathrm{C}\right)$ for 10 minutes. After heating period, transfer to a room temperature bath and cool to room temperature. After cooling add another $10 \mathrm{mg} \mathrm{Ba}$ while carefully stirring. Centrifuge strongly and pour supernatant into a cone containing $\approx 10 \mathrm{mg} \mathrm{Ba}$. Heat in a hot water bath for 10 minutes. Cool to room temperature in a room-temperature water bath and add $\approx 10 \mathrm{mg} \mathrm{Ba}$ while carefully stirring. Centrifuge strongly and pour supernatant into a $50-\mathrm{ml}$ Lusteroid tube. Add $\approx 2 \mathrm{ml}$ conc. HF. Stir, cool, and centrifuge, discarding supernatant. Wash once with $\approx 20 \mathrm{ml}$ water (see Notes 2 and 3 ).

7. Repeat step (3).

8. Dissolve $\mathrm{Y}(\mathrm{OH})_{3}$ in $6 \mathrm{M}^{-} \mathrm{HNO}_{3}$ and transfer to a $40-\mathrm{ml}$ glass cone. Make volume up to $20 \mathrm{ml}$ with $6 \underline{\mathrm{M}} \mathrm{HNO}_{3}$. Add $\approx 2 \mathrm{mg} \mathrm{Zr}$ and $1 \mathrm{ml}$ of a saturated soln. of $\mathrm{NaBrO}_{3}$ and stir. Heat for $5 \mathrm{~min}$ in a hot water bath. Add $3 \mathrm{ml}$ of $5 \mathrm{M} \mathrm{HIO}_{3}$ and stir. Centrifuge and pour supernatant into a new glass cone containing $\approx 2 \mathrm{mg} \mathrm{Zr}$. Stir, centrifuge, and discard ppt., pouring supernatant into a $50-\mathrm{ml}$ Lusteroid cone (see Note 4 ).

9. Repeat steps (2) and (3).

10. Dissolve ppt. in $\mathrm{HCl}$, dilute to $\approx 20 \mathrm{ml}$ volume and make basic with $\mathrm{NH}_{4} \mathrm{OH}$. Filter through a No. 42 filter paper. Ignite at $\approx 900^{\circ} \mathrm{C}$ for $\approx$ one hour. Count $1.85-\mathrm{Mev}$ gamma ray on 2 -in. Nal scintillation counter using 1186 $\mathrm{mg} \mathrm{Cm}{ }^{-2} \mathrm{Cu}$ as absorber to stop betas. (Lower discriminator is set at $1.7 \mathrm{Mev}$ and upper at $2.0 \mathrm{Mev}$.)

Notes

1. This procedure does not separate from Sc Quantitatively. If $\mathrm{Sc}^{46}$ is present as one of the activities, it will interfere in the counting of the sample.

2. When opening a new bottle of $\mathrm{CrCl}_{2}$, it is best to put a benzene layer over the $\mathrm{CrCl}_{2}$ as soon as it is opened and to add to the benzene layer as $\mathrm{CrCl}_{2}$ is used.

3. This step gives a separation factor from Eu of $\approx 2 \times 10^{5}$.

4. This step gives a separation from Ce of $\approx 4 \times 10^{4}$. 


\section{Y-3. YTTRIUM (Carrier-Free)}

Procedure by: Anders 307

Target material: $\mathrm{Zr}$

Type of bbdt: $\approx 7.8-\mathrm{Mev}$ deuterons

Yield: $\quad \approx 85 \%$

Degree of purification: $\approx 10^{5}$
Time separation: 3 hours

Equipment required: 4 pyrex beakers $(50-\mathrm{ml})$; centrifuge ; centrifuge tubes, 40-ml, 15-ml (Pyrex); Lusteroid tube $(10-\mathrm{ml})$; micro pipette 50; platinum wire; small anionexchange column; medicine droppers; calcium carrier (10 $\mathrm{mg}-\mathrm{ml})$; zirconium carriex (10 mg-ml); Dowex2 (200-400 mesh); conductivity water; conc. $\mathrm{H}_{2} \mathrm{SO}_{4}, \mathrm{NH}_{4} \mathrm{OH}, \mathrm{HCl}, 30 \%$ $\mathrm{H}_{2} \mathrm{O}_{2} ; \mathrm{HCl}$-gas tank.

\section{Procedure}

1. Cut the tracer yttrium, deposited on Zapon film, from aluminum sample plate and place in small beaker; add bombarded zirconium foil plus Mylar substrate. Add $1.5 \mathrm{ml}$ conc. $\mathrm{H}_{2} \mathrm{SO}_{4}$ and a few drops $30 \% \mathrm{H}_{2} \mathrm{O}_{2}$. Heat to fumes until dissolved (cool and add more $\mathrm{H}_{2} \mathrm{O}_{2}$ at intervals). (Note l)

2. Transfer clear solution to a $40-\mathrm{ml}$ centrifuge tube, add $30 \mathrm{ml} \mathrm{H}_{2} \mathrm{O}$ and precipitate zirconium hydroxide with conc. $\mathrm{NH}_{4} \mathrm{OH}$. Stir with platinum wire; centrifuge and wash twice.

3. Dissolve precipitate with a minimum amount of conc. $\mathrm{HCl}$, add $3 \mathrm{mg}$ calcium carrier and one drop $\mathrm{NbCl}_{5}$ carrier $\left(10 \mathrm{mg}-\mathrm{cm}^{3}\right)$. Transfer to $10-$ ml Lusteroid tube.

4. Precipitate $\mathrm{CaF}_{2}$ (and $\mathrm{YF}_{3}$ ) with $3 \mathrm{ml}$ conc. HF. Centrifuge (water in centrifuge cups!) and wash twice.

5. Transfer precipitate to a 15-ml centrifuge cone, centrifuge, decant, add $0.5 \mathrm{~m}$. conc. $\mathrm{H}_{2} \mathrm{SO}_{4}$.

6. Heat to fumes to drive off $\mathrm{HF}$. Cool. Add $3 \mathrm{mg} \mathrm{Zr}$ carrier and dissolve residue in $10 \mathrm{ml}$ warm water.

7. Precipitate zirconium hydroxide with conc. $\mathrm{NH}_{4} \mathrm{OH}$. Wash three times with conductivity water. (Note 2)

8. Dissolve precipitate with a few drops conc. $\mathrm{HCl}$ and saturate with $\mathrm{HCl}$ gas.

9. Transfer solution to a small anion-exchange column charged with $1 \mathrm{ml}$ Dowex-2 resin saturated with conc. $\mathrm{HCl}$.

10. Adsorb zirconium onto the resin slowly. After liquid level reaches resin bed add 5 drops of conc. HCl and permit to soak in. (Note 3) 


$$
\mathrm{Y}-3 \text { (Continued) }
$$

11. Elute carrier-free yttrium reaction product with $5 \mathrm{ml}$ conc. $\mathrm{HCl}$ at a rate of 1 drop in 7 seconds. (Note 4 )

12. Collect eluate when activity starts coming through. Evaporate to near dryness and plate for counting.

Note

1. A homogeneous solution is obtained under rather severe conditions. Complete isotopic interchange between the $\mathrm{Y}^{88}$ tracer and the reaction product is thus accomplished.

2. This washing removes the calcium carrier and must be done thoroughly, if carrier-free yttrium is to be obtained.

3. Try to wash the walls of the column free of activity with these 5 drops.

4. The yttrium is not absorbed by the resin in hydrochloric acid but is easily eluted, while zirconium and niobium are strongly absorbed from a conc. HC1 medium.

\section{Y-4. YTTRIUM}

C. W. Stanle $y^{233}$

\section{Introduction}

The separation of radioyttrium from rare-earth fission products is accomplished by extraction of the nitrate from concentrated nitric acid solution with tributyl phosphate (TBP) dilute with Gulf Solvent BT. The yttrium is backextracted into water. Two extractions give excellent separation from europium and samarium. The method, therefore, is superior to other procedures in current use.

\section{$\underline{\text { Reagents }}$}

Y carrier: $10 \mathrm{mg} \mathrm{Y-ml} \mathrm{(see} \mathrm{Preparation} \mathrm{and} \mathrm{Standardization} \mathrm{of} \mathrm{Carrier)}$

$\mathrm{Zr}$ carrier: $10 \mathrm{mg} \mathrm{Zr-ml}$ (added as $\mathrm{ZrO}\left(\mathrm{NO}_{3}\right)_{2} \cdot 2 \mathrm{H}_{2} \mathrm{O}$ in 1 M $\mathrm{HNO}_{3}$ )

$\mathrm{HCl}: 6 \mathrm{M}$

$\mathrm{HNO}_{3}$ : conc.

HF: conc.

$\mathrm{H}_{3} \mathrm{BO}_{3}$ : saturated solution

$\mathrm{NH}_{4} \mathrm{OH}$ : conc.

$\left(\mathrm{NH}_{4}\right)_{2} \mathrm{C}_{2} \mathrm{O}_{4}$ : saturated solution 


$$
\text { Y-4 (Continued) }
$$

Tributyl phosphate

(TBP) reagent: $60 \%$ by volume TBP, $40 \%$ Gulf BT; freshly equilibrated with conc. $\mathrm{HNO}_{3}$

$\mathrm{CH}_{3} \mathrm{OH}$ : anhydrous

\section{Equipment}

Centrifuge

Block for holding centrifuge tubes

Forceps

Mounting plates

Porcelain crucibles: Coors 000 (one per sample)

Porcelain crucibles: Coors 00 (one per standardization)

Ground-off Hirsch funnels: Coors 000A (one per sample)

Filter chimneys: (one per sample)

Filter flasks

No. 42 Whatman filter circles: 7-8 in. diameter

Pipets: assorted sizes

50-ml Lusteroid tubes: (one per sample)

40-ml conical centrifuge tubes: (three per sample, one per standardization)

$125-\mathrm{ml}$ separatory funnels: (two per sample)

2-in., 600 funnels: (one per standardization)

Steam bath

Ice bath

Stirring rods

Muffle furnace

Preparation and Standardization of Carrier

Dissolve $43 \mathrm{~g}$ of $\mathrm{Y}\left(\mathrm{NO}_{3}\right)_{3} \cdot 6 \mathrm{H}_{2} \mathrm{O}$ in $\mathrm{H}_{2} \mathrm{O}$, add $5 \mathrm{ml}$ of $6 \mathrm{M} \mathrm{HNO}$, and dilute to 1 liter. To $5.00 \mathrm{ml}$ of the carrier solution in a $40-\mathrm{ml}$ centrifuge tube add $20 \mathrm{ml}$ of $\mathrm{H}_{2} \mathrm{O}$, heat to boiling, and add $20 \mathrm{ml}$ of saturated $\left(\mathrm{NH}_{4}\right)_{2} \mathrm{C}_{2} \mathrm{O}_{4}$ solution with stirring. Heat for $10 \mathrm{~min}$ on a steam bath and then cool in an ice bath for $4 \mathrm{~min}$. Centrifuge the $\mathrm{Y}_{2}\left(\mathrm{C}_{2} \mathrm{O}_{4}\right)_{3}$ and decant the supernate. Take up the precipitate in $10 \mathrm{ml}$ of $\mathrm{H}_{2} \mathrm{O}$ and filter through a $2-i n ., 60^{\circ}$ funnel. Wash the precipitate with $\mathrm{H}_{2} \mathrm{O}$, transfer to a porcelain crucible, burn of the paper, and ignite at $800^{\circ}$ for 1 hour. Cool and weigh as $\mathrm{Y}_{2} \mathrm{O}_{3}$.

Four standardizations are carried out with results agreeing within $1 \%$ 。

Procedure

1. To the sample in a $50-\mathrm{ml}$ Lusteroid tube, add $2.0 \mathrm{ml}$ of standard $Y$ carrier and make the solution $2 \underline{\mathrm{M}}$ in $\mathrm{HNO}_{3}$. Add $2 \mathrm{ml}$ of $\mathrm{Zr}$ holdback carrier and 


\section{$\mathrm{Y}-4$ (Continued)}

make the solution $4 \underline{M}$ in $H F$. Centrifuge the $\mathrm{YF}_{3}$ precipitate and discard the supernate. Wash the precipitate with $10 \mathrm{ml}$ of $5 \mathrm{M} \mathrm{HF}$.

2. Dissolve the $\mathrm{YF}_{3}$ in $2 \mathrm{ml}$ of saturated $\mathrm{H}_{3} \mathrm{BO}_{3}$ solution and $2 \mathrm{ml}$ of conc. $\mathrm{HNO}_{3}$, and dilute $10 \mathrm{ml}$. Add $2 \mathrm{ml}$ of $\mathrm{Zr}$ carrier and enough conc. $\mathrm{HF}$ to make the solution $4 \underline{M}$ with respect to this acid. Centrifuge the $Y_{3}$, decant the supernate, and wash the precipitate with $10 \mathrm{ml}$ of $5 \mathrm{M} \mathrm{HF}$.

3. Dissolve the precipitate in $2 \mathrm{ml}$ of saturated $\mathrm{H}_{3} \mathrm{BO}_{3}$ solution and $2 \mathrm{ml}$ of conc. $\mathrm{HNO}_{3}$. Dilute the solution to $10 \mathrm{ml}$ and precipitate $\mathrm{Y}(\mathrm{OH})_{3}$ by the addition of conc. $\mathrm{NH}_{4} \mathrm{OH}$. Centrifuge and discard the supernate.

4. Dissolve the $\mathrm{Y}(\mathrm{OH})_{3}$ in $50 \mathrm{ml}$ of conc. $\mathrm{HNO}_{3}$ and transfer the solution to a $125-\mathrm{ml}$ separatory funnel. Add $10 \mathrm{ml}$ of TBP reagent and shake the solution for $5 \mathrm{~min}$. Discard the aqueous layer and wash the TBP phase twice by shaking for 2 -min intervals with $50 \mathrm{ml}$ of conc. $\mathrm{HNO}_{3}$. Remove the $\mathrm{Y}$ from the TBP by shaking for $1 \mathrm{~min}$ each with three $10-\mathrm{ml}$ portions of $\mathrm{H}_{2} \mathrm{O}$. Combine the water extracts in a $40-\mathrm{ml}$ centrifuge tube and precipitate $\mathrm{Y}(\mathrm{OH})_{3}$ with conc. $\mathrm{NH}_{4} \mathrm{OH}$. Centrifuge and discard the supernate.

5. Repeat step (4).

6. Dissolve the $\mathrm{Y}(\mathrm{OH})_{3}$ precipitate in $2 \mathrm{ml}$ of $6 \mathrm{M} \mathrm{HCl}$ and dilute the solution to $10 \mathrm{ml}$ with $\mathrm{H}_{2} \mathrm{O}$. Transfer the solution to a clean $40-\mathrm{ml}$ centrifuge tube and reprecipitate $\mathrm{Y}(\mathrm{OH})_{3}$ with conc. $\mathrm{NH}_{4} \mathrm{OH}$. Centrifuge and discard the supernate. Dissolve the precipitate in $2 \mathrm{ml}$ of $6 \mathrm{M} \mathrm{HCl}$ and dilute to 15 $\mathrm{ml}$ with $\mathrm{H}_{2} \mathrm{O}$. Heat the solution on a steam bath and add $20 \mathrm{ml}$ of saturated $\left(\mathrm{NH}_{4}\right)_{2} \mathrm{C}_{2} \mathrm{O}_{4}$ solution. Continue heating for $10 \mathrm{~min}$ and then cool in an ice bath for 4 min. Centrifuge the $\mathrm{Y}_{2}\left(\mathrm{C}_{2} \mathrm{O}_{4}\right)_{3}$ and discard the supernate. Take up the precipitate in $10 \mathrm{ml}$ of $\mathrm{H}_{2} \mathrm{O}$ and pour onto a $7 / 8$-in. -diam No. 42 Whatman filter circle in a standard chimney arrangement with the suction off. Allow the precipitate to settle for a minute or two and then apply suction. Wash the precipitate with anhydrous $\mathrm{CH}_{3} \mathrm{OH}$ and transfer to a porcelain crucible. Ignite at $800^{\circ}$ for $1 / 2$ hour. Cool, weigh, and mount on an Al plate in a centered depression 5/16 in. in diameter and 1/32 in. deep. Beta-count (Note 1).

\section{Notes}

1. The isotopes counted are $65-\mathrm{h} \mathrm{Y}^{90}$ and $61-\mathrm{d}^{91}$. 


\section{Ce-1. CERIUM}

Procedure by: H. G. Hicks 271

Decontamination: $5 \times 10^{13}$ Atoms of $\mathrm{Ce}^{143}$ isolated from a 1 -day-old solution containing $10^{15}$ fissions showed no trace of a foreign radioactivity when followed through three half-lives.

Yield: About 60\%.

Separation time: About eight hours for four samples.

\section{Procedure}

1. To an acid solution of the activities, add $10 \mathrm{mg}$ cerium carrier, about $3 \mathrm{mg} \mathrm{Zr}^{\mathrm{IV}}$, and about $1 \mathrm{mg}$ lanthanum carrier. Make the solution ammoniacal. Centrifuge the precipitate and wash once with water.

2. Dissolve in $8 \mathrm{ml}$ conc. $\mathrm{HNO}_{3}$. Add one drop $30 \% \mathrm{H}_{2} \mathrm{O}_{2}$ (to reduce Ce $\mathrm{IV}$ to $\mathrm{Ce}$ III) and $20 \mathrm{ml} 0.35 \mathrm{M} \mathrm{HIO}_{3}$. Let stand two to three minutes, cool in ice. Centrifuge and discard the precipitate.

3. To supernatant add $2 \mathrm{ml} \mathrm{l} \underline{\mathrm{M}} \mathrm{NaBrO}_{3}$, digest at room temperature five to ten minutes and cool in an ice bath. Centrifuge and discard supernatant. Wash with $20 \mathrm{ml}$ of a solution of two parts $0.35 \mathrm{M} \mathrm{HIO}_{3}$ and one part conc. $\mathrm{HNO}_{3}$; then once with $20 \mathrm{ml}$ water.

4. Dissolve the precipitate in $2 \mathrm{ml}$ cold conc. $\mathrm{HCl}$ and pass through Dowex A-1 column. Wash column with an additional $2 \mathrm{ml}$ conc. $\mathrm{HCl}$.

5. Add $3 \mathrm{mg} \mathrm{Zr}$ to eluate (no La) and repeat steps (1) through (4).

6. Dilute eluate and adjust to $\mathrm{pH} 2-3$. Precipitate cerium oxalate with saturated $\mathrm{H}_{2} \mathrm{C}_{2} \mathrm{O}_{4}$, wash twice with $\mathrm{H}_{2} \mathrm{O}$, once with acetone, dry, ignite at red heat for 20 minutes, weigh as $\mathrm{CeO}_{2}$.

\section{Ce-2. CERIUM}

\section{LRL Livermore}

G. M. Iddings

\section{Procedure}

1. To the active solution add $10 \mathrm{mg}$ of $\mathrm{Ce}^{+3}$ and $\approx 1 \mathrm{mg}$ of $\mathrm{Y}$ and $\approx 1 \mathrm{mg}$ of $\mathrm{Zr}$. Add conc. $\mathrm{NH}_{4} \mathrm{OH}$ to precipitate $\mathrm{Ce}(\mathrm{OH})_{3}$. Centrifuge and discard the supernatant. Wash the $\mathrm{Ce}(\mathrm{OH})_{3}$ once with water.

2. Dissolve the hydroxides in $\approx 25 \mathrm{ml}$ of $6 \underline{\mathrm{M}} \mathrm{HNO}_{3}$. Add $1 \mathrm{drop}$ of $30 \%$ $\mathrm{H}_{2} \mathrm{O}_{2}$ (to keep $\mathrm{Ce}$ in the +3 state). Add $3 \mathrm{ml}$ of $5 \mathrm{M} \mathrm{HIO}_{3}$ to precipitate 
$\mathrm{Zr}\left(\mathrm{IO}_{3}\right)_{4}$. Centrifuge and discard the precipitate. While vigorously stirring the supernatant, add $1 \mathrm{mg}$ of $\mathrm{Zr}$ carrier. Centrifuge and discard the precipitate.

3. To the supernatant add $1 \mathrm{ml}$ of saturated $\mathrm{NaBrO}_{3}$ solution and heat in hot bath for $\approx 3$ minutes. Cool to room temperature and centrifuge the $\mathrm{Ce}\left(\mathrm{IO}_{3}\right)_{4}$. Discard the supernatant.

4. Dissolve the $\mathrm{Ce}\left(\mathrm{IO}_{3}\right)_{4}$ in $25 \mathrm{ml}$ of $6 \underline{\mathrm{M}} \mathrm{HNO}_{3}$. Add $1 \mathrm{mg}$ of $\mathrm{Y}$ holdback carrier, $1 \mathrm{ml}$ saturated $\mathrm{NaBrO}_{3}$ solution and $3 \mathrm{ml}$ of $5 \mathrm{M} \mathrm{HIO}_{3}$. Heat in hot bath for $\approx 3$ minutes. Cool to room temperature and centrifuge. Discard the supernatant.

5. Repeat step (4).

6. Dissolve the $\mathrm{Ce}\left(\mathrm{IO}_{3}\right)_{4}$ in $\approx \mathrm{i} 0 \mathrm{ml}$ of conc. $\mathrm{HCl}$ and pour it through a Dowex-l anion-exchange column $(7 \mathrm{~cm}$ long and $6 \mathrm{~mm}$ i.d., 50-100 mesh). Wash the column with $\approx 3 \mathrm{ml}$ conc. HCl. Discard the resin column.

7. Partially neutralize the $\mathrm{HCl}$ solution of Ce with conc. $\mathrm{NH}_{4} \mathrm{OH}$. Cool and add $1 \mathrm{ml} 6 \% \mathrm{H}_{2} \mathrm{SO}_{3}$ solution. Make basic with $\mathrm{NH}_{4} \mathrm{OH}$. Centrifuge and discard the supernatant. Wash the precipitate once with water.

8. Dissolve the $\mathrm{Ce}(\mathrm{OH})_{3}$ with $\approx 15 \mathrm{ml}$ of $\approx \mathrm{pH} 4.5$ buffer solution $(0.1 \mathrm{M}$ formic acid - $1 \mathrm{M}$ Na formate). Transfer the solution to a $60-\mathrm{ml}$ cylindrical separatory funnel containing $30 \mathrm{ml}$ of $0.4 \underline{\mathrm{M}}$ TTA in benzene. Extract by stirring for $\approx 3$ minutes. Discard the aqueous layer. Wash the organic layer twice with $\approx 15 \mathrm{ml}$ of $\mathrm{pH} 4.5$ buffer solution for $\approx 3$ minutes. Discard aqueous solutions.

9. Back-extract the $\mathrm{Ce}^{+3}$ with $\approx 15 \mathrm{ml}$ of $\mathrm{pH} \approx 4.0$ buffer solution $(0.4 \underline{\mathrm{M}}$ formic acid - IM Na formate) for 3 minutes. Repeat the back-extraction and combine the aqueous layers in a $40-\mathrm{ml}$ centrifuge cone.

10. Add $3 \mathrm{ml}$ of conc. HCl. The $\mathrm{pH}$ is now $\approx 0.4$. Add $5 \mathrm{ml}$ of saturated oxalic acid. Stir vigorously to precipitate cerium oxalate. Heat on hot bath for $\approx 3$ minutes, then cool to room temperature. Centrifuge and discard the supernatant. Wash the precipitate with a few $\mathrm{ml}$ of $0.2 \mathrm{M}$ oxalic acid. Filter through 7-cm No. 42 Whatman paper. Ignite. Weigh mount, and count. 


\section{Ce-3. CERIUM}

The procedure for the determination of cerium in fission-product material was developed by D. P. Ames and is based on a method described by N. E. Ballou, CN-2815 (June 30, 1945). 233

Introduction

In the analysis for radiocerium, exchange between carrier and fissionproduct cerium is effected by a Ce (III)-Ce (IV) oxidation-reduction cycle. Cerium (III) and other rare earths are separated from other fission product by precipitation as fluorides with hydrofluoric acid. Cerium is then oxidized to the +4 state and separated from other rare earths by precipitation as the rodate, $\mathrm{Ce}\left(\mathrm{IO}_{3}\right)_{4}$. Cerium is converted to the +3 state and zirconium, plutonium (IV), and thorium activities are removed by zirconium lodate scavenging. Precipitation of $\mathrm{Ce}(\mathrm{OH})_{3}$ separates cerium from alkaline earth activities. Cerium is finally precipitated as the oxalate and ignited to the oxide $\mathrm{CeO}_{2}$, in which form it is weighed and counted. The chemical yield approximates $75 \%$. Quadruplicate analyses can be performed in about 7 hours.

\section{$\underline{\text { Reagents }}$}

Ce carrier: $10 \mathrm{mg} \mathrm{Ce} / \mathrm{ml}$ (added as $\mathrm{Ce}\left(\mathrm{NO}_{3}\right)_{3} \cdot 6 \mathrm{H}_{2} \mathrm{O}$ in $\mathrm{H}_{2} \mathrm{O}$ ), standardized

La carrier: $10 \mathrm{mg} \mathrm{La} / \mathrm{ml}$ (added as $\mathrm{La}\left(\mathrm{NO}_{3}\right)_{3} \cdot 6 \mathrm{H}_{2} \mathrm{O}$ in $\mathrm{H}_{2} \mathrm{O}$ )

$\mathrm{Zr}$ carrier: $10 \mathrm{mg} \mathrm{Zr} / \mathrm{ml}$ (added as $\mathrm{ZrO}\left(\mathrm{NO}_{3}\right)_{2} \cdot 2 \mathrm{H}_{2} \mathrm{O}$ in 1 M $\mathrm{HNO}_{3}$ )

\section{$\mathrm{HCl}: 6 \mathrm{M}$}

$\mathrm{HCl}$ : conc.

$\mathrm{HNO}_{3}$ : conc.

$\mathrm{HF}$ : conc.

$\mathrm{H}_{3} \mathrm{BO}_{3}$ : saturated aqueous solution

$\mathrm{HIO}_{3}: 0.35 \underline{\mathrm{M}}$

$\mathrm{NH}_{4} \mathrm{OH}$ : conc.

$\mathrm{NaBrO}_{3}$ : saturated aqueous solution

$\left(\mathrm{NH}_{4}\right)_{2} \mathrm{C}_{2} \mathrm{O}_{4}$ : saturated aqueous solution

$\mathrm{H}_{2} \mathrm{O}_{2}: 30 \%$

\section{Equipment}

Muffle furnace

Centrifuge

Block for holding centrifuge tubes

Forceps

Mounting plates

Pipets: assorted sizes

Hirsch funnels: Coors 0000 (one per sample) 


\section{Ce-3 (Continued)}

Filter flasks (one each per standardization and sample)

No. 42 Whatman filter paper: $11-\mathrm{cm}$

No 42 Whatman filter cirlces: 1/2-1n. drameter

2-1n., $60^{\circ}$ fllter funnels (one per standardization)

100-ml beakers (one per standardization)

Porcelain crucibles: Coors 00 (one per standardization)

Porcelain crucibles: Coors 000 or 0000 (one per sample)

$50-\mathrm{ml}$ Lusterond tubes (two per sample)

40-ml conical centrifuge tubes: Pyrex 8320 (three per sample)

Ice bath

Steam bath

Stirring rods.

Preparation and Standardization of Carrier

Dissolve $31.0 \mathrm{~g}$ of $\mathrm{Ce}\left(\mathrm{NO}_{3}\right)_{3} \cdot 6 \mathrm{H}_{2} \mathrm{O}$ in $\mathrm{H}_{2} \mathrm{O}$ and dilute to 1 liter. To obtain cerium free from other rare earths it may be necessary to purify by two $\mathrm{Ce}\left(\mathrm{IO}_{3}\right)_{4}$ precipitations (see steps 4 and 5 of Procedure).

Pipet $5 \mathrm{ml}$ of the cerium carrier solution into a $100-\mathrm{ml}$ beaker and $\mathrm{d}_{1-}$ lute to about $20 \mathrm{ml}$ with $\mathrm{H}_{2} \mathrm{O}$. Warm on a steam bath and add about $50 \mathrm{ml}$ of saturated $\left(\mathrm{NH}_{4}\right)_{2} \mathrm{C}_{2} \mathrm{O}_{4}$ solution. Continue heating on the steam bath until the precipitate has coagulated. Cool in an ice bath for $15 \mathrm{~min}$ and filter through a filter funnel, using a No. 42 Whatman filter paper $(11-\mathrm{cm})$. Ignite in a porcelain crucible at $800^{\circ}$ for $30 \mathrm{~min}$, cool, and weigh as $\mathrm{CeO}_{2}$.

Four standardizations, with results agreeing within $0.5 \%$, are carried out.

\section{Procedure}

1. To a 40-ml centrifuge tube, add $2 \mathrm{ml}$ of Ce carrier and $5 \mathrm{ml}$ of conc. $\mathrm{HNO}_{3}$, and pipet in the sample for analysis. Add $1 \mathrm{ml}$ of saturated $\mathrm{NaBrO}_{3}$ solution and heat on a steam bath for $10 \mathrm{~min}$ (Note 1 ).

2. Remove the tube from the steam bath and add $30 \% \mathrm{H}_{2} \mathrm{O}_{2}$ dropwise with vigorous stirring (Note 2) until the solution has a light reddish-brown color. Heat on the steam bath until the $\mathrm{Br}_{2}$ color disappears, adding a drop or two of $\mathrm{H}_{2} \mathrm{O}_{2}$ if necessary.

3. Add $2 \mathrm{ml}$ of La carrier and $2.5 \mathrm{ml}$ of $\mathrm{Zr}$ holdback carrier and transfer the solution to a $50-\mathrm{ml}$ Lusteroid tube. Add $3 \mathrm{ml}$ of conc. HF to precipitate $\mathrm{CeF}_{3}$ and $\mathrm{LaF}_{3}$. Centrifuge and discard the supernate. Wash the precipitate with $10 \mathrm{ml}$ of $5 \mathrm{M} H F$, centrifuge, and discard the supernate.

4. To the precipitate add 1 to $2 \mathrm{ml}$ of saturated $\mathrm{H}_{3} \mathrm{BO}_{3}$ solution and suspend the precipitate by stirring. Then add $4 \mathrm{ml}$ of conc. $\mathrm{HNO}_{3}$ and stir vigorously 
until a clear solution is formed. Transfer to $40-\mathrm{ml}$ glass centrifuge tube and add $4 \mathrm{ml}$ of conc. $\mathrm{HNO}_{3}$ and $1 \mathrm{ml}$ of saturated $\mathrm{NaBrO}_{3}$ solution. Heat on a steam bath for about $10 \mathrm{~min}$.

5. Add $20 \mathrm{ml}$ of $0.35 \underline{\mathrm{M}} \mathrm{HIO}_{3}$ and stir vigorously. Cool for 5 to $10 \mathrm{~min}$ in an ice bath. Centrifuge and discard the supernate, retaining the $\mathrm{Ce}\left(\mathrm{IO}_{3}\right)_{4}$ precipitate (Note 3 ).

6. Suspend the precipitate in a solution made up by the addition of $8 \mathrm{ml}$ of $\mathrm{H}_{2} \mathrm{O}, 3 \mathrm{ml}$ of conc. $\mathrm{HNO}_{3}$, and $3 \mathrm{ml}$ of $0.35 \mathrm{M} \mathrm{HIO}_{3}$. Centrifuge and discard the supernate. Repeat this washing step twice, suspending the precipitate each time.

7. Add $1 \mathrm{ml}$ of La carrier to the precipitate. Add $4 \mathrm{ml}$ of conc. $\mathrm{HNO}_{3}$ and a drop or two of conc. $\mathrm{HCl}$ and slurry the $\mathrm{Ce}\left(\mathrm{IO}_{3}\right)_{4}$ by stirring vigorously. Add $0.2 \mathrm{ml}$ of $30 \% \mathrm{H}_{2} \mathrm{O}_{2}$ and stir until dissolution of $\mathrm{Ce}\left(\mathrm{IO}_{3}\right)_{4}$ is complete. Add $1 \mathrm{ml}$ of saturated $\mathrm{NaBrO}_{3}$ and $4 \mathrm{ml}$ of conc. $\mathrm{HNO}_{3}$. Reoxidize Ce (III) to $\mathrm{Ce}$ (IV) as in step (4).

8. Repeat step (5).

9. Repeat step (6), washing the precipitate three times. (All other rare earths have now been removed from the cerium.)

10. Add $1 \mathrm{ml}$ of $\mathrm{Zr}$ carrier to the precipitate from step (9) and dissolve the precipitate as in step (7), using $8 \mathrm{ml}$ of conc. $\mathrm{HNO}_{3}, 0.2 \mathrm{ml}$ of conc. $\mathrm{HCl}$, and 0.2 to $0.3 \mathrm{ml}$ of $30 \% \mathrm{H}_{2} \mathrm{O}_{2}$. Add $20 \mathrm{ml}$ of $0.35 \mathrm{M} \mathrm{HIO}_{3}$ to clear solution to precipitate $\mathrm{Zr}\left(\mathrm{IO}_{3}\right)_{4}$ (Note 4$)$. Centrifuge and transfer the supernate to a $50-\mathrm{ml}$ Lusteroid tube, discarding the $\mathrm{Zr}\left(\mathrm{IO}_{3}\right)_{4}$ precipitate.

11. Add $5 \mathrm{ml}$ of conc. HF to precipitate $\mathrm{CeF}_{3}$. Centrifuge and discard the supernate. Wash the precipitate with $10 \mathrm{ml}$ of $5 \underline{\mathrm{M}} \mathrm{HF}$. Centrifuge and discard the supernate.

12. Dissolve the $\mathrm{CeF}_{3}$ by making a slurry in $1 \mathrm{ml}$ of saturated $\mathrm{H}_{3} \mathrm{BO}_{3}$ and adding $2 \mathrm{ml}$ of conc. $\mathrm{HNO}_{3}$. Transfer to a $40-\mathrm{ml}$ centrifuge tube. Heat on a steam bath for $5 \mathrm{~min}$ to insure complete dissolution.

13. Dilute to $10 \mathrm{ml}$ with $\mathrm{H}_{2} \mathrm{O}$ and make strongly basic with conc. $\mathrm{NH}_{4} \mathrm{OH}$ to precipitate $\mathrm{Ce}(\mathrm{OH})_{3}$. Centrifuge and discard the supernate. Wash the precipitate with $10 \mathrm{ml}$ of $\mathrm{H}_{2} \mathrm{O}$. Centrifuge and discard the supernate.

14. Dissolve the $\mathrm{Ce}(\mathrm{OH})_{3}$ in 1 to $2 \mathrm{ml}$ of $6 \underline{\mathrm{M}} \mathrm{HCl}$. Heat on the steam bath to insure complete dissolution.

15. Add $25 \mathrm{ml}$ of saturated $\left(\mathrm{NH}_{4}\right)_{2} \mathrm{C}_{2} \mathrm{O}_{4}$ to precipitate $\mathrm{Ce}_{2}\left(\mathrm{C}_{2} \mathrm{O}_{4}\right)_{3}$. Allow the precipitate to coagulate before removing the tube from the steam bath $(3$ to $5 \mathrm{~min}$ ).

16. Cool the precipitate for $15 \mathrm{~min}$ in an ice bath. Filter on a No. 42 Whatman filter circle, $1 / 2$ in. diameter, using a Hirsch funnel. 
17. Transfer the precipitate to a porcelain crucible and ignite at $800^{\circ}$ for $30 \mathrm{~min}$. Cool for $30 \mathrm{~min}$ and weigh as $\mathrm{CeO}_{2}$ (Note 5).

18. Mount on an Al plate in a centered depression 5/16 in. in diameter and $1 / 32$ in deep, and count (Note 6).

\section{Notes}

1. In strongly acid $\left(\mathrm{HNO}_{3}\right)$ medium, $\mathrm{BrO}_{3}^{-}$ion oxidizes $\mathrm{Ce}$ (III) to Ce (IV).

2. $\mathrm{Ce}(\mathrm{IV})$ is reduced by $\mathrm{H}_{2} \mathrm{O}_{2}$ in acid medium. The oxidation-reduction cycle performed in steps (1) and (2) promotes exchange between radiocerium and carrier.

3. If the concentration of $\mathrm{HNO}_{3}$ is low, $\mathrm{La}\left(\mathrm{IO}_{3} \mathrm{~J}_{3}\right.$ will also precipitate at this stage.

4. The $\mathrm{Zr}\left(\mathrm{IO}_{3}\right)_{4}$ scavenging step removes any $\mathrm{Th}$ and $\mathrm{Pu}$ isotopes which may be present, as well as active $\mathrm{Zr}$.

5. $\mathrm{CeO}_{2}$ should be white. If it is not white at this stage, decontamination from other rare earths is not complete.

6. If it is desired to obtain the mass 144 chain, count the samples immediately through $217 \mathrm{mg} \mathrm{Al} / \mathrm{cm}^{2}$ to cut out the $32.5 \mathrm{~d} \mathrm{Ce}^{141}$ and the $290 \mathrm{~d} \mathrm{Ce} \mathrm{d}^{144}$ betas. This gives only the activity from the $17.5 \mathrm{~m} \operatorname{Pr}^{144}$. To eliminate $33 \mathrm{~h} \mathrm{Ce}{ }^{143}$, one should allow 20 days from the end of bombardment before beginning the analysis. If it is desired to determine $\mathrm{Ce}^{141}$, it is best to count with no added absorber and use a least-squares separation of the $\mathrm{Ce}^{141}$ and $\mathrm{Ce}^{144}$ activities.

\section{Ce-4. CERIUM}

Glendenin, Flynn, Buchanan, and Steinberg 174

\section{Procedure}

1. To the aliquot $(1-5 \mathrm{ml})$ taken for analysis add $1 \mathrm{ml}(10 \mathrm{mg})$ of standardized Ce carrier, $2 \mathrm{ml}$ of $2 \underline{\mathrm{M}} \mathrm{NaBrO}_{3}$, and sufficient conc. $\mathrm{HNO}_{3}$ to make the solution 8-10M in $\mathrm{HNO}_{3}$.

2. Transfer to a separatory funnel containing $50 \mathrm{ml}$ of methyl isobutyl ketone (which has just been equilibrated with $50 \mathrm{ml}$ of $9 \mathrm{M}$ nitric acid containing $2 \mathrm{ml}$ of $2 \mathrm{M} \mathrm{NaBrO}_{3}$ ) and shake for 15-30 seconds. Withdraw the aqueous phase and wash the methyl isobutyl ketone phase twice with $1 \mathrm{ml}$ of 9 M $\mathrm{HNO}^{3}$ containing a few drops of $2 \mathrm{M} \mathrm{NaBrO}_{3}$. (Caution: Combine the aqueous phase and washings, and neutralize with $\mathrm{NH}_{4} \mathrm{OH}$ before discarding.) 


\section{Ce-4 (Continued)}

3. Back-extract the cerium by shaking the methyl isobutyl ketone phase with $5 \mathrm{ml} \mathrm{H}_{2} \mathrm{O}$ containing 2 drops of $30 \% \mathrm{H}_{2} \mathrm{O}_{2}$. (Caution: Wash the methyl isobutyl ketone three times with $50 \mathrm{ml}$ of $\mathrm{H}_{2} \mathrm{O}$ before discarding).

4. Neutralize the aqueous phase by adding concentrated $\mathrm{NH}_{4} \mathrm{OH}(3-5 \mathrm{ml})$ until a precipitate just appears, and acidify with $1.5 \mathrm{ml}$ of $6 \mathrm{M} \mathrm{HNO}_{3}$. Dilute the solution to $15 \mathrm{ml}$ with $\mathrm{H}_{2} \mathrm{O}$, heat just to boiling, and add $15 \mathrm{ml}$ saturated $\mathrm{H}_{2} \mathrm{C}_{2} \mathrm{O}_{4}$. Cool for 2-3 minutes in running water or ice bath, centrifuge, and wash the precipitate with water.

5. Dissolve the precipitate in $1 \mathrm{ml} 6 \mathrm{M} \mathrm{HNO}_{3}$ (warming if necessary) and dilute to $15 \mathrm{ml}$ with $\mathrm{H}_{2} \mathrm{O}$. Repeat the oxalate precipitation, centrifuge, and filter with suction on a weighed filter-paper disc in a small funnel, transferring and washing with three 5-ml portions of $\mathrm{H}_{2} \mathrm{O}$. Wash three times with $5 \mathrm{ml}$ of ethyl alcohol, three times with $5 \mathrm{ml}$ of ether, and place in a vacuum desiccator. Evacuate for $2 \mathrm{~min}$, release and evacuate again for $5 \mathrm{~min}$. Weigh the cerium oxalate, mount, and count.

The yield of cerium through the above procedure is usually about $80 \%$, and the time required is approximately 1 hour.

\section{Eu-1. EUROPIUM}

The procedure described below for the analysis of radioeuropium in fission-product material is essentially that developed by $R$. N. Keller at the Argonne National Laboratory. 233

Introduction

The separation of europium from the other rare earths present in fissionproduct solutions is based upon its reduction from the +3 to the +2 state by zinc dust, followed by precipitation of the unreduced rare earths as hydroxides. Samarium, the other rare earth in fission products which is capable of existence in the +2 state, is not reduced by zinc dust. Barium and strontium activities are removed as sulfates prior to the reduction process. Separation of the rare earths from other activities is effected by fluoride precipitations in the presence of zirconium holdback carrier; this separation is also carried out prior to the reduction by zinc. After reduction of europium and precipitation of the +3 rare earths as hydroxides, the europium is oxidized to the tripositive state and precipitated as the oxalate, in which form it is 


\section{Eu-1 (Continued)}

weighed and counted. The chemical yield is 55 to $65 \%$. A set of eight samples can be analyzed in about 8 hours.

Reagents

Eu Carrier: $10 \mathrm{mg} \mathrm{Eu} / \mathrm{ml}$ (added as $\mathrm{EuCl}_{3}$ in dilute $\mathrm{HCl}$ solution), standardized

Ba carrier: $10 \mathrm{mg} \mathrm{Ba} / \mathrm{ml}$ (added as $\mathrm{Ba}\left(\mathrm{NO}_{3}\right)_{2}$ in $\mathrm{H}_{2} \mathrm{O}$ )

Sr carrier: $10 \mathrm{mg} \mathrm{Sr} / \mathrm{ml}$ (added as $\mathrm{Sr}\left(\mathrm{NO}_{3}\right)_{2} \cdot 4 \mathrm{H}_{2} \mathrm{O}$ in $\mathrm{H}_{2} \mathrm{O}$ )

$\mathrm{Zr}$ carrier: $10 \mathrm{mg} \mathrm{Zr} / \mathrm{ml}$ (added as $\mathrm{ZrO}\left(\mathrm{NO}_{3}\right)_{2} \cdot 2 \mathrm{H}_{2} \mathrm{O}$ in $1 \mathrm{M} \mathrm{HNO}_{3}$ )

Ce carrier: $10 \mathrm{mg} \mathrm{Ce} / \mathrm{ml}$ (added as $\mathrm{Ce}\left(\mathrm{NO}_{3}\right)_{3} \cdot 6 \mathrm{H}_{2} \mathrm{O}$ in $\mathrm{H}_{2} \mathrm{O}$ )

$\mathrm{HCl}: 6 \mathrm{M}$

$\mathrm{HNO}_{3}:$ conc.

$\mathrm{H}_{2} \mathrm{SO}_{4}: 6 \underline{\mathrm{M}}$

$\mathrm{HF}$ : conc.

$\mathrm{H}_{3} \mathrm{BO}_{3}$ : saturated aqueous solution

$\mathrm{H}_{2} \mathrm{C}_{2} \mathrm{O}_{4}$ : saturated aqueous solution

$\mathrm{NH}_{4} \mathrm{OH}$ : conc.

$\mathrm{NH}_{4} \mathrm{OH}$ : conc. (Free From $\mathrm{O}_{2}$ and $\mathrm{CO}_{2}$ )

$\mathrm{NaOCl}: 6 \%$ solution

Zn dust

Aerosol: $1 \%$ in $\mathrm{H}_{2} \mathrm{O}$

Methanol: anhydrous

$\mathrm{N}_{2}$ : tank

\section{Equipment}

Bunsen burner

Drying oven

Centrifuge

Block for holding centrifuge tubes

\section{Forceps}

Mounting plates

Pipets: assorted sizes

Ground-off Hirsch funnels: Coors 000A (one per sample)

Filter chimneys (one per sample)

Filter flasks

60-ml sintered glass crucibles: fine porosity (one per standardization)

No. 42 Whatman filter circles: 7/8-in. diameter, wieghed

$40-\mathrm{ml}$ conical centrifuge tubes: Pyrex 8320 (four per sample)

40-ml narrow neck, round bottom centrifuge tubes: Pyrex 8420 (four per sample) 
$100-\mathrm{ml}$ beaker (one per standardization)

Ice bath

Wash bottle

Stirring rods.

Preparation and Standardization of Carrier

Dissolve $23.1 \mathrm{~g}$ of $\mathrm{Eu}_{2} \mathrm{O}_{3}$ in $50 \mathrm{ml}$ conc. $\mathrm{HCl}$ and make the solution up to a volume of 1 liter with $\mathrm{H}_{2} \mathrm{O}$. If the initial reaction of acid and oxide is too violent use an equivalent amount of dilute acid in place of the concentrated acid.

Pipet $5 \mathrm{ml}$ of the above carrier solution into a $100-\mathrm{ml}$ beaker and add $10 \mathrm{ml}$ of $\mathrm{H}_{2} \mathrm{O}$ and $15 \mathrm{ml}$ of saturated $\mathrm{H}_{2} \mathrm{C}_{2} \mathrm{O}_{4}$ solution. Heat the solution on a steam bath for 15 to $20 \mathrm{~min}$ and then cool to room temperature. Filter on a weighed $60-\mathrm{ml}$ sintered glass crucible (fine porosity). Wash the europium oxalate precipitate several times with small quantities of $\mathrm{H}_{2} \mathrm{O}$ and once with anhydrous $\mathrm{CH}_{3} \mathrm{OH}$. Dry at $100^{\circ}$ for 1 hour and then permit the crucible to cool for 20 to $30 \mathrm{~min}$. Weigh.

Two standardizations, with results agreeing to within $0.5 \%$, are performed.

Procedure

1. Mix $1 \mathrm{ml}$ of $\mathrm{Ba}$ and $\mathrm{Sr}$ carriers and exactly $2 \mathrm{ml}$ of Eu carrier in a $40-\mathrm{ml}$ short-taper conical centrifuge tube. Add an aliquot of the active sample.

2. Heat the solution on a steam bath for 5 min and add 5 drops of $6 \mathrm{M} \quad \mathrm{H}_{2} \mathrm{SO}_{4}$ and a few drops of aerosol solution. Centrifuge the $\mathrm{BaSO}_{4}$ precipitates and decant the supernate to another 40-ml centrifuge tube. Discard the precipitate.

3. Add $\mathrm{l} \mathrm{ml}$ each of $\mathrm{Ba}$ and $\mathrm{Sr}$ carriers to the supernate and heat for $5 \mathrm{~min}$ on a steam bath. After precipitation is complete ( $\mathrm{SrSO}_{4}$ forms somewhat slowly), centrifuge thoroughly. Transfer the supernate to another 40-ml tube and discard the precipitate. (It is frequently necessary to recentrifuge this supernate and decant from the small amount of precipitate which has floated over.)

4. To the supernate add $3 \mathrm{ml}$ of conc. $\mathrm{HNO}_{3}, 4 \mathrm{ml}$ of $\mathrm{Zr}$ carrier, and $3 \mathrm{ml}$ of conc. $\mathrm{HF}$ to precipitate $\mathrm{EuF}_{3}$ and other rare-earth fluorides. Centrifuge and wash the $\mathrm{EuF}_{3}$ with $10 \mathrm{ml}$ of $0.1 \mathrm{M} \mathrm{HF}$, discarding both supernate and washings. (If the analysis is being run on samples containing $\mathrm{U}$ or $\mathrm{Pu}$, place the supernate and washings in the appropriate waste bottle.)

5. Dissolve the EuF 3 precipitate in $1 \mathrm{ml}$ of saturated $\mathrm{H}_{3} \mathrm{BO}_{3}$ and $1 \mathrm{ml}$ of conc. $\mathrm{HNO}_{3}$ and dilute to 20 to $30 \mathrm{ml}$. Precipitate $\mathrm{Eu}(\mathrm{OH})_{3}$ with $2 \mathrm{ml}$ of conc. $\mathrm{NH}_{4} \mathrm{OH}$. Centrifuge and discard the supernate. 
6. Dissolve the precipitate in $3 \mathrm{ml}$ of conc. $\mathrm{HNO}_{3}$ and dilute to $20 \mathrm{ml}$ with $\mathrm{H}_{2} \mathrm{O}$. Add $4 \mathrm{ml}$ of $\mathrm{Zr}$ carrier and reprecipitate and wash EuF $\mathrm{Fs}_{3}$ in step (4). Dissolve the precipitate in $1 \mathrm{ml}$ of $\mathrm{H}_{3} \mathrm{BO}_{3}$ and $1 \mathrm{ml}$ of conc. $\mathrm{HCl}$ and dilute to 20 to $30 \mathrm{ml}$ with $\mathrm{H}_{2}$ O.

7. Precipitate $\mathrm{Eu}(\mathrm{OH})_{3}$ by the addition of $2 \mathrm{ml}$ of conc. $\mathrm{NH}_{4} \mathrm{OH}$. Centrifuge and discard the supernate.

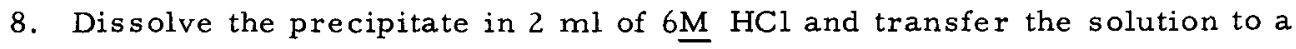
40-ml narrow-neck centrifuge tube. Precipitate $\mathrm{Eu}(\mathrm{OH})_{3}$ as in step (7). centrifuge and discard the supernate.

9. Dissolve the precipitate in $2 \mathrm{ml}$ of $6 \mathrm{M} \mathrm{HCl}$ and dilute to 20 to $30 \mathrm{ml}$ with $\mathrm{H}_{2} \mathrm{O}$. Add $2 \mathrm{ml}$ of $\mathrm{Ce}^{+3}$ carrier (Note 1) and again precipitate $\mathrm{Eu}(\mathrm{OH})_{3}$ with conc. $\mathrm{NH}_{4} \mathrm{OH}$ (Note 2).

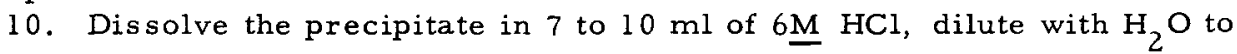
15 to $20 \mathrm{ml}$, and add approximately $0.5 \mathrm{~g} \mathrm{Zn} \mathrm{dust.}$

11. Heat the tube in a steam bath for $10 \mathrm{~min}$ with stirring, using as a stirring device a $4-\mathrm{mm}$ tube through which is passing a stream of $\mathrm{CO}_{2}$-free and $\mathrm{O}_{2}$-free $\mathrm{N}_{2}$ (Note 3 ).

12. With the $\mathrm{N}_{2}$ still bubbling through the solution, quickly plunge the centrifuge tube into an ice bath and chill for 2 to $3 \mathrm{~min}$. Add an excess of $\mathrm{O}_{2}$-free and $\mathrm{CO}_{2}$-free $\mathrm{NH}_{4} \mathrm{OH}$ from a dropping bottle to precipitate $\mathrm{Ce}(\mathrm{OH})_{3}$ (Note 4). Immediately stopper the tube, swirl, and centrifuge. Decant the supernate at once into another narrow-neck centrifuge tube and add $0.5 \mathrm{ml}$ of $6 \% \mathrm{NaOCl}$ to the decantate to oxidize $\mathrm{Eu}^{+2}$ to the +3 state and thus precipitate $\mathrm{Eu}(\mathrm{OH})_{3}$.

13. Centrifuge and discard the supernate. Dissolve the precipitate in $2 \mathrm{ml}$ of $6 \mathrm{M} \mathrm{HCl}$ and reprecipitate $\mathrm{Eu}(\mathrm{OH})_{3}$ with $2 \mathrm{ml}$ of conc. $\mathrm{NH}_{4} \mathrm{OH}$.

14. Repeat steps (9)-(13).

15. Repeat steps (9)-(11) and also the precipitation and centrifugation of $\mathrm{Ce}(\mathrm{OH})_{3}$ and decantation of supernate (see step 12) as before. Transfer the decantate into a clean 40-ml narrow-neck centrifuge tube. (This is to remove any $\mathrm{Ce}(\mathrm{OH})_{3}$ which has floated over in the original decantation.) Stopper immediately and centrifuge. Transfer the supernate to a regular 40-ml centrifuge tube containing $0.5 \mathrm{ml}$ of $\mathrm{NaOCl}$ solution. Centrifuge and discard the supernate.

16. Dissolve the $\mathrm{Eu}(\mathrm{OH})_{3}$ in $2 \mathrm{ml}$ of $6 \mathrm{M} \mathrm{HCl}$, dilute to $20 \mathrm{ml}$ with $\mathrm{H}_{2} \mathrm{O}$, and centrifuge. Discard any precipitate which forms. Reprecipitate Eu(OH) 3 by the addition of $2 \mathrm{ml}$ of conc. $\mathrm{NH}_{4} \mathrm{OH}$. Centrifuge and discard the supernate.

17. Wash the precipitate once with $\mathrm{H}_{2} \mathrm{O}$, dissolve it in $1 \mathrm{ml}$ of $6 \underline{\mathrm{M}} \mathrm{HCl}$, and dilute to $15 \mathrm{ml}$ with $\mathrm{H}_{2} \mathrm{O}$. Add $15 \mathrm{ml}$ of saturated $\mathrm{H}_{2} \mathrm{C}_{2} \mathrm{O}_{4}$ solution and place the tube in a steam bath for 10 to $20 \mathrm{~min}$. Cool to room temperature, cen- 
trifuge, and discard the supernate. Transfer the precipitate by means of a stream of $\mathrm{H}_{2} \mathrm{O}$ onto a No. 42 Whatman (preweighed) 7/8-in.-diameter filter circle in a ground-off Hirsch funnel mounted in a chimney. As soon as the precipitate has been transferred and has partially settled, turn on the suction. Filter and wash the precipitate and also the outside of the chimney twice with small quantities of $\mathrm{H}_{2} \mathrm{O}$ and once with $\mathrm{CH}_{3} \mathrm{OH}$. Dry at $110^{\circ}$ for $15 \mathrm{~min}$. Let the precipitate cool for 12 to $15 \mathrm{~min}$, weigh, and mount (Note 5).

Note

1. The $\mathrm{Ce}^{+3}$ carrier is added to act as a scavenger for rare earths after Eu has been reduced to the +2 state. $\mathrm{Ce}(\mathrm{OH})_{3}$ is precipitated and carries down unreduced rare earths.

2. A number of $\mathrm{Eu}(\mathrm{OH})_{3}$ precipitations are carried out for the purpose of removing $\mathrm{H}_{3} \mathrm{BO}_{3}$ and $\mathrm{HNO}_{3}$ prior to the reduction of $\mathrm{Eu}^{+3}$ with zinc dust.

3. $\mathrm{CO}_{2}$-free and $\mathrm{O}_{2}$-free $\mathrm{N}_{2}$ is obtained by passage of the gas through a Utube containing Ascarite, then through fresh $\mathrm{CrCl}_{2}$ solution (Oxsorbent) contained in a wash bottle with a sintered glass dispersing disk, and finally through a spray trap, such as a Kjeldahl trap.

4. $\mathrm{O}_{2}$-and $\mathrm{CO}_{2}$-free $\mathrm{NH}_{4} \mathrm{OH}$ is obtained by the transfer of the base from a freshly opened bottle to a 500-ml graduated dropping funnel, made with two ground joints at the top--one to lead $\mathrm{N}_{2}$ in and the other, which is fastened to a glass check valve, to permit $\mathrm{N}_{2}$ to go through the funnel over the surface of the $\mathrm{NH}_{4} \mathrm{OH}$ and prevent air from backing up into the funnel.

5. For the determination of $15.4 \mathrm{~d} \mathrm{Eu}^{156}$, which has a $10 \mathrm{~h} \mathrm{Sm}{ }^{156}$ parent, the chemistry is performed 4 days after bombardment time so that the $\mathrm{Sm}$ parent will have decayed. Counting is done 6 days after bombardment to permit the decay of $15.4 \mathrm{~h} \mathrm{Eu}{ }^{157}$.

\section{$\underline{\text { Eu-2. EUROPIUM }}$}

Element separated: Europium

Target material: Thorium (metal)

Type of bbdt: $60-$ in. a's
Procedure by: Newton 306

Time for sep'n: 4 hours

Equipment required: Tank $\mathrm{N}_{2}$ $\left(\mathrm{O}_{2}\right.$ and $\mathrm{CO}_{2}$ free $)$

Yield: $40 \%$

Degree of purification: $10^{6}$ except from RE; $\approx 10^{4}$ from RE. 


\section{Eu-2 (Continued)}

Procedure: The Th metal is dissolved in conc. HCl + a few drops of $0.2 \mathrm{M}$ $\left(\mathrm{NH}_{4}\right)_{2} \mathrm{SiF}{ }_{6}$ solution to clear up the black residue. The $\mathrm{HCl}$ is diluted to $2 \underline{\mathrm{N}}$ and an aliquot taken.

1. To aliquot add $10 \mathrm{mg} \mathrm{Eu}{ }^{+++}$and $10 \mathrm{mg} \mathrm{Ce}^{+++}$carriers. Add $8 \mathrm{ml} \mathrm{conc}$.

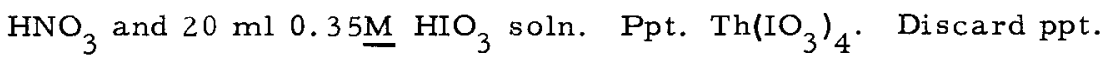

2. To centrifugate add $19 \underline{\mathrm{M}} \mathrm{NaOH}, \mathrm{ppt} . \mathrm{Ce}(\mathrm{OH})_{3}$ and $\mathrm{Eu}(\mathrm{OH})_{3} \cdot$ Centrifuge and wash ppt. once with $\mathrm{H}_{2} \mathrm{O}$.

3. Dissolve ppt. in $8 \mathrm{ml}$ conc. $\mathrm{HNO}_{3}$, add $2 \mathrm{ml} \mathrm{Zr}$ and $20 \mathrm{ml} \mathrm{HIO}$, ppt. $\mathrm{Zr}\left(\mathrm{IO}_{3}\right)_{4}$. Centrifuge and discard ppt.

4. Add $19 \mathrm{M} \mathrm{NaOH}$ to ppt. $\mathrm{Eu}(\mathrm{OH})_{3}$ and $\mathrm{Ce}(\mathrm{OH})_{3}$. Discard supernate. Wash ppt. once with $\mathrm{H}_{2} \mathrm{O}$.

5. Dissolve hydroxides in $1 \mathrm{ml} 6 \mathrm{~N} \mathrm{HCl}$. Add $10 \mathrm{mg}$ each $\mathrm{Ba}$ and $\mathrm{Sr}$ carriers. Pass in $\mathrm{CO}_{2}$-free $\mathrm{NH}_{3}$, ppt. hydroxides.

6. Repeat (5).

7. Dissolve ppt. in $1 \mathrm{ml} \mathrm{HCl}$. Add $\mathrm{Cb}$ and $\mathrm{Zr}$ carrier and $3 \mathrm{ml} 27 \mathrm{~N} \mathrm{HF}$. Ppt. $\mathrm{CeF}_{3}+\mathrm{EuF}_{3}$. Wash ppts. once.

8. Dissolve ppt. in $1 \mathrm{ml} 6 \mathrm{~N} \mathrm{HCl}$ and $1 \mathrm{ml}$ sat. $\mathrm{H}_{3} \mathrm{BO}_{3}$. Dilute, pass in $\mathrm{NH}_{3}$, ppt. $\mathrm{RE}(\mathrm{OH})_{3}$.

9. Dissolve $\mathrm{RE}(\mathrm{OH})_{3}$ in $1 \mathrm{ml} 6 \mathrm{NHCl}$. Pass in $\mathrm{NH}_{3}$, ppt. $\mathrm{RE}(\mathrm{OH})_{3}$.

10. Dissolve $\mathrm{RE}(\mathrm{OH})_{3}$ in $1 \mathrm{ml} 6 \mathrm{~N} \mathrm{HCl}$. Add $0.5 \mathrm{~g} \mathrm{Zn}(\mathrm{Hg})$. Dilute to $5 \mathrm{ml}$, fass in pure $\mathrm{N}_{2}$ through stirring rod. Heat, stirring with rod through which gas is passing. Place in ice bath and pass in $\mathrm{NH}_{3}$ to ppt. $\mathrm{Ce}(\mathrm{OH})_{3}$. Stopper tube and centrifuge. Pipette off supernate to another tube.

11. Dissolve ppt. in $1 \mathrm{ml}$ 6 N HCl, dilute, and repeat step (10).

12. To combined supernates of steps (10) and (11) add 1 drop $\mathrm{NaOCl}(6 \%)$ or pass in ozone. Ppt. $\mathrm{Eu}(\mathrm{OH})_{3}$. Centrifuge. Dissolve in $6 \underline{\mathrm{N}} \mathrm{HCl}$ and repeat steps (10), (11), and (12).

13. Dissolve $\mathrm{Eu}(\mathrm{OH})_{3}$ from step (12) in $1 \mathrm{ml} 6 \mathrm{~N} \mathrm{HCl}$. Dilute to $10 \mathrm{ml}$. Heat. Add $10 \mathrm{ml}$ saturated $\mathrm{H}_{2} \mathrm{C}_{2} \mathrm{O}_{4}$ and place in ice bath $10 \mathrm{~min}$. Filter on weighed filter paper and wash three times with $5 \mathrm{ml} \mathrm{H} \mathrm{H}_{2} \mathrm{O}$, three times with $5 \mathrm{ml} \mathrm{EtOH}$ and three times with $5 \mathrm{ml} \mathrm{Et}_{2} \mathrm{O}$. Evacuated and weigh.

$\underline{\text { Remarks }}$

1. $\mathrm{N}_{2}$ gas must be Free From $\mathrm{O}_{2}$ and $\mathrm{CO}_{2}$.

2. Save all Eu residues, active or not. Eu is extremely rare and hard to get.

This method has been described previously in Phys, Rev. 75, 17 (1949). Preparation of Europium Carrier

About $1.5 \mathrm{~g}$ of europium oxalate originally prepared by McCoy was puri- 


\section{Eu-2 (Continued)}

fied. There are both $a$ and $\beta$ activities associated with this Eu and it is necessary to separate it in order to obtain a good carrier solution. The process is given below.

1. $E u_{2}\left(\mathrm{C}_{2} \mathrm{O}_{4}\right)_{3}$ ignited and dissolved in $\mathrm{HCl}$.

2. $\mathrm{NH}_{4} \mathrm{OH}$ passed to ppt. $\mathrm{Eu}(\mathrm{OH})_{3}$.

3. $\mathrm{Eu}(\mathrm{OH})_{3}$ dissolved in $10 \mathrm{ml} 16 \mathrm{~N} \mathrm{HNO}_{3}, \mathrm{Zr}^{+4}$ carrier added.

4. $\mathrm{HIO}_{3}$ added ppt. $\mathrm{Zr}\left(\mathrm{IO}_{3}\right)_{4}$ carrying all $\mathrm{Th}$ impurities.

5. 19N $\mathrm{NaOH}$ added to ppt. $\mathrm{Eu}(\mathrm{OH})_{3}$.

6. $\mathrm{Eu}(\mathrm{OH})_{3}$ dissolved in $6 \underline{\mathrm{N}} \mathrm{HCl}$. $\mathrm{Ba}^{++}$added and $\mathrm{H}_{2} \mathrm{SO}_{4}$ added while hot to ppt. $\mathrm{BaSO}_{4}$, carrying $\mathrm{Ra}$ and $\mathrm{MsTh}$ activities.

7. $\mathrm{Eu}(\mathrm{OH})_{3}$ pptd. with $\mathrm{NH}_{4} \mathrm{OH}$, washed and dissolved in dilute $\mathrm{HCl}$.

8. $\mathrm{Zn}(\mathrm{Hg})$ added to reduce Eu with $\mathrm{N}_{2}$ bubbling through solution. Then $\mathrm{NH}_{3}$ passed into ppt. RE and Ac hydroxides. Ppt. redissolved in acid and recycled since some Eu not reduced.

9. $\mathrm{Eu}^{++}$oxidized with $\mathrm{NaOCl}$ and pptd. as hydroxide, washed and dissolved in $\mathrm{HCl}$ as carrier.

\section{Standardization of Carrier}

Take $2 \mathrm{ml}$ carrier solution, heat and ppt. oxalate with $\mathrm{H}_{2} \mathrm{C}_{2} \mathrm{O}_{4}$. Cool $10 \mathrm{~min}$ in ice bath, filter. Wash three times with $5 \mathrm{ml} \mathrm{H}_{2} \mathrm{O}$, three times with $5 \mathrm{ml} \mathrm{EtOH}$ and three times with $5 \mathrm{ml} \mathrm{Et}{ }_{2} \mathrm{O}$. Dry by evacuation. Weigh as the oxalate. Ignite to oxide and weigh as the oxide.

$$
\mathrm{Eu}_{2}\left(\mathrm{C}_{2} \mathrm{O}_{4}\right)_{3} \cdot 10 \mathrm{H}_{2} \mathrm{O}(24.6 \mathrm{mg} \text { per } 10 \mathrm{mg} \mathrm{Eu}) \text {. }
$$




\section{Eu-3. EUROPIUM}

Element separated: Europium

Target material: $\approx 1 \mathrm{~g} \mathrm{Bi} \mathrm{metal}$

Type of bbdt: 184-in., all particles

Yield: Eu approx. $15 \%$

Degree of Purification: Eu decontamination factor $>10^{4}$ from non-RE fission and spallation products.

Advantages: Good for separating small amounts of Ce and Eu activity from large amts. of non-RE activities.

Procedure: Cerium and Europium were purified together and then separated from the other rare earths.

1. To aliquot of $\mathrm{HNO}_{3}$ soln. of target add $20 \mathrm{mg} \mathrm{Ce}, \mathrm{Eu}$, and $\mathrm{Y}$. Make $2 \mathrm{~N}$ in $\mathrm{HCl}$ with $\mathrm{Zr}, \mathrm{Cb}$, and $\mathrm{Sr}$ present and precipitate $\mathrm{RE}$ fluorides.

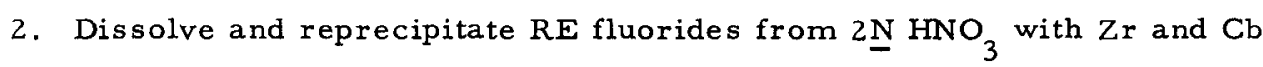
present.

3. Scavenge twice with $\mathrm{Bi}_{2} \mathrm{~S}_{3}$ and RuS from $0.5 \mathrm{~N} \mathrm{HCl}$.

4. Precipitate $\mathrm{RE}$ hydroxides twice with $\mathrm{NH}_{3}\left(\mathrm{CO}_{3}{ }^{-2}\right.$-free $)$ and $\mathrm{Sr}$ present.

5. Precipitate RE fluorides from $2 \underline{N} \mathrm{HCl}$ twice with $\mathrm{Zr}$ and $\mathrm{Cb}$ present.

6. Scavenge with $\mathrm{Bi}_{2} \mathrm{~S}_{3}$ and RuS from 0. 3N HCl.

7. Precipitate REHydroxides with $\mathrm{NH}_{3}$ three times with $\mathrm{Sr}$ present.

8. Precipitate REoxalates from dilute $\mathrm{HCl}$.

9. Precipitate RE fluorides from $\mathrm{HNO}_{3}$.

10. Repeat step (7).

11. Displace air with $\mathrm{N}_{2}$ that is free of $\mathrm{O}_{2}$ and $\mathrm{CO}_{2}$, reduce with $\mathrm{Zn}$ amalgam, precipitate $\mathrm{Y}(\mathrm{OH})_{3}$ and $\mathrm{Ce}(\mathrm{OH})_{3}$ with $\mathrm{NH}_{3}$. Dissolve and reduce again, reprecipitate hydroxides.

12. Oxidize supernatants from hydroxide precipitations with ozone, precipitate $\mathrm{Eu}(\mathrm{OH})_{3}$ with $\mathrm{NH}_{3}$. Dissolve in $\mathrm{HCl}$, add Ce, reduce to $\mathrm{Eu}^{+2}$ and precipitate $\mathrm{Ce}(\mathrm{OH})_{3}$. Repeat separation cycle three times. Precipitate $\mathrm{Eu}_{2}\left(\mathrm{C}_{2} \mathrm{O}_{4}\right)_{3}$ like $\mathrm{Y}_{2}\left(\mathrm{C}_{2} \mathrm{O}_{4}\right)_{3}$ and treat similarly. Weigh as Eu $\mathrm{E}_{2}\left(\mathrm{C}_{2} \mathrm{O}_{4}\right)_{3} \cdot 10 \mathrm{H}_{2} \mathrm{O}$ (24.6 $\mathrm{mg}$ per $10 \mathrm{mg} \mathrm{Eu}$ ). See $(58-2)$ for cerium separation from the same target. 306 In these bbdts., the amount of $Y$ activity produced was $10^{3}$ times the RE activity. 1-2 mg of holdback carriers or scavengers are used. 


\section{Ac-1. ACTINIUM}

$$
\begin{gathered}
\text { G. M. Iddings (LRL, Livermore) } \\
5-17-60
\end{gathered}
$$

Actinium can be mildly purified and mounted weightless by the following procedure:

1. To the Ac tracer in mixed activities add $\approx 5 \mathrm{mg}$ of pure Lu carrier. Precipitate $\mathrm{Lu}(\mathrm{OH})_{3}$ with $\mathrm{NaOH}$ at $\mathrm{pH}>13$ (see Note 1). Wash the precipitate once with water.

2. Dissolve the $\mathrm{Lu}(\mathrm{Ac})$ in $\approx 5 \mathrm{ml}$ of buffer solution- $01 \mathrm{M}$ acetic acid and $1 \mathrm{M}$ sodium acetate- which is $\approx \mathrm{pH}$ 5.7. Transfer the solution to a $60-\mathrm{ml}$ cylindrical separatory funnel and extract the Ac and Lu into $\approx 30 \mathrm{ml}$ of $0.40 \mathrm{M}$ TTA in benzene for 3 minutes, stirring with a motor-driven glass paddle. Wash the organic layer twice with $\approx 15 \mathrm{ml}$ of $\mathrm{pH} 57$ buffer solution.

3. Back-extract the Ac (but not the Lu) into $\approx 10 \mathrm{ml}$ of $\mathrm{pH} 4.5$ buffer solution made of $0.1 \underline{M}$ formic acıd and $1 \underline{M}$ sodium formate. Repeat the backextraction and combine the solutions (see Note 2).

4. Adjust the $\mathrm{pH}$ of the solution to $\approx 5.7$ with saturated sodium acetate solution. Extract the Ac into a new batch of $0.40 \mathrm{M} T \Gamma A$ in benzene. Wash the organic layer with pH 5.7 buffer solution. Wash out the buffer solution with water without stiring.

5. Back-extract the Ac into a few $\mathrm{ml}$ of $0.05 \mathrm{M}$ HCl. Repeat the back-extraction with a new portion of $0.05 \mathrm{M} \mathrm{HCl}$.

6. Evaporate the combined solutions of Ac on a Pt plate under a heat lamp. Ignite gently and count.

\section{Notes}

1. Ac carries much better on $\mathrm{Lu}$ at $\mathrm{pH} 13$ or 14 with $\mathrm{NaOH}$ than at $\mathrm{pH} 8$ or 9 with $\mathrm{NH}_{4} \mathrm{OH}$.

2. The $\mathrm{pH} 4.5$ back-extraction is a good separation of Ac from Y earths and the heavier Ce earths. There is only a partial separation of Ac from La.

\section{Ac-2 ACTINIUM (From Its Daughters)}

$$
\text { Cabel1 }{ }^{67}
$$

\section{Chemical Purification of Ir radiated Actinium}

Cation-and anıon-exchange chromatography were used to purify the irradiated actınıum 
Each cation column consisted of $1.00 \mathrm{~g}$ (dry weight) of 200-400 mesh Dowex-50 (hydrogen form) contained in a glass tube $10 \mathrm{~cm}$ long and $6 \mathrm{~mm}$ in diameter sealed onto a reservolr $10 \mathrm{~cm}$ long and $3 \mathrm{~cm}$ in diameter. Both column and reservorr were jacketed at $60^{\circ}$. Before they were loaded, the columns were prepared by washing with water.

Each anion column contained $0.25 \mathrm{~g}$ of 200-400 mesh Dowex-1 (chloride form) in a tube $6 \mathrm{~cm}$ long and $6 \mathrm{~mm}$ in diameter sealed onto a reservoir $5 \mathrm{~cm}$ long and $1.5 \mathrm{~cm}$ in diameter. The anion columns, which were operated at room temperature, were washed with $5 \mathrm{ml}$ of $10 \underline{\mathrm{M}}$ hydrochloric acid before loading.

The irradiated actinium sample was dissolved in $5 \mathrm{ml}$ of $2 \underline{\mathrm{M}}$ hydrochloric acid and the solution was warmed to $80^{\circ}$ before 1 t was fed to a cation exchange column without application of pressure. When the feed had passed, the column was eluted successively with $5 \mathrm{ml}$ of hot $2 \mathrm{M}$ hydrochloric acid (to remove bismuth, lead, and francium) and $20 \mathrm{ml}$ of hot $3 \mathrm{M}$ nitric acid (to remove radium). Finally the column was eluted with $25 \mathrm{ml}$ of hot $6 \mathrm{M}$ nitric acid, the first $5 \mathrm{ml}$ of eluated was rejected and the remainder, which contained the purified actinium, was collected in a centrifuge tube. The $\mathrm{Th}^{227}$ daughter of the actinium was left on the column.

The progress of this separation is 1llustrated in Fig. 105 (each peak was identified by separate experiments using only one of the five components each time).

Three drops of a ferric nitrate solution (10 mg iron per $\mathrm{m} 1$ ) were added to the eluate obtained from the cation column; the solution was neutralized with ammonia, cooled to room temperature, and the ferric hydroxide precipitate, which carries the actinum, was collected by centrifuging. The precipitate was dissolved in 2 drops of concentrated hydrochloric acid, diluted to $20 \mathrm{ml}$, and the iron was precipitated again with ammonia. This solutionprecipitation cycle was then repeated.

The precipitate was next dissolved in $1 \mathrm{ml}$ of concentrated hydrochloric acid and fed to an anion exchange column at the rate of $0.2 \mathrm{ml} / \mathrm{min}$ to remove the iron carrier. After the feed had passed, the column was eluted with $1 \mathrm{ml}$ of $10 \mathrm{M}$ hydrochloric acid and the total eluate was collected in a small platinum crucible and evaporated to dryness under an infrared lamp. The crucible was then heated in a furnace at $700^{\circ}$ for 5 minutes and cooled; 2 ml concentrated nitric acıd was added and the solution was again evaporated to dryness under an infrared lamp. Finally the residue, which was invisible to the naked eye, was dissolved in $1 \mathrm{ml}$ concentrated nitric acid and the resulting solution was used for making sources on thin films for counting. 


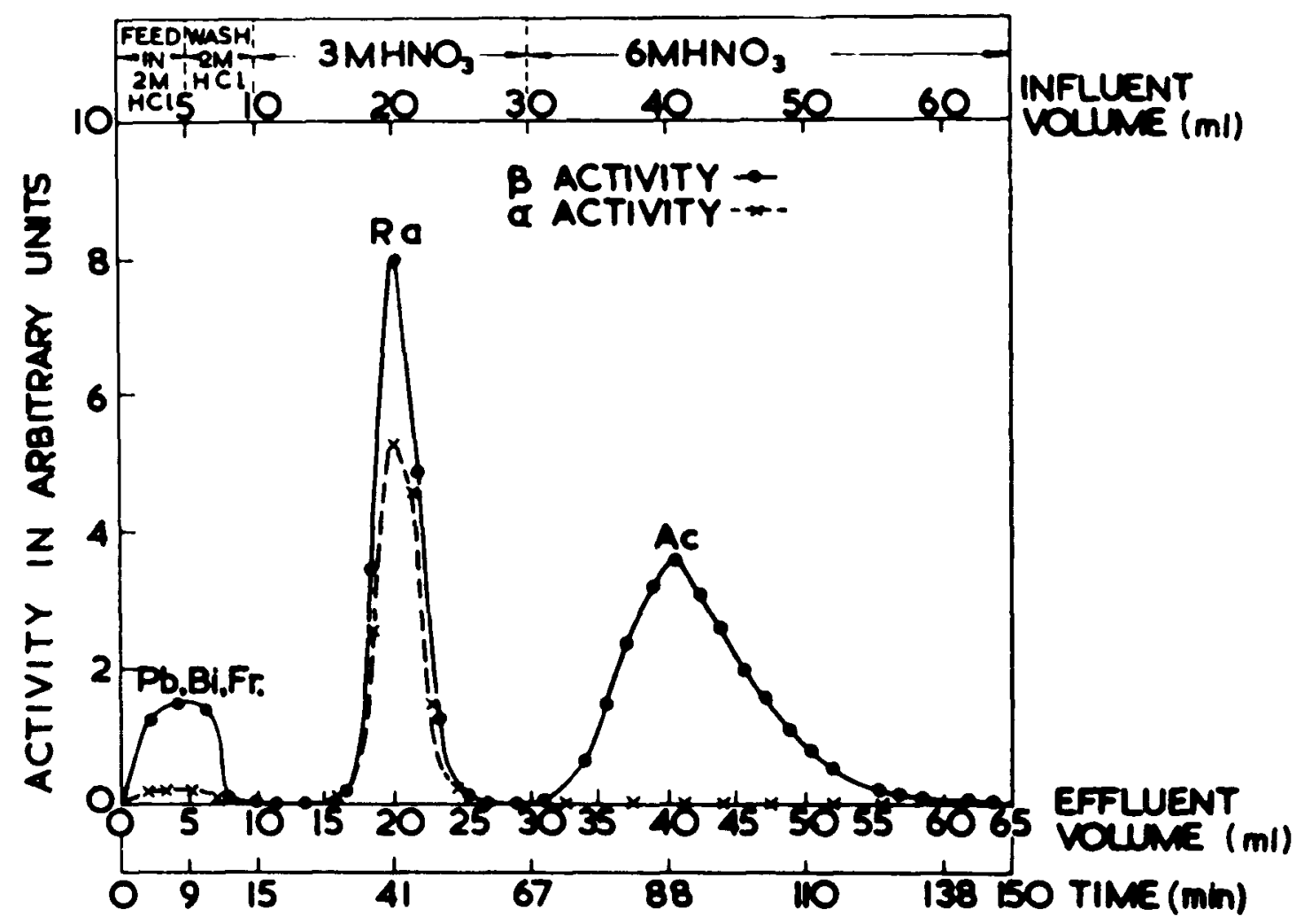

Fig. 105. The separation of $\mathrm{Ac}^{227}$ from its daughters by cation-exchange chromatography (67) 


\section{Ac-3. ACTINIUM}

Element separated: Actinium (procedure designed for $\mathrm{Ac}^{225}$ and $\mathrm{Ac}^{226}$ )

Target material: Thorium metal about Procedure by: Hyde 306

Time for sep'n: 24 hours $25 \mathrm{~g}$ (two 25-mil foils $1-1 / 2$ in. square bombarded on edge)

Type of bbdt: Protons from 184-in.

Equipment required: beakers, cencyclotron trifuge cones, $250-\mathrm{ml}$ separatory funnel, resin column, automatic sampler, pH meter

Yield: Not known, estimated $75 \%$

Degree of purification: Complete separation from all other elements by factor of at least $10^{4}$.

$\underline{\text { Procedure }}$

1. Dissolve thorium in hot conc. $\mathrm{HNO}_{3}$. Add l drop 1 N HF occasionally to catalyze dissolution.

2. Evaporate solution nearly to crystallization. Cool. Transfer to $250-\mathrm{ml}$ pear-shaped separatory funnel. One which has been modified to provide a side funnel as shown in Fig. $1^{306}$ is recommended.

3. Add 1-2 volumes pentaether (dibutoxytetraethylene glycol). ${ }^{*}$ Stir. Let settle. Drain aqueous layer into original beaker. Drain pentaether layer into bottle for storage.

4. Return aqueous layer to funnel. Add solid ammonium nitrate with stirring until solution is saturated. Add 2-3 volumes pentaether. Stir. Drain aqueous into $50-\mathrm{ml}$ centrifuge cone. Drain pentaether layer into storage bottle.

5. Repeat pentaether extraction once again after adding $0.5 \mathrm{ml}$ conc. $\mathrm{HNO}_{3}$ to replace that extracted by solvent.

6. Centrifuge aqueous layer in $50-\mathrm{ml}$ centrifuge cone to separate last $\mathrm{cc}^{\prime} \mathrm{s}$ of pentaether, which are pipetted off.

7. Add $\mathrm{NH}_{4} \mathrm{OH}$ to ppt. last amounts of thorium as $\mathrm{Th}(\mathrm{OH})_{4}$. This serves to carry the actinium out of the salted solution. Wash twice with $\mathrm{H}_{2} \mathrm{O}$.

* It is quite important that the solution be cool before the solvent is added as pentaether is rapidly decomposed by hot nitric acid.

** Pentaether is used to extract the bulk of the thorium away. The thorium serves as its own salting agent in the first pass which extracts the bulk of it and reduces the aqueous volume greatly. Subsequent extractions must be aided by $\mathrm{NH}_{4} \mathrm{NO}_{3}$ salting. 
8. Dissolve mixed hydroxides in minimum amount HCl. Dilute to $5 \mathrm{ml}$. Adjust pH to 1.5-2.5, ${ }^{* * *}$ check with Beckman pH meter using 1-drop glass electrode. Add $10 \mathrm{ml} 0.15 \mathrm{M}$ TTA in benzene. Stır. Recheck and if necessary readjust $\mathrm{pH}$. Stir well'10-20 minutes.

9. Centrifuge. Pipet off benzene layer containing thorium.

10 To aqueous add $10 \mathrm{ml}$ fresh TTA. Stir, check pH. Stır 10-20 minutes. Centrifuge. Pipet off benzene layer.

11. To aqueous layer containing actinium, rare-earth, and other activities add $\mathrm{NH}_{4} \mathrm{OH}$ to adjust $\mathrm{pH}$ to 5.5-7.0.

12. Add $10 \mathrm{ml}$ TTA-benzene. Stır. Recheck pH. Contact 20 minutes.

13. Pipet benzene layer containing actinium and rare earths into clean $50-\mathrm{ml}$ centrifuge cone. Re-extract activity 1 nto $2.5 \mathrm{ml} 0.1 \mathrm{~N} \mathrm{HCl}$ by $2 \mathrm{~min}-$ utes of stirring. (At this point the only likely impurities are rare-earth fission products. If these do not interfere, this solution may be considered the final solution. If separation from rare earths is desired the following resin separation is recommended.)

14. Add a few $\mathrm{mg}$ of ammonium-form, colloxdal Dowex-50 resin to the dilute $\mathrm{HCl}$ solution. Warm to $\approx 60^{\circ} \mathrm{C}$ in water bath for 2-3 minutes. Centrifuge.

15. If assay of supernate indicates nearly complete adsorption on resin, pipet the resin on to the top of a short resin column. Elute with $5 \%$ citrate solution of $\mathrm{pH}$ 3.8-4.0. Use a mechanical sampler to take samples every 20 minutes.

The rare-earth and actinium peaks cannot be predicted accurately enough to eliminate the necessity of alpha and beta counts to determine their location. The rare-earth fractions come off in the first samples as indicated by the beta counts. The actinium peak is located by the alpha counts of Ac 225 The solution of $\mathrm{Bi}^{213}$ and its associated $\mathrm{Po}^{213}$ daughter alpha activity in the early fractions obscures the location of the actinium peak unless samples are pulse-analyzed or unless the 47-minute $\mathrm{B}_{1}^{213}$ is allowed to decay before counting.

My experience with a column $6 \mathrm{~cm} \times 2 \mathrm{~mm}$ of colloidal resin eluted with $\mathrm{pH} 3.9$ citrate at a rate of 1 drop per 2.5 minutes was that the rare-

\footnotetext{
*** An equal volume of TTA-benzene will extract thorium essentially completely from an aqueous solution of $\mathrm{pH}>1$. Actinium extraction is 0 at $\mathrm{pH}$ 2.5 or less, is $10 \%$ at $\mathrm{pH} 4$, and rises sharply to essentially complete extraction at $\mathrm{pH} 5.5$ or greater. See Hagemann, AECD-1933.
} 
earth fraction came off within two hours and the actinium fraction, well separated from the rare earths, started to come off after 5 hours and was spread over 2-3 hours. Others (Orth and Street) report much more rapid elution under essentially the same conditions.

\section{Ac-4. ACTINIUM}

Element separated: Actinium

Parent material: Tracer $\mathrm{Pa}^{230}$

Milking experiment
Procedure by: Meinke 306

Time for sep'n: $3-4$ hours

Equipment required: Standard, centrifuge

Yield: $\approx 40 \%$

Degree of purification: Factor of at least $10^{7}$ from $\mathrm{Pa}, \mathrm{U}$, and $\mathrm{Th}$.

Advantages: Can separate very small amounts of Ac from large amounts of $\mathrm{Pa}, \mathrm{U}$, and $\mathrm{Th}$ activity. In one experiment separated $500 \mathrm{~d} / \mathrm{m} \mathrm{Ac}{ }^{226}$ from 10 total $\mathrm{d} / \mathrm{m}$ of $\mathrm{Pa}^{250}$ and about equivalent amounts of $\mathrm{U}$ and 30 -minute $\mathrm{Th}^{226}$ Procedure: $\mathrm{Pa}^{230}$ in $6 \underline{\mathrm{N}} \mathrm{HNO}_{3}$ after DIPK extractions (procedure 91-1). ${ }^{306}$

1. Take $10 \mathrm{cc}$ of $\mathrm{Pa}$ soln. and add $1 / 4 \mathrm{mg} \mathrm{La}^{+3}$ and $5 \mathrm{mg} \mathrm{Ce}^{+3}$ carriers.

2. Add 10 drops of conc. HF to ppt. the fluorides. Centrifuge.

3. Metathesize ppt. to La and Ce hydroxides and wash once with $5 \mathrm{ml}$ alkaline water.

4. Dissolve ppt. in few drops $6 \mathrm{~N} \mathrm{HCl}$ and dilute to $5 \mathrm{cc}$.

5. Add $1 / 4 \mathrm{mg} \mathrm{Zr}{ }^{+4}$ carrier and $\mathrm{H}_{3} \mathrm{PO}_{4}$ to make $3 \mathrm{~N} \mathrm{PO}_{4}^{-3}$. Discard ppt. Steps (2) through (5) are repeated alternately or consecutively until the desired degree of purification is obtained. For the purifications noted above, 10 fluoride pptns. and 9 phosphate pptns. were made. After the 10 th fluoride ppt. had been metathesized to the hydroxide, the following procedure was used:

6. Dissolve hydroxide ppt. in $10 \mathrm{M} \mathrm{HNO}_{3}$, make. $01 \underline{\mathrm{M}} \mathrm{Fe}^{+3}$ and oxidize $\mathrm{Ce}^{+3}$ to $\mathrm{Ce}^{+4}$ with solid sodium bismuthate (warm to speed up reaction). (Ce will now carry on the $\mathrm{Zr}_{3}\left(\mathrm{PO}_{4}\right)_{4}$ ppt.)

7. Repeat step (5).

8. Repeat steps (2) and (3).

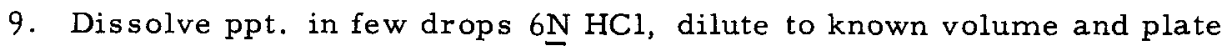
aliquot for counting. 


\section{Remarks:}

The fluoride cycles decontaminate primarily from $\mathrm{Pa}$, the phosphate from Th. If further purification is required include more cycles in procedure.

Only one milking can be made from a given batch of $\mathrm{Pa}$ by this procedure since it is difficult to again get the $\mathrm{Pa}$ into an extractable form once fluoride ion has been added.

It has been found that the $\mathrm{LaCl}_{3}$ solution makes a more adherent and thinner plate than the $\mathrm{LaF}_{3}$ ppt. The amount of $\mathrm{La}^{+3}$ carrier used in step (1) should be determined by the amount of bulk that can be tolerated on the final plate.

\section{Ac-5. ACTINIUM}

Element separated: Actinium (procedure Procedure by: Hall ${ }^{306}$ designed for $\mathrm{Ac}^{226}$ )

Target material: Tharium metal $\left(\approx 0.5 \quad\right.$ Time for $\operatorname{sep}^{\prime} n: \approx 24$ hours g 5-mil forl)

Type of bbdt: $340-$ Mev protons

Equipment required: Beakers, resin column, automatic sampler, $\mathrm{pH}$ meter, stirrex

Y1eld: Not known, probably at least $75 \%$.

Degree of purification: Factor of at least $10^{4}$ from other elements.

Advantages: TTA separation of Th target material faster and cleaner than pentaether extraction.

$\underline{\text { Procedure }}$

1. Dissolve thorium in hot concentrated $\mathrm{HCl}$ in 50-ml beaker. Add 1 drop only of $0.2 \underline{\mathrm{M}}\left(\mathrm{NH}_{4}\right)_{2} \mathrm{~S}_{1} \mathrm{~F}_{6}$ (more causes $\mathrm{S}_{1}$ to precipitate).

2. Evaporate to dryness to expel most of the $\mathrm{HCl}$.

3. Take up residue with water and adjust the pH meter and glass and calomel electrodes, Nos. 1170 and 1190 .

4. Extract the thorium away with an excess of IM TTA in benzene, previously washed first with acid then with water.

(a) Add $\approx 25 \mathrm{ml}$ TTA.

(b) Ádjust $\mathrm{pH}$ throughout extraction period to 1.0-2.0.

(c) Stır 20 minutes. 
(d) Pipet off the aqueous layer and transfer to a clean beaker.

5. Repeat the thorium extraction three times using clean stirrers, beakers, etc., each time. Smaller portions of TTA may be used.

6. Similarly, extract the actinium and rare earths into the benzene phase at $\mathrm{pH}$ of $6.0-7.0$, using $\approx 5-\mathrm{ml}$ portions of TTA. Repeat if necessary.

7. Finally, extract the actinium and rare earths into the aqueous phase using $\approx 3 \mathrm{ml} 0.1 \mathrm{M} \mathrm{HCl}$. Repeat if necessary.

8. Transfer the activity to a resin column and complete the actinium separation as indicated in steps (14)-(15) of Hyde's procedure.

\section{Sp-1. SCANDIUM}

\section{Determination of Chemical Yield of Scandium}

This is a spectrophotometric method depending on the color of the 8hydroxyquinoline complex in amyl acetate solution. 544

\section{Reagents}

Carrier solution, $10 \mathrm{mg}$ scandium/g: Weigh out $0.768 \mathrm{~g}$ Johnson Matthey Specpure scandium oxide $\left(\mathrm{Sc}_{2} \mathrm{O}_{3}\right)$ into a platinum dish and add $5 \mathrm{ml}$ of $16 \underline{\mathrm{M}} \mathrm{ni}-$ tric acid and a few drops of $1 M$ hydrofluoric acid. Heat under the lamp until dissolved and then evaporate off most of the acid. Add more nitric acid and again evaporate nearly to dryness. Dilute to $50 \mathrm{~g}$.

Dilute scandium standard: About $200 \mu \mathrm{g} / \mathrm{g}$ prepared by accurate dilution of the carrier solution.

8-hydroxyquinoline (oxine): $1 \mathrm{~g}$ dissolved in $100 \mathrm{ml} 95 \%$ alcohol.

\section{Procedure}

Transfer the sample containing 20-60 $\mu \mathrm{g}$ of scandium in dilute acid solution $^{*}$ to a $40-\mathrm{ml}$ centrifuge tube and bring the final volume to about $5 \mathrm{ml}$ with water. Add $2.0 \mathrm{ml}$ of the oxine reagent, and $0.5 \mathrm{ml}$ of $6 \underline{\mathrm{M}}$ ammonium hydroxide. Add $10.0 \mathrm{ml}$ of Analar-grade amyl acetate and stir the layers together mechanically for $5 \mathrm{~min}$. Centrifuge and transfer some of the top (amyl acetate) layer to a $1-\mathrm{cm}$ cell. Measure the absorbancy against a blank solution, similarly prepared, at $380 \mathrm{~m} \mu$. (This is not the peak wavelength,

* The sample taken must contain less than 1 milliequivalent of free acid. 


\section{SP-1 (Continued)}

which is below the range of the SP 600 but the absorbancy is changing quite slowly with wavelength over the range 395-375 $\mathrm{m \mu}$ and the re is adequate sensitivity for the purposes of this analysis.)

Carry out similar determinations on accurately measured portions of the dilute scandium standard solution.

The Beer-Lambert law is obeyed.

Under the above conditions $50 \mu \mathrm{g}$ of scandium give an absorbancy of about 0.6 .

Reference: The method was developed by J. Herrington at AWRE. ${ }^{544}$

\section{Sp-2. RARE EARTHS}

Determination of Chemical Yield of Cerium, Praseodymium, Neodymium, Samarium, Europium, Gadolinium, Terbium, and Yttrium

This is a spectrophotometric method depending on the blue colors of the complexes with bromopyrogallol red. ${ }^{544}$

\section{Reagents}

Carrier solutions: $5 \mathrm{mg}$ element/g in $0.1 \underline{\mathrm{M}}$ nitric acid.

Cerium: Dissolve $1.96 \mathrm{~g}$ Analar-quality ceric ammonium nitrate in 5 $\mathrm{ml} 0.5 \mathrm{M}$ nitric acid and add sufficient 100 -volume hydrogen peroxide to decolorize the solution. Dilute to $5 \mathrm{~g}$.

Praseodymium: $1.54 \mathrm{~g}$ praseodymium nitrate $\operatorname{Pr}\left(\mathrm{NO}_{3}\right)_{3} \cdot 6 \mathrm{H}_{2} \mathrm{O}$ in $100 \mathrm{~g}$ solution. Standardize gravimetrically, using duplicate $10-g$ portions, by evaporating nearly to dryness in a tared silica crucible, adding a little cellulose powder to absorb the solution, igniting carefully at $800-900^{\circ} \mathrm{C}$, and weighing as $\operatorname{Pr}_{6} \mathrm{O}_{11}$.

Solutions of the other elements are prepared by dissolving weighed amounts of Johnson Matthey "Specpure" oxides in $5 \mathrm{ml}$ of $6 \mathrm{M}$ nitric acid, evaporatıng to about $05 \mathrm{ml}$, and then diluting quantitatively to $50 \mathrm{~g}$. The following weights of oxides are needed.

$\begin{array}{lcccc}\text { Neodymium } & 0291 \mathrm{~g} \mathrm{Nd}_{2} \mathrm{O}_{3} & \text { Gadolınıum } & 0.288 \mathrm{~g} \mathrm{Gd}_{2} \mathrm{O}_{3} \\ \text { Samarium } & 0.290 \mathrm{~g} \mathrm{Sm}_{2} \mathrm{O}_{3} & \text { Terbium } & 0.288 \mathrm{~g} \mathrm{~Tb}_{2} \mathrm{O}_{3} \\ & \text { Yttrium } & 0.318 \mathrm{~g} \mathrm{Y}_{2} \mathrm{O}_{3} & \end{array}$

Dilute standards: About $200 \mu \mathrm{g} / \mathrm{g}$ prepared by accurate dilution of the carried solutions. 
Bromopyrogallol red: $0.05 \% \mathrm{w} / \mathrm{v}$ solution in $50 \%$ ethyl alcohol.

Sodium acetate: $54 \mathrm{~g} \mathrm{CH}_{3} \mathrm{COONa} 3 \mathrm{H}_{2} \mathrm{O}$ per 100 aqueous solution.

Sodium bicarbonate: $5 \mathrm{~g}$ per $100 \mathrm{ml}$ aqueous solution

Hydrochloric acid: $02 \mathrm{M}$.

Ascorbic acid: $1 \mathrm{~g}$ per $100 \mathrm{ml}$ aqueous solution, freshly prepared.

$\underline{\text { Procedure }}$

Yttrium and rare earths. Transfer the sample containing $15-35 \mu g$ yttrium or $20-50 \mu \mathrm{g}$ of rare earth, in acid solution, to a $25-\mathrm{ml}$ measuring flask. Dilute to $15-16 \mathrm{ml}$ with water. Add $2.0 \mathrm{ml}$ of the bromopyrogallol red reagent and then sodium bicarbonate solution dropwise, until one drop produces a permanent blue color. Wash down the neck of the flask with water and then add $0.2 \mathrm{M}$ hydrochloric acid dropwise, until the blue color is discharged, leaving a clear red solution. Add $0.5 \mathrm{ml}$ of the sodium acetate solution, and stand the flask in a bolling water bath for $10 \mathrm{~min}$. Cool and dilute to the mark with water. Measure the absorbancy of the solution against water, in $1-\mathrm{cm}$ cells at $660 \mathrm{~m} \mu$.

The color is quite stable and obeys the Beer-Lambert law. Carry out similar determinations on accurately measured portions of the diluted car rier solution Plot a calıbration curve of absorbancy against concentration of rare earth. Obtain the blank from the value of the intercept of the calibration line with the absorbancy axis (about 0.005).

Under the above conditions, $40 \mu \mathrm{g}$ of rare earths give an absorbancy of about $0.56,30 \mu \mathrm{g}$ of yttrium give an absorbancy of about 0.66 .

Cerium. As for yttrium and rare earths (above) except that $0.2 \mathrm{ml}$ of $1 \%$ ascorbic acid is added before the bromopyrogallol red, and the final solution is measured is measured at $680 \mathrm{~m} \mu$. Under the above conditions, $40 \mu \mathrm{g}$ of cerium give an absorbancy of about 0.64 .

\section{Interfering Ions}

The most serious interference is occasioned by the presence of $\mathrm{Zr}^{4+}$, $\mathrm{Fe}^{2+}$, and $\mathrm{Fe}^{3+}$. The first two increase the absorbancy and $\mathrm{Fe}^{3+}$ decolorizes the solution. Peroxide interferes and must be eliminated from samples by careful evaporation to dryness before adding any reagents.

\section{Reference}

Both of these procedures were developed at AWRE by J. Herrington and K.C. Steed. ${ }^{544}$ The use of bromopyrogallol red as a chromogenic reagent was suggested by its use as an indicator for rare-earth titrations with EDTA (see A. Jenıckova, V. Suk, and M. Malat: Chem. listy 50, 760 (1956) 


\section{REFERENCES}

1. J. Achard, "Preparation of Pure Cerium Earths by Ion Exchange. Use of Ethylenediaminetetraacetic Acid," Compt. rend. 241, 800 (1956).

2. J. C. Achard, "Separation of Certain Rare-Earth Elements by a Dry Method. Application to Ytterbium," Compt. rend. 244, 3059-62 (1957).

3. J. C. Achard, "Separation of Certain Rare-Earth Elements by a Dry Method. Application to Samarium and Europium," Compt. rend. 245, 1064-66 (1957).

4. U. S. Atomic Energy Commission Document TID-5194 (1952)。

5. B. N. Afanas'ev and P.A. Tsyganova, "The Existence of Stable Organometallic Compounds of the Lanthanides," Zhur. Obshchei Khim. 18, 306 (1948); "Reaction of Metallic Iron with Ethyl Bromide, "Ibid. 21, 485 (1951).

6. I. P. Alimarin, E. S. Przheval'skii, I. V. Puzdrenkova, and A. P. Golovina, "Study of the Absorption Spectra of the 8-hydroxyquinolates of Certain Rare Elements, "Trudy Komissi Anal。Khim. Akad. Nauk S.S.S.R. 8, 152-60 (1958); Referat. Zhur.Khım。1958, (23) Abstr. No. 77, 181; Anal.Abstr. 6, 2027.

7. A. Almasey, "Determination of Rare Earth Metals in Their Mixtures," Acta Chim. Acad. Sci. Hung.17, 55-69 (1958).

8. M. N. Ambrozhii and E. F. Luchnikova, "Detection of Samaruum," Nauch. Ezhegodnik Za 1954, Saratov. Univ., Saratov,, 486-87 (1955); Referat, Zhur. Khim. 1956, Abstr。No。51126, CA 53 , 14835b.

9. Ames Laboratory Staff, Semi-Annual Research Report in Chemistry for Jan.-June 1958, Iowa State College Report ISC-1049 (1958).

10. See ION EXCHANGE (Section IV. 7., this report) for additional references.

11. J. M. Axelrod, "The Rare Earth Carbonates, "Univ. Microfilm 
L. C. Card No. Mic 59-3008 (85 pages) (1959); Dissertation Abstr. 20, 876-77 (1959); Chem.Abstr. 54, 2069 f。

12. M. Bachelet, E. Cheylan and Le Bris, "Recherches sur la Solubilite des Nitrates Métalliques dans l'Éther Ethylique, "J. Chim. Phys. 47, 62 (1950).

13. R. W. Ball and L. F. Yntema, "The Separation of Ytterbium by Electrolytic Reduction. Observations on the Rare Earths:XXXVI," J. Am. Chem. Soc. 52, 4264 (1930).

14. C. V. Banks and D. W. Klingman, "Spectrophotometric Determination of Rare Earth Mixtures," Anal. Chim. Acta 15, 356-63 (1956).

15. C. V. Banks, J. A. Thompson, and J. W. O'Laughlin, "Separation and Determination of Small Amounts of Rare Earths in Uranium," Anal. Chem. 30, 1792-95 (1958).

16. C. V. Banks, O. N. Carlson, A. H. Daane, V. A. Fassel, R. W. Fisher, E. H. Olson, J. E. Powell, and F. H. Spedding, "Studies on the Preparation, Properties, and Analysis of High Purity Yttrium Oxide and Yttrium Metal at the Ames Laboratory, "Iowa State College Report IS-1 (July 1959).

17. G. Barbieri, "A New Type of Rare-Earth Salt," Atti accad. Lincei 9, 906 (1929).

18. A. J. Barnard, Jr., W. C. Broad, and H. Flaschka, "The EDTA Titration: Nature and Methods of End Point Detection": I Chemist Analyst 45, No. 4, 86-93, $111-12$ (1956); II. Ibid. 46, No. 1, 18-28 (1957); III. Ibid. 46 , No. 2, 46-56 (1957); IV. Ibid. $\underline{46}$, No. 3, 76-84 (1957). H. Flaschka, A. J. Barnard, Jr., and W. C. Broad, "The EDTA Titration: Application": I. Ibid. 46, No.4, 106-12 (1957); II. Ibid. 47, 22-28 (1958); III. Ibid. 47, 52-56 (1958); IV. Ibid. 47, 78-84 (1958); V. Ibid. 47, 109-12 (1958). (Note: This series is unusual in that it maintains a running bibliography through all nine separate articles.)

19. G. Beck, Helv. Chim. Acta 29, 357 (1946).

20. G. Beck, "New Fractionating Principle for the Rare Earths with Nitriloacetate: a Displacement Method," Mikrochemie ver. Mikrochim. Acta 33, 344 (1948).

21. G. Beck and A. Gasser, "Analytical Chemistry of the Rare Earths," Anal. Chim. Acta 3, 41 (1949).

22. G. Beck, "Über Fällungsreaktionen des Aneurinpyrophosphates mit Scandium und Einigen Schwermetallen, "Anal. Chim. Acta 4, 21-22 (1950).

23. G. Beck, "Detection of Rare Earth Elements (Lanthanons) as Complex Pyrocatechol Compounds," Mikrochim. Acta 3-4, 337 (1954). 
24. J. Bellon1, M. Haissinsky, and H. N. Salıma, "On the Adsorption of Some Fission Products on Various Surfaces," J. Phys. Chem. 63, $881-87$ (1959).

25. K. S. Bergstresser, "Spectrophotometric Determination of Lanthanum in Plutonium," Anal. Chem. 30, 1630-32 (1958).

26. B. Bernström and J. Rydberg, "Studies on the Extraction of Metal Complexes. XXVIII. The Distribution of Some Actinides and Fission Products Between Tributyl Phosphate (TBP) and Aqueous Solutions of $\mathrm{HNO}_{3}$ and $\mathrm{Ca}\left(\mathrm{NO}_{3}\right)_{2}$," Acta Chem. Scand. 11, 1173 (1957).

27. R. H. Betts, O. F. Dahlinger, and D. M. Munro, "A Radiochem1cal Study of Some Kinetic and Thermodynamic Properties of Complex Ions of the Rare Earths," Radioisotopes Sc1. Research, Proc. Intern. Conf. Paris, 1957 Vol. 2, 326-45 (Pub. 1958): Chem. Abstracts $\underline{54}, 54 \mathrm{~d}$.

28. R. H. Betts and O. F. Dahlinger, "The Heat and Entropy of Assoc1ation of the Complex Ions Formed by EDTA with the Lanthanide Elements in Aqueous Solution," Can. J. Chem. 37, 91-100 (1959).

29. J. Birmingham and G. Wilkinson, "Cyclopentadienides of Scandium, Yttrium and Some Rare Earth Elements, J. Am. Chem. Soc. 78, 42 (1956).

30. E. A. Biryuk and V. A. Nazarenko, "Use of Trihydroxyfluorone Derivatives in Photometric Analysis. Determination of Scandium," Zhur. Anal. Khim. 14, (3), 298-302 (1959); Anal. Abstr. 7, 418.

31. J. Bjerrum, G. Schwarzenbach, and L. G. Sillen, "Stability Constants, Part I: Organic Ligands, "Chem. Soc. (London) p. 47 (1957).

32. S. Bjornholm, O. B. Nielson, and R. K. Sheline, "A Microchemical Method for the Preparation of Sources of Actinium and Europium for $\beta$-Ray Spectroscopy, "Nature 178, 1110-11 (1956).

33. S. Bjornholm, P. H. Dam, H. Nordby, and N. O. Poulsen, "A Method for the Preparation of Cyclotron Targets of Rare Earth Oxides by Electrophoresis," Nuclear Instr. \& Methods ㅁ, 196-98 (Sept. 1959).

34. R. H. Blackmore, A. E. Bearse, and G. D. Calkins, "Distribution of Rare-Earth Tracers Between Aqueous and Tributyl PhosphateDiluent Phases," U. S. Atomic Energy Commission Document BMI-261 (1952).

35. M. Bobtelsky and B. Graus, "Cerous Citrate Complexes, Their Composition, Structure, and Behavior," J. Am. Chem. Soc. 77, 1990 (1955).

36. J. Bochinsk1, M. Smutz, and F. H. Spedding, "Separation of Indi- 
vidual Rare Earths by Liquid-Liquid Extraction from Multicomponent Monazite Rare Earth Nitrates. I. Undiluted Tributyl Phosphate and Concentrated Aqueous Rare Earth Nitrate Systems at Low Acid Concentrations, "U. S. Atomic Energy Commission Document ISC-348 (1953).

37. R. Bock and E. Bock, "Über die Verteilung von Nitraten Seltener Erden Zwıschen wässrigen Lösungen und organıschen Lösungsmitteln," Naturwissenschaften 36, 344 (1949).

38. R. Bock and E. Bock, "Die Darstellung reiner Thorium - und CerVerbındungen durch Ausschütteln wãsserıger Nitratlơssungen mit organıschen Lơsungsmitteln," Z. anorg. u. allgem. Chem. 263, 146 (1950).

39. R. Bock, "Über die trennung anorganısche Stoffgemische durch Vertellung zwischen zweı Lösungsmitteln No. VI; Die Verteılung von Metallrhodanıden zwıschen wässrigen Lösungen und Diăthyläther, " Z. anal. Chem. 133, 110 (1951).

40. D. R. Bomberger, "Hypophosphorous Acıd as a Gravimetric Reagent for Scandium," Anal. Chem. 30, 1907-08 (1958).

41. N. Bonner (See Section VII this report, SCANDIUM CHEMISTRY).

42. A. Bonnin, "M Éthode Simple de Preparation de $\mathrm{Y}^{90}$ de Grande Pureté et de Grande Actıvité Specifıque," Bull. Soc. Chım. France, 1563 (1956).

43. F. Boulanger, "Determination of the Complexes Formed by the Trilons with Rare Earths," Chim. Analyst. 35, No. 10, 253 (1953). 44. G. E. Boyd, J. Schubert, and A. W. Adamson, "The Exchange Adsorption of Ions from Aqueous Solutions by Organic Zeolites: I. Ion-Exchange Equilibria," J. Am. Chem. Soc. 69, 2818-29 (1947).

45. N. E. Brezhneva, V. I. Levin, G. V. Korpusov, N. M. Manko, and E. K. Bogachova, "Isolation of Radioactive Fission Elements," Proc. U. N. Intern. Conf. Peaceful Uses Atomic Energy, 2nd Geneva, 1958, Vol. 18, 219 (Pub. 1959).

46. K. Bril, S. Bril, and P. Krumholz, "Separation of Metal Ions by Means of Ion Exchange Membranes. I. Separation of Rare Earth Mixtures, and of Thorium-Rare Earth Mixtures Using Ethylenediaminetetraacetic Acıd," J. Phys. Chem. 63, 256-59 (1959).

47. K. Y. Bril, S. Holzer, and B. Réthy, "Photometric Titration of Thorium and the Rare Earths with (Ethylenedinitrilo) - Tetraacetıc Acid, "Anal. Chem. 31, 1353-57 (1959).

48. P. H. M. P. Brinton and C. James, "The Determination of Cerium in the Presence of Other Rare Earths by Precipitation as Ceric Iodate," J. Am. Chem. Soc. 41, 1080-85 (1919). 
49. A. Broido, "Application of Thenoyltrifluoroacetone (TTA) Extraction to the Preparation of Radioisotopes: I. Purification of Scandium and Preparation of $\mathrm{Ca}^{45}, "$ U. S. Atomic Energy Commission Document AECD-2616 (1947).

50. H. J. Bronaugh and J. F. Suttle, "Chelation of the Rare Earth Elements as a Function of $\mathrm{pH}$ using Thenoyltrifluoracetone, "U. S. Atomic Energy Commission Document LA-1561 (1953).

51. W. A. Brooksbank and G. W. Leddicotte, "Ion Exchange Separation of Trace Impurities," J. Phys. Chem. 57, 819-23 (1953).

52. K. B. Brown, C. F. Coleman, D. J. Crouse, J. O. Denis, and J. O. Moore, "The Use of Amines as Extractants for Uranium from Acidic Sulfate Liquors: A Preliminary Report," U. S. Atomic Energy Commission Document ORNL-1734 (1954).

53. K. B. Brown, C. F. Coleman, D. J. Crouse, and A. D. Ryan, "Progress Report on Raw Materials for September 1957," U. S. Atomic Energy Commission Document ORNL-2443 (1958).

54. G. Brunischolz, E. Vescovi, and M. Loretan, "The Separation of the Rare Earths with Ethylenediaminetetraacetic Acid. II. Properties of the Complex Salts, Na(RY), "Chim. Acta 38, 1186 (1955).

55. G. Brunischolz, "Separation of Rare Earths with Ethylenediaminetetraacetic Acid. III. Separation by Crystallization of the Complex Salts $\mathrm{NH}_{4}$ (RY)," Helv. Chim. Acta 38, 1654 (1955).

56. G. Brunischolz and R. Cahen, "Complexometric Determination of the Rare Earths," Helv. Chim. Acta 39, 324-25 (1956).

57. G. Brunischolz, "Sur la Séparation des Terres Rares à l'Aide de 1'Acide Éthylène-Diamine-Tétraacétique. IV. Séparation sur Échangeurs d'Ions, " Helv. Chim. Acta 40, 2004-07 (1957).

58. G. Brunischolz, "Procede Pour le Controle du pH Lors de la Separation des Terres Rares par Chromatographie sur Echangeurs d'Ions, "Chim. 12, 180 (1958).

59. G. Brunischolz and R. Cahen, "Sur La Séparation des Terres Rares à 1 'Aide de 1 'Acide Éthylène-Diamine-Tétraacétique. VII. Procédé en Cycle pour le Fractionnement des Terres Cériques, "Helv. Chim. Acta 41, 460-67 (1958).

60. G. Brunischolz and R. Cahen, "Sur la Séparation des Terres Rares à l'Aide de l'Acide Éthylène-Diamine-Tétraacétique. V. Les Diagrammes de Solubilité $\mathrm{NH}_{4}$ (La-EDTA), $\mathrm{NH}_{4}(\mathrm{Sm}-\mathrm{EDTA})-\mathrm{H}_{2} \mathrm{O}$, $\mathrm{K}(\mathrm{La}-\mathrm{EDTA})$, et $\mathrm{K}(\mathrm{Sm}-\mathrm{EDTA})-\mathrm{H}_{2} \mathrm{O}$ a $0^{\circ}, " \mathrm{Helv}$. Chim. Acta $\underline{4}$, 188-99 (1958).

61. R. F. Buchanan, J. P. Faris, K. A. Orlandini, and J. P. Hughes, 
"The Analytical Application of the Nitric Acid Anion Exchange System to Plutonium-Fission and Plutonium-Binary Alloys Used in Metallurgical Studies, "TID-7560 (1958).

62. L. R. Bunney, E. C. Freiling, L. D. McIsaac, and E. M. Scadden, "Radiochemical Procedure for Individual Rare Earths," Nucleonics 15, 81-83 (1957)

63. L. R. Bunney, N. E. Ballou, J. Pascual, and S. Foti, "Anion" Exchange Behavior of Several Metal Ions in $\mathrm{HCl}, \mathrm{HNO}_{3}$, and $\mathrm{H}_{2} \mathrm{SO}_{4}$ Solutions with Dowex 2," USNRDL-TR-228 (1958).

64. L. Bunney (USNRDL, San Francisco) and W. Hutchin (LRL, Liver. more), private communications.

65. F. D. S. Butement, "Absorption and Fluorescence Spectra of Bivalent Samarium, Europium, and Ytterbium, "Trans. Faraday Soc. 44, 617-26 (1947).

66. A. G. Buyers, E. Giesbrecht, and L. F. Audrieth, "Phosphates and Polyphosphates of the Rare Earth Elements," J. Inorg. \& Nuclear Chem. 5, 133-40 (1957).

67. M. J. Cabell, "The Purification, Determination, and Neutron Capture Cross Section of Ac 227 , Can. J. Chem. 37. 1094-1103 (1959).

68. M. J. Cabell, "Ion Exchange Chromatography," Chem. in Can. 11, No. 4, 25-30 (1959); Nuclear Sci. Abstr. 13, 20917

69. J. Canneri, "The Acetates of the Earths with Organic Bases," Gazz. chim. ital. 55, 33 (1925).

70. P. Caro and J. Loriers, "Courbes de Thermolyse de Quelques Oxalates de Terres Rares," J. recherches centre nat. recherche scı. Lab. Bellevue (Paris) 39, 107-18 (1957).

71. E. J. Center, W. M. Henry, and R. D. Householder, "The Deter" mination of Rare Earths in Thorium, "Battelle Memorial Institute Report No. BMI-260 (1952).

72. Tiao-Hsu Chang, "Separation of Europium from Other Rare Earths by the 'Oxine Sulfonic Acid Method "," J. Chinese Chem. Soc. (Taiwan), Sec. II. , 3, 23-29 (1956).

73. G. Charpak and F. Suzor, "Étude de la Désintégratıon de l'Erbium "169," J. Phys. radium 20, 513-15 (1959).

74. K. L. Cheng and T. R. Williams, Jr., "Complexometric Titration of Scandium with 1-(2-pyridyl-AZO)-2-naphthol as Indicator," Chemist Analyst $\underline{44}$, 96-98 (1955).

75. K. L. Cheng, "EDTA Titration of Micro Quantities of Rare Earths," Chemist Analyst 47, 93-94 (1958).

76. G. R. Choppin and R. J. Silva, "Separation of the Lanthanides by 
Ion Exchange with Alpha-Hydroxy Isobutyric Acid," J. Inorg. \& Nuclear Chem. 3, 153-54 (1956).

77. G. R. Choppin, B. G. Harvey, and S. G. Thompson, "A New Eluant for the Separation of the Actinide Elements," J. Inorg. \& Nuclear Chem. 2, 66-68 (1956).

78. A. Chretien and M. Capestan, "Thermolyse des Amidosulfonates de Lanthane-Cerium-Neodyme-Samarium," Compt. rend.248, $3176-78$ (1959).

79. "Chromatographic Analysis," Discussions Faraday Soc., No. 7, (1949). (Gurney and Jackson, London, 1949).

80. A. Clark, Am. J. Sci. 7, 1 (1924).

81. A. F. Clifford and H. C. Beachell, "The Chemical Isolation of Samarium from Lanthanide Mixtures," J. Am. Chem. Soc. 70, 2730-31 (1948).

82. K. Clusius and E. R. Ramirez, "Zur Trennung der seltener Erden in wässeriger Lösung durch Ionenwanderung, "Helv. Chim. Acta 36, 1160 (1953).

83. J. S. Coleman, R. A. Penneman, T. K. Keenan, L. E. LaMar, D. E. Armstrong, and L. B. Asprey, "An Anion-Exchange Process for Gram-Scale Separation of Americium from Rare-Earths," J. Inorg. \& Nuclear Chem. 3, 327-28 (1956).

84. F. W. Cornish, "The Equilibrium for the Dysprosium-ThenoylTrifluoracetone-Benzene System, "United Kingdom Atomic Energy Authority Document AERE-C/R-891.

85. F. W. Cornish, G. Phillips, and A. Thamas, "Ethylene Diamine Tetra-Acetic Acid and Citric Acid as Eluants in Ion Exchange Separations of the Rare Earths," Can. J. Chem. 34, 1471-82 (1956).

86. F. W. Cornish, "A Preliminary Report on the Determination of Submicrogram Quantities of Individual Rare Earths by Radioact1vation Using Ion Exchange Separation, "United Kingdom Atomic Energy Authority Document AERE C/R 1224 (1956).

87. F. W. Cornish, "Some notes on an Attempt to Use TTA in Conjunction with Chromatography for the Separation of Rare Earths," United Kingdom Atomic Energy Author1ty Document AERE-C/M145 (1957).

88. S. Cotelle and M. Haissinsky, "On the Preparation of Thin Layers of Thorium and Actinium by Electrolysis in Ethyl Alcohol, "NP2269 (1938).

89. F. A. Cotton, "Alkyls and Aryls of Transition Metals," Chem。Revs, 55, 551 (1955).

90. G. A. Cowan, "Salicylate Process for Thorium Separation from the 
Rare Earths," U. S. Patent 2, 901,496 (1959); Nuclear Sci. Abstr. 14, 6363 .

91. D. Cozzi and S. Vivarelli, "The Chemistry of Indium. Il," Z, Elektrochem. 58, 907 (1954).

92. E. A. C. Crouch and I. G. Swainbank, "An Ultra-Micro Method for the Estimation of the Rare Earths by Complexometric Titration, " United Kingdom Atomic Energy Authority Documert AERE C/R 2843 (1959).

93. D. J. Crouse and J. O. Denis, "The Use of Amines as Extractants for Thorium (and Uranium) from Sulfuric Acid Digests of Monazite Sands," U. So Atomic Energy Commission Document ORNL- 1859 (1955).

94. D. J. Crouse, K. B. Brown, W. D. Arnold, J. G. Moore, and R. S. Lowrie, 'Progress Report on Uranium Extract:on with Organonitrogen Compounds, "U.S. Atomic Energy Commission Document ORNL- 2099 (1956).

95. D. J. Crouse and K. B. Brown, 'Recovery of Thordum, Urarium, and Rare Earths from Monazite Sulfate Liquors by the Amine Extraction (Amex) Process," U. S. Atomic Energy Commission Document ORNL- 2720 (1959).

96. C. E. Crouthamel and D. S. Martin, Jr., "The Solubility of Ytterbium Oxalate and Complex Ion Formation in Oxalate Solutions," J. Am. Chem. Soc. 72, 1382-86 (1950).

97. C. E. Crouthamel and D. S. Martin, Jr., "Solubility of the Rare Earth Oxalates and Complex Ion Formation in Oxalate Solution: II. Neodymium and Cerium (+3)," J. Am. Chom. Soc, 73, 569-73 (1951).

98. J. G. Cuninghame, P. Scargill, and H. H. Willis, "The Solvent Extraction of Praseodymium and Neodymium," United Kingdom Atomic Energy Authority Document AERE-C/M- 215 (1954).

99. J. G. Cuninghame, M. L. Sizeland, H. H. Willis, J. Eakins and E. R. Mercer, "The Rapid Separation of Rare Earth Fission Products by Cation Exchange Using Lactic -Acid Eluant," J. Inorg. \& Nuclear Chem. 1, 163-64 (1955).

100. J. G. Cuninghame, M. L. Sizeland, and H. H. Willis, "The SelfAbsorption and Window-Absorption Correction in the 2 Pi-BetaProportional Counter for Certain Fission Products," United Kingdom Atomic Energy Authority Document AERE C/R - 2054 (1955).

101. J. Danon, "Anion-Exchange Studies with Actinium and Lanthanides in Nitrate Solutions," J. Inorg. Nuclear Chem. $7,422-24$ (1958). 
102. J. Danon and M. C. Levi. "Paper Chromatography of Inorganic Ions in Nitrate Media: I. Scandium, Yttrium, Actinium, and the Lanthanides," NP- 7697 (1959).

103. E. P. Dergunov, "Complex Formation Between Fluorides of Alkali Metals and of Lanthanide-Group Metals," Doklady Akad. Nauk S. S. S. R. 85,1025 (1952).

104. R. M. Diamond, K. Street, Jr., and G. T. Seaborg, "An Ion- Exchange Study of Possible Hybridized 5F Bonding in the Actinides," J. Am. Chem. Soc. 76, 1461-69 (1954).

105. Ya. Donov and S. B. Pirkes, "Camphorates of Some Rare Earth Elements," Zhur. Obshchei Khim. 26, 379 (1956).

106. I. Draganic. "A Study of the Extraction of Europium Nitrate Traces Using Radioactive Eu ${ }^{152}$ as Indicator," Bull. Inst. Nuclear Sci. "Boris Kidrich" (Belgrade) 2. 73 (1953).

107. B. Drake, "Theory of Gradient Elution Analysis," Arkiv Kemi $\underline{8}, 1$ (1955).

108. F. R. Duke and J. A. Anderegg, "The Oxidation of Water by Cerium IV Perchlorate," Iowa State Coll. J. Sci. 27, 491-93 (1953).

109. F. R. Duke and F, R. Parchen, "The Kinetics of the $\mathrm{Ce}^{+4}-\mathrm{Ce}^{+3}$ Exchange Reaction in Perchloric Acid," J. Am. Chem. Soc. 78, $1540-43$ (1956).

110. N. K. Dutt and A. K. Gupta, "Chemistry of the Rare Earths: IX. Dissociation Constants of the Double Thiosulfates of the Rare Earths," J. Indian Chem. Soc. 29, 105 (1952).

111. N. Dutt and N. Goswami, 'Rare Earths: XI. Urotropine and Antipyrine Complexes of Tetrathionates of Rare Earths, "J. Indian Chem. Soc. 30, 275 (1953).

112. N. K. Dutt and P. Bandyopadhyay, " $\beta$ - Diketone Complexes of Lanthanons," Sci. and Culture (Calcutta) 22. 69091 (1957); Ibid. 23. 105-06 (1957); Ibid. 23, 365-66 (1958).

113. J. E. Duval and M. H. Kurbatov, "Separation of Carrier-Free Scandium From a Calcium Target, "J. Am. Chem. Soc. 75, 2246-48 (1953).

114. G. Duyckaerts and J. Fuger, 'Contribution à L'Étude de la Séparation des Terres Rares de Fission par l'Acide Éthylènediaminetétraacetique, " Anal. Chim. Acta 14, 243-46 (1956).

115. D. Dyrssen and V. Dahlberg, "Studies on the Extraction of Metal Complexes. VIII. The Extraction of La, Sm, Hf, Th, and U (VI) with Oxine and Cupferron." Acta Chem. Scand. 7. 1186 (1953).

116. D. Dyrssen, "Studies on the Extraction of Metal Complexes. XVII. 
On the Complex Formation of Lanthanum and Samarium with Oxine and Cupferron," Svensk Kem. Tidskr. 66, 234 (1954).

117. D. Dyrssen, "Studies on the Extraction of Metal Complexes. XXI. The Complex Formation of Thorium with Tropolone, "Acta Chem. Scand. 9, 1567 (1955).

118. D. Dyrssen, 'Tnvestigations on Chelating Agents for the Extraction of Lanthanide and Actinide Elements, "Svensk Kem. Tidskr. 68, 212 (1956).

119. D. Dyrssen, M. Dyrssen, and E. Johansson, "Studies on the Extractions of Metal Complexes. XXXI. Investigations of Some 5, 7Dihalogen Derivatives of 8-Quinolinol, "Acta Chem. Scand. 10, 341 (1956).

120. D. Dyrssen, "Studies on the Extraction of Metal Complexes. XXXII. N-Phenylbenzo-hydroxamic Acid, "Acta Chem. Scand. 10, 353 (1956).

121. D. Dyrssen, "Separation of Strontium-90 and Yttrium-90 and Preparation of Carrier-Free Yttrium-90," Acta Chem. Scand. 11, 1277 (1957).

122. A. R. Eberle and M. W. Lerner, "Separation and Determination of Scandium; Spectrophotometric Method Using Alizarin Red S, "Anal. Chem. 27, 1551 (1955).

123. A. R. Eberle and M. W. Lerner, 'Solvent Extraction of Certain Rare Earths in Yttrium, "U. S. Atomic Energy Commission Document AECD- 4286 (1957).

124. D. Eckardt and L. Holleck, "Complex Chemistry of Bi- and Trivalent Rare Earths. Polarographic Investigations on Europium Complexes," Z. Elektrochem. 59, 202 (1955).

125. F. Ephraim and P. Ray, 'The 'Lanthanum Contraction' and Spectral Displacements in Compound Formation-Changes in the Samarium Spectrum," Ber. 62B, 1639 (1929).

126. O. Erametsa and S. Hămälä, "On the Solubility of Acetylacetonates of Rare Earth Metals," Suomen Kemistilehti 31B, 204 (1958).

127. N. Eswaranarayana and Bh. S. Rao, "Thorium - Its Estimation and Separation From Cerite Earths - Use of Aryloxyacetic Acids, "J. Sci. Ind. Research 13, 657 (1954); Nuclear Sci. Abstr. 9, 594 (1955).

128. N. Eswaranarayana and Bh. S. V. Raghava Rao, "The Oxinates of Thorium and Some Cerite Earths, "Anal. Chim. Acta 11, 339-49 (1954).

129. M. G. Evans and N. Uri, "Photo-Oxidation of Water by Ceric Ions," Nature 166, 602-03 (1950).

130. J. P. Faris, "Adsorption of the Elements from Hydrofluoric Acid by Anion Exchange," Anal. Chem. 32, 520- 22 (1960). 
131. A. M. Feibush, K. Rowley, and L. Gordon, "Solubility of Yttrium Oxalate," Anal. Chem. 30, $1610-12$ (1958).

132. L. Fernandes, "The Coordination Valence of Two Hydroxyl Groups in O-position. III. Polyphenolic Complexes of the Rare Earths," Gazz. Chim. Ital. 56, 682 (1926); "A Sensitive Differential Reaction of Cerium," Ibid. 55, 616 (1925).

133. A. Ferrari, L. Cavalca, and M. Nardelli, "Rare Earths Whose Elements are Coordinated in Metal Hexanitrites, "Gazz, Chim. Ital. 83, 1082 (1953).

134. Ya.A. Fialkov and V. I Ermolenko, "Lanthanum Salicylates," Zhur. Neorg. Khim. 4, 359-66 (1959).

135. Ya.A. Fialkov and V. I. Ermolenko, "Lanthanum Salicylate Complexes, "Zhur. Neorg. Khim. 4, 1369-76 (1959); Nuclear Sci. Abstr. 13, 18996; Transl. in Russ. J. Inorg. Chem. 4, No. 6, 615-19 (1959).

136. W. Fischer, W. Dietz, and O. Jübermann, "Separation of the Rare Earths," Naturwissenschaften 25, 348 (1937).

137. W. Fischer and R. Bock, "Die Darstellung reiner Scandiumverbindungen, "Z. anorg. u. allgem. Chem. 249, 146 (1942).

138. W. Fischer, J. Werner, and M. Zumbusch-Pfisterer, IÜber die Lőslichkeit der Chloride der Seltenen Erden im Salsäure als Grundlage Neuer Trennungsmöglichkeiten," Z. anorg. Chem. 258, 15761 (1949).

139. W. Fischer, O. Steinhauser, and E. Hohmann, IÜber die Bestımmung Kleiner Scandiumgehalte auf Chemischem Wege, " $\mathrm{Z}$. anal. Chem. 133, 57- 72 (1951)。

140. W. Fischer and R. Bock, "The Production of Pure Scandium Compounds," Z. anorg. u. allgem. Chem. 249, 146-97 (1942).

141. W. Fischer, G. Braune, W. Dietz, O. Jübermann, G. Krause, K. E. Niemann, and G. Siekemeier, "Über die Trennung der Seltenen Erden durch Verteilen zwischen zwei Lösungsmitteln, " Angew. Chem. 66, 317 (1954).

142. W. Fischer, J. Müller, and K. Niemann, "Separation of the Rare Earths by Fractional Precipitation of Their Carbonates, "Z. anorg, u. allgem. Chem. 282, 63 (1955).

143. F. T. Fitch and D. S. Russell, 'The Separation of Rare Earths by Ion-Exchange Procedures, "Can. J. Chem. 29, 363-71 (1951).

144. F. T. Fitch and D. S. Russell, 'Determination of Lanthanum in Rare Earth Mixtures," Anal. Chem. 23, 1469-73 (1951).

145. H. Flaschka, "Microtitrations with EDTA: XIV. Determinations of Rare Earths, "Mickrochim. Acta, 55-60 (1955). 
146. H. Flaschka and H. Abdine, "Complexometric Titrations with PAN (1- (2- pyridylazo) -2 naphthol) as Indicator, "Chemist Analyst 45 , $2-3$ (1956).

147. R. A. Foos and H. A. Wilhelm, "Separations of Yttrium and Some Rare Earths by Liquid-Liquid Extraction, "U. S. Atomic Energy Commission Document ISC- 695 (1954).

148. D. C. Foster and H. E. Kremers, "Europium Determination in Rare Earth Mixtures," Anal. Chem. 25, 1921-22 (1953).

149. B. F. Freasier, A. G. Oberg. and Wesley W. Wendlandt, "The 8Quinolinol-5 Sulfonic Acid Chelates of Some Rare Earth Metal Ions." J. Phys. Chem. 62, 700-02 (1958).

150. E. C. Freiling and Leland R. Bunney, 'Ion Exchange as a Separations Method: VII. Near Optimum Conditions for the Separation of Fission Product Rare Earths with Lactic Acid Eluant at $87^{\circ} \mathrm{C}, " \mathrm{~J}$. Am. Chem. Soc. 76, 1021-22 (1954).

151. E. C. Freiling, "Ion Exchange as a Separations Method: IX. Gradient Elution Theory," J. Am. Chem. Soc. 77, 2067-71 (1955).

152. E. C. Freiling, "Gradient Elution Theory," J. Phys. Chem. 61, 54348 (1957).

153. E. C. Freiling, J. Pascual, and A. A. Delucchi, "Anion Exchange Studies in Phosphoric Acid Solutions, "USNRDL- TR- 231 (1958).

154. S. Fried, F. Hagemann, and W. H. Zachariasen, "The Preparation and Identification of Some Pure Actinium Compounds, "J. Am. Chem. Soc. 72, 771-75 (1950).

155. J. S. Fritz, M. J. Richard, and W. J. Lane, "Spectrophotometric Determination of Rare Earths, "Anal. Chem. 30, 1776- 79 (1958).

156. J. S. Fritz, R. T. Oliver, and D. J. Pietrzyk, "Chelometric Titrations Using an Azoarsonic Acid Indicator," Anal. Chem. 30, $1111-14$ (1958).

157. J. S. Fritz and G. R. Umbreit, "Ion Exchange Separation of Metal Ions, "Anal. Chim. Acta 19, 509-16 (1958).

158. J. S. Fritz and D. J. Pietrzyk, "Photometric Titration of Scandium," Anal. Chem. 31, 1157-59 (1959).

159. S. Fronaeus, "An Ion Exchange Study of the Cerous Sulfate System," Svensk Kem. Tidskr. 64, 317-24 (1952).

160. F. S. Frum, "Color Reactions for Distinguishing Lanthanum from Cerium, "Trudy Khim. i Khim. Tekh. No. 1, 132-33 (1958); Nuclear Sci. Abstr. 14, 200.

161. J. Fuger, "Contribution a l'Étude de la Séparation des Terres Rares par 1'Acide Éthylènediaminetetraacétique," Bull. Soc.Chim. Belg. 66, 151-68 (1957). 
162. N. Furman, W. Mason, and J. Pekola, "Extraction of Cupferrates." Anal. Chem. 21, 1325 (1949).

163. I. J. Gal and A. Ruvarac, 'Extraction of Chlorides from Hydrochloric Acid Solutions with Tributyl Phosphate," Bull. Inst. Nuclear Sci. "Boris Kidrich" (Belgrade) ㅁ, 67 (1958).

164. 'Khromatographicheskii metod rasdeleniia ionov, "(Chromatography Method for Separating Ions), Collection edited by E. N. Ganov, IL, Moscow, 1949.

165. D. G. Gardner, 'Nuclear Decay Scheme Analysis and Characterization Studies of $(d, a)$ Reaction Products, "Univ。 of Mich. MISC $1957-157$.

166. J. E. Gates and D. F. Edwards, "Pm 147 Point Source," Nucleonics 13, No. 12, 57 (1955).

167. E. Gelles and G. H. Nancollas, "Electrochemical Studies in the Rare Earth Series. II. Rare Earth Malonates, "Trans. Faraday Soc. 52, No. 5, 680 (1956).

168. E. Gelles and G. H. Nancollas, 'Electrochemical Studies in the Rare Earth Series. I. Rare Earth Oxaloacetates, "Trans. Faraday Soc. 52, 1, 98 (1956).

169. J. A. R. Genge and J. E. Salmon, 'Ion Exchange Studies of Phosphates, Part III-Complex Formation Between Tervalent Metals and Orthophosphoric Acid," J. Chem. Soc. 1459-63 (1959).

170. H. Gest, N. E. Ballou, B. M. Abraham, and C. D. Coryell, "Coseparation of Aqueous Barium Ion with Solid Lathanum Fluoride," in "Radiochemical Studies: The Fission Products," edited by C. D. Coryell and N. Sugarman, McGraw-Hill Book Company, Inc., New, 1951, pp. 145-56. (Nat. Nuclear Energy Ser., Div. IV, Vol. 9, Book 1.)

171. H. Gest, W. H. Burgus, and T. H. Davies, "Coseparation of Aqueous Fluozirconate Ion with Solid Lanthanum Fluoride," Ibid., pp. 157-69.

172. J. A. Gibson, J. F. Miller, P. S. Kennedy, and G. W. P. Rengstorff, "The Properties of the Rare Earth Metals and Compounds," Battelle Memorial Inst., Columbus, Ohio (1959).

173. E. Giesbrecht and L. F. Audrieth, "Phosphates and Polyphosphates of the Rare Earth Elements, II, "J. Inorg. \& Nuclear Chem. 6, 30813 (1958).

174. L. E. Glendenin, K. F. Flynn, R. F. Buchanan, and E. P. Steinberg, "Radiochemical Determination of Cerium in Fission," Anal. Chem. 27, $59-60$ (1955).

175. L. Gordon and L. Shaver, "Fractionation of Some Rare Earth Pairs 
by Precipitation from Homogeneous Solution, "Anal. Chem. 25, 748 (1953).

176. H. Goto and Y. Kakita 'New Photometric Determination of Cerium with Methylene Blue," J. Chem. Soc. Japan Pure Chem. Sect. 79. (12), 1524-28 (1958); Anal. Abstr. 6, 3915.

177. P. R. Gray and S. G. Thompson, "Extraction Behavior of Trivalent Lanthanide and Actinide Elements into Tributyl Phosphate from Hydrochloric and Nitric Acids," U. S. Atomic Energy Commission Document UCRL-2069, p. 29 (1952).

178. H. L. Greenhaus, A. M. Feibush, and L. Gordon, "Ultraviolet Spectrophotometric Determination of Cerium (III) "Anal. Chem. 29, $1531-34$ (1957).

179. B. Grinberg and Y. LeGallic, "Absolute Measurement of Beta Emitters by $4 \pi$ Counter, "Proc. U. N. Intern. Conf. Peaceful Uses Atomic Energy, 2nd Geneva, 1958, Paper 1208, 1-11.

180. W. G. Gruzensky and G. T. Engel, "Separation of Yttrium and Rare Earth Nitrates with the Solvent Extraction System Tri-N-Butylamine in 3-Methyl -2 Butanone,"Trans. AIME 215, 738-42 (1959) Oct.

181. E. Gulyas, "Observations on the Rare Earths: Some Studies Involving Chelate Compounds," Ph. D. Thesis, Univ, of Illinois (1955).

182. R. Gunnink and J.W. Cobble, "The Self-Absorption Corrections and Counting Efficiencies of Certain Fission Products in the $\beta$ Proportional Counter," AECU 4340 (Aug. 1959).

183. F. Hagemann, "The Isolation of Actinium and Preparation of Some of Its Compounds," U. S. Atomic Energy Commission Document MDDC- 1738 (1947).

184. F. Hagemann "The Isolation of Actinium." J. Am. Chem Soc. 72 768 (1950).

185. D. K. Hale, 'Recent Advances in the Preparation and Uses of Ion Exchange Resins, "Analyst 83, 3-9 (1958).

186. J. L. Hall, J. A. Gibson, Jr., P. R. Wilkinson and H. O. Philips, "Conductometric Standardization of Solutions of Common Divalent Metallic Ions Using Disodium Salt of EDTA,"Anal. Chem. 26, 148486 (1954).

187. H. Hamaguchi, N. Ikeda, and T. Kawashima, "Isolation of CarrierFree Yttrium from the Radioactive Strontium-Yttrium System by Electrodeposition, "Bunseki Kagaku 7, 243-46 (1958); Chem. Abstr. 54, $3080 \mathrm{i}$.

188. P. G. Hansen and R. K. Sheline, 'Chemical Techniques Used in 
Connection with $\beta$-Spectroscopic Work on Rare Earth Elements," Nuclear Instr. 2, 39-43 (1958).

189. R. D. Hansen and Stanley Chaberek, Dow Chem. Co., unpublished data.

190. R. Hara and P. W. West, "High Frequency Titrations Involving Chelation with Ethylenediaminetetraacetic Acid, V-Complexation with Rare Earths," Anal. Chim. Acta 14, 280-86 (1956).

191. R. Harder and S. Chaberek, "The Interaction of Rare Earth Ions with Diethylenetriaminepentaacetic Acid, "J. Inorg. \& Nuclear Chem. 11, 197-209 (1959).

192. T. J. Hardwick and E. Robertson, "Association of Ceric Ions with Sulfate (A Spectral Study), "Can. J. Chem. 29, 828-37 (1951).

193. T. V. Healy and H. A. C. McKay, "The Extraction of Nitrates by Tri-n-Butyl Phosphate (TBP)," Trans. Faraday Soc. 52, 633 (1956).

194. W. Herr, "Trägerfrei Isolierung der durch Neutroneneinfangreaktion enstandenen Radioisotope der Seltenen Erden, "Angew. Chem. 65, 303 (1953).

195. E. Hesford, E. E. Jackson, and H. A. C. McKay, "Tributyl Phosphate as anExtracting Agent for Inorganic Nitrates, VI. Further Results for the Rare Earth Nitrates," J. Inorg. \& Nuclear Chem. 279 (1959).

196. C. E. Higgins and W. H. Baldwin, "The Separation of Yttrium and Europium with Anion Exchange Resins," ORNL- 894 (1951).

197. D. M. Hiller and D. S. Martin, Jr., "Radiochemical Studies on the Photofission of Thorium," Phys. Rev. 90, 581 (1953).

198. M. A. Hiller, "Physical and Chemical Properties of Scandium and The Rare Earths, "Univ. Microfilms L. C. Card No. Mic. 59-5054 (180 pg.); Dissertation Abstr. 20, 2039 (1959); Chem. Abstr. 54, $6377 \mathrm{i}$.

199. "Handbook of Chemistry and Physics," 39 th Edition, ed. by C. D. Hodgman, Chemical Rubber Publishing Co., Cleveland, 1957-58.

200. B. Hok-Bernstrom, "Studies on the Extraction of Metal Complexes. XXIV. The Extraction of La, Th and U (VI) with Some Phenylcarboxylic Acids, "Svensk Kem. Tidskr. 68, 34 (1956).

201. L. Holleck and W. Noddack, "Eine neue Methode zur Darstellung von Verbindungen zweiwertiger Erden," Angew. Chem. 50, Jahrg. No. 43, 819-24 (1937).

202. L. Holleck and L. Hartinger, "The Effect of Amino-Polyacetic Acids and the Exchanger Form on the Separation of Cerite Earths, "Angew. Chem. 66, 586-89 (1954).

203. L. Holleck and L. Hartinger, Molar Extinction Coefficients of the 
Rare Earths and Their Analytical Uses," Angew. Chem. 67, 64851 (1955).

204. L. Holleck, D. Eckardt, and L. Hartinger, "Complex Colorimetry of the Rare Earths," Z. anal. Chem. 46, 103-07 (1955).

205. L. Holleck and L. Hartinger, 'Quantitative Trennung von CeritErden und pH-Wert des Elutionsmittels beim Ionenaustauscherverfahren." Angew. Chem. 68, 411-12 (1956).

206. E. P. Horwitz, "Observations on the Rare Earths Chelates Derived from Diamine Tetra- and Tri-Acetic Acids,"Univ. of Il1. (1957).

207. J. E. Hudgens, Jr., "Ion Exchange in Analytical and Radiochemistry," ASTM Spec. Tech. Publ. No. 195, $11-26$ (1958).

208. E. H. Huffman and R. L. Oswalt, "A Rare Earth Separation by Anion Exchange, "J. Am. Chem. Soc. 72, 3323 (1950).

209. E. K. Hulet, R. G. Gutmacher, and M. S. Coops, "Group Separation of the Actinides from the Lanthanides by Anion Exchange, "UCRL-5639 (1960).

210. L. Imre, "A Method for Purifying Cerium,"Z. anorg。u。allgem. Chem. 164, 214 (1927).

211. S. Ionescu, O. Constantinescu, D. Topor, and E. Gârd, "Contributions to the Use of Organic Solvent Eluants in Cationic Exchange, " A/Conf. 15/P/1424 (2nd Geneva Conf., 1958).

212. T. Ishimori, Bull. Chem. Soc. Japan 28, No. 3, 203 (1955).

213. V. K. Iya and J. Loriers, "Utilisation des Acides Amino-polyacétiques pour la Purification du Scandium par Échange d'Ions," Compt. rend. 237, 1413-15 (1953).

214. V. K. Iya, "Contribution a l'étude de la chimie du Scandium," J. recherches centre nat, recherche sci. Labs. Bellevue (Paris) 35 , $91-111$ (1956).

215. R. M. Izatt, W. C. Fernelius, C. G. Haas, Jr., and B. P. Block, 'Studies on Coordination Compounds, XI--Formation Constants of Some Tervalent Ions and the Thorium (+4) Ion with the Acetylacetonate Ion, "J. Phys. Chem. 59, 170-74 (1955).

216. D. E. Jackson, "Observations on the Rare Earths; 8-Quinolinol and Substituted 8-Quinolinol Chelates of Certain Rare Earth Elements," U. S. Atomic Energy Commission Document NP- 1800 (1950).

217. R. A. James and W. P. Bryan, "The Use of Thenoyltrifluoroacetone in Ion Exchange Separations," J. Am. Chem. Soc. 76, 1982-84 (1954).

218. G. Jantsch, "Salts of Rare Earths with Hydroxycarboxylic Acids (I) Glycollates of Rare Earths,"Z. anorg. Chem. 79, 305 (1913).

219. A. Jenickova, V. Suk, and M. Malat, "Complexometric Titration 
(Chelatometry), XIX--Brompyrogallol Red as a Complexometric Indicator, "Chem. listy $\underline{50}, 760-64$ (1956).

220. W. C. Johnson, L. Quill, and F. Daniels, "Rare Earth Separations Developed on the Manhattan Project,"Chem. Eng. News 25, 2494(1947).

221. H. Johnston, "Chelation Between Calcium and Organic Anions," New Zealand J. Sci. Technol. B37, No. 4, 522- 37 (1954).

222. M. Jones, "Bonding in the Lanthanon Chelates, "Science 121, 371 72 (1955).

223. K. Jorgensen, "Absorption Spectra of Dysprosium (+3), Holmium (+3), and Erbium (+3) Aquo Ions," Acta Chem. Scand. 11, $981-89$ (1957).

224. T. K. Keenan and J. F. Suttle, "The Chelation of Praseodymium by Thenoyltrifluoracetone," J. Am. Chem. Soc. 76, 2184 (1954).

225. A. S. Kertes, "Separation of Gadolinium From ${ }^{2} 35$ U Fission Product Rare Earths," J. Inorg. \& Nuclear Chem. 10, 161 (1959).

226. B. H. Ketelle and G. E. Boyd, "The Exchange Adsorption of Ions from Aqueous Solutions by Organic Zeolites, IV--The Separation of the Yttrium Group Rare Earths," J. Am. Chem. Soc. 69, 2800-12 (1947).

227. B. H. Ketelle and G. E. Boyd, "Further Studies of the Ion-Exchange Separation of the Rare Earths," J. Am. Chem.'Soc. 73, $1862-63$ (1951).

228. G. Kheveshi, "Rare Earths From the Standpoint of Their Atomic Structure," (Redkie zemli s tochki zreniia stroeniia ikh atomov) (1929).

229. T. Kiba, S. Ohashi, and S. Tada, "Preparation of Carrier-Free $\mathrm{Y}^{90}$ by Paper Chromatography," Bull. Chem. Soc. Japan 29, 74548 (1956).

230. H. W. Kirby, "Preparation of Radiochemically Pure Cerium by Solvent Extraction, "Anal. Chem. 29, 1599 (1957).

231. J. A. Kitchener, "Ion Exchange Resins," John Wiley \& Sons, Inc., New York, 1957.

232. J. A. Kitchener, "Physical Chemistry of Ion Exchange Resins," in "Modern Aspects of Electrochemistry,"ed. by. J. O'M. Bockris, Academic Press Inc., New York, 1959.

233. "Collected Radiochemical Procedures," Los Alamos Scientific Lab. Report No. LA- 1721 (2nd. ed.), ed. by J. Kleinberg (1958).

234. V. M. Klinaev and M. M. Senyavin, "Separation of Spectroscopically Pure Cerium from Natural Mixtures by Extraction," Primenenie Mechenykh Atomov v Anal. Khim., Akad. Nauk S. S. S. R., Inst. Geokhim. i Anal. Khim im. V. I. Vernadskogo p. 118 (1955). 
235. V. M. Klinaev and M. M. Senyavin, "The Use of Tagged Atoms in Analytical Chemistry," (Primenenie mechenikh atomov $v$ analiticheskoi ximii), M., Izd. Akad. Nauk S. S.S. R., Otdel. Khim. Nauk, p. 118 (1955).

236. L. L. Knapp, M. Smutz, and F. H. Spedding, "Solvent Extraction Equilibria for Rare Earth Nitrate- Tributyl Phosphate Systems," U. S. Atomic Energy Commission Document ISC- 766 (1956).

237. A. Kolb, "Antipyrine and $\mathrm{NH}_{3}$ Compounds of Rare Earth Nitrates," Z. anorg. Chem. 83, 143 (1913).

238. D. Kolp and H. C. Thomas, 'Rates of Water Oxidation in Ceric Perchlorate Solutions," J. Am. Chem. Soc. 71, 3047-49 (1949).

239. A. S. Komarovakii and S. M. Korenman, "Sensitive Test for Cerium with Phosphomolybdic Acid. Some Cases of Molybdenum Blue Formation in Alkaline Solutions," Mikrochemie 12, 211 (1932).

240. I. M. Korenman, "The Solubility Product of the Oxalates of Some Rare Earth Elements and the Dissociation Constants of Their complex Sulfates," Zhur. Obshchei Khim. 24, 1910 (1954).

241. I. M. Korenman, "Solubility Products for the Hydroxides of Some of the Rare Elements," Zhur. Obshchei Khim. 25, 1859-61 (1955).

242. I. M. Korenman, V. P. Gunina, and L. K. Trifinova, "Color Reactions for Scandium," Zhur. Anal. Khim. 14, 547-49 (1959); Nuclear Sci. Abstr. 14, 1523.

243. K. A. Kraus, R. W. Holmberg, and F. Nelson, "Preliminary Report on the Hydrolytic Behavior of Cerium (+4)," AECD- 2070 (1948).

244. K. A. Kraus and F. Nelson, "Metal Separations by Anion Exchange," ASTM Spec. Tech. Publ. No. 195, 27-57 (1958).

245. K. A. Kraus and F. Nelson, "Anion Exchange Studies of Metal Complexes," in "The Structure of Electrolytic Solutions," ed. by W. J. Hamer, John Wiley \&ons, Inc., New York, 1959.

246. K. A. Kraus and R. J. Raridon, "Temperature Dependence of Some Cation Exchange Equilibria in the Range 0 to $200^{\circ}, " \mathrm{~J}$. Phys. Chem. 63, $1901-07$ (1959).

247. A. Krishen, "A Systematic Study of Solvent Extraction with Acetylacetone," U. S. Atomic Energy Commission Document NYO-6498 (1957).

248. I. Kudo and Y. Nakatsuka, "Oxinate of Tetrapositive Praseodymium," J. Inst. Polytech. Osaka City Univ. C4, 50 (1953).

249. A.H. Kunz, "The Reduction Potential of the Ceric-Cerous Electrode," J. Am. Chem. Soc. 53, 98 (1931).

250. J.W. Kury, "Problems in the Aqueous Chemistry of Cerium (+3) Fluoride and Lanthanum (+3) Fluoride," University of California 
Radiation Lab. (Berkeley) Report No. UCRL-2271 (1953).

251. J.W. Kury, A.D. Paul, L.G. Hepler and R.E. Connick, "The Fluoride Complexing of Scandium (+3) in Aqueous Solution: Free Energies, Heats, and Entropıes," University of Calıfornia Lawrence Radiation Lab (Berkeley) Report No. UCRL-8630 (1959), J. Am. Chem. Soc. 81, 4185-89 (1959).

252. A.F. Kuteinikov, "Use of Arsenazo Reagent for Determining Rare Elements," Zavod. Lab. 24, 1050-52 (1958), (Eng. Trans1.) Zavod. Lab. 24, $1171-73$ (1958), Anal. Abstr. 6, 2473.

253. V.I. Kuznetsov, "Colorimetric Reactıons of the Rare Earth Elements," Zhur. Anal. Khım. 226-32 (1952), Translated in AWRE-Trans-3.

254. V.I. Kuznetsov and T.V. Petrova, "Thermospectrophotometric Determination of Rare Earths in the Presence of Thorium," Zhur. Anal. Khim. 14, 404-10 (1959), Nuclear Sc1. Abstr. 13, 19918.

255. N.A. Lange, "Handbook of Chemistry," Handbook Publ. Inc., Sandusky, Ohıo, 1956.

256. G. Lange, G. Herrmann, and F. Strassmann, "Die Darstellung von Stront1um 90-freiem Yttrium 90 durch Electrolyse" J. Inorg. \& Nuclear Chem. 4, 146-54 (1957).

257. W.M. Latımer, "Oxidation Potentials," Second Editıon, PrenticeHall, Inc., New York, 1952.

258. M. Lederer, "Electrochromatographie sur papier de lanthanides et des homologues du Lanthane," Compt. rend. 236, 200 (1953).

259. M. Lederer, "The Separation of Lanthanum and Actinium by Continuous Paper Electrophoresis," Anal. Chim. Acta 11, 145 (1954).

260. M. Lederer, "Separation of Rare-Earth Elements," Nature 176, 462 (1955).

261. M. Lederer, "Chromatography on Paper Impregnated with Ion Exchange Resins: A Preliminary Report," Anal. Chim. Acta 12, 142 (1955).

$262 M$ Lederer, "Paper Chromatography of Inorganic Ions, XIII The Separation of Non-Complexed Rare Earth Ions," Anal. Chim Acta 15, 46- 50 (1956).

263. M Lederer, "Paper Chromatography of Inorganic Ions, XIV. Separation of Gadolinium Group Rare Earths," Anal. Chim. Acta 15, $122-24$ (1956).

264. M. Lederer, 'Recent Progress in Chromatography, III. Paper Chromatography of the Radioelements," Actualites sci et ind. No 1240, 6400 (1956)

$265 M$ Lederer, "The Paper Electrophoretic Separation of Rare Earths Using 1\% Citric Acid as Electrolyte," J. Chromatog 1, 86 (1958) 
266. Y. LeGallic and M. Thenard, 'Reducing Autoabsorption in Beta Measurements with a $4 \pi$ Counter," Compt. rend. 244, 2909-12 (1957).

267. C. Legrand and S Loriers, "Sur la Determination Quantitative de 1'Yttrium par Spectrométrie de Rayons X," Compt. rend. 249, 256567 (1959).

268. C Lepscky and G. Ristell1, "Separation of Carrier-Free $Y^{90}$ from $\mathrm{Sr}^{90}$," Comit. naz. ricerche nucleari CNI-13, 1959.

269. Shu-Chuan Liang and Ta-Fa Yeh, 'Extraction of Cerium (IV) with Butyl Acetate,"K'o Hsueh T'ung Pao, No. 3, 87 (1958).

270. R. Lindner, "Adsorption Separation of Ceric Earths, Especially Those Isotopes Formed in Uranium Fission," Z. Naturforsch. 2a 329- 32 (1947).

271. M. Lindner, 'Radiochemical Procedures in Use at the University of Calıfornia Radiation Laboratory (Livermore)," Unıversity of Calıfornia Radiation Lab. (Livermore) Report No. UCRL 4377 (1954).

272. J. Loriers and D. Carminatı, "Utilisation de l'acide Nitrilotriacetique pour la Separatıon des Terres Cérıques par Échange d'ıons," Compt. rend. 237, 1328-30 (1953).

273. J. Loriers, "Separation of Yttrium Earths by Ion Exchange-Use of Ethylenediaminetetraacetic Acid," Compt. rend. 240, 1537 (1955).

274. G. E. F. Lundell and J. I. Hoffman, "Outlines of Methods of Chemical Analysıs," John Wiley \& Sons, Inc., New York, 1938.

275. L. B. Magnusson and M. L. Anderson, "Chelation of the +3 Ions of Elements 95 Through 100 with Thenoyltrifluoracetone," J. Am Chem Soc. 76, 6207 (1954).

276. M. Maki, "Electrochromatography XVIII. Separatıon of Rare Earths" Japan Analyst $\underline{5}, 571$ (1956)

277. Many authors, "The Separation of Rare Earth, Fission Product, and Other Metal Ions and Anions by Adsorption on Ion-Exchange Resins," J. Am. Chem. Soc. 69, 2769-2881 (1947).

278. Y. Marcus and F. Nelson, "Anion Exchange Studies, XXV The Rare Earths in Nitrate Solutions," J. Phys Chem. 63, 77-79 (1959)

279. J. K. Marsh, "The Dimethyl Phosphates of the Rare Earth Metals," J. Chem. Soc., 554-58 (1939).

280. J. K. Marsh, 'Rare-Earth Metal Amalgams, Part I. The Reaction Between Sodium Amalgam and Rare Earth Acetate and Chloride Solutions," J. Chem. Soc., 398-401 (1942).

281. J. K. Marsh, 'Rare-Earth Metal Amalgams, Part II The Separation of Neodymium, Samarıum, and Gadolinıum," J. Chem. Soc, $523-26$ (1942). 
282. J. K. Marsh, "Rare-Earth Metal Amalgams, Part III. The Separation of Ytterbium from Its Neighbors," J. Chem. Soc., 8-10 (1943)

283. J. K. Marsh, 'Rare-Earth Metal Amalgams, Part IV. The Isolation of Europium," J. Chem. Soc., $531-35$ (1943).

284. J. K. Marsh, "The Relation of Yttrium to the Lanthanons: A Study of Molecular Volumes," J. Chem. Soc., 1084 (1947).

285. J. K. Marsh, "Separation of the Lanthanons with the Aid of Ethylenediamine-N, N, N, N-tetra-acetic Acid," J. Chem. Soc., 1819 (1950).

286. J. K. Marsh, "The Purification of Lutecium by Fractionation of Hexaantipyrinelutecium Iodide," J. Chem. Soc., 577 (1950); Lanthanon Purification by the Use of Hexaantipyrine Lanthanon Iodides," J. Chem. Soc., 1337 (1951).

287. J. K. Marsh, "The Separation of the Lanthanons with the Aid of Ethylenediaminetetraacetic Acid (Enta Acid). V. The Solubilities of some Alkali Lanthanon Enta Salts," J. Chem. Soc., 451 (1955).

288. J. K. Marsh, 'Isolation of Samarium, Europium, and Ytterbium Materials by Means of Sodium Amalgams,"Inorg. Syntheses, 3237 (1957).

289. R. M. Marshall, Wbservations on the Rare Earths: Studies on Some Rare Earth Metal Chelate Compounds," Thesis, Univ. of Illinois (1954). (Includes EDTA, Antipyrine, Aminopyrine, and TTA.)

290. A. E. Martell and M. Calvin, "Chemistry of the Metal Chelate Compounds," Prentice-Hall, Inc., New York, 1953.

291. T. C. Martin and O. E. Green, "Improved $4 \pi$ Proportional Gas Flow Counter," Rev. Sci. Instr. 29, $1147-48$ (1958).

292. K. Martinson, "Absolute Measurements with $4 \pi$ Counter," Swedish Atomic Energy Report AE-5, $1-25$ (1958).

293. J. Massonne, "Die Darstellung grössere Mengen reiner Seltenen Erden durch Ionenaustauschverfahren," Chem. Tech. (Berlin) 10, $591-99$ (1958).

294. J. Massonne, "Die Trennung grösserer Mengen Seltener Erden am Kationenaustauscher mittels Nitrilotriessigsäure als Elutionsmittel," Österr. Chemiker-Ztg. 60, 16-22 (1959).

295. K. L. Mattern, "Complex Ions of Lanthanum in Aqueous Solutions," UCRL-1407 (1951).

296. S. W. Mayer and S. D. Schwartz, "The Association of Cerous Ion with Sulfite, Phosphate, and Pyrophosphate Ion," J. Am. Chem. Soc. 72, $5106-10$ (1950).

297. S. W. Mayer and E. C. Freiling, 'Ion Exchange as a Separation Method. VI. Column Studies of the Relative Efficiencies of Various 
Complexing Agents for the Separation of Lighter Rare Earths," J. Am. Chem. Soc., 75, 5647-49 (1953).

298. H. N. McCoy, "Chemistry of Europium," J. Am. Chem. Soc., $\underline{58}$, 1577-80(1936).

299. H. N. McCoy, 'Europium and Ytterbium Amalgams," J. Am. Chem. Soc., 63, 1622-24 (1941).

300. H. N. McCoy, "The Electrolysis of Rare Earth Acetates and the Separation of Europium as Amalgam from Other Rare Earths," J. Am. Chem. Soc. 63, 3432-33 (1941).

301. H. A. C. McKay and D. Rees, "Some Experiments on Rates of Transfer of Nitrates Between an Aqueous and a Tributyl Phosphate Phase," United Kingdom Atomic Energy Authority Document C/R 1199 (1957).

302. H. A. C. McKay, K. Alcock, and D. Scargill, "Some Fission Product Partition Data for Butex (Dibutyl Carbitol)," United Kingdom Atomic Energy Authority Document AERE C/R 2221 (1958).

303. C. K. McLane and S. Peterson, "Tracer Chemistry of Actinium," AECD- 2497 (1948).

304. G. V. Medoks, "Double Salts of Lanthanum, Cerium, Praseodymium and Neodymium with Triphenylbenzylphosphonium Nitrate," Zhur. Obshchei Khim. 26, 382 (1956).

305. D. J. Meier and C. S. Garner, "The Kinetics of the Europium (+2) Europium (+3) Exchange Reaction;" J. Phys. Chem. 56, 853-57 (1952).

306. W. W. Meinke, "Chemical Procedures Used in Bombardment Work at Berkeley," UCRL-432 (1949).

307. W. W. Meinke, 'Nuclear Chemical Research Progress Report - Nov., 1956--Oct., 1957," AECU- 3641 (1957).

308. C. C. Meloche and F. Vratny, "Solubility Product Relations in the Rare Earth Hydrous Hydroxides," Anal. Chim. Acta 20, 415-18 (1959).

309. J. S. Merritt, J. G. V. Taylor, and P. J. Campion, "Self-Absorption in Sources Prepared for $4 \pi$ Beta Counting," Can. J. Chem. 37, 1109- 14 (1959).

310. R. J. Meyer and H. Goldenberg, Nernst-Festschift, S. 302, Halle, 1912; R. J. Meyer, Z. anorg. Chem. 86, 267 (1914); R. J. Meyer and O. Hauser, "Die Analyse der Seltenen Erden," S. 43, 248, Stuttgart, 1912.

311. C. C. Miller, "Qualitative Semimicro-Analysis with Reference to Noyes and Bray's System: Partial Analysis of the Combined Nickel, Zirconium, and Rare-Earth Groups," J. Chem. Soc., p. 1347 (1947). 
312. T. Moeller and H. E. Kremers, "Extraction of Ytterbium from Rare Earth Mixtures with Sodium Amalgam," Ind. Eng. Chem. Anal. Ed. 17, 798-800 (1945).

313. T. Moeller and H. E. Kremers, "The Basicity Characteristics of Scandium, Yttrium and the Rare Earth Elements," Chem. Rev. 37, 97- 159 (1945).

314. T. Moeller and J. C. Brantley, "Spectrophotometric Estimation of Certain Rare Earth Elements," Anal. Chem. 22, 433-41 (1950).

315. T. Moeller and D. E. Jackson, "The Rare Earths: Separative Extraction of Certain Rare Earth Elements as 5-7-Dichloro- 8 Quinolinol Chelates," Anal. Chem. 22, 1393 (1950).

316. T. Moeller, "Coordination Chemistry of the Rare Earth Metal Ions," Record Chem. Progr. 14, 69-81 (1953).

317. T. Moeller and P. A. Zimmerman, "Observations on the Rare Earths. LXII. Some Observations on Solutions of Certain Rare Earth Metal Salts in Basic Solvents," J. Am. Chem. Soc. 75, 3940-43 (1953).

318. T. Moeller and P. A. Zimmerman, "Some Observations on the Electrolysis of Solutions of Rare Earth Metal Salts in Basic Solvents," Science 120, 539-40 (1954).

319. T. Moeller, F. Moss, and R. Marshall, "Rare Earths. LXVI. Some Characteristics of Ethylenediaminetetracetic Acid Chelates of Certain Rare Earth Metal Ions," J. Am. Chem. Soc. 77, 3182 (1955).

320. T. Moeller and M. Tecotzky, 'Rare Earths. LXV. Naphthazarin Complexes of Certain Rare Earth Metal Ions," J. Am. Chem. Soc. 77, 2649 (1955).

321. T. Moeller, E. Gulyas, and R. H. Marshall, "Observations of the Rare Earths. LXVIII--Partial Resolution of Yttrium and Gadolinium Acetylacetonates by Means of a Chromatographic Technique," J. Inorg. * Nuclear Chem. 9, 82-85 (1959).

322. F. L. Moore, "Metals Analysis with Thenoyltrifluoracetone," Am. Soc. Testing Materials, Spec. Tech. Publ. 238, 13 (1958).

323. S. Moosath, "Preparation of Normal Ceric Hydroxide," Current Sci. (India) 25, 14 (1956).

324. A. Sitaramachandra Murthy, T. P. Sarma, and B. S. V. R. Rao, "Yttrium-Its Gravimetric and Colorimetric Estimation with 8-Quinolinol,"Z. anal. Chem. 145, 418 (1955).

325. C. Musante, "Compounds of Kojic Acid (5-hydroxy-2 hydroxymethyl4 Pyrone) with Some Metals," Gazz. Chim. ital. 79, 679-83 (1949).

326. G. Muto and M. Mamiya, "Analysis of Rare Earth Elements II. The Absorption Spectra of Lanthanide Elements in the Near Infrared 
Region," J. Chem. Soc. Japan, Pure Chem. Sect. 79, 809-12 (1958). (The authors report the $\mathrm{Sm}$ band at $1090 \mathrm{~m} \mu$ to be superior to the one at $405 \mathrm{~m} \mu$ for determining $\mathrm{Sm}$.)

327. "Ion Exchange Theory and Application," ed. by F. C. Nachod, Academic Press, Inc., New York, 1949.

328. "Ion Exchange Technology," ed. by F. C. Nachod and J. Schubert, Academic Press, Inc., New York, 1956.

329. R. A. Nagle and T. K. S. Murthy, "An Ion-Exchange Method for the Separation of Thorium from Rare Earths, and Its Application to Monazite Analysis," Analyst 84, 37-41 (1959).

330. Y. Nakatsuka and J. Kudo, "8-Hydroxyquinolate of Tetrapositive Neodymium," J. Chem. Soc. Japan, Pure Chem. Sect. $\underline{72}, 655$ (1951).

331. F. Nelson, R. M. Rush, and K. A. Kraus, "Anion Exchange Studies XXVII. Adsorbability of a Number of Elements in HCl-HF Solutions," J. Am. Chem. Soc. 82, 339 (1960).

332. D. S. Nemoda, "Separation of Fission Products and Corrosion Elements on Aluminum Oxide," Bull. Inst. Nuclear Sci. "Boris Kidrich" (Belgrade) 9, No. 178, 95-103 (1959).

333. W. E. Nervik and P. C. Stevenson, "Self-Scattering and Self-Absorption of Betas by Moderately Thick Samples," Nucleonics 10, 18-22 (1952).

334. W. E. Nervik, "An Improved Method for Operating Ion-Exchange Resin Columns in Separating the Rare-Earth Elements," J. Phys. Chem. 59, 690 (1955).

335. A. N. Nesmeyanov, "Organic Compounds and the Periodic System," Uspekhi Khim. 14, 261 (1945).

336. T. W. Newton and G. M. Arcand, "A Spectrophotometric Study of the Complex Formed Between Cerous and Sulfate Ions," J. Am. Chem. Soc. 75, 2449-53 (1953).

337. A. V. Nikolaev, A. A. Sorokina, and A. S. Maslennikova, 'Extraction (of Cerium) with Tributylphosphate," Zhur. Neorg. Khim. 3, 160 (1958).

338. A. V. Nikolaev and A. A. Sorokina, "Reciprocal Influence of Rare Earth Elements When Extracted by Tributylphosphate," Doklady Akad. Nauk S.S.S.R. 129, $341-44$ (1959); Nuclear Sci. Abstr. 14, 6344.

339. W. Noddack and E. Wicht, "Eine neue Methode zur Trennung der seltener Erden," Z. Elektrochem. 56, 893 (1952).

340. W. Noddack and G. Oertel, IÜber die Austauschgleichgewichte zwischen Seltenerden-Komplexen der Nitrilotriessigsãure und 
Ionenaustauscher Dowex-50 $\mathrm{Cu}^{++}, \mathrm{Ni}^{++}$und $\mathrm{Na}^{+}$Stadium," $\mathrm{Z}$. Electrochem. 61, 1216-24 (1957).

341. W. Noddack, "Techniques for Separation of Rare Earths by Ion Exchange," Chem. Tech. (Berlin) 10, 586-90 (1958).

342. W. Noddack, I. Noddack, and E. Wicht, "Zur Trennung der seltenen Erden im Inhomogenen Magnetfeld," Z. Elektrochem. 62, 77 (1958).

343. A. Noyes and C. Garner, "Strong Oxidizing Agents in Nitric Acid Solution. I. Oxidation Potential of Cerous-Ceric Salts," J. Am. Chem. Soc. 58, 1265 (1936).

344. E. I. Onstott, "The Separation of Europium from Samarium by Electrolysis," J. Am. Chem. Soc. 77, 2129-32 (1955).

345. E. I. Onstott, "Separation of Lanthanons at Amalgam Cathodes. II. The Separation of Samarium from Gadolinium and Purification of Europium at a Lithium Amalgam Cathode," J. Am. Chem. Soc. 78, 2070- 76 (1956).

346. E. I. Onstott and C. J. Brown, "Absorption Spectra of Terbium Perchlorate and Terbium Chloride Solutions," Anal. Chem. 30, 172 (1958).

347. E. I. Onstott, "Separation of the Lanthanons at Amalgam Cathodes. III. Electrochemical Fractination of the Lanthanons at a Lithium Amalgam Cathode," J. Am. Chem. Soc. 81, $4451-58$ (1959).

348. N. A. Orlov, "The Rare Earths," Zhur. Russ. Fiz. -Khim. Obshchestva 60,515 (1928).

349. G. H. Osborn, "Synthetic Ion-Exchangers: Recent Developments in Theory and Application, The Macmillan Co., New York, 1956.

350. S. Otani, M. Miura, and H. Monda, "Sorption of Barium, Lanthanum, and Sulfate Ions on Glasses, "J. Sci. Hiroshima Univ. A22, 61-68 (1958).

351. J. Pascual and E. C. Freiling, "Rare Earth Solutions for $4 \pi$ Counting," Nucleonics 15, No. 5, 94 (1957).

352. A. D. Paul, "The Fluoride Complexing of $\mathrm{Sc}^{+++}, \mathrm{Cu}^{++}, \mathrm{Pb}^{++}, \mathrm{Zn}^{++}$, $\mathrm{Hg}^{++} \mathrm{Hg}_{2}^{++}, \mathrm{Sn}^{++}$, and $\mathrm{Ag}^{+}$in Aqueous Solutions," UCRL 2926 (1955).

353. R. A. Penneman and T. K. Keenan, "The Radiochemistry of Americium and Curium," NAS- NS 3006 (Jan. 1960), Procedure 13, p. 49.

354. D. F. Peppard, J. P. Faris, P. R. Gray, and G. W. Mason, 'Studies of the Solvent Extraction Behavior of the Transition Elements. I. Order and Degree of Fractionation of the Trivalent Rare Earths,"J. Phys. Chem. 57, 294 (1953).

355. D. F. Peppard, P. R. Gray, and M. M. Markus, "The ActinideLanthanide Analogy as Exemplified by Solvent Extraction Behavior," 
J. Am. Chem. Soc. 75, 6063 (1953).

356. D. F. Peppard, G. W. Mason, and J. L. Maier, 'Interrelationships in the Solvent Extraction Behavior of Scandium, Thorium and Zirconium in Certain Tributyl Phosphate-Mineral Acid Systems,"

J. Inorg. Nuclear Chem. 3, 215 (1956).

357. D. F. Peppard, G. W. Mason, and S. W. Moline, "The Use of Dioctyl Phosphoric Acid Extraction in the Isolation of Carrier-Free ${ }^{90} \mathrm{Y}$, ${ }^{140} \mathrm{La},{ }^{144} \mathrm{Ce},{ }^{143} \mathrm{Pr}$, and ${ }^{144} \mathrm{Pr}, " \mathrm{~J}$. Inorg. Nuclear Chem. 141 (1957).

358, D. F. Peppard, W. J. Driscoll, R. J. Sironen, and S. McCarty, "Nonmonotonic Ordering of the Lanthanides in Tributyl PhosphateNitric Acid Extraction Systems," J. Inorg. Nuclear Chem. 326 (1957).

359. D. F. Peppard, G. W. Mason, J. L. Maier, and W. J. Driscoll, "Fractional Extraction of the Lanthanides as Their Di-Alkyl Orthophosphates," J. Inorg. Nuclear Chem. 4, 334 (1957).

360. D. F. Peppard and E. S. Nachtman; U. S. Patent No. 2,824,783.

361. M. Perey, "Dosage de l'Actinium par Mesure Directe du Produit en Solution," Compt. rend. 243, 1411-14 (1956).

362. R. W. Perkins, "Filtration-Precipitation Separation of $\mathrm{Ba}^{140}$ from La ${ }^{140}$," Anal. Chem. 29, 152-53 (1957).

363. T. P. Perros and C. Q. Naeser, "A Complex Praseodymium Fluoride Readily Soluble in Dilute Acids," J. Am. Chem. Soc. 71, 3847-48 (1949).

364. H. G. Petrow, 'Radiochemical Determination of $\mathrm{Nd}, \mathrm{Pr}$, and $\mathrm{Ce}$ in Fission Products," Anal. Chem. 56, 1514- 15 (1954).

365. K. A. Piez, "Some Theoretical and Experimental Considerations of pH Gradient Elution Analysis," Anal. Chem. 28, 1451-54 (1956).

366. V. M. Plets, "Organic Derivatives of Scandium and Yttrium," Doklady Akad. Nauk 20, 27 (1938).

367. L. Pokras and P. M. Bernays, "The Chemistry of Scandium-- I.," J. Am. Chem. Soc. 73, 7-9 (1951).

368. L. Pokras and P. M. Bernays, "Determination of Scandium with 8-Quinolinol," Anal. Chem. 23, 757-59 (1951).

369. F. H. Pollard, J. F. W. McOmie, and H. M. Stevens, "The Analysis of Inorganic Compounds by Paper Chromatography, Part V. The Separation and Detection of Certain Lanthanons," J. Chem. Soc., 4730-34 (1952); Part VI. of this series, entitled "Further Studies on the Separation and Detection of Lanthanons," appears in J. Chem. Soc., 3435-40 (1954). 
370. G. Popa, D. Negoiu, and Gh. Baiulescu, "Zur Colorimetrischen Bestimmung von Cer (IV) bei Anwesenheit von Eisen(III) und Lanthan (III) mittels orthodianisidin," Z. anal. Chem. 167, 329-31 (1959).

371. A. I. Popov and W. Wendlandt, "Some Aspects of the Chemistry of Samarium (II) Compounds," Proc. Iowa Acad. Sci. 60, 300 (1953).

372. A. I. Popov and W. W. Wendlandt, 'Cupferron and Neocupferron Complexes of the Rare Earth Elements," Anal. Chem. 26, 883-86 (1954).

373. A. I. Popov and W. Wendlandt, "Methylamine Complexes of the Rare Earth (III) Chlorides," J. Am. Chem. Soc. 77, 857 (1955).

374. J. E. Powell; Iowa State Coll. J. Sci. 28, 386 (1954).

375. J. E. Powell and F. H. Spedding, "Basic Principles Involved in the Macro-Separation of Adjacent Rare Earths from Each Other by Means of Ion Exchange," ISC- 617 (1955).

376. J. E. Powell and F. H. Spedding, "The Separation of Rare Earths by Ion Exchange," Trans. AIME 215, 457-63 (1959).

377. W. Prandtl and K. Scheiner, "Über die Absorptionsspektren der seltenen Erden,"Z. anorg. u. allgem. Chem. 220, 107-12 (1934).

378. B. K. Preobrazhensky, A. V. Kalyamin, and O. M. Lilova, "The Separation of Radioactive Rare-Earth Elements by Ion Exchange," Soviet J. Inorg. Chem. 2, $1164-66$ (1957); Translated in AEREIGRL- T/R- $\underline{81}$ (1958).

379. R. E. Pressly, "Separation of Am from Pm,"U. S. Patent 2, 893, 827 (July 7, 1959).

380. B. C. Purkayastha and S. N. Bhattacharyya, "On the Study of the Use of Calcium Oxalate Monohydrate in the Investigation of Rare Earth and Thorium Activities," J. Indian Chem. Soc. 34, No. 6, 427-33 (1957).

381. B. C. Purkayastha and S. N. Bhattacharyya, "The Coprecipitation of Rare Earths with Calcium Oxalate," J. Inorg. \& Nuclear Chem. 10, $103-09$ (1959).

382. V. Ramachandra Rao, A. Sitaramachandramurty, and Bh. S. V. Raghava Rao, "Metal Lakes of Group III A with Alizarin-S: Lanthanum and Yttrium," J. Sci. Ind. Research (India) (B-C) 14B 190 (1955).

383. P. Radhakrishna, "La Séparation de Scandium, de Lanthane, et de 1'Yttrium," Anal. Chim. Acta 8, 140-45 (1953).

384. W. Ramsey, D. Douglas, and D. Yost, "Praseodymium and Neodymium Complexes with 8-Quinolinol-5-Sulfonic Acid," J. Am. Chem. Soc. 72, 2782 (1950).

385. P. J. Reddy, D. V. N. Sarma, and Bh. S.V. Raghava Rao, "Sep- 
aration of Lanthanum from Other Cerite Earths Excluding Cerium," Z. anal. Chem. 160, (6), 426-29 (1958); Anal. Abstr. 5, 4031.

386. J. C. Reid, "Chemistry of Fluorinated $\beta$-Diketones," U. S. Atomic Energy Commission Document CN- 3343 (1943).

387. R. W. Rinehart, "Spectrophotometric Determination of Some Rare Earths and Yttrium with Alizarin Red S," Anal. Chem. 26, 1820 22 (1954).

388. C. J. Rodden, "Spectrophotometric Determination of Praseodymium, Neodymium and Samarium," J. Research Natl. Bur. Standards 26, 557- 70 (1941).

389. C. J. Rodden, "Spectrophotometric Determination of Dysprosium, Holmium, Erbium, Thulium, and Ytterbium," J. Research Natl. Bur. Standards 28, 265 (1942).

390. N. E. Rogers and R. M. Watrous, 'Radiochemical Separation of Actinium and its Daughters by Means of Lead Sulfate," Anal. Chem. 27, 2009-12 (1955).

391. E. Ruch, Sitzber. math.-naturw. Kl. bayer. Akad. Wiss. Munchen 347, (1954-55).

392. N. P. Rudenko, "Carrier-Free Preparation of Radiochemically Pure Yttrium-90," Russ. J. Inorg. Chem. 4, No. 1, 92 (1959).

393. D. I. Ryabchikov and E. A. Terent'eva, "Complex Compounds of Rare Earth Metals and Some Organic Amines," Doklady Akad. Nauk 51, 291 (1946).

394. D. I. Ryabchikov and V. Ya. Volkova, "Rare Earth Thiosulfates," Doklady Akad. Nauk 55, 501 (1947).

395. D. I. Ryabchikov and E. A. Terent'eva, "Citrate Complexes of Rare-Earth Elements of the Cerium Group," Doklady Akad. Nauk 58, 1373 (1947).

396. D. I. Ryabchikov and E. A. Terent'eva, "Complex Formation of Rare Earth Elements," Izvest. Akad. Nauk S.S.S. R., Otdel Khim. Nauk 44, (1949); Translated in NRC--Tech. Trans. No. IS- 7 (1949).

397. D. I. Ryabchikov and E. A. Terent'eva, "New Methods for Separation of Rare Earth Elements," Uspekhi Khim. 24, 260 (1955).

398. D. I. Ryabchikov, Iu. S. Skliarenko, and N. S. Stroganova, "Abnormal Valences of Rare Earth Elements in the Processes of Their Separation. I. Electrolytic Reduction of Ytterbium," Zhur. Neorg. Khim. 1, No. 9, 1954-67 (1956); French translation, CEA-TR-R273.

399. D. S. Ryabchikov and N. S. Vagina, "The Complex Form of Tetravalent Cerium with Acetate and Oxalate Ions," Zhur. Neorg. Khim. 2. 2109-14 (1957); Translated in UCRL Trans. No. 516 (L) (1960). 
400. J. Rydberg, "Studies on the Extraction of Metal Complexes. XIV. The Separation of Metal Acetylacetonates," Arkiv Kemi 9, 95 (1955).

401. J. Rydberg and B. Bernstrom, "Studies on the Extraction of Metal Complexes. XXVII. The Distribution of Some Actinides and Fission Products Between Methyl Isobutyl Ketone and Aqueous Solutions of $\mathrm{HNO}_{3}$ and $\mathrm{Ca}\left(\mathrm{NO}_{3}\right)_{2}$," Acta Chem. Scand. 11, 86 (1957).

402. L. Sacconi and R. Erkoli, "Some Complexes of the Rare Earths with $\beta$-Diketones," Gazz. chim. ital. 79, 731 (1949).

403. N. Saito and T. Sekine, "Anion Exchange Behavior of Yttrium," Nature 180, 753 (1957).

404. M. L. Salutsky and H. W. Kirby, "Precipitation of Actinium Oxalate from Homogeneous Solution," Anal. Chem. 28, 1780 (1956).

405. O. Samuelson, "Ion Exchangers in Analytical Chemistry," John Wiley \& Sons, Inc., New York, 1953.

406. B. Sarma, "Inorganic Separation by Paper Chromatography, Part II. Separation of Uranium, Thorium and Rare Earth by Partition Chromatography on Filter Paper," Sci. and Culture (India) 17, $139-41$ (1951).

407. T. P. Sarma and S. V. R. Rao, "Hematoxylin (Oxidized) - A Colorimetric Reagent for Lanthanum and Yttrium," J. Sci. and Ind. Research, (B-C) 14B, 450 (1955).

408. T. R. Sato, H. Diamond, W. P. Norris, and H. H. Strain, 'Electrochromatographic Separations of the Rare Earths," J. Am. Chem. Soc. 74, 6154 (1952).

409. E. M. Savitskii, "Physico-Chemical Properties and Uses of the Rare Earth Metals," Metalloved. i Obrabotka Metal. 8, 2-13 (1958).

410. E. Scadden and N. Ballou, "Solvent Extraction Separations of Zirconium and Niobium," Anal. Chem. 25, 1602 (1953).

411. D. Scargill, K. Alcock, J. M. Fletcher, E. Hesford, and H. A. C. McKay, "Tri-N-Butyl Phosphate as an Extracting Solvent for Inorganic Nitrates. II. Yttrium and the Lower Lanthanide Nitrates," J. Inorg. \& Nuclear Chem. 4 , 304 (1957).

412. U. Schindewolf and J. W. Irvine, Jr., "Preparation of CarrierFree Vanadium, Scandium, and Arsenic Activities from Cyclotron Targets by Ion Exchange," Anal. Chem. 30, 906-08 (1958).

413. T. Schonfeld, M. Wald, and M. Brund, "Radiochemical Separations on Anion Exchange Columns with Employment of Strong Complexing Agents," Proc. U. N. Intern. Conf. Peaceful Uses Atomic Energy, 2nd Geneva 28, 48-54 (1958).

414. J. Schubert, "Separation of Fission Products by Adsorption from Organic Solvents," U. S. Patent 2,717,696 (Sept. 13, 1955). 
415. E. Schumacher, "Über Fokussierenden Ionentausch. I. Prinzip und Einfache Theorie," Helv. Chim. Acta 40, 221 (1957).

416. E. Schumacher and H. J. Streiff, "Über Fokussierenden Ionentausch.

II. Quantitative Schnellanalyse von Kationen,"Helv. Chim. Acta 40, 228 (1957).

417. E. Schumacher and H. J. Streiff, "Über Fokussierenden Ionentausch. III. Schnellentrennung von Radioaktiven Indikatoren," Helv. Chim. Acta 40, 234 (1957).

418. E. Schumacher, "Über Fokussierenden Ionentausch. IV. Zur Theorie des Fokussierungseffektes," Helv. Chim. Acta 40,2322 (1957).

419. E. Schumacher and H. J. Streiff, "Über Fokussierenden Ionentausch. V. Trennung von Metallionen, Insbesondere von Radioaktiven Indikatoren durch Austausch mit Protonen," Helv. Chim. Acta $\underline{41}$, 824 (1958).

420. E. Schumacher and R. Fluhler, IÜber Fokussierenden Ionentausch VI. Eine Apparatur zur Praparativen Trennung von Metallionen," Helv. Chim. Acta 41, 1572 (1958).

421. E. Schumacher and H. J. Streiff, "Über Fokussierenden Ionentausch VII. Quantitative Mikroanalyse von Schwermetallen und Seltenen Erden," Helv. Chim. Acta 41,1771 (1958).

422. G. Schwarzenbach, E. Kampitsch, and R. Steiner, 'Complexons. I. Salt Formation of Nitrilotriacetic Acid,"Helv. Chim. Acta 28, 828 (1945).

423. G. Schwarzenbach and W. Biedeman, "Complexons. VII. Titration of Metals with Nitrilotriacetic Acid $\mathrm{H}_{3} \mathrm{X}$. Indication of the End Point by pH Effects," Helv. Chim. Acta 31, 331 (1948).

424. G. Schwarzenbach, R. Gut, and G. Anderegg, "Komplexone XXV," Helv. Chim. Acta 37, 937 (1954).

425. G. Schwarzenbach, G. Anderegg, W. Schneider, and H. Senn. "Complexons. XXVI. The Coordination Tendency of N-Substituted Iminoacetic Acids," Helv. Chim. Acta 38, 1147 (1955).

426. G. K. Schweitzer and W. M. Jackson, "Studies in L ow Concentration Chemistry, I. The Radiocolloidal Properties of Lanthanum-140," J. Am. Chem. Soc. 74, 4178-80 (1952).

427. G. K. Schweitzer, B. R. Stein, and W. M. Jackson, "Studies in Low Concentration Chemistry, III. The Radiocolloidal Properties of Yttrium-90," J. Am. Chem. Soc. 75, 793-95 (1953).

428. J. A. Seaton, "Reaction of Rare Earths in Acetic Acid," Thesis, Univ. Illinois (1958).

429. M. Seehof, "Preparation of Cerous Ammonium Acetylacetonate," J. Am. Chem. Soc. 74, 3960 (1952). 
430. A. Seidell, "Solubilities of Inorganic and Metal Organic Compounds," 3rd. Ed., by W. F. Linke, D. Van Nostrand Co., Inc., Princeton, New Jersey supplement to 3rd. Ed., 1952; 4th. Ed., 1958.

431. T. Sekine and N. Saito, "Separation of Lanthanum from Thorium by Anion Exchange," Nature 181, 1464-65 (1958).

432. V. V. Serebrennikov, "Complex Formation by Rare Earths. Some Characteristics of Complex Formation by Quadrivalent Cerium" (Soobschcheniia o Nauchnikh Rabotakh), Vsesoyuz Khim. Obshchestvo in D.I. Mendeleyeva 1, 50 (1953); Ghem. Abstr. 49, 3713h (1955).

433. V. V. Serebrennikov, M. A. Padalka, and I. S. Levin; Uchenye Zapiski Tomsk. Gosudarst. Univ. 26, 26 (1955).

434. K. Shaver, "The Coprecipitation of Rare Earth Iodates with Thorium Iodate Precipitated from Homogeneous Solution," MLM- 1031 (1955).

435. F. M. Shemyakin, V. A. Volkova, and A. S. Bozhko, "Reactions of Rare Earths and Allied Elements with Polyphenols and Alkaloids. VI. A New Colorimetric Method for the Determination of Cerium by Means of Brucine," Zhur. Obshchei Khim. 8, 452 (1938); Chem. Abstr. 32, $7369^{3}$.

436. E. Sheperd and W. W. Meinke, "TTA Extraction Curves," U. S. Atomic Energy Commission Document AECU- 3879 (1958).

437. S. Shibata, F. Takeuchi, and T. Matsumas, "Spectrophotometric Determination of Lanthanum with Neo-Thorone," Anal. Chim. Acta 21 , 177-81 (1959); Chem. Abstr. 53, 196931.

438. R. J. Silva, 'Ion-Exchange Column Calculations for Actinides and Lanthanides," U. C. Rad. Lab. (1955).

439. R. P. Singh, "Metallic Complexes Formed by 1,3-Diphenylvioluric Acid," Current Sci. (India) 24, No. 6, 208 (1955).

440. B. Singh and S. Singh, "Diethylenetetra-Ammonium Sulphatocerate as Volumetric Reagent. I. Iodine Monochloride Method," Anal. Chim. Acta 14, 109 and 405 (1956).

441. S.K. Sinha and S.C. Shome, "Gravimetric Determination of Thorium and Cerium with N-Benzoylphenylhydroxylamine," Anal. Chim. Acta 21, 415-17(1959).

442. H. Louise Smith and Darlene C. Hoffmann, "Ion Exchange Separations of the Lanthanides and Actinides by Elution with Ammonium AlphaHydroxy-Isobutyrate," J. Inorg. \& Nuclear Chem. 3, 243-47 (1956).

443. G.W. Smith and F.L. Moore, "Separation and Determination of Radiocerium by Liquid-Liquid Extraction," Anal. Chem. 29, 448 (1957).

444. A. Sonesson, "On the Complex Chemistry of the Tervalent Rare Earth Ions, I. The Acetate Systems of Lanthanum, Cerium, Neodymium 
and Gadolinium," Acta Chem. Scand. 12, 165-81 (1958).

445. A. Sonesson, "On the Complex Chemistry of the Tervalent Rare Earth Ions, III. The Glycolate Systems," Acta Chem. Scand. 13, 998$1010(1959)$.

446. A. Sonesson, "On the Complex Chemistry of the Tervalent Rare Earth Ions, IV. Ion Exchange Studies of the Gadolinium Acetate and Glycolate System," Acta Chem. Scand. 13, 1437-52 (1959).

447. F.A. Spedding et al., "The Separation of Rare Earths by Ion Exchange," Part I, J. Am. Chem. Soc. 69, 2777-81 (1947); Part II, Ibid. 69, 2786-92 (1947); Part III, Ibid. 69, 2812-18 (1947), Ibid. 70, 1671-72 (1948), Ibid. 72, 5350 (1950); Part IV, Ibid. 72, 2349-54 (1950); Part V, Ibid. 72, 2354-56 (1950); Part VI, Ibid 73, 4840-47 (1951), Ibid. 74, 856-57 (1952).

448. F.H. Spedding, "Improved Ion Exchange Method for Separating Rare Earths in Macro Quantities," J. Am. Chem. Soc. 70, 1671 (1950).

449. F.H. Spedding and A.H. Daane, "Production of Rare Earth Metals in Quantity Allows Testing of Physical Properties," J. Metals $\underline{6}$. 502-10 (1954).

450. F. H. Spedding and J. E. Powell, "The Separation of Rare Earths by Ion Exchange. VIII. Quantitative Theory of the Mechanism Involved in Elution by Dilute Citrate Solutions," J. Am. Chem. Soc. 76, $2550-57$ (1954).

451. F. Spedding, J. Powell, and E. Wheelwright, "The Separation of Adjacent Rare Earths with Ethylenediamine-Tetraacetic Acid by Elution from an Anion Exchange Resin," J. Am. Chem. Soc. 76, $612-13$ (1954).

452. F. H. Spedding and J. E. Powell, "The Separation of Rare Earths by Ion Exchange. VII. Quantitative Data for the Elution of Neodymium," J. Am. Chem. Soc. 76, 2545-50 (1954).

453. F. H. Spedding, J. E. Powell, and E. J. Wheelwright, "The Use of Copper as the Retaining Ion in the Elution of Rare Earths with Ammonium-Ethylene-Diamine-Tetraacetate Solutions," J. Am. Chem. Soc. 76, 2557-60 (1954).

454. F. H. Spedding and A. H. Daane, "The Preparation and Properties of Rare Earth Metals," in "Progress in Nuclear Energy," Vol. 1, Series 5, pp. 413-32, Pergamon Press, Inc., New York, 1956.

455. F. Spedding, J. Powell, and E. Wheelwright, "The Stability of the Rare Earth Complexes with $\mathrm{N}$ - Hydroxyethyl Ethylenediaminetriacetic Acid," J. Am. Chem. Soc. 78, 34 (1956).

456. G. H. Spedding, J. E. Powell, A. H. Daane, M. A. Hiller, and 
W. H. Adams, "Methods for Preparing Pure Scandium Oxide," J. Electrochem. Soc. 105, 683-86 (1958).

457. I. E. Starik and M. S. Lambert, "State of Microelements in Aqueous Solutions," Zhur. Neorg. Khim. 3, 136- 38 (1958); translated in AECTR- 3499 .

458. D. Stewart, "Rapid Separation of Tracer Amounts of Rare Earth Elements of The Yttrium Group," Anal. Chem. 27, 1279 (1955).

459. D. C. Stewart, "Absorption Spectra of Lanthanide and Actinide Rare Earths. II. Transition Probabilities for +3 Ions in the Two Series," ANL- 4812 (1952).

460. D. C. Stewart, 'Rapid Separation of Tracer Amounts of Rare Earth Elements of the Yttrium Group," Anal. Chem. 27, 1279-82 (1955).

461. D. C. Stewart, "Rare Earth and Transplutonium Element Separation by Ion Exchange Methods," Proc. Intern. Conf. Peaceful Uses Atomic Energy, Geneva, 1955, 7, $321-30$ (1956).

462. D. C. Stewart and D. Kato, "Analysis of Rare Earth Mixtures by a Recording Spectrophotometer," Anal. Chem. 30, 164- 72 (1958).

463. D. F. Stewart and W. W. Wendlandt, "The Solubility and Heat of Solution of Lanthanum Nitrate- 6 Hydrate in Non-Aqueous Solvents," J. Phys. Chem. 63, 1330-31 (1959).

464. J. Stites, "The Rare Earth Metals and Their Compounds. VIII. An Improved Method for the Synthesis of Some Rare Earth Acetylacetonates," J. Am. Chem. Soc. 70, 3142 (1948).

465. D. Stone, "Preparation of Actinium Metal," J. Am. Chem. Soc. 77, $237-40$ (1955).

466. K. Street, Jr. and G. T. Seaborg, "The Separation of Americium and Curium from the Rare Earth Elements," J. Am. Chem. Soc. 72, $2790-$ 92 (1950).

467. P. R. Subbaraman, K. S. Rajan, and J. Gupta, 'Ion-Exchange Separation of Light Rare Earths Using Sodium Tripolyphosphate," Current Sci. (India) 28, 63-64 (1959).

468. P. R. Subbaraman, K. S. Rajan, and J. Gupta, 'Ion Exchange Separation of Some Light Rare Earths by Elution with Sodium Triphosphate," Z. anorg. u. allgem. Chem. 301, 261-66 (1959); Chem. Abstr. 54, $4106 i$.

469. B. N. Sudarikov, V. A. Zaytsev, and Yu. G. Puchkov, 'Extraction of Sc, Y, Ce, La, U, and Th Salicylates," Nauch. Doklady Vysshei Shkoly, Khim. i Khim. Tekhnol. 1, 80-83 (1959).

470. J. P. Surls and G. R. Choppin, "Equilibrium Sorption of Lanthanides, Americium, and Curium on Dowex- 50 Resin," J. Am. Chem. Soc. 79, $855-59$ (1957). 
471. J. P. Surls, Jr. and G. R. Choppin, "Ion-Exchange Study of Thiocyanate Complexes of the Actinides and Lanthanides," J. Inorg.

\& Nuclear Chem. 4, 62-73 (1957).

472. J. F. Suttle and J. F. Stampfer; Note in Prog. Rep. No. 12, Contract SC- 5, University of New Mexico (1954).

473. Y. Takashima, "Determination of Metals by Means of HexammineCobalt Chloride and Sodium Fluoride, I. Scandium," Nippon Kagaku Zasshi 79. 243-46 (1958); "II. Radiometric Analysis of Scandium," Ibid. 79, 246-48 (1958); UCRL-Trans 539(L) (1960).

474. I. V. Tananaev and G. B. Seifer, "Yttrium and Cerium Ferrocyanides," Zhur. Neorg. Khim. 1, No. 1, 53-63 (1956).

475. C. C. Templeton and J. A. Peterson, "Fractionation of Lanthanum and Neodymium Nitrates by Solvent Extraction," J. Am. Chem. Soc. 70, 3967 (1948).

476. E. A. Terent'eva, "Dissertatsiia," Moskv. MGU (1951).

477. E. A. Terent'eva, "Complex Compounds of Rare Earth Elements," Uspekhi Khim. 26, 1007-35 (1957); UCRL-Trans 522(L) (1960).

478. H. C. Thomas and G. R. Frysinger, "Ion Exchange," Ann. Rev. Phys. Chem. 7, 137-66 (1956).

479. S. G. Thompson, B. G. Harvey, G. R. Choppin, and G. T. Seaborg, "Chemical Properties of Elements 99 and 100," J. Am. Chem. Soc. 76, 6229 (1954).

480. L. I. Tikhonova and M. M. Senyavin, "Chromatographic Method for the Relative Evaluation of the Stability of Complex Compounds. II. The Complex Compounds of $\mathrm{Y}(\mathrm{Yb})$ with Some Organic Substances," Zhur. Neorg. Khim 2, 74 (1957); Chem. Abstr. 51, $16185 \mathrm{e}$.

481. E. R. Tompkins and S. W. Mayer, 'Ion Exchange as a Separation Method. III. Equilibrium Studies of the Reactions of Rare Earth Complexes with Synthetic Ion Exchange Resins," J. Am. Chem. Soc. 69, $2859-65(1947)$.

482. E. R. Tompkins, D. H. Harris, and J. X. Khym, "A Study of the Effect of a Number of Column Variables," J. Am. Chem. Soc. 71 , 2504- 10 (1949).

483. E. R. Tompkins, "Ion Exchange Separation," Anal. Chem. 22, $1352-$ 59 (1950).

484. J. Y. Tong and E. L. King, "A Spectrophotometric Investigation of the Cerium (IV)-Chromium (VI) Complex Ion Equilibria in Perchloric Acid Solution," J. Am. Chem. Soc. 76, 2132 (1954).

485. A. C. Topp and B. Weaver, "Distribution of Rare-Earth Nitrates between Tributyl Phosphate and Nitric Acid,"U.S. Atomic Energy Comm. Document ORNL-1811 (1954). 
486. N. E. Topp, "The Use of Complexing Agents for Rare Earth Separation by Ion-Exchange Techniques," Chem. \& Ind., 1320- 23 (1956).

487. J. Troianello and T. T. Sugihara, "Separation of Yttrium and FissionProduct Rare Earths by Ion Exchange at Room Temperature," AECU 3807 (1957).

488. F. Trombe, "Observations on the Vapor Pressures of the Rare Earth Metals, Their Separation and Their Purification," Bull. Soc. Chim. France 10, 1010-12 (1953).

489. F. Trombe, "Rare Earth Metals," Rev. Met. 53, 2-33 (1956) (Translated in AEC - TR-3479).

490. Y. J. Tsong, "Séparation, Par Échange Ionique, de Traces Actınium 227 d'une Quantité Pondérable de Lanthane," J. Chim. Phys.477, 80506 (1950).

491. G. Urbain, Compt. rend. 15, 347 (1896).

492. G. Urbain, Bull. Soc. Chim. France 15, 338 (1896).

493. R. Vanossi, "Identification of Scandium," Am Assoc. Quim. Argentina 46, 291-309 (1959); Anal. Abstr. 7, 417.

494. M. Venkataramaniah and Bh. S. V. Raghavarao, "Separation of Tetravalent Cerium from Thorium and Other Trivalent Rare Earths-The Use of Potassium Periodate," Current Sci. (India) 18, 248-49 (1949).

495. R. C. Vickery, "Chemistry of the Lanthanons," Butterworths Scientific Publications, London, 1953.

496. R. C. Vickery, "Adsorption on Carbon of Rare Earth Organic Complexes," Nature 158, 623-24 (1946).

497. R. C. Vickery, "Polynuclear Complexes of Lanthanon Sulphates," J. Chem. Soc., I101 (1950).

498. R. C. Vickery, "Separation of Lanthanons by Means of Complexes with Amino Acids," J. Chem. Soc., 2058 (1950); "Lanthanon Complexes with Ethylenediamine- NNN' $N^{\prime}-$ Tetra-Acetic Acid. Part III," J. Chem. Soc., 1895 (1952).

499. R. C. Vickery, "Lanthanon Complexes with Ethylenediaminetetraacetic Acid. Parı I," J. Chem. Soc., 1817 (1951); Part IV, Ibid., 1181 (1954).

500. R. C. Vickery, "Lanthanon Complexes with Ethylenediaminetetraacetic Acid. Part II," J. Chem. Soc., 421 (1952); "Separation of The Lanthanons by Ion-Exchange. A Comparison of Eluants," J. Chem. Soc., 4357 (1952).

501. R. C. Vickery, "Chemistry of the Lanthanons," Butterworths Scientific Publications, London, 1953. 
502. R. C. Vickery, "Production, Analysis, and Applications of the Lanthanons," Ind. Chemist 29, 291 (1953).

503. R. C. Vickery, "Lanthanon Complexes with Hydrazine-N, N- Diacetic Acid," J. Chem. Soc., 385 (1954).

504. R. C. Vickery, "Lanthanon Sulfites and Their Separation by Selective Oxidation," J. Chem. Soc., 2360-67 (1955); Chem. Abstr. 50, $13638 f$.

505. R. C. Vickery, "The Extraction and Purification of Scandium," J. Chem. Soc., 245 (1955).

506. R. C. Vickery, "Scandium Hydroxide and Scandate Ion," J. Chem. Soc., 251 (1955).

507. R. C. Vickery, "Scandium Oxalate and Its Ammine Complexes," J. Chem. Soc., 255 (1955).

508. R. C. Vickery, "Some Reactions of Scandium," J. Chem. Soc., 3113 (1956).

509. R. I. Walter, "Anion Exchange Studies of Sc(+3) and V(+4). Separation of Scandium, Titanium, and Vanadium," J. Inorg. \& $\mathrm{Nu}-$ clear Chem. 6, 58 (1958).

510. J. C. Warf, "Extraction of Cerium (IV) Nitrate by Butyl Phosphate," J. Am. Chem. Soc. 1, 3257 (1949).

511. B. Weaver, "Fractional Separation of Rare Earths by Precipitation with Mandelic Acid," Anal. Chem. 26, 476 (1954).

512. J. C. Weaver and W. C. Purdy, "The Apparent Solubility Product of Cerous Fluoride," Anal. Chim. Acta 20, 376- 79 (1959).

513. G. Weidmann and G. Liebold, 'Einfluss der $\mathrm{Cu}-, \mathrm{Ni}-$, und CoBeladung von Austauschersäulen auf die Trennung eines $\mathrm{Pr} / \mathrm{Nd}$ Gemisches bei der Elution mit Trilon A," Angew. Chem. 69, 753 (1957).

514. R. Weinlandt and A. Henrichson, "Polynuclear Acetato and Formato Cations of Barium and Cerium," Ber. 56B, 528 (1923).

515. W. Wendlandt and J. Bryant, "Thermogravimetric Pyrolysis of Cupferron Complexes of Scandium, Yttrium, and Rare Earth Elements," Anal. Chem. 27, 1277 (1955).

516. W. Wendlandt and J. Bryant, "The Thermolysis of the Neocupferron Chelates of Yttrium and the Rare Earth Elements," Anal. Chim. Acta 13, 550 (1955).

517. W. Wendlandt, "Methylamine Complexes of Yttrium Chloride," Science 122,197 (1955).

518. W. W. Wendlandt, "The Thermolysis of the 8-Quinolinol Chelates of Yttrium and the Rare Earth Elements," Anal. Chim. Acta 15, $109-13$ (1956). 
519. W. Wendlandt, "Reaction of 8-Quinolinol with Cerium (III)," Science 124, 682 (1956).

520. W. W. Wendlandt and J. M. Bryant, "The Solubilities of Some Metal Nitrate Salts in Tri-n-Butyl Phosphate," J. Phys. Chem. 60, 1145 (1956).

521. W. W. Wendlandt and D. W. Hayes, "Detection of Rare Earth Oxalates and Cupferrates," Scrence 126, 451-52 (1957).

522. W. W. Wendlandt, "The Thermal Decomposition of the 2-Methyl- $\varepsilon$ Quinolinol (8-Hydroxyquinaldine) Chelates of Scandium, Thorium, Uranium (VI), and the Rare Earth Elements," Anal. Chim. Acta 17, $274-79$ (1957)

523. W. W. Wendlandt, "The Thermal Decomposition of the 5, 7-dihalo8 -Quinolinol Rare Earth Metal Chelates," Anal. Chim. Acta 17, 428- 33 (1957).

524. W. W. Wendlandt, "The Thermal Decomposition of Yttrium, Scandium, and Some Rare Earth Chloride Hydrates," J. Inorg. \& Nuclear Chem. 5, 118-22 (1957).

525. W. W. Wendlandt, "Thermal Decomposition of Scandium, Yttrium, and Rare Earth Metal Oxalates," Anal. Chem. 30, 58 -61 (1958).

526. W. W. Wendlandt, "Thermal Decomposition of the Rare Earth Metal Oxalates," Anal. Chem. 31, 408-10 (1959).

527. W. W. Wendlandt, "The Thermal Decomposition of the Heavier Rare Earth Metal Chlorıde Hydrates," J Inorg. \& Nuclear Chem. 9, 13638 (1959).

528. W. W. Wendlandt, "Thermal Decomposition of Rare Earth Fluoride Hydrates," Science 129, 842 (1959).

529. W. W. Wendlandt, "Thermal Decomposition of Some Rare Earth Metal Cupferrates and Neocupferrates," Anal. Ch1m. Acta 21, $116-$ 20 (1959).

530. L. B. Werner and I. Perlman, "Isolation and Properties of Curium," U. S. Atomic Energy Comm. Document UCRL-1 56 (1948).

531. T. S. West, "Liquid-Liquid Extraction Procedures in Inorganic Analysis," Metallurgia 53,185 (1956).

532. E. Wheelwright and Spedding, J. Am. Chem. Soc. 75, 2529 (1953).

533. E. J. Wheelwright and F. H. Spedding, "The Use of Chelating Agents in the Separation of the Rare Earth Elements oy Ion Exchange Methods," ISC-637 (1955).

534. G. Wilkinson and H G. Hicks, "Radioactıve Isotopes of the Rare Earths. I. Experımental Techniques and Thulıum Isotopes," Phys. Rev. $75,1370-78$ (1948)

535. G. Wilkinson and J Birmingham, "Cyclopentadienyl Compounds of 
Sc, Y, La, Ce and some Lanthanıde Elements," J Am. Chem Soc. 76, 6210 (1954).

536. L. Wish, E. Freiling, and L. Bunney, "Ion Exchange as a Separation Method. VIII. Relatıve Elution Position of Lanthanide and Actinide Elements with Lactic Acid Eluant at $87^{\circ}, " \mathrm{~J}$. Am. Chem Soc $\underline{76}$, 3444 (1954).

537. L. Wolf and J. Massone, "Weitere Untersuchungen üver die Trennung Seltener Erden durch Komplexelution von Kationenharzaustauscher (Die Elution mittels $4 \% \beta$-oxyäthylıminodiessigsäurelösung be $10^{\circ} \mathrm{C}$ ), " J. prakt. Chem. (4), 5, 14-20 (1957), Ib1d. 5, 21-33 (1957), Ib1d, 5, 288- 90 (1957).

538 L. Wolf and J. Massone, "Über eine schnelle Ionenaustauschtrennung grossere Mengen Ceriterden unter Verwendung von AmmoniumNitrilotriacetat als Elutionsmittel," Chem. Tech. (Berlin) 10, 290-96 (1958).

539. L. Wunsch, "Complexometric Titrations (Chelatometry). XIII The Determination of Scandium," Collection Czechoslov. Chem. Communs. 20, 1107-12 (1955), AEC-TR 3833, Nuclear Sc1. Abstr. 13, 20908.

540. A. W. Wylie, 'Spectrophotometric Determination of Praseodymium, Neodymium, and Samarium," J. Soc. Chem. Ind. (London) 143-47 (1950).

541. A. W. Wylie, 'Extraction of Ceric Nitrate by Solvents," J. Chem. Soc., 1474 (1951).

542. L. Yntema, "The Separation of Europium by Electrolytic Reduction. Observations on the Rare Earths XXXV," J. Am. Chem. Soc. 52, $2782(1930)$.

543. J. Yoshimura, Y. Takashima, and H. Wak2, "Ion Exchange Separation of Scandium and the Lanthanides," Nippon Kagaku Zasshi 79 , 1169- 72 (1958); UCRL-Trans 540(L), (1960). 
544. R. G. Monk (ed.) et al., "Radiochemical Methods," AERE Report No. NR/C-17/59 (Aug. 1959).

545. B. K. Preobrazhenskii, "Utilization of Ion-Exr hange Chromatography for the Separation of Transuranic and Radioactive Rare-Earth Elements," Khim. Nauka i Prom. 4, 521-6 (1959); UCRL-Trans 551(L) (1960).

546. O. Menis, T. C. Rains, and J. A. Dean, "Extraction and Flame Spectrophotometric Determination of Lanthanum," Anal. Chem. 31 , No. 2, $187-91$ (1959).

547. G. B. Seifer and E. A. Ionova, "Scandium Ferrocyanides," Zhur. Neorg. Khim. 4, 1362-68 (1959); Russian J. Inorg. Chem. 4, No. 6, $612-15$ (1959).

548. C. L. Huffine and J. M. Williams, "Refining and Purification of Rare-Earth Metals," AECU- 4426 (Nov. 1959).

549. E. Morrice, J. Darrah, E. Brown, C. Wyche, W. Headrick, R. Williams, and R. G. Knockerbocher, 'Metallurgical Laboratory Data on Reduction and Refining of Ceric Oxide and Cerous Fluoride to Cerium Ingot, "Bur. of Mines-RI- 5549 (1960).

550. D. A. Douglass and D. J. Bauer, "Liquid-Liquid Extraction of Cerium," Bur. of Mines-RI- 5513 (1959).

551. L. O. Tuazon, "The Nature of Cerium (IV) in Aqueous Nitric Acid Solutions," Ph. D. thesis, Iowa State Coll., Ames, Iowa (1959).

552. W. W. Wendlandt and R. G. Sewell, "Detection of the Heavier Rare Earth Metal Ions with Several Organic Reagents," Anal. Chim. Acta 21, 94-95 (1959).

553. S. Siekierski and I. Fidelis, "Separation of Some Rare Earths by Reversed-Phase Partition Chromatography," J. Chromatog. 4, 6064 (1960).

554. D. K. Hale, 'Methods or Processes of Extracting a Solute from a Solution," British Patent 738, 500 (Oct. 12, 1955). 